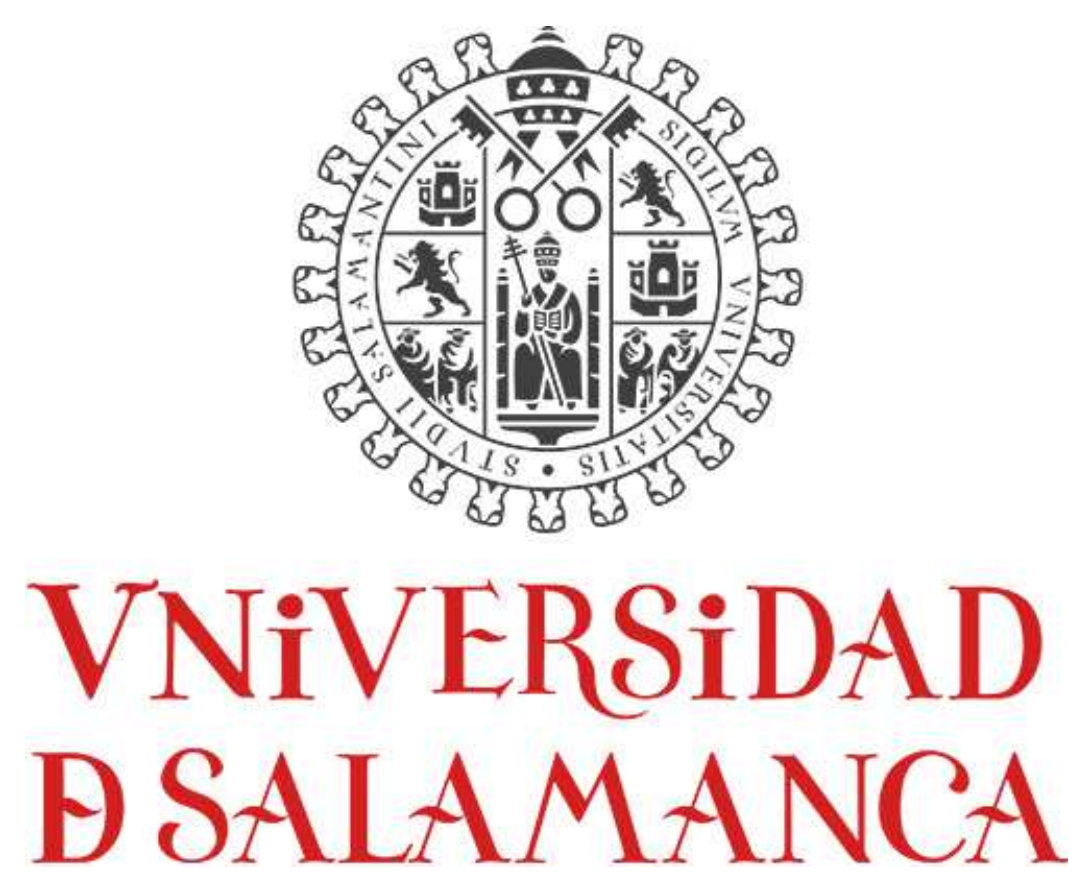

FACULTAD DE PSICOLOGÍA

DEPARTAMENTO DE PSICOLOGÍA SOCIAL TESIS DOCTORAL

"VARIABLES PSICOSOCIALES DEL ACOSO LABORAL EN DIRECCIÓN DE CENTROS RESIDENCIALES"

AUTOR: D. JOSÉ MARÍA SACRISTÁN RODRÍGUEZ DIRECTOR: Dr. D. JOSE CARLOS SÁNCHEZ GARCÍA 


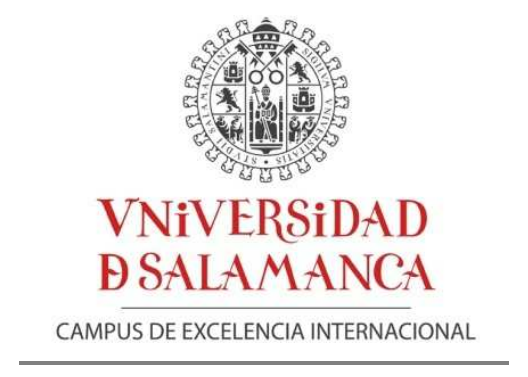

D. JOSÉ CARLOS SÁNCHEZ GARCÍA, Doctor en Psicología, Catedrático del Área de Psicología Social, del Departamento de Psicología Social y Antropología de la Universidad de Salamanca

\section{INFORMA que}

La tesis doctoral titulada "Variables Psicosociales del Acoso Laboral en Dirección de Centros Residenciales", realizada por D. José María Sacristán Rodríguez, bajo mi dirección reúne los requisitos de calidad, originalidad y presentación exigibles a una investigación científica y está en condiciones de ser sometida a la valoración del Tribunal encargado de juzgarla para optar al título de Doctor.

En Salamanca, a 8 de Junio de, dos mil diecisiete.

Fdo. Dr. D. José Carlos Sánchez García

Sr. Presidente de la Comisión Académica del Programa de Doctorado en Psicología de la Universidad de Salamanca. 


\section{RESUMEN - ABSTRACT}

Antecedentes: El número creciente de conflictos derivados en acoso laboral o mobbing resultantes de la dinámica laboral en la dirección de centros residenciales del territorio Español, con el acuciante perjuicio para la sociedad en su conjunto comprometiendo así la prestación de un servicio profesional de éxito en las funciones directivas.

Objetivos: La presente investigación se propuso explorar la relación existente y el impacto de los factores psicosociales y organizacionales más relevantes en la dirección de centros residenciales con el acoso laboral, estableciendo así relaciones de antecedencia con la edad, el sexo, el estilo de liderazgo, las competencias en el sector, la ambigüedad de rol, la justicia organizacional, los resultados económicos y el grado de autonomía laboral y relaciones de consecuencia con el grado de satisfacción laboral, la intención de abandono, el rendimiento laboral, el compromiso con la organización, el clima organizacional y la finalización de las tareas.

Métodos: Se realizó un estudio con metodología cuantitativa, que comprendió dos fases; una primera fase en la que se elaboró el cuestionario para la recogida de la información y una segunda fase en la que se obtuvieron los resultados y se analizaron estadísticamente mediante el programa informático SPSS 19. Se utilizaron así instrumentos para la evaluación de las características sociodemográficas, clínicas, organizacionales y psicosociales de los individuos evaluados en la muestra de estudio, para lo cual se emplearon la Escala Cisneros y la Escala de Perfil Profesional.

Resultados obtenidos: De un total de 59 casos evaluados, se detectaron diferencias estadísticamente significativas en las variables estudiadas tales como el grado de autonomía laboral, la satisfacción laboral, el rendimiento laboral, el clima organizacional y la finalización de las tareas. No se obtuvieron diferencias estadísticamente significativas con las variables enunciadas como la justicia organizacional, la edad, el sexo, el estilo de liderazgo, las competencias en el sector, la ambigüedad de rol, los resultados económicos y el compromiso con la organización

Conclusiones: En la presente investigación fue posible determinar la existencia de diferencias con significación estadística de los factores psicosociales $y$ organizacionales que conforman la realidad directiva de los centros residenciales en la actualidad, así como dar respuesta a los diferentes objetivos inicialmente propuestos en la investigación. 


\section{RESUMEN - ABSTRACT}

Background: The rising numbers of labour dynamics conflicts resulting in workplace harassment, or mobbing, that reach the head/management department of residential care homes in Spanish territory and the resulting harm it may cause to the society as a whole, and in particular, to the desirable successful service, offered not only by the head/management department, but by all professionals involved.

Objetives: The current investigation aimed to explore both the actual relationship and the impact of psycho-social and main organising factors, inside the head department in residential care homes, with workplace harrassment. Aspects such as age, sex, leadershipstyle, sector expertise, ambiguity in the role, justice organization, economic outcomes, and the degree of autonomy in the workplace could be posible background causes, among the likely connected consecuences: job satisfaction degree, leaving job intention, work perfomance, commitment to the organization, organization atmosphere and tasks achievement may be mentioned.

Methods: A quantitative methodology study in two stages was conducted. A survey to gather information was developed in the first stage. Results were obtained in the second stage, which were later statistically anlalysed through the software SPSS 19. In order to evaluate clinical features, socio-demographic, psycho-social, and organizational characteristics in the individuals under study, the following tolos were used: Cisneros Scale and The Scale of Professional Profile.

Resultsachieved: Out of the 59 evaluated cases, statistically significant differences were detected in studied variables such as the degree of autonomy in the workplace, both job satisfaction and performance, organization atmosphere and tasks achievement. However no statistically significant differences were found in other mentioned variables such as organization justice, age, sex, leadershipstyle, sector expertise, ambiguity in the role, economic outcomes, or commitment to the organization.

Conclusion: The current investigation made it to possible determine the actual existence of statistically significant differences concerning the psycho-social and organizational factors which make up the reality of the management departments in residential care homes nowadays, it also serves as achievement to the goals aimed in the investigation. 
DEDICATORIA.

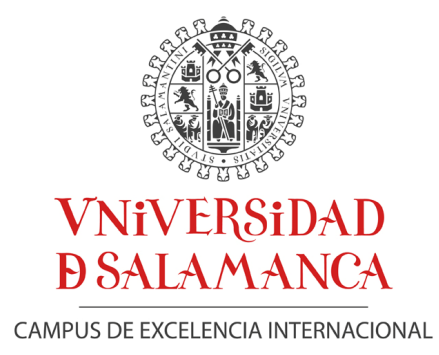

A mis padres y a mi hermana

A todas aquellas personas que han hecho posible la realización de esta Tesis...

Y a quienes me han apoyado y querido incondicionalmente... 


\section{AGRADECIMIENTOS.}

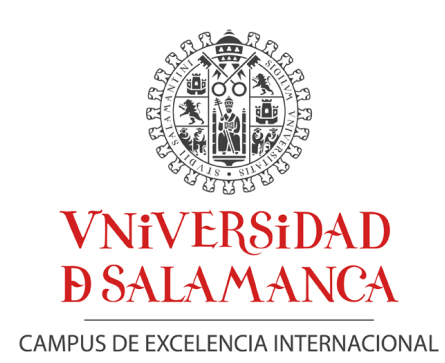

\section{AGRADECIMIENTOS}

Me gustaría agradecer a la Universidad de Salamanca y en especial al Departamento de Psicología Social de la Facultad de Psicología la oportunidad de realizar esta tesis.

Al coordinador del Programa de Doctorado en Psicología y Director de esta Tesis Doctoral Dr. D. José Carlos Sánchez García, por su preocupación e interés por mi investigación, su confianza, su apoyo incondicional y su inestimable colaboración sin la cual no hubiera podido llevarse a cabo este trabajo.

A la profesora Dra. Dña. María José Fernández Guerrero Catedrática de Psicoanálisis y Psicopatología de la Facultad de Psicología de la Universidad Pontificia de Salamanca por su apoyo en mi desarrollo académico durante mis años de Licenciatura, durante los cuales despertó en mí el interés por la investigación clínica.

Al conjunto de Directores de Centros Residenciales por su participación desinteresada en la dinámica de estudio de campo, sin los cuales no hubiera sido posible el muestreo necesario para ratificar este estudio.

A mi compañero y amigo, D. Miguel Ángel Meneses Villamediana, por su apoyo desinteresado, su inestimable colaboración y su amistad.

Por último agradecer a todas aquellas personas que me han apoyado en la decisión de realizar esta Tesis, por su amistad, su ayuda y su interés por el éxito de la misma.

Gracias a todos. 
CITA.

VNIVERSiDAD

BSALAMANCA

CAMPUS DE EXCELENCIA INTERNACIONAL

"Un día voy a escribir todo lo que siento, y vas a leerlo y a preguntarte si se trata de ti, y probablemente sí, y posiblemente ya no..."

(Anónimo) 
NOTA.

"Una mañana, usted llega a su despacho, se sienta en su escritorio, y enciende su ordenador. Igual que el día anterior y como muchos otros días anteriores; pero esa mañana hay algo nuevo en el aire, algo inusual, vagamente hostil. Quizá sea el Director General, quien absorto en sus pensamientos, no lo saludo en el pasillo; tal vez sus colegas quienes no lo han invitado a tomar el café con ellos.

¡Qué extraño, ellos normalmente lo llaman!

Tal vez sea la secretaria allá abajo, la que lo mira y susurra algo en el oído de su amiga, usted se pregunta porque...

Quizá no significa algo, es sólo una coincidencia, y mañana todo volverá a ser normal. O quizá, algo se ha roto en las relaciones entre usted y su ambiente de trabajo. Tal vez alguien decidió volverse contra usted, para aislarlo y excluirlo del grupo: y desde ese día, poco a poco, todo comienza a cambiar en el trabajo...para empeorar.

Es una cadena de eventos aparentemente desarticulados que ocultan una estrategia precisa y progresiva. Al comienzo la amenaza es soterrada e indirecta, compuesta de insinuaciones, miradas, gestos y comentarios aparentemente insignificativos. Primero, es difícil comprenderlos, entenderlos, identificarlos...Pero pronto se hacen más obvios y violentos.

Parece irreversible y quienquiera que usted sea, se sentirá terriblemente sólo: usted no sabe que otros millones de personas en todo el mundo están en la misma trampa.

Usted no sabe que es un mal social, el cual se está haciendo cada vez más serio, más propagado y todavía es severamente ignorado. Tiene un nombre preciso: se llama Mobbing".

Este trabajo de investigación está dedicado a todos aquellos que sufren en soledad los efectos del Mobbing. 


\section{ÍNDICE}

\section{ÍNDICE DE TABLAS}

-Tabla 1.1."Últimos barómetros Cisneros Ilevados a cabo". 65.

-Tabla 5.1. "Ítems que componen la subescala de desprestigio laboral". 308.

-Tabla 5.2. "Ítems que componen la subescala de entorpecimiento del progreso"... 309.

-Tabla 5.3. "Ítems que componen la subescala de incomunicación o bloqueo de la comunicación" 309-310.

-Tabla 5.4. "Ítems que componen la subescala de intimidación encubierta". 310.

-Tabla 5.5. "Ítems que componen la subescala de intimidación manifiesta".. 311.

-Tabla 5.6. "Ítems que componen la subescala de desprestigio personal". 311-312.

-Tabla 5.7. "Ítems no incluidos en las diferentes dimensiones". 312.

-Tabla 5.8. "Ítems que conforman el LIPT original". 313-314.

-Tabla 5.9. "Ítems que conforman el LIPT-60". 315.

-Tabla 7.1. "Variables descriptivas del informante". 409.

-Tabla 7.2. "Ficha técnica de la investigación". 415.

-Tabla 7.3. "Estructura de la Escala Cisneros". 439.

-Tabla 7.4. "Estructura de la Escala de Perfil Profesional". 440.

-Tabla 8.1. "Tabla SPSS 19, relativa a los estadísticos descriptivos de los índices de la Escala Cisneros". .448.

-Tabla 8.2. "Tabla SPSS 19, relativa a los estadísticos descriptivos de los ítems de la Escala Cisneros". 449-450.

-Tabla 8.3. "Índice de homogeneidad corregido de la Escala Cisneros". 451-453.

-Tabla 8.4. "Estadísticos Alfa de Cronbach". 453.

-Tabla 8.5. "Estadísticos Spearman Brown". 454.

-Tabla 8.6. "Puntuaciones obtenidas por los sujetos en la Escala Cisneros".. 455-456.

-Tabla 8.7. "Análisis factorial de la Escala Cisneros". 458.

-Tabla 8.8. "Gráfico de sedimentación de la Escala Cisneros".. .459. 


\section{ÍNDICE}

\section{ÍNDICE DE TABLAS}

-Tabla 8.9. "Matriz de componentes rotados de la Escala Cisneros". 460-461.

-Tabla 8.10. "Estadísticos descriptivos de la Escala de Perfil Profesional". 462.

-Tabla 8.11. "Índice de homogeneidad corregido de la Escala de Perfil Profesional”..462-464.

-Tabla 8.12. "Estadísticos de fiabilidad Escala de Perfil Profesional".. 465.

-Tabla 8.13. "Estadísticos Spearman Brown". .466 .

-Tabla 8.14. "Fiabilidades por variable obtenida. 469.

-Tabla 8.15. "Análisis descriptivo parámetros de referencia" 472.

-Tabla 8.16. "Análisis correlaccional acoso laboral - antecedentes". .473.

-Tabla 8.17. "Análisis correlaccional acoso laboral - consecuentes". .474.

-Tabla 8.18. "Análisis de regresión de los antecedentes predictores del acoso laboral.....478.

-Tabla 8.19. "Análisis de regresión de los consecuentes que predice el acoso laboral”.....482. 


\section{ÍNDICE}

\section{ÍNDICE DE GRÁFICOS}

-Gráfico 1.1. "Modelo de Zapf (2004)". 48.

-Gráfico 1.2. "Modelo de violencia en el lugar de trabajo (2004)". 59.

-Gráfico 2.1. "Evolución del trastorno antisocial". 107.

-Gráfico 2.2. "Trastorno de personalidad disocial (OMS, 1992)" 109 .

-Gráfico 3.1. "Fases de un proceso de mobbing directivo" 142.

-Gráfico 3.2. "Características de las organizaciones psicosocialmente tóxicas (Piñuel, 2004) 148.

-Gráfico 3.3. "Factores culturales y socioeconómicos en el estudio del mobbing".

-Gráfico 4.1. "Alteraciones habituales en personas sometidas a mobbing directivo (Pérez Bilbao, 2001)" 191.

-Gráfico 4.2. "Componentes del clima organizacional".

-Gráfico 4.3. "Clasificación de los costes empresariales derivados de los problemas de salud (Lobo et al, 2004). 229.

-Gráfico 5.1. "El ciclo estratégico de la comunicación". 264.

-Gráfico 5.2. "Dirección vs toma de decisiones". 297.

-Gráfico 5.3. "Organigrama estándar de un centro residencial”. 300.

-Gráfico 6.1. "Indicadores de la inseguridad de un directivo" 350.

-Gráfico 6.2. "Mediación de la programación de la persona en la reacción de ira después del ataque (Piñuel, 2003).

-Gráfico 6.3. "Fases en la recuperación del mobbing o psicoterror laboral (Piñuel, 2003)".

-Gráfico 6.4. "Cómo se retroalimenta el insomnio y la fatiga crónica en el psicoterror (Piñuel, 2003). 


\section{ÍNDICE}

\section{ÍNDICE DE GRÁFICOS}

-Gráfico 6.5. "Mecanismo de refuerzo de la confianza a través de la elaboración de la respuesta (Piñuel,2003)". 359.

-Gráfico 6.6. "Modelo inicial de relaciones entre el acoso laboral, antecedentes y consecuentes" 378.

-Gráfico 7.1. "Descriptivos sociodemográficos de la edad". 407.

-Gráfico 7.2. "Descriptivos sociodemográficos del sexo". .408.

-Gráfico 7.3. “Descriptivos sociodemográficos de los años de experiencia en el sector”......408.

-Gráfico 7.4. "Descriptivos sociodemográficos del nivel de estudios alcanzados". 409.

-Gráfico 7.5. “Descriptivos sociodemográficos de los puestos ocupados con anterioridad .410.

-Gráfico 7.6. "Esquema del estudio". 414.

-Gráfico 7.7. "Modelo experimental hipotetizado". 421.

-Gráfico 8.7. "Análisis Percentil NEAP" 483. 


\section{ÍNDICE}

PREFACCIO. $19-24$.

\section{PRIMERA PARTE}

\section{FUNDAMENTACIÓN TEÓRICA}

\section{Capítulo I.}

"Epidemiología y Planteamiento inicial del Acoso Psicológico Laboral en puestos Directivos" (p, 27-34).

1.1. Introducción (p, 34-38).

1.2. Delimitación Conceptual del término “Mobbing” o “Acoso Psicológico" (p, 39-443).

1.2.1. Terminología destacada a lo largo de la Historia ( $p, 44-50)$.

1.2.2. Conceptos relacionados $(p, 50-55)$.

1.2.3. Situaciones que no deben interpretarse como acoso laboral ( $p, 55-60)$.

1.3. El Mobbing en el Mundo; Cifras y Datos de interés ( $p, 61-63)$.

1.3.1. En España (p, 63-68).

1.3.2. En Europa y el resto de Países (p, 68 -79).

1.4. Jurisprudencia, Tratamiento y Marco Legal Español (p, 79-84).

1.4.1. Óptica constitucional del Acoso Moral ( $p, 84-93)$.

1.4.2. Análisis Jurisprudencial en España ( $p$, 93-100).

Resumen - Abstrat (p, 100-101). 


\section{ÍNDICE}

\section{Capítulo II.}

"La Psicopatía como característica basal y definitoria de las conductas acosadoras" (p, 103-106).

2.1. Concepto de Psicopatía según el DSM y el CIE 10 (p, 106-108).

2.2. Visión Histórica y Actual del rasgo psicopático (p, 109-115).

2.3. Rasgos Definitorios ( $p, 115-116)$.

2.3.1. Rasgos Endógenos, "para con uno mismo" (p, 116-128).

2.3.2. Rasgos Exógenos, "conductas para con los demás" (p, 128-134).

2.4. El “Ciclo Manipulativo" (p, 134-136).

Resumen - Abstrat $(p, 137)$.

\section{Capítulo III.}

"El Desarrollo y las Fases de un proceso de Mobbing Directivo" (p, 139-142).

3.1. Antecedentes sociales, entorno laboral y cultura organizacional ( $p, 143-149)$.

3.2. Fases Estereotípicas del Mobbing (p, 149-152).

3.2.1. Fase de "Conflicto Inicial o de Incidentes Críticos" (p, 153).

3.2.2. Fase de "Estigmatización de la Víctima o del Entorno" ( $p, 154)$.

3.2.3. Fase de "Intervención desde la Organización o de Jerarquías Superiores" (p, 155-156).

3.2.4. Fase de "Exclusión o de Salida de la Organización" (p, 156-158).

3.3. Protagonistas; el acosador, la víctima y el entorno ( $p, 158-159)$.

3.3.1. Principales trastornos asociados al acosador $(p, 160-171)$.

3.3.2. Perfil Psicológico de la víctima ( $p, 171-175)$.

3.3.3. Características del entorno ( $p, 175-178)$.

Resumen - Abstrat $(p, 179)$. 


\section{ÍNDICE}

\section{Capítulo IV}

"Consecuencias del acoso psicológico en puestos directivos". (p, 181-183).

4.1. Para la víctima y su entorno Familiar (p, 183 - 192).

4.1.1. El concepto de víctima (p, 193 - 195).

4.1.2. Tipos de Victimización (p, 196 - 200).

4.1.3. La Lesión y Secuela Psicológica (p, 201 - 202).

4.1.4. Estado Psicológico anterior a la victimización (p, 203 - 207).

4.2. Para la Organización Empresarial a la que pertenece (p, 208 - 212).

4.2.1. Clima organizacional y modalidad de Liderazgo predominante (p, 212 - 227).

4.2.2. Costes laborales del Mobbing ( $p, 228$ - 234).

4.2.3. Establecimiento de un Sistema Perverso (p, 235 - 240).

4.3. Para la Sociedad ( $p, 240$ - 243).

Resumen - Abstrat $(p, 244)$.

\section{Capítulo V}

"Técnicas de Manipulación reseñables en el proceso coercitivo del Mobbing e Instrumentos de Evaluación de las Víctimas de Mobbing" (p, 246 - 251).

5.1. Diferentes estrategias de Manipulación (p, 252 - 256).

5.1.1. Principales Mecanismos Psicológicos que Interfieren (p, 256 - 261).

5.1.2. La Comunicación Interpersonal como vía de expresión (p, 261 - 282). 


\section{ÍNDICE}

5.1.2 1.Violencia Psicológica en las Organizaciones ( $p, 282$ - 285).

5.1.2.2. Diversidad de situaciones posibles y tipos de acoso ( $p, 285$ - 287).

5.1.2.2.1. Acoso vertical descendente o "bossing" (p, 287 - 290).

5.1.2.2.2. Acoso horizontal o "de iguales" (p, 290 - 291).

5.1.2.2.3. Acoso Mixto $(p, 292)$.

5.1.2.2.4. Acoso Vertical ascendente ( $p, 292$ - 293).

5.1.2.2.5. Otros tipos de acoso (p, 294 - 295).

5.1.3. El Aislamiento y la soledad del directivo acosado ( $p, 296$ - 301).

5.2. Descripción de los Instrumentos existentes para evaluar a las víctimas del mobbing ( $p, 302$ - 304).

5.2.1. LIPT ("Leymann Inventory Of Psychological Terrozization" (p, 305 - 315).

5.2.2. NAQ ("Negative Acts Questionnaire") (p, 315 - 319).

5.2.3. WHS ("Work Harassment Scale") (p, 319 - 321).

5.2.4. Escala "Cisneros" (p, 321 - 326).

5.2.5. ISTAS 21 ("Escala Psicosocial de Copenhague") (p, 327 - 331).

Resumen - Abstrat (p, 332 - 333).

\section{Capítulo VI}

"Identificación y Tratamiento del Acoso Laboral" (p, 335 - 345).

6.1. Fases en la Superación del Acoso en el Trabajo ( $p, 345$ - 354).

6.2. Factores de Resistencia al Mobbing ( $p, 355$ - 365).

6.3. Líneas de Actuación Terapéutica (p, 365 - 374).

6.4. El regreso a un nuevo Trabajo ( $p, 374-378)$.

6.5. Hipótesis de Estudio ( $p, 378-396)$.

Resumen - Abstrat ( $p, 397$ - 398). 


\section{ÍNDICE}

\section{SEGUNDA PARTE}

\section{INVESTIGACIÓN EMPÍRICA}

\section{Capítulo VII}

"Metodología Empírica y Proceso" (p, 401 - 405).

7.1. Análisis de datos (p, 405-406).

7.2. Participantes ( $p, 406-415)$.

7.3. Diseño experimental ( $p, 416-422)$.

7.4. Variables e instrumentos de evaluación (p, 422-435).

7.5. Descripción del Cuestionario: La Escala Cisneros y la Escala de Perfil Profesional ( $p$, 435-440).

7.6. Procedimiento $(p, 441-443)$.

Resumen - Abstrat ( $p$, 444-445).

\section{Capítulo VIII}

"Resultados Obtenidos" (p, 447)

8.1. Resultados de los análisis referidos a las escalas $(p, 448)$.

8.1.1. Escala Cisneros ( $p, 448-461)$.

8.1.2. Escala Perfil Profesional. (p, 461-469).

8.2. Resultados de los análisis referidos a las hipótesis ( $p, 470-471)$.

8.2.1. Resultados del análisis " $\mathrm{t}$ " de diferencias de medias y resultados del análisis Descriptivo $(p, 471-472)$.

8.2.2. Resultados del análisis correlaccional de los antecedentes ( $p$, 472-474).

8.2.3. Resultados del análisis correlaccional de los consecuentes ( $p$, 474-475).

8.3. Resultados referidos al modelo de los análisis predictivos ( $p, 476-483)$.

Resumen - Abstrat (p, 484-485). 


\section{ÍNDICE}

\section{Capítulo IX}

“Discusión Final y Conclusiones" (p, 487 - 494).

9.1. Conclusiones obtenidas en la muestra de estudio ( $p, 495-501)$.

9.2. Características de los Perfiles Victimológicos (p, 503-506).

9.3. Líneas Futuras de Investigación ( $p$, 506-515).

Resumen - Abstrat (p, 516-517).

\section{Capítulo X}

"Referencias Bibliográficas y Páginas Web Relacionadas" ( $p, 519-528)$.

10.1. Referencias Bibliográficas ( $p, 519-525)$.

10.2. Páginas web relacionadas ( $p, 526-528)$.

\section{ANEXOS (p, 530-542).}

1. Cuestionario $(p, 531-536)$.

2. Tablas SPSS 19 (p, 537-542). 
PREFACCIO.

\section{PREFACIO}

\section{TESIS DOCTORAL}

“VARIABLES PSICOSOCIALES

DEL ACOSO LABORAL EN

DIRECCIÓN DE CENTROS

RESIDENCIALES"

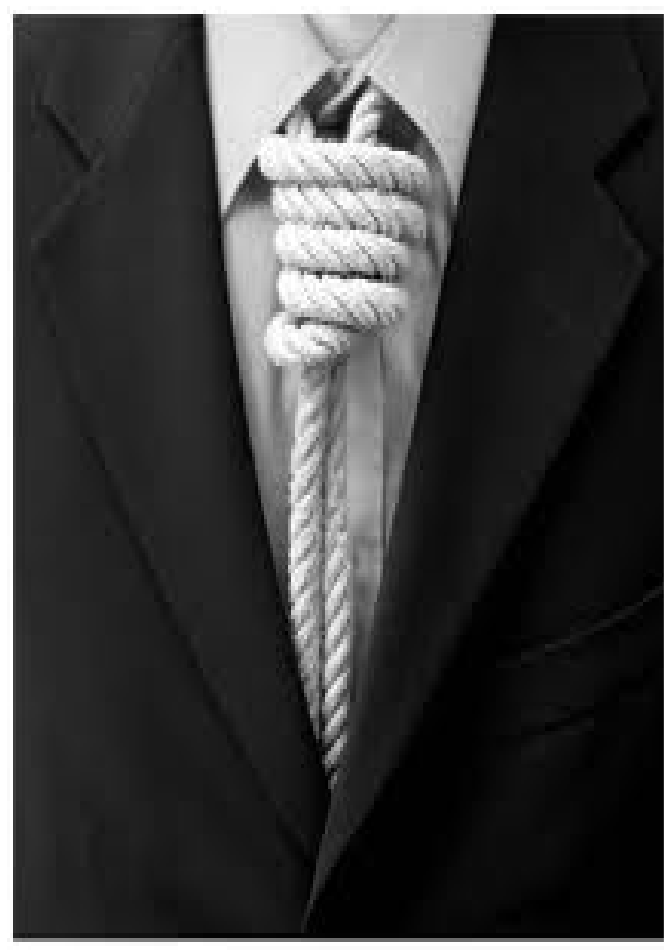

"Pregúntate si lo que estás haciendo hoy te acerca al lugar en el que quieres estar mañana"

Walt Disney (Productor, Director y Guionista Estadounidense). 
PREFACIO.

El origen de esta investigación tiene varias fases; en un principio mi primer contacto con temática de esta índole se produce en la Universidad Pontificia de Salamanca. En ella en quinto curso de Psicología (año 2006) nos proponen presentar un trabajo durante las fiestas de la Facultad de Psicología y su patrono Juan Huarte de San Juan, en la que un buen amigo y compañero de curso y yo presentamos un trabajo sobre Violencia de Género en el que nos acercamos al Mobbing como temática relacionada a la violencia empresarial, que en la actualidad se daba, obteniendo el Primer Premio y publicándose nuestro trabajo como reconocimiento de la Universidad al mismo.

En un segundo momento termino la carrera de Psicología (año 2006) y la profesora de Psicopatología Dña. María José Fernández Guerrero, me anima a realizar la Tesina de Investigación como medio para obtener el Título Pontificio que la Universidad concede tras su finalización con éxito. Así lo llevo a cabo y bajo su tutorización realizo la Tesina de Investigación correspondiente, ahondando en la temática de la Psicopatía y tratando ya de aproximar mi investigación al acoso laboral que ya comenzaba a ser muy notable en la realidad del momento.

Pasan algunos años y decido realizar un Máster en Dirección de Centros Residenciales, tras el cual me ofrecen la oportunidad de dirigir dos residencias de ancianos de nueva apertura. En un principio el proyecto es apasionante pero tras el paso de varios meses, la directiva general del Grupo comienza a asumirse en deudas millonarias. Es entonces cuando comienzo a ver a mí alrededor una serie de actitudes acosadoras.

Estas actitudes o tipos de relación, ocasionan en las personas una serie de trastornos, sufrimientos y situaciones de impotencia ante las cuales no se sabe responder. Esto puede ser debido a que las mencionadas actitudes no son las que se tiene por costumbre observar, como por ejemplo el ejercicio de abuso de autoridad. 
PREFACIO.

Ante todo ello decido documentarme y leer sobre la literatura existente, con la finalidad de intentar ayudar a los compañeros que se veían en esta situación de la cual yo también soy protagonista.

Tras poner fin a mi relación como director de los centros residenciales me empiezo a plantear la posibilidad de escribir e investigar en relación con esto; es entonces cuando decido poner un punto y final como culmen a mis estudios con esta tesis doctoral que espero pueda poner de relieve todos los hechos que yo mismo viví.

Es a partir de este contexto desde donde se produce mi elección de Programa de Doctorado en Psicología en la Universidad de Salamanca (curso académico 2014-2015) en el que me pongo como objetivo profundizar en la cultura del trabajo desde una perspectiva social y psicológica, con el fin de investigar "las variables psicosociales del acoso laboral en dirección de centros residenciales".

Comienza así esta Tesis de Investigación que a continuación procedo a describir y que está compuesta por:

\section{Primera Parte: "Fundamentación Teórica”, compuesta por 6 capítulos:}

\section{$>$ Capítulo I.}

"Epidemiología y planteamiento inicial del Acoso Psicológico Laboral en puestos Directivos".

En él se hace una breve introducción a la Temática de la Investigación, una delimitación conceptual del término Mobbing, diferenciado entre situaciones que se asemejan pero que no se pueden considerar como tales y algunos conceptos relacionados. Hablaremos además de algunos datos estadísticos en los que se muestra una visión global del Mobbing, en España, Europa y el resto de países del mundo, con el fin de dar una óptica amplia del fenómeno ante el que nos encontramos. Finalmente, abordaremos el tratamiento jurídico del acoso laboral en España, analizando la óptica constitucional y el análisis y marco legal existente en la actualidad. 


\section{Capítulo II.}

"La Psicopatía como característica basal y definitoria de las conductas acosadoras".

En este segundo capítulo se relata la psicopatía como base para el estudio del Acoso Laboral, tratando el concepto de Psicopatía desde las diferentes clasificaciones Internacionales (DSM y CIE), dando una visión histórica y actual del concepto, sus rasgos definitorios y poniendo coto al "Ciclo Manipulativo".

\section{Capítulo III.}

"Desarrollo y Fases de un proceso de Mobbing Directivo".

En el desarrollo del capítulo III, se describen los antecedentes sociales previos, las fases del Mobbing, con su estereotipia definida y un estudio minucioso sobre los protagonistas (acosador, víctima y entorno en el que se da el acoso laboral).

\section{Capítulo IV.}

"Consecuencias del acoso psicológico en puestos directivos".

El Capítulo IV es uno de los más amplios y extensos de toda la investigación. En él se repasa el concepto de víctima, los tipos de victimización, la lesión y secuela psicológica, las consecuencias psicopatológicas y físicas derivadas, el estado psicológico anterior a la victimización, la aproximación al clima organizacional, el liderazgo predominante para dar lugar al acoso, los costes laborales y las consecuencias que todo ello conlleva para nuestra sociedad.

\section{Capítulo V.}

"Técnicas de Manipulación reseñables en el proceso coercitivo del Mobbing e Instrumentos de Evaluación de las Víctimas de mobbing.".

En el quinto capítulo se relatan las diferentes estrategias de manipulación, los principales mecanismos Psicológicos que interfieren en el proceso manipulativo, la comunicación interpersonal como medio manipulador (mostrando la relevancia de esta en profundidad, la violencia psicológica que se padece en las organizaciones y los diferentes tipos de violencia que puede originar) y el aislamiento y la soledad que sufre la víctima del acoso. Se resumen y describen además en él, los diferentes instrumentos y escalas de medida de las víctimas de Mobbing, LIPT, NAQ, WHS, Escala "Cisneros" e ISTAS 21 (escala psicosocial de Copenhague). 
PREFACIO.

Capítulo VI.

"Identificación y Tratamiento del Acoso Laboral".

En el sexto capítulo se describen, las diferentes fases que transcurren hasta la superación del acoso, cuáles son los factores de resistencia al Mobbing, las líneas terapéuticas de actuación y cómo es el regreso a un nuevo trabajo tras padecer el acoso, concretando la formulación de hipótesis de estudio de esta tesis.

\section{Segunda Parte: "Investigación Empírica", compuesta de 3 capítulos:}

\section{Capítulo VII.}

"Metodología Empírica y Proceso".

Estamos ante el capítulo central y más extenso de la Investigación Empírica. En él se describe la fundamentación de la metodología elegida, la justificación del estudio desarrollado, los objetivos propuestos, la representatividad de la muestra y método (participantes, diseño experimental, e instrumentos de evaluación), las variables intervinientes, el procedimiento y el análisis de los datos obtenidos.

\section{Capítulo VIII.}

"Resultados Obtenidos".

En el capítulo VIII se analizan los resultados obtenidos poniendo especial énfasis en las propiedades psicométricas de los instrumentos de medida utilizados (escalas e inventarios y su análisis crítico), notas preliminares y variables de interés en el acoso directivo (tipología, número, sexo y duración percibida).

\section{Capítulo IX.}

"Discusión Final y Conclusiones".

En este capítulo se subrayan las deliberaciones finales de la investigación, analizando detenidamente las características del acoso moral en la muestra de estudio recogida y las características de los perfiles Victimológicos. Se sintetizan las conclusiones que arroja la investigación realizada, destacando en él, algunos tintes de cuáles son los diferentes caminos que en la actualidad se están siguiendo como 
PREFACIO.

líneas centrales de investigación tomándolas como base para futuras investigaciones.

Además de estos 9 capítulos esta tesis la compone un capítulo más, el Capítulo $X$ dedicado a resaltar las referencias bibliográficas consultadas para la realización de este estudio y las páginas web relacionadas con la temática estudiada.

Comenzaremos por realizar un repaso a través de la Primera Parte de esta investigación: "Fundamentación Teórica".

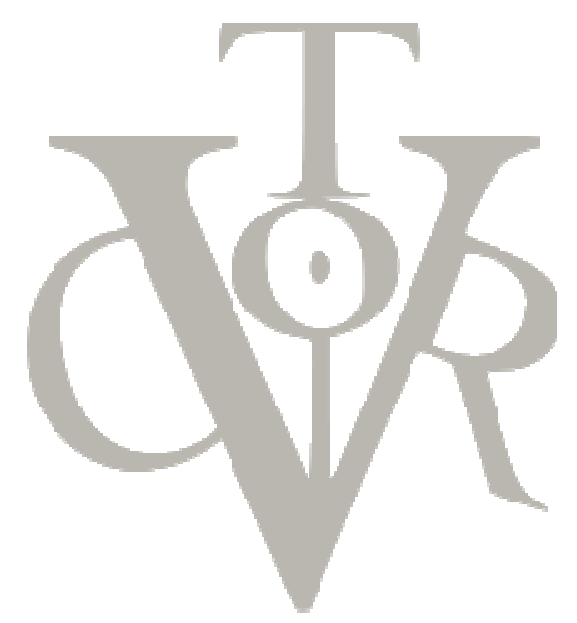




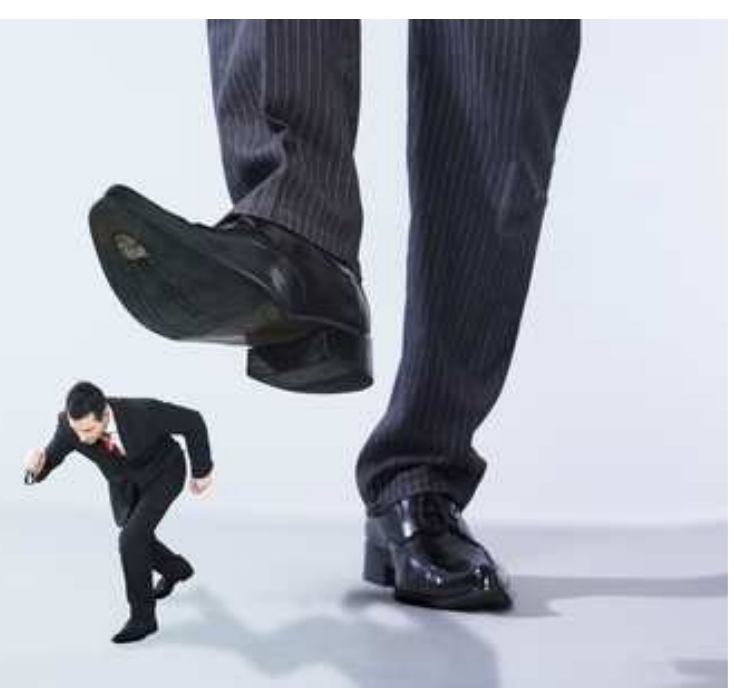

\section{PRIMERA} PARTE

"Hace falta un sueño para crear un concepto de negocio que tenga éxito. Hacen falta personas para convertir los sueños en realidad".

Anónimo. 


\section{CAPÍTULO I}

\section{"Epidemiología y Planteamiento inicial del Acoso Psicológico Laboral en puestos Directivos"}

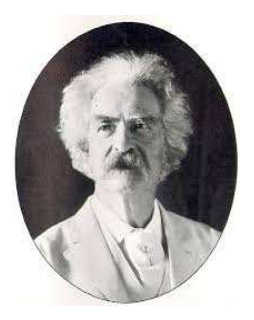

"Aléjate de la gente que trata de empequeñecer tus ambiciones. La gente pequeña siempre hace eso, pero la gente realmente grande, te hace sentir que tú también puedes ser grande"

Mark Twain (escritor estadounidense) 


\section{CAPÍTULO I.}

"Epidemiología y planteamiento inicial del Acoso Psicológico Laboral en puestos Directivos".

\section{Epidemiología y planteamiento inicial del Acoso Psicológico Laboral en puestos Directivos.}

El etólogo Konrad Lorenz, en 1963, estudiando un grupo de determinadas especies animales, se dio cuenta que en ciertas ocasiones los más débiles del grupo se acompañaban para atacar a otro más fuerte, refiriéndose y describiendo este fenómeno como "mobbing";

"Es curioso que, aparentemente, en ese momento los animales aborrecedores no muestran ningún temor del depredador al que aborrecen. Las golondrinas, las aguzanieves y otras aves de gran movilidad parecen mostrarse impertérritas ante las aves rapaces que surcan los aires. Esta reacción se denomina en inglés mobbing, lo cual supone con mucho acierto que una multitud de seres débiles unidos acosa a otros más fuertes, justamente como ocurre en el caso del aborrecimiento... Representa en todos los casos un simulacro de ataque contra un enemigo: sólo a título excepcional el potencial animal rapaz, el depredador, osa atacar de verdad. Resulta, pues evidente la finalidad de conservar la especie cuando se disuade de la caza al depredador, se persigue corriendo o nadando al ser aborrecido y se proclama a voces la posición de su guarida. Ello puede tener como consecuencia, entre las especies animales de larga vida y capaces de aprender, que ciertos lugares bajo la amenaza del animal rapaz queden desacreditados... El objetivo...no es por lo general, un rival de la misma especie, sino un peligro proveniente del exterior o un congénere que se sale del marco por causa de un comportamiento anómalo (por ejemplo, una enfermedad)"

(Lorenz, 1963, pp 154-155.) 


\section{CAPÍTULO I. EPIDEMIOLOGÍA Y PLANTEAMIENTO INICIAL DEL ACOSO PSICOLÓGICO LABORAL EN PUESTOS DIRECTIVOS.}

Lorenz, describió el mobbing, como "el ataque de una coalición de miembros débiles de una misma especie contra otro individuo más fuerte que ellos". Para él, la agresión que provoca daño físico en los demás se origina en un instinto de lucha que los seres humanos comparten con otros organismos vivos, llegando a concluir que la agresión es inevitable y surge, en ciertas ocasiones de forma espontánea. Por otro lado Lorenz señaló que las agresiones dentro de una misma especie animal son mínimas y habitualmente tienen justificaciones relacionadas con situaciones extremas.

Ciertamente no ocurre así con el ser humano. Dicho de otra manera, si bien la conducta agresiva animal es instintiva y puede responder al instinto de supervivencia, la agresión entre los conocidos como animales racionales parece ser una conducta aprendida, difícil de explicar la mayoría de las veces en función del beneficio de la especie.

En 1972, el médico sueco Peter Paul Heinemann adoptó el concepto de mobbing para definir una actividad similar en el mundo de los humanos; concretamente apreció cómo entre los niños de edades escolares, y en el tiempo entre clase y clase, se producía un comportamiento hostil muy destructivo, llevado a cabo por grupos de ellos sobre otros individuos que se encontraban aislados, situación que definió mediante el término "bullyng".

No fue hasta finales de los años 70 cuando el concepto de mobbing se traslada al campo de las relaciones humanas para hacer referencia al hostigamiento psicológico que hoy conocemos como tal. En 1976 Carroll M. Brodsky, psiquiatra norteamericano publica "The Harassed Worker", en la que por primera vez se emplea la palabra "harassment" para referirse al acoso psicológico en el trabajo, llegándose a afirmar que "el efecto del hostigamiento sobre las víctimas de acoso puede ser devastador".

Con todo y con ello no fue hasta los años 80, cuando comienzan a aparecer las primeras investigaciones científicas acerca del acoso psicológico laboral o mobbing. Es 


\section{CAPÍTULO I. EPIDEMIOLOGÍA Y PLANTEAMIENTO INICIAL DEL ACOSO PSICOLÓGICO LABORAL EN PUESTOS DIRECTIVOS.}

en algunos países escandinavos donde surge el interés por la temática, probablemente debido a que en estos países existen legislaciones que enfatizan en materia laboral y social de los trabajadores.

Así, en 1982 nace el primer estudio internacional acerca del fenómeno del mobbing, llevado a cabo en Suecia por Leymann y Gustafsson, cuyos resultados fueron publicados en 1984 por el National Board Of Occupational Safety and Health, en Estocolmo (Suecia) bajo el título "Psychological violence at the workplace: Two exploratives studies". La mayoría de los autores lo consideran como el verdadero padre del estudio científico sobre acoso psicológico en el trabajo.

En los años 90, el fenómeno del mobbing comienza a convertirse en materia muy habitual para los investigadores, extendiéndose la investigación desde los países escandinavos a otros países centroeuropeos y anglosajones, siendo a finales de esta década cuando se comienza a hacer referencia a este concepto en España. En 1999, el $30 \%$ de los trabajadores encuestados dijo haber sufrido acoso laboral, mientras que un $42 \%$ dijo haber sido testigo de esta conducta respecto a sus compañeros (Mac Donald, 2006).

Organismos como la Organización Internacional del Trabajo (OIT), la Organización Mundial de la Salud (OMS) y distintas universidades del mundo han estado trabajando en la investigación de este fenómeno, el cual atenta contra la integridad moral del trabajador, produciendo en él problemas psicológicos, físicos, sociales y familiares, que se traducen en depresiones, sentimiento de culpabilidad, estrés, ansiedad, pérdida de autoestima, irritabilidad, dificultad para concentrarse...entre otros efectos devastadores.

En un informe suministrado por la Organización Internacional del Trabajo (OIT) en el año 2004, un $6 \%$ de la población asalariada estaría afectada por este fenómeno, lo cual podría alcanzar cerca de un millón de trabajadores. 


\section{CAPÍTULO I. EPIDEMIOLOGÍA Y PLANTEAMIENTO INICIAL DEL ACOSO PSICOLÓGICO LABORAL EN PUESTOS DIRECTIVOS.}

Con la llegada de la globalización se produce una revolución tecnológica que trae consigo efectos laborales demoledores tales como contratos precarios o aumento del estrés laboral, que en buena medida obligan a pensar en profundidad sobre algunos aspectos laborales tan importantes como el propio concepto de trabajo.

Por tanto algunos autores como Alonso, Gallego y Ongallo en el año 2003 definen una organización de trabajo, como un grupo de personas, variable en número, con un fin común, y un grado variable de reglamentación, lo que la convierte en una organización social, por ello en las organizaciones de trabajo suelen estar contempladas las relaciones que se deben establecer entre los distintos individuos y grupos para la realización de las tareas encomendadas.

Según Pérez-Bilbao et al. (2001), los conflictos interpersonales en los entornos de trabajo, al igual que en otras áreas de la vida, pueden adoptar formas muy variadas y muy variables grados de intensidad, pudiendo ir desde desencuentros o encontronazos hasta situaciones de abierta hostilidad e incluso llegar a la emisión de conductas claramente agresivas y violentas, aunque el ser humano es capaz de generar conductas mucho más refinadas para hostigar y acosar.

El término mobbing deriva del verbo anglosajón to mob que significa asaltar o acosar, aunque hay que señalar que en un principio no se utilizó este término para describir el acoso psicológico en el trabajo tal y como es entendido hoy en día.

Actualmente en nuestra sociedad, el centro de trabajo constituye un lugar destacado e importante en nuestras vidas, debido a que en él pasamos unas 8 horas diarias o más. Las relaciones con los compañeros de trabajo en ocasiones están estrechamente vinculadas a las funciones que desempeñan. En las organizaciones, los trabajadores de acuerdo al rol organizacional que cumplen, están sometidos a un estado de subordinación laboral implicando necesariamente la conexión con un superior jerárquico que constituye una mayor posibilidad de acoso. 


\section{CAPÍTULO I. EPIDEMIOLOGÍA Y PLANTEAMIENTO INICIAL DEL ACOSO PSICOLÓGICO LABORAL EN PUESTOS DIRECTIVOS.}

El Acoso no sólo está presente en las actitudes y comportamientos que se muestran hacia la víctima o cómo se le trata, sino en la frecuencia con la que se ponen en práctica tales comportamientos y durante cuánto tiempo, es decir una comunicación hostil o una muestra de agresividad puede ser un indicio de un conflicto puntual y no tener mayores consecuencias para el individuo; es la repetición sistemática de tales comportamientos a lo largo de un tiempo prolongado lo que causa los efectos patológicos.

La violencia en el ámbito laboral ha alcanzado grandes dimensiones a nivel mundial, traspasando entornos de trabajo y grupos profesionales. Esta situación es preocupante ya que este tipo de violencia afecta y de qué manera a la calidad de vida de las personas, repercutiendo sobre su dignidad y afectando no sólo a la persona que lo sufre sino a todo su entorno personal y laboral.

España es uno de los países con más estudios sobre el mobbing y con más dominio público. El profesor Iñaki Piñuel ha estudiado el fenómeno a través de la creación de un cuestionario denominado Escala Cisneros, el cual ha permitido medir el porcentaje de la población afectada por acoso laboral cada año. Según Piñuel los sectores más afectados son la administración pública, la sanidad y la educación.

El trabajo de investigación que a continuación se presenta pretende abordar el fenómeno del mobbing en puestos directivos de centros residenciales, un sector que padece en la actualidad las consecuencias de la crisis en la que España está inmersa desde hace ya unos cuantos años, y que hace que se agudice aún más el acoso laboral.

Se pretende con ello realizar una investigación innovadora que aporte significativamente conocimiento a los trabajadores, en este caso directivos de centros residenciales. 


\section{CAPÍTULO I. EPIDEMIOLOGÍA Y PLANTEAMIENTO INICIAL DEL ACOSO PSICOLÓGICO} LABORAL EN PUESTOS DIRECTIVOS.

Así se plantean los siguientes:

- 1)Objetivos generales:

OG1: Poner de manifiesto la magnitud del acoso laboral, analizando el proceso, sus posibles causas, las variables intervinientes y los factores organizacionales influyentes, que dan o puedan lugar a la aparición del acoso laboral.

OG2: Determinar si existe acoso laboral en los puestos directivos de los centros residenciales en España.

- 2)Objetivos específicos:

OE1: Examinar si la edad es un elemento determinante a la hora de poder sufrir acoso laboral en puestos directivos.

$\checkmark$ OE2: Diagnosticar si existe relación alguna entre el sexo del sujeto y la aparición del acoso laboral.

OE3: Identificar si el estilo de liderazgo es un factor que pueda influir positivamente en el acoso laboral.

OE4: Constatar como aquellos directivos con menores competencias en el sector socio sanitario sufren un mayor acoso laboral. 


\section{CAPÍTULO I. EPIDEMIOLOGÍA Y PLANTEAMIENTO INICIAL DEL ACOSO PSICOLÓGICO LABORAL EN PUESTOS DIRECTIVOS.}

OE5: Inferir si la ambigüedad de rol puede considerarse como una de las causas del surgir del acoso.

OE6: Considerar si la justicia organizacional puede ser un factor desencadenante del acoso.

OE7: Establecer si puede existir una relación directa entre los resultados económicos de la empresa y el acoso laboral.

OE8: Confrontar como cuanto mayor es el grado de autonomía laboral del que dispone el directivo del centro residencial menor es el grado de acoso laboral.

OE9: Determinar si el acoso laboral tiene menor incidencia en aquellos directivos que experimentan una mayor satisfacción laboral.

OE10: Confirmar como el directivo acosado no tiene ninguna intención previa de abandonar su puesto de trabajo.

OE11: Verificar la relación existente entre el rendimiento y el acoso laboral en puestos directivos de centros residenciales.

OE12: Mostrar como la existencia de un mayor compromiso del directivo con la organización en la que desempeña su actividad laboral no es sinónimo de no ser objeto de acoso laboral.

OE13: Corroborar como un clima organizacional positivo hace que se reduzca el número de casos de acoso laboral en puestos directivos de centros residenciales. 


\section{CAPÍTULO I. EPIDEMIOLOGÍA Y PLANTEAMIENTO INICIAL DEL ACOSO PSICOLÓGICO LABORAL EN PUESTOS DIRECTIVOS.}

OE14: Analizar como el acoso laboral incide directamente en la finalización de las tareas en la dirección de un centro residencial.

\subsection{Introducción.}

El mundo laboral que nos rodea, reflejo de la sociedad en la que se integra, asume de forma rápida, intensa y poco segura, todos los cambios organizativos y de gestión que se plantean en aras de una mayor eficiencia y calidad de servicios, buscando el mayor beneficio empresarial y económico para los intereses de la empresa.En numerosas ocasiones, ocultos por la cuenta de ingresos y los resultados en balances más que positivos, se esconden toda una serie de fenómenos que surgen con fuerza e intensidad en el medio laboral y que de forma directa afectan al personal perteneciente a la empresa, sin distinción de edad, experiencia, sexo, raza, religión o puesto que se ocupe dentro de la propia organización.Los puestos directivos en centros residenciales no escapan a esta realidad cambiante. La rotación en los puestos de trabajo, las remuneraciones cada vez más ajustadas, los horarios inestables e incluso impredecibles que se llevan a cabo, el reciclaje continuo y extenso, la remuneración por objetivos como medida motivacional y en resumen el ambiente de extrema competitividad y ahorro en el que están inmersos los centros sociosanitarios son factores que comienzan a asumirse como un mal menor, en un momento en el que el empleo es un bien escaso y a conservar.

Esta situación nos puede hacer olvidar que el trabajo organizado de forma eficiente, óptima, correcta y garantizando la integridad y la dignidad de la persona constituye en sí mismo un medio para evaluar los niveles de salud.La salud del trabajador, entendida desde un punto de vista holístico, se ve afectada por estos cambios. 


\section{CAPÍTULO I. EPIDEMIOLOGÍA Y PLANTEAMIENTO INICIAL DEL ACOSO PSICOLÓGICO LABORAL EN PUESTOS DIRECTIVOS.}

del trabajo en nuestro país tras la aprobación de la Ley 31/1995 de Prevención de Riesgos Laborales.

Periódicamente los medios de comunicación y también en ocasiones los propios directivos y algunos profesionales de la prevención olvidan que, en el mundo laboral se desarrollan comportamientos que pueden llegar a producir la muerte de una persona, muerte que muy probablemente nunca se relacionará con su actividad laboral, y es que como dice el Profesor Leymann;

"el lugar de trabajo constituye el último campo de batalla en el que una persona puede matar a otra sin ningún riesgo de llegar a ser procesado por un tribunal"

Los problemas ocasionados en la salud del trabajador como consecuencia de un acoso moral no son los más visibles, pero sin lugar a duda si los más graves. Para detectarlos no existe un técnico de prevención capaz de enumerártelos, ni un compañero que venga a explicártelos, sino que en el mejor de los casos si la víctima es capaz de detectarlos los vivirá en soledad, apesadumbrado y a menudo incluso culpabilizándose de la situación en la que se encuentra, y cree él mismo se la ha buscado;

¿Me podrá estar pasando esto a mí? Pero con lo bien que iba todo ¿qué he hecho mal para que esto suceda? ¿Por qué nadie piensa o ve lo mismo que creo estoy viendo yo? ¿Me estaré equivocando y los demás llevaran la razón? No es posible que solo me pase a mí... ¿Estaré exagerando? ¿Será una mala racha que estoy atravesando y creo que todo me pasa a mí..?.

Estas son sólo algunas de las preguntas que una persona se puede llegar a hacer en una situación de tales características.

La investigación que se va a desarrollar enfoca el acoso laboral en puestos directivos en centros residenciales, también conocido como mobbing, el cual fue 


\section{CAPÍTULO I. EPIDEMIOLOGÍA Y PLANTEAMIENTO INICIAL DEL ACOSO PSICOLÓGICO LABORAL EN PUESTOS DIRECTIVOS.}

definido por el profesor Heinz (1996) como:

"Ia situación en la que una persona ejerce una violencia psicológica extrema, de forma sistemática y recurrente y durante un tiempo prolongado sobre otra persona o personas en el lugar de trabajo".

Esta definición como ya se ha mencionado con anterioridad data de los años 80 , década en la que comienza a denotarse un cierto interés sobre la temática. Dejando clara la importancia de conocer este fenómeno, es de suma importancia socialmente y para la población económicamente activa conocer su desarrollo dentro de una organización sociosanitaria, desde un punto de vista directivo.

Por parte de las organizaciones es importante evitar que este tipo de comportamientos se produzca ya que, no solo tiene incidencia en los trabajadores que lo padecen sino también en la productividad y en el clima empresarial.

Urquijo, en el año 2001 postulo que a medida que se desarrollan y expanden las organizaciones, las relaciones sociales tanto en la empresa, como en la sociedad alcanzan un inmenso auge, esto en gran medida, no solo por tratarse de relaciones que afectan fundamentalmente a la vida económica de las sociedades sino también porque la actividad laboral determina y conforma en gran parte al ser humano para satisfacer sus necesidades individuales y colectivas para seguir existiendo.

Por tanto podemos decir que la violencia psicológica en los puestos directivos se encuentra muy extendida en la actualidad, independientemente del nivel de desarrollo del país y sus circunstancias internas.

Es un fenómeno que no sólo no está en declive sino que tiende a expandirse en los próximos años. 


\section{CAPÍTULO I. EPIDEMIOLOGÍA Y PLANTEAMIENTO INICIAL DEL ACOSO PSICOLÓGICO LABORAL EN PUESTOS DIRECTIVOS.}

Parece evidente pues que nos encontramos ante un fenómeno real, extendido y muy perjudicial para diferentes ámbitos, y que ningún tipo de sector o industria está exento a la violencia psicológica, aunque aparentemente si existan grupos que potencialmente podrían ser más vulnerables a padecerlo.

Así , el mobbing, o acoso moral en el trabajo, ha irrumpido fuertemente en el escenario de lo sociolaboral, acompañado de toda la constelación de factores que caracteriza a dicho escenario y que amplifica aún más un fenómeno ya muy grave en su propio concepto, pero esa irrupción no es, en realidad, más que el inicio de la toma social de conciencia de un fenómeno grave, extendido y con consecuencias de alcance y complejidad poco conocidas hasta el momento; desconocidas pero nada nuevas, ya que posiblemente su etiología, tal y como se ha señalado con anterioridad, resida en el origen mismo de la división del trabajo y su evolucionar vaya ligado a éste (Cossío, 2003; Fuertes, 2004; Hernández, 2002; Moradillo, 2003; Polonio,2005).

Cabe señalar que lo que resulta evidente hoy en día es que la actitud hacia el acoso psicológico es muy distinta a cuando comenzó a estudiarse este complejo fenómeno en la década de los ochenta, dato que al menos supone una esperanza hacia un mejor futuro para numerosos investigadores de la materia ( Hoel et al.,2003; Vartia, 2004).

Las sociedades toleran cada vez menos este tipo de comportamientos, aunque a pesar de ello la violencia psicológica extrema existe y en qué grado en la actualidad. La crisis económica que padecemos es caldo de cultivo para aquellos que pretenden conseguir altas remuneraciones económicas a base de lo que sea y sin importarle lo más mínimo el daño que pueda causar.

En la mayoría de las ocasiones esto se enmascara pareciendo que sólo es válido el modelo de liderazgo totalitario y notorio más propio de nuestros antepasados que de los años en los que nos encontramos. 


\section{CAPÍTULO I. EPIDEMIOLOGÍA Y PLANTEAMIENTO INICIAL DEL ACOSO PSICOLÓGICO LABORAL EN PUESTOS DIRECTIVOS.}

"Este tipo de violencia, en la medida en que es contenida por ciertos límites sociales, se va desmaterializando cada vez más o psicologizando, (...). La violencia se va haciendo tanto más presente como invisible a los ojos de los observadores externos a la propia organización. El refinamiento de la violencia hasta convertirse en violencia psicológica se ha convertido en una constante en nuestros entornos laborales (...).

En pocas ocasiones, se encuentran agresiones físicas, siempre limitadas por un régimen disciplinario que penaliza tales formas externas y manifiestas de comportamiento. Más bien, la violencia abierta es sustituida por formas difusas o camufladas de violencia: la violencia psicológica o de "guante blanco".

Un tipo de violencia difícilmente acreditable ante un tribunal de justicia, pero que preside las reuniones, los comités, las reuniones de equipos, las negociaciones y hasta las charlas de media mañana ante una máquina de café."

Piñuel 2014.

El trabajo de investigación que a continuación se desarrollará poseerá un enfoque claramente descriptivo y por su carácter vigente e innovador pretende tener un aporte significativo al conocimiento de los trabajadores tanto de las organizaciones socio sanitarias privadas como públicas.

Así pues en las siguientes líneas abordaremos el resto de componentes de este primer capítulo; la delimitación conceptual del término mobbing, la diferente terminología que se ha utilizado a lo largo de la historia, algunos conceptos relacionados y las diferentes situaciones que aunque presenten cierta semejanza no pueden ni deben considerarse como acoso laboral. Además abordaremos las estadísticas más significantes y el tratamiento jurídico del término en España. 


\section{CAPÍTULO I. EPIDEMIOLOGÍA Y PLANTEAMIENTO INICIAL DEL ACOSO PSICOLÓGICO LABORAL EN PUESTOS DIRECTIVOS.}

\subsection{Delimitación Conceptual del término “Mobbing” o “Acoso Psicológico”.}

El propósito de las relaciones empresariales se centra o debería centrarse, en crear un ambiente armonioso, profesionalizado, supervisado y altamente productivo para los objetivos económicos de la empresa. Por esta razón es importante resaltar y profundizar en el estudio de nuevos fenómenos que surgen en el ambiente laboral y que ponen en riesgo el mismo y la salud del trabajador, como lo es el acoso laboral o mobbing, el cual como hemos resaltado en las líneas anteriores va creciendo y creciendo, creando así numerosos conflictos y de diversa índole en al ámbito laboral repercutiendo finalmente en la sociedad que nos rodea.

Desde el punto de vista directivo de un centro residencial nunca se ha de perder de vista la óptica de la importancia que tiene, para obtener éxitos profesionales y conseguir los objetivos empresariales perseguidos, el crear un clima laboral adecuado, el fomentar el compañerismo por encima de la competitividad, el crear unas relaciones humanas de calidad, el fomentar la escucha y participación de todos y cada uno de los trabajadores, haciendo así que todos formen un todo con unos únicos objetivos y fines comunes. Solo así se podrá conseguir crear un verdadero equipo de trabajo eficiente y con un alto rendimiento.

A menudo los directivos de estos centros se olvidan de que en el ámbito socio sanitario además de tener que obtener unos resultados económicos positivos se trabaja con personas.

La primera persona que estudió el fenómeno del mobbing en el sitio de trabajo y a su vez causante de patologías psicológicas y violentas en el trabajo, fue el psicólogo alemán Heinz Leymann, que en la década de los años 80, describió las consecuencias del acoso laboral "mobbing" en personas expuestas a un comportamiento hostil durante un tiempo prolongado por parte de sus mismos compañeros de trabajo o de los superiores y en ciertos casos hasta de subordinados. 


\section{CAPÍTULO I. EPIDEMIOLOGÍA Y PLANTEAMIENTO INICIAL DEL ACOSO PSICOLÓGICO LABORAL EN PUESTOS DIRECTIVOS.}

Toda esta investigación lo llevó a definir el acoso en las organizaciones en los años 80 , para posteriormente a principios de los años 90 exponer sus conclusiones en el "Congreso sobre Higiene y Seguridad en el Trabajo".

El acoso laboral, también conocido como hostigamiento laboral, acoso moral, o mobbing, es una sofisticada forma de persecución que persigue en última instancia la autoexclusión, inculpación y abandono del puesto de trabajo por parte de la víctima, exponiéndole a múltiples muestras de agresividad solapada, creándole un desgaste psicológico de grandes dimensiones.

Este hostigamiento, intimidación y perturbación a la persona permanece perpetuo hasta que se produce el abandono del puesto de trabajo. Este fenómeno "se inicia con una serie de conductas que persiguen calumniar, ofender, ridiculizar y conducir a la víctima al aislamiento del grupo" (Ventin, 2008).

Si algo caracteriza al acoso laboral es que en la mayoría de las ocasiones comienza de manera silenciosa con el fin de desestabilizar a la víctima tanto psicológicamente como físicamente.

Según el profesor Leymann, citado por Reyes (2002) las $\underline{45 \text { conductas }}$ constitutivas de mobbing son:

\section{Actitudes que intentan impedir que la víctima se exprese.}

Los compañeros de trabajo no le permiten expresarse.

$>$ Es interrumpida constantemente.

$>$ Los compañeros la critican.

$>$ El superior no le permite expresarse.

$>$ Critican su vida privada y su trabajo.

$>$ La aterrorizan con llamadas telefónicas. 


\section{CAPÍTULO I. EPIDEMIOLOGÍA Y PLANTEAMIENTO INICIAL DEL ACOSO PSICOLÓGICO} LABORAL EN PUESTOS DIRECTIVOS.

La amenazan verbalmente y por escrito.

Ignoran su presencia.

$>$ Evitan el contacto visual con la víctima.

\section{Aislamiento de la víctima.}

No permitirle que se exprese.

No hablarle.

Negar su presencia física.

Designarle un puesto de trabajo que la aísle de sus compañeros.

Prohibir a sus compañeros que le dirijan la palabra.

3. Desacreditar el trabajo de la víctima.

No confiarle ninguna tarea.

Exigiéndole tareas totalmente absurdas o inútiles.

Se le priva de toda ocupación.

Darla tareas superiores o muy inferiores a sus competencias.

Darle incesantemente tareas nuevas.

Hacerle realizar tareas humillantes.

4. Descrédito de la víctima frente a sus compañeros.

Lanzar rumores sobre ella.

Ridiculizarla o reírse de ella.

Murmurar sobre ella.

Intentar que parezca una enferma mental.

Burlarse de sus dolencias o minusvalías.

Imitar sus gestos, voz, etc.., solo para ridiculizarla.

Burlarse de su vida privada. 


\section{CAPÍTULO I. EPIDEMIOLOGÍA Y PLANTEAMIENTO INICIAL DEL ACOSO PSICOLÓGICO LABORAL EN PUESTOS DIRECTIVOS.}

Criticar sus convicciones políticas o creencias religiosas.

Reírse de su nacionalidad.

Comentar su trabajo de manera malintencionada.

Desautorizar las decisiones de la víctima.

\section{Comprometer la salud de la víctima.}

Amenazarla y agredirla físicamente.

Exigiéndola trabajos peligrosos o que podrían perjudicar su salud.

Ocasionarle gastos innecesarios solo para perjudicarla.

Agredirla sexualmente.

Estos comportamientos hostiles no son significativos si no es por su repetición, es decir es su frecuencia repetitiva y su intencionalidad consciente de hacer daño a la víctima lo que constituye el verdadero acoso.

Una de las primeras cuestiones que hay que plantearse en relación con el acoso psicológico en el lugar del trabajo tiene que ver con el propio término para identificar el mobbing (De Elena, 2005; Liefooghe, 2003; Mayhew y Chappell, 2001; Pérez Bilbao et al., 2001).

En la actualidad, aún no ha sido adoptada ninguna definición internacional consensuada de acoso moral en el lugar de trabajo (Einarsen y Hauge, 2006; Zapf, 2004). Por ello, existen una gran variedad de términos utilizados para definir el fenómeno mobbing, siendo además a menudo mal utilizados y confundidos unos con otros (Einarsen et al., 2003; Escudero y Poyatos, 2004; Keashly y Jagatic, 2003; Fiefooghe y Mackenzie, 2001, 2003). 


\section{CAPÍTULO I. EPIDEMIOLOGÍA Y PLANTEAMIENTO INICIAL DEL ACOSO PSICOLÓGICO LABORAL EN PUESTOS DIRECTIVOS.}

Esta variada terminología ha creado un importante problema a la hora de investigar el acoso laboral en puestos directivos de centros residenciales.

Si bien, si podemos decir que el perfil del ejecutivo o director general que tiende a cometer conductas de acoso en un centro socio sanitario, a expensas de lo que pueda arrojar esta investigación empírica, suele ser una persona de entre 55 y 60 años de edad, con una amplia trayectoria profesional, en la mayoría de los casos radicalmente opuesta al cargo que ostenta en la actualidad, con un alto ego, que no ha tenido una vida estable en la infancia, con gran capacidad para la oratoria y la escucha activa, con una imagen cuidada, capaz de transmitir un elevado nivel económico aunque este no sea tal, aparentemente encantador y sutil, con grandes dotes para el convencimiento, al que le gusta que sus propios trabajadores teman cuando entra por la puerta, tomando incluso está conducta como base para un liderazgo totalitario y silencioso, sin importarle para nada las circunstancias propias del centro ni las específicas de sus propios trabajadores, carente de escrúpulos, aparentemente perfeccionista aunque es incapaz de hacer una autocrítica ni de escuchar o tomar por bueno lo que sus más estrechos colaboradores le aconsejan o transmiten, celoso de su intimidad y de sus propios compañeros directivos de otras grandes empresas o grupos residenciales, con una gran avaricia económica y profesional, incapaz de ver lo que tiene delante de sus propios ojos, con una vida social elevada y al que le gusta reunirse prácticamente a diario con personas de elevado nivel social y económico, eminentemente políticos y cargos relevantes en el sector de los servicios sociales con el fin de aparentar ser un gran director general, algo de lo que carece. Todo ello lo abordaremos con mayor profundidad en el capítulo 4, de esta tesis.

A continuación se describirán algunas de las definiciones más destacadas, así como algunos conceptos íntimamente relacionados y otros términos más confusos y de gran divulgación que en nada se asemejan a una situación hostigante de mobbing. 


\section{CAPÍTULO I. EPIDEMIOLOGÍA Y PLANTEAMIENTO INICIAL DEL ACOSO PSICOLÓGICO LABORAL EN PUESTOS DIRECTIVOS.}

\subsubsection{Terminología destacada a lo largo de la Historia.}

El concepto de Mobbing o acoso laboral en el trabajo ha sido objeto de estudio a lo largo de la historia por diversos autores como hemos podido ver en apartados anteriores.

No ha sido banal su estudio y han sido diversas las matizaciones que cada autor ha aportado en un momento dado del tiempo.

Básicamente, y en lo que si están de acuerdos numerosos investigadores, es en que el hostigamiento psicológico en el trabajo hace referencia a aquellas situaciones en las que una persona o grupo de personas ejerce un conjunto de comportamientos caracterizados por una violencia psicológica extrema, de forma sistemática y prolongada en el tiempo, sobre una persona en el lugar de trabajo, manifestándose en forma de conflictos interpersonales y cuyo objetivo es eliminarla de la organización (Lahera y Góngora, 2002; Piñuel, 2001; Rodríguez-López, 2004).

Si cabe reseñar que el mobbing implica una agresión psicológica, pero ni física, ni de contenido sexual (González, Cabo, Martín y Franco, 2004; Escudero y Poyatos, 2004).

El acoso psicológico en el trabajo tiene como objeto intimidar, apocar, reducir, amedrentar y consumir emocionalmente e intelectualmente a la víctima (Leymann, 1996; Muñoz-Flores, 2006; Piñuel, 2001), por ello, los tres principales rasgos que diferencian el acoso moral de cualquier otro tipo de conflicto interpersonal en el medio laboral son la presencia de un agresor, o varios, la repetitividad de las conductas de acoso, la duración de la situación de hostigamiento y la existencia de una víctima que sufre las consecuencias (Leymann, 1996). A continuación profundizaremos en las definiciones más relevantes que han aportado algunos autores, así como a diversas definiciones aportadas por algunos estamentos sociales y académicos. 


\section{CAPÍTULO I. EPIDEMIOLOGÍA Y PLANTEAMIENTO INICIAL DEL ACOSO PSICOLÓGICO LABORAL EN PUESTOS DIRECTIVOS.}

En cuanto a los autores se refiere cabe destacar las siguientes definiciones:

\section{1) Heinz Leymann (1996).}

Fue el primer autor en sugerir una definición operativa del concepto mobbing (Zapf et al., 1996). Lo definió como "el encadenamiento a lo largo de un periodo de tiempo bastante corto de intentos o acciones hostiles consumadas, expresadas o manifestadas por una o varias personas hacia una tercera: el objetivo", además debe darse "una comunicación hostil y sin ética, que es dirigida de modo sistemático por uno (o varios) individuos contra otro, que debido a esta situación le coloca en una posición de indefensión y desvalimiento, y es activamente mantenido en ella. Este hecho suele ocurrir de una forma muy frecuente (al menos una vez a la semana) y durante un cierto tiempo (al menos seis meses de duración)."

\section{2) Marie France Hirigoyen (2001).}

Aporta una de las definiciones más destacadas a nivel internacional, en la que define el acoso moral en el trabajo como "toda conducta abusiva (gestos, palabras, comportamientos, actitudes) que atenta, por su repetición o sistematización, contra la dignidad o la integridad psíquica o física de una persona, poniendo en peligro su empleo o degradando el ambiente de trabajo, produciendo una destrucción insidiosa y fría mediante frecuentes ademanes de desprecio y de humillación de una persona hacia otra durante un periodo de tiempo largo. Se trata de una violencia son tregua que aniquila la autoestima de la víctima y la descalifica con una simple mirada o un cierto tono de voz. El agresor busca a menudo aliados entre el resto de trabajadores".

Esta es una de las definiciones más utilizadas por los investigadores Europeos, y una de las más relevantes a nivel científico. 


\section{CAPÍTULO I. EPIDEMIOLOGÍA Y PLANTEAMIENTO INICIAL DEL ACOSO PSICOLÓGICO LABORAL EN PUESTOS DIRECTIVOS.}

3) Ausfelder (2002).

Describe el fenómeno del mobbing como "el conjunto de actitudes vejatorias, que por regla general, se repiten una y otra vez durante un largo espacio de tiempo; estas implican fundamentalmente la intención del autor de perjudicar a la víctima o de desprestigiarla y en caso necesario expulsarla de su puesto".

4) Piñuel (2001).

Define el concepto de mobbing como "el deliberado y continuado maltrato moral y verbal que recibe un trabajador, hasta entonces válido, adecuado, o incluso excelente en su desempeño, por parte de uno o varios compañeros de trabajo (incluido muy frecuentemente el propio jefe), que buscan con ello desestabilizarlo y minarlo emocionalmente con vistas a deteriorar y hacer disminuir su capacidad laboral o empleabilidad y poder eliminarlo así más fácilmente del lugar y del trabajo que ocupa en la organización".

5) Zapf (2004).

Propone un modelo para ilustrar y facilitar la comprensión del mobbing, y sus distintas manifestaciones. Este modelo lo representa en forma de cinco círculos concéntricos (ver gráfico 1.1);

El círculo externo "considera los distintos conflictos sociales que pueden influir en una organización dada (por ejemplo, situación determinada del mercado laboral, condiciones particulares de un sector productivo o acciones señaladas como reestructuraciones de plantilla, fusiones etc...) que tienen capacidad para crear un clima negativo propicio para el aumento de la incertidumbre y el malestar de los trabajadores". 


\section{CAPÍTULO I. EPIDEMIOLOGÍA Y PLANTEAMIENTO INICIAL DEL ACOSO PSICOLÓGICO LABORAL EN PUESTOS DIRECTIVOS.}

El siguiente círculo "representa los conflictos laborales internos dentro de las organizaciones, las distintas situaciones de tensión que se producen en la empresa como consecuencia de una relación distante entre los trabajadores y la dirección, o entre los representantes de estos con aquella (por ejemplo, la conflictividad que puede originarse ante graves desacuerdos con las políticas organizativas, las luchas internas, etc...)".

El tercer círculo "representa las políticas organizativas que son percibidas como injustas por los empleados. Lo que denominamos "mobbing organizativo", donde se adoptan decisiones que son fuente de malestar (por ejemplo, imponer una política retributiva o de clasificación profesional de forma insatisfactoria para los trabajadores".

El cuarto círculo "conlleva la aparición de actos hostiles y negativos sobre algunos miembros de una organización (conductas que suelen estar representadas en las evaluaciones sobre mobbing). Estos actos suelen ser repetidos y frecuentemente sobre una o varias personas".

En el último círculo "estaría representado quien se siente el blanco y objetivo del acoso, y la percepción de víctima de mobbing, objeto de ataques continuos, directos y recurrentes".

Este es un modelo que representaría perfectamente el acoso a directivos en centros residenciales, resaltando en él lo que Zapf denominó segundo círculo y en el que otras cosas aparece la conflictividad originada fruto de las políticas organizativas y de liderazgo. 


\section{CAPÍTULO I. EPIDEMIOLOGÍA Y PLANTEAMIENTO INICIAL DEL ACOSO PSICOLÓGICO LABORAL EN PUESTOS DIRECTIVOS.}

Zapf en una revisión de las distintas investigaciones realizadas destacó además varios elementos característicos del mobbing: (1) Una frecuencia y una duración repetitiva y persistente de conductas hostiles, (2) Una acción que se ejerce mediante estas conductas, (3) Una serie de reacciones de las víctimas, (4) La intención del acosador, y (5) Un Desequilibrio de poder de las Partes.

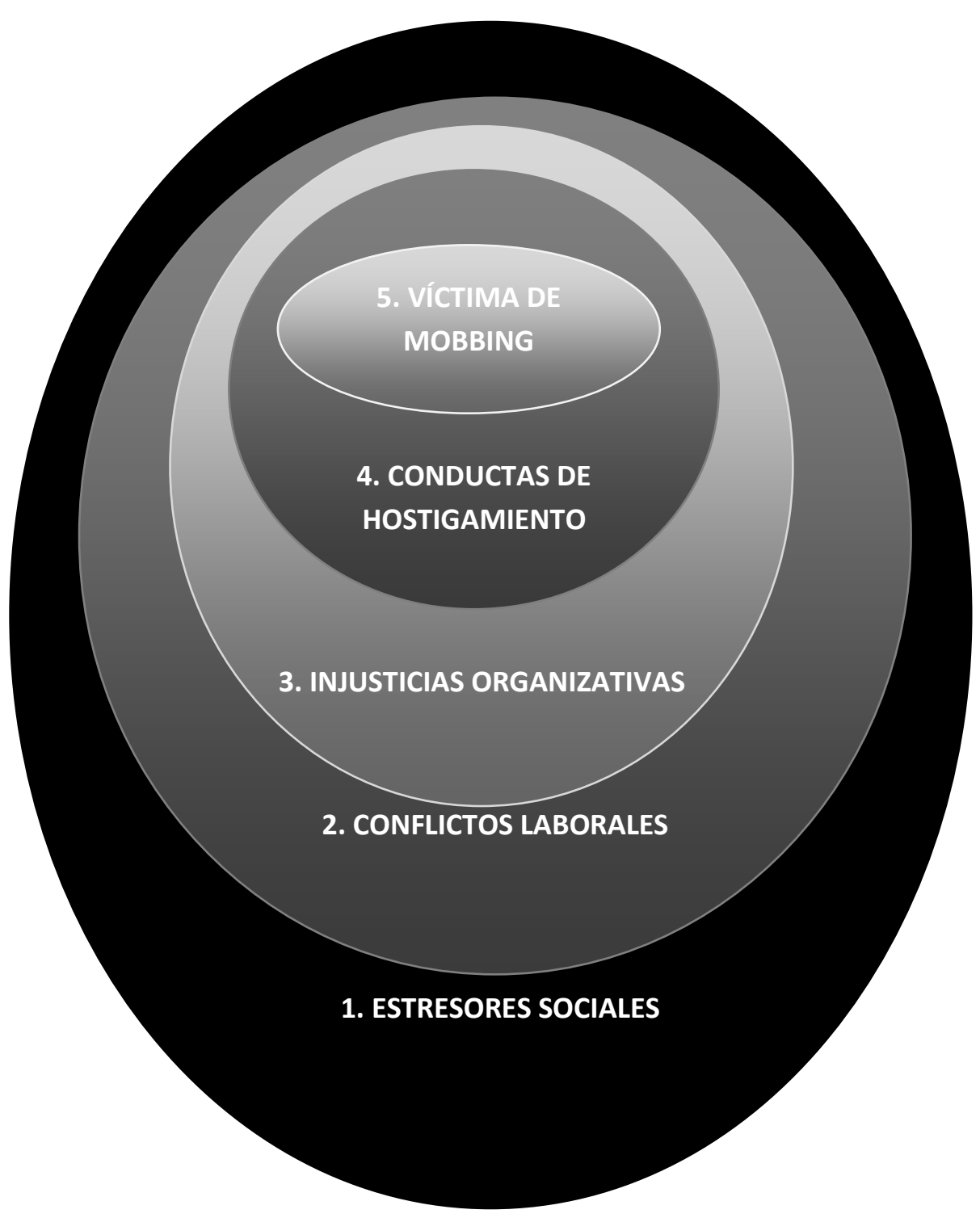




\section{CAPÍTULO I. EPIDEMIOLOGÍA Y PLANTEAMIENTO INICIAL DEL ACOSO PSICOLÓGICO LABORAL EN PUESTOS DIRECTIVOS.}

En cuanto a las diferentes instituciones y estamentos sociopolíticos cabe destacar las siguientes definiciones:

\section{1) La Unión Europea (2001).}

Definió el acoso moral en el trabajo como "un comportamiento negativo entre compañeros o entre superiores o inferiores jerárquicos, a causa del caul el afectado es objeto de acoso y ataques sistemáticos durante mucho tiempo, de modo directo o indirecto, por parte de una o más personas con el objetivo de hacerle el vacío. Entre las conductas de acoso moral se encuentran las que pretenden atentar contra la reputación de la víctima o contra el ejercicio de su trabajo" (López y Vázquez, 2003).

\section{2) PSOE en proposición de Ley (2001).}

Describía el acoso moral como "toda conducta abusiva o de violencia psicológica que se realiza de forma sistemática sobre una persona en el ámbito laboral, manifestada especialmente a través de reiterados comportamientos, palabras o actitudes que lesionen la dignidad o integridad psíquica del trabajador y que pongan en peligro o degraden sus condiciones de trabajo".

\section{3) El Instituto Nacional de Seguridad e Higiene en el Trabajo (1998).}

Relata el acoso psicológico en el contexto laboral como "una situación en la que una persona (o en raras ocasiones un grupo de personas) ejerce una violencia psicológica extrema, de forma sistemática y recurrente (como media una vez por semana) y durante un tiempo prolongado (como media unos seis meses) sobre otra persona o personas en el lugar de trabajo con la finalidad de destruir las redes de comunicación de la víctima o víctimas, destruir su 


\section{CAPÍTULO I. EPIDEMIOLOGÍA Y PLANTEAMIENTO INICIAL DEL ACOSO PSICOLÓGICO LABORAL EN PUESTOS DIRECTIVOS.}

reputación, perturbar el ejercicio de sus labores y lograr que finalmente esa persona o personas acaben abandonando su lugar de trabajo".

\section{4) Diccionario de la Real Academia Española (2001).}

En la vigésimo tercera edición del Diccionario de la Real Academia Española ya hay una mención de los conceptos de acoso moral o psicológico tomando como bueno "la práctica ejercida en las relaciones personales, especialmente en el ámbito laboral, consistente en un trato vejatorio y descalificador hacia una persona, con el fin de desestabilizarla psíquicamente".

A continuación describiremos algunos conceptos que están íntimamente relacionados con el acoso laboral.

\subsubsection{Conceptos relacionados.}

Existen numerosos términos utilizados por diversos investigadores que a continuación se describen, íntimamente relacionados con el mobbing:

\section{Harassment.}

Brodsky (1976) lo definió como "los intentos repetidos y persistentes por parte de una persona de atormentar, agotar, frustrar o lograr una reacción de otra persona; es un trato que se caracteriza por la provocación persistente, la presión, el enfrentamiento, la intimidación u otros modos de comportamiento que causan incomodidad a otra persona".

Björkqvist, Osterman y Hjelt-Bäck (1994) se refirieron "al conjunto de actividades repetidas con el fin de causar sufrimiento psicológico (aunque algunas veces también físico), y dirigido hacia uno o más individuos, que son capaces de defenderse por sí mismos". 


\section{CAPÍTULO I. EPIDEMIOLOGÍA Y PLANTEAMIENTO INICIAL DEL ACOSO PSICOLÓGICO LABORAL EN PUESTOS DIRECTIVOS.}

Vartia (1996) hacía mención a "situaciones donde una persona es expuesta repetidamente y durante cierto tiempo a acciones negativas por parte de una o más personas".

\section{Bullyng.}

Hadjifotiou (1983) define bullyng como "la serie de acciones repetidas y prácticas que se dirigen a uno o más trabajadores, que son indeseables, que pueden hacerse deliberada o inconscientemente, pero ocasionan la humillación, ofensa y distrés, que interfieren el desempeño o trabajo y/u ocasiona un ambiente de trabajo desagradable".

Adams (1992) lo matizó como "la crítica continua y abuso personal en público o en privado, con el fin de humillar y degradar a una persona".

Lyons, Tivey y Ball (1996) hablan de "conductas persistentes, ofensivas, abusivas, intimidatorias, maliciosas o insultantes, abuso de poder o amenaza de sanciones, donde el receptor se siente desconcertado, amenazado, humillado o vulnerable, que socavan su autoconfianza y que puede causar en ella sufrimiento".

O'Moore, Seigne, McGuire y Smith (1998) lo califican como "conducta destructiva. Agresión repetida verbal, psicológica o física dirigida a un individuo o grupo de individuos".

Hoel y Cooper (2000) lo describen como "la situación donde uno o varios individuos perciben ser receptores de acciones negativas de una o varias personas de forma persistente durante un periodo de tiempo, donde la víctima tiene dificultad para defenderse".

Salin (2001) se refiere a "comportamientos negativos repetidos y persistentes que se dirigen hacia uno o varios individuos, y que crean un ambiente hostil de trabajo. Cuando la víctima está sometida a este hostigamiento tiene dificultades para defenderse por sí misma; por lo que hace del conflicto una lucha de poder desigual". 


\section{CAPÍTULO I. EPIDEMIOLOGÍA Y PLANTEAMIENTO INICIAL DEL ACOSO PSICOLÓGICO} LABORAL EN PUESTOS DIRECTIVOS.

\section{Health Endangering Leadership.}

Kile (1990) lo define como "los actos de humillación y acoso continuos de larga duración por parte de un superior y son expresados abiertamente o de modo encubierto".

\section{Petty Tyranny.}

Ashforth (1994), hace referencia a "la situación en la que un superior utiliza su poder sobre los demás mediante la arbitrariedad, despreciando a los subordinados, mostrando escasa consideración, utilizando un estilo basado en la fuerza para resolver conflictos, impidiendo la iniciativa, y usando castigos no contingentes".

\section{Bossing.}

Escudero y Poyatos (2004) lo refieren como "una modalidad de acoso laboral, concretamente como un mobbing vertical descendente" que en capítulos siguientes definiremos.

$>$ ljime.

Luna e Hirigoyen (2004), hablan de ljime como el término japonés con el que se define el acoso laboral. El objeto del ijime consiste en "integrar a los individuos en el grupo y en acomodarles a las reglas, no siendo partidaria la organización laboral del individualismo".

\section{Psicoterrorismo.}

González de Rivera, Piñuel (2001) y Leyman en un principio lo usaban como sinónimo de mobbing, aunque su uso con el paso de los años ha ido decayendo a medida que se ha ido implantando el término mobbing. 


\section{CAPÍTULO I. EPIDEMIOLOGÍA Y PLANTEAMIENTO INICIAL DEL ACOSO PSICOLÓGICO LABORAL EN PUESTOS DIRECTIVOS.}

\section{Worktrauma o Workplace Trauma.}

Wilson (1991) toma como connotación, "la desintegración de la autoestima del empleado como resultado del tratamiento continuo, real o percibido, deliberadamente maligno o malévolo por parte de un empleador o supervisor".

\section{Acoso Institucional.}

González de Rivera (2002) lo define como "una forma especialmente grave de mobbing que cuenta con la permisividad y la colaboración del conjunto de la organización. El concepto tiene en cuenta la función que el acoso cumple en la dinámica del contexto o del grupo en que tiene lugar, la situación relacionada con ciertas políticas de empresa".

\section{Scapegoating.}

Thylefors (1987) hace uso de él para referirse "al acoso sufrido por una o más personas, durante un periodo de tiempo extenso, siendo sometidas estas y expuestas de manera repetida a acciones negativas".

\section{Acoso Grupal.}

Escudero y Poyatos (2004), describen este fenómeno como "síndrome del chivo expiatorio" y/o "síndrome del rechazo de cuerpo extraño".

Se aplica a situaciones en las que un sujeto es sometido a persecución, agravio o presión psicológica por uno o varios miembros del grupo al que pertenece, con la complicidad o la aquiescencia del resto, que acepta esta dinámica como necesaria para mantener la estabilidad del grupo, resultando habitual en organizaciones altamente reglamentadas y homogéneas".

Podemos decir que en la actualidad es un concepto funcionalmente inoperativo para hacer referencia al acoso laboral 


\section{CAPÍTULO I. EPIDEMIOLOGÍA Y PLANTEAMIENTO INICIAL DEL ACOSO PSICOLÓGICO LABORAL EN PUESTOS DIRECTIVOS.}

\section{Atestar.}

Escudero y Poyatos (2004), hacen uso de él. Pese a tratarse de un verbo no especialmente habitual en su empleo, puede decirse que se trata de un concepto inicialmente formulado por Leymann "para hacer referencia a situaciones de acoso laboral", continuando su empleo en la actualidad en los países escandinavos y en Alemania y en menor medida en Italia.

\section{Shunting.}

Escudero y Poyatos (2004) se refieren a "un supuesto en el cual al aislamiento, a la restricción de datos y de instrumentos necesarios y a la negación de las comunicaciones, se añade la encomienda de tareas de menor categoría en interés y la supresión de áreas de actividad claves".

\section{Whist Leblowing.}

Hostmaelingen, Severinsen, Matthiesen, Escudero y Poyatos (2004), lo describen como "la denuncia pública por un miembro de una organización de actos, omisiones, procedimientos o políticas organizativas que considera moralmente defectuosa, y cuya denuncia es considerada o tratada como errónea o falsa por las autoridades de la organización". La relación del Whistleblowing con el mobbing se inicia a partir de la reacción de la entidad denunciada.

\section{Goslight.}

González de Rivera (2002), Soria y Garrido (2005) lo definen como "una modalidad de acoso moral en la que el acosador, más que aterrorizar a la víctima, intenta debilitar su razón o hacerla dudar de sus propios sentidos y percepciones". 


\section{CAPÍTULO I. EPIDEMIOLOGÍA Y PLANTEAMIENTO INICIAL DEL ACOSO PSICOLÓGICO LABORAL EN PUESTOS DIRECTIVOS.}

Una vez hemos descrito en profundidad los términos más relacionados en investigación con el término mobbing pasaremos a describir aquellas situaciones que aún siendo muy similares no pueden ser consideradas como acoso laboral o mobbing.

\subsubsection{Situaciones que no deben interpretarse como acoso laboral.}

Si en los apartados anteriores se ha delimitado el acoso laboral abarcando la complejidad del concepto, la diferente terminología utilizada a lo largo de la historia por los investigadores del fenómeno, los conceptos más próximos, que hemos definido como conceptos relacionados, en estas líneas se hará referencia a aquellas situaciones que aún siendo muy semejantes, y en numerosas ocasiones pueden aparecer y se pueden dar junto con el Mobbing, no pueden considerarse como tales y han de distinguirse claramente del Acoso Laboral, aún siendo cierto que pueden llegar a ser generadoras de un malestar laboral.

Algunas de las situaciones que también ocasionan un gran sufrimiento, son las que a continuación se enumeran:

\section{Burn Out o "Síndrome del Quemado".}

Luna y Morán (2006) definen el Burn Out como "un estado de agotamiento físico y mental como consecuencia de factores estresantes en el lugar de trabajo".

Maslach y Jackson (1997) lo caracterizaron por "agotamiento emocional (disminución y pérdida de energía, fatiga), despersonalización (desarrollo de actitudes negativas, de insensibilidad y respuestas frías e impersonales hacia los receptores del servicio prestado) y la baja realización personal (tendencia a evaluar el propio trabajo de manera negativa)".

Piñuel (2003) diferencia claramente Mobbing de Burn Out, "en el Burnout los sujetos afectados se caracterizan por una pérdida de interés por su trabajo, pudiendo llegar incluso a ver a sus clientes o usuarios como verdaderos enemigos, 


\section{CAPÍTULO I. EPIDEMIOLOGÍA Y PLANTEAMIENTO INICIAL DEL ACOSO PSICOLÓGICO LABORAL EN PUESTOS DIRECTIVOS.}

en el mobbing los individuos que se configuran como agresores forman parte de la empresa".

\section{Estrés Laboral.}

Del Hoyo (2001) considera el estrés laboral como "la respuesta fisiológica, psicológica y de comportamiento de un individuo que intenta adaptarse a presiones internas y externas". Por tanto se puede afirmar que el estrés laboral surge cuando se da un desajuste entre la persona, el puesto de trabajo y la propia organización; por ello la persona percibe que no dispone de recursos y estrategias suficientes para afrontar la problemática laboral.

Peiró (1999) matizó que "puede ser desencadenado por diversos factores, entre los que destacan el ambiente físico de trabajo (ruido, vibraciones, iluminación y temperatura), los contenidos del puesto (variedad de las tareas y la complejidad del trabajo), la definición de rol, las relaciones interpersonales, las situaciones propias del desarrollo de una carrera profesional, los aspectos organizacionales y los aspectos relacionados con las nuevas tecnologías".

Así pues se puede afirmar y concluir que el concepto de estrés laboral es más amplio que el concepto de mobbing.

Psicológicamente es relevante destacar que el estrés es una reacción del organismo, un mecanismo de defensa innato como respuesta a una situación amenazante, mientras que el mobbing es una situación hostil, denigratoria y mitigante llevada a cabo meticulosamente por una persona hacia otra con fines definidos previamente.

\section{Sobrecarga e Infracarga Laboral.}

Almodóvar (2003) hizo hincapié en este concepto trasmitiendo que "si el trabajo, de forma transitoria, nos exige un esfuerzo excesivo o un esfuerzo 


\section{CAPÍTULO I. EPIDEMIOLOGÍA Y PLANTEAMIENTO INICIAL DEL ACOSO PSICOLÓGICO LABORAL EN PUESTOS DIRECTIVOS.}

insignificativo, podemos adaptarnos, pero si esta situación se repite de forma cotidiana, tanto el exceso de trabajo o sobrecarga laboral, como el hecho de no tener actividad ( Infracarga laboral), pueden convertirse en fuentes importantes de estrés y malestar personal".

\section{Tensiones Laborales.}

Los conflictos cotidianos, no han de confundirse con el mobbing. No es fácil desde un punto de vista directivo gestionar las ambiciones y egos profesionales, individuales, pero ante todo debe primar la profesionalidad y el rigor a la hora de tomar decisiones.

No existe puesto laboral en el que en un momento dado no exista cierta tensión siendo tomada incluso esta como positiva para algunos autores en términos de productividad. No obstante cabe señalar que una tensión laboral no resuelta, o resuelta de manera insatisfactoria puede dar lugar a situaciones y actitudes de acoso.

Escudero y Poyatos (2004) describen que "la acción organizativa empresarial, con sus imposiciones de orden y disciplina pueden ser fuente de malestar cuando no de frustración, ahora bien, no pueden calificarse como acoso laboral".

Velázquez (2002) aclara que "los enfrentamientos y antipatías entre el empresario y el trabajador (entre los que destaca fundamentalmente la violación de los derechos profesionales del trabajador afectado en su relación contractual laboral) no son constitutivos de una situación de mobbing propiamente dicha".

\section{Maltrato Empresarial.}

Soria y Garrido (2005) consideran el maltrato empresarial como "la exposición continuada al trabajador a unas condiciones de trabajo negativas inherentes a la 


\section{CAPÍTULO I. EPIDEMIOLOGÍA Y PLANTEAMIENTO INICIAL DEL ACOSO PSICOLÓGICO LABORAL EN PUESTOS DIRECTIVOS.}

tarea que desarrolla, sean físicas, higiénicas, ergonómicas, psicosociales, organizativas o sociales".

Angulo (2002) matiza que "la diferencia entre el acoso moral y el maltrato de la dirección radica en que el procedimiento de acoso es oculto, mientras que el maltrato empresarial resulta más evidente aunque no afecte a todos los trabajadores".

\section{Acoso Sexual.}

McGolgan (2004) define el acoso sexual en el lugar de trabajo como "aquellas ofensas de carácter verbal o físico con un alto contenido sexual que tienen lugar en el entorno laboral".

Si se debe tener en cuenta que en numerosas ocasiones el acoso sexual lleva implícito un alto contenido de meticulosidad sobre todo de carácter verbal con lo que el acosador cuida en detalle el dónde, cómo y cuándo acorrala a su víctima, proceso muy semejante en su forma al del Ciclo Manipulativo del mobbing.

Destacar además que en algunos casos el acoso laboral puede ser el resultado de la negatividad de la víctima a mantener relaciones sexuales o de otra índole con su acosador lo cual deriva en prácticas nocivas laboralmente para la víctima.

\section{Violencia en el lugar de Trabajo.}

La Organización Internacional del Trabajo (OIT) afirma que "la noción de violencia en el trabajo está evolucionando en el sentido de que ya se le concede tanta importancia a los comportamientos psicológicos como a los comportamientos físicos y que se reconoce plenamente el alcance de los actos de la violencia menor" (Bowie 2002).

A continuación en el Gráfico 1.2, se muestra un modelo de la violencia en el lugar de trabajo; 


\section{CAPÍTULO I. EPIDEMIOLOGÍA Y PLANTEAMIENTO INICIAL DEL ACOSO PSICOLÓGICO LABORAL EN PUESTOS DIRECTIVOS.}

Gráfico 1.2. Modelo de Violencia en el lugar de trabajo (2004).

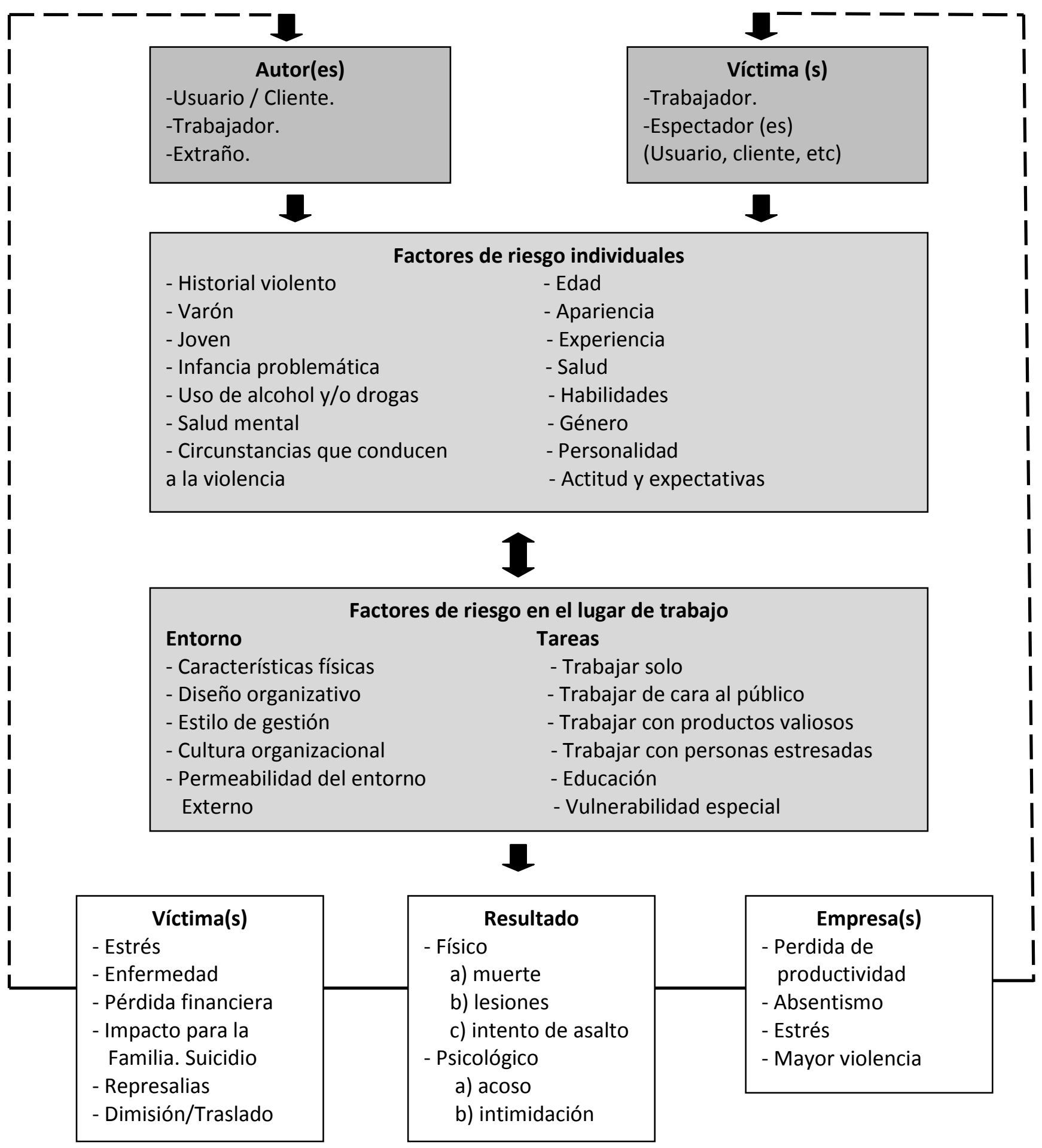

Fuente: Rogers, K. A. y Chappell, D. (2004). Prevención y respuesta a la violencia en el trabajo. Madrid: Ministerio de Trabajo y Asuntos Sociales. 


\section{CAPÍTULO I. EPIDEMIOLOGÍA Y PLANTEAMIENTO INICIAL DEL ACOSO PSICOLÓGICO} LABORAL EN PUESTOS DIRECTIVOS.

\section{Tecno Estrés.}

Rivas (2005), lo define como "la dificultad de adaptación a las nuevas tecnologías, situación caracterizada por la aparición de síntomas de ansiedad, depresión y sentimientos de incompetencia entre otros".

\section{Falso Mobbing.}

No todas las personas que dicen estar o haber sido acosadas lo están forzosamente, por lo que se debe prestar especial atención a estas situaciones que en la mayoría de los casos lo único que presentan son términos como los que hemos venido definiendo en este apartado; presiones en el trabajo, situaciones de tensión y estrés laboral, conflictos sin una resolución óptima o al menos así visto y vivenciado por el trabajador...

\section{Novatada.}

Se trata de un término español equivalente al francés bizutage y al inglés hazing; tratándose de una costumbre de origen medieval, consistente en gastar bromas toscas y pesadas a los nuevos miembros (González de Rivera, 2002).

A continuación daremos algunos de los datos estadísticos en los que se muestra una visión global del Mobbing, tanto es España y Europa, como en el resto de los países del mundo, con el fin de dar una óptica amplia del fenómeno ante el que nos encontramos. 


\section{CAPÍTULO I. EPIDEMIOLOGÍA Y PLANTEAMIENTO INICIAL DEL ACOSO PSICOLÓGICO LABORAL EN PUESTOS DIRECTIVOS.}

\subsection{El Mobbing en el Mundo; Cifras y Datos de Interés.}

En la actualidad, el nivel de competencia entre empresas es extremadamente alto, lo que conlleva a una serie de consecuencias positivas y negativas en el mundo organizacional y directivo. Los cambios constantes y las nuevas necesidades del mercado de trabajo, junto con la aparición de nuevas habilidades y competencias profesionales, forman el caldo de cultivo para aumentar la frecuencia del acoso laboral en puestos directivos de centros residenciales.

Las consecuencias negativas del mobbing, como veremos a lo largo de la investigación, son inmediatas, tanto en la salud de las víctimas, como en el aumento de los costes que se generan en las organizaciones. Resulta por tanto necesario promover la identificación y prevención del mobbing como un riesgo psicosocial derivado del trabajo.

El acoso laboral, como veíamos en líneas anteriores ha sido descrito históricamente por diversos científicos y psicólogos, pero la acusante crisis económica que está atravesando España, la mayor parte de Países Europeos y numerosos países de América, entre otros, y el número creciente de casos divulgados por los medios de comunicación ha puesto en primera línea de actualidad, un fenómeno que no es ciertamente nuevo, pero cuya prevalencia y crecimiento en los últimos años es verdaderamente alarmante.

Según la "Tercera Encuesta Europea sobre Condiciones de Trabajo en la Unión Europea", publicada por la Organización Internacional del Trabajo (OIT), en el año 2000, un 9\% de los trabajadores europeos han sido víctimas de mobbing, trece millones de personas.

En España, el porcentaje se sitúa en torno al $10 \%$, lo que tiene unos costes salariales de más de noventa millones de euros por las bajas laborales ocasionadas o por la invalidez profesional. 


\section{CAPÍTULO I. EPIDEMIOLOGÍA Y PLANTEAMIENTO INICIAL DEL ACOSO PSICOLÓGICO LABORAL EN PUESTOS DIRECTIVOS.}

Existen muchas dificultades para llegar a una medición "real", principalmente porque la información se recoge casi exclusivamente, de las manifestaciones realizadas por los afectados, quienes, la mayor parte de las veces, tienden a negarlo o minimizarlo (Randall, 1992).

Así, seguramente, estamos infravalorando la verdadera dimensión del mobbing, ya que admitir que se es víctima, es como aceptar que se ha fracasado en el afrontamiento del problema, lo que puede dañar la autoestima de quien lo asume (Einarsen y Skogstad, 1996; O'Moore y Hellery, 1989).

Debemos añadir, además que en las estimaciones sobre la incidencia de mobbing, existen diferencias según el país donde se analicen, el tipo de actividad laboral que se desempeñe, las distintas definiciones de mobbing que se adopten y los distintos criterios empleados para su evaluación.

Las investigaciones realizadas hasta el momento concluyen que:

1) La utilización de un criterio estricto y el autoetiquetado proporcionan índices de incidencia muy similares.

2) Las diferencias es las diferentes estimaciones nos dan una visión más amplia del significado de la incidencia en cada una de las organizaciones, y permite explicar cuestiones relacionadas con la naturaleza del fenómeno, las características de los sectores estudiados o de la evolución del mismo.

3) Para realizar una incidencia óptima y precisa, es recomendable la utilización de más de una estimación en los trabajos sobre incidencia.

En cuanto a los sectores económicos se refiere y los estudios realizados sobre las distintas ramas de la actividad empresarial, algunos estudios han mostrado que el mobbing es más común en la administración pública (14\%), en educación y salud (12\%), hoteles y restaurantes (12\%) y transportes y comunicaciones (12\%). (Di Martino, 2003). 


\section{CAPÍTULO I. EPIDEMIOLOGÍA Y PLANTEAMIENTO INICIAL DEL ACOSO PSICOLÓGICO LABORAL EN PUESTOS DIRECTIVOS.}

Por tanto, aunque el acoso laboral se practique en todos los trabajos donde el modo de organización lo permita, como vimos en el estudio de Di Martino, resulta evidente que existen puestos de trabajo donde los trabajadores están más expuestos a sufrir dicho tipo de conductas abusivas; de hecho, la mayoría de los estudios realizados así lo confirman, el acoso predomina mayoritariamente en el sector servicios, el sector medicosocial (donde encuadraríamos la dirección de centros residenciales), y la enseñanza, es decir en los sectores en los que las tareas no están bien definidas y donde es más fácil el reproche (Piñuel, 2004; Hirigoyen, 2001).

Con todo ello podemos afirmar que si hay un apartado en todo trabajo o estudio de mobbing, relativo, este es sin duda el relacionado con las estadísticas. Una vez hechas todas las consideraciones oportunas al respecto recogeremos en las siguientes líneas los resultados más destacados en cuanto a estudios recientes se refiere, analizando estos en España por un lado, y en Europa y el resto de países con mayor incidencia por otro, haciendo hincapié en los matices más elocuentes que podemos observar desde la óptica directiva.

\subsubsection{En España.}

España, es uno de los países con mayor número de casos de acoso laboral de la Unión Europea. Como hemos visto el índice estadístico se sitúa en torno al 10\% según las diversas investigaciones que se han llevado a cabo hasta el momento. Con el llamado "estado del bienestar" es de esperar, una serie de mejoras laborales que, deberían de afectar por encima del resto de sectores, al sector terciario y concretamente a los llamados "riesgos psicosociales".

Para diversos investigadores, la situación en nuestro país resulta preocupante, llegando estos a informar de que los principales focos donde se concentran un mayor número de casos, se encontrarían en la Comunidad de Madrid y Cataluña. 


\section{CAPÍTULO I. EPIDEMIOLOGÍA Y PLANTEAMIENTO INICIAL DEL ACOSO PSICOLÓGICO LABORAL EN PUESTOS DIRECTIVOS.}

Según estas estimaciones, al menos un $25 \%$ de la población activa española padecerá acoso psicológico laboral a lo largo de su carrera profesional (Cortés, 2001). El último informe de la "Fundación Europea para la mejora de las condiciones de trabajo", estimaba que en España, unas 800.000 personas sufrían acoso psicológico en sus actuales empleos (Piñuel, 2001).

Por tanto podemos afirmar que en nuestro país, los casos de acoso laboral son cada vez más frecuentes y habituales. La Organización Mundial del Trabajo ofrece datos de un $5 \%$ de trabajadores con este mal, lo que superaría ampliamente las 800.000 personas.

En España son muchos los investigadores, que han iniciado una recepción de la inquietud internacional sobre la materia, y a tales efectos se han llevado a cabo gran variedad de estudios, pero quizás por su divulgación sea necesario mencionar al psicólogo de la Universidad de Alcalá de Henares, Piñuel y Zabala, al difundir el Barómetro Cisneros sobre la materia, exponiendo como el acoso laboral tiene por objeto apocar, reducir, intimidar, consumir emocionalmente a la víctima, con vista a eliminarla de la organización o a satisfacer la necesidad patológica de su ego.

Piñuel (2001), con el objetivo de evaluar no sólo el mobbing en el entorno laboral de las organizaciones, sino también sus consecuencias más comunes, elaboró el llamado barómetro, primera herramienta que se utilizó en nuestro país para medir la prevalencia del fenómeno de acoso psicológico (Fidalgo y Piñuel, 2004).

Desde entonces los barómetros Cisneros (Cuestionario Individual sobre Psicoterror, Ninguneo, Estigmatización y rechazo en Organizaciones Sociales), han ido sucediéndose periódicamente, arrojando luz sobre importantes aspectos de nuestras relaciones laborales, siendo quizás el dato más significativo de todos ellos el que revela que el número de trabajadores afectados en España, supera los dos millones (Piñuel y Oñate, 2002). 


\section{CAPÍTULO I. EPIDEMIOLOGÍA Y PLANTEAMIENTO INICIAL DEL ACOSO PSICOLÓGICO LABORAL EN PUESTOS DIRECTIVOS.}

En la Tabla 1.1, se muestran, los diferentes Barómetros Cisneros sobre riesgos psicosociales, llevados a cabo;

Tabla 1.1. Últimos Barómetros Cisneros llevados a cabo.

\begin{tabular}{|c|c|}
\hline & $\begin{array}{c}\text { BARÓMETROS CISNEROS } \\
\text { (AÑO-MUESTRA-POBLACIÓN) }\end{array}$ \\
\hline o & Cisneros I. Año 2000-2001, n=980, Trabajadores de Todos los Sectores. \\
\hline o & Cisneros II. Año 2001-2002. n=2410, Todos los Sectores + S. Turismo. \\
\hline o & Cisneros III. Año 2002-2003, n=850, Sector Sanitario. \\
\hline O & Cisneros IV. Año 2002-2004, n=1000, Educación Universitaria. \\
\hline O & Cisneros V. Año 2004, n= 4200, Administración Pública. \\
\hline ○ & Cisneros VI. Año 2005, n= 4250, Comunidad de Madrid. \\
\hline ○ & Cisneros XI. Año 2008, n= 1250, Comunidad de Madrid. \\
\hline
\end{tabular}

Fuente: Instituto de Innovación Educativa y Desarrollo Directivo.

Así pues las conclusiones que podemos extraer del Barómetro Cisneros ${ }^{1}$, en España, son las siguientes; el acoso psicológico es una realidad para el $13^{\prime} 2 \%$ de los trabajadores en activo, ello supone más de 2,5 millones de trabajadores; en 3 años, la tasa de mobbing se ha incrementado en 4 puntos, lo que supone un $43 \%$ más de casos que en 2006; la crisis económica obliga a muchos más trabajadores a someterse al maltrato psicológico en el trabajo; el $70 \%$ de los casos se inicia durante el primer año de contrato; casi la mitad, el 42\%, presenta daños psicológicos; los hombres superan a las mujeres como víctimas de acoso; la tasa de mobbing entre mujeres llega al 10,70\% mientras que la tasa de mobbing entre varones se torna hasta el $15,80 \%$; referente al sexo de los acosadores, la mitad de las víctimas refieren a un hombre como acosador, mientras que una de cada cuatro víctimas refieren como acosadora a una mujer; el

\footnotetext{
${ }^{1}$ Fuente: Instituto de Innovación Educativa y Desarrollo Directivo.
} 


\section{CAPÍTULO I. EPIDEMIOLOGÍA Y PLANTEAMIENTO INICIAL DEL ACOSO PSICOLÓGICO LABORAL EN PUESTOS DIRECTIVOS.}

mobbing más habitual sería el ascendente (64\%), seguido del horizontal (18\%), y del ascendente (12\%); referente a la tasa de acoso por puesto destacan los mandos intermedios $(21,80 \%)$ donde podríamos encuadrar a los directivos de los centros residenciales, seguido de los operarios (16,50\%), mandos superiores $(13,20 \%)$, administrativos (12,60\%), y trabajadores calificados-especialistas-técnicos (11,60\%).

Referente a que suelen hacer las víctimas ante tal situación de hostigamiento: el $8,10 \%$ intentan cambiar de trabajo, el 2,70\% intentan cambiar de departamento o unidad, el 1,90\% habla con el médico de la empresa, el 4,50\% habla con el comité de empresa, el 0,60\% habla con salud laboral, el 5,90\% habla con el departamento de personal y recursos humanos, el 13,70\& habla con el jefe de su acosador si le hubiere, el $43 \%$ habla con un algún compañero, y el 19,60 no habla de ello con nadie, cifras sin duda preocupantes para cualquier empresa.

En cuanto a cómo responden habitualmente ante el acosador, el 18\% de manera pasiva, sin hacer nada, el 6\% agresivamente, intentando devolver la agresión, un 19\% con conductas sinérgicas y un $48 \%$ de manera asertiva.

Relacionado con que conductas explican o pueden explicar el comportamiento del acosador, un $7,40 \%$ lo atribuye a las políticas de empresa, un $5 \%$ a la promoción inadecuada del acosador, un 18,10\% a la envidia-los celos-o la rivalidad que experimenta el acosador, un $12,20 \%$ a la falta de formación del acosador, un 16,60\% al estrés, y el 20,10\% al desequilibrio emocional personal del acosador.

Las causas del mobbing, se explican, el $33 \%$ por la envidia, el $26 \%$ el éxito profesional de la víctima, el $21 \%$ no ceder ante el servilismo, el $16 \%$ la reivindicación de los derechos laborales, el $16 \%$ al éxito personal del trabajador, el $12 \%$ a suponer una amenaza, el $11 \%$ aparecer como vulnerable, el $11 \%$ ser diferente a los demás, el $11 \%$ conductas de solidaridad con otros compañeros, el $9 \%$ no querer participar en ilegalidades, y el 8\% por razón de género. 


\section{CAPÍTULO I. EPIDEMIOLOGÍA Y PLANTEAMIENTO INICIAL DEL ACOSO PSICOLÓGICO LABORAL EN PUESTOS DIRECTIVOS.}

Referente a la organización, podemos concluir que el 53\% de las organizaciones no disponen de protocolos específicos de actuación ante el mobbing; un $20 \%$ de las que disponen de protocolos de actuación, no los aplican; 2 de cada 3 víctimas sienten que son abandonadas por la organización; tan solo un $1 \%$ de los casos llegan a los tribunales en forma de denuncia.

En cuanto al estilo de liderazgo predominante (Management), el control, la jerarquía y la participación, el 35\% afirma que otras personas reciben el conocimiento del trabajo suyo; el 43\% dicen no recibir el adecuado reconocimiento por la realización de su trabajo; el $29 \%$ suele tener problemas en el trabajo para saber qué tiene que hacer; el $31 \%$ dice no tener claramente definidas sus funciones; el $25 \%$ no tiene claras cuáles son las características específicas de su puesto; el 32\% asume cambios continuados y frecuentes en la organización del trabajo; el 36\% no recibe, ni dispone de directrices claras para realizar su trabajo; el $42 \%$ dice que existe falta de de comunicación en el seno del grupo de trabajo; el $40 \%$ no suele participar en la toma de decisiones; el $38 \%$ sufre un control excesivo sobre su trabajo; el $37 \%$ no dispone de apoyo suficiente por parte de sus superiores y el $16 \%$ nota una ausencia de jerarquía eficiente.

Relacionando esto con el entorno de trabajo percibido, conflictividad, incidentes, rivalidad y competitividad se obtiene que, a menudo se producen faltas de respeto entre compañeros, los trabajadores compiten unos contra otros, existen rivalidades y envidias en el grupo de trabajo, cada día es más frecuente el no poder contar con el compañerismo y la colaboración de los compañeros en el desempeño de las funciones de trabajo y suelen producirse conflictos que nadie resuelve de manera óptima y eficaz.

Con todo ello los trabajadores perciben que aunque les evalúen el trabajo óptimamente no sirven para mucho, no tienen una igualdad de oportunidades de 


\section{CAPÍTULO I. EPIDEMIOLOGÍA Y PLANTEAMIENTO INICIAL DEL ACOSO PSICOLÓGICO LABORAL EN PUESTOS DIRECTIVOS.}

promocionar, existen además grandes discrepancias entre los valores personales y los de la organización de trabajo, realizan tareas que en numerosas ocasiones van en contra de sus principios y denotan falta de equidad en los salarios percibidos.

No obstante $y$ antes de finalizar este apartado resaltar como se ha dicho al comienzo del mismo, que si hay un capítulo con disparidad de resultados este es sin duda el relativo al estadístico, en lo que al mobbing se refiere. Por lo que respecta a nuestro país, la terminología directa del término anglosajón "mobbing" favorece una interpretación subjetiva y no formateada de lo que es en realidad este.

\subsubsection{En Europa y el resto de Países.}

En Europa, la violencia, la intimidación y el acoso psicológico son problemas cada vez más frecuentes en las organizaciones empresariales. Han sido los países nórdicos y especialmente Suecia, Noruega, Finlandia y Alemania, quienes más han trabajado sobre la materia y más producción científica han generado en relación al acoso laboral (Pérez-Bilbao et al., 2001; Salin, 2001).

La Agencia Europea de Seguridad y Salud en el Trabajo (European Agency for Safety and Health at Work), publicó el 31 de Enero de 2011, un informe, titulado "Workplace Violence and Harassment: a European Picture" (Violencia y Acoso Laboral: Una Panorámica Europea), en el que recoge datos sobre la prevalencia del acoso laboral, extraídos de estadísticas nacionales e internacionales referidas a países europeos, así como los principales resultados de estudios científicos en relación con los antecedentes y las repercusiones del mobbing para el trabajador y para la propia empresa.

Según se desprende de este informe, entre un 5\% y un $20 \%$ de los trabajadores europeos sufre violencia y acoso laboral, el porcentaje varía dependiendo del país, 


\section{CAPÍTULO I. EPIDEMIOLOGÍA Y PLANTEAMIENTO INICIAL DEL ACOSO PSICOLÓGICO LABORAL EN PUESTOS DIRECTIVOS.}

el sector y la metodología empleada. Por otro lado destaca que el $40 \%$ del personal directivo encuestado se muestra preocupado ante la violencia actual y el acoso psicológico en el puesto de trabajo. Tan solo el $25 \%$ de los directivos ha implantado medidas correctoras, y en la mayor parte de los países de la Unión Europea, este porcentaje no supera el $10 \%$.

Los datos arrojan mayores problemas de violencia y acoso laboral, en los sectores relacionados con la salud, el trabajo social y la educación, donde se estima que el $50 \%$ de los directivos consideran el mobbing como un grave problema de seguridad y salud en el trabajo.

Por tanto podemos afirmar que el acoso laboral tiene una gran repercusión en toda la Unión Europea lo cual tiene unas grandes repercusiones a todos los niveles. Los trabajadores sometidos a este tipo de circunstancias, presentan un claro y notable aumento de problemas de salud mental y malestar psicológico.

El informe de la Agencia Europea también advierte de los costes que el acoso laboral supone para la empresa, como veremos a lo largo de toda la investigación; descenso de la productividad, repercusión negativa en la imagen de la compañía, mayor rotación de personal (lo que supone una gran inestabilidad para todo el personal que conforma la organización), pérdidas económicas en litigios jurídicos, pérdida de personal cualificado y formado en las necesidades de la propia empresa, adelanto de la jubilación anticipada provocada por incapacidad... Con todo ello dicha agencia señala que el acoso laboral es un problema que no solo afecta a un país o región, sino que es un problema que afecta a la sociedad en general.

Los gobiernos Europeos adolecen de una falta de sensibilización y de una escasa atención a este grave problema, puesto que sería urgente expandir las buenas prácticas empresariales que sean sensibles a esta realidad, como resaltan numerosos letrados de la abogacía. 


\section{CAPÍTULO I. EPIDEMIOLOGÍA Y PLANTEAMIENTO INICIAL DEL ACOSO PSICOLÓGICO LABORAL EN PUESTOS DIRECTIVOS.}

A continuación se exponen las cifras más representativas acerca del acoso laboral en el contexto laboral en distintos países europeos, así como algunos que se han considerado a tener en cuenta:

- Alemania.

En Alemania se estima que el acoso laboral afectaría al 9\% de la población activa. En cuanto a la duración del acoso que sufren las víctimas cabe resaltar que oscilarían entre los 24 y 46 meses, mientras que sobre el número de acosadores hay que destacar que en el $50 \%$ de los casos se trataría de grupos de dos a cuatro hostigadores (Zapf et al.,2003).

Destacan los estudios de investigadores tales como Minkel (1996) que basó sus estudios en los trabajadores de una clínica de rehabilitación, Mühlen (2001), cuyos estudios se centraron en trabajadores de la administración pública, o Von Astfeld (2003) que reflejó sus estudios centrándose en el estudio de las fuerzas armadas germanas y trabajadores de la administración pública alemana. (Ibíd., 2003).

- Austria.

La OIT (Organización Internacional del Trabajo), señala en Austria ${ }^{2}$ una prevalencia del mobbing entorno al $6 \%$ de la población activa. Se aprecian índices similares a los encontrados en los países escandinavos. En el 52\% de los casos de las situaciones detectadas a través de las investigaciones realizadas, se hallan grupos de dos a cuatro acosadores.

Cabe reseñar las investigaciones llevadas a cabo por Niedl (1995), basándose en empleados hospitalarios, y en trabajadores de un instituto de investigación austriaco (Zapf et al., 2003).

\footnotetext{
${ }^{2}$ Cabe destacar que Austria, introdujo en Enero de 2002, la obligación de consultar a psicólogos en empresas de más de cincuenta empleados si se consideran elevados los riesgos psicosociales asociados al entorno de trabajo, siendo su función el establecimiento de medidas preventivas (Arroyuelo,2002).
} 


\section{CAPÍTULO I. EPIDEMIOLOGÍA Y PLANTEAMIENTO INICIAL DEL ACOSO PSICOLÓGICO LABORAL EN PUESTOS DIRECTIVOS.}

- Bélgica.

La OIT cifra en un $11 \%$ la prevalencia del acoso laboral en este país. La ley del 11 de Junio de 2002, referente a esta temática, en este país, uno con las tasas más altas, sobre la protección contra la violencia, impone un conjunto de obligaciones a los empresarios al objeto de reducir el riesgo de violencia en el lugar de trabajo, y a los trabajadores les exige una participación activa en la prevención.

- Dinamarca.

Dinamarca tiene una tasa próxima al 7\% de la población según la OIT. Por tanto el acoso laboral es un fenómeno bien conocido en este país. En la mayoría de las ocasiones este tipo de acoso cometido es horizontal, es decir entre iguales (Hogh y Dofradottir, 2001).

Las investigaciones más relevantes llevadas a cabo son las realizadas por Hogh y Dofradottir (2001) basadas en muestras aleatorias de trabajadores pertenecientes a cualquier sector. Destacan también los estudios de Mikkelsen y Einarsen (2001), encontrando estos cifras dispares en la conclusión de sus investigaciones.

- Finlandia.

En Finlandia nos encontramos con tasas según la OIT del 15\%. Un dato a destacar en las investigaciones llevadas a cabo hasta el momento en Finlandia es que un $32 \%$ de la población activa reconoce no haber padecido acoso laboral pero si haberlo observado en otros compañeros de trabajo, por lo que la estimación probablemente será aún mayor en términos estadísticos.

Destacan los estudios realizados al respecto por Paanamen y Vartia (1991) basados en una muestra de visitadores médicos y los de Björkqvist (1994) tomando como muestra trabajadores universitarios, entre otros. 


\section{CAPÍTULO I. EPIDEMIOLOGÍA Y PLANTEAMIENTO INICIAL DEL ACOSO PSICOLÓGICO LABORAL EN PUESTOS DIRECTIVOS.}

- Francia.

La OIT acerca al 10\% la prevalencia del acoso psicológico en los puestos de trabajo para el país galo. La figura que hemos de destacar en Francia es Marie France Hirigoyen, figura destacada en el estudio de acoso laboral y mobbing a nivel internacional.

Hirigoyen en sus estudios enfatiza en la circunstancia del género femenino como grupo de mayor riesgo para ser víctima del acoso laboral (Escudero y Poyatos, 2004).

- Grecia.

Grecia es un país en el que el mobbing es algo prácticamente circunstancial, si cabe destacar, que la actual crisis económica que ha afectado duramente al país y que aún torna en sí las consecuencias, han propiciado un mayor número de casos.

La OIT cifra la prevalencia del mobbing para el país griego entorno al $5 \%$ de la población, cifras muy bajas en comparativa con el resto de los países que conforman la unión europea como se puede observar a lo largo de este capítulo. Resaltar además que no existen apenas investigaciones al respecto dignas de ser mencionadas.

- Holanda.

Holanda en un país con muchos matices en lo relativo a materia laboral; si algo destaca allí es que la prevalencia del acoso laboral es muy distinta en cada sector estudiado, aunque destacan fundamentalmente los puestos financieros, administrativos y en el ámbito educativo como, como sectores con mayor riesgo de padecerlo.

La OIT estima un 14\%, cifra muy elevada y preocupante para las autoridades holandesas. 


\section{CAPÍTULO I. EPIDEMIOLOGÍA Y PLANTEAMIENTO INICIAL DEL ACOSO PSICOLÓGICO LABORAL EN PUESTOS DIRECTIVOS.}

- Hungría.

En Hungría el acoso laboral es un fenómeno apenas estudiado. La OIT, estima su prevalencia allí oscila entre el 5 y el $6 \%$ de la población activa, aunque algunos autores cifran en un porcentaje sensible menor el número de casos existentes.

Destacar que en el $62 \%$ de los casos estudiados, las situaciones de acoso se han desarrollado por un gran número de acosadores, entre 2 y 4 . (Kaucsek y Simon, 1995). Estos mismos autores llevaron a cabo, en 2006 una investigación tomando como muestra a personal de las fuerzas armadas, trabajadores de banca e inspectores de hacienda.

- Irlanda.

Irlanda es un país con una elevada tasa de acoso laboral. La OIT, cifra en un $10 \%$ los casos de acoso laboral en este país. La cifra es contradictoria con uno de los estudios más relevantes llevados a cabo por O'Moore (2000), realizado con una muestra aleatoria de 1.009 trabajadores y en el que encontró tasas cercanas al $17 \%$.

El ámbito de mayor prevalencia en el que se produce este fenómeno en Irlanda lo podemos encontrar en el sector educativo (Minton y O'Moore, 2004), con una media de duración de 41 meses.

- Italia.

Es uno de los países con menor tasa de acoso laboral de toda la Unión Europea. La OIT arroja cifras de entorno al $4 \%$ de prevalencia, lo que le convierte en uno de los países con mejores políticas respecto al acoso en materia laboral.

Cabe reseñar las investigaciones llevadas a cabo por Ege (2002) y por Gilioli (2004). 


\section{CAPÍTULO I. EPIDEMIOLOGÍA Y PLANTEAMIENTO INICIAL DEL ACOSO PSICOLÓGICO LABORAL EN PUESTOS DIRECTIVOS.}

- Lituania.

Es el país de la Unión Europea en el que menos estudios encontramos al respecto. La OIT, da elevadas cifras de acoso, en torno al 13\% de la población activa.

Malinauskiene (2004), realizó uno de los escasos estudios existentes en este país, para lo que estudió una muestra de 54 profesores universitarios, encontrando que un $13,9 \%$ decían haber sido víctimas de acoso laboral.

- Luxemburgo.

Luxemburgo conforma uno de los países con mayores tasas de acoso laboral dentro de la Unión Europea. La OIT, arroja cifras de entre un 7 y un 8\%. Paralelamente cabe destacar pese a la importancia de la cifra y lo alarmante de la situación, las escasas investigaciones que se llevan a cabo en este país, siendo apenas existentes los estudios llevados a cabo.

- Noruega.

En Noruega la OIT aproxima la cifra, hasta el $10 \%$ de casos de la población activa. Resaltar además que es uno de los países en el que se han llevado a cabo mayor número de investigaciones sobre mobbing de toda la Unión Europea.

De entre todos los estudios es relevante señalar el llevado a cabo por Einarsen y Raknes, (2000), que pusieron su énfasis en una muestra de 2.215 trabajadores afiliados a diversas organizaciones sindicales. Además de este destacan en Noruega los estudios llevados a cabo por Skogtad y Einarsen (1996), debido a entre otras circunstancias, a la muestra del estudio, compuesta por 7.787 trabajadores, pertenecientes a 14 sectores laborales diferentes. Las conclusiones arrojaron que la mayor parte de las víctimas serían hombres, mayores de 45 años. 


\section{CAPÍTULO I. EPIDEMIOLOGÍA Y PLANTEAMIENTO INICIAL DEL ACOSO PSICOLÓGICO LABORAL EN PUESTOS DIRECTIVOS.}

- Portugal.

Portugal es uno de los países en los que menor conciencia se ha tomado del acoso laboral. La OIT referencia una prevalencia del $4 \%$ en el país vecino con lo que estaría en cifras medias de la Unión Europea.

Los estudios más destacables son los llevados a cabo por Cowie (2000) tomando como muestra a 221 trabajadores pertenecientes a una multinacional.

- Reino Unido.

El Reino Unido suma una de las mayores tasas de toda la Unión Europea, según la OIT, cifras con una prevalencia cercana al 14\%. Podemos señalar incluso que la mayor parte de los estudios llevados a cabo arrojan cifras muy superiores, algunas incluso llegando a hablar de un 33\% de la población activa, lo que conllevaría a situar al Reino Unido como el país con mayores tasas y menos seguro en lo que a materia laboral se refiere.

El estudio de mayor relevancia es el de Hoel, Cooper y Faragher (2001), basándose este en los datos obtenidos a partir de una muestra de 5.288 trabajadores, pertenecientes a setenta organizaciones diferentes, encontrando una mayor prevalencia en las que se dedican a las tecnologías de la información y telecomunicaciones, el profesorado escolar y universitario y el personal que podríamos definir de prisiones (Piñuel, 2001).

Por último señalar que en el Reino Unido el acoso vertical descendente es el tipo de acoso predominante en todos los estudios desarrollados (Hogh y Dofradottir, 2001).

Con todo ello podemos afirmar que los costes laborales en este país son muy significativos, cifrándose las pérdidas anuales que el acoso produce en el país británico en 18,9 millones de jornadas laborales perdidas (Piñuel, 2001). 


\section{CAPÍTULO I. EPIDEMIOLOGÍA Y PLANTEAMIENTO INICIAL DEL ACOSO PSICOLÓGICO LABORAL EN PUESTOS DIRECTIVOS.}

- Suecia.

Hablar de Suecia en materia de acoso laboral, es hablar de uno de los mayores referentes en cuanto a estudios se refiere. Es el país que más ha enfatizado siempre en la prevención de las causas organizativas y ambientales susceptibles de generar violencia en el lugar de trabajo, y en la responsabilidad de los empresarios para desarrollar y llevar a cabo políticas activas que reduzcan los riesgos y aseguren un ambiente físico y psicológico positivo y respetuoso (Arroyuelo, 2002).

La OIT, cifra en torno al $12 \%$ la prevalencia de casos en Suecia, cifra de extrema gravedad si tenemos en cuenta la cantidad de políticas llevadas a cabo en este país para salvaguardar la salud laboral de los trabajadores como hemos señalado en líneas anteriores.

Cabría reseñar numerosas investigaciones, pero de entre todas ellas resaltaremos las llevadas a cabo por Leyman, uno de los investigadores pioneros en el estudio de este fenómeno. Las conclusiones que podemos extraer de las mismas, concluyen que el acoso psicológico mayormente se produciría en los ambientes sanitarios y educativos.

Destacar por último como dato especialmente preocupante que en Suecia entre un 7 y un $17 \%$ de los suicidios son atribuidos al hostigamiento psicológico en el lugar de trabajo (Leymann, 1996).

Debemos concluir este estudio estadístico europeo haciendo de nuevo hincapié en la dificultad para la obtención de estas cifras, debido en gran medida a los óbices encontrados a la hora de realizar los estudios y las muestras llevadas a cabo.

Una vez estudiadas las estadísticas de los países de la Unión Europea, profundizaremos ahora en algunos países del resto del mundo donde el acoso laboral representa una amenaza real para los trabajadores: 


\section{CAPÍTULO I. EPIDEMIOLOGÍA Y PLANTEAMIENTO INICIAL DEL ACOSO PSICOLÓGICO LABORAL EN PUESTOS DIRECTIVOS.}

- Australia.

Australia presenta una prevalencia del 10,5\% según la OIT. Representa por tanto un elevado número de casos de acoso laboral fuera de la Unión Europea. Los estudios e investigaciones en este país son escasos, cabe citar los llevados a cabo por Knott (2004), con un estudio sobre una muestra de 158 empleados de prisiones, donde encontró resultados aún mayores a los ya dados por la OIT.

- Brasil.

En la actualidad, y pese a la crisis económica que azota a la economía global, Brasil es uno de los considerados países emergentes en el ámbito económico, donde numerosas empresas ven una oportunidad de negocio.

La cifra dada por la OIT es del 15,6\%, resultando los estudios llevados hasta el momento muy escasos y puntualmente realizados. Podemos destacar en él que el sector más castigado, y en el que más casos de acoso laboral se dan, es en el sector sanitario.

- Canadá.

La OIT cifra en un $11 \%$ la prevalencia del mobbing en este país, dato alarmante, unos resultados preocupantes, teniendo en cuanta además que casi un $7 \%$ de la población, afirma haber sido testigo directo de escenas de acoso en el lugar del trabajo.

En cuanto a las víctimas que suelen padecerlo sorprende contra los resultados obtenidos en la Unión Europea, que en la mayoría de los casos serían mujeres (71\%).

Resaltar además que Canadá es uno de los países que en la actualidad más preocupación social muestra por el contexto laboral de sus trabajadores, poniendo con asiduidad en marcha políticas laborales. 


\section{CAPÍTULO I. EPIDEMIOLOGÍA Y PLANTEAMIENTO INICIAL DEL ACOSO PSICOLÓGICO LABORAL EN PUESTOS DIRECTIVOS.}

- Colombia.

Para Colombia la OIT arroja resultados de un $9 \%$ de prevalencia en casos de acoso laboral. Recientemente ha sido aprobada una ley pionera en Latinoamérica en lo que al acoso laboral se refiere, concretamente la Ley 1010 del 23 de Enero de 2006, cuyo objetivo es definir, prevenir, corregir y sancionar las diversas formas de agresión, maltrato y en general, todo ultraje a la dignidad humana que se ejerza en el ámbito laboral de las personas.

- Estados Unidos.

La OIT cifra en casi un $21 \%$ la prevalencia de las conductas acosadoras en los Estados Unidos. La encuesta nacional sobre la ética en los negocios del año 2003, revela que entre los tipos de mala conducta llevados a cabo, la más frecuente es la intimidación y el comportamiento abusivo. Además y pese a ser la primera potencia económica mundial encontramos que un $44 \%$ de los empresarios no divulga manuales de buenas prácticas profesionales.

Resaltar, que el acoso laboral tiene una mayor prevalencia allí que el acoso sexual, o las conductas racistas, y que uno de cada cinco trabajadores han sido víctimas de esta problemática, siendo las mujeres víctimas más habituales que los hombres, situación que, como hemos visto en líneas anteriores, no se da en Europa.

- Japón.

La OIT cifra en Japón una prevalencia del $29 \%$ de la población activa, con lo que estaríamos ante la mayor cifra global dada hasta el momento por un organismo oficial. La recesión económica que azotó en los años 90 al país le condujo a unas precarias condiciones laborales. Además, resulta interesante destacar la preocupación existente por las muertes por exceso de trabajo (karoshi). (Hurrel, 1998). 


\section{CAPÍTULO I. EPIDEMIOLOGÍA Y PLANTEAMIENTO INICIAL DEL ACOSO PSICOLÓGICO LABORAL EN PUESTOS DIRECTIVOS.}

- Sudáfrica.

Es uno de los países africanos pioneros en el estudio y preocupación de las condiciones laborales. Es uno de los países fundadores de la OIT y aunque en la actualidad no disponemos de cifras exactas, los datos existentes hasta el momento indican que el $78 \%$ de la población activa ha padecido conductas de acoso a lo largo de su vida laboral. La OIT cifra la prevalencia entorno al $20 \%$. (Cassitto, 2002).

Con el estudio estadístico de los países no europeos concluimos las estadísticas mencionadas con el fin de relatar y mostrar la magnitud del fenómeno a nivel global. A continuación haremos un análisis exhaustivo del tratamiento jurídico y legal que se hace del acoso laboral en el territorio español.

\subsection{Jurisprudencia, Tratamiento y Marco Legal Español.}

"En realidad, a nuestro juicio, la persistente atipicidad legislativa no obsta en modo alguno para afirmar su tipicidad jurídica, en tanto que están creadas las condiciones básicas necesarias para comprender en términos jurídicamente significativos esta forma de resolución violenta de conflictos laborales" 3

En las siguientes líneas, se pretende facilitar una revisión general de la jurisprudencia, el tratamiento y el marco legal español relacionado con el mobbing. Primeramente se ha de incidir y de poner en relieve, que a día de hoy, el ordenamiento jurídico español no contempla de forma específica el acoso en el lugar de trabajo.

\footnotetext{
${ }^{3}$ Cristóbal Molina Navarrete. "La tutela frente a la violencia moral en los lugares de trabajo: entre prevención e indemnización”. Aranzadi Social. Revista Quincenal n⒙ Enero 2002, pág. 56.
} 


\section{CAPÍTULO I. EPIDEMIOLOGÍA Y PLANTEAMIENTO INICIAL DEL ACOSO PSICOLÓGICO LABORAL EN PUESTOS DIRECTIVOS.}

Si cabe reseñar que el 15 de Diciembre de 2006, resultó aprobada por el Consejo de Ministros la modificación del Código Penal, reforma mediante la cual el acoso laboral quedó tipificado como delito, con penas de prisión de entre seis meses y dos años.

Sin embargo, el hecho de que no exista en nuestro país ninguna ley específica en relación al acoso psicológico en el trabajo, no impide que la víctima de dicha situación esté amparada por varios preceptos de nuestro ordenamiento jurídico (Escudero y Poyatos, 2004), aunque no se debe obviar que, pese a la existencia de otras alternativas jurídicas, en diversas ocasiones, el insuficiente conocimiento por parte de nuestros tribunales ante el fenómeno del mobbing puede hacer que la vía jurídica sea, en numerosas ocasiones, incluso perjudicial para la víctima, por lo que muchos investigadores y juristas consideran que es en los servicios de prevención donde más se debe incidir a la hora de abordar este tipo de casuística, y no tanto en el abordaje jurídico, debido en gran medida a las dificultades inherentes que presenta. (Barón, 2002).

En España, el interés por las denominadas conductas de acoso y de mobbing, estuvieron centradas en los estudios surgidos desde la psiquiatría y la psicología, desde donde se elaboró un concepto social del mismo, delimitado por la incidencia de conductas de violencia psicológica habituales, que perseguían la destrucción personal y profesional del trabajador acosado. Pronto la gravedad, habitualidad e intensidad de este tipo de conductas hostigadoras suscitó la necesidad de una intervención jurídica.

Cuando el trabajador/a detecta que está siendo víctima de una situación de acoso psicológico en el lugar de trabajo es preciso que de forma inmediata se ponga en contacto con aquellos profesionales que en sus distintas disciplinas puedan prestarle ayuda, tanto para paliar los efectos de dicha situación como a neutralizar el propio acoso, siendo habitual que en el primer momento que el trabajador-víctima de 


\section{CAPÍTULO I. EPIDEMIOLOGÍA Y PLANTEAMIENTO INICIAL DEL ACOSO PSICOLÓGICO LABORAL EN PUESTOS DIRECTIVOS.}

mobbing exponga lo que le está sucediendo pueda facilitar un relato poco claro, proporcionado inicialmente, y en numerosas ocasiones, una explicación ambigua de las conductas de acoso padecidas (Liefooghe y Mackenzie,2003).

La situación personal de la víctima de mobbing es realmente terrible cuando llega al despacho del asesor jurídico; la dificultad de saber lo que está ocurriendo en un primer momento, los esfuerzos de auto superación, la falta de información, el temor a lo desconocido, la incertidumbre y las expectativas de poder abandonar la empresa,...etc, son elementos que inciden negativamente para que exista una respuesta rápida; pero este tiempo no es inocuo para la salud del sujeto, y en ocasiones cuando se llega al despacho del abogado, se llega "al límite". Es el momento en el que el trabajador se siente "más fuera", que "dentro" de la empresa, y comienza en la mayoría de los casos a tomar conciencia de la magnitud de los acontecimientos vividos en los meses anteriores.

El primer paso que debería dar una víctima de mobbing es poner en conocimiento de la organización en la que trabaja el trato degradante del que está siendo objeto. Esta comunicación debe realizarse por escrito y por duplicado, de manera que el trabajador se quede con una copia del documento con el sello de entrada de la empresa. De esta forma, en un hipotético enfrentamiento judicial con el acosador ante los tribunales, el escrito servirá de prueba de que la empresa conocía el problema y no actuó. Este primer paso puede complejizarse aún más, cuando empresa y acosador sean solo una misma cosa lo cual dificultara aún más a la víctima.

Al mismo tiempo, la víctima del acoso debe comunicar al Comité de Seguridad y Salud de su centro de trabajo o, en su defecto, al representante legal de los trabajadores, la situación de acoso hacia su persona por parte del agresor (Morant, 2002). Como norma general el comité o en su caso el representante de los trabajadores debe iniciar una investigación de forma discreta y objetiva. 


\section{CAPÍTULO I. EPIDEMIOLOGÍA Y PLANTEAMIENTO INICIAL DEL ACOSO PSICOLÓGICO LABORAL EN PUESTOS DIRECTIVOS.}

Si todas estas acciones no han desembocado en una solución del conflicto entre el agresor y la víctima, ésta puede acudir por vía administrativa a la Inspección de Trabajo, ante a que deberá presentar una denuncia en la que deben constar necesariamente los siguientes datos (Morant, 2002):

$>$ Datos de identificación personal del denunciante.

$>$ Hechos constitutivos de acoso moral.

D Datos cronológicos de la comisión de los mismos.

$>$ Identificación de las personas consideradas responsables o cómplices (testigos mudos).

Firma del denunciante.

Junto con la denuncia, la víctima puede presentar todas aquellas pruebas que hagan al inspector de trabajo tener un conocimiento más amplio del proceso de acoso. A lo largo de todo este proceso, el acosado debe ir acompañado del delegado del comité de seguridad y salud, del representante de los trabajadores, o incluso, de un asesor designado por el sindicato de trabajadores especializado en la materia. La razón del comparecimiento de estas personas es que resulta difícil para una persona ajena a la empresa, en este caso que nos ocupa, el inspector de trabajo, apreciar la situación de acoso, ya que los indicios materiales que le permitan determinar que la persona está sufriendo mobbing serán escasos o incluso nulos, ya que el acosador intentara por todos los modos eliminarlos en caso de que existieran.

Las declaraciones de los compañeros de la víctima seguramente serán contrarias a lo que ésta manifiesta, bien por la complicidad con el agresor o bien por miedo a convertirse en una nueva víctima. De ahí, la importancia de la investigación interna de los representantes legales de los trabajadores y de la propia inspección de trabajo. Como vimos en líneas anteriores el miedo es un factor determinante a la hora de las 


\section{CAPÍTULO I. EPIDEMIOLOGÍA Y PLANTEAMIENTO INICIAL DEL ACOSO PSICOLÓGICO LABORAL EN PUESTOS DIRECTIVOS.}

declaraciones de los compañeros, ya que temen perder su trabajo e incluso no volver a tener uno de similares características. El acosador suele amenazarles de manera individual y sutil, con el fin de infundir en ellos un temor generalizado en caso de declarar a favor del acosado. Como hemos visto la actual situación económica que atraviesa el país ayuda a favorecer este tipo de conductas acosadoras y comportamientos hostiles lo cual han denunciado en numerosas ocasiones los letrados y representantes de la abogacía española.

Ante estos inconvenientes, la víctima suele salir decepcionada de la inspección de trabajo, con una sensación de vacío vital ya que, perplejo, observa cómo sus propios compañeros de trabajo, callan y ocultan la verdad, en un silencio cómplice y banal, que no conlleva más que a que se sigan sucediendo nuevos casos dentro de la misma empresa con diferentes trabajadores.

Una vez llegados a este punto a la víctima solo le queda la opción de emprender acciones legales por las diferentes vías que contempla la justicia española: social, penal, civil o contencioso administrativa; como norma debería presentar una primera denuncia en el juzgado de lo social de primera instancia, lo cual conllevaría a un primer acto de conciliación y a un posterior juicio oral si en este primero no hubiere entendimiento. Una vez dictada sentencia y en caso de ser esta desfavorable se debería recurrir al tribunal superior de justicia de la comunidad autónoma en que se encuentre, para posteriormente seguir los cauces ordinarios de la justicia española.

La resolución del conflicto por cualesquiera de las mencionadas vías, nos asoma al mayor problema al que se enfrenta la víctima de mobbing cuando inicia acciones legales contra su agresor...la inexistencia de una regulación específica de acoso laboral o mobbing en el Ordenamiento Jurídico español. Todo ello supone para la víctima proseguir su sufrimiento en soledad, sin que nadie le dé una solución óptima al problema ante el cual se enfrenta. 


\section{CAPÍTULO I. EPIDEMIOLOGÍA Y PLANTEAMIENTO INICIAL DEL ACOSO PSICOLÓGICO LABORAL EN PUESTOS DIRECTIVOS.}

Por tanto es conveniente como se va a hacer en las siguientes líneas un estudio pormenorizado del acoso moral en la articulación de la constitución española y en la jurisprudencia que pueda facilitar y apoyar el reconocimiento legal que condene las conductas acosadoras y los procesos de mobbing de manera inequívoca y poniendo de manifiesto los hechos sufridos, penándoles en su justa medida para evitar que estos actos se sucedan periódicamente.

\subsection{1. Óptica constitucional del Acoso Moral.}

Como puede observarse en las líneas anteriores, el ámbito jurídico español da una respuesta escasa e insuficiente, ante el acoso moral en el puesto de trabajo, cada vez más propagado entre la sociedad española. Ante esta escasez de normativa, el estudio, de la perspectiva constitucional se revaloriza poniendo de relieve la importancia que esta toma en su aproximación y análisis del fenómeno.

Durante muchos años han sido numerosos los profesionales que han tratado a las víctimas, los cuales incidían en que las mismas ponían de manifiesto que "lo que han pasado", no puede ni debería estar permitido por la Constitución, visión perfectamente entendible desde la visión de la víctima, pues nadie como ellos puede comprender el sufrimiento vivenciado. Lo ilógico es saber cómo aún encontrándonos en el año 2015, no existe una normativa específica capaz de regular este tipo de situaciones de manera solvente, concreta y eficaz.

Al tratarse de una actuación que incide en la integridad física y moral de la persona, el acoso moral vulneraría el núcleo fundamental de derechos contenidos en nuestra Constitución (Rodríguez-López, 2004), de hecho, la Constitución Española (CE) no deja desamparadas a las víctimas del mobbing a las que protege en la redacción de los siguientes artículos que se enumeran: 


\section{CAPÍTULO I. EPIDEMIOLOGÍA Y PLANTEAMIENTO INICIAL DEL ACOSO PSICOLÓGICO LABORAL EN PUESTOS DIRECTIVOS.}

(1) Artículo 10.1. de la C.E.

"La Dignidad de la persona, los derechos inviolables que le son inherentes, el libre desarrollo de la personalidad, el respeto a la ley y a los derechos de los demás son fundamento del orden político y de la paz social".

El Título Primero de la C.E., se denomina "de los derechos y deberes fundamentales" y comienza con el artículo 10, que a modo de introducción, establece en su apartado primero, que la dignidad de la persona, los derechos inviolables que le son inherentes, el libre desarrollo de la personalidad, el respeto a la ley y a los derechos de los demás son fundamento del orden político y de la paz social.

Cuando el Tribunal Constitucional se ha tenido que pronunciar respecto a la alegación de infracción del art. 10.1. de la C.E., lo ha hecho en sentido restrictivo, afirmando que el hecho de que la dignidad de la persona y los derechos inviolables que le son inherentes, junto con el libre desarrollo de la personalidad, el respeto a la Ley y a los derechos de los demás, sean "fundamento del orden político y de la paz social", no significa ni que todo derecho sea inherente, y por ello inviolable, ni que los que se califican de fundamentales sean condiciones imprescindibles para su efectiva incolumidad, de modo que de cualquier restricción que a su ejercicio se imponga devenga un estado de indignidad.

De esta forma, la sentencia del Tribunal Constitucional 120/90 de 27 de junio afirma:

"Proyectada sobre los derechos individuales, la regla del art. 10.1 de la C.E. implica que, en cuanto al valor espiritual y moral inherente a la persona, la dignidad ha de permanecer inalterada cualquiera que sea la situación en que la persona se encuentre...constituyendo, en consecuencia, un mínimum invulnerable que todo estatuto jurídico debe asegurar, de modo que, sean unas u otras las limitaciones que se 


\section{CAPÍTULO I. EPIDEMIOLOGÍA Y PLANTEAMIENTO INICIAL DEL ACOSO PSICOLÓGICO LABORAL EN PUESTOS DIRECTIVOS.}

impongan en el disfrute de derechos individuales, no conlleven menosprecio para la estima que, en cuanto ser humano, merece la persona. Pero sólo en la medida en que tales derechos sean tutelares en amparo y únicamente con el fin de comprobar si se han respetado las exigencias que, no en abstracto, sino en el concreto ámbito de cada uno de aquellos, deriven de la dignidad de la persona, habrá de ser ésta tomada en consideración por este Tribunal como referente. No, en cambio, de modo autónomo para estimar o desestimar las pretensiones de amparo que ante él se deduzcan".

En cuanto al artículo 14 de la Constitución Española;

2 Artículo 14 de la CE.

"Los españoles son iguales ante la ley, sin que pueda prevalecer discriminación alguna por razón de nacimiento, raza, sexo, religión, opinión o cualquier otra condición o circunstancia personal o social".

La visión general del principio de igualdad ante la ley y no discriminación se encuentra en las grandes declaraciones internacionales de derechos. Aquí debemos de citar la Declaración Universal de derechos Humanos de 10 de Diciembre de 1948 (artículos 1,2 y 7) ; el Pacto Internacional de derechos Civiles y Políticos de 19 de diciembre de 1966 (artículos 2.1ำ y 2으, 20.2, 26 y 27): el Pacto Internacional de Derechos Económicos, Sociales y Culturales de 19 de diciembre de 1966 (artículos 2.2으 y 3); el Convenio Europeo para la Protección de los Derechos Humanos y de las libertades Públicas de 4 de Octubre de 1950 (artículo 17), y a la Carta de los derechos fundamentales de la Unión Europea proclamada solemnemente en Niza el 7 de diciembre de 2000 (artículos 20,21 y 23).

En un gran esfuerzo de síntesis se podrían destacar varios puntos de interés para el caso que nos ocupa. Así, el Tribunal Constitucional ha definido el principio de igualdad 


\section{CAPÍTULO I. EPIDEMIOLOGÍA Y PLANTEAMIENTO INICIAL DEL ACOSO PSICOLÓGICO LABORAL EN PUESTOS DIRECTIVOS.}

como la prohibición de toda diferencia de trato que carezca de una justificación objetiva y razonable; ha afirmado el carácter vinculante de este principio tanto para el legislador, como para los órganos aplicadores de derecho y particulares. Ha matizado la vinculación de los particulares al principio de igualdad al señalar que su libertad de actuación sólo está limitada constitucionalmente de forma directa por la prohibición de discriminar por las causas mencionadas en el artículo 14.

Señalado es también el Artículo 15 de la Constitución española;

3 Artículo 15 de la CE.

"Todos tienen derecho a la vida y a la integridad física y moral, sin que, en ningún caso, puedan ser sometidos a tratos inhumanos o degradantes. Queda abolida la pena de muerte, salvo lo que puedan disponer las leyes penales militares para tiempos de guerra".

Determinar qué es la integridad moral de la persona no es tarea fácil, dado que el texto constitucional no se detiene en su definición. Cuando el Tribunal Constitucional se ha aproximado a tal definición, lo ha hecho diciendo "mediante este derecho se protege la inviolabilidad de la persona, no sólo contra ataques dirigidos a lesionar su cuerpo o espíritu, sino también contra toda clase de intervención en esos bienes que carezca del consentimiento de su titular". Así, afirma, que "todos tienen derecho a la vida y a la integridad física y moral, sin que, en ningún caso, puedan ser sometidos a tortura ni apenas de tratos inhumanos o degradantes...". De dicha afirmación podemos concluir sin temor a equivocación, que el hecho de que la integridad moral se mencione junto a la integridad física, induce una equiparación dada la tradicional división de la integridad personal, en integridad física (tangible) e integridad psíquica (intangible). 


\section{CAPÍTULO I. EPIDEMIOLOGÍA Y PLANTEAMIENTO INICIAL DEL ACOSO PSICOLÓGICO LABORAL EN PUESTOS DIRECTIVOS.}

Por tanto la persona tiene el derecho fundamental a ser preservada en su salud mental, pero también en su desarrollo mental. La integridad moral se constituye así, junto con la integridad física, en el instrumento jurídico de protección de la dignidad de la persona.

Referente al Artículo 18.1 de la Constitución española;

4 Artículo 18.1 de la CE.

"Se garantiza el derecho al honor, a la intimidad personal y familiar y a la propia imagen".

Tradicionalmente el honor ha sido considerado como un derecho fundamental menor, no equiparado a otros, tales como, el derecho a la vida, a la integridad física, a la libertad...En parte podríamos decir que ha sido un derecho que la historia ha involucionado. El Tribunal Constitucional hace mención al mismo, recordando que es un concepto jurídico indeterminado, cuya delimitación depende de las normas, valores e ideas sociales vigentes en cada momento, y de ahí que los órganos judiciales dispongan de un cierto margen de apreciación a la hora de concretar en cada caso qué deba tenerse por lesivo de tal derecho.

De esta forma el Tribunal Constitucional en la sentencia 160/2003 de 15 de Septiembre refiere a "la reputación ajena, en expresión del art. 10.2 del Convenio Europeo de derechos Humanos, como un límite del derecho a expresarse libremente y de la libertad de informar...En suma, el derecho al honor, opera como un límite insoslayable que la misma Constitución impone al derecho a expresarse libremente, prohibiendo que nadie se refiera a una persona de forma insultante o injuriosa, o atentando injustificadamente contra su reputación, haciéndola desmerecer ante la opinión ajena". 


\section{CAPÍTULO I. EPIDEMIOLOGÍA Y PLANTEAMIENTO INICIAL DEL ACOSO PSICOLÓGICO LABORAL EN PUESTOS DIRECTIVOS.}

Por tanto ante todo debe señalarse que el Tribunal constitucional, no duda en considerar que en ciertos casos y bajo determinadas circunstancias, el juicio crítico o la información divulgada acerca de la conducta profesional o laboral de una persona puede constituir un auténtico ataque a su honor personal.

Reseñable además es el artículo 18.3 de la Constitución española;

5 Artículo 18.3 de la CE.

"Se garantiza el secreto de las comunicaciones y, en especial de las postales, telegráficas y telefónicas, salvo resolución judicial".

Al igual que sucede con el derecho al honor, la extensión del derecho se ve condicionada por el carácter de la persona o el aspecto concreto de su vida que ve afectado, de acuerdo además con las circunstancias particulares del caso. Por otra parte, el Tribunal Constitucional ha interpretado en alguna ocasión que el alcance de la intimidad viene marcado por el propio afectado. La sentencia del Tribunal Constitucional 132/2002, de 20 de Mayo, dice así "en una sociedad tecnológicamente avanzada como la actual, el secreto de las comunicaciones constituye no sólo la garantía de libertad individual, sino instrumento de desarrollo cultural, científico y tecnológico colectivo".

Este derecho es de especial relevancia, pues en el acoso laboral en el puesto de trabajo, el acosador trata de eliminar toda fuente de comunicación que rodee a la víctima y que pueda interferir en el proceso de coerción al que somete a su víctima. Cabe señalar que aunque en el artículo 18.3 de la C.E, se mencionan sólo las comunicaciones postales, telegráficas o telefónicas, dado el carácter abierto de su enunciado, cabe entender comprendidas otro tipo de comunicaciones como pueda ser el correo electrónico, chats u otros medios. 


\section{CAPÍTULO I. EPIDEMIOLOGÍA Y PLANTEAMIENTO INICIAL DEL ACOSO PSICOLÓGICO LABORAL EN PUESTOS DIRECTIVOS.}

Digno de mención encontramos también el artículo 20.1 de la Constitución española;

6 Artículo 20.1 de la CE.

"Se reconoce el derecho a expresar y difundir libremente los pensamientos, ideas y opiniones mediante la palabra, el escrito o cualquier otro medio de reproducción".

El artículo 20.1 recoge la denominada "libertad de expresión". En el lugar que nos ocupa el acosador precisamente busca denigrar la libertad de la víctima y uno de los canales más utilizados como medio coercitivo es la prohibición de expresión, de expresarse libremente con sus trabajadores subordinados lo cual refiere una gran amenaza para el acosador.

A menudo es uno de los fines que pretende el individuo que acosa. Con ello no solo consigue coartar la libertad del degradado sino que además trata de aislar psicológicamente y socialmente a su víctima, lo cual va a generar en esta última sentimientos de soledad y baja autoestima.

De especial importancia consideramos el artículo 35.1 de la Constitución Española;

$(7$ Artículo 35.1 de la CE.

"Todos los españoles tienen el deber de trabajar y el derecho al trabajo, a la libre elección de profesión u oficio, a la promoción a través del trabajo y a una remuneración suficiente para satisfacer sus necesidades y las de su familia, sin que en ningún caso pueda hacerse discriminación por razón de sexo".

Podemos afirmar con rotundidad que el artículo 35.1 de la Constitución española es el primer precepto constitucional que se conculca cuando se produce un acoso laboral en el puesto de trabajo. 


\section{CAPÍTULO I. EPIDEMIOLOGÍA Y PLANTEAMIENTO INICIAL DEL ACOSO PSICOLÓGICO LABORAL EN PUESTOS DIRECTIVOS.}

La Carta Magna dispone como hemos visto en este artículo que todos los españoles tienen el deber de trabajar y el derecho al trabajo, a la libre elección de profesión u oficio, a la promoción a través del trabajo y a una remuneración suficiente para satisfacer sus necesidades y las de su familia.

Considerando el mobbing como la presión laboral tendente a la autoeliminación de un trabajador mediante su denigración, es lícito decir que dicho comportamiento, precisamente por la búsqueda de dicha autoeliminación, es contrario al deber de trabajar, al derecho que tiene el trabajador a trabajar, y por supuesto es contrario a la libre elección de profesión u oficio, y a la promoción a través del trabajo.

El sustrato fundamental de este artículo deriva no sólo del sustento personal y familiar, sino de la relevancia que tiene el trabajo, para satisfacer las necesidades de desarrollo personal en nuestra sociedad. Resaltar además que uno de los problemas más importantes que acompañan al acoso laboral es el desempleo posterior lo que supone la pérdida de autoestima del trabajador desempleado.

Significante es además el artículo 40.2 de la Constitución Española;

8 Artículo 40.2 de la CE.

"Asimismo, los poderes públicos fomentarán una política que garantice la formación y readaptación profesionales; velarán por la seguridad e higiene en el trabajo y garantizarán el descanso necesario, mediante la limitación de la jornada laboral, las vacaciones periódicas retribuidas y la promoción de centros adecuados".

El artículo 40.2 de la Constitución Española, se hace eco de tres ámbitos donde la intervención de los poderes públicos debe ser prioritaria para mejorar las condiciones laborales de los trabajadores: formación y readaptación profesional, la seguridad e higiene en el trabajo, y la garantía del descanso mediante la limitación de la jornada 


\section{CAPÍTULO I. EPIDEMIOLOGÍA Y PLANTEAMIENTO INICIAL DEL ACOSO PSICOLÓGICO LABORAL EN PUESTOS DIRECTIVOS.}

laboral y las vacaciones. En el tema que nos ocupa la seguridad e higiene en el trabajo se ha definido como el conjunto de instrumentos de protección del ambiente de trabajo y de ordenación de la actividad productiva que tiene como objetivos fundamentalmente evitar daños a la vida, la integridad y la salud e los trabajadores y el logro de mejores condiciones en el centro de trabajo.

Por último señalar el artículo 43.1 de la Constitución Española;

(9) Artículo 43.1 de la CE.

"Se recoge el derecho a la protección de la salud".

Para finalizar el estudio exhaustivo del ámbito constitucional en el que podemos encontrar amparo jurídico es relevante mencionar el artículo 43.1 de la Constitución Española. En él como se puede observar se recoge el derecho que desde el inicio de la investigación hemos considerado fundamental como es el derecho a la protección de la Salud.

Cuando hablamos de Salud, no nos estamos refiriendo solamente a la salud como estado físico homeostático y óptimo sino a la salud mental, la cual como hemos visto a lo largo de la investigación queda gravemente dañada en un proceso de acoso laboral en el puesto de trabajo.

Es un derecho amplio y en muchas ocasiones aunque nadie lo sugiere, incluso subjetivable, puesto que los letrados en numerosas ocasiones sentencian en función de sus propias interpretaciones intrínsecas, lo cual da lugar a mostrar la especial importancia que se sebe hacer de él. 


\section{CAPÍTULO I. EPIDEMIOLOGÍA Y PLANTEAMIENTO INICIAL DEL ACOSO PSICOLÓGICO LABORAL EN PUESTOS DIRECTIVOS.}

Una vez realizado un estudio pormenorizado de la óptica constitucional haremos a continuación un análisis jurisprudencial en el territorio español.

\subsubsection{Análisis Jurisprudencial en España.}

La definición jurídica del acoso moral en el puesto de trabajo ha sido a lo largo de los años uno de los temas más discutidos, tanto por los diversos investigadores, como por los juristas.

Como referencia podríamos tomar numerosas definiciones, entre las cuales cabe citar como ejemplo la que realiza el Tribunal Superior de Justicia de Castilla y León, de 22 de Abril de 2003, en la que se indica que:

"la doctrina entiende por mobbing toda conducta abusiva o de violencia psicológica que se realice de forma sistemática sobre una persona en el ámbito laboral, manifestada especialmente a través de reiterados comportamientos, palabras o actitudes que lesionen la dignidad o integridad psíquica del trabajador y que pongan en peligro o degraden sus condiciones de trabajo.

Por tanto, debe tratarse de una conducta sistemática, repetitiva y reiterada que, por su duración en el tiempo puede atentar contra la dignidad o integridad de la víctima. No debe considerarse por ello acoso laboral, los ataques puntuales y de duración limitada, que tienen otras vías para ser sancionados y erradicados.

Asimismo, es preciso para estemos ante un caso de acoso moral, que la conducta abusiva del empresario, u otro trabajador de la empresa, ponga en peligro el empleo y denigre el puesto de trabajo del trabajador igual, inferior o superior agredido". 


\section{CAPÍTULO I. EPIDEMIOLOGÍA Y PLANTEAMIENTO INICIAL DEL ACOSO PSICOLÓGICO LABORAL EN PUESTOS DIRECTIVOS.}

En cuanto al empleo de los distintos términos usados por parte de los Tribunales, se observa una tendencia a su uso indistinto, empleándose por igual el de mobbing que los de acoso ambiental, violencia en el puesto de trabajo...etc. Por ello la aproximación a un concepto jurídico de mobbing resulta difícil.

Así pues, desde el punto de vista jurídico, el concepto debe resultar más explícito y relacionarse tanto con los comportamientos constitutivos del mismo, como con los derechos y bienes jurídicos lesionados, de tal forma, que la identificación de estas conductas no resulte una tarea de difícil realización. No obstante, no debemos de obviar que en la construcción de un concepto de mobbing, no debe prescindir del concepto social o psicológico ya existente, a partir del cual habrá que delimitar las exigencias que materializan jurídicamente el término (Kahale, 2003; Pérez-Machío, 2004).

Otra de las aproximaciones doctrinales y jurisprudenciales entorno a la definición jurídica que asume el concepto viene a concretarse en lo siguiente:

"un comportamiento negativo entre compañeros o entre superiores o inferiores jerárquicos, a causa del cual, el afectado es objeto de acoso y ataques sistemáticos durante mucho tiempo, de modo directo o indirecto, por parte de una o más personas, con el objetivo y/o efecto de ignorarla (...) un continuo y deliberado maltrato verbal y modal que recibe un trabajador por parte de otro u otros, que se comportan con él cruelmente con vistas a lograr su aniquilación o destrucción psicológica y a obtener su salida de la organización a través de diferentes procedimientos, encuadramiento sobre un periodo de tiempo bastante corto de intentos o acciones hostiles consumadas, expresadas o manifestadas, por una o varias personas hacia una tercera: el objetivo, debiendo situar el criterio definitorio en la intensidad y repetición sistemática de la agresión y en la ilegitimidad ética que se percibe de 


\section{CAPÍTULO I. EPIDEMIOLOGÍA Y PLANTEAMIENTO INICIAL DEL ACOSO PSICOLÓGICO LABORAL EN PUESTOS DIRECTIVOS.}

inmediato en un acto que se dirige a la destrucción de la persona de forma intelectual (...) una situación de conflicto interpersonal o grupal en la que, como medio para poner fin al mismo, una persona o grupo de personas deciden formal o informalmente, expresa o tácitamente, ejercer sobre otra persona prevaliéndose de cualesquiera relación de poder asimétrico instaurada en el lugar de trabajo, una violencia psicológica extrema, de forma sistemática y recurrente durante un tiempo prolongado, con el fin de conseguir su estigmatización o aislamiento respecto del grupo, haciéndole perder su autoestima personal y su reputación profesional, bien para ensayar las ventajas competitivas de un estilo autoritario de gestión, afirmando su poder, bien para provocar su dimisión mediante una fórmula alternativa que cree la apariencia de autoexclusión".

Con todo ello podemos afirmar que los principales problemas ${ }^{4}$ que derivan del tratamiento jurídico del mobbing son los siguientes:

Un problema de tipificación normativa del comportamiento o delimitación de la conducta jurídicamente relevante.

(p.e., definición del supuesto de hecho o ámbito material de aplicación de las normas).

Un problema de fundamentación jurídica, de falta de amparo recurrente legal en la legislación española vigente.

(p.e., delimitación del derecho fundamental vulnerado de forma específica por el comportamiento del acosador u hostigador, ya sea empresario o cualquier otra persona de la línea jerárquica).

\footnotetext{
${ }^{4}$ Molina citado en López-Cabarcos, 2001 y Vázquez Rodríguez, 2003.
} 


\section{CAPÍTULO I. EPIDEMIOLOGÍA Y PLANTEAMIENTO INICIAL DEL ACOSO PSICOLÓGICO LABORAL EN PUESTOS DIRECTIVOS.}

Un problema de selección de la técnica reguladora más adecuada para una tutela efectiva y eficaz del derecho lesionado y fijación de las consecuencias jurídicas o sanciones derivadas del comportamiento ilícito.

A pesar de todo ello y como se ha señalado con anterioridad aún careciendo de una definición jurídica concreta y una legislación específica es erróneo pensar que las víctimas de este fenómeno no deben denunciar $u$ hacer nada al respecto (Escudero y Poyatos, 2004). Por tanto serían varios los preceptos legales en los que se podría amparar; un ejemplo de ello lo encontramos en la propia Declaración Universal de Derechos Humanos, adoptada y proclamada por la Asamblea General de la Organización de las Naciones Unidas, en su resolución 217 A (III), de 10 de Diciembre de 1948, en sus artículos:

\section{○ Artículo 1.}

"Todos los seres humanos nacen libres e iguales en dignidad y derechos y, dotados como están de razón y conciencia, deben comportarse fraternalmente los unos con los otros".

\section{Artículo 3.}

"Todo individuo tiene derecho a la vida, a la libertad y a la seguridad de su persona".

\section{Artículo 5.}

"Nadie será sometido a torturas ni a penas o tratos crueles, inhumanos o degradantes".

\section{Artículo 12.}

"Nadie será objeto de injerencias arbitrarias en su vida privada, su familia, su domicilio o su correspondencia, ni de ataques a su honra o a su reputación. 


\section{CAPÍTULO I. EPIDEMIOLOGÍA Y PLANTEAMIENTO INICIAL DEL ACOSO PSICOLÓGICO LABORAL EN PUESTOS DIRECTIVOS.}

Toda persona tiene derecho a la protección de la ley contra tales injerencias o ataques".

Con todo ello podemos afirmar que en realidad, la función de los tribunales en este campo ha consistido en:

1) Delimitar qué situación puede calificarse como acoso y cuáles otras no pueden merecer tal tratamiento, por tratarse de meras irregularidades en el ejercicio del poder de dirección por el empresario, o situaciones de abusos empresariales con sistematicidad o reiteración ni intención de dañar la dignidad del trabajador.

2) Establecer qué soluciones jurídicas caben desde el derecho, encontrándose la frontera entre el ejercicio, abusivo o no del poder de dirección y el acoso hacia un trabajador, en el punto en que, abusando del principio de jerarquía o dirección, el empresario convierte el "ius variandi" en una especie de "iter criminis" para decidir sobre los derechos de la personalidad (Gimeno, 2004; Rivas, 2005).

En definitiva, los elementos subjetivos y objetivos, que exige la jurisprudencia española y tiene en cuenta para que pueda calificarse, desde la doctrina judicial, una conducta de acoso laboral o mobbing, serían los que a continuación se enumeran:

1) Debe existir una presión laboral tendenciosa ${ }^{5}$, cuya finalidad debe ser inexpugnablemente la de destruir la autoestima y fortaleza psíquica y profesional de la víctima.

\footnotetext{
${ }^{5}$ Debe de darse con una consciencia plena por parte del individuo que la ejerce.
} 
CAPÍTULO I. EPIDEMIOLOGÍA Y PLANTEAMIENTO INICIAL DEL ACOSO PSICOLÓGICO LABORAL EN PUESTOS DIRECTIVOS.

2) Existirá además una relación de causalidad con el trabajo y en este contexto se desarrolla, frecuentemente con el consentimiento o indiferencia de quienes conforman el entorno de trabajo.

3) Excederá los límites del poder de dirección de la empresa. Por tanto ha de considerarse un abuso de poder o un uso de poder incorrecto o dañino $y$ perjudicial, tanto para el trabajador que lo padece, como para la propia empresa y el resto de trabajadores.

4) Debe ser de carácter laboral, puesto que ha de producirse en el contexto de las relaciones interpersonales que se establecen entre individuos dentro del marco de la relación laboral.

5) Debe primar el carácter individual o personalizado, nunca generalizando a un colectivo de trabajadores de la empresa.

6) Ha de reunir además un elemento subjetivo, es decir, el carácter intencional dirigido a un fin, que debe ser inexorablemente la denigración laboral de la persona.

7) Primará el trato vejatorio y ultrajante, que provoque síntomas clínicos de ansiedad, insomnio, inadaptabilidad laboral, pérdida de autoestima, úlcera gastrointestinal y depresión.

8) Se ha de manifestar en hostigamiento y humillación de la víctima de manera constante y reiterada.

9) Se puede producir en determinadas circunstancias en el ámbito de trabajo, aún cuando el origen sea personal y pueda tener su reflejo en el ámbito laboral. 


\section{CAPÍTULO I. EPIDEMIOLOGÍA Y PLANTEAMIENTO INICIAL DEL ACOSO PSICOLÓGICO} LABORAL EN PUESTOS DIRECTIVOS.

10) Debe producirse de manera reiterada en el tiempo, además de sistemáticamente.

11) Se ocultará bajo actos aparentemente inocuos, puesto que se trata de una intención de dañar oculta, actos incluso amparados en el uso social, unidos al carácter complejo, continuado, predeterminado, y sistemático. Esto obliga a una valoración global de las conductas, de modo que, si se disgregan, la intencionalidad no se manifiesta, y la situación de acoso resultará difuminada.

12) Por último existirá una situación de desigualdad entre el acosador y la víctima, que no necesariamente se ha de identificar con una determinada posición jerárquica en la empresa.

Seguidamente se muestra un breve resumen del Capítulo que acabamos de concluir, con las principales ideas, que se han tratado. 


\section{CAPÍTULO I. EPIDEMIOLOGÍA Y PLANTEAMIENTO INICIAL DEL ACOSO PSICOLÓGICO LABORAL EN PUESTOS DIRECTIVOS.}

RESUMEN - ABSTRACT

CAPÍTULO I.

“Epidemiología y Planteamiento inicial del Acoso Psicológico Laboral en puestos Directivos".

En el Capítulo l, hemos abordado una breve introducción a la temática objeto de estudio, fundamentando la etiología del concepto mobbing desde sus orígenes con los estudios del etólogo Konrad Lorenz (1963) hasta la actualidad, con las investigaciones del profesor Iñaki Piñuel (2014), entre otros.

El objetivo fundamental de este capítulo ha sido aproximarnos y hacer una clara distinción del constructo, para lo cual tratamos las diferentes conceptualizaciones de los diversos autores; Heinz Leymann (1996), Marie France Hirigoyen (2001), Ausfelder (2001), Piñuel (2001) o Zapf (2004), y de diversas Instituciones tales como la Unión Europea (2001), el Instituto Nacional de Seguridad e Higiene en el Trabajo, o el Diccionario de la Real Academia de las Letras.

Una vez delimitado el concepto de acoso laboral, estudiamos en minucia, los términos intimamente relacionados como son harassment, bullyng, health endangering leadership, petty tyranny, bossing, ljime, psicoterrorismo, worktrauma, acoso institucional, scapegoating, acoso grupa, atestado, shunting, whist leblowing, o goslight, y las diversas situaciones que a menudo tienden a confundirse con el mobbing, pero no deben ser consideradas como tales; el burn out, el estrés laboral, la sobrecarga e Infracarga laboral, las tensiones laborales, el maltrato empresarial, el acoso sexual, la violencia en el lugar de trabajo, el tecno estrés, el falso mobbing o las novatadas.

Seguidamente se ha realizado un pormenorizado análisis estadístico. Debemos resaltar las dificultades existentes para encontrar una medición real del fenómeno. 


\section{CAPÍTULO I. EPIDEMIOLOGÍA Y PLANTEAMIENTO INICIAL DEL ACOSO PSICOLÓGICO LABORAL EN PUESTOS DIRECTIVOS.}

Ello se debe principalmente a la gran infravaloración que se hace, a la hora de hablar de acoso laboral. Los datos que se recogen parten de los diferentes estudios realizados por la OIT (Organización Internacional de Trabajo), así se hace un estudio exhaustivo, tanto del territorio en el que nos encontramos, España, como de diferentes países de Europa ( Alemania, Austria, Bélgica, Dinamarca, Finlandia, Francia, Grecia, Holanda, Hungría, Irlanda, Italia, Lituania, Luxemburgo, Noruega, Portugal, Reino Unido, Suecia).

Finalmente, el Capítulo concluye haciendo referencia a la vertiente de la Jurisprudencia y al tratamiento y marco legal español, en la cual se recoge la preocupante falta de legislación específica acerca de este tipo de situaciones. No menos importante es la reseña de los preceptos jurídicos que se hace, puesto que la falta de leyes específicas no implica el desamparo de las víctimas. Así pues, se relata cuál es el proceso que debería de seguir el acosado hasta llegar en última instancia a los tribunales, qué artículos de la constitución le ampararían, cuáles son los principales problemas derivados del tratamiento e intervención de la justicia, y qué funciones deberían de cumplir los tribunales.

Además el Capítulo I, concluye realizando un análisis jurisprudencial del concepto, tomando como referencia a algunas de las sentencias más destacadas hasta el momento que podemos encontrar, haciendo hincapié en la referente al TSJCYL (Tribunal Superior de Justicia de Castilla y León).

A continuación abordaremos el Capítulo ll, centrado en el estudio de la Psicopatía como factor definitorio y basal en las conductas acosadoras. 


\section{CAPÍTULO II}

\section{"La Psicopatía como característica basal y definitoria de las conductas acosadoras"}

VNIVERSITAS STVDII SALAMANTINI

"Eran momentos, sensaciones, cosas, circunstancias que nunca nadie antes me habían hecho llegar a sentir..."

J. María Sacristán Rodríguez (Lcdo. Psicología) 


\section{CAPITULO II.}

"La Psicopatía como característica basal y definitoria de las conductas acosadoras".

\section{La Psicopatía como característica basal y definitoria de las conductas acosadoras.}

"La buena gente no suele sospechar de los demás: no pueden imaginarse al prójimo haciendo cosas que ellos son incapaces de hacer; normalmente aceptan como explicación lo menos extraordinario y ahí se acaba todo.

Por otro lado, la gente normal se inclina por ver al psicópata con un aspecto tan monstruoso como su mente, pero no hay nada más lejos de la realidad (...).

Esos monstruos de la vida real suelen tener un aspecto y un comportamiento más corrientes que sus hermanos y hermanas normales; presentan una imagen virtuosa más convincente que la virtud misma, de la misma manera que una rosa de cera o un melocotón de plástico parecen más perfectos al ojo que el original que les ha servido de modelo".

(William March, The Bad Seed en Robert D. Hare. "Sin Conciencia. El inquietante mundo de los psicópatas que nos rodean”.

Una vez que ha quedado delimitado y bien definido el concepto de Acoso Laboral o Mobbing en el Capítulo I, estudiaremos la Psicopatía como rasgo definitorio de las conductas de acoso en los puestos directivos. 


\section{CAPÍTULO II. LA PSICOPATÍA COMO CARACTERÍSTICA BASAL Y DEFINITORIA DE LAS} CONDUCTAS ACOSADORAS.

Desde que en España ha comenzado la crisis las tasas de acoso laboral se han incrementado un $40 \%$. Algunos autores como Robert Hare afirman que "no todos los psicópatas están en la cárcel; algunos de ellos están en la sala de juntas".

Lejos de la visión que podemos tener, las personas con un alto perfil psicopático están plenamente integradas en la vida normal. Normalmente se esconden detrás de grandes dotes seductoras y desarrollan una gran habilidad directiva, de ahí que muchos de ellos alcancen puestos directivos de gran calado.

Se diferencian de lo que entendemos como persona patológicamente normal por su falta de empatía, lo que les permite ser fríos, calculadores, muy inteligentes, sin alteraciones mentales, realizando conductas lógicas pero perversas en su finalidad.

A causa de esta incapacidad para ponerse en el lugar del otro tienen una ausencia patológica de sentido ético, remordimientos o culpa, lo que les convierte en eficaces depredadores sociales sin importarles el dolor o el daño que sus acciones puedan causar.

Cuando hablamos de psicopatía en puestos directivos, nos referimos a cómo un directivo anula con sus acciones a alguno de sus trabajadores, en este caso que nos ocupa Directores de centros residenciales, hasta conseguir su fin, que es matarla laboralmente.

El trabajador que resulta objeto, es o se ha convertido en alguien que, por alguna razón, resulta amenazante para sus propios códigos internos. El factor más frecuente según la estadística de los estudios que padecen los acosados son los celos por una aceptación o aprecio, del resto de trabajadores y clientes o la capacidad profesional extraordinaria que la víctima tiene y de la cual el acosador carece. 


\section{CAPÍTULO II. LA PSICOPATÍA COMO CARACTERÍSTICA BASAL Y DEFINITORIA DE LAS CONDUCTAS ACOSADORAS.}

Así pues, no importa lo que haga el trabajador, siempre todo está mal. Todo, absolutamente todo termina dramatizándose y globalizándose a un supuesto mal desempeño laboral inexistente en la realidad. A este trabajador se le va a atribuir no solo un desempeño negativo, sino una mala actitud, una mala conducta, una mala intención e incluso una perseveridad con sus comportamientos en la empresa prolongada en el tiempo. Todo ello normalmente se le traslada en solitario, sin estar presente en cada situación nada más que el acosador y la víctima.

Los ataques avanzan y se desarrollan sobre todo atacando el auto concepto que tiene la persona de sí misma. Así es como un directivo inicialmente válido e incluso brillante, pasa a ser una sombra de lo que fue. El objetivo del acosador es este proceso es destruir su desempeño para incluir o facilitar su salida, abandono o exclusión de la empresa.

Puede cometer acciones o actos cuestionables con total falta de escrúpulos y sin sentir culpa, no dudan en mentir, manipular, engañar, estafar, robar y hacer daño para conseguir sus objetivos, sin sentir por ello remordimiento alguno. Su fin supremo es ellos mismos, eso está por encima de todo y de todos.

Otra característica de gran relevancia es la tendencia al engaño, a la mentira patológica, que muchas veces va acompañada de locuacidad, encanto superficial y sensación de grandiosidad y autovalía. Realmente son capaces de crear una imagen que en realidad no tienen y que ellos mismos inventan. Suelen cuidar su apariencia de manera exquisita.

Como norma general tienen siempre su visión personal de los hechos, poseen sentimientos de resentimiento, nadie puede sugerirles nada. Son sumamente locuaces: siempre tienen una respuesta rápida para cada situación que se les presente, tienden a ser muy convincentes y saben expresarse con encanto. 


\section{CAPÍTULO II. LA PSICOPATÍA COMO CARACTERÍSTICA BASAL Y DEFINITORIA DE LAS} CONDUCTAS ACOSADORAS.

Su meta permanente es buscar el poder y el control de la víctima; esa necesidad lo convierte en un ser incapaz de comprender que haya personas que tengan ideas diferentes a las suyas. Considera al otro un simple objeto, un medio a través del cual pretende conseguir un fin y satisfacer sus necesidades que llenen su vacio interior.

Por tanto podemos afirmar que la Psicopatía es uno de los elementos basales clave para entender las conductas de acoso en puestos directivos en centros residenciales. A lo largo de este segundo Capítulo iremos revisando y analizando en profundidad el concepto de psicopatía, haciendo un recorrido desde su conceptualización patológica, pasando por una breve análisis histórico y actual del rasgo psicopático, desgranando los rasgos definitorios tanto los endógenos como los exógenos, terminando este capítulo con el estudio del denominado "Ciclo Manipulativo".

\subsection{Concepto de Psicopatía según el DSM y el CIE 10.}

Pese a que el término psicopatía se utiliza en diversos ámbitos, psicológicos, psiquiátricos, legales..., no es fácil dar una definición precisa del constructo. La Real Academia, solo dice de la psicopatía que es una enfermedad mental, por ello y para una correcta definición del concepto, es necesario acudir al DSM (Manual Diagnóstico y Estadístico de los Trastornos Mentales) y al CIE-10 (Clasificación Internacional de las Enfermedades).

El primer problema que nos encontramos cuando acudimos al DSM (Diagnostic and Statistical Manual Of Mental Disorders), elaborado por la Asociación de Psiquiatría Americana, es que el término psicopatía no aparece como tal. 


\section{CAPÍTULO II. LA PSICOPATÍA COMO CARACTERÍSTICA BASAL Y DEFINITORIA DE LAS}

CONDUCTAS ACOSADORAS.

Por tanto hablaremos de Trastorno Antisocial de la Personalidad que es el trastorno que más se ajusta a lo que llamamos psicopatía, dentro de los trastornos clasificados en el DSM. En el Gráfico 2.1, que observamos a continuación, aparece la evolución de la definición del Trastorno Antisocial de la Personalidad a lo largo de las últimas y diferentes ediciones del DSM-III, DSM-III-R, DSM-IV Y DSM-IV-TR.

\begin{tabular}{|c|c|c|}
\hline DSM-III & DSM-III-R & DSM-IV/DSM-IV-TR* \\
\hline $\begin{array}{l}\text { A. La persona ha de tener } \\
\text { al menos } 18 \text { años } \\
\text { B. Debe haber manifestado } \\
\text { un trastorno de conducta } \\
\text { evidente antes de los } 15 \\
\text { años, indicado por una } \\
\text { historia de tres o más de } \\
\text { una serie de hasta } 12 \\
\text { conductas: haber hecho } \\
\text { novillos, peleas físicas, } \\
\text { crueldad con los } \\
\text { animales... }\end{array}$ & $\begin{array}{l}\text { A. La persona ha de tener al menos } 18 \\
\text { años } \\
\text { B. Debe haber manifestado un trastorno } \\
\text { de conducta evidente antes de los } 15 \\
\text { años (mentir, robar...) }\end{array}$ & $\begin{array}{l}\text { A. Un patrón general de } \\
\text { desprecio y violación de } \\
\text { derechos de los demás que se } \\
\text { presenta desde la edad de los } \\
15 \text { años como lo indican tres o } \\
\text { más de los siguientes ítems } \\
\text { fracaso para adaptarse a las } \\
\text { normas sociales, } \\
\text { deshonestidad, impulsividad, } \\
\text { irresponsabilidad... }\end{array}$ \\
\hline $\begin{array}{l}\text { C. Después de los } 15 \text { años, } \\
\text { el sujeto debe haber } \\
\text { mostrado un patrón de } \\
\text { conducta irresponsable y } \\
\text { antisocial, indicado por al } \\
\text { menos cuatro de una serie } \\
\text { de hasta } 10 \text { conductas } \\
\text { (incapacidad de conducta } \\
\text { laboral consistente, ser } \\
\text { irritable y agresivo, } \\
\text { impulsividad...) } \\
\text { D. La conducta antisocial } \\
\text { no debe manifestarse } \\
\text { durante el curso de } \\
\text { episodios esquizofrénicos o } \\
\text { maníacos. }\end{array}$ & $\begin{array}{l}\text { C. Después de los } 15 \text { años, el sujeto debe } \\
\text { haber mostrado un patrón de conducta } \\
\text { irresponsable y antisocial, indicado por al } \\
\text { menos tres de las siguientes conductas } \\
\text { (incapacidad para mantener un trabajo, } \\
\text { incapacidad para mantener una relación } \\
\text { monógama durante más de un año, } \\
\text { irritable y agresivo...) } \\
\text { D. La conducta antisocial no debe } \\
\text { manifestarse durante el curso de } \\
\text { episodios esquizofrénicos o maníacos. }\end{array}$ & $\begin{array}{l}\text { B. El sujeto tiene al menos } 18 \\
\text { años. } \\
\text { C. Existen pruebas de un } \\
\text { trastorno disocial que } \\
\text { comienza antes de la edad de } \\
\text { los quince años. } \\
\text { D. La conducta antisocial no } \\
\text { debe manifestarse durante el } \\
\text { curso de episodios } \\
\text { esquizofrénicos o maníacos. }\end{array}$ \\
\hline
\end{tabular}




\section{CAPÍTULO II. LA PSICOPATÍA COMO CARACTERÍSTICA BASAL Y DEFINITORIA DE LAS} CONDUCTAS ACOSADORAS.

Como su propio nombre indica se refiere, principalmente, a la presencia de una conducta antisocial persistente, obviándose los rasgos de personalidad a la hora de realizar el diagnóstico.

El Gráfico muestra, como el concepto va matizándose, va evolucionando; la categoría Trastorno Antisocial de la Personalidad ha recibido fuertes críticas y, en particular, el DSM-III, debido a su excesiva y/o exclusiva incidencia en muestras de la conducta antisocial, dejando de lado factores de personalidad que sí eran recogidos en el DSM-I y en el DSM-II y que son centrales en el diagnóstico de la psicopatía desde un punto de vista clínico.

EI DSM-IV y el DSM-IV-TR (pese a la ligera modificación sufrida) no han contribuido a aumentar la validez de la categoría, limitándose a reducir el número de indicadores en la edad adulta y ocultando rasgos de personalidad básicos para el diagnóstico de la psicopatía.

Actualmente, la segunda gran definición de la psicopatía la podemos encontrar en el CIE-10. El CIE-10 es la Clasificación Europea de las Enfermedades Mentales propuesta por la OMS (Organización Mundial de la Salud).

Los criterios del CIE-10 se asemejan a la concepción original de psicopatía, propuesta por Cleckley (pionero de la investigación sobre psicopatía), quien consideraba al individuo psicopático "como una persona con encanto externo y notable inteligencia, ausencia de alucinaciones $u$ otros signos de pensamiento irracional, ausencia de nerviosismo o de manifestaciones psiconeuróticas, poca formalidad, falsedad, falta de remordimientos, con conductas antisociales, razonamiento insuficiente, egocentrismo patológico, pobreza en las relaciones afectivas, sin intuición, insensible a las relaciones interpersonales, vida sexual impersonal y con fracasos para seguir un plan de vida saludable". 


\section{CAPÍTULO II. LA PSICOPATÍA COMO CARACTERÍSTICA BASAL Y DEFINITORIA DE LAS} CONDUCTAS ACOSADORAS.

Al igual que ocurre en el DSM, en el CIE-10 tampoco aparece el término psicopatía, sino que se hace referencia al Trastorno de Personalidad Disocial. Las características que se proponen para la descripción del trastorno son las que podemos observar en el Gráfico 2.2, que a continuación aparece;

\section{CARACTERÍSTICAS DEL TRASTORNO DE PERSONALIDAD DISOCIAL.}

A. Despreocupación cruel por los sentimientos de los demás e incapacidad para la empatía

B. Actitud irresponsable persistente y marcada, y desinterés por las normas sociales, leyes y obligaciones.

C. Incapacidad para mantener relaciones duraderas.

D. Escasa tolerancia a la frustración y bajo umbral para la descarga de la agresión, incluida la violencia.

E. Incapacidad para experimentar culpabilidad o beneficiarse de la experiencia, particularmente del castigo.

F. Predisposición marcada a culpar a los demás o a ofrecer racionalizaciones plausibles para las conductas que hacen entrar al sujeto en conflicto con la sociedad.

G. Irritabilidad persistente

Gráfico 2.2. Trastorno de Personalidad disocial (OMS, 1992).

Una vez introducido el concepto y visto las dos grandes definiciones del constructo psicopatía analizaremos las diferentes definiciones de los grandes investigadores a lo largo de la historia hasta la actualidad.

\subsection{Visión Histórica y Actual del rasgo psicopático.}

La psicopatía es un problema que preocupa desde la antigüedad, ya que siempre ha habido personalidades anómalas. Estas personas siempre han Ilamado la atención y han sido fuente de preocupación y objeto de estudio para la sociedad. Realmente no se les podía calificar de enfermos ni de cuerdos, sino que eran considerados individuos conductualmente separados del grueso de la población. Estarían pues en un campo intermedio, distinto al ocupado por los demás. 


\section{CAPÍTULO II. LA PSICOPATÍA COMO CARACTERÍSTICA BASAL Y DEFINITORIA DE LAS} CONDUCTAS ACOSADORAS.

De entre todos los estudios realizados a lo largo de la historia merecen una mención especial los que a continuación se van a enumerar:

1) Philippe Pinel (1745 - 1826).

Para muchos es considerado el padre de la Psiquiatría moderna y fundador de la Psiquiatría en Francia. En 1801 escribe Traite Médico Philosófique Sur I'aliénation Mentale, donde postula la psicopatía como un trastorno psicológico-psiquiátrico donde aparecerían episodios de manía, entendida esta como estados de exaltación, de furor, de hiperactividad patológica pero no aparecerían síntomas en los que se pudiera observar delirio alguno. Así pues habría únicamente estados maniacos con ausencia de delirio.

Esto supuso una auténtica revolución en el mundo clínico de la época puesto que hasta el momento era inconcebible la aparición de episodios maniacos con ausencia de delirio.

\section{2) James Cowles Prichard (1786 - 1861).}

Psiquiatra belga, que en 1835 redacta Treatise on Insanity and other Disorders Affecting The Mind donde aparece el término "Moral Insanity". Era defensor de la teoría expuesta por Pinel y luchaba contra las ideas de la época que decían que no podía existir manía sin delirio. Pinel y Prichard trataban de imponer el concepto de que existían insanias sin compromiso intelectual, y si afectivo y volitivo.

Es decir que las funciones mentales (intelecto, afectividad, voluntad) podían enfermar independientemente. Conceptualizan la insania moral como equivalente a nuestro concepto de psicopatía. Prichard crea el término para referirse a trastornos del comportamiento cuya insania característica común era la ausencia de delirio. 
3) Bénedict Augustin Morel (1809 - 1873).

Creador de "La teoría psiquiátrica de la degeneración" (1857) tuvo un importante impacto en la clínica psiquiátrica europea del último cuarto del siglo XIX, si bien su difusión superó con creces este ámbito afectando a diversos campos de la medicina.

Morel en su Teoría de la Degeneración, expone en una línea limítrofe a la teoría Darwinista, cómo la degeneración del individuo se va transmitiendo y agravando a través de las generaciones. Iguala el término psicopatía con su definición de enfermedad, considerada ésta desde su visión más religiosa como "la expresión sintomática de las relaciones anormales establecidas entre la inteligencia y su instrumento enfermo, el cuerpo". Esta nueva dimensión rompe con lo que hasta ahora se matizaba del término psicopatía.

\section{4) J. Koch y Otto Gross.}

Psiquiatras, alemán y austriaco respectivamente, hablaban desde una visión más fisio-anatómica del término que ellos mismos acuñaron como "inferioridades psicopáticas". Este novedoso concepto definía la psicopatía como la inferioridad congénita de la constitución cerebral, y no lo consideraba como enfermedad alguna. Dentro de las Inferioridades Psicopáticas de las que hablaban se podían distinguir tres formas:

a) Disposiciones Psicopáticas (donde se encuentran los asténicos).

b) Tara Psíquica Congénita (donde se encontraban los excéntricos, justicieros...).

c) Degeneración Psicopática (donde aparecerían el resto de patologías).

La psicopatía quedaba encasillada dentro de la forma Tara Psíquica Congénita, ya que lo consideraban como una exaltación, pero siempre desde la visión general donde no estaba considerada como una enfermedad. 


\section{5) Emil Kraepelin (1855 - 1926).}

Psiquiatra alemán, fundador del concepto de la demencia precoz, entre muchos de sus logros. En 1904 Kraepelin hace una clasificación de las enfermedades mentales donde se refiere a las personalidades psicopáticas como formas frustradas de psicosis, definiéndolas siguiendo un criterio fundamentalmente genético.

Además considera que sus efectos se limitan esencialmente a la vida afectiva y a la voluntad. Una de las mayores aportaciones que realizó a la psicología además de las ya citadas fue su propia tesis titulada "El Lugar de la Psicología en la Psiquiatría".

\section{6) Kurt Schneider (1887 - 1967).}

Psiquiatra Alemán. Para Schneider las personalidades psicopáticas son un subconjunto de las personalidades anormales. Según él, acosador psicopático es un individuo que por sí solo, aunque no se tengan en cuenta las circunstancias sociales, es una personalidad extraña, apartada del término medio.

La psicopatía se manifiesta, y debe ser observada por los otros como una conducta anómala en relación al término medio.

El acosador busca su equilibrio en el otro complementario. La vivencia de no completud genera tensión y sufrimiento; aunque encuentre las circunstancias, personas, cosas o actos complementarios que hacen bajar su nivel de tensión, siempre le queda un quantum de tensión vivenciada como insatisfacción o vacío interior. Es un pensamiento de estar viviendo una vida que no es realmente la suya, o que no es capaz de vivirla y disfrutarla como el querría para sí. Se podría incluso hacer mención comparativamente de esta 
situación que vivencia el sujeto con lo que Leon Festinguer denominó la Teoría de la Disonancia Cognoscitiva (1957).

Scheneider postula que sería complementario el que debe pagar por ese ajuste incompleto, por esa disonancia que existiría. Para el acosador su incompletud es o fue producida por otros, por lo que le parece justo que alguien o algunos paguen por ello. Este autor diferenció los siguientes tipos:

a-Hipertímicos.

b-Depresivos.

c-Inseguros de sí mismos.

d-Fanáticos.

e-Necesitados de estimación.

f-Lábiles.

g-Explosivos.

h-Desalmados.

i-Abúlicos.

j-Asténicos.

7) Hervey Cleckley (1903 - 1999).

Profesor de Psiquiatría de la Facultad de Medicina de Georgia. Autor del libro "La Máscara de la Cordura" (1981), dice que el perfil psicopático vendría marcado por las siguientes características conductuales:

-Inexistencia de alucinaciones o de otras manifestaciones de pensamiento irracional.

-Encanto externo y notable inteligencia.

-Egocentrismo patológico e incapacidad de amar.

-Gran pobreza de reacciones afectivas básicas.

-Vida sexual impersonal, trivial y poco integrada. 


\section{CAPÍTULO II. LA PSICOPATÍA COMO CARACTERÍSTICA BASAL Y DEFINITORIA DE LAS} CONDUCTAS ACOSADORAS.

-Falta de remordimiento.

-Falta de sentimiento de culpa y de vergüenza.

-Indigno de confianza.

-Mentiras e insinceridad.

-Pérdida específica de la intuición.

- Incapacidad para seguir cualquier plan de vida.

-Conducta antisocial sin aparente remordimiento.

-Amenazas de suicidio raramente cumplidas.

-Razonamiento insuficiente o falta de capacidad para aprender la experiencia vivida.

-Irresponsabilidad en las relaciones interpersonales.

\section{8) Otto Kernberg.}

Psiquiatra y presidente de la Asociación Psicoanalítica Internacional, nos muestra la perspectiva psicoanalítica del trastorno. Para él los fundamentos de la personalidad psicopática son: autorreferencia excesiva, grandiosidad, tendencia a la superioridad, superficialidad emocional, crisis de inseguridad e intensa envidia consciente e inconsciente. Define la psicopatía como una patología grave del Super-Yo.

Como se puede observar existen una gran cantidad de autores que han estudiado en profundidad el fenómeno de la psicopatía. Actualmente se pueden destacar dos grandes autores; Robert D. Hare y Vicente Garrido.

Hare en su libro "Sin Conciencia. El inquietante mundo de los psicópatas que nos rodean" (2003), define el perfil psicopático como "aquellos depredadores que encandilan, manipulan, y se abren camino en la vida sin piedad, dejando una larga 


\section{CAPÍTULO II. LA PSICOPATÍA COMO CARACTERÍSTICA BASAL Y DEFINITORIA DE LAS} CONDUCTAS ACOSADORAS.

estela de corazones rotos, expectativas y vidas arruinadas y billeteras vacías, con una total carencia de conciencia y sentimientos por los demás, tomando lo que les apetece de la forma que les viene en gana, sin respeto por las normas sociales y sin el menor rastro de arrepentimiento o piedad".

Por otro lado Vicente Garrido (2004) aborda la temática desde un punto de vista no solo psicológico, social y psiquiátrico, sino también haciendo especial hincapié en la criminalidad, equiparando psicopatía con asesinato.

Una vez estudiado el perfil psicopático a lo largo de la historia por algunos de los investigadores más representativos y en la actualidad, mostraremos ahora cuáles son los rasgos que definen claramente a la psicopatía.

\subsection{Rasgos Definitorios.}

“Te escogerá de entre la multitud, te desarmará con sus palabras y te controlará con su presencia. A ti te encantarán su ingenio y sus planes. Te lo hará pasar bien, pero piensa que después te pasará factura Te sonreirá y te engañará y, luego te atemorizara con su mirada.

Y cuando haya acabado contigo, y ten por seguro que lo hará, te abandonará llevándose consigo tu inocencia y tu orgullo. Te dejará más triste, pero no más sabio, y durante mucho tiempo te preguntarás qué pasó y que hiciste mal.

Y, después, si otra persona llamara a tu puerta, ¿abrirás? (...)"

(De un escrito firmado por un "psicópata en la cárcel" en D. Hare (2003) 


\section{CAPÍTULO II. LA PSICOPATÍA COMO CARACTERÍSTICA BASAL Y DEFINITORIA DE LAS} CONDUCTAS ACOSADORAS.

Clasificaremos los rasgos que presenta el perfil psicopático en endógenos "para con uno mismo" y rasgos exógenos o "conductas para con los demás" .El objetivo de esta clasificación no es otro que mostrar la doble moralidad del sujeto. A continuación se van a ir describiendo cada uno de los rasgos según el autor R. D. Hare

\subsubsection{Rasgos Endógenos, "para con uno mismo".}

\section{a- Locuacidad / encanto superficial.}

Es una persona, que se presenta agradable en su forma de ser con los demás, divertida, dispuesta a hacer cosas por los demás "a ayudar a los demás", siempre tiene una sonrisa para cada momento y para cada persona, sabe cómo debe tratar a los demás e incluso suele tener un trato exquisito. Es capaz de inventar su propia historia de vida durante una simple conversación.

La primera impresión es la de ser un hombre formado, culto, con conocimiento de muchas áreas, nada más lejos de la realidad. Es una persona atractiva para los demás (rasgo fundamental para la captación de su víctima). Se podría decir que a simple vista, es una persona completa, formada y muy preparada para la vida.

Suele mostrarse con asiduidad en charlas, conferencias, reuniones a alto nivel con el fin de hacer ver a los demás un status social, económico y laboral que en realidad no tiene y que desea encarecidamente, para lo cual es capaz de mentir reiteradamente e incluso de mostrarse muy generoso con aquellos que ostentan puestos de gran calado en la sociedad y más aún en el sector de los servicios sociales con el fin de crearse a sí mismo y hacer creer a los demás en una identidad que no se ajusta en absoluto en la realidad.

Crea una autoimagen entre directivos de persona respetable en todos los ámbitos, que intenta prolongar en el tiempo para darle mayor veracidad. 


\section{CAPÍTULO II. LA PSICOPATÍA COMO CARACTERÍSTICA BASAL Y DEFINITORIA DE LAS} CONDUCTAS ACOSADORAS.

\section{b- Egocentrismo /sensación grandiosa de autovalía.}

No es una persona que considere que ha fracasado en la vida, sino que para él su situación es consecuencia del trato que ha recibido de los demás, de sus amigos, de su familia y de la sociedad en general. Sin embargo se ve altamente cualificado, seguro de sus habilidades, con una alta valoración personal, con un pensamiento correcto y claramente definido. En algunos momentos incluso hace alarde de sí mismo, mostrándose chulesco y burlón con los demás.

Él considera que ha tenido mala suerte, ya que sus habilidades no han sido reconocidas por los demás por lo que no ha logrado alcanzar un status, ni una profesión que le corresponden a una persona como él.

Como directivo tiene un ego externo desmesurado, aunque él en su intimidad sabe que no posee prácticamente ninguna de las habilidades de las que alardea con los demás. Es tal su auto creencia de valía que como Director General no reúne a los Directivos de sus centros residenciales, ya que considera que estos últimos no son capaces de aportarle nada que él ya no sepa o conozca.

Este reconocimiento a su propia valía hace que además el mismo se haga una alta remuneración económica mensual, mientras que al resto de directivos les ofrece un salario base y unos objetivos laborales como complemento salarial anual inalcanzables.

Considera que él lo merece, y los demás no, porque él posee una valía, unos conocimientos y unos contactos de los que el resto de directores carecen y ello conlleva a otro status social y económico.

Es frecuente además que no permita que ninguno de sus directores acudan a reuniones con altos cargos, aunque les hayan invitado expresamente ya que esto podría obstaculizar su afán de poder y pondría en peligro su "imagen". 


\section{CAPÍTULO II. LA PSICOPATÍA COMO CARACTERÍSTICA BASAL Y DEFINITORIA DE LAS} CONDUCTAS ACOSADORAS.

\section{c- Necesidad de estimulación / tendencia al aburrimiento.}

Por norma general, son personas que no aceptan una rutina vital, sino que buscan siempre nuevos retos, nuevos objetivos capaces de hacer que su vida no se vea amenazada con el vacio. Buscan submetas, les gusta ser "protagonistas" y no "observadores" de la vida. En el trabajo suelen estar poca estabilidad ya que no les resulta excitante ni estimulante el desarrollar siempre las mismas tareas.

Es una persona que cree que las oportunidades en la vida son pocas, y quiere aprovecharlas al máximo ya que "la vida hay que vivirla con audacia y rapidez". Por tanto se puede decir que no toleran la monotonía, ni la consistencia. Tal es así que ni tan siquiera pese a ser Director General no posee ni despacho físico propio ya que esto le aburre y haría que su status social se rebajase, ya que sería fácilmente localizable para los demás.

Así pues de lo único que dispone es de un pequeño escritorio en su propia casa, (casa de alquiler), desde el cual rara vez supervisa mediante un servidor remoto, el propio día a día de los centros residenciales, centros de los cuales es Director general.

Anteriormente a alcanzar este puesto, ha ocupado diferentes puestos de muchísima menor relevancia, en los cuales la característica fundamental ha sido la falta de estabilidad en los mismos, ya que como mucho ha tenido continuidad 2 ó 3 años en cada uno.

El acudir a los centros residenciales le resulta aburrido, ya que ello conlleva, entre otras cosas tener que relacionarse con "gente" que no posee la misma "categoría" que él y con la que él considera "no poseen las mismas características que él".

Así pues dispone de tanto tiempo libre, que decide dedicar todo ese tiempo a cuidar sus relaciones, sus "contactos" que a posteriori tendrá que utilizar. 


\section{CAPÍTULO II. LA PSICOPATÍA COMO CARACTERÍSTICA BASAL Y DEFINITORIA DE LAS} CONDUCTAS ACOSADORAS.

\section{d- Mentira patológica.}

Cuando hablamos de mentira patológica, nos estamos refiriendo al modo de interacción con los demás, a la manera de establecer vínculos personales, y afectivos. Todas sus relaciones vienen precedidas de la mentira. Se excusan, prometen, aclaran y defienden en vano.

Es capaz de reconstruir su historia de vida en un simple relato, o conversación intrascendente. Jamás se siente abochornado por ello sino que más bien es su manera de defenderse ante la realidad, de protegerse de los demás. A menudo las personas que se relacionan con este tipo de personas, se muestran contrariadas, decepcionadas y desorientadas.

Crea los constructos huecos necesarios con el fin de dar credibilidad a su historia. La mentira es el epicentro de su propia vida. Es tal su necesidad de reconocimiento social, laboral y económico que incluso llega a hacer ver que posee una gran vivienda, (vivienda el alquiler), posee un gran coche de alta gama (comprado con un leasing difícilmente pagable), compra ropa de prestigiosas marcas con las que cuidar su imagen e impresionar a altos cargos, realiza viajes caros al menos una vez al semestre, normalmente al menos uno de ellos al extranjero, como indicador bajo su visión egocéntrica, de su poder económico, y realiza algunas jornadas en las que como anfitrión se encarga de transmitir su estabilidad e incluso crecimiento económico, nada más lejos de la realidad.

Con todo ello y como resultado de sus actuaciones, nos encontramos ante un perfil, una persona que interiormente vive en soledad y que solamente se dedica a proyectar lo que realmente le gustaría que hubiera sido su vida. Psicológicamente inestable, aunque no se muestra en público como tal e incluso propenso a estadios depresivos de breve duración. 


\section{CAPÍTULO II. LA PSICOPATÍA COMO CARACTERÍSTICA BASAL Y DEFINITORIA DE LAS} CONDUCTAS ACOSADORAS.

\section{e- Manipulación / dirección.}

Busca su satisfacción personal sin importarle las consecuencias negativas que pueda ocasionar a los demás. No se rige por normas, ni estructuras de normalidad. Busca dinero, status, sexo, poder, reconocimiento, salud, bienestar social y laboral... Por ello "elige a sus víctimas", ya que éstas deben de reportarle algo a cambio. Elabora, estudia, procesa y planifica cada situación y cada conducta que realiza. No actúa al azar. Antes de llevarla a cabo ha realizado un estudio minucioso de la situación.

Cuando se dirige a su víctima, como norma siempre lleva el discurso escrito ya que es incapaz de concentrarse. Es capaz de manipular hábilmente las situaciones laborales con el único fin de culpabilizar a su víctima.

\section{f- Falta de remordimiento / culpabilidad.}

Es una persona incapaz de valorar, apreciar la magnitud de sus hechos. Suelen culpar a la sociedad de dañar su imagen y su reputación, y a menudo a su propia víctima. Ellos creen que esta ha destruido su empresa, su negocio nada más lejos de la realidad.

Esto para ellos es un daño irreparable, ya que si algo les importa es la imagen que se pueda tener de ellos. Sólo están interesados en hechos actuales sin importarles lo más mínimo lo que haya pasado ayer. Nunca les importa los sentimientos, las emociones o las reacciones de las víctimas. El sufrimiento para ellos no existe. Su frialdad emocional hace que no sepan realmente valorar la situación. Presentan una alexitimia persistente.

No valoran el impacto que sus hechos puedan causar en los demás. Se cuidan muy mucho de dirigirse a sus víctimas en privado. 


\section{CAPÍTULO II. LA PSICOPATÍA COMO CARACTERÍSTICA BASAL Y DEFINITORIA DE LAS} CONDUCTAS ACOSADORAS.

\section{g- Escasa profundidad de los afectos.}

A menudo son individuos, superficiales emocionalmente, son incapaces de expresar y comprender reacciones emocionales intensas. Por ello realmente actúan, sus actuaciones tienen poco de real. En estas actuaciones se denota una clara inmadurez psicológica, con posturas infantiles, absurdas, con una desesperación muy acentuada cuando no logran lo que quieren propias de un pensamiento preoperacional piagetiano.

Buscan la inmediatez (lo que para autores como Seigmund Freud constituye el principio de placer). Por tanto nos encontramos ante una persona que se encuentra en unos estadios primarios en cuanto a desarrollo emocional se refiere.

Para muchos investigadores "conocen la letra pero no la música". Son incapaces realmente de sentir, de vivir plenamente cada situación de la vida, solo interpretan como ellos creen que sería cada situación o como debería ser según sus propios criterios internos de la vida.

\section{h- Insensibilidad / falta de empatía.}

Se puede decir que es un individuo incapaz de ponerse en el lugar del otro. También podemos decir que quizás sea capaz de ponerse en el lugar del otro pero realmente no es capaz de sentir por los demás. Muestra una insensibilidad que hace que prescinda de los sentimientos, los derechos, la felicidad, el daño, la angustia, la desazón y el dolor de los otros.

Para él "los otros" son meros objetos, medios a través de los cuales busca alcanzar sus fines. Es egoísta en su estilo de vida quiere siempre "ser más que...". Suelen vivir la vida de una manera solitaria, encerrados en sí mismos, y en sus propias 


\section{CAPÍTULO II. LA PSICOPATÍA COMO CARACTERÍSTICA BASAL Y DEFINITORIA DE LAS} CONDUCTAS ACOSADORAS.

convicciones ya que éstas y sólo éstas son las correctas. No aceptan que nadie pueda hacer que duden o pongan en entredicho y hagan tambalear sus creencias ya que se sienten amenazados, por la posibilidad de perder su identidad.

Como Director General no acepta propuestas ni mejora alguna de ninguno de sus subordinados, ya que les considera inferiores tanto socialmente como intelectualmente, considera que nadie tiene mejores ideas y recursos que él mismo. Todas absolutamente todas las decisiones relevantes que se tomen en cada centro deben ser revisadas por él. Si existen comunicaciones vía email, deberá ir siempre en copia, ya que no es capaz de confiar en nadie.

Por tanto podemos decir que jamás delega, sus directores a cargo son meros transmisores de sus mandatos y órdenes como él mismo las define, y como tales se han de cumplir sin poner ni una sola pega, y aunque con ellas sea capaz de llevar a su propia empresa hasta la quiebra.

En numerosas ocasiones les recalca que él es el Director General y ellos son simples trabajadores con un sueldo establecido por él mismo, por tanto él y solo él es quien da las órdenes y ellos (los directores) solo deben de cumplirlas sean estas de la índole que sean e incluso aunque estas estén fuera de las propias funciones como Director que previamente tiene asignadas.

\section{i-Estilo de vida parásito.}

Como ya hemos mencionado con anterioridad se podría definir su estilo de vida como un estilo de vida parasitario. En este caso el acosador abusa de sus innumerables contactos como el mismo relata con el fin de mostrarse necesitado de cara a una gestión aún más exitosa según él. Es una persona capaz de encontrar empleo remunerado con facilidad, sin embargo esto no le interesa demasiado, e incluso es 


\section{CAPÍTULO II. LA PSICOPATÍA COMO CARACTERÍSTICA BASAL Y DEFINITORIA DE LAS} CONDUCTAS ACOSADORAS.

capaz de abandonar otros puestos de trabajo anteriores que tenía mediante excedencia, ya que los considera inferiores a sus propias características laborales y "son poco" para él, que posee esas grandes dotes para el liderazgo organizacional.

\section{j- Falta de control conductual.}

Conductualmente el comportamiento que lleva a cabo no es el adecuado. Es una persona que se muestra ofendido verbalmente con facilidad, irritable, se enfurece y enfada trivialmente. Además de esto tiende a responder a estas situaciones con amenazas, enfrentamientos físicos, conductas verbales abusivas y con un lenguaje no verbal inadecuado.

Estas conductas harán que los otros se sorprendan dado el contexto en que se producen. Por tanto presenta un inadecuado control conductual que en ocasiones muestra de manera sutil.

La mejor manera para él de que sus subordinados le presten atención y respeto es que le tengan miedo, miedo a lo que sea capaz de decirles y como no miedo a un despido que se antoja inminente si no haces lo que él quiere que hagas. Normalmente hace referencia a frases tales como "para eso te pago". "yo soy el que pago" o el "dinero es mío".

Realmente es incapaz de mostrarse cercano a sus trabajadores, y suele marcar una distancia, que le sirve como defensa ante su ineptitud laboral. Sería un grave error para él que alguno de sus trabajadores descubra realmente su manera de ser y su proceder ya que esto conllevaría al posible riesgo de desenmascararlo, con las innumerables consecuencias que esto traería para su figura. Así pues intenta aparecer como una persona altamente ocupada, cuyo tiempo es oro. 


\section{CAPÍTULO II. LA PSICOPATÍA COMO CARACTERÍSTICA BASAL Y DEFINITORIA DE LAS} CONDUCTAS ACOSADORAS.

\section{k- Conducta sexual promiscua.}

Sexualmente es una persona muy activa, sin embargo las relaciones que tiene son habitualmente impersonales, carentes de sentimientos, breves, con distintas personas, "casuales", e indiscriminadas.

Suele ser infiel, dispuesto a participar en una gran variedad de formas sexuales e incluso mantiene varias relaciones al mismo tiempo. Esto es debido a su continua falta de responsabilidad y de toma de decisiones vitales y cumbres.

En algunas ocasiones se relaciona con la prostitución ya que esta es una forma de obtener sexo con facilidad y sin responsabilidad. Esto por supuesto lo mantiene al margen de su vida cotidiana.

Como consecuencia de esta inadaptabilidad conductual para el sexo, suele intentar proponer a algunas de sus trabajadoras encuentros esporádicos fuera del trabajo, a lo cual estas en ocasiones ceden debido a su amenaza laboral en caso de no hacerlo.

\section{I-Problemas de conducta precoces.}

En algunas ocasiones han tenido problemas en la infancia, sobre todo abuso de sustancias, falta de respeto o actos vandálicos. Todo ello suele tener su culmen en la expulsión de la escuela y en contactos con la policía.

\section{m- Falta de metas realistas a largo plazo.}

Podríamos decir que es una persona que vive la vida "día a día", es incapaz de hacer planes para el futuro y mucho menos llevarlos a cabo. Para él importa el aquí y ahora. Además suele ser poco consistente en cuanto a sus planes se refiere, cambia 


\section{CAPÍTULO II. LA PSICOPATÍA COMO CARACTERÍSTICA BASAL Y DEFINITORIA DE LAS} CONDUCTAS ACOSADORAS.

facilidad de opinión sobre lo que desea hacer. El futuro le importa más bien poco. Sin embargo a su entorno más cercano le transmite sus ansias por llegar a ser alguien en la vida y tener un trabajo fijo y seguro que le reporte estabilidad. Por tanto sus expectativas estarían centradas sólo a corto plazo, y tan sólo tiene "algunos planes" que la mayoría de las veces no es capaz de llevar a cabo.

Aquí aparece una gran disonancia cognoscitiva ya que por un lado es incapaz de fijarse metas a largo plazo y por otro busca poder y dinero sin saber cómo conseguirlo por sus propios medios.

Como directivo analiza numerosos proyectos que le ofrecen pero sin tener un interés real por ninguno de ellos, tan solo busca hacer ver a los demás que es tan bueno en su faceta laboral, que todos quieren contar con él en futuros proyectos, que a posteriori ni son futuro ni son negocio, es más tan solo suelen llegar a ofrecerle empresas, centros hundidos que nadie antes ha mostrado interés por ellos, aunque él se lo comunique a los demás como grandes proyectos, innovadores y con unas grandes expectativas de futuro.

\section{n- Impulsividad.}

Se muestra con una personalidad altamente impulsiva sobre todo en lo que a sus conductas laborales se refiere. Es poco irracional e incapaz de ver en muchas ocasiones lo que tiene ante sus propios ojos. Está tan preocupado de sí mismo, que no muestra el más mínimo interés por lo ajeno. Hace un constante cambio de planes.

Como Director General, esta impulsividad le lleva a tomar graves decisiones ya que es incapaz de sopesar los pros y los contras de tomar una o tomar otra. Esto le lleva despedir a una gran cantidad de trabajadores sin ni tan siquiera pedir opinión al director de referencia del centro al que pertenece al trabajador. En la mayoría de los 


\section{CAPÍTULO II. LA PSICOPATÍA COMO CARACTERÍSTICA BASAL Y DEFINITORIA DE LAS} CONDUCTAS ACOSADORAS.

casos estos ceses se llevan a cabo de manera arbitraria, sin ningún juicio anterior o hechos relevantes que permitan llevar a cabo o explicar una decisión tan radical y drástica sin ni tan siquiera valorar las actuaciones del trabajador.

Esto en sus últimas consecuencias conlleva a crear un malestar generalizado entre los trabajadores del centro, que ven como en numerosas ocasiones sus compañeros pierden su puesto de trabajo sin motivo alguno o al menos sin motivos suficientes como para hacerlo.

Por ello observamos cómo esta impulsividad lleva a una inestabilidad al centro rompiendo la homeostasis óptima para el buen funcionamiento del centro y él para bien de los ancianos que en él conviven y a los cuales, que como veremos más adelante, también termina afectando.

\section{ñ- Irresponsabilidad.}

Debido en gran parte a su falta de madurez, es una persona que evita cualquier hecho que implique alguna responsabilidad. No suele cumplir los acuerdos con los demás, no tiene sentido de responsabilidad para con su familia, amigos, compañeros de trabajo, vecinos... Tan sólo mira por él, por encontrarse cómodo en cada situación en la que se ve implicado.

Podríamos decir que es un individuo que moralmente vive sin unas normas que rijan su vida; sólo acepta y toma por buenas sus propias reglas. En el trabajo es incapaz de tomar decisiones con lo que cuando ostentan cargos relevantes lo único que hacen es delegar en los demás todo el trabajo y ellos apoderarse de él como si fuera intelectualmente suyo.

Como Directivo es tal tu falta de responsabilidad que poco le importa el para bien de su empresa a largo plazo, o que sus trabajadores cobren o no en los plazos 


\section{CAPÍTULO II. LA PSICOPATÍA COMO CARACTERÍSTICA BASAL Y DEFINITORIA DE LAS} CONDUCTAS ACOSADORAS.

legalmente establecidos por los convenios. Siempre tiene una excusa para autoexculparse y tomar como buena su gestión. Sus proveedores pueden estar hasta años sin cobrar, prometiéndoles siempre el pronto y totalidad del pago, lo cual en la mayoría de las ocasiones es una auténtica quimera. Si estos deciden dejar de servirles buscan a otros ajenos a las circunstancias de la empresa y de un lugar lo suficientemente lejano como para no saber qué tipo de personas gestionan los centros y así de nuevo seguir cometiendo abusos, a sabiendas que en caso de que se produzcan denuncias, la tardanza actual de la justicia y el impacto económico que supone no le va a ser rentable al propio denunciante.

\section{o-Incapacidad para aceptar la responsabilidad de las propias acciones.}

Usualmente tiene alguna excusa para su conducta, tal como la racionalización o situar la culpa en los otros (familia, víctimas, sociedad). Es lo que en psicología designamos como atribución de éxito o fracaso como sesgo cognitivo. Cuando aparecen resultados óptimos o brillantes él mismo se hace responsable de ellos, haciendo ver a los demás que ha sido el elemento clave y artífice de tales resultados.

Por el contrario, cuando los resultados no son los esperados, son negativos o no son tan brillantes como se esperaba el acosador tiende a culpabilizar a los otros de los mismos, e incluso es capaz de en un reducido espacio de tiempo crear una auténtica teoría en contra de sus subordinados, con el fin de hacer ver a los demás que efectivamente la negatividad de los resultados se debe a la inoperancia de los demás, lo cual artificializa, con argumentos y recursos vagos en su forma y carentes de sentido, pero que rara vez no le son adecuados.

Con ello consigue el objetivo que se plantea, que no es otro más que siempre "ser más que... los demás". 


\section{CAPÍTULO II. LA PSICOPATÍA COMO CARACTERÍSTICA BASAL Y DEFINITORIA DE LAS} CONDUCTAS ACOSADORAS.

\section{p- Varias relaciones maritales breves.}

Cuando hablamos de relaciones maritales breves, nos estamos refiriendo a relaciones con una duración inferior a un año. Suelen ser matrimonios formales y legales y algunas relaciones de convivencia tanto homosexuales como heterosexuales.

Como ya hemos visto con anterioridad la sexualidad está muy presente en este tipo de personas. La consideran casi fundamental para su vida. Mantienen numerosas relaciones extramatrimoniales y en el mismo periodo de tiempo, ya que son incapaces de lograr una estabilidad emocional óptima.

Una vez hemos estudiado a fondo los rasgos endógenos, pasaremos a describir los llamados rasgos exógenos, como segunda gran batería de principales rasgos que determinarían la psicopatía como factor determinante en las conductas acosadoras y del mobbing.

\subsubsection{Rasgos Exógenos, "conductas para con los demás".}

\section{a- Manipulación Psicológica.}

Es una persona que hace creer a sus víctimas que son libres, radicaliza su pensamiento en términos de todo o nada o bueno o malo... Fomenta su discurso siempre con una fuerte carga emocional, repitiendo constantemente su mensaje, no dejando pensar críticamente a la víctima. Habitualmente controla también el ambiente, canalizando la estimulación (elimina fuentes alternativas de comunicación) que pueda hacer ver la realidad a la víctima.

Su objetivo no es otro más que elegir, manipular y beneficiarse de sus víctimas. En definitiva puede decirse que usan como medio técnicas de persuasión coercitiva lo que hace mermar significativamente la capacidad de los otros. 


\section{CAPÍTULO II. LA PSICOPATÍA COMO CARACTERÍSTICA BASAL Y DEFINITORIA DE LAS} CONDUCTAS ACOSADORAS.

Son personas con una inteligencia más que notable, capaces de reconocer con agilidad las deficiencias de los demás y aprovecharlas para conseguir sus objetivos. Aparecen enmascarados detrás de una personalidad encantadora, amable, sensible, e incluso débil que va a hacer muy difícil su reconocimiento. La víctima le ve como la "persona adecuada" capaz de dar respuesta y poner fin a sus problemas.

Como Directivo tan solo reduce el campo de actuación de sus subordinados hasta dejarles incluso sin firma ni postestad para tomar decisiones en el propio centro residencial que la víctima dirige. Si se dan las circunstancias para mantener alguna reunión con la víctima y más directores o personas de relevancia social, el acosador interrumpirá constantemente a la víctima, no dejándola exponer ninguna de sus ideas o puntos de vista, haciéndola sentirse inoperativa y poco válida.

Con todo esto, consigue estigmatizar gratuitamente, desplazar en silencio a alguien de su puesto de trabajo, hacerle sentir que reúne pocas características personales y laborales para un puesto que hasta hacía unos meses ocupaba con brillantez y sin ningún tipo de problema relevante.

\section{b- Sin reglas / normas sociales.}

Esta clase de personas no aceptan ninguna norma socialmente impuesta, sino que tienen sus propias reglas y sólo verán las suyas como buenas, correctas y adecuadas. Las normas por las que se rigen el resto de personas son vistas como una mordaza e incluso como una amenaza, ya que puede que sus habilidades sociales se vean debilitadas.

Podríamos decir por tanto que no tienen una estructura interna de valores, capaz de servir de referencia en su modo de actuar. No evalúan el daño de los otros, solo el suyo mismo. 


\section{CAPÍTULO II. LA PSICOPATÍA COMO CARACTERÍSTICA BASAL Y DEFINITORIA DE LAS} CONDUCTAS ACOSADORAS.

Es muy improbable verle relacionarse con sus propios trabajadores e incluso cuando en algunos de los centros se celebra algún acto en el que no hay cargos de relevancia social, rara vez acude y de hacerlo no permanece durante mucho tiempo. L

\section{c- Personalidad egocéntrica.}

Esta característica describe a una persona que se ve así mismo con unas características personales, emocionales, afectivas, cognitivas, intelectuales y comportamentales por encima de los demás. Todo, absolutamente todo, está hecho con miras a él. Se atribuye como norma todos los éxitos y niega el fracaso. Es un sesgo muy común que destaca en su estructura de personalidad.

\section{d- Falta de empatía.}

Es impasible para con los demás. Es incapaz de ponerse en el lugar del otro. Es tal la preocupación que siente por si mismo que hace que no se pare a pensar que consecuencias pueden tener sus actos. Ello le lleva a incluso falta de relaciones verdaderamente plenas de amistad u confianza, salvo con aquellas personas que él considera pueden aportarle algo, normalmente sujetos con un status social por encima de la media y que en algún momento dado pueden ayudarle a conseguir sus objetivos.

Suelen vivir obsesionados con su etiqueta profesional, tan sólo se preocupan que bajo su nombre aparezca el rótulo de "Director General", tal es así que incluso cuando la empresa comienza a dar quiebra y se pierden las concesiones de los diferentes centros residenciales, hasta solo permanecer uno en activo, él sigue denominándose a sí mismo, Director General del Grupo.

Esto hace que el resto de subordinados que permanecen a su alrededor piensen que él mismo ha tomado las decisiones para deshacerse de algunos centros. 


\section{CAPÍTULO II. LA PSICOPATÍA COMO CARACTERÍSTICA BASAL Y DEFINITORIA DE LAS} CONDUCTAS ACOSADORAS.

\section{e-Conducta impredecible.}

Este es uno de los rasgos principales que lo caracterizan. Como dicen algunos autores "nunca se sabe por dónde te va a salir". Es como Sarah Hampson relata, "consistentemente inconsistente en sus conductas cotidianas". Rompe con el principio de Premack "ante una situación antes vivenciada el acosador no actúa de la misma manera en que lo hizo la vez anterior".

Se adapta con gran facilidad y rapidez a las nuevas situaciones, tiene una gran capacidad para el tratamiento y el procesamiento de nueva información. Aprende con facilidad de sus errores y no vuelve a cometerlos. Tiene una gran capacidad de atención selectiva, para quedarse con aquello más valioso de la situación ante la que se encuentre.

\section{f- "El fin justifica los medios".}

Estamos ante una persona que es capaz de hacer cualquier cosa con tal de conseguir sus metas y objetivos que se haya propuesto, sin importarle el cómo, a quién o el daño que pueda provocar en los demás. Lo importante para él es lograr su bienestar.

Internamente cree que cualquier conducta que él lleve a cabo está justificada ya que la consecuencia que deriva de esa conducta no es otra más que lograr su homeostasis personal.

\section{g- Palabras / vocabulario banales.}

Si observamos detenidamente su vocabulario veremos cómo utiliza un lenguaje corto y repetido. Su mensaje siempre es el mismo. Además va cargado de un fuerte componente emocional y afectivo. 


\section{CAPÍTULO II. LA PSICOPATÍA COMO CARACTERÍSTICA BASAL Y DEFINITORIA DE LAS} CONDUCTAS ACOSADORAS.

\section{h- Discurso incoherente / contradicciones.}

A lo largo de la exposición de su discurso se puede observar cómo existen contradicciones, incoherencias lingüísticas que crean en la víctima aún más desconcierto si cabe.

Estas contradicciones se deben en parte a la falta de interés por el receptor. En ocasiones se muestran dubitativos, con falta de claridad psicológica. Como directivo suele tener su discurso bien escrito y previamente preparado, no deja nada al azar puesto que podría debilitar su imagen.

\section{i-Conocimiento de las debilidades ajenas.}

Poseen una gran facilidad para desentrañar las debilidades y los déficits de sus víctimas. Son unos grandes descriptores de rasgos psicológicos. Esta agilidad para el conocimiento de los demás hace que los posibles mecanismos de defensa de los afectados queden totalmente fuera del campo de acción.

La mayoría de sus víctimas cuando se han dado cuenta de la situación ya están al borde de perder su puesto de trabajo y en algunas ocasiones incluso ya lo han perdido. Son capaces de dar un giro de trescientos sesenta grados a las situaciones laborales, mediante medias verdades, mentiras e invenciones que poco tienen que ver con la realidad en la que están inmersos.

\section{j-Carencia vital / pobreza de vida.}

Es alguien que carece de una vida plena, deseada por él mismo. En realidad se siente vacío, carente de vida, como si se notara que no está disfrutando realmente de todo lo que le rodea. Solo vivencia lo que les ocurre a los demás. Se considera un actor secundario, pasivo de su propia vida. 


\section{CAPÍTULO II. LA PSICOPATÍA COMO CARACTERÍSTICA BASAL Y DEFINITORIA DE LAS} CONDUCTAS ACOSADORAS.

\section{k- Actitudes y conductas inestables e inexplicables hacia los demás.}

Para describir esta característica haremos alusión a la "Teoría de la Construcción de la Personalidad" de Sarah Hampson (profesora del departamento de Psicología del Birkbeck College de Londres). En su teoría menciona la conducta humana como consistentemente inconsistente; el acosador desarrolla conductas distintas constantemente, no es constante en su manera de actuar. Su comportamiento viene motivado de una manera impulsiva.

\section{I- Devaluación.}

Son individuos que constantemente están intentando devaluar las cualidades de sus víctimas, con el fin de mermarlas hasta casi su desaparición. En muchas de las ocasiones esta devaluación la realiza en público. Es una devaluación sutil, sagaz, a simple vista prácticamente inapreciable, pero altamente peligrosa y perjudicial para la víctima.

\section{m-Proyección de hostilidad.}

Tienden a proyectar en las víctimas su personalidad, sus inquietudes, sus miedos, sus logros, sus éxitos, sus fracasos...Atribuyen a las víctimas cualidades que en realidad no poseen.

Como Directores Generales suelen acusar a la víctima de falta de carisma, de falta de cercanía a sus empleados, de falta profesionalidad, de falta de responsabilidad, de honestidad, de fidelidad, de incapacidad para llevar a cabo las tareas y obligaciones cotidianas que demanda el puesto, paradójicamente atribuciones que la víctima si posee y de manera exitosa y de las que el propio acosador carece en su vida profesional. 


\section{CAPÍTULO II. LA PSICOPATÍA COMO CARACTERÍSTICA BASAL Y DEFINITORIA DE LAS} CONDUCTAS ACOSADORAS.

\section{n-No acepta críticas.}

Es una persona incapaz de asimilar las críticas hacia su persona. Su visión es la correcta, y su egocentrismo hace que se vea casi perfecto, sin defectos, sin límites...Las críticas de los demás siempre son vistas para él de una manera negativa y amenazante de su yo.

En algunas ocasiones escucha la opinión de los demás, pero sin darlas ningún tipo de relevancia. Por tanto la relación que se establece y los vínculos socio-afectivos entre el acosador y la víctima, siempre van a estar en el marco de la asimetría, son relaciones centradas en la desigualdad.

\subsection{El “Ciclo Manipulativo”.}

“... Son muy buenos a la hora de concentrarse en las cosas que les interesan y obviar todo lo demás.

Algunos clínicos han comprado ese proceso con un foco que se concentra en una sola cosa cada vez.

Otros sugieren que es similar a la concentración con la que los depredadores acechan a su presa (...)".

Hare (2003).

Una vez que hemos visto los rasgos característicos tanto los endógenos como los exógenos, haremos hincapié en el Ilamado "Ciclo Manipulativo" de la Psicopatía. A lo largo de este apartado vamos a tratar de desmenuzar y describir con la mayor precisión posible qué hace el acosador para atrapar y engañar de manera sutil a sus víctimas. Para ello presentaremos el "Ciclo de Manipulación", propuesto por Vicente Garrido Genovés en el año 2004. 


\section{CAPÍTULO II. LA PSICOPATÍA COMO CARACTERÍSTICA BASAL Y DEFINITORIA DE LAS} CONDUCTAS ACOSADORAS.

En dicho modelo se diferencian las siguientes fases:

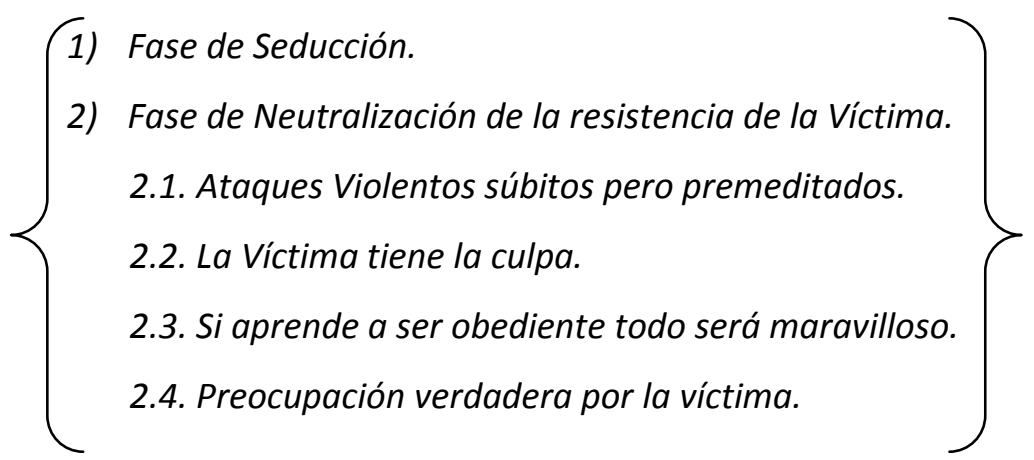

1) Fase de Seducción.

Consta de un primer contacto manipulativo más una etapa de presión, vulnerabilidad y seducción. Es la primera fase del proceso. El acosador, como ya hemos mencionado a lo largo del trabajo es un gran detector de las debilidades del otro, aprovechando la vulnerabilidad de la víctima logra seducirla. Esto lo hace mediante halagos, intentando deslumbrarla, no dejándola pensar, presionándola para que decida lo que él quiere que haga. Toda capacidad del afectado de respuesta o voluntad ha de ser neutralizada.

2) Fase de Neutralización de la resistencia de la Víctima.

Formada por el comienzo de la intimidación y un ciclo manipulativo puro; captación, explotación y revelación. El sistema más habitual de neutralización es la intimidación. Para llevar a cabo este proceso se suelen usar amenazas directas, miradas desafiantes, una forma peculiar de comportamiento que detallamos a continuación.

\subsection{Ataques Violentos súbitos pero premeditados.}

Humilla reiteradamente a la víctima. Muchas de esas humillaciones se dan en público, desvalorizando así a la víctima y tratándola de anular 


\section{CAPÍTULO II. LA PSICOPATÍA COMO CARACTERÍSTICA BASAL Y DEFINITORIA DE LAS} CONDUCTAS ACOSADORAS.

en su forma de pensamiento. Además hay una fuerte carga emocional lo que hace que el proceso manipulativo sea aún más profundo y eficaz.

\subsection{La Víctima tiene la culpa.}

Crea sentimientos de culpabilidad en la víctima, explica que es algo que él no quiere hacer, pero que se ve obligado por el bien de él / ella, o por otra razón. El acosador aparece como una ayuda para la víctima, sin embargo la hará pagar un alto precio.

\subsection{Si aprende a ser obediente todo será maravilloso.}

La víctima puede evitar que todo esto se produzca, si entra en razón y no le desafía, "simplemente" debe acatar sin razón, las maneras y formas de entender del acosador.

\subsection{Preocupación verdadera por la víctima.}

El objetivo final del acosador es que la víctima sienta que realmente le importa, nada más lejos de la realidad.

El resultado es que la víctima se bloquea, quiere que todo vaya bien, pero ha de aprender que eso implica renunciar a su individualidad, a sus derechos. Hasta que lo aprenda tendrá que sufrir ataques sorpresa, que lo serán menos a medida que él / ella "comprenda qué los provoca".

A continuación se muestra un breve resumen del Capítulo que acabamos de concluir. 
CAPÍTULO II. LA PSICOPATÍA COMO CARACTERÍSTICA BASAL Y DEFINITORIA DE LAS CONDUCTAS ACOSADORAS.

RESUMEN - ABSTRACT

CAPÍTULO II.

"La Psicopatía como característica basal y definitoria de las conductas acosadoras".

En el Capítulo II, hablamos de la Psicopatía como rasgo psicológico definitorio, sin el cual no podríamos hablar de conductas de acoso laboral. Se hace por tanto un estudio del concepto de la Psicopatía, abordándolo desde las diferentes clasificaciones patológicas existentes, como son el DSM (Manual Diagnóstico y Estadístico de los Trastornos Mentales) y el CIE, (Clasificación Internacional de las Enfermedades) enumerando detalladamente qué entiende cada una de ellas por este término.

A continuación y una vez se ha detallado el mismo, se da una visión histórica, del llamado perfil psicopático, partiendo de las definiciones dadas por investigadores tales como Pinel, Prichard, Morel, Koch, Gross, Kraepelin, Schneider, Cleckley o Kernberg, hasta los estudios más recientes, como son los de Robert. D. Hare y Vicente Garrido.

Seguidamente se realiza un minucioso análisis pormenorizando los rasgos que caracterizan la psicopatía descrita como tal, en sus rasgos endógenos y exógenos.

Para finalizar y concluir este Capítulo II, se realiza un desglose $y$ caracterización, de lo que muchos autores han denominado "el ciclo manipulativo" o "de la manipulación", que se da en un fenómeno de tales características.

En el siguiente Capítulo, Capítulo III revisaremos cuál es el desarrollo y las fases que se dan en un proceso de mobbing directivo, detallando cada una de ellas, y poniendo en relieve los datos más significativos que arroja el fenómeno, así como todos aquellas situaciones que vivencia un directivo de un centro residencial en tal situación. 


\section{CAPÍTULO III}

\section{“El Desarrollo y las Fases de un proceso \\ de Mobbing Directivo"}

VNIVERSITAS STVDII SALAMANTINI

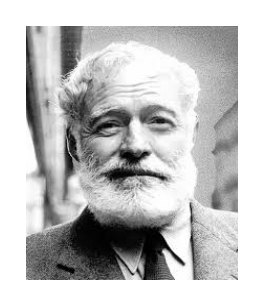

"Las mejores personas poseen un sentido de la belleza, el valor para asumir riesgos, la disciplina para decir la verdad, la capacidad de sacrificio...Irónicamente, sus virtudes los hacen vulnerables; y a menudo resultan heridos, a veces destruidos"

Ernest M. Hemingway escritor y periodista estadounidense) 


\section{CAPÍTULO III.}

"El Desarrollo y las Fases de un proceso de Mobbing Directivo".

\section{El Desarrollo y las Fases de un proceso de Mobbing Directivo.}

Una vez que hemos analizado en qué consiste el perfil psicopático, abordaremos en profundidad cual es el desarrollo "normal" por el que discurre el acoso laboral y cuáles son las fases que se suceden en el proceso.

El primer requisito del cual debemos hablar es que el trabajador, en este caso el director de un centro residencial, se encuentre indefenso, cuanto más indefenso se encuentre mejor para el acosador. Esta situación de indefensión puede estar motivada por causas relacionadas con, género, relación laboral, jerarquía laboral, o incluso por problemas o trastornos psicológicos, percibidos por el acosador.

Piñuel (2001), señala algunos perfiles, a los que califica como "objetivos preferentes":

1) Trabajadores que tienen mayor probabilidad de ser "envidiados" por sus éxitos profesionales o personales. Es el "otro", el extraño que se sale de la normalidad del grupo. Suelen ser personas con grandes resultados profesionales tras de sí o al menos con numerosas expectativas laborales, en un corto periodo de tiempo. Normalmente estos logros, suelen ir acompañados de una vida personal plena y satisfactoria, lo cual hace enfurecer aún más al acosador.

2) Trabajadores amenazantes del status quo de la organización, por ser innovadores, creativos, etc.

3) Trabajadores amenazantes de la capacidad irregular o fraudulenta de la organización, es muy frecuente cuando se "trabaja más de lo normal", 


\section{CAPÍTULO III. EL DESARROLLO Y LAS FASES DE UN PROCESO DE MOBBING DIRECTIVO.}

se denuncian irregularidades, o infringen las injustas normas de conducta del grupo.

4) Trabajadores más vulnerables por carecer de apoyos internos o externos, que proceden de otros entornos, frecuente en caso de trabajadores de otros países, o de otras comunidades autónomas.

5) Trabajadores con mayor vulnerabilidad física, enfermos o discapacitados.

6) Trabajadores recién llegados, contra los que es fácil generar el "síndrome del cuerpo extraño" ${ }^{\prime \prime}$. Esto explica que los trabajadores jóvenes sean más acosados, y en mayor medida si son mujeres.

Además de estos perfiles es también muy frecuente, no solo culpabilizar a la víctima, sino achacarle posibles desequilibrios o trastornos psicológicos, la víctima no solo es culpable sino que también "está mal de la cabeza", ve "fantasmas" donde no los hay, nadie acosa a la víctima. El acosador se auto convence y convence a los demás de que, la víctima sufre un trastorno psicológico previo, no posterior al acoso, que nunca ha existido para él. Si la víctima se da de baja al no poder soportar más el acoso y la situación que está viviendo, confirma que "estaba enferma".

Esta baja es aprovechada aún más por el acosador para tratar de convencer a los subordinados del director del centro, de que este padecía algún tipo de enfermedad, que algo le estaba "pasando por la cabeza" y que realmente él era culpable de lo que le estaba ocurriendo. Nada más lejos de la realidad, lo único que ocurría es que el acosador comenzaba a verse "acorralado" por su víctima.

\footnotetext{
${ }^{6}$ La Teoría del "Síndrome del Cuerpo Extraño", explica como los grupos humanos, en algunos aspectos funcionan como un sistema, ante la presencia de un "elemento extraño", se protegen, eliminado al sujeto que supone un elemento de riesgo en la estabilidad de las cohesiones internas que mantienen vivo y funcional al grupo en cuestión.
} 


\section{CAPÍTULO III. EL DESARROLLO Y LAS FASES DE UN PROCESO DE MOBBING DIRECTIVO.}

Podemos hablar además de algunos factores causantes, influyentes en el proceso de acoso laboral, que a posteriori estudiaremos con detenimiento a lo largo de este capítulo;

\section{Factores Objetivos: "El Clima Organizacional”.}

La estructura jerárquica, el modo en que se reparte el poder, los canales de comunicación e información, las relaciones personales, la asignación de promociones y desarrollos de carrera, la flexibilidad o rigidez de horarios, las relaciones interpersonales y sociolaborales, el estilo de dirección, etc..

\section{Factores Subjetivos: "Características del Acosador y de la Víctima".}

Son unos de los elementos más importantes en el estudio del acoso laboral en dirección, estaríamos hablando de las características que definen psicológicamente a la víctima y al acosador.

\section{Factores Sociales: "El Contexto Sociocultural".}

Se trata de aquellos matices, que caracterizan el lugar donde se producen los hechos, tanto sociales como culturales.

\section{Factores Económicos: "Estado Económico de la Empresa".}

Es un matiz novedoso en el estudio del Mobbing directivo, en tanto en cuanto entendemos la actual situación económica y en ocasiones la avaricia del empresario por obtener mayores réditos económicos le motiven a realizar este tipo de comportamientos, con el fin de lograr que uno de sus directivos abandone su puesto de trabajo "voluntariamente", ahorrándose así los costes tanto del salario del trabajador, como de su despido improcedente, ocultando además la realidad económica en la que se encuentra inmersa la empresa o el conglomerado empresarial. 
CAPÍTULO III. EL DESARROLLO Y LAS FASES DE UN PROCESO DE MOBBING DIRECTIVO.

Por tanto al hablar de Mobbing directivo hablaremos en este Capítulo, de 4 Fases claramente diferenciadas (Gráfico 3.1):

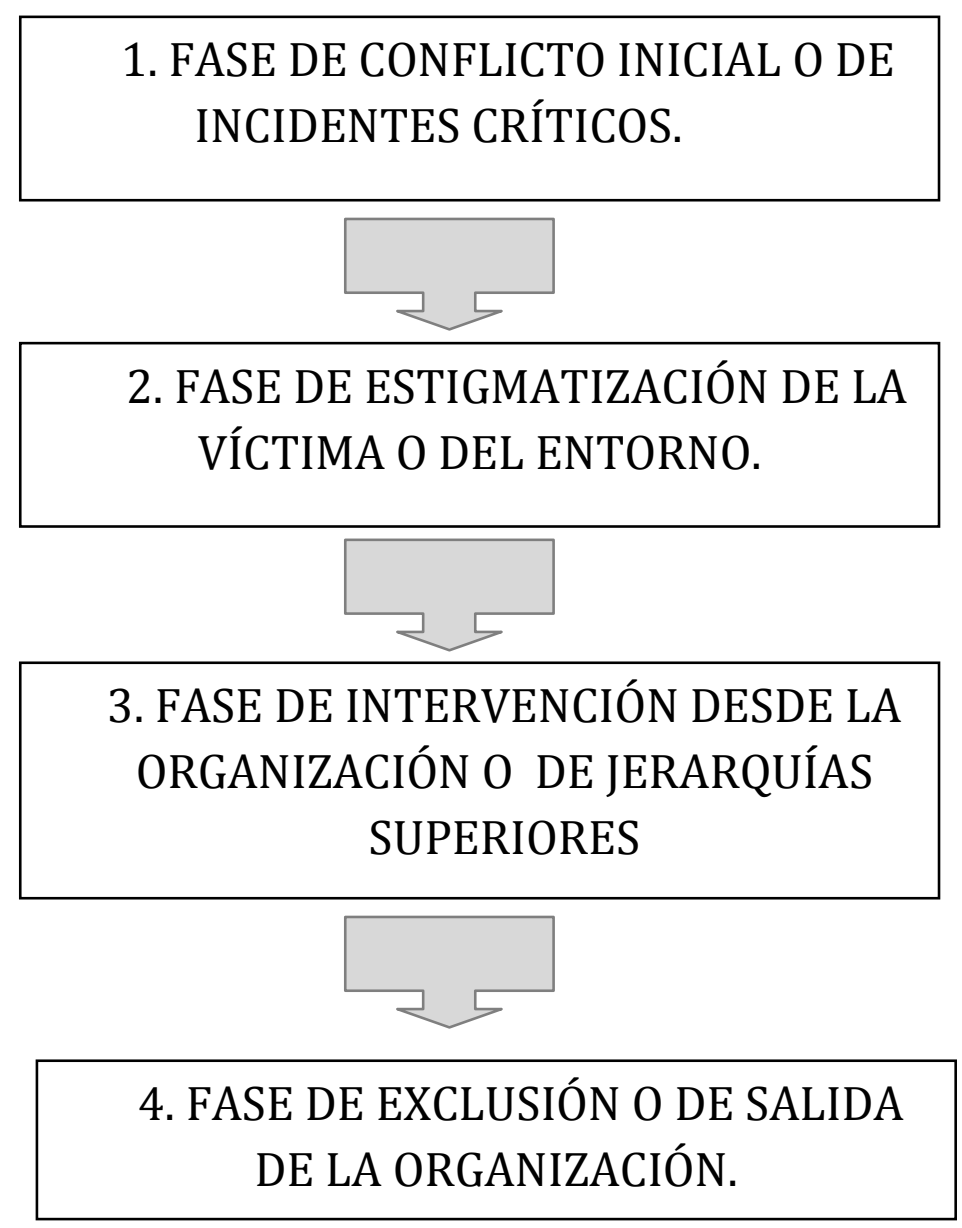

Gráfico 3.1. Fases de un proceso de mobbing Directivo.

No obstante hablaremos en las siguientes líneas, de la importancia de los antecedentes sociales, culturales y el entorno laboral, que autores como Milgram o Zimbardo, entre otros, pusieron de relieve en algunos de sus experimentos sociales más conocidos, con el fin de ahondar en la temática que nos ocupa y resaltando, el valor que tiene, para el funcionamiento óptimo de un centro residencial, y para sus trabajadores, el clima laboral existente. 


\section{CAPÍTULO III. EL DESARROLLO Y LAS FASES DE UN PROCESO DE MOBBING DIRECTIVO.}

\subsection{Antecedentes sociales, entorno laboral y cultura organizacional.}

El fenómeno del acoso psicológico en el contexto laboral es demasiado complejo como para poder explicarlo basándonos en un solo elemento, ya que se trata de un tipo de conflicto claramente multicausal (Bosqued, 2006: McCarthy, 2003; Einarsen, 1998, Fernández-Ríos, 2006), ya indicaron que la violencia en el trabajo generalmente es consecuencia y resultado de una combinación de diversas variables relativas a las personas, al entorno en general, a las condiciones del puesto de trabajo, a las características de la interacción entre trabajadores, al clima organizacional, y al clima específico del puesto de trabajo.

Por todo ello, el origen o motivo del problema puede resultar muy diverso, aunque básicamente, el substrato que favorece la aparición de este tipo de conductas se encuentra ligado a dos aspectos: a) la organización del trabajo y b) la gestión de los conflictos por parte de los superiores (Hoel y Salin, 2003; Rodríguez-López, 2004).

Por lo tanto, para numerosos autores, el caldo de cultivo del acoso psicológico en el lugar de trabajo no está determinado tanto en la personalidad de acosadores y acosados, sino en la forma de organización del trabajo y en las estrategias de precariedad del mismo, en las fórmulas de resolución de conflictos y los estilos de mando imperantes (Belandia, 2002; González Cuevas, 2002: Hoel y Salin, 2003).

Resulta evidente que el mobbing, no es tan solo un problema del individuo que lo padece o del acosador que lo desencadena, sino que se trata de todo un signo o síntoma de que las cosas no marchan bien en la manera de organizar el trabajo, de asignar las cargas del mismo, de definir adecuadamente los roles de los empleados, de seleccionar y/o promocionar a los directivos clave, o bien en lo que respecta a los valores, la cultura y el estilo de management de la organización en la que se producen tales situaciones (Leyman, 1996; Piñuel, 2001). 


\section{CAPÍTULO III. EL DESARROLLO Y LAS FASES DE UN PROCESO DE MOBBING DIRECTIVO.}

Para Davenport (2002), existen cuatro evidentes factores organizacionales favorecedores del acoso psicológico laboral, como son: a) una inadecuada gestión, donde se valore más la competencia que la eficiencia; b) un lugar de trabajo estresante, donde se trabaje constantemente presionado; c) la incredulidad o negación por parte de los responsables de la organización de la existencia del fenómeno mobbing, y d) una ausencia de ética laboral en la organización, donde quien se atreve a denunciar una situación percibida como injusta se convierte en un objeto de acoso.

Dicha situación, resulta evidentemente más probable en organizaciones en las que aspectos tales como el poder o el control priman sobre la productividad, la cooperación o la eficacia (López y Vázquez, 2003).

Diversos autores han realizado investigaciones sobre la importancia del clima laboral y la cultura organizacional a la hora de abordar el fenómeno del acoso laboral, encontrando que se dan mayores situaciones de violencia en general y de acoso laboral en particular en situaciones donde existe falta de armonía entre los grupos de trabajo y donde existe poco apoyo a los compañeros (Archer, 1999; Cole y Grubb, 1997: Einarsen, 2000).

En cuanto a los estilos de dirección, se debe señalar que en las pocas investigaciones que han tratado el fenómeno del mobbing se ha encontrado una evidente relación entre los estilos de dirección autoritarios y los ambientes laborales favorecedores de situaciones de acoso (Aassland, 2004).

O’Moore (2000), encontró que un número significativo de víctimas de acoso decían trabajar en situaciones de liderazgo autoritario. Por otra parte Vartia (2003), descubrió que las personas que nunca habían sufrido acoso o nunca habían sido testigos del mismo decían trabajar en entornos donde los problemas se solucionaban a través de estrategias de negociación empresarial. 


\section{CAPÍTULO III. EL DESARROLLO Y LAS FASES DE UN PROCESO DE MOBBING DIRECTIVO.}

Robert W, Fuller (2003), habla de control freak, refiriéndose a aquellos líderes acosadores que están obsesionados con el control, fanáticos de los detalles, que mantienen un patrón anormal de conducta controladora y de dominio sobre los demás trabajadores. Tienen tendencia a amonestar públicamente y de manera airada a los demás trabajadores, culpándoles de cualquier falta por nimia que sea, mostrándose agresivos cuando se les contradice. Se consideran superiores a los demás, pensando que los demás trabajadores no son capaces de llevar los asuntos correctamente, temiendo que todo irá mal si no están pendientes de todos los detalles, son hipercríticos, atemorizantes y estresantes de los trabajadores.

Entrarían dentro de lo que se conoce como "líder tóxico" o "líder destructivo", que son aquellos directivos que por sus características personales disfuncionales causan un daño en los trabajadores y en la propia empresa.

Bárbara Kellerman clasifica los líderes tóxicos en:

1) Incompetente: son aquellos que carecen de voluntad o de habilidad, o de las dos, para realizar una acción eficaz, siendo incapaces de crear un ambiente de trabajo positivo en su centro de trabajo.

2) Rígido: inflexible, pudiendo ser competente, no puede o no quiere adaptarse a las nuevas ideas, nuevos modelos de trabajo o a cualquier cambio en su modelo de organización laboral.

3) Intemperante: carece de autocontrol, o de cualquier freno a su voluntad, no soportando que lo contraríen.

4) Insensible: indiferente, poco amable, ignorando las necesidades y deseos de la mayoría de los miembros del grupo u organización, especialmente los subordinados.

5) Corrupto: pone su propio interés por delante del interés de la empresa, intentando conseguir un provecho personal. 


\section{CAPÍTULO III. EL DESARROLLO Y LAS FASES DE UN PROCESO DE MOBBING DIRECTIVO.}

6) Introvertido: carente de empatía, ignora la salud y el bienestar de las personas del grupo u organización para la que trabajan.

7) Sádico: usa el dolor y la intimidación como instrumento de poder. El daño puede ser físico, psicológico o ambos.

Estos tipos de líderes, suelen utilizar los siguientes medios de acoso:

- Carga de trabajo: aumentar la cantidad o la dificultad del trabajo contra sus rivales y subordinados.

> Sistemas de control corporativo: usar los procesos empresariales para controlar a las víctimas. Los sistemas disciplinarios son utilizados con abuso de derecho como medio de acoso.

$>$ Estructuras de organización: abusar de las jerarquías, las relaciones personales y la forma en que se organiza el trabajo en la empresa.

> Símbolos de la autoridad personal: uso de elementos indicativos del status jerárquico, como por ejemplo el derecho a las plazas de aparcamiento, aseos distintos al resto de los trabajadores, etc...Una plaza de aparcamiento no es sólo un lugar para estacionar el coche, es un símbolo de jerarquía y status laboral, si alguien se lo ocupa es una ofensa personal, una falta grave de indisciplina.

$>$ Los rituales de trabajo y rutinas: las reuniones de gestión, informes de las juntas, audiencia disciplinaria, los ensayos de rendimiento y así sucesivamente, utilizados como elementos de poder, siendo más habituales que lo que las relaciones laborales y el adecuado funcionamiento de la empresa necesitan.

Con todo ello podemos afirmar que la víctima está más pendiente de todas estas cuestiones que del trabajo, con lo cual su rendimiento disminuirá, lo que a su vez permitirá al líder seguir acosándola con esta justificación, el trabajador víctima perderá la confianza en sí mismo, disminuirá su autoestima, aumentará su estrés, acabando 


\section{CAPÍTULO III. EL DESARROLLO Y LAS FASES DE UN PROCESO DE MOBBING DIRECTIVO.}

con un grave trastorno psicológico y posiblemente la baja, con lo que el líder tóxico demostrará que llevaba razón.

Podemos decir que este tipo de líder, es narcisista, es aquel que tiene una gran arrogancia, ensimismamiento y una necesidad patológica y egoísta por el poder y la admiración de los demás.

Cuando alcanza un puesto elevado jerárquicamente, todo debe girar en torno a él, las decisiones de la empresa y de la organización están subordinadas a su propio ego. Todo aquel que le haga sombra o le contraríe acabará convirtiéndose en una víctima del acoso, ya que suelen ser muy sensibles a la crítica.

Además debemos señalar que cuando el acoso se desarrolla en un contexto social, como es el caso del acoso institucional (producido en puestos directivos de centros residenciales) o del mobbing, resulta imprescindible la colaboración y permisividad del resto del personal de la organización.

La persecución psicológica se desarrolla en medio de un sorprendente silencio e inhibición de los observadores que, aunque son plenamente conscientes del abuso e injusticia de la situación, se abstienen de intervenir, bien sea por complicidad implícita con el plan de eliminación del acosado, o sea para evitar convertirse ellos mismos en objetos de represalia (González de Rivera, 2002, Piñuel, 2004).

Sea cual fuere el motivo de la organización laboral que esté facilitando la aparición de conductas de hostigamiento psicológico en el trabajo, se trata de una organización tóxica, lo que supone numerosas consecuencias negativas para todos los integrantes (Piñuel, 2004).

En el Gráfico 3.2 que a continuación se muestra se pueden observar algunos de los indicadores de "toxicidad" psicosocial en una organización, según el investigador Iñaki Piñuel (2004) y sus diferentes niveles de análisis. 
Gráfico 3.2. "Características de las Organizaciones Psicosocialmente "Tóxicas"” (Piñuel, 2004).

\begin{tabular}{|c|c|}
\hline $\begin{array}{l}\text { NIVEL DE } \\
\text { ANÁLISIS }\end{array}$ & $\begin{array}{c}\text { INDICADORES DE “TOXICIDAD” PSICOSOCIAL } \\
\text { EN UNA ORGANIZACIÓN }\end{array}$ \\
\hline Ético-Filosófico & $\begin{array}{l}\text {-Darwinismo social: supervivencia del más fuerte. } \\
\text {-Neoliberalismo económico. } \\
\text {-Racionalidad económica. } \\
\text {-El éxito como valor de valores. } \\
\text {-Ética teleológica o finalista. } \\
\text {-Concepción antropológica instrumental. }\end{array}$ \\
\hline De Gestión & $\begin{array}{l}\text {-El conflicto como herramienta de gestión social. } \\
\text {-Carácter orgánico y corporativista de los órganos de gobierno. } \\
\text {-Dirección no profesional. } \\
\text {-Desestructuración y caos en la organización. } \\
\text {-Riesgos laborales psicosociales descuidados. } \\
\text {-Precariedad de los RR.HH. } \\
\text {-Feudalización de la organización. } \\
\text {-Instauración del régimen del miedo como forma de control. } \\
\text {-Distorsión de la comunicación y negación del problema. }\end{array}$ \\
\hline Social & $\begin{array}{l}\text {-Competitividad y precariedad laboral. } \\
\text {-Errores de atribución (“algo habrá hecho”). } \\
\text {-Integración social mediante mecanismos de victimización. } \\
\text {-Desintegración social en grupos internos. } \\
\text {-Gestión por valores. } \\
\text {-Miedo a la represalia. } \\
\text {-Síndrome de supervivencia organizacional. }\end{array}$ \\
\hline Individual & $\begin{array}{l}\text {-Desarrollo de comportamientos psicopáticos. } \\
\text {-Desarrollo de comportamientos de sumisión. } \\
\text {-Desarrollo del síndrome de afiliación. } \\
\text {-Falta de capacidad directiva. }\end{array}$ \\
\hline Grupal & $\begin{array}{l}\text {-Secretismo y testigos "mudos". } \\
\text {-Redes perversas de comunicación: la rumorología. } \\
\text {-Ausencia de integración entre colectivos / baja integración grupal. } \\
\text {-Relaciones grupales basadas en la falta de respeto. }\end{array}$ \\
\hline Jurídico & $\begin{array}{l}\text {-Impunidad de comportamientos fraudulentos. } \\
\text {-Indefensión jurídica. } \\
\text {-Fraude de ley: cumplimiento del tenor literal para vulnerar el sentido de } \\
\text { norma. } \\
\text {-Vulneración de los valores constitucionales y los derechos fundamentales. } \\
\text {-Exposición de los trabajadores a riesgos psicosociales. } \\
\text {-Vulneración del derecho a la dignidad. } \\
\text {-Justicia social como mero y exclusivo resarcimiento económico. }\end{array}$ \\
\hline
\end{tabular}




\section{CAPÍTULO III. EL DESARROLLO Y LAS FASES DE UN PROCESO DE MOBBING DIRECTIVO.}

Por tanto y después de estudiar algunos de los datos más relevantes de diversos investigadores podemos afirmar que el mobbing se vincula con factores organizacionales, y concentra su atención en los contextos sociales de interacción de los trabajadores. Así se considera indispensable contemplar variables organizacionales tales como la cultura organizacional, en tanto en cuanto favorecen o contribuyen a la emergencia del mobbing. (Hoel y Salin, 2003).

Hofstede (1997), considera la cultura organizacional como "un conjunto de patrones colectivos de pensamiento, sentimiento y actualización, aprendidos y compartidos".

Por su parte, Schein (1992), considera que la cultura organizacional "...es un patrón de presunciones básicas compartidas (principios inconscientes). Estos principios han funcionado suficientemente bien como para considerarlos válidos y, por tanto, para enseñarlos a los miembros como la forma correcta de percibir, pensar, sentir en relación con los problemas cotidianos. En otras palabras, esos principios regulan y determinan, en alguna medida, las percepciones, pensamientos, sentimientos y acciones de las personas de la organización. Además son elaborados colectivamente a partir de la experiencia".

En las siguientes líneas abordaremos las diferentes fases estereotípicas que conforman el llamado mobbing o acoso laboral en puestos directivos.

\subsection{Fases Estereotípicas del Mobbing.}

Una vez visto la importancia de los antecedentes sociales, el entorno laboral y la cultura organizacional en un proceso de mobbing, abordaremos las fases en las que se sucede este fenómeno, pero para ello, debemos de tener en cuenta algunos criterios diagnósticos.

A diferencia de los llamados "conflictos normales" en el trabajo, que se presentan de forma repentina, esporádica y de poca duración, el mobbing tiene criterios de 


\section{CAPÍTULO III. EL DESARROLLO Y LAS FASES DE UN PROCESO DE MOBBING DIRECTIVO.}

identificación particulares. Los criterios diagnósticos o características necesarias, más comúnmente aceptadas por los investigadores europeos, que sirven para dilucidar si estamos o no ante un caso de mobbing son:

1-La existencia de una o más conductas de hostigamiento.

2-La existencia de un elemento de temporalidad y habitualidad. El acoso no se produce de un día para otro; es un proceso lento, de modo que se precisa que la conducta hostil sea ejercida de modo sistemático y persistente, reiterada en el tiempo, "de modo que una conducta puntual puede ser leve, pero reiterada en el tiempo puede llegar a tener una gravedad notoria". Estaríamos hablando de una frecuencia semanal durante un prolongado tiempo, en términos jurídicos se toma como referencia un mínimo de seis meses. De este modo, estos comportamientos hostiles nunca pueden considerarse como causales. A pesar de ello, los intentos de los hostigadores por hacerlos pasar como insignificantes o incluso anodinos suelen ser casi siempre exitosos.

3-Intencionalidad; el comportamiento se dirige a dañar, perjudicar, castigar a la víctima, minando psicológicamente al trabajador a fin de lograr su sometimiento y/o su expulsión (Einarsen, 2003; Piñuel, 2007).

4-Un cuarto requisito es que esos comportamientos devengan en el lugar de trabajo y de una relación de trabajo, por parte de uno o varios individuos, ya sea del mismo nivel jerárquico que la persona agredida, de nivel superior o de nivel inferior como hemos descrito en el Capítulo 3. Los hostigadores suelen disponer de facto de una situación de poder formal o informal sobre la víctima, lo que en el argot psicológico denominados una asimetría de poder y de estados homeostáticos organizacionales, esta asimetría deriva en abuso de poder, en puestos directivos de centros residenciales, privando a la víctima en este caso director de uno de los centros de poder ejercer sus funciones en su puesto de trabajo. 


\section{CAPÍTULO III. EL DESARROLLO Y LAS FASES DE UN PROCESO DE MOBBING DIRECTIVO.}

La concurrencia de estas características acredita la existencia de un trabajador sometido a un cuadro de acoso psicológico en el lugar de trabajo o mobbing.

Los conflictos puntuales o los desencuentros son parte de las relaciones humanas y no son situaciones de acoso psicológico, sin embargo si suelen ser el escalamiento de un conflicto en el tiempo, que sin una gestión directiva, proactiva si pueden llevar a casos de mobbing.

Atendiendo al profesor Piñuel (2007) y Mir (2007), es necesario hacer un diagnóstico diferencial del acoso psicológico en el trabajo con respecto a otras problemáticas, como ya vimos en el Capítulo 1, ya que si no se puede cometer el error de trivializar o banalizar este problema.

El término acoso laboral o mobbing, no puede ser utilizado para todo tipo de conflictividad interpersonal en el mundo laboral, capaz de generar una situación de sentida agresión. La expansión incontrolada del concepto sin duda lo desnaturaliza, de manera que la ausencia de un tratamiento serio puede acabar perjudicando a las auténticas víctimas del maltrato psicológico en el trabajo.

Así pues hasta la fecha, la forma más habitual de explicar el fenómeno del mobbing ha sido a través de un proceso que comienza a desarrollarse de un modo insidioso y que pronto alcanza tan magnitud que resulta difícil el retorno al estado anterior (Einarsen, 2003).

Por ello estudiaremos en profundidad las siguientes fases, en las que los autores más especializados han señalado se produce el acoso (Piñuel, 2003);

- 1. Fase de Conflicto Inicial o de Incidentes Críticos.

- 2. Fase de Estigmatización de la Víctima o del Entorno.

- 3. Fase de Intervención desde la Organización o de Jerarquías Superiores.

○ 4. Fase de Exclusión o de Salida de la Organización. 


\section{CAPÍTULO III. EL DESARROLLO Y LAS FASES DE UN PROCESO DE MOBBING DIRECTIVO.}

Además de los factores anteriormente señalados en el estudio de estas fases y en el marco teórico debemos resaltar los factores culturales y socioeconómicos que influyen en el mobbing directivo y que a continuación se exponen en el Gráfico 3.3 (Einarsen, Hoel, Zapf y Cooper, 2003).

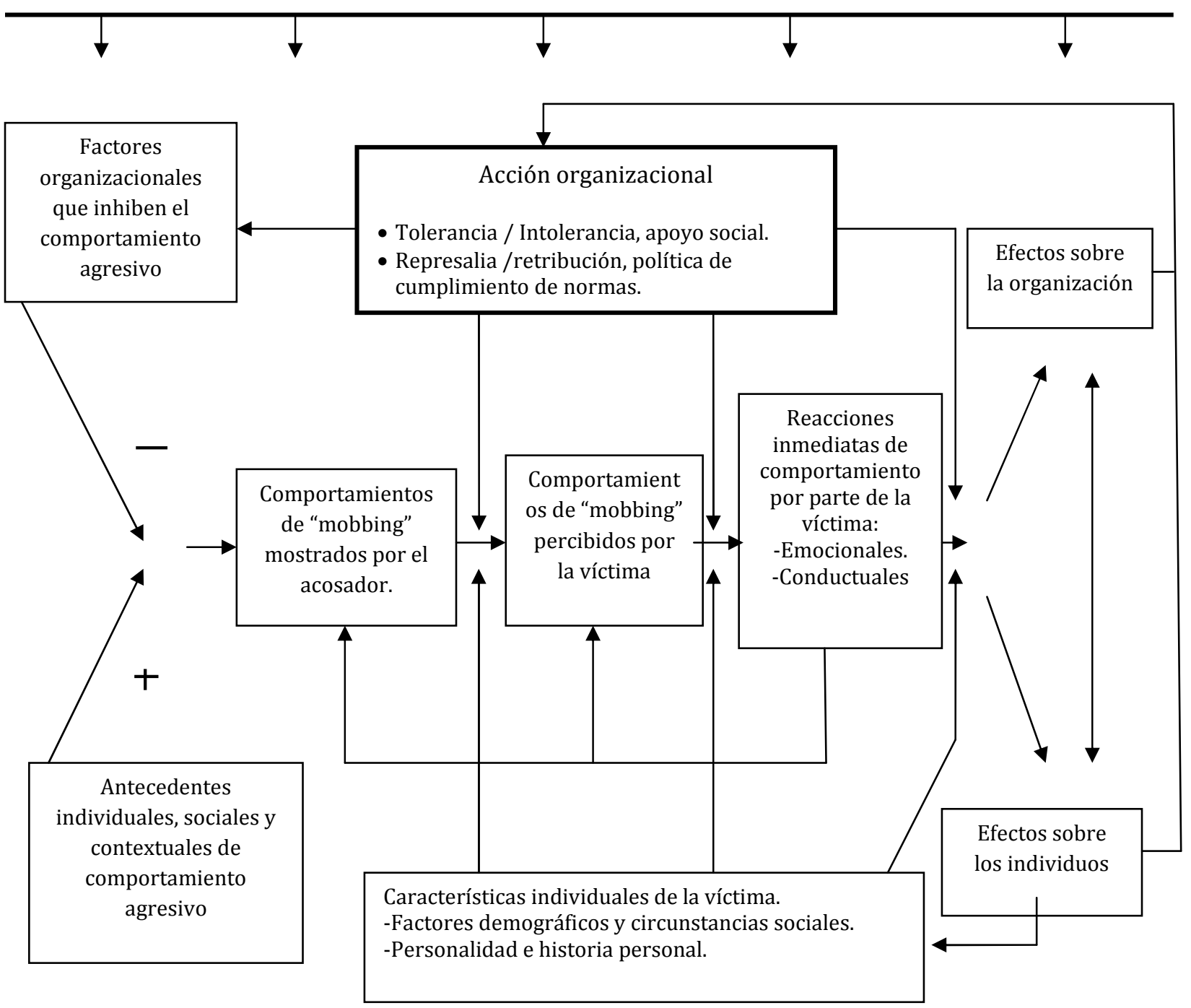

Por tanto a continuación describiremos los diferentes sucesos que caracterizan a cada una de las fases que componen el denominado proceso del acoso laboral. 


\section{CAPÍTULO III. EL DESARROLLO Y LAS FASES DE UN PROCESO DE MOBBING DIRECTIVO.}

\subsubsection{Fase de Conflicto Inicial o de Incidentes Críticos.}

Constituye la primera fase del proceso. Estaríamos en un primer momento ante un abuso de poder que provocaría un aparente conflicto donde no lo hay. El acosador ha creado un conflicto laboral interpersonal inexistente, que lejos de resolverse, se vuelve crónico para la víctima.

Tal y cómo se ha explicado anteriormente, en cualquier organización laboral existen conflictos, es algo esperable e inevitable, y en algunos casos incluso favorecen la madurez del grupo, superándolos de manera exitosa y constructiva.

Las razones por las que el acosador actúa de esta manera pueden ser variadas, pudiendo deberse a cuestiones relacionadas con la propia organización del trabajo, o bien con problemas de orden interpersonal, pero lo habitual es que los comportamientos, las actitudes, las formas de relación, los estilos de vida de los trabajadores...sean distintos e incluso incompatibles.

Tal diversidad suele ser una fuente segura de diferencias y tensiones, que cuando no se resuelven de manera adecuada llegan a producir situaciones tóxicas, tanto para la víctima, como para sus compañeros, como para su empresa, el único que sale beneficiado es el acosador.

Estaríamos ante una fase que en sí misma no constituye propiamente una situación de mobbing y que vendría caracterizada por su breve duración en el tiempo (Pérez-Bilbao, 2001).

Comenzarían a darse los primeros incidentes, el primer caldo de cultivo para que una situación tal se pueda sostener y desarrollar. Los conflictos se suceden y no hay una respuesta óptima que calme a la víctima, por consiguiente el conflicto se cronifica y comienza lo que se ha denominado "fase de estigmatización de la víctima o del entorno".

La víctima comienza a sentir los primeros efectos de este complejo proceso, del cual va a ser protagonista. 


\section{CAPÍTULO III. EL DESARROLLO Y LAS FASES DE UN PROCESO DE MOBBING DIRECTIVO.}

\subsubsection{Fase de Estigmatización de la Víctima o del Entorno.}

El acoso ya está en marcha, comienzan acciones contra la víctima y se configura una imagen de ella; "incompetente, incumplida, individualista, descuidada, poco ejemplar, poco constante, indigna para el cargo que ostenta", con ello lo que se busca es apartar socialmente a la víctima del grupo.

Se trata por tanto de conseguir "la autorización necesaria" del grupo para ejercer impunemente la violencia psicológica contra la víctima a través del consentimiento e incluso de la participación activa del entorno laboral.

Una vez que se hace perder el respeto a la dignidad del trabajador, todo es más fácil, sobre todo si este no hace nada por defenderse o no poder hacer frente. En esta fase comienzan a aparecer una serie de secuelas psíquicas que interfieren con el desempeño laboral afectándolo y modificándolo a la baja.

El trabajador entra en confusión, la inseguridad va a generar lentitud e incrementará los errores y fallos del directivo. Es una fase caracterizada por comportamientos agresivos y por la manifestación de ataques psicológicos que ponen en marcha una dinámica de acoso propiamente dicha (Pérez Bilbao, 2001).

Lo que en un principio puedo comenzar como un conflicto, probablemente irrelevante, entre dos personas, puede llegar a adoptar la forma de un conflicto de varias, e incluso muchas personas contra una, con la adopción de conductas hostigadoras grupales sutiles y complejas (Leyman, 1990; Piñuel, 2001).

La prolongación de esta fase suele deberse normalmente a actitudes y conductas de evitación o de negación de la realidad por parte del trabajador, otros compañeros no participantes en el acoso, sindicatos y representantes de los trabajadores e incluso la dirección (Pérez Bilbao, 2001).

Todo ello conformaría la antesala de lo que se ha denominado la fase de intervención desde la organización o de jerarquías superiores. 


\section{CAPÍTULO III. EL DESARROLLO Y LAS FASES DE UN PROCESO DE MOBBING DIRECTIVO.}

\subsubsection{Fase de Intervención desde la Organización o de Jerarquías Superiores.}

El instigador trata de "dar transparencia a los hechos", a instancias superiores de la empresa, apareciendo a consecuencia de sus noticias acciones ejemplarizantes, tales como una persecución directa de la víctima para buscar "pruebas incriminatorias de la misma".

En esta fase, al intervenir los superiores de la organización, normalmente la empresa enfoca la situación identificando a la víctima como el problema y lo interpreta cono un conflicto interpersonal.

En el caso que nos atañe, el hostigador enfoca la situación como una rivalidad personal entre directivos, nada más lejos de la realidad, con ello desvía la atención de lo que realmente sucede.

Esta investigación del caso por parte de autoridad superior suele completar la estigmatización del trabajador afectado, debido a que los canales que utiliza la propia dirección para informarse, suelen estar afectados e "infectados" por la propia acción de la estigmatización inicial.

El mecanismo psicológico del que ya hemos hablado en capítulos anteriores conocido como "error básico de atribución" es la causa de porqué compañeros, jefes y directivos tienden a buscar la explicación de la situación de hostigamiento en supuestas características individuales de las víctimas, en lugar de intentar intervenir sobre los factores de un entorno organizativo "tóxico".

Lo lógico, dada ya la magnitud del problema, es que en esta fase se tome conciencia de la situación que se está viviendo y se adopten un conjunto de medidas dirigidas a paliar y resolver los acontecimientos por parte de la organización (Pérez Bilbao, 2011). Normalmente tales medidas suelen ser adoptadas por alguno de los escalones superiores en la jerarquía. El tipo de medidas a adoptar variará en función de los hechos concretos, las circunstancias de la víctima, y la parte acosadora, el tipo de organización, la legislación vigente y el estilo de dirección, que en ese momento rija el rumbo de la empresa. 


\section{CAPÍTULO III. EL DESARROLLO Y LAS FASES DE UN PROCESO DE MOBBING DIRECTIVO.}

Evidentemente estas medidas no contribuyen a finalizar con el problema de manera satisfactoria para la parte acosada, sino que llevan como resultado a entrar en la cuarta y última fase del proceso, la fase de exclusión o de salida de la organización (Leymann, 1990; Piñuel, 2001).

\subsubsection{Fase de Exclusión o de Salida de la Organización.}

Antes de producirse la exclusión o salida de organización se produce una solicitud de ayuda especializada externa y un diagnóstico profesional.

Evidentemente todo este proceso ofrece una amplia gama de efectos psicológicos que aparecen como consecuencia natural de las experiencias de violencia que viven los trabajadores, aparece cierto "desgano vital" o comportamientos que son indicadores de estados depresivos. Según Piñuel (2007), suele acudirse en busca de ayuda cuando es tarde.

Además, atendiendo a Aggerbold y Mikkelsen (2004), "la víctima de acoso suele recibir de su médico de empresa si le hubiere, de cabecera, o del propio servicio de salud, una serie de diagnósticos erróneos o sólo parcialmente correctos, que incrementan aún más su confusión y sufrimiento, al hacerle sentir responsable de su propio acoso psicológico. Los diagnósticos habitualmente realizados a víctimas de casos de mobbing suelen ser:

Estrés laboral; debido al estrés postraumático que suelen presentar.

$>$ Depresión; debido a la indefensión generada por el acoso continuado y la consiguiente distimia.

$>$ Burnout; debido al estrés, y a la distimia producida.

$>$ Personalidad Paranoide; debido a la hipervigilancia.

> Maníaco- depresivo: debido a los altibajos en el estado de ánimo.

> Desajustes de personalidad; debido a las alteraciones y cambios en la personalidad que suele provocar el acoso.

$>$ Neurosis; debido a la falta de homeostasis general.

$>$ Trastornos de ansiedad generalizada y ataques de pánico. 


\section{CAPÍTULO III. EL DESARROLLO Y LAS FASES DE UN PROCESO DE MOBBING DIRECTIVO.}

Según Piñuel (2007), estos diagnósticos son incorrectos en la medida en que olvidan o restan importancia explicativa a los aspectos situacionales laborales tóxicos que lo están causando y que tienen su origen en una agresión externa, continuada y mantenida, y no en una fragilidad psicológica de la víctima.

Estos diagnósticos clínicos no suelen verificar la existencia de comportamientos de hostigamiento en el ámbito del trabajo de la víctima.

Al llegar a este punto, y viéndose sin otra opción profesional interna, las víctimas del mobbing deciden terminar con la relación laboral por sí mismas, piden un cambio del lugar de trabajo o bien abandonan la empresa.

Quienes continúan en su puesto de trabajo sin hacer frente al acoso que padecen, entran en la indefensión, comienzan a caer en bajas sucesivas que se van incrementando a través del tiempo, con la "probabilidad de ser despedidas por una baja productividad o por sus reiteradas ausencias al trabajo".

Se considera que deviene también una fase de asimilación: la víctima comprende parcialmente los hechos que le sobrevienen y se vuelve muy sensible. Así pues, inconscientemente cae en una apatía, retraimiento y desgano preocupante.

Por tanto el acosador habrá logrado su objetivo, que no es otro más que el trabajador acosado abandone la organización laboral a la que pertenece. A modo de conclusión de este apartado, se debe poner énfasis en que es posible identificar el mobbing en sus fases iniciales, por lo que la prevención resultará esencial (Spurgeon, 2003).

Los servicios de prevención, ayudados por los sindicatos, mutuas de accidentes laborales y enfermedades profesionales e inspección de trabajo deberían ser los actores principales de la prevención del acoso, pero la realidad en nuestro país es bien distinta; mientras en otros países el papel de los servicios de prevención resulta fundamental, aunque mejorable, en España no cuentan con medidas suficientes que garanticen su independencia profesional, por lo que aumenta considerablemente el riesgo de que aparezcan cada vez más casos de acoso laboral (Nuñez, 2002). 


\section{CAPÍTULO III. EL DESARROLLO Y LAS FASES DE UN PROCESO DE MOBBING DIRECTIVO.}

Una vez ahondado en las diferentes fases que se suceden en un episodio de acoso laboral hablaremos en las siguientes líneas de los protagonistas necesarios para que se dé un suceso de estas características: el acosador, la víctima y el entorno en que se lleva a cabo.

\subsection{Protagonistas; el acosador, la víctima y el entorno.}

Hirigoyen (2004) afirma que no se puede interpretar una situación de acoso al margen de sus protagonistas, de su trayectoria y su concepción del mundo:

"El modo en que cada uno reacciona ante un contexto hostil, está (...) en función de la propia historia, pero también de la historia de la empresa en la que trabaja, de la sociedad en la que vive y de su economía, de las micrososciedades que le rodean".

Así pues, podemos afirmar que para que el mobbing se consume y sea un hecho se precisan al menos tres elementos: un acosador, una víctima y un entorno, como puede ser una organización incapaz de solucionar un problema. El fenómeno sucedería debido a la interacción de estos elementos individuales y sociales:

\section{(1) El Acosador.}

Sería una persona que goza de una posición jerárquica superior a la de su acosado, tendría más recursos materiales, mayor capacidad de tomar decisiones dentro de la organización, mayor número de recursos materiales, más apoyos humanos que su subordinado y puede desarrollar su actuación en secreto, sin peligro de ser descubierto (Piñuel, 2001).

En algún momento del proceso usará esta circunstancia para lograr diferentes objetivos; revalorizarse dentro de la propia empresa, ante sus compañeros o subordinados, salir triunfador de una situación que él considera de alto alcance, o afianzar su poder dentro de la organización. 


\section{CAPÍTULO III. EL DESARROLLO Y LAS FASES DE UN PROCESO DE MOBBING DIRECTIVO.}

\section{La Víctima o acosado.}

Estaríamos ante la persona que recibe los actos del acosador, ante el receptor de las conductas. Sus características psicológicas y su actitud, responderán intentando neutralizar sistemáticamente a las de su agresor (Garrido, 2001).

Una "función reparadora" le inclinará incluso a comparecerse de su verdugo psicológico (Hirigoyen, 1999), sus sentimientos infundados de vergüenza y culpabilidad harán el resto (Piñuel, 2001).

\section{El Entorno laboral.}

En el estudio que nos ocupa el entorno laboral actuará como cómplice activo o pasivo de la situación, o bien favorece directamente la existencia del acosador y promueve este tipo de actuaciones (Hirigoyen, 1999), o en el mejor de los casos, se convierte en consentidor del maltrato mediante la inacción de los compañeros de la víctima y del resto de trabajadores y directivos que componen el organigrama organizativo empresarial.

El miedo suele ser un elemento definitorio a la hora del estudio de este concepto; en la actualidad la mayoría de los compañeros de la víctima suelen identificar lo que está ocurriendo, o al menos intuir lo que puede llegar a suceder pero la actual situación económica hace que permanezcan inmunes ante los hechos que están aconteciendo en su propio lugar de trabajo.

Cabe reseñar que tanto psicólogos, psiquiatras y demás médicos y expertos, investigadores de este concepto, resaltan la excesiva oposición que suele darse entre el hostigador y el hostigado.

Son numerosos los autores que se inclinan hacia una enorme proyección de rasgos personales definitorias desde el acosador hasta el acosado, culpabilizando a este último de carencias que no posee.

Así pues a lo largo de los siguientes apartados iremos conceptualizando y llenando de matices a cada uno de estos elementos: 


\section{CAPÍTULO III. EL DESARROLLO Y LAS FASES DE UN PROCESO DE MOBBING DIRECTIVO.}

\subsubsection{Principales trastornos asociados al acosador.}

¿Es posible que una persona normal y corriente se transforme en un acosador bajo determinadas circunstancias? Podemos afirmar que la presión psicológica actual que ejerce la nueva organización del trabajo puede posibilitar este hecho.

En mayor o menor grado todas las personas son egocéntricas, agresivas y sensibles a las críticas, y a todas les agrada ser admiradas, aunque muchas de ellas lo nieguen por sistema. Estos signos se mostrarían en el maltratador de forma significativa y acentuada, interfiriendo en su relación con el medio y en la percepción de los otros. (Elisa Múgica, 2002).

Mediocridad, envidia de las cualidades ajenas y necesidad de control serían los rasgos específicos que definirían su psicología y estos a su vez se plasmarían, entre otros trazos, en una apropiación de la creatividad del otro, de su mérito y un gran afán de notoriedad, profundos y desestabilizadores sentimientos de inadecuación personal y profesional, complejo de inferioridad, miedo e inseguridad hacia el entorno y hacia sí mismo, e intento de encubrir o camuflar las propias deficiencias ( Leyman, en Piñuel, 2001; González de Rivera, 2002).

Estaríamos por tanto no ante una enfermedad propiamente dicha, pero sí frecuentemente ante una combinación de elementos psicopatológicos que ayudarían a entender este comportamiento destructivo (Rojas, 2002). In extenso a continuación desarrollaremos algunos de los principales trastornos asociados al agresor:

\section{- Narcisismo.}

El narcisismo en estos términos es entendido como la actitud de una persona en la que lo subjetivo (sentimientos, necesidades físicas y no físicas...), tienen una realidad muchísimo mayor que lo objetivo, lo exterior. Para estos sujetos, sólo es real lo que existe en su interior $y$, en consecuencia, los hechos provenientes del mundo externo se perciben exclusivamente desde el punto de vista de la utilidad o el peligro que suponen para uno mismo. (From, 1994). 


\section{CAPÍTULO III. EL DESARROLLO Y LAS FASES DE UN PROCESO DE MOBBING DIRECTIVO.}

\section{- Obsesión por la imagen.}

En un mundo en el que prima la imagen, que vende imagen y en el que el acosador vive de ella, este estaría obsesionado por la que proyecta en los demás, por lo que piensen de él.

Una imperiosa preocupación le obligaría a dedicar gran parte de su tiempo a elaborar mensajes y emitir señales para dar forma a ese YO ideal, y gastar mucha de su energía en alimentar esa imagen pública fabricada, e inexistente en la realidad, mantenerla y si puede ser mejorarla. Estaríamos ante una persona bella por fuera, pero vacía por dentro.

Le faltaría profundidad emocional, ello supone un sinfín de contradicciones entre el "cómo es" y el "cómo se muestra", que el sujeto vive en la más absoluta privacidad. Preocupado sobre todo por causar una buena impresión y parecer especial a toda costa. De "puertas hacia afuera" se mostraría sistemáticamente positivo, amable, educado, comprensivo, humano..., es decir encantador y de "puertas hacia fuera" sería muy diferente, sobre todo con la víctima y sus allegados.

Mark Snyder, psicólogo de la Universidad de Minnesota define a estas personas como "camaleones sociales", personas que desarrollan habilidades que les permiten causar normalmente una excelente impresión social; magníficos actores, acostumbrados a representar personajes y roles muy distintos, que controlan muy bien sus emociones, están muy pendientes de la reacción de su auditorio y son capaces de adaptar muy bien su actividad laboral, para lograr lo que quieren (Goleman, 1996).

Jones (1987) habla de sujetos que "cuidan su envoltura" como nadie, el aspecto físico (suelen acudir varios días en semana al gimnasio), la vestimenta y otros adornos. Medirían muy bien sus formas y movimientos, intentando en todo momento mostrarse elegantes, exquisitos, dignos, respetables, desinteresados y nobles en su naturaleza. Tratan de esa manera causar una fuerte sensación en el público, procurando proyectar la imagen de persona sabía, con grandes dotes y recursos personales. 


\section{CAPÍTULO III. EL DESARROLLO Y LAS FASES DE UN PROCESO DE MOBBING DIRECTIVO.}

Su aspiración con ahínco a cargos directivos se debe más a la necesidad de figurar y aparentar, que al interés por la propia actividad a desarrollar. Así pues estaríamos ante personas dependientes de la aprobación social y sin problemas de conciencia por vivir en una permanente contradicción, diciendo una cosa y haciendo otra muy distinta, manifestando a unos una opinión y a otros la contraria, excesivamente amables, incluso con aquellos a quienes desprecian.

Por todo ello podemos afirmar que las relaciones de estos sujetos son forzosamente superficiales, cortas y poco gratificantes.

\section{- Autoimagen y Autoengaño.}

Ante sí mismos, serían sensibles, nobles, con un elevado sentido de la ética, incapaces de hacer algo negativo o de albergar malos pensamientos, muy generosos, ya que no pedirían nada a cambio de lo que dan, atentos. Crearían ante sí un mundo bidimensional en el que solo cabrían buenos y malos, amigos y enemigos, villanos y víctimas...Los otros serían los conflictivos o los equivocados en eta concepción del mundo.

\section{- Egocentrismo.}

Forzosamente tendría dificultades para poder apreciar en su justa medida la ostredad de los demás. Su óptica estrecha y parcial haría que sólo se conecte con lo más grande que cree que existe, que no es otra cosa más que él mismo.

Se trata de un ser caprichoso, guiado por sus impulsos, necesidades, deseos momentáneos o placeres inmediatos más que por principios o metas permanentes. Obra impulsivamente sin poder esperar.

No le bastaría con su propia veneración, sino que precisaría constantemente la de los demás. Esto le llevaría a rodearse únicamente de quienes le alimentan su ego, de palabra y de hecho, y a huir de quienes no le rinden pleitesía o le otorgan privilegios. El resultado serían unas relaciones poco espontáneas, poco fluidas, no articuladas entorno a la reciprocidad, en consecuencia frustrantes. 


\section{CAPÍTULO III. EL DESARROLLO Y LAS FASES DE UN PROCESO DE MOBBING DIRECTIVO.}

\section{- Carencia de empatía.}

Podemos hablar de dos tipos de empatía; la empatía, como habilidad "que nos permite comprender de qué modo la gente difiere de nosotros en sus opiniones acerca de las cosas", denominada esta empatía cognitiva, y la empatía emocional, que "permite que tú te sientas como se siente otra persona" (Garrido, 2001).

Cuando afirmamos que carece de empatía, estamos señalando una falta de profundidad emocional, la indiferencia ante cualquier sentimiento ajeno, próximo o lejano, al no poder experimentarlo, es incapaz de "ponerse en el puesto de otra persona" (lack of role-taking) (Bilbeny, 1995).

Por tanto además sería un inmaduro emocional, el individuo en cuestión detestaría las lamentaciones y los problemas ajenos. En la valoración que hace a los demás, éstos quedarían reducidos a instrumentos utilitarios, estereotipos u objetos.

\section{- Pseudoempatía o empatía artificial.}

Se habla de Pseudoempatía o empatía artificial cuando esta habilidad aparece con fines manipuladores, y en lugar de llegar a comprender auténticamente las necesidades ajenas, se utiliza para seducir y dominar.

Como ya hemos visto en el Capítulo 3, el estilo de comunicación de un acosador, está basado en la mentira, en la deformación y delata una gran falta de respeto, debido, a que el otro para él es solo una cosa, a la que engaña y traiciona vilmente. (Goleman, 1996).

\section{- Megalomanía.}

El acosador vive de ilusiones, cree firmemente en su superioridad sobre el resto de los mortales, se ve así mismo, como único especial, merecededor de todo lo bueno.

Crean por tanto una realidad alternativa a la vida en la que están inmersos, en la que se sitúan por encima de los demás y aparecen como los más inteligentes, los más dotados, en definitiva, son los mejores. (Bernstein, 2001). 


\section{CAPÍTULO III. EL DESARROLLO Y LAS FASES DE UN PROCESO DE MOBBING DIRECTIVO.}

Están ajenos a la masa social, y al margen de cualquier norma o convención establecida. En su concepción un ser superior como ellos debe regirse por sus propias reglas (Gavilán, 2000), cree poder cobrarse en hostigamientos y humillaciones, lo que todos le deben (Piñuel, 2003).

Algunos de los síntomas que presentaría serían (Piñuel, 2001):

- Creencia de que es imprescindible, aunque él mismo suele manifestar que nadie tiene esa condición.

- Piensa que constituye el soporte de la organización, es lo que se llama "pensamiento autorreferencial", lo bueno que sucede en la empresa tiene que ver con su persona, su sabiduría y su valía, él de alguna manera se atribuye el éxito debido a su asesoramiento o intervención.

- Se ve a sí mismo como el líder ideal, salvador de la empresa, con una idea clara de cómo se deben hacer las cosas.

- Resalta "historias exageradas de grandes logros profesionales", olvidando intencionadamente las aportaciones o colaboraciones de los otros.

- Aparenta relacionarse única y exclusivamente con gente muy cualificada, intelectual o socialmente.

- Se muestra muy contrariado si tiene que realizar tareas o funciones que estima inferiores a su status.

\section{- Aires de superioridad moral.}

Se mostraría distante y con aires de superioridad moral, trata de imponer a todo el mundo y exhibir "unos valores morales irreprochables con los que da el pego" (Hirigoyen, 1999). Adoptan en su lenguaje la moralidad por bandera y atesoran una gran intensidad de justicia.

Privados de muchas estrategias y recursos, se verían forzados a apoderarse de alguna característica psicológica valiosa que no poseen, con el objetivo de aproximarse a los demás y así alimentar su ego. Detrás de todo ello tan solo se oculta una gran pobreza interior y numerosos complejos. 


\section{CAPÍTULO III. EL DESARROLLO Y LAS FASES DE UN PROCESO DE MOBBING DIRECTIVO.}

- Mediocridad.

Por lo general, el ser humano aspira a superarse desde el punto de vista personal, o a identificarse o proyectarse en aquellos a los que admira. Es una tendencia normal. El acosador sin embargo no participará de esta cualidad.

Algunos expertos destacan la "reactividad" de algunos de estos sujetos, cuya mediocridad les induciría a compensarla, tratando de eliminar a las víctimas competentes. Así pues en el fondo, lo que se pondría en evidencia es el miedo e inseguridad del individuo.

\section{- Desvalorización de los demás.}

Lo que realmente emerge de la personalidad del acosador es un gran complejo de inferioridad, por lo que intentan rebajar o destruir la autoestima del otro, y con ello engrandecerse a sí mismos.

Aunque a veces ocultan sus debilidades detrás de formas compensatorias, intentan quedar por encima de los demás mediante la ridiculización, la humillación o la hipercrítica sistemática a sus víctimas (Piñuel, 2003).

Hay en ellos una exacerbación de la función crítica que les conduce a pasar el tiempo criticándolo todo y a todo el mundo. De este modo, se mantienen en su omnipotencia, ya que "si los demás son una nulidad, forzosamente yo soy mejor que ellos" (Hirigoyen, 1999).

Son las dudas sobre su propia valía las que les harían reaccionar de un modo agresivo contra todo lo que pueda recordarles sus limitaciones o reproches internos, de ahí la emisión de esos juicios rotundos, radicales, negativos y continuos sobre los demás.

El trabajo del otro, no sólo nunca merecerá un elogio espontáneo por su parte, sino que será censurado directa o indirectamente. Criticará de forma sistemática e infundada las iniciativas y los éxitos de los otros, en particular de aquellos que les pueden eclipsar.

Aunque creyéndose en la vanguardia y última moda de actualidad, se suelen colocar en la retaguardia, observando a quienes ponen en marcha algo para 


\section{CAPÍTULO III. EL DESARROLLO Y LAS FASES DE UN PROCESO DE MOBBING DIRECTIVO.}

comprobar si triunfan o fracasan.

\section{- Intolerancia a las críticas.}

La creencia irracional de estar en posesión de la verdad, y la incapacidad para asumir sus propios defectos, hacen que pongan en cuestión sus actos. No hay lugar para la autocrítica, y mucho menos para la reprobación que le puedan efectuar los otros. La más mínima oposición desarmaría psicológicamente al acosador.

Las relaciones sociales suelen causarle un gran temor y ansiedad generalizada, ya que esto significa exponerla a los ojos de los demás y estar sometida a la crítica social.

La rabia, la ira o el resentimiento constituyen sus emociones típicas, cuando alguien le critica o no le reconoce lo que él cree que vale, y tras ellas unos profundos deseos de venganza y destrucción de esa persona. Tiene por tanto verdadera necesidad de reconocimiento por parte del público que le rodea.

\section{- Paranoia.}

Acostumbran a dar lecciones de rectitud a los demás, lo saben todo mejor que nadie y no dudan jamás de sí mismos. (Hirigoyen, 1999). Poseen un gran sentimiento de superioridad, desprecian al otro. El rasgo más destacado es la permanente desconfianza hacia los demás; no se fía de nada ni de nadie y siempre supervisa todo cuanto gira a su alrededor. Tiene que controlarlo todo.

Así pues, percibe siempre dobles intenciones en las palabras de los demás, en sus gestos y hasta en sus silencios, analiza meticulosamente toda la comunicación, los signos verbales y no verbales, extrayendo siempre conclusiones negativas, raras, y malintencionadas (Rojas, 2002).

Síntomas de esta actitud hacia los demás según el DSM IV, serían en síntesis los siguientes (Piñuel, 2001):

-Sospecha, sin base suficiente, de que los demás le están explotando, perjudicando o engañando.

-Preocupación por la lealtad, o fiabilidad de los amigos y las personas próximas. 


\section{CAPÍTULO III. EL DESARROLLO Y LAS FASES DE UN PROCESO DE MOBBING DIRECTIVO.}

-Hipersensibles, se sienten humillados y ofendidos a la más mínima oportunidad.

-Reticentes a confiar en los demás, debido al temor injustificado a que la información sea utilizada contra él.

-Sentimientos de desconfianza, que llevan al acosador a esconder toda la información sobre sí mismo, a ocultar a tosa costa todos sus puntos débiles y evitar las críticas, y en definitiva a mostrarse hermético ante la gente.

-Interpreta amenazas en comentarios inocentes o situaciones triviales.

-Incapacidad para perdonar a los demás.

-Percibe ataques a su reputación que no son visibles para los demás, y reaccionan rápidamente ante ellos con agresividad, contraatacando.

Por todo ello en la práctica directiva pretenden controlar de manera absoluta el trabajo y los movimientos de todos y cada uno de sus empleados. Están siempre en alerta y pendientes de todo y de todos. Es frecuente que implementen sistemas de intervención del correo electrónico, de grabaciones...etc. (Piñuel, 2001).

\section{- Irresponsabilidad.}

Suele desentenderse de sus obligaciones deriva todo absolutamente todo en los demás, niega todo aquello que pueda hacer mal y se atribuye a si mismo grandes éxitos profesionales. Siempre busca la justificación y excusa necesaria para encargar a los demás todas sus funciones.

Es incapaz de mantener un esfuerzo intelectual en el tiempo, tan sólo pequeños momentos instantáneos, suficientes para supervisar todo aquello que hacen los demás.

Son capaces de hacer ver que todo funciona correctamente, cuando ni tan si quiera se han parado a "hacer números", para saber si es posible que el negocio que dirigen pueda ser rentable.

Esta falta de responsabilidad a menudo deriva en numerosos problemas para sus empleados, ya que el acosador intenta siempre culpabilizarlos a ellos de todo cuanto ocurra 


\section{CAPÍTULO III. EL DESARROLLO Y LAS FASES DE UN PROCESO DE MOBBING DIRECTIVO.}

- Necesidad / ilusión de control.

Dogmático, autoritario y dominante, el agresor desarrollaría un "sistema férreo de control mediante el cual pretende monitorizar cualquier movimiento, actividad, iniciativa e idea (...), que pudiera amenazarle" (Piñuel, 2001).

Tiene una imperiosa necesidad de enterarse de todo lo que ocurra a su alrededor para que nada se le escape. Esto a menudo suele llevarlo a cabo en parte desde el propio sistema de gestión de los centros residenciales, ya que en vez de utilizar algún programa estándar utilizado por parte del sector, utiliza un mecanismo mediante un servidor a través del cual registra todos y cada uno de los movimientos de sus empleados.

No se trata en este caso, como parece evidente, de una supervisión exhaustiva de la actividad laboral de sus empleados en aras de un mejor funcionamiento de la empresa (en cuyo caso se podría hablar de un comportamiento responsable por su parte), sino que el acosador solo busca vigilar, de manera nociva las tareas.

\section{- Culpabilización del otro.}

Acostumbra a culpar a los demás de sus frustraciones, fracasos y problemas. No se siente responsable de lo que hace o hizo en el pasado a sus víctimas, por lo que no puede arrepentirse de ello ni sentir pena, ni vergüenza por su actuación. El objetivo último de este comportamiento, es tener la conciencia tranquila.

\section{- Ausencia de compromiso.}

Manifiesta una falta total de compromiso en sus acciones, iniciativas y decisiones, procura no contraer acuerdos $u$ obligaciones con nadie, a fin de sobrevolar cualquier situación con la menor implicación posible.

Como ya hemos mencionado en líneas anteriores, el acosador suele desentenderse de sus obligaciones y no se responsabiliza del malestar que origina su conducta en el resto de trabajadores. Con ello evita tener que cuestionarse a si mismo. 


\section{CAPÍTULO III. EL DESARROLLO Y LAS FASES DE UN PROCESO DE MOBBING DIRECTIVO.}

\section{- Envidia y miedo a sentirse eclipsado.}

El frecuente complejo que persiste en este sujeto, hace que él mismo se crea que tiene una serie de cualidades y atributos positivos, que en verdad no posee. Al encontrarse con alguien realmente dotado de estas características de las que el carece, estallaría en él un gran conflicto interno. Desestabilizado psicológicamente, no aceptaría la evidencia y la negaría, y a continuación iniciaría la persecución contra esa persona que se ha atrevido a mostrar indirectamente sus carencias.

Suele envidiar aquellos dotes que considera brillantes en su escala de valores, tales como juventud, bondad, riqueza, popularidad, facilidad para relacionarse, carisma, don de gentes, optimismo vital, felicidad, vida privada satisfactoria, mejor educación y o formación que él, sensibilidad, personalidad, independencia de criterio, crítica constructiva, seguridad, carácter emprendedor, competencia profesional, iniciativa, capacidad en la toma de decisiones, creatividad, conducta ética, asertividad, flexibilidad, gran capacidad en el manejo de equipos...

Como buen simulador, sabría ocultar sus sentimientos, finge ignorar la superioridad de alguien e intenta a la vez proyectar oscuridad sobre su víctima. Niega sus méritos o cualidades, desprecia o invalida sus tareas, silencia todo aquello relacionado con una evaluación positiva, tergiversa sus comentarios, y difunde rumores falsos para desprestigiarla.

Por tanto podemos decir que un acosador haría todo lo que esté en sus manos para impedir que sus subordinados destaquen o para obstaculizar que asciendan por sus propios méritos. Se liberará e intentará eliminar de quienes puedan poner en entredicho su labor, "con el paso del tiempo, sólo quedan a su lado quienes se someten (...) y se vuelven aduladores" (Rojas, 2002).

\section{- Ansia de poder.}

Los puestos directivos o de mando, a menudo proporcionan amparo y sostén a una persona frustrada e insegura; el acosador ama todo lo relacionado con el poder y a todos aquellos que lo ostentan o que están cerca de él. 


\section{CAPÍTULO III. EL DESARROLLO Y LAS FASES DE UN PROCESO DE MOBBING DIRECTIVO.}

Su modo de operar y de aparecer ante la opinión pública, consistiría en parecer justos y decentes, ser agradables pero astutos, democráticos pero autoritarios y en definitiva hacer creer a los demás no tener nada que ver con la persecución de poder por el poder.

Algunos expertos llaman la atención sobre una característica peculiar de la personalidad de estos individuos, que no es otra más que una "admiración o una sumisión extrema frente a personas que encarnan la autoridad" (Benesch y Schmandt, 1982), sean sus superiores o gente con prestigio o influencia, y un comportamiento deplorable y explotador con sus subordinados o con quienes no consideran de su nivel Así rinde pleitesía a quienes consideran poderosos. Para él solo existen las personas que tienen poder y las que no lo tienen.

\section{- Instrumentación de las relaciones.}

Es acosador entiende las relaciones sean estas de la índole que fueren como meros instrumentos para conseguir sus objetivos planteados. Estas se inician y/o mantienen en función de objetivos o intereses determinados, y están marcadas por una despersonalización de las mismas (Benesch y Schmandt, 1982). Ven así a los demás como proveedores de algo que desean o precisan (Fromm).

Estaríamos así ante individuos, a quienes no les importa como obtienen lo que quieren de otras personas. Si aparentan sensibilidad y comprensión por el otro es tan solo para seducirlo y luego dominarlo, hasta obtener todo lo que quiere de él.

Por tanto son verdaderos especialistas en servirse de los sentimientos ajenos para cumplir sus objetivos, tratan de no incomodarse o no experimentar disonancia cognoscitiva alguna cuando emiten mensajes en los que no creen o cuando mienten (Steinfatt, 1983). Tampoco acostumbrarían a decir las cosas claras ni a arriesgarse a que les digan que no, sino que "utilizan sub refugios y crean situaciones que hacen que sea muy difícil rehusar sus planes" (Mayor, 2002). 


\section{CAPÍTULO III. EL DESARROLLO Y LAS FASES DE UN PROCESO DE MOBBING DIRECTIVO.}

\section{- Incapacidad para gestionar la frustración.}

Los investigadores dibujan a un ser muy variable e irregular en sus reacciones, e inestable emocionalmente, que pasa de la euforia a la melancolía o la depresión casi inmediatamente (Rojas, 2002).

Es alguien inmaduro, pese a su edad cronológica, se movería guiado de ciertos impulsos, no habría aprendido a sobreponerse ante los problemas o dificultades ni a solucionarlos, y tendría "tendencia a refugiarse en un mundo fantástico que le aleja de la realidad" (Rojas, 2002).

Todos ellos serían los rasgos, trastornos más definitorios, junto con la psicopatía de base como hemos visto en el Capítulo 2, del agresor. A continuación intentaremos dar de la manera más precisa posible todos aquellos detalles que ahondan y matizan psicológicamente a la víctima.

\subsubsection{Perfil Psicológico de la víctima.}

Constituiría el segundo elemento para que podamos hablar y referirnos a una situación de acoso laboral. Algunos autores hablan de algunos déficits en el perfil de la víctima, pero aunque se identifiquen determinadas debilidades o fragilidades en el carácter de la víctima, como elementos facilitadores en ocasiones del surgimiento del fenómeno, hay que matizar que una persona normalmente designada objeto de acoso por su acosador no lo es porque carezca de algo, sino porque posee algo que según el acosador él no tiene y desea apropiarse de ello, por lo que podemos afirmar que toda persona en un momento dado y ante ciertas circunstancias puede ser objeto de este tipo de acoso (Hirigoyen, 1999).

Hablaríamos, por tanto, de personas con más factores de riesgo, para ser acosadas, de aquellas, cuyo "estilo personal no confrontativo, garantice al acosador no quedar expuesto a una vulnerabilidad que no podría soportar" (Piñuel, 2001). 


\section{CAPÍTULO III. EL DESARROLLO Y LAS FASES DE UN PROCESO DE MOBBING DIRECTIVO.}

Existirían así, algunas personas más susceptibles de sufrir acoso laboral en función de presentar algunos rasgos de personalidad específicos; autenticidad, dependencia afectiva, vitalidad y trasparencia, elevado sentido de la ética y del trabajo que desempeña, implicación en el mismo, y Culpabilización.

\section{(1) Autenticidad.}

González de Rivera (2002), define la autenticidad como el "compromiso con las propias dinámicas de desarrollo interno", con la autorrealización y el autoconocimiento, y sin que a su poseedor le importen demasiado las conveniencias materiales o las convenciones sociales.

La víctima actua y manifiesta sus conductas acorde a su pensamiento de ser y de entender la vida, sin maldad, con una mentalidad de ayuda al otro y de honestidad real para con lo demás.

Esta característica personal, en principio positiva, podría hacer sin embargo que otros la aprovechen para manifestar hostilidad hacia él, y su titular sería incapaz de hacer frente de manera adecuada a esa hostilidad. No concibe además como alguien pudiera comportarse así con los demás.

Por tanto se mostraría incapaz de dañar, pero también de descubrir en los demás la capacidad de hacer daño; no me maldad a su alrededor, porque cree que todo el mundo es bueno como ella, nadie la recuerda que el mal existe y existe en las personas, en los grupos y en las organizaciones.

Consecuentemente esta característica constituiría una gran carencia de personalidad para la víctima.

\section{Dependencia Afectiva.}

La dependencia afectiva se produce por la necesidad que el ser humano sano o normal tiene de aprecio y cariño de ser aceptado, querido o amado. Esta necesidad cuando es imperiosa o exagerada en su forma, suele terminar en dependencia, pudiendo dar lugar a relaciones personales y laborales dañinas o perjudiciales, en 


\section{CAPÍTULO III. EL DESARROLLO Y LAS FASES DE UN PROCESO DE MOBBING DIRECTIVO.}

las que se puede dar incluso reacciones de apoyo al acosador, dando lugar en muchos casos al llamado "Síndrome de Estocolmo". En este, la víctima tiende a justificar las acciones del agresor, a la vez que se infravalora personal y profesionalmente (Piñuel, 2001).

\section{Vitalidad.}

Normalmente las víctimas de acoso poseen una gran vitalidad, que les hace envidiables. Suelen ser personas que como ya hemos mencionado en líneas anteriores, tienen una brillante escala de valores, juventud, bondad, popularidad, facilidad para relacionarse, grandes dotes para la comunicación y las habilidades sociales, un gran carisma que le llena de atractivo interpersonal, don de gentes, optimismo vital (no encuentra obstáculos ante nada ni nadie), felicidad y satisfacción en su vida privada, una gran sensibilidad, independencia de criterio y gran capacidad para la crítica constructiva, una gran formación, carácter emprendedor que le lleva siempre a la susceptibilidad para la mejora de cualquier aspecto, iniciativa, capacidad en la toma de decisiones (cuanto más compleja se torna ésta más capacidad de resolución suele mostrar, posee unas grandes competencias profesionales y recursos, creatividad, una gran conducta ética ejemplarizante para sus empleados, asertividad, flexibilidad reflexionada, y en definitiva una gran capacidad en manejo de personas y equipos interdisciplinares que conforman el centro residencial

\section{Transparencia.}

Como ya hemos visto en capítulos anteriores, el agresor tiende a aparentar lo que no es, engaña continuamente insinuando a los demás una vida y comportamiento ante ella que no se ajusta a la realidad. No así se presentaría la víctima, la cual no se provee de envolturas que la protejan u oculten realidades, ni tiene pensamientos para imaginar en la maldad y las manipulaciones del otro. 


\section{CAPÍTULO III. EL DESARROLLO Y LAS FASES DE UN PROCESO DE MOBBING DIRECTIVO.}

Así pues, podemos decir que se muestra transparente, con disposición a aclarar lo que ellos consideran mal entendidos, abriéndose al agresor, se justificarían "si le explico, comprenderá..." y aumentaría así más aún si cabe la intensidad de los ataques de su agresor.

Conforme se desarrolla el hostigamiento, aflorarían las cualidades protectoras y la función reparadora, intentarían adaptarse, comprender, perdonar, culpabilizarse, buscar la lógica a la conducta del otro... (Hirigoyen, 1999).

Este comportamiento chocaría de plano con la actitud de los manipuladores, que rechazan el diálogo y no dan a sus víctimas ninguna oportunidad para esclarecer la situación y solucionar el conflicto (ibíd., 2001).

\section{Elevado sentido de la ética.}

Son personas, empleados honrados, con la suficiente valentía para criticar lo que consideren injusto, indigno o inmoral, para reclamar la verdad y la legalidad, o para denunciar las mentiras o los tejemanejes en el funcionamiento de un centro residencial y que tan de actualidad están hoy en día.

Así podemos decir que estaríamos ante personas realmente auténticas, comprometidas con sus ideas y principios morales y que acostumbran a actuar en todos los ámbitos de su vida con una gran escrupulosidad.

Habitualmente, la víctima sería acusada de ser infiel a la empresa, de mirar más por los empleados que por la empresa, y sería calificado casi como un auténtico enemigo de la misma (González de Rivera). Suele tachársele además de ser problemático o de cometer muchas equivocaciones en su puesto de trabajo y en sus tomas de decisiones, nada más lejos de la realidad (Hirigoyen, 2001).

En casos muy extremos incluso le adjetivan de indigno para el puesto, o de falto de confianza para dirigir un centro sociosanitario. Descubrir públicamente las conductas y acciones irregulares detectadas le llevarían a constituirse en objeto de descrédito, represalias y agresiones psicológicas constantes, lo que le llevarían a abandonar la propia organización y su puesto de trabajo. 


\section{CAPÍTULO III. EL DESARROLLO Y LAS FASES DE UN PROCESO DE MOBBING DIRECTIVO.}

\section{Implicación.}

Muchas de las víctimas suelen llegar a serlo, debido a su perfil idealista y de perfección en lo que hacen, personas muy motivadas por el trabajo, que suelen olvidarse de sí mismos, y casi de su vida personal, puesto que la mayor parte del día la pasan en su lugar de trabajo. No faltan nunca a su puesto, hacen más horas de las inicialmente estipuladas en su contrato, se sobrecargan de tareas y funciones, se llevan el trabajo a casa o van a la empresa hasta los fines de semana. Suelen por tanto asumir un volumen de trabajo superior a la media.

Podemos afirmar que son muy perfeccionistas, muy exigentes consigo mismas, con gran sentido de responsabilidad, y en permanente lucha con sus propias exigencias (Rodríguez, 2002).

\section{Culpabilización.}

Las víctimas de acoso laboral tienen una clara tendencia a culpabilizarse a sí mismos de lo ocurrido ya que no comprenden cómo les ha podido pasar eso a ellos. Esta naturaleza del acosado encaja perfectamente en la especificación de la relación con el agresor, pues como hemos visto a lo largo de todo este capítulo, la tendencia de este es la contraria, echar la culpa de todo lo que sucede a los demás.

\subsubsection{Características del entorno. ${ }^{7}$}

El acoso laboral ha de producirse en el seno de una organización, que es a su vez parte un grupo social muy amplio. El entorno estaría formado por; el medio laboral, en el que se encontrarían el hostigador, otros superiores, y los compañeros de la víctima; el ámbito familiar, en el que se encontrarían la pareja o cónyuge si la tuviere, familia directa (padres, hermanos, hijos, tíos, sobrinos...), y amigos; la relación con la sociedad en general:

\footnotetext{
${ }^{7}$ Entendido este como el medio necesario en el que se produce el acoso laboral por medio del acosador. Suele ser un factor clave para entender la complejidad del proceso, que va a fomentar o no la aparición de este fenómeno.
} 


\section{CAPÍTULO III. EL DESARROLLO Y LAS FASES DE UN PROCESO DE MOBBING DIRECTIVO.}

\section{(1) El medio laboral.}

Una organización puede favorecer o no la existencia del acosador facilitando sus actuaciones o tomando las medidas oportunas para que no se produzca. Los miembros que van a componer la organización, en el caso que nos ocupa que forman parte del equipo del centro residencial, pueden comportarse de manera más o menos colaboradora, permisiva o enfrentarse también al fenómeno.

Por norma general, los compañeros tienden a ser testigos mudos, desconfían del acosado, sospechan de él y no creen en su buen hacer. Raro es que alguno de ellos no acepte lo que está viendo con sus propios ojos y denuncie al acosador, puesto que entre otras cosas teme por su puesto de trabajo. Su intervención de ser así resultaría imprescindible para frustrar o frenar el proceso (Piñuel, 2001).

Para explicar este comportamiento habría un hecho evidente; la imposibilidad o dificultad de los observadores externos (en este caso los compañeros) para dar crédito de los niveles de insensibilidad del acosador. El ataque es tan sutil y tan perverso que resulta de gran eficacia y difícilmente de creer.

Consecuencia lógica de todo ello, es muy común que el acosado (incapaz de comprender lo que está ocurriendo), comente la situación con algunos compañeros de su confianza, los cuales suelen minimizar los hechos ocurridos sin ver ninguna señal de alarma, sino falsas interpretaciones y exageraciones. (Mediavilla, 2003).

La incomprensión hacia el agredido por parte del entorno tendría que ver también con el comportamiento patológico que la víctima suele presentar, producto del desequilibrio y el miedo que el acosador crea e infunde en ella. Causas y efectos se invierten, de tal modo que las reacciones del acosado pasan a ser ante los ojos de los demás, el motivo del maltrato. (Hirigoyen, 1999).

La psicología social, ha estudiado desde años este mecanismo, denominado "error atribucional o error en la atribución", en virtud del cual la gente del entorno de una víctima tiende a atribuir ésta la responsabilidad de lo que le ocurre (Piñuel, 2001). El acosador se serviría de las descalificaciones y acusaciones repetidas para lograr ese resultado: que una persona acabe asumiendo las cualidades/defectos que se le adjudican y convirtiéndose en aquello de lo que se le acusa. 


\section{CAPÍTULO III. EL DESARROLLO Y LAS FASES DE UN PROCESO DE MOBBING DIRECTIVO.}

Con todo ello el acosador, comienza a lograr sus objetivos. Para que el proceso se desarrolle de forma rápida y efectiva, lo que pretende es aislar y separar a la víctima de los demás. La persecución se orientaría, pues, hacia el deterioro de la imagen pública y hacia la fragmentación y ruptura de las relaciones sociales del trabajador en cuestión, en su medio laboral e incluso y si el acosador tiene capacidad para ello intentara interferir en sus relaciones personales, muchas de ellas, fruto de su labor al frente del centro residencial (Piñuel, 2003).

Así pues podemos afirmar que lo que realmente pretende el acosador es que el entorno reaccione en la dirección que él pretende, que no es otra que en poner en contra de la víctima a todos los adeptos posibles, y cuantos más, mejor. La estigmatización de la víctima, iniciada por el acosador culminaría progresivamente en un consenso. Con ello el grupo de trabajadores se vería reforzado en su forma como tal, cohesionando el grupo a costa del hostigado.

Por tanto podremos observar como la persecución psicológica se desarrollará en medio de un sorprendente silencio e inhibición de terceras personas "observadoras obligadas" del conflicto (González de Rivera, 2000). El concepto utilizado para describir este comportamiento es el "principio de Florian" según el cual todos piensan que es a los demás a quien corresponde intervenir (Ausfelder, 2002).

\section{El ámbito familiar.}

Psicológicamente podemos considerar que el acosado es un incomprendido. Su familia más próxima y sus amistades serían personas totalmente ajenas a la situación, que no percibirían el conflicto de manera directa, por lo que tendrían serias dificultades para hacer frente este fenómeno de manera efectiva, al no ser capaces de captar la índole y transcendencia, ni siquiera aproximada, del sufrimiento de la víctima. (Nazaré-Aga, 2002). 


\section{CAPÍTULO III. EL DESARROLLO Y LAS FASES DE UN PROCESO DE MOBBING DIRECTIVO.}

Los más allegados, pareja, familiares y amigos, contemplan de manera estupefacta el deterioro progresivo de su ser querido, sin tener una respuesta para lo que observan, e incluso a menudo auto inculpando a su ser querido de lo que le está ocurriendo. Ante este escenario de escepticismo e incredulidad ante los hechos, la reacción más habitual suele ser la de intentar restar importancia a la situación, e incluso haciendo algunas críticas al comportamiento de la víctima.

Las quejas reiteradas por parte de la víctima no serían tomadas en serio y llegarían incluso a cansar tanto a compañeros como a familiares, que tratarían de desviar el tema hacia otras conversaciones (Hirigoyen, 1999).En el caso de la propia pareja, esta perdería la paciencia y se alejaría, "harta de que toda la comunicación y conversación gire sistemáticamente en torno al tema laboral del acoso" (Piñuel, 2003).

Situación similar se vivirá con los familiares más cercanos y el círculo de amistades; el desequilibrio emocional que padece la víctima fruto de los sistemáticos y sutiles ataques del agresor. Con todo ello se conformaría una situación de soledad de la víctima, que cada vez más aislada, ve como todo se vuelve en contra de sus intereses, sin encontrar una explicación a todo lo que le está ocurriendo.

\section{La sociedad en general.}

Los acosados tampoco encuentran cobijo u apoyo en la sociedad que les rodea. La mayoría de personas que de alguna forma se relacionan con ella, son incapaces de entender la situación por la que atraviesa. La víctima suele ocultarles los hechos, o contarles parcialmente lo que está padeciendo, ya que le resulta harto vergonzoso contar algo así. Cabe recordar que la propia naturaleza de la situación vivenciada, hace casi imposible que la víctima pueda aportar pruebas objetivas y tangibles de lo sucedido, con lo que complica aún más que pueda probar los hechos.

Con todo ello concluiríamos el Capítulo 3, para abordar en el Capítulo 4, las consecuencias del acoso psicológico en puestos directivos. 


\section{CAPÍTULO III. EL DESARROLLO Y LAS FASES DE UN PROCESO DE MOBBING DIRECTIVO.}

\section{RESUMEN - ABSTRACT}

\section{CAPÍTULO III.}

“El Desarrollo y las Fases de un proceso de Mobbing Directivo”.

A lo largo de este tercer capítulo hemos abordado los antecedentes sociales previos, necesarios para el desarrollo de un proceso de Mobbing, analizando los diversos factores; objetivos, subjetivos, sociales y económicos que interfieren en el mismo. Se describen además en él los denominados "líderes tóxicos" y los diferentes medios que estos utilizan en el acoso.

Una vez analizados todos estos aspectos, reflejamos en profundidad las diferentes fases que se suceden en un proceso de esta índole, fase de conflicto inicial o de incidentes críticos, fase de estigmatización de la víctima o del entorno, fase de intervención desde la organización o de jerarquías superiores y fase de exclusión o salida de la organización.

Seguidamente y una vez detalladas en minucia cada una de las fases, realizamos un estudio de los "protagonistas" necesarios, como son el acosador y sus principales trastornos asociados, ( narcisismo, obsesión por la imagen, autoengaño, egocentrismo, carencia de empatía, pseudoempatía, megalomanía, superioridad moral, mediocridad, intolerancia a las críticas, paranoia, irresponsabilidad, necesidad de control, culpabilización del otro, ausencia de compromiso, envidia, miedo a sentirse eclipsado, ansia de poder, instrumentación de las relaciones e incapacidad para gestionar la frustración) la víctima y su perfil psicológico ( autenticidad, dependencia afectiva, vitalidad, transparencia, elevado sentido de la ética, implicación y Culpabilización) y el entorno en que se produce el acoso, estudiado este último tanto en su medio laboral, como en su ámbito familiar y en la sociedad en general que lo rodea. 


\section{CAPÍTULO IV}

"Consecuencias de acoso psicológico en puestos Directivos"

VNIVERSITAS STVDII SALAMANTINI

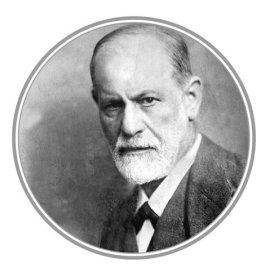

"La voz del intelecto es apagada, pero no descansa hasta haber logrado hacerse oír, y siempre termina por conseguirlo, después de ser rechazada infinitas veces".

Sigmund Freud (médico, neurólogo, padre del Psicoanálisis). 


\title{
CAPITULO IV.
}

\section{Consecuencias del acoso psicológico en puestos directivos.}

\begin{abstract}
"La naturaleza de la conducta agresora, más allá de las múltiples y variadas formas de expresión que puede adoptar, integra un juicio de valor claramente negativo (comunicación hostil y sin ética, de carácter abusivo) y, por tanto son merecedoras de reprobación en términos morales, en la medida en que suponen, desde una perspectiva individual, una pérdida de respeto a la persona agredida y provocan desde una perspectiva colectiva, un deterioro intolerable $(\ldots)^{\prime \prime}$
\end{abstract}

\section{Correa (2006).}

Iniciamos este nuevo capítulo haciendo hincapié en una idea que se debe tomar como referencia a la hora de entender este fenómeno; cualquier persona en un momento de su vida profesional puede sufrir acoso laboral. Como hemos visto a lo largo del Capítulo III, las víctimas son a menudo personas brillantes, atractivas, con una gran personalidad y por ello consideradas peligrosas por su acosador, su mera presencia le van a hacer sentirse cuestionado. Todo ello junto con su actitud, eficacia y buen hacer para el trabajo les hacen ser víctimas del acoso.

El acosador por tanto se coloca en una posición de patrón de referencia del bien y de la verdad (Hirigoyen, 1999). Presenta una ausencia total de interés y de empatía por los demás, pero desea que los demás se interesen por él. Critica a todo el mundo y no 


\section{CAPÍTULO IV. CONSECUENCIAS DEL ACOSO PSICOLÓGICO EN PUESTOS DIRECTIVOS.}

admite ninguna acusación o reproche de nadie, señalar los errores de los demás es una manera de no querer ver los suyos.

Así pues, el acosador se presenta como una persona seductora y brillante, nada más lejos de la realidad. Lo que realmente siente, es una envidia muy intensa e incontrolable hacia los que parecen poseer cosas que ellos no tienen o hacia los que simplemente, están satisfechos con su propia vida.

No son nunca responsables, ni son culpables, todo lo que va mal siempre es culpa de otros, se defienden como hemos visto en líneas anteriores mediante mecanismos de proyección, atribuyendo a los demás todas sus dificultades y todos sus fracasos, no se sienten culpables de nada, niegan la realidad más evidente y se presentan como moralizadores, dando incluso lecciones de rectitud a los demás. Su único objetivo es destruir al otro porque le percibe como peligro.

Hirigoyen (1999), al describir a la víctima, dice que es el objeto del perverso o acosador y que ésta se convierte en la responsable de todos sus males. Las víctimas mientras, sienten vergüenza por no saber defenderse, hecho sorprendente, cuando a la vez son personas muy dotadas intelectualmente, pero creen que deben demostrárselo a sí mismas. Las dudas que crea el acosador en ellas, las hace vulnerables.

Por tanto las víctimas, son personas apegadas al orden en el puesto de trabajo, y de las relaciones sociales, que se sacrifican por los demás. Su gusto por el orden y su deseo de hacer bien las cosas les conducen a asumir un volumen de trabajo muy superior a la media.

Son foco de envidia porque son muy transparentes, no ocultan nada de su vida. Poseen además una gran lucidez que les permite nombrar las fragilidades y debilidades de su agresor, lo que les hacen ser aún más objeto de las conductas de acoso. Así pues a continuación haremos un análisis exhaustivo de las consecuencias que todo ello 


\section{CAPÍTULO IV. CONSECUENCIAS DEL ACOSO PSICOLÓGICO EN PUESTOS DIRECTIVOS.}

conlleva para la víctima y su entorno familiar, para la propia empresa y para la sociedad en general.

\subsection{Para la víctima y su entorno Familiar.}

Son numerosas las consecuencias que se generan para las víctimas de acoso laboral en puestos directivos de centros residenciales. A continuación enumeraremos algunas de las más relevantes:

\section{Daños sobre el área psíquica:}

1) Miedo acentuado y continuo.

La víctima tiene episodios de miedo infundado, temor a diversas situaciones, entre las que podemos destacar, a la pérdida de empleo, al daño causado a su imagen personal y laboral, a la pérdida de confianza de sus trabajadores, a vivir situaciones estresantes, desavenencias con el propio acosador, a ser acusado de actuaciones laborales que nunca realizó, a la incertidumbre que le rodea en ese momento, a que no le crean sus familiares y amigos más cercanos, en definitiva un miedo continuo y generalizado proveniente de las conductas hostiles que sobre él se han llevado a cabo por parte de su acosador.

\section{2) Ansiedad como estado constante.}

La ansiedad surgirá como una necesidad del organismo de reaccionar ante los hechos de acoso y las constantes conductas de amenaza que el sujeto ha vivido. Esta reacción no será directamente proporcional a los daños causados, es decir irá incrementándose poco a poco a medida que la situación de acoso se mantenga en el tiempo. El acosado sentirá como día a día el estado ansioso aumenta sin poder controlarlo, ni saber a que es debido. Inicialmente lo interpretará como un estado de nerviosismo fruto, creerá él, de las desagradables situaciones que está vivenciado en su lugar de trabajo, pero sin darlas la mayor importancia. 


\section{CAPÍTULO IV. CONSECUENCIAS DEL ACOSO PSICOLÓGICO EN PUESTOS DIRECTIVOS.}

\section{3) Sentimientos de amenaza.}

El acosado paulatinamente va sintiendo como su labor profesional se siente amenazada. Está siendo minuciosamente observado por su acosador. La víctima comienza a percibir situaciones hostiles contra su persona, y contra la toma de decisiones en su puesto de trabajo. Es el inicio de lo que se convertirá en algo cada más intenso y frecuente en su día a día laboral.

\section{4) Sentimientos de fracaso.}

La víctima siente como no puede seguir con el "ritmo" y las "tareas" que se le exigen desde la dirección general del grupo día a día. Siente que "ahora" es incapaz de sobrellevar situaciones y afrontar problemas, que hace tan solo unos meses si llevaba a cabo con éxito. El fracaso comienza a apoderarse de sus sentimientos, hasta llegar a creer que no es válido para ostentar la dirección de un centro residencial.

\section{5) Impotencia.}

Se siente incapaz de sobreponerse a la situación que vive actualmente. Observa perpleja como sus trabajadores y colaboradores más próximos, no se inmutan ante la situación que él está padeciendo. Esto le lleva a plantearse el abandono del puesto de trabajo, como única vía de escape. Cualquier situación que se plantee que no sea esta será interceptada por el acosador. Ve como todo se le vuelve en contra de sus propios intereses.

\section{6) Frustración.}

Todo ello le va a llevar a sentir una gran frustración, frustración al observar cómo a pesar de su preparación, de su dedicación a su puesto de trabajo, de su brillantez tanto personal, como laboral y de su buen hacer, la situación permanece estable en el tiempo, y sus circunstancias laborales frente a su superior empeoran día a día, sufriendo continuos e intensos reproches. 


\section{CAPÍTULO IV. CONSECUENCIAS DEL ACOSO PSICOLÓGICO EN PUESTOS DIRECTIVOS.}

\section{7) Infravaloración.}

Por tanto la víctima comienza a sentirse poco valorada, bien porque su acosador la exige realizar mayor número de tareas de las que un directivo de un centro residencial puede llevar a cabo, o bien porque no se le asignan las tareas que corresponden a tal puesto.

\section{8) Apatía.}

Todo ello le lleva a sentir una gran falta de ilusión por las tareas que desempeña, aspecto que poco a poco irá experimentando en su vida personal. La indiferencia se apodera de su manera de proceder hasta creer que no merece la pena hacer "nada". Sus emociones disminuyen de manera preocupante hasta lo patológico.

\section{9) Trastornos emocionales.}

Surgen debido a la falta de homeostasis psicológica en el día a día de la víctima. El aislamiento al que es sometida, es la principal causa de que poco a poco el sujeto acosado experimente cada vez menos emociones y que las que experimente sean prácticamente en su totalidad negativas. Esto conduce a una alexitimia crónica. La persona afectada no expresa ninguna emoción ni negativa, ni positiva, fruto del miedo a las consecuencias que pueda llevar la expresión de las mismas.

\section{0) Distorsiones Cognitivas.}

Como veremos en las siguientes líneas el área cognitiva es una de las más afectadas durante el fenómeno. La falta de sueño, hace que la víctima vea mermada su cognición. Comienza a experimentar una falta de concentración para desempeñar las tareas en el lugar de trabajo, su atención disminuye y su memoria comienza a sufrir algunos lapsus. El sujeto comienza así a preocuparse por su falta de rendimiento. 


\section{CAPÍTULO IV. CONSECUENCIAS DEL ACOSO PSICOLÓGICO EN PUESTOS DIRECTIVOS.}

11) Conductas de evitación.

Aparecen situaciones nuevas para el trabajador, intenta así evitar encontrarse con su acosador, con sus propios trabajadores e incluso con sus familiares más cercanos. Siente vergüenza e incomprensión ante la situación que está viviendo y no es capaz de entender qué puede haber pasado o estar pasando, para que él esté viviendo este calvario. Nadie ni nada consigue darle una solución óptima.

12) Agravación de problemas previos.

Este estado en el que se encuentra la víctima, hace que cualquier tipo de patología anterior que tuviera se potencie, agravando su estado psicológico que paulatinamente es cada más insostenible. El mantenimiento de la problemática en el tiempo agrava preocupantemente la situación. Todo ello en la mayoría de los casos es vivido en soledad.

\section{3) Cambios de personalidad.}

La víctima como mecanismo de defensa, amplia su repertorio conductual, y actua de una manera diferente a como lo hacía antes de comenzar a sufrir el acoso. Estos cambios, en lo que podíamos llamar su personalidad, son utilizados por el propio acosador para mostrar a los demás cómo a la víctima la está sucediendo algo y así, agudizar aún más si cabe el acoso.

\section{4) Alteraciones del sueño.}

Fruto de todo ello, la víctima comienza a no ser capaz de conciliar el sueño, y si lo hace, lo hace durmiendo menos horas de las que habitualmente dormía o teniendo sueños negativos e incluso pesadillas. Es frecuente que debido a la sobrecarga laboral a la que está expuesto, las jornadas laborales se alarguen, llegando a su domicilio a altas horas de la noche, lo que conllevará además problemas para conciliar su vida personal. 


\section{CAPÍTULO IV. CONSECUENCIAS DEL ACOSO PSICOLÓGICO EN PUESTOS DIRECTIVOS.}

\section{5) Trastornos de la alimentación.}

Comienzan a darse diferentes trastornos en la alimentación de la víctima: pérdida de apetito, ingesta de comida a deshoras, episodios aislados de bulimia... además evita cualquier tipo de "comida social" que pueda hacer que sus más allegados observen que no come con normalidad. Por tanto aparece un retraimiento y aislamiento social a la hora de comer. En algunos momentos del fenómeno, al individuo incluso no le importa no hacer las comidas ordinarias que haría en su día a día "normal".

\section{6) Susceptibilidad.}

El miedo y la incertidumbre se apoderan de tal manera de la psique de la víctima que esta se muestra irreceptiva. Su conducta comienza a ser irreflexiva y autómata, reacciona ante cualquier situación que la parezca susceptible de amenaza hacia su persona. Comienza a sospechar de todo y de todos, dando lugar así a episodios ansioso-depresivos, propios de cuadros clínicos.

\section{7) Hipersensibilidad.}

Refiere además reacciones inmunitarias exacerbadas que llegan a producir de nuevo cuadros psicopatológicos. La persona comienza a sentir un malestar generalizado y sentimientos contradictorios de culpabilidad ante la situación que está viviendo. Debate intrínsecamente entre los hechos que se están sucediendo, lo que le va a producir vivir en un constante estado de alerta ante la conducta de los demás.

\section{8) Aislamiento.}

Todo ello hace que el sujeto se aísle y se "encierre" en sí mismo. Evita cualquier tipo de contacto social. Vive los acontecimientos en soledad, soledad que no hace más que mermarle aún más y a llevarle a experimentar sentimientos muy negativos ante la propia vida. Teme que sus familiares más cercanos, amigos y trabajadores le culpen de ser el causante de todo ello. 


\section{CAPÍTULO IV. CONSECUENCIAS DEL ACOSO PSICOLÓGICO EN PUESTOS DIRECTIVOS.}

\section{9) Irritabilidad.}

Mostrara una gran receptividad para responder ante estímulos que él considere, lesionen o puedan lesionar su bienestar o estado psíquico. Esta característica va a permitir a la víctima eventualmente adaptarse a los cambios y a sobreponerse de posibles amenazas. Por tanto entenderá la mayor parte de estímulos que reciba como negativos. Identificara los cambios negativos que se produzcan en su entorno y reaccionará inmediatamente ante ellos.

\section{0) Indefensión.}

Su comportamiento irá acentuándose hacia matices negativos. Mostrará una pasividad, fruto de los ataques recibidos y experimentara una sensación subjetiva de "no poder hacer nada". La falta de recompensas positivas, hace que el sujeto permanezca inalterable en su forma de conducta. Siente como "haga lo que haga" siempre estará mal hecho para su superior. Esta falta de reconocimiento laboral positivo hará a la víctima aún más vulnerable si cabe. Su entorno más próximo, sus trabajadores, tampoco serán capaces de reconocer el trabajo de su superior, de tal manera que la víctima se encuentra indefensa ante los hechos. Pierde la ilusión por su trabajo.

\section{1) Depresión aguda.}

Si ante todos los hechos acontecidos anteriormente la víctima no abandona la empresa, y continua su relación parasitaria con la misma comenzará a mostrar los primeros síntomas de una depresión. Su salud mental se verá afectada, de modo que su estado anímico confrontará sentimientos de tristeza, pérdida, ira, o frustración que a su vez interferirán con su vida diaria durante semanas o incluso por más tiempo. Inicia así un estado psicológico preocupante que hace que distorsione la forma de verse a sí mismo y su relación con el mundo. Perderá el interés por realizar actividades que hasta el momento le producían placer, sintiendo inquietud, agitación e irá, entre otros sentimientos. 


\section{CAPÍTULO IV. CONSECUENCIAS DEL ACOSO PSICOLÓGICO EN PUESTOS DIRECTIVOS.}

\section{2) Suicidio.}

De prolongarse en demasía el estado anterior, y sin obtener una respuesta óptima, que le ayude a tomar de nuevo "sentido a la vida", podrá experimentar pensamientos de muerte y suicidio. Este es el estado más agudo, que puede llegar a desencadenar un episodio de mobbing directivo. Es muy frecuente que las víctimas del mismo, atraviesen por fases depresivas cumbre que concluyen en este tipo de pensamientos, lo cual hace aún más alarmante el fenómeno que en esta tesis se recoge.

\section{Daños sobre el área física:}

\section{1) Cansancio o debilidad.}

Cuando nos referimos al cansancio en el caso que nos ocupa, nos estamos refiriendo a un cansancio considerado anómalo. Es una respuesta del organismo que se produce tras una gran tensión emocional. Algunos autores lo definen como una "sensación subjetiva de falta de energía física e intelectual o de ambas". Para otros es conocido como "astenia, cansancio patológico, anormal y desproporcionado" fruto de estar expuesto a situaciones estresantes y de fatiga crónica.

\section{2) Síntomas de desgaste físico.}

En la mayoría de los casos de víctimas de mobbing, el desgaste físico se manifiesta, debido a la creencia que tienen las personas de que al pedir ayuda a los demás, bien sean amigos, familiares, compañeros de trabajo e incluso profesionales de la sanidad, hará que sean juzgadas, creyendo así, que son incapaces o inadecuadas para realizar correctamente su trabajo. En numerosas ocasiones, como hemos visto en líneas anteriores, este desgaste físico también se debe a los trastornos del sueño y a los trastornos alimenticios que se producen en un cuadro de estas características. 


\section{CAPÍTULO IV. CONSECUENCIAS DEL ACOSO PSICOLÓGICO EN PUESTOS DIRECTIVOS.}

\section{3) Síntomas psicosomáticos.}

Todo este estado psicológico detallado en líneas anteriores repercutirá en lo corpóreo. Aparecerán así algunas enfermedades derivadas, tales como hipertensión arterial, úlceras, síndrome de colon irritable, síndrome de fatiga crónica, fribromialgía, neurodermatitis, colitis ulcerosa, tirotoxicosis, artritis reumatoide, asma bronquial...etc. Es importante no confundir los trastornos psicosomáticos en los cuáles el organismo se ve afectado, con trastornos somatoformes en los cuales sólo se manifiesta una reacción física externa sin desprender patologías orgánicas visibles.

\section{4) Conductas de dependencia.}

Al hablar de conductas de dependencia debemos de diferenciar entre la denominada "dependencia normal", apropiada a las circunstancias y la "dependencia patológica". En el caso que nos ocupa estamos haciendo referencia a este segundo tipo. Fruto de todo el proceso de mobbing, la víctima desarrolla conductas inapropiadas, dando lugar a sí a episodios de bulimia, alcoholismo, o toxicomanía entre otros. El sujeto siente necesidad de llevar a cabo estas conductas, como único medio, cree él, para sentirse "mejor". Toma este camino como guía de conducta.

\section{5) Síntomas de desajuste del sistema nervioso autónomo.}

El resultado fisiológico más importante que puede llegar a ocasionarse es el incorrecto funcionamiento del sistema nervioso autónomo. El sistema nervioso autónomo, controla las acciones involuntarias del organismo, tales como los latidos cardiacos y el ensanchamiento o estrechamiento de los vasos sanguíneos. Cuando se presentan situaciones negativas, aparecen alteraciones en este sistema, tales como problemas en la presión arterial, problemas cardíacos, dificultad en la respiración y en la deglución o disfunciones orgánicas, entre muchos otros. Estos problemas pueden presentarse aislados. 


\section{CAPÍTULO IV. CONSECUENCIAS DEL ACOSO PSICOLÓGICO EN PUESTOS DIRECTIVOS.}

6) Otras alteraciones habituales.

A continuación se muestra en el Gráfico 4.1, algunos de los síntomas y alteraciones que pueden observarse habitualmente ante situaciones de acoso psicológico en el contexto laboral (Pérez-Bilbao, 2001).

Gráfico 4.1. Alteraciones habituales en personas sometidas a mobbing directivo (Pérez Bilbao, 2001).

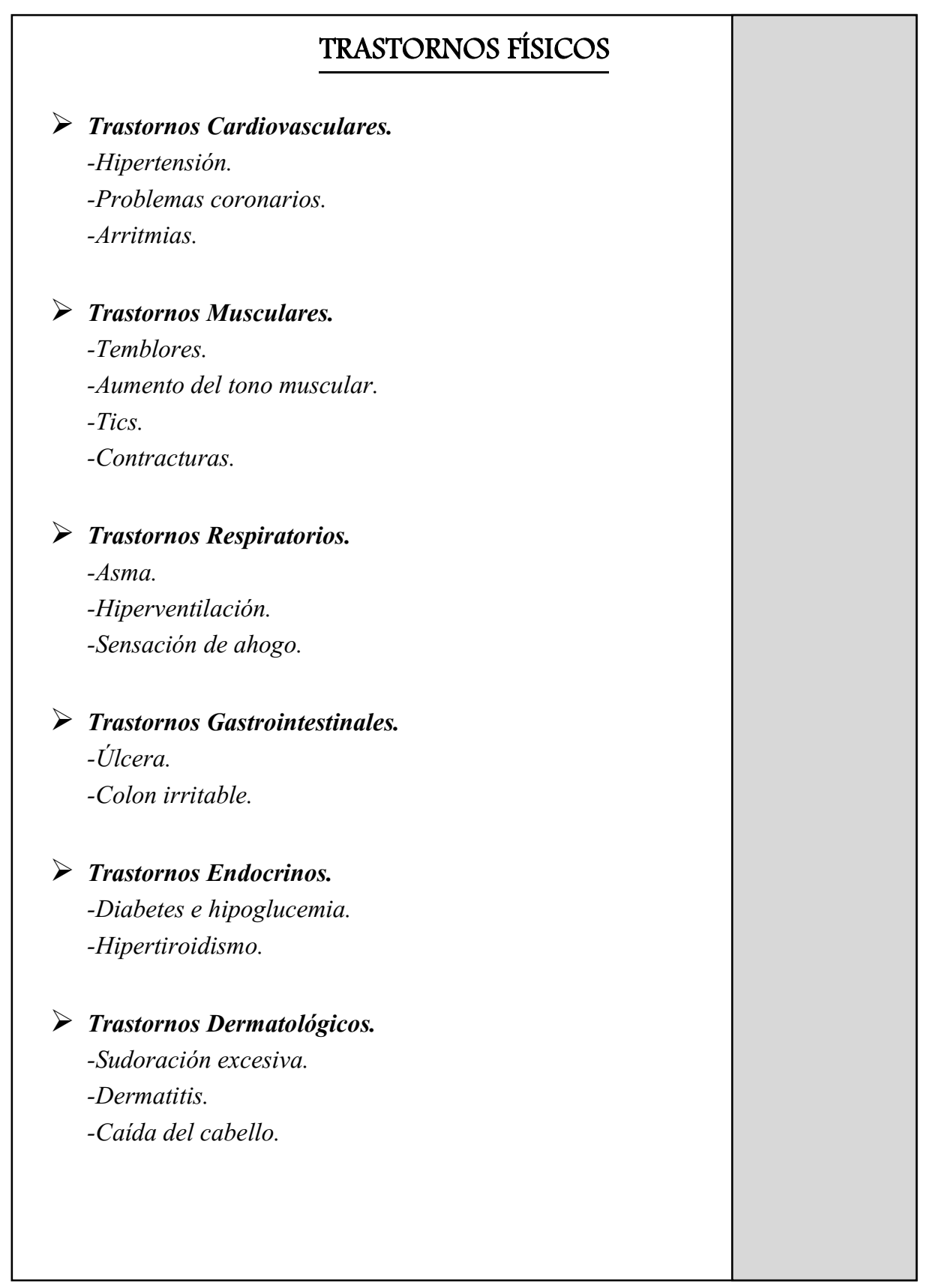




\section{CAPÍTULO IV. CONSECUENCIAS DEL ACOSO PSICOLÓGICO EN PUESTOS DIRECTIVOS.}

En cuanto a las consecuencias en su entorno familiar debemos señalar, que se manifiestan en el aumento de tensión entre los cónyuges, logrando en algunos casos hasta la separación de esta. Como hemos visto a lo largo de este capítulo el daño que el acosador hace a la víctima trasciende a su esfera familiar e individual, produciendo grandes daños familiares.

La persona se muestra en su hogar muy susceptible, desmotivada, sin expectativas ni ganas de trabajar, hipersensible a la crítica, con actitudes de desconfianza hacia sus más allegados, con conductas de aislamiento, evitación, retraimiento y por otra parte con otras de agresividad u hostilidad, inadaptación social, con sentimientos de ira, rencor, sentimientos de venganza incontrolados (Piñuel, 2001) y contradictorios.

Algunas investigaciones demuestran que se ve seriamente afectada la comunicación del núcleo familiar, las actividades que se realizan conjuntamente (Alonso, Peris y Fuertes, 2003). Todo ello no hace sino más que complicar aún más la vida del afectado, agudizando más si cabe su estado psicológico y su vida laboral y personal.

Los familiares más allegados de la víctima no comprenden que está sucediendo, ni porque su marido, mujer, padre, madre, hijo, hija... etc tienen esos comportamientos y reaccionan de esa manera con ellos. La confusión se apodera de la vida familiar y comienzan a surgir discrepancias entre ellos, e incluso muchas veces, culpabilizan a la víctima erróneamente.

Por tanto en acosador no solo destruye la vida laboral de su acosado, sino que destruye también o cuanto menos, perjudica seriamente la vida personal de la víctima. Ello es motivo de satisfacción para el acosador, pues a su entender, ello hace que corrobore su versión de los hechos, haciendo ver a los trabajadores y demás observadores, que el origen de todo ello está en los comportamientos de su víctima, cumpliendo así sus expectativas de acoso frente a su acosado. 


\section{CAPÍTULO IV. CONSECUENCIAS DEL ACOSO PSICOLÓGICO EN PUESTOS DIRECTIVOS.}

\subsubsection{El concepto de víctima.}

El concepto de víctima es un concepto muy amplio, con diversidad de matices y acepciones. Por tanto debemos decir que no hay un único concepto de víctima. Históricamente 8 no se ha prestado una atención especial a la víctima, sino que es a partir de 1950 cuando comienza a tratarse como tal, hasta esa fecha tan solo existían autores como Ferri, que hablaba de la víctima desde el punto de vista de la reparación del daño o Garofalo, que únicamente aludía a la víctima cuando se refería a las indemnizaciones económicas.

Así pues, el primer autor que habla de víctima como tal, dándole al concepto una dimensión trascedente fue Von Hentig, que junto con Mendelsohn se preocuparon por los derechos victímales.

Centrándonos en ese concepto de víctima podemos acotar un sinfín de definiciones según la perspectiva que se adopte:

1) Tomando como referencia su etimología: viene a ser "la persona o animal sacrificada o que se destina al sacrificio", este concepto, obviamente va ir evolucionando con el paso del tiempo y se va a empezar a hablar de la persona que se sacrifica por algo o como aquel sujeto que sufre o padece dolor por culpa de otro. En la actualidad se entiende desde este punto de vista, a aquella persona que padece un daño o lesión por culpa ajena o de otra persona o grupo de personas. Esta última interpretación es la más próxima a lo que desde la psicología interpretaríamos como víctima.

2) Tomando como referencia su gramática: se toma como concepto aquella persona que se expone $u$ ofrece un grave riesgo a favor de los interés de otra. Esta segunda interpretación, por tanto dista del concepto al que hacemos referencia desde la perspectiva psicológica.

\footnotetext{
${ }^{8}$ (Marisol Collazos Soto, 2006).
} 


\section{CAPÍTULO IV. CONSECUENCIAS DEL ACOSO PSICOLÓGICO EN PUESTOS DIRECTIVOS.}

El primer foro en el que se trato el concepto de víctima, fue en el seno de la ONU (Organización de Naciones Unidas), durante el VI Congreso de Caracas (Venezuela), celebrado en 1980. Posteriormente se celebro el VII Congreso de Milán (Italia) en el cual se matizaron diversos aspectos entorno a la conceptualización (1983). En ambos congresos, se determinó que la víctima por definición, era la persona que había sufrido una pérdida de daño o lesión, bien sea en su persona propiamente dicha, o su propiedad o derechos humanos, como resultado de una conducta que englobe diversas situaciones.

Cabe destacar la tipificación del término que se llevo a cabo en este último congreso:

1) Víctimas de delitos: entendidas como tales aquellas personas que de manera individual o colectivamente hayan sufrido algún daño, incluyendo lesiones físicas o mentales, sufrimiento emocional, pérdida financiera o menoscabo sustancial de derechos fundamentales como consecuencia de acciones $u$ omisiones que violen la legislación. Está primera tipificación, habla de que también serán considerados como víctimas los familiares o personas cercanas a la misma.

2) Víctimas de abuso de poder: identifica como tales a aquellas personas que individual o colectivamente hayan sufrido algún daño, principalmente de carácter moral, con consecuencias físicas derivadas, violando derechos de la legislación vigente.

Tras estos congresos comenzaron a darse numerosas investigaciones, y aparecieron así diversas definiciones, que a la postre fueron el origen de la terminología con la que hoy nos referimos a las personas que padecen mobbing:

\section{Definición de Mendelsohn.}

Define a la víctima como la personalidad del individuo o de la colectividad en la medida en que se encuentre afectada por las consecuencias sociales de 


\section{CAPÍTULO IV. CONSECUENCIAS DEL ACOSO PSICOLÓGICO EN PUESTOS DIRECTIVOS.}

un sufrimiento determinado por factores de muy diverso origen, como pueden ser físico, psíquico, económico, político o social, así como el ambiente natural o técnico.

\section{Definición de Separavic.}

Define víctima como cualquier persona física o moral que sufre, como resultado de un despiadado designio incidental o accidentalmente.

\section{Definición de naturaleza victimológica general.}

Entiende a la víctima como el individuo o grupo que padece un daño por una acción u omisión propia o ajena o por causa fortuita.

\section{Definición victimológica-criminal.}

Define a la víctima como aquella persona física o moral que sufre un daño producido por una infracción propia o ajena aún no siendo el detentador (propietario) del derecho vulnerado.

\section{$>$ Definición jurídica de la víctima.}

Jurídicamente la víctima se relaciona con la figura del perjudicado, que muchas veces será el sujeto pasivo del delito. El perjudicado, sería la persona física o jurídica que a consecuencia de la comisión de un delito, sufre un daño, mientras que el sujeto pasivo será el titular del bien jurídico protegido o puesto en peligro.

Así pues, en el caso que nos ocupa, entendemos por víctima, como aquella persona que ha sufrido un daño o perjuicio psicológico grave, con secuelas fisiológicas, por acción u omisión, de una persona, o grupo de personas concretas causando un daño real, concreto y específico. 


\section{CAPÍTULO IV. CONSECUENCIAS DEL ACOSO PSICOLÓGICO EN PUESTOS DIRECTIVOS.}

\subsubsection{Tipos de Victimización.}

Cuando hablamos de Victimización en personas que han padecido mobbing en puestos directivos de centros residenciales, podemos diferenciar varios tipos, ya que el daño psicológico generado por un suceso traumático puede ampliarse o reducirse en función de una serie de circunstancias que van más allá del mero hecho traumático en sí mismo.

Así pues, el daño psicológico sufrido por la víctima, se relaciona directamente con el hecho traumático (victimización primaria), pero también con otros factores que pueden agravar el daño psicológico de la víctima, tales como el funcionamiento del sistema judicial (victimización secundaria), e incluso a veces la victimización deriva indirectamente de los efectos negativos derivados de la relación que mantiene una persona con otra que se encuentra en una situación especial (victimización terciaria). A continuación precisaremos en qué consiste cada una (Paz del Corral Gargallo, 2002).

\section{a) Victimización Primaria.}

Deriva directamente del hecho violento, en este caso de las sucesivas y reiteradas conductas hostiles recibidas. De este modo, el suceso vivido como traumático va a afectar profundamente a la confianza de la persona en sí misma y en la de los demás, podemos decir que la víctima se queda sin elementos sociales de referencia, de tal manera que los síntomas derivan de las vivencias súbitas de indefensión y pérdida de control.

Es muy frecuente que las víctimas revivan intensamente y de forma involuntaria el episodio vivido, bien en forma de recuerdos agobiantes o bien en forma de sentimientos perturbadores. La persona se encuentra permanentemente sensibilizada frente a posibles señales de alarma. Estos "flashback" suponen una evocación claramente involuntaria, el sujeto no tiene capacidad de decisión frente a ellos, de tal manera que por un espacio de tiempo que puede oscilar entre algunos segundos y unas cuantas horas, pierde total o parcialmente el contacto con la realidad actual. 


\section{CAPÍTULO IV. CONSECUENCIAS DEL ACOSO PSICOLÓGICO EN PUESTOS DIRECTIVOS.}

La intensidad con la que son vividas estas situaciones y su carácter impredecible van a dar lugar a sensaciones de miedo e incertidumbre. Así pues se tiende a rehuir de las situaciones y los lugares relacionados directa o indirectamente con el suceso. Las víctimas tienden a no compartir sus sentimientos y sus recuerdos dolorosos (como consecuencia de la actitud evitativa y del temor a la reexperimentación), por lo que sufren solas, temiendo haberse convertido en seres anómalos o extraños.

Un síntoma característico de la afectación además de los directamente observables es la llamada "anestesia emocional", las víctimas, pueden en algunos casos describir lo ocurrido, pero manifiestan problemas de expresión emocional. Este embotamiento afectivo y bloqueo emocional es un caparazón, para protegerse de lo traumático.

Por paradójico que pueda parecer, los síntomas experimentados por la víctima, no son más que un intento fallido de adaptarse a la nueva situación que atraviesa. Intentan así prevenir futuros daños que le podrían ocurrir si se implicase de nuevo en una vida activa y recuperase la confianza en las personas. La falta de comunicación, como veremos en el siguiente capítulo, delata la vergüenza experimentada por la víctima, y su afán por proteger y no abrumar con sus pensamientos a sus seres queridos. En tanto en cuanto la víctima se ha sentido degradada y humillada, puede llegar a verse a sí misma como despreciable, llegando incluso a sentirse así de manera irreversible.

En suma de todo ello, dará lugar a la pérdida de la espontaneidad emocional y la tendencia al aislamiento social, el sujeto será incapaz de disfrutar de la vida cotidiana y de implicarse en nuevos proyectos de futuro. Se niega a aceptar sus propias necesidades emocionales. 


\section{CAPÍTULO IV. CONSECUENCIAS DEL ACOSO PSICOLÓGICO EN PUESTOS DIRECTIVOS.}

Al darse cuenta la víctima de que ya no es la que era y que los demás esperan una vuelta a su conducta anterior al trauma, se cuestiona el valor de su vida y el significado de seguir viviéndola. La indecisión y la falta de seguridad pueden plasmarse a veces en un mayor número de errores y en una inadecuada realización de las actividades laborales. Hay veces, las que menos, en las que el trauma puede manifestarse de una forma enmascarada (persistencia de imágenes, conductas de evitación y estado permanente de alarma).

\section{b) Victimización Secundaria.}

Deriva directamente de la interacción necesaria entre la víctima y los órganos encargados del control social de los sucesos delictivos, entendidos estos, como policía, centros de atención social, servicios sociales específicos, abogados, juristas...pero principalmente de la acción del complejo aparato jurídico que actualmente existe.

Es necesario resaltar la complejidad de un proceso como el que estamos estudiando, y la falta de formación e información que aún hoy en día poseen los diferentes órganos mencionados al respecto. Por tanto más allá de la victimización que se pueda ocasionar como consecuencia de los hechos del acosador, este tipo de victimización ocasiona un malestar aún mayor en la víctima agravando así y empeorando su estado psicológico. Esta falta de sensibilidad y de reacción ante los hechos sucedidos hacen que la situación empeore, se complejice y que la persona sufra aún más si cabe las consecuencias del acoso.

En la mayor parte de los casos el procedimiento judicial se demora, siendo un proceso largo, complejo, y en el cual la víctima lucha por demostrar su inocencia y porque se reconozca la culpabilidad del acosador, lo que a menudo resulta una quimera. 


\section{CAPÍTULO IV. CONSECUENCIAS DEL ACOSO PSICOLÓGICO EN PUESTOS DIRECTIVOS.}

Este tipo de victimización suele producirse por:

a) La deformación sufrida por la propia víctima respecto a sus derechos y la forma de hacerlos efectivos.

b) La impresión subjetiva que la víctima intuye de cómo a su vez ella está siendo percibida por los diferentes órganos.

c) El mal funcionamiento de las instituciones públicas.

d) El trato negativo dado a la víctima por los profesionales que la corresponden.

e) La negativa visión que la víctima tiene del proceso judicial y de la complejidad del mismo.

f) La incertidumbre y la ansiedad generada, por enfrentarse a lo desconocido y nuevo para él, como pueda ser un proceso judicial.

g) El conocimiento que el letrado posea al respecto de la materia a tratar y la sensibilidad de este al respecto.

h) La aparición de reacciones inadecuadas de los diversos medios sociales y agentes a los que se acuda en busca de ayuda o amparo legal.

En definitiva podemos decir que la víctima no solo padece el sufrimiento propio de una víctima de mobbing sino que además se enfrenta a situaciones nuevas y desagradables para ella, de tal manera que no solo no va a mejorar su estado de salud y su bienestar sino que normalmente tenderá a empeorar de manera gradual, hasta la celebración del juicio si en su caso se diera, o incluso hasta la emisión de la sentencia por parte de la juez de turno.

Por tanto es de suma importancia que las víctimas de este tipo de fenómeno acudan a profesionales cualificados, capaces de entender la situación que está vivenciando y de darla en su momento el tipo de apoyo pertinente, bien sea desde el punto de vista policial, de los diferentes servicios y centros de atención social o desde los diferentes estamentos judiciales del estado. 


\section{CAPÍTULO IV. CONSECUENCIAS DEL ACOSO PSICOLÓGICO EN PUESTOS DIRECTIVOS.}

Cabe reseñar que la jurisprudencia española no está pensada para proteger a las víctimas, sino para perseguir a los culpables de los hechos, por lo que prima la presunción de inocencia, de ahí que siempre se ponga en duda la declaración de la víctima, lo que va a resultar altamente lesivo para la misma.

Un aspecto fundamental es el juicio oral, celebrado con asiduidad mucho tiempo después de haberse producido los hechos, y en el cual la víctima revive en público la situación experimentada, donde además se enfrenta a preguntas no siempre formuladas con delicadeza en la cual la parte defensora va a poner en duda su relato de los hechos.

Con todo ello podemos afirmar que en la victimización secundaria:

1) Provoca un daño emocional suplementario, especialmente en aquellas personas con un nivel de autoestima limitado, como consecuencia del impacto generado por el acosador con anterioridad.

2) Proviene y se genera, principalmente por la actuación de instituciones públicas, diseñadas en su fin, para el amparo y protección de los afectados por las conductas lesivas de otras personas.

3) Daña a las personas que acuden y promueven las denuncias de los hechos delictivos, como los ocurridos en una situación de mobbing directivo, ante los cuales el demandante va a sentir una sensación de vacío y una falta de aliento para seguir adelante, que va a agudizar el sentimiento de dolor que ya por si siente la víctima.

c) Victimización Terciaria.

Cuando hablamos de victimización terciaria nos estamos refiriendo al conjunto de costes experimentados como resultado de la victimización primaria y secundaria que en líneas anteriores hemos expuesto 


\section{CAPÍTULO IV. CONSECUENCIAS DEL ACOSO PSICOLÓGICO EN PUESTOS DIRECTIVOS.}

\subsection{La Lesión y Secuela Psicológica.}

La lesión y secuela psicológica, son dos términos anexionados a las consecuencias padecidas por una víctima de mobbing directivo.

$\underline{\text { A efectos legales, }}$ el concepto de lesión debe ser entendido como "una deficiencia o dificultad, para desempeñar las funciones de un puesto de trabajo específico" (Esbec, 2000).

En cuanto a la patología clínica y médica, la lesión debe entenderse como "un cambio anormal en la morfología o estructura de una parte del cuerpo, producida por un daño o agente externo, lo que conlleva a una rotura del equilibrio y la homeostasis celular en el organismo del individuo que lo padece".

Generalmente esta lesión se produce de manera repentina, pese a ser la víctima en numerosos casos consciente de la situación que está padeciendo. Si es destacable a la hora de valorar las lesiones psicológicas, conocer el grado de violencia al que ha estado sometida la víctima, ya que esto puede hacer variar la intensidad de la lesión.

Las lesiones psíquicas más frecuentes en estadios de mobbing directivo, son los cuadros mixtos ansiosos depresivos, el trastorno debido al estrés postraumático, el estrés agudo, los trastornos adaptativos mixtos y los trastornos de personalidad de base (Cabrera y Fuertes, 1997).

Así pues, el ordenamiento jurídico español refiere en el artículo 147 de su código penal "al que por cualquier medio o procedimiento causare a otro una lesión que menoscabe su integridad corporal o su salud física o mental".

Por otra parte hablamos de secuela psicológica o psíquica para referirnos a la discapacidad o minusvalía permanente que tiene su origen en las conductas iniciales de acoso que el acosador lleva a cabo durante el tiempo en que se prolongue el acoso laboral. 


\section{CAPÍTULO IV. CONSECUENCIAS DEL ACOSO PSICOLÓGICO EN PUESTOS DIRECTIVOS.}

Autores como Esbec (2000), señalan además en sus investigaciones que estas discapacidades o minusvalías no han de ser susceptibles de mejoría en un tiempo razonable ni con tratamiento ni por supuesto de forma espontánea para considerarse como tales.

Este concepto de secuela psicológica ha sustituido al de daño moral, que es una noción más imprecisa, subjetiva y que implica más una percepción de perjuicio. Se trata por tanto, de una alteración irreversible en el funcionamiento psicológico habitual.

La secuela psicológica más frecuente en las víctimas de acoso laboral en puestos directivos de centros residenciales, es la transformación permanente de la personalidad contemplada por la OMS (Organización Mundial de la Salud) en el CIE-10 (Manual sobre la Clasificación Internacional de las Enfermedades Mentales), es decir la aparición de nuevos y constantes rasgos de personalidad, de carácter estable y desadaptativos, tales como dependencia emocional, suspicacia infundada, hostilidad...etc que se mantienen durante al menos dos años y que llevan a un deterioro de las relaciones interpersonales y a una falta de rendimiento en la actividad laboral (Esbec, 2000).

La dificultad de valoración de este tipo de secuelas estriba en la evaluación post hoc, en donde no siempre es fácil delimitar el daño psicológico producido durante el acoso, así como en la necesidad de establecer un pronóstico diferido (curabilidad/incurabilidad) (Echeburúa et al., 2002).

Además de esta evaluación debemos tener en cuenta, la concausalidad existente en este tipo de situaciones, lo cual va a dificultar aún más el establecimiento de una psicopatología clara y unívoca.

Todo ello complica enormemente la evaluación no solo psicológica, sino también la pericial que a posteriori se hará a la víctima. 


\section{CAPÍTULO IV. CONSECUENCIAS DEL ACOSO PSICOLÓGICO EN PUESTOS DIRECTIVOS.}

\subsubsection{Estado Psicológico anterior a la victimización.}

La víctima de acoso laboral en puestos directivos de centros residenciales, como hemos visto hasta el momento, sufre un tipo de agresión sutil, perversa, muy difícil de identificar, tanto para la víctima, como para el resto de compañeros, familiares y amigos que la rodean; todo ello se debe a que el acosador actúa premeditadamente, planificando con minuciosidad cada detalle, con un fin determinado.

Es bien sabido que en la actividad laboral actual, es frecuente los habituales "roces", las fricciones, las tensiones y hasta los incidentes aislados entre compañeros, fruto del grado de interdependencia que surge del propio desempeño de las funciones asignadas en el lugar del trabajo, más aún cuando estamos refiriéndonos a un centro sociosanitario en el cual prima la labor en equipo, lo cual será utilizado por el acosador en favor de facilitar y ocultar aún más su acoso.

El acoso comienza de manera repentina para la víctima, es un proceso brusco, donde las relaciones entre el acosador y el acosado cambian de una forma radicalmente opuesta a la relación que se tenía hasta el momento. Es muy frecuente en la actualidad que el acosador acuse al directivo del centro residencial de no cumplir de manera "satisfactoria" con algunas de sus obligaciones; nada más lejos de la realidad; entre ellas, en numerosas ocasiones utiliza el nivel de ocupación del centro, como "excusa" para dirigirse a su directivo de manera diferente a como lo hacía hasta el momento.

La relación que antes era cordial, positiva, e incluso de complacencia con su víctima se convierte en negativa. En este momento la víctima comienza a sufrir una gran confusión, se cuestiona las razones para ello, los problemas con el acosador,... por lo que comienza a buscar en sí mismo una explicación de la causa y desarrolla sentimientos encontrados y confusos, especialmente de culpabilidad. Este estado de confusión hace que, comience a sentir vergüenza ante el resto de compañeros e incluso ante sus propios trabajadores. 


\section{CAPÍTULO IV. CONSECUENCIAS DEL ACOSO PSICOLÓGICO EN PUESTOS DIRECTIVOS.}

Este proceso de cambio conductual y de actitud, viene motivado por los celos, la envidia, las competencias profesionales o la promoción de la víctima. El fin como ya hemos visto, no es otro más que denigrar la imagen del acosado, mediante críticas sistemáticas carentes de fundamento, acompañadas de rumores, mentiras, y burlas. Todo lo que hasta el momento eran alabanzas, y evaluaciones excelentes, y positivas se convierten ahora en críticas infundadas.

El hostigador trata de ambientar la percepción pública del acosado con el fin de culparlo de todo cuanto sucede. Con ello pretende causarle un daño extremo emocional y físico ya que comienzan a reflejarse los primeros síntomas, tales como trastornos del sueño, estrés, ansiedad... El único fin que persigue el acosador es que la víctima renuncie a su empleo voluntariamente al no poder soportar más la situación que atraviesa.

Ante todo ello la víctima presenta una serie de conductas, tales como hipervigilancia, bloqueo psicológico, automatismo conductual, ansiedad, miedo, incapacidad de expresar las emociones o desconfianza entre muchas otras.

La hipervigilancia comienza cuando la víctima es culpabilizada de todo cuanto le rodea, cualquier circunstancia o problema tomado este como dentro de la normalidad, en circunstancias ordinarias, es ahora tratado como fruto de su acción cotidiana laboral. Los ataques que recibe son tan cuidados y sutiles, que sus subordinados comienzan a creer que la víctima es la culpable de todo cuanto está aconteciendo en el centro residencial.

Ello, no en vano, comienza a ser percibido por la víctima, lo cual no hace más que agudizar sus sentimientos encontrados que ha comenzado a experimentar, sintiéndose mermado en sus dotes directivas y en sus habilidades para gestionar el centro de manera exitosa, como hasta el momento venía haciendo. Deviene ante sí una lucha interna, surgiendo una inmensa disonancia entre lo que él sabe que es capaz de hacer y lo que está ocurriendo ante sí. Denota así, una intranquilidad, que le lleva a permanecer en un continuo estado de alerta ante los demás. 


\section{CAPÍTULO IV. CONSECUENCIAS DEL ACOSO PSICOLÓGICO EN PUESTOS DIRECTIVOS.}

Una vez que comienza a asimilar en soledad lo que le está ocurriendo, decide esperar un tiempo. Durante este tiempo, permanece encerrado en sí mismo, esperando que sus circunstancias laborales mejoren, o al menos se aclaren, espera una explicación "lógica" de que es lo que está ocurriéndole.

No solo no va a obtener respuesta alguna, sino que sus condiciones laborales empeoran día a día. El acosador incrementa sus ataques y de manera sistemática, le sigue culpando de todo. Es tal la perseverancia que sufre, que comienza a padecer un bloqueo psicológico infundado, no es capaz de saber que está ocurriendo, ni se atreve a comunicárselo a nadie, ya que se muestra incapaz de transmitirles una explicación exacta de lo que está ocurriendo.

Comienza a si a enfrentarse a su trabajo de manera autómata, se desplaza hasta su puesto de trabajo con pensamientos contradictorios; debemos de decir que el hecho de ser acosado no implica una debilidad previa de la víctima, no se debe confundir la realidad personal con la imagen que se tiene de la víctima, cuando ya ejerce como tal, la víctima como la persona que queda después del acoso, personas que cuando pasan a ser el blanco del acoso se convierten en débiles, pero por estar afectadas, ya que en la realidad cotidiana no lo son, si lo fueran habrían cedido antes o después a las pretensiones del acosador, que establece inicialmente una lucha de poder con ella, aunque dicha lucha sea unilateral, ya que la víctima en principio, ni repara en la persona del acosador como hemos visto en líneas anteriores.

Generalmente la víctima además de no encontrar una solución al problema, advierte que sus acciones, sean estas cuales sean, no logran sino empeorar la situación, y esto es debido fundamentalmente a que el acosador de ninguna manera quiere una solución, el problema lo ha creado él, con un fin, deshacerse de la víctima, por supuesto no le interesa dialogar ni pactar nada con ella, a menos que sea en términos de dominación, lo cual sabe de antemano no va a conseguir. Su último objetivo es reducir a su víctima, que no es sino un objeto pasivo de su admiración, por lo que decide atacar lo que no puede alcanzar. 


\section{CAPÍTULO IV. CONSECUENCIAS DEL ACOSO PSICOLÓGICO EN PUESTOS DIRECTIVOS.}

La imagen que pretende proyectar el acosador de su víctima, tiene muy poco que ver con la realidad, pretenderá presentarla como alguien falto de valores, mediocre, holgazán y poco profesional, siendo en realidad todo lo contrario, inteligentes, honestos, con un alto valor por el trabajo, exitosos en su desempeño laboral e incluso debido a su preparación suelen situarse por encima del resto, de tal manera que pueden llegar a cuestionar sistemáticamente los métodos y fórmulas de organización del trabajo que les vienen impuestos, siempre de manera constructiva y con afán de mejora. Ello hace que sea muy envidiable a los ojos del acosador, que llegara incluso a envidiar las condiciones favorables de carácter extralaboral de las víctimas, como la vida familiar y social, considerada esta como satisfactoria desde la óptica del acosador.

Así, podemos decir que en el momento en que el acosador decide iniciar su ataque contra la víctima, esta es considerada una auténtica amenaza siendo considerada brillante y atractiva para el resto de trabajadores. Suele ser un directivo honesto con sus trabajadores, cercano y exigente en sus formas, muy profesional en sus tareas laborales, capaz de sacrificarse por los demás aún teniendo un status laboral superior a sus subordinados, perfeccionista, empático, capaz de valorar las situaciones laborales que se le plantean en su justa medida, asumiendo un volumen de trabajo superior a la media y tomando decisiones arriesgadas que a la larga resultan eficaces.

Todo ello es lo que en ese momento motiva las conductas de acoso del superior, ya que para él, es considerado como una amenaza; descubre indicios de superioridad, tanto en la preparación académica, como en el manejo de equipos y habilidades sociales, teme perder el poder o que el directivo subordinado pueda alcanzarlo en su detrimento, por tanto decide atacarlo para ocultar sus propias incompetencias, sus debilidades e inseguridades.

Así comienza el acoso, autores como Leyman postulan 5 tipos básicos de acoso:

1) Actividades para reducir las posibilidades de la víctima de comunicarse adecuadamente con otras, incluido el propio acosador. 


\section{CAPÍTULO IV. CONSECUENCIAS DEL ACOSO PSICOLÓGICO EN PUESTOS DIRECTIVOS.}

2) Actividades para evitar que la víctima tenga la posibilidad de mantener contactos sociales.

3) Actividades dirigidas a desacreditar o impedir a la víctima mantener su reputación personal o laboral.

4) Actividades dirigidas a reducir la ocupación de la víctima y su empleabilidad mediante la desacreditación profesional.

5) Actividades de acoso que afecten a la salud física y psíquica de la víctima.

La víctima, por tanto, comienza a experimentar una ansiedad generalizada, que afecta plenamente a su vida laboral y personal, lo cual no va a hacer más que alimentar el acoso.

El miedo y la incertidumbre comienzan a hacer mella en su estado de salud, tanto físico, como psíquico, la víctima es incapaz de describir lo que está viviendo, se muestra apesadumbrada y desconfía de todo aquello cuanto le rodea. Se reduce así, la calidad y cantidad de trabajo realizado exitosamente, y disminuye la productividad de la víctima, en gran medida debido a la falta de concentración.

Por tanto, la víctima del Mobbing en puestos directivos de centros residenciales, sufrirá en soledad. Autores como Frida Kahlo, postulan que "amurallar en propio sufrimiento es arriesgarse a que te devore desde dentro".

No es más, que el inicio de lo que en esta tesis, hemos denominado mobbing o acoso laboral en puestos directivos de centros residenciales.

Una vez hemos estudiado en profundidad las consecuencias que este fenómeno tiene para la víctima y su entorno familiar, procederemos a analizar las consecuencias derivadas para la organización o empresa a la que pertenece el trabajador, haciendo hincapié en cuáles son las condiciones organizacionales que favorecen la aparición de conductas de acoso, en qué tipos de liderazgo emerge con mayor frecuencia e intensidad, y en qué consiste lo que consideramos un "sistema laboral perverso". 


\section{CAPÍTULO IV. CONSECUENCIAS DEL ACOSO PSICOLÓGICO EN PUESTOS DIRECTIVOS.}

\subsection{Para la Organización Empresarial a la que pertenece.}

"El Incremento de los problemas de salud asociados con la percepción del mobbing puede también desmotivar a los trabajadores y reducir su satisfacción.

Como la relación causal entre la satisfacción del trabajo y los problemas de salud es bidireccional y dinámica, los crecientes problemas de salud que son el resultado de mobbing pueden afectar a la satisfacción del trabajo y a la motivación para asistir, siendo el absentismo un posible resultado.

Sin embargo, la presión para asistir, real o percibida, puede actuar como un motivador negativo, forzando a las víctimas a ir al trabajo (...)"

Hoel, (2003, pp. 147-148)

Es un hecho que el acoso laboral, tiene una gran repercusión en la propia organización en la que se da. Tener trabajadores que sufren este hostigamiento afecta a la productividad laboral, ya que al verse distorsionada la comunicación y la colaboración entre los trabajadores, se producirán graves desavenencias en las relaciones que los trabajadores deben establecer para ejecutar sus tareas de manera satisfactoria.

Se producirá una disminución en la calidad y cantidad de trabajo que desarrolla la víctima, imposibilidad de trabajo en grupo y se verá mermada la información que se maneja. El mal clima laboral se apodera de la organización creando así un ambiente de trabajo negativo, lo que supone una pérdida de motivación para los empleados, un descenso en la creatividad e innovación, un mayor absentismo laboral y una gran despreocupación por la satisfacción de los ancianos (en este lugar que nos ocupa, nuestros clientes), con lo que aumenta la probabilidad de accidentes por descuidos o negligencias. 


\section{CAPÍTULO IV. CONSECUENCIAS DEL ACOSO PSICOLÓGICO EN PUESTOS DIRECTIVOS.}

Por otro lado, los costes económicos derivados de la violencia laboral son muy cuantiosos. Algunos estudios en los países con mayor número de empresas arrojan los siguientes datos (Escudero Moratalla, 2005):

\section{1) Estados Unidos.}

En Estados Unidos se ha calculado en 1,8 millones los días laborales perdidos, como consecuencia del acoso laboral. Un estudio realizado por el Nacional Safe Workplace Institut estimó que el coste de la violencia en el trabajo, para las empresas americanas, se elevo en el año 1992 a cuatro mil millones de dólares. En la actualidad, esta tasa se ha multiplicado por diez, lo cual pone de manifiesto la gravedad de la situación.

2) Alemania.

En Alemania, los costes se elevan hasta los 200 millones de Euros por año. El costo directo para una empresa de mil trabajadores es de $\mathbf{3 5 0 . 0 0 0}$ euros por año. Debemos recordar que Alemania, es uno de los países con más industrialización de la zona euro, y uno de los grandes referentes de toda la Unión Europea.

3) Canadá.

En Canadá destacan los datos arrojados por el British Workers Compensacion Borrad, el cual denuncia que los gastos de hospitalización de trabajadores debido a la violencia psicológica en el puesto de trabajo, han aumentado en un 88\% desde el año 1985.

4) Suecia.

En Suecia es tal el número de afectados, que a finales de 1993, el Gobierno aprobó el Acta Vocacional de Rehabilitación ${ }^{9}$, por la que se obliga a las

\footnotetext{
${ }^{9}$ Modificación de la Ley Básica de Prevención de Riesgos Laborales.
} 


\section{CAPÍTULO IV. CONSECUENCIAS DEL ACOSO PSICOLÓGICO EN PUESTOS DIRECTIVOS.}

empresas a presentar un plan de rehabilitación ante la Administración tan pronto un trabajador cause baja por un tiempo superior a un mes, o diez veces dentro de un periodo de 12 meses. Con ello se pretende transferir los costes asistenciales al lugar del que provienen, que no es otro más que la empresa.

\section{5) España.}

En España no hay estudios pormenorizados en relación a los costes económicos derivados del mobbing.

De los escasos datos que podemos analizar encontramos los dados por Ibermutua, que tras analizar un colectivo de 6.500 trabajadores de baja por I.T. (Incapacidad Temporal), de los cuales se sospechó la concurrencia de mobbing en un $1^{\prime} 71 \%$ de los casos, y calculando una media de 252 días de baja, 42 días más de proceso previo, teniendo en cuenta la base reguladora de los afectados, el resultado del coste era de 9.110 Euros por cada I.T. derivada de casos de mobbing.

Estos datos, trasladados al conjunto del país, suponen como resultado que el coste por acoso laboral sería de 1.850 .000 días de trabajo perdido y de unos 60.000 millones de euros por año (Pastrana, 2002).

Así pues debemos resaltar, que en el último informe encargado por la OIT (Organización Internacional de los trabajadores) a los profesores Helge Hoel, Kate Sparks y Cary L. Cooper (2000), éstos cifran el coste global por violencia en el lugar de trabajo en un porcentaje de entre el 1 y el 3`5\% del Producto Interior Bruto en un país desarrollado como es España.

Por otro lado la III Encuesta de la Fundación Europea para las condiciones de vida y trabajo, en un informe, aporta que el $31 \%$ de los afectados de acoso, estuvieron más de un año de baja laboral. 


\section{CAPÍTULO IV. CONSECUENCIAS DEL ACOSO PSICOLÓGICO EN PUESTOS DIRECTIVOS.}

En cualquier caso la mayor o menor importancia de los costes económicos de la violencia en los lugares de trabajo, no debe suponer afrontar el problema únicamente en términos de beneficios o pérdidas económicas para la organización, sino que el criterio fundamental debe estar basado en términos de la salud de los trabajadores.

Debe prestarse especial importancia al comportamiento de los líderes, de los altos directivos o también llamados "ejecutivos" de las empresas, capacitándolos para reconocer conflictos y manejarlos correctamente, ya que de ellos en gran medida dependen no sólo los beneficios de la empresa sino los costes y la salud de los trabajadores.

Por tanto, el mobbing representa numerosos riesgos y costes laborales no sólo para el trabajador, sino como acabamos de ver y veremos en las siguientes líneas para la empresa, hasta tal punto de constituirse en una preocupación y un problema no sólo jurídico, sino social y económico. Por este motivo los altos directivos de las empresas deben de ser personas y líderes formados, capaces de representar a la empresa en todas y cada una de sus vertientes, buscando armonizar los intereses económicos de la empresa, con los de sus propios trabajadores.

Así pues, la OIT (Organización Internacional del Trabajo) a través de su informe 98/30, contiene una serie de propuestas o medidas tendientes a enfrentar dicho fenómeno:

- Preventivas: tienden a considerar los orígenes de la violencia laboral.

- Específicas: cada forma de violencia exige remedios distintos.

- Múltiples: necesitan combinar diferentes tipos de respuesta.

- Inmediatas: hay que establecer con anticipación un plan de intervención para contener los efectos de la violencia psicológica.

- Favorables: a la participación de todas las personas que directa o indirectamente se ven afectadas, desde los familiares, a los directivos de las empresas. 


\section{CAPÍTULO IV. CONSECUENCIAS DEL ACOSO PSICOLÓGICO EN PUESTOS DIRECTIVOS.}

- Largo Plazo: las medidas coyunturales no bastan ya que las consecuencias de la violencia también se manifiestan a largo plazo.

- Informativas: el empresario debe mantener informado a sus subordinados a fin de entender sus necesidades y requerimientos.

- Regladas: toda empresa debe contener reglamentos internos debidamente actualizados, en los cuales se recojan las medidas de protección contra los casos de acoso laboral.

Todas estas medidas deberían ser tomadas por las empresas, con el fin de evitar la aparición de casos de este tipo, pero en la actualidad, muchos de los directivos "acosadores" tienen la visión de que "tener un empleo hoy es un privilegio" ya que la crisis económica que ha azotado al país, ha provocado el cierre de cientos de miles de empresas, usan así el miedo al "paro", a los posibles problemas familiares y económicos que pueden suponer el no tener un puesto de trabajo digno para fortalecer sus beneficios y con ellos su status social y financiero.

En el siguiente apartado abordaremos cual es el clima laboral en el que emerge el acoso psicológico y qué tipo de liderazgo favorece su aparición.

\subsubsection{Clima organizacional y modalidad de Liderazgo en que predomina.}

A lo largo de los años, se ha definido al ser humano como un ser social, que requiere de la interacción con los demás para sentirse realizado y conseguir sus objetivos. En el caso que nos ocupa, la dirección de un centro residencial, aparecen infinidad de relaciones interpersonales ya que necesariamente el trabajo realizado ha de ser en equipo. Aparecen así, sentimientos positivos y negativos, que han de ser debidamente interpretados para obtener el resultado que se busca. Esto genera lo que se conoce como "clima organizacional" o "clima laboral", en los que el liderazgo ejerce un rol preponderante. 


\section{CAPÍTULO IV. CONSECUENCIAS DEL ACOSO PSICOLÓGICO EN PUESTOS DIRECTIVOS.}

En las siguientes líneas, se pretende estudiar cómo afecta un mal liderazgo en el trabajo en equipo y éste en el clima laboral, entendido este tipo de liderazgo, como la incorrecta forma en que se ejerce el poder dentro del equipo, la incapacidad del líder para motivarlo, así como para proporcionar buenas relaciones interpersonales.

No siempre la interacción con nuestros pares y demás compañeros de trabajo son como quisiéramos, así van surgiendo conflictos que nos llevan a tomar decisiones que afectan de manera positiva o negativa a nuestra relación con los demás integrantes del equipo.

Por clima laboral se entiende el conjunto de cualidades, atributos o propiedades relativamente permanentes de un ambiente de trabajo concreto que son percibidas, sentidas o experimentadas por las personas que componen la organización y que influyen sobre su conducta. Así, se puede definir como el medio ambiente humano y físico en el que se desarrolla el trabajo cotidiano; influye en la satisfacción y por tanto en la productividad de los individuos y por ende en el buen funcionamiento de la empresa. Podemos afirmar que está relacionado con el "saber hacer" del directivo, con su comportamientos con los trabajadores, con su interacción con la empresa, y con la propia conducta con la que se tiende a dirigir a cada persona que interactúa de una u otra forma con el centro residencial.

Algunos de los factores que inciden en el clima laboral u organizacional, en un centro sociosanitario son lo que a continuación se enumeran:

1) La "dirección": estableciendo objetivos claros e identificando las metas que se deben alcanzar y los medios al alcance para lograrlos.

2) El "estímulo a la excelencia": se logra cuando la jefatura demuestra preocupación por el desarrollo de las personas.

3) El "estímulo por el trabajo en equipo": la participación organizada es el elemento indispensable en el trabajo en equipo, la cual tiene cabida siempre y cuando se estructure en un ambiente de apoyo mutuo. 


\section{CAPÍTULO IV. CONSECUENCIAS DEL ACOSO PSICOLÓGICO EN PUESTOS DIRECTIVOS.}

4) La "solución de conflictos": percepciones e intereses diferentes que compiten sobre una misma realidad, enfrentarlos en conjunto, conllevara un potencial desarrollo para la organización.

5) Los "factores de motivación y nivel de satisfacción personal": la motivación laboral ha de ser entendida como el conjunto de reacciones y actitudes naturales propias de cada persona, que se manifiestan cuando determinados estímulos del medio se hacen presentes.

6) El "sentido de pertenecía": la reciprocidad existente entre la empresa y los miembros del equipo.

7) La "Retribución": sistema de beneficios entendidos estos, como sistemas justos de remuneración, sistemas de promoción, sistemas de integración de nuevos empleados, sistemas de capacitación y desarrollo de los recursos humanos, sistemas o programas de bienestar social, y el sistema equitativo en el acceso a las retribuciones.

En el Gráfico 4.2, podemos observar la composición representativa de los componentes del clima organizacional.

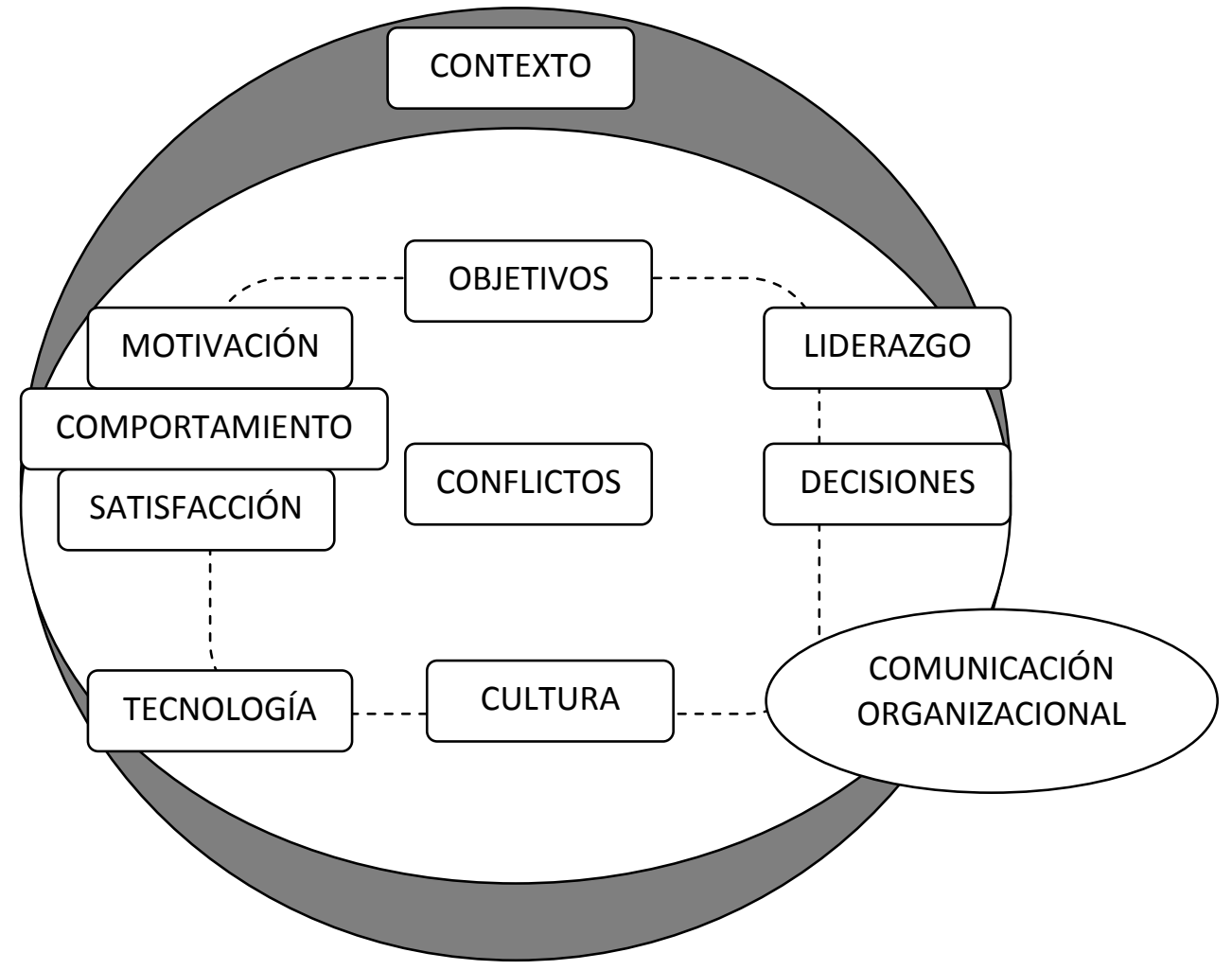




\section{CAPÍTULO IV. CONSECUENCIAS DEL ACOSO PSICOLÓGICO EN PUESTOS DIRECTIVOS.}

Hablaremos a continuación de la importancia del liderazgo para entender el fenómeno del mobbing en puestos directivos de centros residenciales. El término de líder dentro de una organización debe entenderse en un contexto en el que las organizaciones requieren de personas que dadas sus cualidades innatas o aprendidas sean capaces de dirigir a un grupo y conseguir las metas fijadas.

Lo primero que es importante discernir es la naturaleza de lo que denominamos autoridad $^{10}$, para poder acercarnos a comprender cómo su ejercicio afectará la conducta de las personas y las relaciones interpersonales en el lugar de trabajo. Podemos afirmar que autoridad y liderazgo son formas distintas de ejercer el poder en una relación.

Cuando hablamos de poder, estamos hablando de una relación social en la cual una de las partes determina el comportamiento de la otra parte; uno manda, otro obedece, uno toma las decisiones, el otro las acata. Se puede "mandar" de muchas maneras y se puede obedecer en distintos estados de ánimo, por tanto se puede tener la capacidad de determinar la conducta de otro a partir de diferentes fuentes que posibilitan esa situación. Esta naturaleza de la relación de poder permite distinguir distintas maneras de ejercerlos, cada una de las cuales tiene consecuencias y plantea requisitos muy distintos para ejercer la relación de poder.

Autores como Wrong, definen el "poder" como "la capacidad que poseen algunas personas para producir los efectos queridos y previstos en otras". Cohen, habla de "la capacidad para afectar al comportamiento de los demás y/o inferir en el control de las acciones más preciadas".

Así pues, en función, del distinto origen que puede tener el poder, se distinguen dos formas en las organizaciones del trabajo:

1) La autoridad.

2) El liderazgo.

\footnotetext{
${ }^{10}$ Sonia Sescovich Rojas, Socióloga de la Universidad de Chile.
} 


\section{CAPÍTULO IV. CONSECUENCIAS DEL ACOSO PSICOLÓGICO EN PUESTOS DIRECTIVOS.}

Analizaremos en primer lugar el concepto de autoridad; surge de la posición que la persona ocupa en la organización, es decir su origen proviene de la posición formal e institucional que se le dé en la empresa, lo cual le va a dar la posibilidad de "mandar", independientemente de cómo esa persona ejerza esa posibilidad, la organización va a respaldar ese ejercicio del poder, obligando al resto de trabajadores a "obedecer", simplemente por la posición relativa que ocupan en la organización. Por tanto, la legitimidad viene de la aceptación por parte de la organización y de sus miembros, de las condiciones formales establecidas, sin importan quien ocupe esa posición. La forma en la que esa persona, ejerza la autoridad va a ser determinante en la gestión del acoso.

En cuanto al concepto de liderazgo, entendemos es fundamental para que se lleve a cabo el acoso laboral en el puesto de trabajo. Hablamos de liderazgo cuando se "presupone", que una persona tiene la capacidad para determinar el comportamiento de otras personas, con el fin de lograr los objetivos de una empresa, de una manera armoniosa, eficaz y altamente satisfactoria tanto para los subordinados, como para la propia organización. Debe darse para ello un alto componente personal, en la persona que se va a tomar como líder, además de un componente que pudiéramos denominar situacional-social. Ciertamente hay personas en las que concurren estos aspectos y poseen unas características que les sitúan en el liderazgo, siempre y cuando se encuentren en el momento preciso y en la situación adecuada.

Algunas cualidades, que se toman como necesarias para que una persona ejerza el liderazgo han de ser las siguientes:

Saber comunicar: un líder efectivo ha de ser capaz de escuchar activamente y de expresarse tomando en cuenta el lenguaje del grupo.

> Saber respetar: los seres humanos, tenemos estructuras de pensamiento y comunicación diferentes lo cual va a conllevar diferencias, que se han de resolver desde el diálogo. 


\section{CAPÍTULO IV. CONSECUENCIAS DEL ACOSO PSICOLÓGICO EN PUESTOS DIRECTIVOS.}

$>$ Saber generar procesos de confianza: entendida esta como la certeza que tiene de que la otra persona no lo dañara deliberadamente, de que actuará siempre de buena fe, incluso en las situaciones de conflicto.

> Ser un facilitador, orientar a los demás y dejar hacer. No hace por los demás, hace con los demás, y para ello facilita las condiciones que lo permitan.

$>$ Se preocupa por generar espacios que faciliten las relaciones entre los diferentes miembros de la organización.

En cuanto a las capacidades deseables de un líder serían de especial importancia las que nombramos a continuación:

- Una capacidad técnica: lo que supone un alto conocimiento del trabajo, con o sin especialización, y que se manifiesta por una capacidad analítica, una facilidad de manejo de instrumentos y técnicas, y una habilidad a la hora de compaginar de forma coherente la organización del trabajo. Todo ello se consumara en la obtención de resultados tangibles.

- Una capacidad humana: básicamente hace referencia al trabajo con personas, y que le ha de permitir manejarse con desenvoltura ante las actitudes, opiniones y suposiciones de otras personas o grupos, así como intuir y mostrar sensibilidad hacia sus sentimientos, lo cual le va a permitir influir en su conducta. Esta capacidad humana puede estar basada en la creación de una atmósfera de miedo e inseguridad que cree dependencia o sumisión de los otros (como ocurre en el caso que nos ocupa), o por el contrario, en la creación de un ambiente de aprobación, de respeto y de transmitir seguridad a sus subordinados, lo cual sería altamente satisfactorio, tanto para los trabajadores de la propia empresa como para la obtención de las metas empresariales fijadas. Por tanto la auténtica capacidad para trabajar con otras personas debe convertirse en una actividad natural y continua ya que no es algo que se necesite solamente en los momentos de toma de decisiones, sino en la actuación individual de cada día. 


\section{CAPÍTULO IV. CONSECUENCIAS DEL ACOSO PSICOLÓGICO EN PUESTOS DIRECTIVOS.}

- Una capacidad intelectual: basada en la comprensión de la empresa como un todo y en una captación de todos los elementos relevantes que pueden influir en ella.

Estas capacidades están interrelacionadas entre sí, de forma que resulta difícil delimitar los límites de cada una, todas en su conjunto conforman un sistema. En los niveles directivos más altos, la capacidad intelectual es la más importante de todas, pues es la que da visión empresarial, cultura, organización y todos sus elementos intangibles. En los niveles directivos denominados "más bajos", se necesita ante todo una mayor capacidad técnica y humana, debido en gran medida al mayor contacto con sus superiores y sus subordinados.

Pero lejos de todas estas cualidades y capacidades que ha de tener un liderazgo positivo, en las empresas en las que aparece el acoso laboral nos vamos a encontrar con un liderazgo negativo, tóxico y autocrático. Estaríamos ante un tipo de líder que posee unas capacidades para influir en los demás, en su conducta, pero que lo hará en la dirección opuesta a los objetivos de la organización. Tan solo pensará en su propio beneficio, busca "el poder por el poder" ya que ello supone una gran atracción para la mayoría de las personas.

Para algunos expertos como Jean Lipman-Blumen ${ }^{11}$, el liderazgo tóxico es sencillamente un liderazgo deficiente, se identifica por su efecto negativo en la organización, y su origen puede deberse a la incompetencia profesional. En el año 2004, este autor ofrece tres rasgos del liderazgo tóxico:

1. Aparente falta de preocupación por el bienestar de los subordinados.

2. Personalidad que afecta negativamente al ambiente de la organización.

3. Convicción por parte de los subordinados de que el líder está motivado por intereses propios.

\footnotetext{
${ }^{11}$ Profesor de Comportamiento Organizacional en UGE Peter F. Drucker y Masatoshi Ito Graduate School of Management.
} 


\section{CAPÍTULO IV. CONSECUENCIAS DEL ACOSO PSICOLÓGICO EN PUESTOS DIRECTIVOS.}

El ejército de EE.UU., publicó recientemente una definición descriptiva del liderazgo tóxico en la "Publicación Doctrinal del Ejército" (pp 6-22):

"El liderazgo tóxico es una combinación de actitudes, motivaciones y comportamientos egocéntricos que tienen efectos adversos en los subordinados, la organización y el desempeño laboral.

Este líder carece de preocupación por los demás y por el clima de la organización, lo que conduce a efectos negativos a corto y largo plazo.

El líder tóxico se comporta con sentido exagerado de autoestima y por intereses propios agudos, utilizan comportamientos disfuncionales para engañar, intimidar, obligar o castigar injustamente a otros para conseguir sus propios fines.

El líder negativo cumple con los requisitos a corto plazo procediendo al fondo del continuo de compromiso, donde los seguidores responden a la autoridad del líder para cumplir con sus solicitudes; logra resulta en el corto plazo, pero pasa por alto las demás categorías de aptitudes del liderar para liderar y desarrollar a sus subordinados.

Este uso prolongado del liderazgo negativo para influir en los subordinados de manera inadecuada, socava la voluntad, iniciativa y potencial de los mismos, además de destruir el estado de ánimo de la unidad".

Así pues, cuando se trabaja para un líder tóxico, como es el caso que nos ocupa, los subordinados típicamente cumplen las tareas encomendadas aunque poco tengan que ver con su trabajo, para evitar la ira de su acosador, pero no se esfuerzan más allá. Este cumplimiento hace que se pierda la falta de compromiso, la creatividad y la innovación. La supervisión abusiva está vinculada con la disminución en la identificación de los valores intrínsecos de la organización. 


\section{CAPÍTULO IV. CONSECUENCIAS DEL ACOSO PSICOLÓGICO EN PUESTOS DIRECTIVOS.}

Algunos estudios de actualidad, sugieren una relación entre el liderazgo tóxico y el incremento en los niveles de cinismo de los empleados, tomado este como una actividad muy negativa acompañada por sentimientos de desesperanza, desilusión, e inclusive desprecio hacia la organización, en este caso que nos ocupa, el centro residencial.

Una encuesta Gallup ${ }^{12}$, muestra como los líderes de una empresa representan el 70 por ciento de la varianza en los resultados de compromiso con la empresa de los empleados. En la mayoría de los casos, el líder tóxico es visto por sus superiores como una persona receptiva, capaz de obtener altos niveles de rendimiento de sus subordinados. Algunos expertos sugieren incluso que son astutos y manejan con destreza las fuentes de poder. Se rodean de personas poderosas y manejan cuidadosamente su reputación, como hemos podido observar a lo largo del capítulo anterior.

Por tanto nos encontramos ante personas inmunes a las preocupaciones e influencias de sus subordinados, rara vez les prestan atención, ya que son considerados inferiores, por lo que, atendiendo a su cognición, nada le pueden reportar; tienden a racionalizar su propio comportamiento, descartan las quejas y sugerencias de sus empleados y evitan cualquier evaluación que puedan hacer de ellos. Intentan así, retirar de su cargo a aquellas personas, (preferiblemente directores de centros) capaces de reconocer sus conductas; tales decisiones difíciles de explicar ante los demás, son consideradas por el acosador como prácticas necesarias para el buen funcionamiento de la empresa, no como lo que en realidad son, un fracaso en la manera de liderar la organización.

A menudo la manera en que un líder tóxico se dirige a sus subordinados, es un fiel reflejo de su estilo de liderazgo.

\footnotetext{
${ }^{12}$ Sondeo de Opinión, frecuentemente utilizado para representar a la opinión pública. La encuesta lleva el nombre de su inventor, el matemático estadístico George Gallup. Esta encuesta usa típicamente un método de muestreo aleatorio simple para mantener la imparcialidad.
} 


\section{CAPÍTULO IV. CONSECUENCIAS DEL ACOSO PSICOLÓGICO EN PUESTOS DIRECTIVOS.}

El enfoque correcto del liderazgo, es aquel que cumple con las necesidades de los subordinados y las demandas de una situación dada, que pueda variar significativamente; la conducta que es apropiada, e incluso agradecida en una situación concreta, podría ser sumamente inapropiada y destructiva en otra situación de diferente índole.

Ya que hemos planteado a lo largo de todo el desarrollo de este capítulo, el caso que el liderazgo tóxico es un problema merecedor de intervención en el acoso laboral, en puestos directivos de centros residenciales, debemos de reconocer que tal vez no sea razonable esperar que sean eliminados de sus puestos de trabajo, sería lo deseable, pero no lo que se puede esperar; lo probable en el mejor de los casos, es que simplemente si se les recociera, se les fuera despidiendo de las organizaciones.

Ahora bien, aún teniendo en cuenta todo lo anterior, cuando el acosador es el máximo responsable, ya sea propietario, presidente, director general o consejero delegado como es el caso, difícilmente el sistema social actual podrá eludir las consecuencias de sus hechos.

Hacia el exterior, constituirá la plasmación de una entidad empresarial preocupada, como su líder, por sus trabajadores y por sus clientes (los ancianos), proyectando más que una buena imagen e intentando cuidar cada detalle de cuantos sean visibles. Sus mensajes, y apariciones, escasos por lo general serán sometidos a procesos de filtro y selección excesivos (González de Rivera, 2002), serán, con frecuencia, poco más que maquillaje, y en la mayoría de las ocasiones el flujo que se establezca irá en una sola dirección, al fallar uno de los elementos clave en un proceso de comunicación, como es la existencia de una adecuada retroalimentación.

Rara vez lleva a sus directivos a desempeñar actividades creativas e intelectuales, como puedan ser reuniones con consejeros regionales, congresos, etc... y cuando les consulta en el proceso de toma de decisiones, no admite que sean ellos quienes las adopten, simplemente se limita a comunicar las ventajas de su ejecución, apropiándose así del intelecto de los demás. 


\section{CAPÍTULO IV. CONSECUENCIAS DEL ACOSO PSICOLÓGICO EN PUESTOS DIRECTIVOS.}

Como consecuencia lógica de todo ello, el líder tóxico acosador genera sentimientos de frustración, hostilidad y resentimiento, y climas laborales cargados de miedo, amenaza, premios ocasionales y castigos, de los que no se siente en absoluto responsable.

Así, a modo de resumen, podemos atribuir los siguientes rasgos a la modalidad de liderazgo predominante en el acoso laboral llevado a cabo en puestos directivos de centros residenciales:

Inexistencia o falta de dirección positiva.

La modalidad de liderazgo desarrollada por el acosador, implica una deficiente organización, tanto en los métodos de trabajo, como en los procesos de apoyo y comunicación. Existe una gran falta de coordinación y participación, al igual que una gran indiferencia por lo resultados.

Prioridad del control sobre la productividad.

El acosador, tiene serias dificultades para compartir el poder. Considera que es algo que ha de ser inaccesible para los demás, eso le atribuirá respeto, seguridad, status... necesita establecer un férreo dominio de la organización y de las personas que tiene a su cargo, lo que le va a llevar a supervisar de manera activa y rígida cualquier actuación y a atisbar, hasta extremos insospechados, el más mínimo movimiento de sus subordinados. El poder y el control, son considerados para él prioritarios ante la productividad y eficacia. Suele preferir la bancarrota económica, antes de tener que modificar sus estructuras internas de poder; busca así la destrucción del llamada "capital intelectual" de los trabajadores (González de Rivera, 2002). Así pues, exige a sus subordinados admiración en vez de lealtad, raramente tolera las discrepancias, vigila los pensamientos y la forma de vida de quienes trabajan a su alrededor, fomenta conductas de alerta, e interpreta en términos de traición o deslealtad cualquier afirmación de la propia personalidad del empleado. 


\section{CAPÍTULO IV. CONSECUENCIAS DEL ACOSO PSICOLÓGICO EN PUESTOS DIRECTIVOS.}

Predominio de la estética sobre la ética.

Si algo ha de preocupar al acosador en puestos directivos, es la imagen, las formas, la estética que muestra de su persona y su empresa a los demás. Transmite valores contrarios a los que posee, hace que la idea que se tenga sobre su persona sea altamente positiva. Incluso con frecuencia pronuncia breves discursos informales a sus trabajadores, denotándose en estos "su elevada ética empresarial" y su rigor para con los demás y a la hora de tomar decisiones trascendentales para el porvenir de la organización y de sus trabajadores. Nada más lejos de la realidad.

Imposición de una apariencia organizacional.

Procura imponer una apariencia de unidad organizacional ante los demás. Intenta mostrar la empresa en este caso el centro residencial, como una institución muy cohesionada entre sus miembros, lo cual dista mucho de la realidad. Sus empleados a menudo evitan coincidir con él por el centro, temen sus continuos reproches, sus críticas infundadas, su falta de preocupación por las necesidades reales que les rodean...etc. Usa su habilidad para movilizar las emociones ajenas, para crear la ilusión de formar parte de una "gran familia"; esto incluso se lo hace saber en la entrevista previa a la contratación. Con ello intenta crear, en lo posible, vínculos afectivos que envuelvan al conjunto y se aproxima a cada empleado preferiblemente de manera individual, más de lo que en buena lógica cabría esperar.

- Falta de correspondencia entre los objetivos declarados y los reales.

Existe una gran diferencia entre lo que el acosador propone, en sus grandes declaraciones de principios y lo que realmente valora, fomenta y espera. Hay una gran divergencia entre el día a día de sus trabajadores y el discurso que a menudo sostiene. Suele alardear de metas colectivas, y responsabilidades compartidas en su mayoría inexistentes en la praxis diaria. 


\section{CAPÍTULO IV. CONSECUENCIAS DEL ACOSO PSICOLÓGICO EN PUESTOS DIRECTIVOS.}

\section{Carencia de planificación estratégica o pseudoplanificación.}

La falta de previsión es una de las grandes carencias que denotaran su comportamiento. Hace un uso incorrecto de los tiempos y de la planificación estratégica del centro, lo cual favorecerá su comportamiento. No le interesaran los cargos que ostente por la actividad que se desarrolle en ellos, sino por la presencia e imagen que confieren ante los demás (González de Rivera, 2002). Cuando define sus objetivos, éstos resultan inevitablemente poco realistas, demasiado ambiciosos y frecuentemente inalcanzables (Goleman, 1999). Así pues este tipo de sujetos, muestran una escasa capacidad para aprender de la experiencia y planificar en profundidad y con pulcritud una situación futura óptima. El diseño que realiza de las tareas, refleja exclusivamente sus deseos, temores y aspiraciones grandiosas, más que satisfacer las necesidades que se le planteen ante sí. Así pues, si se embarcan en grandes proyectos, irremediablemente estará destinado al fracaso.

Bernstein, en el año 2001, los definió así:

"... (...) a ellos no les interesa lo que desean los demás. Creen que son los mejores y que la gente debe seguir el camino hacia su puerta. Esto los hace terribles (...). Su idea es actuar como si fuera estúpido tener en cuenta otra cosa (...)".

$>$ Deficiente organización del trabajo.

Existe una indefinición de funciones por puesto y ambigüedad en los roles asignados a los subordinados. El organigrama directivo presenta un gran oscurantismo, lo que facilitara el desenvolvimiento del acosador en la empresa. Esta desorganización estructural y la no delimitación o imprecisión a la hora de desarrollar las tareas a seguir, allanan el camino del acosador para hacer uso de su abuso de poder. Recurre frecuentemente a una estrategia que utiliza a modo de pretexto para que, al tiempo que defiende su actuación manipuladora, pueda no estar disponible cuando se requiere de su intervención (Nazare-Aga, 2002). 


\section{CAPÍTULO IV. CONSECUENCIAS DEL ACOSO PSICOLÓGICO EN PUESTOS DIRECTIVOS.}

$>$ Gestión manifiestamente mejorable del activo humano.

Carece de habilidades sociales que faciliten el manejo de equipos de trabajo; no admite tener a su alrededor un conjunto de trabajadores que puedan opacarle en el plano profesional o privado, por lo que su política al respecto responde a esta característica de personalidad. Conserva en la empresa a aquellos que considera inferiores y mediocres, que son quienes voluntariamente se someten voluntariamente a sus decisiones y aprueban sus mayores errores aún sabiendo que no son las decisiones correctas.

Suele dirigirse a sus subordinados de manera individual, valorando como mayor mérito, la mayor sumisión, lo que le asegurara una fidelidad ciega hacia sus decisiones y a su manera de "entender" la empresa. En cuanto a los directivos suele remunerarles implementando sistemas de objetivos, lo cual le facilita la evaluación negativa de los mismos ya que a menudo estos, son inalcanzables.

Uso del acoso como herramienta de management.

Persigue a todos aquellos que puedan hacerle "sombra" en la organización, de tal manera, que prima la competitividad frente a la cooperación. No tolera la existencia de órganos de representación de los trabajadores, y si los hubiere intenta minimizar su actividad de tal manera que su influencia sea mínima en la empresa, para así seguir controlando todos sus intereses. Así pues el acosador intenta promocionar la discordia y los enfrentamientos entre los diferentes miembros que componen la organización empresarial.

Aprovecha, asimismo, las elevadas tasas de excitabilidad, y agresividad que con frecuencia surgen hoy en las empresas, debido entre otras causas a la situación actual de crisis económica por la que atraviesa el país.

Con ello, consigue rodearse de personas que responden a su perfil, fomentando un clima de inseguridad e intimidación, lo que convierte el lugar de trabajo en hostil. 


\section{CAPÍTULO IV. CONSECUENCIAS DEL ACOSO PSICOLÓGICO EN PUESTOS DIRECTIVOS.}

$>$ Dificultad en la toma de decisiones y en la asunción de responsabilidades.

El acosador implanta un sistema de toma de decisiones centralizado en su persona. Toma las decisiones unilateralmente, siendo muy escasas e incluso nulas las participaciones de los subordinados en las mismas. Trata de infravalorar las capacidades e inteligencia de los demás, despreciando así sus ideas y cuantos pensamientos pudieran aportar. Posee una "sensibilidad a la jerarquía" que le lleva a respetar sólo a quien tiene un determinado nivel socioeconómico o político" (Piñuel, 2003), es incapaz de delegar absolutamente nada ni en nadie, ya que le supondría experimentar una sensación de pérdida de control.

Vive en un submundo paralelo a la realidad que le rodea, un lugar que el propia crea, motiva y vivencia como real. Niega la realidad, atribuyéndose cualquier decisión exitosa que se produzca a su alrededor. Por ende, su incontrolable envidia, le impide aceptar que otros alcancen el éxito y reciban el reconocimiento de los demás. Como forma de luchar contra la ansiedad que le genera su falta de capacidad, trata, siempre que le resulte factible de desplazar sus decisiones hacia los demás, eximiendo así su responsabilidad y de las consecuencias que puedan darse.

\section{Falta de asunción de errores y apropiación de los éxitos ajenos.}

Es una idea que venimos plasmando a lo largo del desarrollo de toda la tesis doctoral. La atribución de éxito y la negación del fracaso como "sesgo cognitivo", prima en este tipo de sujetos. Su conducta se dirige a evitar la responsabilidad sobre los errores y a apropiarse de los resultados positivos surgidos como consecuencia de las decisiones tomadas por otros. Intenta quedar libre e inmune de los problemas y culpabilizar al otro.

Sus sentimientos son superficiales, incluso llegando a intentar provocar autocompasión en el otro, si fuera necesario y la situación lo requisiera. Intentaran además captar la atención del receptor en todo momento. 


\section{CAPÍTULO IV. CONSECUENCIAS DEL ACOSO PSICOLÓGICO EN PUESTOS DIRECTIVOS.}

\section{Inadecuado manejo de los conflictos.}

Desarrolla una resolución de conflictos, basada en una postura estratégica, que en su momento pueda darle el poder como mediador, e incluso evitar los conflictos, con el fin de que el tiempo de solución, que él es incapaz de afrontar. Aborta cualquier tipo de solidaridad que pueda surgir entre iguales dentro de la organización, crea rivalidades, envidias y en definitiva trata de alejar a los subordinados entre sí, evitando que de la relación de los mismos puedan surgen relaciones perjudiciales para sus intereses.

González de Rivera, en el año 2002 menciona así:

"El origen del acoso no está exactamente en el conflicto en sí, sino en la perversión del conflicto. Lo que hubiera podido arreglarse con una simple explicación o con una oportuna intervención bien intencionada, se convierte en un problema irresoluble y creciente, precisamente porque alguien bloquea los mecanismos de resolución de conflictos y logra que funcionen al revés. El asunto se saca de contexto, se exagera, se difunde de manera inadecuada, innecesaria y tendenciosa, y acaba por utilizarse como excusa para motivar, justificar y potenciar el acoso psicológico del trabajador".

Cabe preguntarse como nota final de estas líneas, si actualmente estamos creando este tipo de líderes tóxicos, si los estamos fomentando, alentando o premiando involuntariamente, si los estamos formando en nuestras universidades y si los estamos tolerando en nuestros entornos. Estas preguntas merecerían una evaluación adicional, mientras tanto, podemos continuar determinando el alcance del problema siguiendo con el desarrollo de esta tesis doctoral. Para ello haremos a continuación una evaluación de costes laborales del mobbing. 


\section{CAPÍTULO IV. CONSECUENCIAS DEL ACOSO PSICOLÓGICO EN PUESTOS DIRECTIVOS.}

\subsubsection{Costes laborales del Mobbing.}

Como puede observarse el acoso laboral o mobbing, ya no es un problema emergente en las empresas actuales, sino que podemos afirmar que nos encontramos ante una realidad consolidada. Aparece así, una situación de conflicto laboral, que afecta, no solo como hemos visto a la persona que lo padece, sino también a su entorno, a su familia, a sus amigos y a la empresa a la que pertenece. Todo ello requiere de una gestión multidisciplinar que haga que disminuya, tanto su incidencia como su gravedad, teniéndose además en cuenta que incide en la organización, funcionamiento, imagen y en los resultados económicos de la empresa.

La asociación gallega contra el acoso moral en el trabajo (Agacamt) ha constatado un incremento del $30 \%$ en el número de afectados por acoso laboral desde el inicio de la crisis económica en el año 2008. El tipo de acoso que aparece en los puestos directivos de centros residenciales es el conocido como "acoso laboral como estrategia empresarial", en el que el hostigamiento se da por parte de la propia dirección ejecutiva de la empresa, buscando el cese por abandono "voluntario" del puesto de trabajo de sus directores de centros sin indemnización económica alguna.

El análisis de costes que a continuación vamos a realizar demuestra que una buena seguridad y salud en el puesto de trabajo, es un buen negocio para el empresario, una buena inversión a nivel de empresa, puesto que la prevención de riesgos psicosociales, no solo reduce los costes, en términos de absentismo, presentismo, rotación de personal, etc... sino que también contribuye a mejorar el desempeño de las tareas en las organizaciones. El ahorro de tales costes, constituiría un incentivo potencial, un nuevo bonus empresarial, para un cambio en la política de asignación de recursos por parte de las empresas y de las organizaciones, hacia un modelo de prevención, que funcionaría en paralelo con otras fuentes motivadoras externas de carácter coercitivo que tienen lugar en la actualidad.

En el Gráfico 4.3 podemos observar la Clasificación de Costes Empresariales derivados de los problemas de Salud. 


\section{CAPÍTULO IV. CONSECUENCIAS DEL ACOSO PSICOLÓGICO EN PUESTOS DIRECTIVOS.}

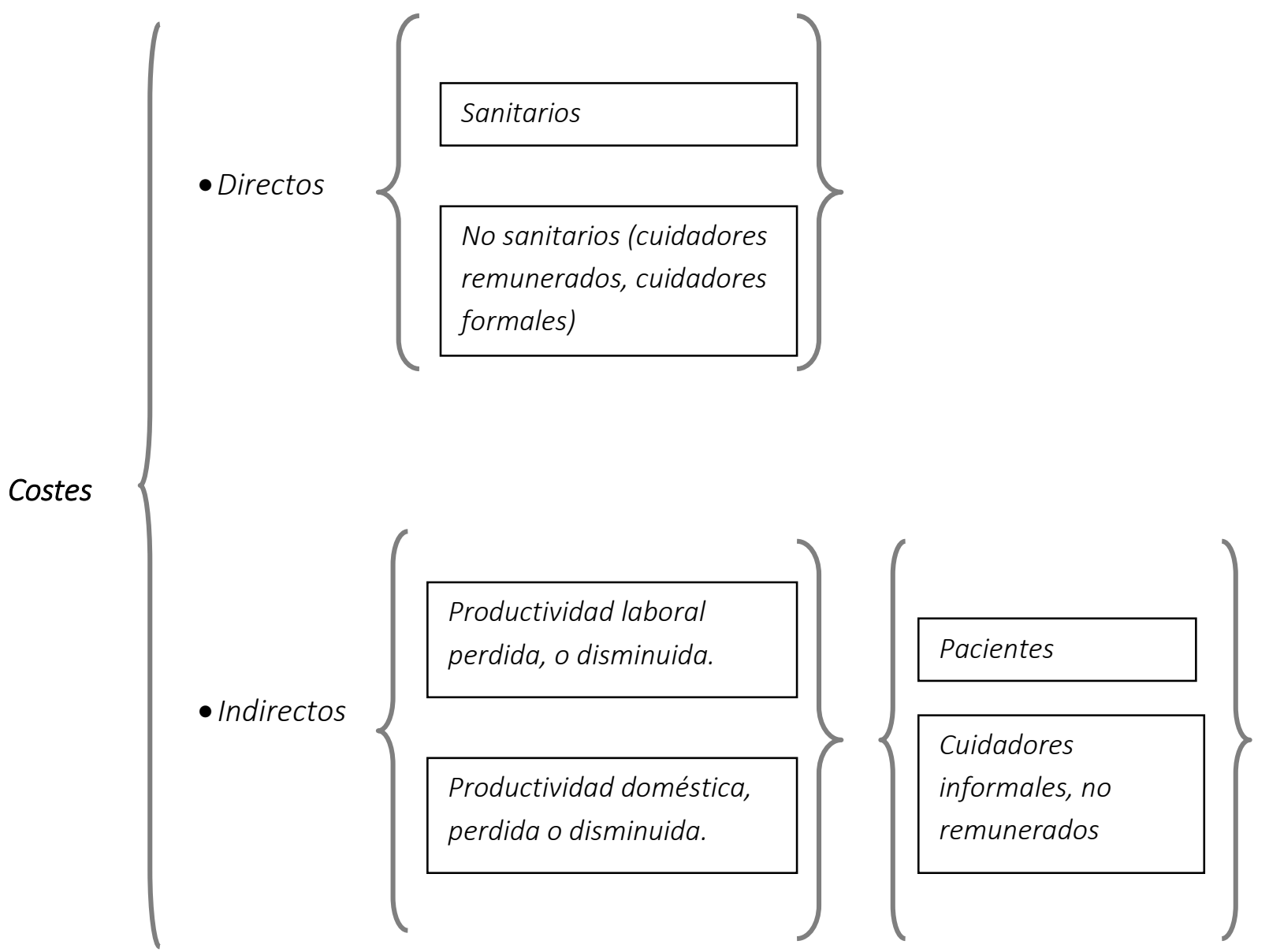

Gráfico 4.3. Clasificación de los Costes Empresariales derivados de los problemas de Salud (Lobo et al, 2004).

Así pues a continuación se enumeran algunos de los costes laborales que surgen en una organización donde se produce acoso laboral:

1) Absentismo Laboral.

Una de las consecuencias más graves para la organización, sin duda, son los periodos de ausencia que se suceden, cuando uno de sus trabajadores es acosado laboralmente. Se estima que un $25 \%$ de los trabajadores que son acosados en su puesto de trabajo, terminan abandonándolo, no sin antes permanecer de baja laboral. 


\section{CAPÍTULO IV. CONSECUENCIAS DEL ACOSO PSICOLÓGICO EN PUESTOS DIRECTIVOS.}

Algunas investigaciones no obstante, señalan que el mobbing sólo explica el $1 \%$ de la varianza total del absentismo (Hoel y Cooper, 2000). Esta relación, relativamente débil, podría explicarse por la presión que, en muchos casos, ejerce la organización sobre los asalariados para asistir al trabajo, aún estando enfermos.

Esta presión percibida para asistir al puesto de trabajo se incrementa cuando además el individuo es consciente que debido a su ausencia sus tareas las tendrán que hacer otros, que suplir sus compañeros, incrementándoles la carga de trabajo, cuando se reduce su salario, o cuando existe un alto riesgo de perder el puesto de trabajo, como es el caso que nos ocupa.

Son numerosas las ocasiones en que los afectados no quieren que se les acuse de estar fingiendo una enfermedad, lo cual como hemos visto a lo largo del desarrollo de esta tesis es aprovechado por el acosador para mostrar a la víctima ante sus subordinados como culpable, de la situación que estos están percibiendo. Hoy en día aún sufre más presión la víctima puesto que no suelen contratarse a nuevos trabajadores sino que el trabajo es asumido por el resto de trabajadores que conforman la empresa.

2) Rotación de Personal.

La rotación de personal en un centro residencial supone una gran inestabilidad para los trabajadores que lo conforman. Es frecuente, en el caso que nos ocupa, observar como en un centro residencial, al menos el $80 \%$ de los trabajadores abandona el puesto de trabajo en busca de una solución alternativa a la situación que está viviendo.

La posible explicación de este hecho estaría en la utilización del abandono del puesto de trabajo, o de buscar otro empleo como un mecanismo de 


\section{CAPÍTULO IV. CONSECUENCIAS DEL ACOSO PSICOLÓGICO EN PUESTOS DIRECTIVOS.}

afrontamiento positivo, intentando así reducir el problema, o minimizarlo, como estrategia psicológica, que permita al individuo al menos aliviar la idea de no tener que permanecer "toda la vida" en esa empresa (Keaslhy y Jagatic, 2000).

3) Disminución de la Productividad y el Rendimiento.

La productividad y el rendimiento de los trabajadores disminuyen de manera alarmante, debido en gran medida a la insatisfacción laboral que emerge en los trabajadores, a la reducción del compromiso con la empresa, y a la baja motivación vivenciada.

Se asocia además al clima laboral negativo en el que desarrollan las tareas diarias propias de su puesto de trabajo. Como hemos visto a lo largo de toda la tesis el clima laboral en un centro residencial es un elemento definitorio para la satisfacción de los residentes (en el caso que nos ocupa los clientes), puesto que la mayor parte de la carga laboral se tiene en contacto con el propio anciano, transmitiendo de manera indirecta el estado de ánimo y la insatisfacción que se tiene con el propio empleo, lo cual produce un contagio social en el propio centro, que a la larga derivará en bajas por traslados a otros centros.

4) Pérdidas económicas.

Todo lo anteriormente descrito hará que los ancianos vayan abandonando el centro residencial, lo cual va a suponer grandes pérdidas económicas. Estas bajas unidas a la baja productividad del centro, la falta de recursos humanos, la reducción del rendimiento y la ausencia de nuevos ingresos de ancianos en el centro, harán que el balance empresarial comience a ser deficitario, lo que conllevará mayores recortes aún en personal y en el bienestar de los clientes, en este caso, los ancianos. 


\section{CAPÍTULO IV. CONSECUENCIAS DEL ACOSO PSICOLÓGICO EN PUESTOS DIRECTIVOS.}

5) Deficiente Clima laboral.

Las situaciones de acoso, continuas y sistemáticas, provocan como hemos visto un ambiente laboral negativo en el que impera el miedo, la incertidumbre y la desconfianza. Los compañeros que no participan en el acoso, viven con el miedo a ser las próximas víctimas, lo que les hace perder motivación, confianza y capacidad de cooperar y trabajar en equipo. Experimentaran la incertidumbre de no saber qué ocurrirá en la empresa. Esto también va a provocar que los empleados no se sientan identificados con la empresa y que busquen un lugar mejor para proseguir su carrera profesional.

6) Costes en bajas laborales.

Numerosos estudios han constatado, que el trabajador acosado trabaja menos, ya sea porque no puede (como consecuencia del acoso al que está siendo sometido) o porque no se lo permiten, por lo que va a rendir menos y a producir menos. Así pues, en la gran mayoría de los casos, el trabajador causa baja laboral, aumentando así los costes para la empresa en salarios y en la contratación y formación de nuevos trabajadores, que ocupen el lugar de la persona acosada.

7) Mayor tasa de accidentes.

El clima laboral existente en una organización en la que se produzcan casos de acoso laboral, unido a la ansiedad generalizada creada y a la falta de concentración que de ello se deriva provocará pérdidas de atención en los equipos de trabajo del centro residencial, que pueden desencadenar en accidentes laborales.

Aumenta por tanto el riesgo de siniestralidad y el riesgo en el puesto de trabajo, de cada componente que conforma el capital humano del centro residencial. 


\section{CAPÍTULO IV. CONSECUENCIAS DEL ACOSO PSICOLÓGICO EN PUESTOS DIRECTIVOS.}

8) Devaluación de la imagen corporativa.

Con todo lo anteriormente descrito la empresa perderá clientes y prestigio dentro del sector de los servicios sociales. Cabe recordar que un centro residencial es un ente abierto a la sociedad que le rodea, que permanece o ha de permanecer en contacto con numerosos organismos locales, provinciales y regionales.

Además no solo se ha de tener contacto con los clientes, en este caso que nos ocupa los ancianos, sino que el contacto con sus familias es muy frecuente y periódico, por lo que este deterioro de la imagen se agudiza y se extiende aún más, si cabe.

Así pues todos ellos, irán conociendo la realidad que rodea al centro; si además en casos puntuales esta situación de acoso es recogida por algún medio de comunicación, bien sea prensa escrita o televisión de carácter local o regional, la imagen se deteriora a mayor velocidad y con consecuencias aún más negativas para la empresa e imprevisibles.

9) Necesidad de formación de trabajadores.

Al producirse bajas en el organigrama directivo empresarial, la empresa se verá obligada a contratar y formar a nuevos directivos, de acorde al sistema implementado ya en la organización.

10) Pérdida de trabajadores brillantes.

En la mayoría de los casos, las personas, (los directivos) sobre los que se produce el acoso, son trabajadores muy cualificados. Su marcha de la empresa supone una gran pérdida en lo que a capital humano se refiere. Suelen ser grandes gestores de equipos, por lo que el resto de trabajadores y subordinados, pierden una gran referencia laboral en sus puestos de trabajo, mermando así su carga laboral y las expectativas puestas en el puesto de trabajo que desempeñan. 


\section{CAPÍTULO IV. CONSECUENCIAS DEL ACOSO PSICOLÓGICO EN PUESTOS DIRECTIVOS.}

Por ello es imprescindible que el acosador modifique su actitud o desaparezca de la empresa, ya que el riesgo de extender dicha situación es muy grande (Rodríguez, 2004). Ciertamente que un acosador sea capaz de modificar su actitud y sobre todo no volver a actuar de forma tan perversa es altamente improbable, dado el perfil que presentan este tipo de personas, así que lo más seguro para la empresa es que no continúe trabajando en ella.

Así pues, la empresa debe ser consciente de que tiene que proteger a sus trabajadores del acoso psicológico en el trabajo, aunque solo sea por su propio interés, para conseguir que su cuenta de resultados no descienda y no ponga en peligro su supervivencia, pero lo cierto es que la empresa en la que acontece un acto de mobbing tiene un problema que no puede obviar, tiene que resolverlo y lo debe de hacer lo antes posible. Acabar con este tipo de prácticas exige situar el problema en el contexto correcto que es la asombrosa despreocupación que actualmente presentan muchas organizaciones por sus trabajadores, por sus personas. Por tanto, parece obvio, como a lo largo de la tesis se dice, que si se quiere erradicar el acoso psicológico en la dirección de los centros residenciales se necesita un comportamiento serio, ético y responsable por parte de la organización y sus miembros.

Hirigoyen, en el año 2001, afirma que "tienen la obligación de luchar contra la violencia bajo todas sus formas tomando las medidas necesarias para sancionarlas. (...). Las jerarquías de las empresas deberían dejar de defender sistemáticamente, por espíritu corporativo, a los ejecutivos acusados de acoso moral (...). Ese proceder es lo que les lleva a perpetuarlas y agravarlas".

La mayor o menor importancia que puedan tener los costes económicos derivados del mobbing en la empresa, no es justificación para que la misma decida afrontar el problema solo por este motivo, sino que el criterio fundamental que debe seguir la empresa es buscar la salud de trabajadores y velar para que esta se mantenga en el tiempo. 


\section{CAPÍTULO IV. CONSECUENCIAS DEL ACOSO PSICOLÓGICO EN PUESTOS DIRECTIVOS.}

\subsubsection{Establecimiento de un Sistema Perverso.}

El resultado del estilo de liderazgo autoritario que en líneas anteriores describíamos hace que se cree un sistema profundamente desorganizado, ineficiente y altamente improductivo, un ambiente muy dañino para los propios trabajadores y para la supervivencia de la propia empresa. Así el acosador consigue instaurar un clima psicosocial asfixiante para su víctima, caracterizado por;

La búsqueda de poder jerárquico.

En este ambiente de menoscabo, originado conscientemente, el acosador asigna unos roles difícilmente explicables desde el punto de vista empresarial. Su poder de seducción arrastra al grupo hacia la perversidad, (Hirigoyen, 2001) incluso originándose dos grupos bien diferenciados dentro del propio centro residencial, los "seguidores" y los "detractores". Su único fin es "alcanzar el poder absoluto", y para ello dedicará todos sus esfuerzos y la energía necesaria; su complacencia personal está por encima de cualquier objetivo organizacional, desplegara cuantas tácticas sean necesarias para conseguir sus metas, tomando siempre como referente la jerarquía y el poder.

\section{Adulación sistemática.}

Los subordinados del acosador que posean grandes aspiraciones profesionales dentro de la organización, alimentaran en todo momento el ego del ejecutivo acosador, cultivando aún más si cabe su autoestima y su motivación para llevar a cabo conductas de hostigamiento hacia su víctima. Cabe recordar que exigirá admiración antes que lealtad, juzgara la subordinación anteponiéndola a los objetivos empresariales y al rendimiento global que alcance en la empresa. Así pues son muchos, los trabajadores que engrandecen su figura y sus cualidades a fin de algún día ,según sus creencias, poder llegar a la cúspide del organigrama residencial. 


\section{CAPÍTULO IV. CONSECUENCIAS DEL ACOSO PSICOLÓGICO EN PUESTOS DIRECTIVOS.}

Identificación psicológica.

Los subordinados tienen la creencia de que aproximándose a los ejecutivos de los centros residenciales en los que trabajan tendrán más oportunidades de llegar temprano a puestos de gran relevancia, o que simplemente con ello mejorarán sus circunstancias laborales, nada más lejos de la realidad. Para el ejecutivo acosador estos serán meros medios para alcanzar sus fines, sin prestarles la más mínima atención, desvanecianedose así la idea de que la cercanía al acosador les acarreará privilegios especiales.

Este tipo de trabajadores a menudo suelen portar pensamientos positivos cuando se encuentran ante el acosador, con el fin de que este fije su atención en ellos.

Ataques a la excelencia profesional.

Si algo anhela el acosador es la excelencia de quien acosa, puesto que él carece de ella. Vigilará muy de cerca a aquellos trabajadores que destaquen por alguna de sus cualidades, intentando apoderarse de la futura brillantez que puedan experimentar, para lo cual hacen un seguimiento y control inusual de todas y cada una de las tareas que van a desempeñar, prestando especial atención a todo aquello que aporten como novedoso y que tenga grandes expectativas de éxito a corto plazo.

Merman sistemáticamente las cualidades de quienes consideran brillantes, 0 potencialmente exitosos, con el fin de destruir las alianzas que puedan poseer dentro de la organización, así los resultados de los equipos que hayan creado dentro del propio centro residencial serán tomados como suyos, nunca de quién fue capaz de crearlos, orientarlos, dirigirlos, motivarlos y guiarlos hacia los objetivos que se persiguen. 


\section{CAPÍTULO IV. CONSECUENCIAS DEL ACOSO PSICOLÓGICO EN PUESTOS DIRECTIVOS.}

Incompatibilidad con otras organizaciones.

Aún promoviendo lo radicalmente opuesto el acosador evita trabajar en lo posible con grandes empresas del sector. Posiblemente los altos cargos de otras entidades conozcan la personalidad del individuo e incluso puede que sean algunas de sus víctimas. Además él vive "bastante satisfecho" consigo mismo en su mediocridad, no entendería otras razones ni maneras de proceder más que las suyas (Gavilán, 2000), envidioso y completamente refractario a cualquier experiencia no deseará escuchar nada ni a nadie sobre sus deficiencias o sobre posibles mejoras (Goleman, 1999), no admitirá ningún fallo que pueda ningunear su posición social. Es frecuente que haga suyas las aportaciones de sus competidores, acudiendo periódicamente a congresos, convenciones, y reuniones en las que se ponga de relevancia los aspectos del sector.

Falta de trabajo en equipo.

Aunque es un defensor a ultranza del trabajo en equipo, lo cierto es que no valora como medio real de dirigir sus negocios el mismo (Bernstein, 2001). Su personalidad imposibilita hablar de cooperación, de colaboración, de preocuparse por el otro, de aproximar posturas, de compartir con los demás los pensamientos experimentados, etc...

Si suele aparentar conductas de equipo, para no dañar la imagen corporativa de la empresa, sin embargo mina todo aquello grupal, considera que la posible unión del grupo de trabajadores pueda debilitarle en su radio de acción en cuanto a lo laboral se refiere.

Para el acosador autoritario, trabajar en equipo consiste en que un grupo de personas hagan lo que él diga (Gavilán, 2000). No reúne ni siquiera a los subordinados más allegados, puesto que considera que nada le pueden reportar de valor. 


\section{CAPÍTULO IV. CONSECUENCIAS DEL ACOSO PSICOLÓGICO EN PUESTOS DIRECTIVOS.}

Reducida libertad de expresión vs ataque al pensamiento creativo.

El acosador coarta la libertad de expresión, el pensamiento crítico y la creatividad de sus subordinados. Intentará crear una rutina, que supervisará meticulosamente. El medio laboral que rodea al acosado y la falta de apoyo entre sus iguales hacen que la víctima no pueda expresar libremente sus opiniones.

Cualquier aportación que pueda hacer o decisión que pueda tomar será banal, sin ser tenida en cuenta por su superior. El acosador no permitirá la cohesión del grupo, fomentando así la cerrazón intelectual del mismo y el pensamiento único y lineal.

Todo ello conllevará a una falta de creatividad, de espíritu innovador y de un retroceso intelectual en la propia organización, de tal forma que solo se tome como válido el pensamiento que desde la ejecutiva se tome como tal. Esta falta de consideración del pensamiento de los trabajadores, repercutirá sobre las acciones con los propios ancianos en el centro residencial, puesto que cualquier consideración especial no podrá ser considerada desde la dirección del centro.

\section{Persecución de la capacitación como medio laboral.}

La realidad imperante, y el perfil del acosador, harán que a este le gusten los directivos sumisos, que sean lo suficientemente eficientes para llevar a cabo las tareas encomendadas, pero que necesiten de su colaboración para desempeñar su trabajo de manera satisfactoria.

En la actualidad desde la Gerencia de Servicio Sociales de Castilla y León, se proponen numerosos cursos de formación para los trabajadores de los centros residenciales, siendo en su totalidad rechazados por este tipo de individuos de manera unilateral, sin ni tan siquiera ser facilitados a los trabajadores. Así estos, quedarán lejos de la actualización profesional, salvo que de manera inusitada decidan formarse por su cuenta y riesgo. 


\section{CAPÍTULO IV. CONSECUENCIAS DEL ACOSO PSICOLÓGICO EN PUESTOS DIRECTIVOS.}

$>$ Comunicación restringida e imperante.

Como veremos en el siguiente capítulo, Capítulo $V$, la comunicación es una de las vías principales de las que se vale el acosador para conseguir sus metas. Mientras que en un sistema abierto se fomentarán los flujos de comunicación entre las personas que lo integran el acosador intentará que estos se desvanezcan o que sean inoperativos, sabedor de que ello incrementaría las posibilidades de desarrollo social y eficiencia.

Los flujos comunicativos estarán claramente centralizados en su persona, lo que agravará aún más si cabe, el clima laboral ponderante. Así pues la información se "manejará" de manera arbitraria.

Según algunos autores, tales como Villafañe, (1993), los objetivos de la comunicación interna deberían ser "implantar y fortalecer la cultura de la organización y reducir la incertidumbre" del trabajador, con el fin de asegurar que todos conozcan y entiendan los principios y metas de la organización, lograr credibilidad y confianza, extender la idea de participación, cooperación y colaboración entre compañeros, agilizar los canales de transmisión de la información, más aún con las nuevas tecnologías emergentes, fortalecer los rasgos jerárquicos, y favorecer y hacer operativa la comunicación.

Uso inadecuado de canales formales: las reuniones.

Los canales formales de comunicación, son utilizados por el acosador como vías para denigrar aún más si cabe al directivo.

Es frecuente que las reuniones de equipo sean un momento adecuado para no tener en cuenta las aportaciones del acosado, pausando constantemente cualquier opinión que pueda emitir, incluso haciendo hincapié negativamente en las mismas, para que el resto de iguales denoten la eficiencia del directivo, en los momentos clave de la organización del trabajo, como son las reuniones de equipo existentes en los centros residenciales. 


\section{CAPÍTULO IV. CONSECUENCIAS DEL ACOSO PSICOLÓGICO EN PUESTOS DIRECTIVOS.}

Una vez hemos analizado en profundidad las consecuencias que del mobbing se derivan para la organización empresarial, estudiaremos a continuación las consecuencias que existen para la sociedad en su conjunto.

\subsection{Para la Sociedad.}

Los efectos del acoso laboral generan graves perjuicios para la sociedad; tras el acoso sufrido la salud social del individuo se ve profundamente afectada, pues el acoso distorsiona las interacciones sociales e interfiere en la vida normal y productiva del individuo.

Las víctimas se vuelven muy susceptibles a la crítica social, mostrando actitudes de desconfianza y conductas de aislamiento y retraimiento, reacciones todas ellas agresivas y hostiles como respuesta al acoso sufrido, en tanto en cuanto generan manifestaciones claras de inadaptación social. La ira, el rencor y los deseos de venganza son muy comunes, entre quienes han vivido algo así.

Para la sociedad todo ello supone una pérdida de la fuerza del trabajo y de población activa asociada además como vimos en líneas anteriores al aumento del gasto económico. Los costes directos e indirectos soportados por todos los ciudadanos por la no prevención a tiempo de estas conductas son muy elevados. Aparece así un gran malestar en las relaciones laborales, con una crítica desmedida, agresividad e irritabilidad, una gran susceptibilidad ante los compañeros y la sociedad que nos rodea, pérdida de interés por los proyectos comunes, abandono de las responsabilidades y compromisos sociales etc..

Se conformará de esta manera, un aislamiento social progresivo, donde la persona acosada no desea tener contacto con otras personas para no tener que dar explicaciones sobre su salida de la organización. La sensación de fracaso y la falta de confianza son factores determinantes en el comportamiento con la sociedad de la víctima. 


\section{CAPÍTULO IV. CONSECUENCIAS DEL ACOSO PSICOLÓGICO EN PUESTOS DIRECTIVOS.}

Inicialmente la víctima detecta el conflicto o el trato despectivo, interpretando que la razón está de su parte y que existe un mal entendido, algunos lo consideran un estadio de autoafirmación. Seguidamente la víctima se sentirá desconcertada, dudará, no sabrá lo que está pasando y comenzara a pensar en su probable responsabilidad sobre lo ocurrido, encontrándose así desconcertada; se esforzara para agradar y para que la tengan en mejor consideración, este esfuerzo terminara desencadenando en un sentimiento de impotencia e indefensión que culminará en un estado de indefensión. Si el acoso persiste, la víctima comenzará a sentirse vulnerable y a presentar un estado de ansiedad generalizada, siendo frecuentes las conductas impulsivas y la pérdida de control. Todo ello derivará en una desestabilización en la que perdurará un sentimiento de desvalorización y falta de autoestima.

La marcha de la empresa, por parte de la persona acosada, resulta muy traumática a nivel social;

-Mermará las habilidades sociales, que se le suponen a un directivo de un centro residencial.

-Abandonara a sus amistades, fruto de la vergüenza que padece.

-Las personas de su entorno más cercano, suelen huir, cansadas de los síntomas de la víctima y de su obsesión por el acoso.

-Se dará una gran estigmatización social en los sectores de desempeño laboral cercanos.

-Postración económica, que se presentara a la víctima como diferentes formas de pérdidas de bienes y derechos.

-Pérdidas económicas en salario.

-Necesidades de afrontar procesos sociales traumáticos como puedan ser las vías legales para encauzar la situación. 


\section{CAPÍTULO IV. CONSECUENCIAS DEL ACOSO PSICOLÓGICO EN PUESTOS DIRECTIVOS.}

Por todo ello, podemos afirmar que todas las empresas deberían de tener una serie de valores éticos y conseguir que sus empleados, de cualquier nivel jerárquico dentro de la empresa, alto, intermedio o bajo, compartan esos valores y realicen su trabajo teniéndolos presentes.

Además la ética y el buen gobierno empresarial deberían ser un criterio fundamental en la toma de decisiones, al igual que lo es el criterio económico, ya que la actividad empresarial diaria de una empresa y su propia imagen como empresa en el sector sociosanitario terminarán reflejando los valores éticos imperantes en la misma.

Lozano (2011), propone los siguientes valores como "el sustrato ético sobre el que se asiente un código ético: libertad, solidaridad, respeto y diálogo". Los códigos éticos deben de establecer las normas de conducta que han de regir el comportamiento individual, tanto en el ámbito interno del propio centro residencial, como en sus relaciones externas con los proveedores, clientes, administraciones públicas, etc (Cuervo García, 2008). Normalmente incidirán aspectos tales como el cumplimiento de las leyes, la corrupción y los sobornos, la violencia y el acoso, la no discriminación, la honestidad e integridad en el trato con los ancianos y proveedores, la protección de la información de la empresa, el tratamiento correcto de la información personal y confidencial de clientes y empleados, el uso correcto de los recursos de la empresa, la salud y la seguridad laboral, las pautas para evitar y resolver conflictos de interés interno para la empresa y el respeto y la protección de las cuestiones medioambientales.

La eficacia de estos códigos depende en gran parte del proceso de elaboración del mismo y de la integración de la cultura ética en el día a día de la organización, por ello la elaboración de los mismos debe ser un proceso participativo y dialogado en el que todos y cada uno de los miembros de la organización vayan tomando conciencia de las responsabilidades que se van a asumir (Lozano, 2011).

Conseguir hacer realidad un entorno de excelencia ética en una empresa requiere por parte de la misma que invierta en tiempo, capacidades y recursos en un proceso 


\section{CAPÍTULO IV. CONSECUENCIAS DEL ACOSO PSICOLÓGICO EN PUESTOS DIRECTIVOS.}

en el que gradualmente los miembros de la organización vayan interiorizando estas ideas, al mismo tiempo que vayan adquiriendo los hábitos y virtudes necesarias para llevarlas a cabo (Fontrodona Felip, Guillén Parra y Rodríguez Sedano, 2010).

Un matiz que cabe reseñar al tratar la ética empresarial, es que legalidad y ética no son los mismos términos, así pues, en España, es posible actuar en contra de la ética y hacerlo dentro del marco legal establecido por la jurisprudencia. Con ello una empresa no puede utilizar el argumento de que cumple estrictamente las leyes vigentes para afirmar que su comportamiento es ético.

Concluiremos este Capítulo IV, afirmando que el mobbing ejercido en puestos directivos de centros residenciales, como estamos estudiando a lo largo del desarrollo de esta tesis, va destruyendo poco a poco al ser humano que lo sufre tanto a nivel psicológico como intelectual, al mismo tiempo que afecta seriamente a la organización en cuyo seno acontece este despreciable comportamiento contrario a la dignidad y respeto que toda persona merece y a la sociedad en la que emerge. Todo ello se agrava por la dificultad de demostrar que el acosado está siendo objeto de acoso laboral. 


\section{RESUMEN - ABSTRACT}

\section{CAPÍTULO IV.}

"Consecuencias del acoso psicológico en puestos directivos".

A lo largo de este Capítulo IV se ha hecho un minucioso análisis de las consecuencias derivadas del acoso psicológico en puestos directivos, análisis realizado sobre las repercusiones derivadas para la víctima, y su entorno, (entendido este como familiares y amigos más cercanos), la empresa u organización en el que emerge, (en este caso para un centro residencial), y para la sociedad en general.

Referente a la víctima y su entorno, se ha estudiado, el concepto de víctima, los diferentes tipos de victimización, (victimización primaria, victimización secundaria y victimización terciaria, matizando cada una de ellas) y el estado psicológico anterior que experimenta el acosado con su caracterización.

En cuanto a la organización empresarial se refiere, ha sido objeto de estudio la aproximación al clima organizacional y la modalidad de liderazgo predominante, un liderazgo laboral tóxico, haciendo hincapié en los diferentes costes laborales como consecuencia del acoso, principalmente en términos psicológicos e indirectamente abordados los costes económicos, finalizando con el estudio exhaustivo lo que hemos denominado "sistema perverso", que hace referencia al estado que el acosador crea en la organización, junto con el clima laboral que fomenta y motiva para llevar a cabo el acoso.

Por último se hace un análisis descriptivo de las consecuencias que se derivan para la sociedad en su conjunto, mostrando además la importancia y necesidad de establecer en la empresa un código ético y de buen gobierno. 


\section{CAPÍTULO V}

\section{"Técnicas de Manipulación reseñables en el proceso coercitivo del Mobbing e Instrumentos de Evaluación de las víctimas de Mobbing"}

VNIVERSITAS STVDII SALAMANTINI

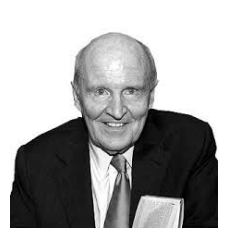

"La Organización sigue el ejemplo de quién está en lo más alto. La fuerza y personalidad de los Directivos determina la fuerza de la organización que dirigen. Según lo duro que trabajen y a cuántas personas involucren determina el alcance de su influencia".

Jack Welch (empresario y escritor estadounidense). 


\section{CAPÍTULO V.}

"Técnicas de Manipulación reseñables en el proceso coercitivo del Mobbing e Instrumentos de Evaluación de las Víctimas de Mobbing".

\section{Técnicas de Manipulación reseñables en el proceso coercitivo del Mobbing e Instrumentos de Evaluación de las Víctimas de Mobbing.}

A lo largo de este Capítulo $V$ haremos un análisis de las diferentes técnicas de manipulación reseñables en el proceso coercitivo que se da en los fenómenos de mobbing así como de los diferentes instrumentos de evaluación existentes en la actualidad para evaluar el impacto causado en las víctimas y las posibles secuelas psicológicas que puedan aparecer.

Debemos resaltar que las técnicas de coerción psicológica conducen a un estado de indefensión positiva dependiente, en el cual la víctima como hemos visto a lo largo de este estudio, no teniendo conciencia de la manipulación a la que está siendo sometida se ve arrastrada por una senda que perjudica claramente sus intereses, libertades y derechos, generando una pseudo personalidad inducida que arrincona su verdadera identidad, y que limita seriamente cuando no anula por completo, las decisiones laborales y personales como sujeto psicológicamente libre y autónomo.

Recordaremos brevemente lo fundamental de la "Teoría de la Indefensión Aprendida" de Martin E.P. Seligman que dice así:

“(...) cuando son expuestos a acontecimientos incontrolables, los organismos aprenden que responder es inútil. Este aprendizaje hace disminuir el incentivo para responder, y produce asi una profunda interferencia en la motivación de la conducta instrumental. También interfiere proactivamente el 


\section{CAPÍTULO V. TÉCNICAS DE MANIPULACIÓN RESEÑABLES EN EL PROCESO COERCITIVO DEL MOBBING E INSTRUMENTOS DE EVALUACIÓN DE LAS VÍCTIMAS DE MOBBING.}

aprender que la respuesta es efectiva cuando los acontecimientos se vuelven controlables, y de esta forma produce distorsiones cognitivas. El miedo de un organismo enfrentado a una situación traumática disminuye si aprende que las respuestas controlan la situación; el miedo permanece si el organismo sigue sin tener la certeza de que la situación es controlable; si el organismo aprende que el trauma es incontrolable, el miedo da paso a la indefensión”.

Observamos así que la indefensión puede surgir en situaciones donde una persona percibe que no tiene control alguno sobre los acontecimientos, como es el caso de acoso laboral a directivos de centros residenciales. La alternancia de castigos y recompensas, de indulgencia y culpabilidad en un entorno totalitario y de severa disciplina provoca sentimientos de indefensión en la víctima. La indefensión conlleva a tres tipos de secuelas; motivacionales, cognitivas y emocionales:

1) Motivacionales: la persona deja de confiar en su propia iniciativa como hacía hasta el momento y en su capacidad para tomar decisiones. Quizá las más graves para un cargo en el que la toma de decisiones es el eje de la mayor parte de la carga laboral.

2) Cognitivas: esta percepción de falta de capacidad se aprende por el acosado y se interioriza. El sujeto comienza a reconocer la situación que está viviendo y toma conciencia de que sus capacidades se están viendo mermadas, lo cual, no hace más que agravar su estado psíquico y de salud.

3) Emocionales: provocan un estado de inseguridad y miedo, que prolongado en el tiempo, conducen a episodios ansioso-depresivos. El sujeto por tanto no tiene el control sobre su propia vida. 


\section{CAPÍTULO V. TÉCNICAS DE MANIPULACIÓN RESEÑABLES EN EL PROCESO COERCITIVO DEL MOBBING E INSTRUMENTOS DE EVALUACIÓN DE LAS VÍCTIMAS DE MOBBING.}

En este punto en el que la víctima se va a encontrar, las únicas respuestas que le van a proporcionar un sentimiento de controlabilidad son las de conformidad y sumisión, ante la situación que está viviendo y de la cual es el protagonista involuntario. Por tanto el acosador ha logrado parte de sus metas; desestabilizar a su víctima.

A medida que el tiempo pasa, el estado psicológico de la víctima empeora, se deteriora. La persona como hemos visto llega a ser incapaz de exponer sus ideas de manera racional, sus respuestas a las preguntas pueden incluso volverse estereotipadas, resultándole difícil tomar incluso las decisiones más sencillas llegándose a alcanzar tal reducción de razonamiento que no llegue a darse cuenta de cuánto ha cambiado. Con todo ello las personas suelen encerrarse en si mismas, asumir nuevos valores y creencias, y comportarse de una forma bastante diferente, sino totalmente opuesta, a la de sus modelos de toda la vida.

Fruto de esta manipulación psicológica surgen graves consecuencias que hemos de tratar antes de analizar las diferentes estrategias de manipulación:

1) Ambivalencia.

La persona que sufre una experiencia de este tipo a menudo tiene sentimientos contradictorios y está muy confundida. Por un lado sabe que algo no ha ido bien, que ha sido sometida y que su relación con el agresor le ha causado mucho sufrimiento, pero por otro lado puede presentar conductas de defensa y protección hacia el agresor, tendiendo a justificar y reinterpretar conductas o situaciones vividas.

2) Culpa.

A la víctima se la ha hecho culparse de todo, haciéndole sentir inferior y despreciable. La persona que interioriza esto, puede verse como culpable y llegar a convencerse de que efectivamente la culpa es suya. 


\section{CAPÍTULO V. TÉCNICAS DE MANIPULACIÓN RESEÑABLES EN EL PROCESO COERCITIVO DEL MOBBING E INSTRUMENTOS DE EVALUACIÓN DE LAS VÍCTIMAS DE MOBBING.}

3) Vacío moral.

Después de estar expuesto durante meses a esta situación o incluso años, la víctima se encuentra angustiada y abrumada respecto de los demás, de lo que ella considera el "mundo exterior".

\section{4) Confusión.}

Es una de las secuelas más graves; la víctima ha de redefinir sus sentimientos y sus pensamientos respecto a su vida laboral y personal. Son normales los sentimientos encontrados y la desorientación.

\section{5) Desconfianza y susceptibilidad.}

La desconfianza hacia otras personas se apodera de la víctima, la dificultad de mantener relaciones sociales y de amistad o el miedo a iniciar una nueva relación laboral se hacen presentes en su vida. Es muy probable que duden de ellas mismas, de lo que dicen, hacen o piensen, mostrando como hemos visto en líneas anteriores, una inseguridad que interfiere significativamente en su vida.

\section{6) Descontrol emocional.}

La persona puede experimentar emociones antagónicas de manera impulsiva y repentina, estallidos de llanto, ira o profundos sentimientos de tristeza y desolación. El sujeto siente que no tiene el control de sus emociones, que ha perdido su yo.

7) Depresión vs riesgo de suicidio.

En una situación de mobbing prolongado en el tiempo, el abuso y la manipulación sufrida pueden dar lugar a una grave y profunda depresión. Los sentimientos de desesperación y desamparo, o las ganas de terminar con un 


\section{CAPÍTULO V. TÉCNICAS DE MANIPULACIÓN RESEÑABLES EN EL PROCESO COERCITIVO DEL MOBBING E INSTRUMENTOS DE EVALUACIÓN DE LAS VÍCTIMAS DE MOBBING.}

sufrimiento muy hondo y que parece que no cesa, así como con los sentimientos de culpabilidad, pueden llegar a provocar ideas suicidas.

\section{8) Miedo al agresor.}

La persona puede vivir en un estado de terror muy grande ante la posibilidad de que el agresor continúe con el acoso laboral fuera ya incluso de la propia empresa, intentando que esta no encuentre un trabajo similar al que desempeñaba. Los pensamientos intrusivos y recurrentes, la falta de concentración y de memoria, los dolores de cabeza, el nerviosismo, la irritabilidad o los ataques de ansiedad son secuelas muy habituales de la manipulación psicológica.

\section{9) Disociación.}

Aparece una gran dificultad para mantener el pensamiento reflexivo y la concentración. Suelen presentar un gran embotamiento cognitivo lo cual interferirá en su toma de decisiones.

\section{0) Incompetencias cognitivas.}

Es muy frecuente que las víctimas presenten dificultades en la atención, en la concentración y en los procesos de pensamiento. Son también normales los fallos en la memoria a corto y largo plazo. Las funciones cognitivas pueden verse caracterizadas por un enlentecimiento y una falta de claridad y coherencia notables.

Así pues, podemos afirmar que la disminución de la eficacia en la toma de iniciativas, en la capacidad de abstracción, en la toma de decisiones o en la capacidad de hacer inferencias o deducciones lógicas es manifiesta, con las consecuencias claras de lo que de ello se han de derivar, en la dirección de un centro residencial. 


\section{CAPÍTULO V. TÉCNICAS DE MANIPULACIÓN RESEÑABLES EN EL PROCESO COERCITIVO DEL MOBBING E INSTRUMENTOS DE EVALUACIÓN DE LAS VÍCTIMAS DE MOBBING.}

\section{1) Indecisión vital generalizada.}

La persona después de vivir en un entorno laboral totalitario y psicológicamente coercitivo y tóxico, puede mostrar serias dudas sobre lo que desea en la vida, sobre su futuro o sobre cuál es su lugar en el mundo.

\section{2) Falta de comprensión.}

Un problema relacionado con el miedo y la ansiedad que experimentan las víctimas es que con frecuencia les resulta difícil lograr que otros, aun siendo estos profesionales, entiendan lo que les pasa.

Además de estudiar las técnicas de manipulación en el proceso coercitivo del mobbing, que producen consecuencias inverosímiles y claramente perjudiciales como acabamos de describir, analizaremos en detalle los diferentes instrumentos de evaluación que existen en la actualidad para evaluar a las víctimas de mobbing. Cabe reseñar que una evaluación adecuada de las mismas, hará que las posibilidades de éxito en su recuperación sean mayores, que las de otras personas que no hayan sido evaluadas correctamente.

Para la correcta evaluación del acoso laboral se debe recabar toda la información posible, tanto de la persona, como del entorno laboral, así como el tipo de trabajo que desempeña, para tener una información mucho más amplia, que permita condicionar la aparición, evolución y pronóstico del caso, no limitándose únicamente a establecer, con base en la presencia de conductas frecuentes y la sintomatología que presenta la víctima, el tipo de trastorno clínico.

Debemos incidir además, en que obtener información solo de la frecuencia de las conductas del acosador, permitirá establecer si alguien puede ser víctima, pero no, ofrece información sobre el proceso de acoso laboral en general y de forma amplia, lo que facilitaría las tareas de prevención e intervención antes de que se presente el fenómeno (Saam, Nicole J., 2010). 


\section{CAPÍTULO V. TÉCNICAS DE MANIPULACIÓN RESEÑABLES EN EL PROCESO COERCITIVO DEL MOBBING E INSTRUMENTOS DE EVALUACIÓN DE LAS VÍCTIMAS DE MOBBING.}

\subsection{Diferentes estrategias de Manipulación.}

Si algo hace reconocible a un ejecutivo hostigador, en un centro residencial, es el empleo sistemático e intenso que realiza de la manipulación psicológica como medio y método para conseguir sus objetivos. El acosador conoce y pone en práctica numerosas estrategias, sabedor del resultado que con ellas obtendrá:

\section{1) Influencia intensa.}

La víctima es sometida a la voluntad ajena, con la puesta en marcha de una presión sutil, vigorosa y persistente. La persuasión se muestra invisible ante la propia víctima y el resto de compañeros y trabajadores del centro. Existirá la voluntad de promover la ambigüedad, un terreno en el cual acontecerán numerosos ataques, éticamente condenables, que no tratan nada más que subordinar al acosado.

\section{2) Doble intencionalidad.}

El discurso del ejecutivo acosador, está cargado de intencionalidad. El emisor organiza el relato de tal forma que intenta ocultar la intención primitiva que persigue, intentando así que esta no sea captada por la víctima ni por el resto de espectadores. Por tanto no manifiestan abiertamente sus metas, ni su propósito. El embaucamiento y el enmascaramiento, son el eje, entorno al cual girarán sus actuaciones.

\section{3) Seducción.}

El encanto que desprende el ejecutivo acosador es solo el inicio de la manipulación que llevará a cabo. Se gana la vida utilizando a otros, convenciéndolos de que él solucionará sus problemas, imitando la calidez humana sin sentir otra cosa que deseo por algo, por algo de lo que carece y que sabe, no podrá conseguir de ninguna otra manera. Así pues intentará despertar el interés de los otros, llegando incluso a mostrarse brillante ante los demás subordinados. 


\section{CAPÍTULO V. TÉCNICAS DE MANIPULACIÓN RESEÑABLES EN EL PROCESO COERCITIVO DEL MOBBING E INSTRUMENTOS DE EVALUACIÓN DE LAS VÍCTIMAS DE MOBBING.}

\section{4) Informidad.}

El ejecutivo adopta diferentes "papeles", "roles o máscaras" para cada situación que se le presenta, respondiendo así, a las diferentes exigencias que se le planteen. Aprovecha además, la tendencia del ser humano a confundir las apariencias con la realidad (Greene, 2001).

\section{5) Nebulosidad.}

No se compromete con nada ni con nadie, tan solo con sí mismo, busca constantemente todo aquello que anhela y no puede conseguir. Se muestra misterioso, inespecífico, diferente en sus formas, buscando lo atractivo, e intentando ser encantador y deseable para los demás.

Nazare-Aga (2002), plantea algunas formas concretas:

“El manipulador no dice claramente que no quiere asistir a tal reunión, a tal comida o a tal recepción. Tiene un impedimento y lo anuncia o hace transmitir el mensaje a un intermediario, en el último momento. La mayoría de las veces pone excusas que evidencian su conciencia profesional; está ocupado con otra tarea a la que da prioridad.

Utiliza pretextos que unas veces lo valorizan y otras veces lo sitúan como víctima. Elude las situaciones que le molestan:

1. No asistiendo.

2. Estando presente en los primeros minutos (cita, reunión o entrevista) y luego se va pretextando cualquier situación concerniente.

3. Llegando sistemáticamente tarde, fruto de su ocupación laboral.

4. Aplaza el asunto para más tarde, poniendo pretextos con la única intención de no abordar nunca el asunto en cuestión.

5. Se niega a resolver un conflicto originado por él, derivando la responsabilidad en los demás.

6. Reprochando a los otros su actitud ante un hecho en cuestión, mostrando así la falta de intención." 


\section{CAPÍTULO V. TÉCNICAS DE MANIPULACIÓN RESEÑABLES EN EL PROCESO COERCITIVO DEL MOBBING E INSTRUMENTOS DE EVALUACIÓN DE LAS VÍCTIMAS DE MOBBING.}

\section{6) Simulación.}

El acosador acostumbra a concordar prontamente con las opiniones del otro, y a dedicarse a la adulación u ofrecer favores (Fernández Collado y Dahnke, 1986). Simula así la práctica totalidad de las estrategias de manipulación que emplea.

\section{7) Familiaridad.}

El ejecutivo que acosa, intenta con prontitud ganarse la confianza de su víctima; puede llegar a mostrarse incluso como "su amigo", alguien muy cercano, con el que se puede incluso llegar a tener cierta amistad persona, lejos del trabajo. Con esta conducta lo que logra el acosador es incrementar la vulnerabilidad de la víctima, ya que esta abandonara algunos de los medios de defensa que utilizaría en una situación de normalidad.

Destaca la creación de primeras impresiones favorables en el otro, y el conocimiento de deseos, metas, conocimientos e información destacada de la vida de la víctima.

\section{8) Autorrevelación.}

El modo de proceder del hostigador va encaminado a revelar y compartir información, que el acosado no desea revelar; con esta actitud, el acosado se ve obligado, a compartir tanta información, como ha recibido por parte de su acosador.

Por tanto el acosador logra obtener una gran cantidad de información, a menudo muy relevante y de carácter personal de su víctima, llegando incluso a conocer sentimientos muy profundos hacia ciertos temas.

Esta reciprocidad, a posteriori, dejara indefensa a la víctima ante los ataques que va a sufrir, los cuales además incidirán en todo aquello que revelo de manera involuntaria. 


\section{CAPÍTULO V. TÉCNICAS DE MANIPULACIÓN RESEÑABLES EN EL PROCESO COERCITIVO DEL MOBBING E INSTRUMENTOS DE EVALUACIÓN DE LAS VÍCTIMAS DE MOBBING.}

9) Proyección de honestidad.

La confianza fingida hasta el momento, y el clima laboral percibido, van a contribuir a proyectar la imagen de honestidad del hostigador. Como hemos visto a lo largo de toda la investigación, el acosador "vive" de la imagen que transmite de sí mismo a los demás. Conoce la importancia de las primeras impresiones, por lo que especialmente cuidara los primeros encuentros que tenga con la víctima, como pueden ser reuniones, charlas, etc...

Es tal el disimulo que llega a mostrar, que alardea su "ética" empresarial ante otros compañeros, e incluso ante el resto de sus trabajadores.

10) Manipulación de sentimientos.

El acosador trata de inducir sentimientos de culpabilidad en su víctima, creando así emociones contradictorias, que ponen en tela de juicio el comportamiento profesional del acosado, sintiendo este contrariado ante tales disonancias cognitivas. El hostigador manejara así los sentimientos, que él mismo infundo en su víctima en su propio beneficio.

\section{1) Secretismo.}

Podemos decir que nos encontramos ante una de las características más relevantes: mantener ocultos sus actos y actitudes de manipulación. Es por tanto una de las condiciones básicas para efectuar de manera exitosa el mobbing en puestos directivos de centros residenciales.

Los acosadores rara vez actúan a la luz pública, sino que suelen elegir los momentos en que se encuentran a solas con la víctima o situaciones, en las que sólo están presentes miembros del acoso (Piñuel, 2001).

Así pues cuanta más gente esté al corriente de lo que realmente sucede, mayor es la probabilidad de que alguien haga algo para impedirlo (González de Rivera, 2002). 


\section{CAPÍTULO V. TÉCNICAS DE MANIPULACIÓN RESEÑABLES EN EL PROCESO COERCITIVO DEL MOBBING E INSTRUMENTOS DE EVALUACIÓN DE LAS VÍCTIMAS DE MOBBING.}

Estas serían las estrategias de manipulación más relevantes que encontramos a la hora de describir una situación de acoso laboral en puestos directivos de centros residenciales. Seguidamente analizaremos los principales mecanismos psicológicos que interfieren en un fenómeno de tales dimensiones.

\subsubsection{Principales Mecanismos Psicológicos que Interfieren.}

En un proceso de acoso laboral en puestos directivos de centros residenciales, no solo se dan diversas estrategias de manipulación, como hemos visto en líneas anteriores, sino que además han de interferir mecanismos psicológicos, los cuales el manipulador planifica y desarrolla de manera sistemática, de la forma menos evidente posible para el público que le rodea. Tales mecanismos podemos enumerarlos a continuación para su estudio en detalle (Piñuel, 2003):

\section{1) Selección.}

El manipulador sesga la realidad, escogiendo solo una parte de una situación específica, aislándola del resto de acontecimientos (Piñuel, 2003). El resto del relato que hace llegar al resto de trabajadores, compañeros y a la propia víctima lo inventa, creando así "su realidad" e intenta hacérsela creer a los demás, de tal manera que los demás perciban tan solo la realidad que él desea.

\section{2) Dramatización.}

El acosador amplifica los hechos perversamente, inventa hechos agravantes de la situación, perjuicios contra sí mismo, enjuiciando implícitamente los hechos aislados, aumentando las consecuencias reales, negativizando con constancia la gravedad de las circunstancias, situándose así como principal víctima de todo ello. 


\section{CAPÍTULO V. TÉCNICAS DE MANIPULACIÓN RESEÑABLES EN EL PROCESO COERCITIVO DEL MOBBING E INSTRUMENTOS DE EVALUACIÓN DE LAS VÍCTIMAS DE MOBBING.}

\section{3) Generalización.}

El hecho aislado será para el acosador el punto de partida, en torno al cual generalice lo insignificante. Esta generalización, estará cargada de culpa o amenaza para la víctima. El hostigador efectúa "una afirmación generalizada y universal" - "Tú lo confundes todo"-, expresada en un tono duro, sarcástico y enojado, que no propone una forma mejor de hacer las cosas ni tampoco deja abierta la menor posibilidad de respuesta (Goleman, 1996).

Por tanto es muy frecuente el uso de expresiones generales e imprecisas que ignoran las particularidades y concreciones de la situación, que no expresan el detalle particular, exagerando pequeñas verdades (Gavilán, 2000)

\section{4) Atribución.}

El ejecutivo acosador, atribuye a su víctima su propio fracaso, bien sea el personal o el profesional por el que suele atravesar. Todo lo negativo que él cree, le ha ocurrido se debe única y exclusivamente a las acciones de su víctima, en este caso a las decisiones que el directivo debe tomar diariamente en el centro residencial que dirige. Considera así oportuno asignar una intencionalidad perversa y malhechora a su víctima.

Le acusa de actuar con mala fe, a sus espaldas, buscando perjudicar los intereses de su propia empresa, dañando su propia imagen de ejecutivo de la empresa o grupo de centros residenciales, espantando a los posibles clientes que hagan positivo el balance del centro, etc...

El acosador atribuye todos estos aspectos, a los rasgos internos indeseables que él considera sesgan a su directivo, y le hacen tomar decisiones erróneas y negativas a su parecer, lo cual repercutirá directamente en su propia acción como ejecutivo de la empresa. 


\section{CAPÍTULO V. TÉCNICAS DE MANIPULACIÓN RESEÑABLES EN EL PROCESO COERCITIVO DEL MOBBING E INSTRUMENTOS DE EVALUACIÓN DE LAS VÍCTIMAS DE MOBBING.}

\section{5) Proyección.}

En la proyección podremos observar como el acosador proyecta sus características, sus intenciones, su manera de ser, de comportarse, de proceder con el otro, en su víctima, de tal manera que acusa a su víctima de lo que en realidad es el mismo. Caracteriza a los demás, dotándoles de su propio yo.

Con ello conseguirá fomentar el miedo, la incertidumbre y la inseguridad en el hostigado; emite juicios de valor, dirigiéndose a la víctima con frases tales como "yo no soy como tú", "nos has traicionado", "no has entendido nada, absolutamente nada de lo que te hemos explicado", "has puesto a los demás en contra de la empresa", "te has creído el salvador de la empresa", etc...

Así pues, el hostigador llega a colocarse en el papel de la víctima, convertir a esta en verdugo, y afirmar que el daño se lo están haciendo realmente los trabajadores a la organización (Mediavilla, 2003).Suelen hacer mención a expresiones como "lamento tener que ser yo quien tenga que hacer in informe desfavorable de ti, respecto a tu trabajo. No te lo he dicho antes porque no quería herirte" (Rodríguez, 2000)".

\section{6) Evitación.}

El manipulador, trata de ignorar a la víctima, e incluso si antes su trato era más cercano, ahora tomara más distancia, tratándola de usted, o dirigiéndose a ella, como si de una persona extraña se tratara. Este distanciamiento se hace más visible si cabe, en público, así pues cuando el ejecutivo hostigador acude al centro, pasa tiempo sin dirigirla la palabra, se muestra parco en palabras, no la mira o se refiere a ella con menosprecio, dejándola claro, que le ha hecho algo, con el fin de hacerla sentir incómoda, temerosa o amenazada. 


\section{CAPÍTULO V. TÉCNICAS DE MANIPULACIÓN RESEÑABLES EN EL PROCESO COERCITIVO DEL MOBBING E INSTRUMENTOS DE EVALUACIÓN DE LAS VÍCTIMAS DE MOBBING.}

\section{7) Racionalización.}

El acosador trata de autojustificar sus hechos con razones "supuestamente lógicas", con el fin de eludir una realidad evidente, que no es otra más que, él mismo carece de numerosos recursos y cualidades que si posee su víctima. Las razones que argumenta son infundadas, falsas y subjetivas de tal manera que difuminan y distorsionan la realidad de su conducta para con el otro hostigado.

Este intento de racionalizar sus actos, se ve persuadido y amenazado, cuando la víctima y alguno de sus trabajadores o colaboradores más cercanos identifican el sometimiento que está llevando a cabo solapadamente y con el mayor de los sigilos.

\section{8) Negación.}

Negara por definición todo de cuanto se le acuse. Es capaz de derivar toda responsabilidad que se le atribuya hacia los demás sin tener el mayor reparo en hacerlo. Desmiente sistemáticamente algo, aún con hechos probatorios tales como emails, correos electrónicos, grabaciones, etc... que demuestren lo contrario.

Frecuentemente su discurso suele mostrarse contradictorio, debido en parte a la adaptabilidad que requiere el eludir responsabilidades ante situaciones dispares, como puedan darse en un puesto de trabajo tal como es la dirección ejecutiva de un centro residencial, lo cual hace más visibles sus conductas hostigadoras.

Por tanto negará taxativamente cualquiera de las afirmaciones hechas a su víctima:

"eso no te lo he dicho jamás", "nunca nadie de esta empresa te ha indicado que hagas esto", "ninguno de nosotros (ejecutivos) te hemos tratado asi", etc... 


\section{CAPÍTULO V. TÉCNICAS DE MANIPULACIÓN RESEÑABLES EN EL PROCESO COERCITIVO DEL MOBBING E INSTRUMENTOS DE EVALUACIÓN DE LAS VÍCTIMAS DE MOBBING.}

\section{9) Equipo forzado.}

Suele usar el plural para referirse a su víctima, cuando da lugar al acoso. Se refiere a "nosotros hemos pensado", "la empresa ha creído conveniente hacerte saber", "desde la dirección ejecutiva se ha tomado la decisión", "tú y yo sabemos", "desde el centro somos conscientes de la realidad que se nos plantea", con ello persigue dar la impresión de que no actua solo, de que las decisiones no son solo suyas, o de que la responsabilidad de lo que está sucediendo o va a suceder o no es de él.

\section{0) Giro.}

Con la técnica del "giro psicológico", muy utilizada en materia política, el sujeto busca redundar en algo, sin expresarlo con certeza o claridad ante su público objetivo. Con esta estrategia, definida de la manera más simple, el acosador intenta que "los buenos sean los malos" y que "los malos sean los buenos", es decir transfiere la culpabilidad a su víctima, la hace responsable de lo que está sucediendo.

\section{1) Triangulación.}

Habitualmente el manipulador utiliza un "tercero" para poder manipular y debilitar a su víctima. Este "tercero" no tiene porque ser necesariamente una única persona, sino que en el caso que nos ocupa este "tercero" podrían ser los propios empleados de la empresa, a la vez subordinados de la propia víctima, quienes involuntariamente pueden ser protagonistas del acoso.

Por tanto se pone de manifiesto el comportamiento sibilino, maquiavélico, tortuoso y perverso al cual se enfrenta la víctima. La sistematización del proceso es tal, que como hemos visto a lo largo de todo esta tesis, logra burlar cuantas defensas plantee el acosado, logrando el objetivo final, que no es otro que llevar a cabo su acoso. 


\section{CAPÍTULO V. TÉCNICAS DE MANIPULACIÓN RESEÑABLES EN EL PROCESO COERCITIVO DEL MOBBING E INSTRUMENTOS DE EVALUACIÓN DE LAS VÍCTIMAS DE MOBBING.}

Una vez analizados los principales mecanismos psicológicos que interfieren en el proceso de mobbing directivo en centros residenciales, estudiaremos en profundidad la importancia de la comunicación interpersonal como habilidad directiva y su importancia en el desarrollo del fenómeno.

\subsubsection{La Comunicación Interpersonal como vía de expresión.}

En la actualidad existe una tendencia al cambio de las habilidades directivas, al liderazgo, así un líder efectivo del siglo XXI coordina, lidera, comparte, propone, motiva, implica, consensua, delega, diversifica, aprende, analiza, evalúa, promueve, confía, controla, integra, innova, conoce y da ejemplo.

Además de todo esto debemos considerar el liderazgo sólo como una parte del trabajo de un directivo, y en tal sentido habría que ampliar el concepto con la inclusión de la toma de decisiones, el conocimiento técnico y una larga lista de atributos necesarios para tener éxito en un puesto de dirección.

Entre todas estas características que definen el liderazgo de un puesto directivo sobresale además la comunicación. En general, la comunicación en los centros sociosanitarios o residencias cumple unos objetivos o funciones básicas. Sólo a través de ella es posible coordinar las actividades de las distintas partes de la organización y transmitir información acerca de las metas organizativas y de las tareas que han de desarrollarse.

Igualmente, es el mecanismo que permite a los trabajadores acceder a los ámbitos superiores de la empresa, haciendo llegar a la dirección sus propias aportaciones, sus quejas, y sus sugerencias acerca de los métodos de trabajo.

Así pues, la comunicación es imprescindible para el buen funcionamiento de un centro de estas características, pues posibilita las informaciones necesarias para su 


\section{CAPÍTULO V. TÉCNICAS DE MANIPULACIÓN RESEÑABLES EN EL PROCESO COERCITIVO \\ DEL MOBBING E INSTRUMENTOS DE EVALUACIÓN DE LAS VÍCTIMAS DE MOBBING.}

desarrollo y supervivencia, ayuda a la puesta en marcha de las actividades directivas de planificación, organización, motivación y control, permite la creatividad de los trabajadores y su integración en grupos de trabajo, mantiene en contacto directo a la organización con el medio exterior y ayuda a ésta a mejorar su competitividad y adaptación a los cambios del entorno.

Para un adecuado estudio de la comunicación en los centros, hay que considerarlos como un sistema abierto, en el cual coexisten un conjunto de personas, unidos por flujos de comunicación, que permiten su unidad y favorecen el cumplimiento de los objetivos propuestos.

Así pues, en este marco conceptual nos encontramos unos flujos de comunicación verticales (ascendentes y descendentes), relacionados con el intercambio de información que se establece entre los diferentes niveles de jerarquía de autoridad, y unos flujos horizontales, relacionados con la coordinación de las distintas áreas de actividad.

Ambos tipos de comunicación, vertical y horizontal, conforman la denominada "comunicación formal", la cual está prevista y diseñada de antemano por la organización para hacer llegar la comunicación allí donde sea necesario y en el momento oportuno. Con ella la organización pretende tener un canal simultáneo y eficiente para el envío y recepción de información relevante para el trabajador.

No obstante, no todos los flujos de información siguen los canales formales establecidos; también surge y se desarrolla un sistema de "comunicación informal", como resultado de las relaciones personales e interacciones cotidianas de los miembros de la empresa.

El acosador con asiduidad ve como una amenaza esta comunicación informal, ya que normalmente este tipo de comunicación da más información a los directivos. 


\section{CAPÍTULO V. TÉCNICAS DE MANIPULACIÓN RESEÑABLES EN EL PROCESO COERCITIVO \\ DEL MOBBING E INSTRUMENTOS DE EVALUACIÓN DE LAS VÍCTIMAS DE MOBBING.}

Dentro de la Comunicación Formal, podemos distinguir los siguientes tipos de expresión:

\section{1) "Comunicación vertical descendente".}

Se trata de la información a través de la cual se hace llegar la información desde la alta dirección hasta los trabajadores. Está vinculada con; política, estrategia, y objetivos de la organización y/o Departamentos, instrucciones de trabajo (importancia de las tareas, posibles variaciones...), procedimientos y prácticas organizacionales (descripción de puestos, organigrama, derechos y obligaciones de los trabajadores...) y retroalimentación del desempeño (valoración, corrección y mejora del rendimiento realizado por el trabajador).

\section{2) "Comunicación vertical ascendente".}

Se trata de la información desde la que se transmite a los órganos de dirección diversos mensajes relacionados con la marcha de las unidades organizativas inferiores, además de transmitir las posibles quejas, aclaraciones, ideas y sugerencias.

\section{3) "Comunicación horizontal".}

Es la información gracias a la cual se facilita el intercambio de información entre personas que se encuentran en el mismo nivel jerárquico, favoreciendo el desarrollo de las tareas y la resolución de problemas que pueden surgir entre los miembros de un mismo departamento o bien entre sus diferentes unidades organizativas.

Por el contrario, la Comunicación Informal, nace de las interacciones sociales que surgen entre los miembros de la organización por motivos de trabajo, por amistad o por intereses comunes. 


\section{CAPÍTULO V. TÉCNICAS DE MANIPULACIÓN RESEÑABLES EN EL PROCESO COERCITIVO}

DEL MOBBING E INSTRUMENTOS DE EVALUACIÓN DE LAS VÍCTIMAS DE MOBBING.

Se caracteriza por favorecer el desarrollo de la actividad profesional a través de contactos entre compañeros de trabajo, y sirve como válvula de escape a quejas interpersonales y conflictos.

En el Gráfico 5.1, podemos observar el denominado "Ciclo Estratégico de la Comunicación";

\section{"EL CICLO ESTRATÉGICO DE LA COMUNICACIÓN"}

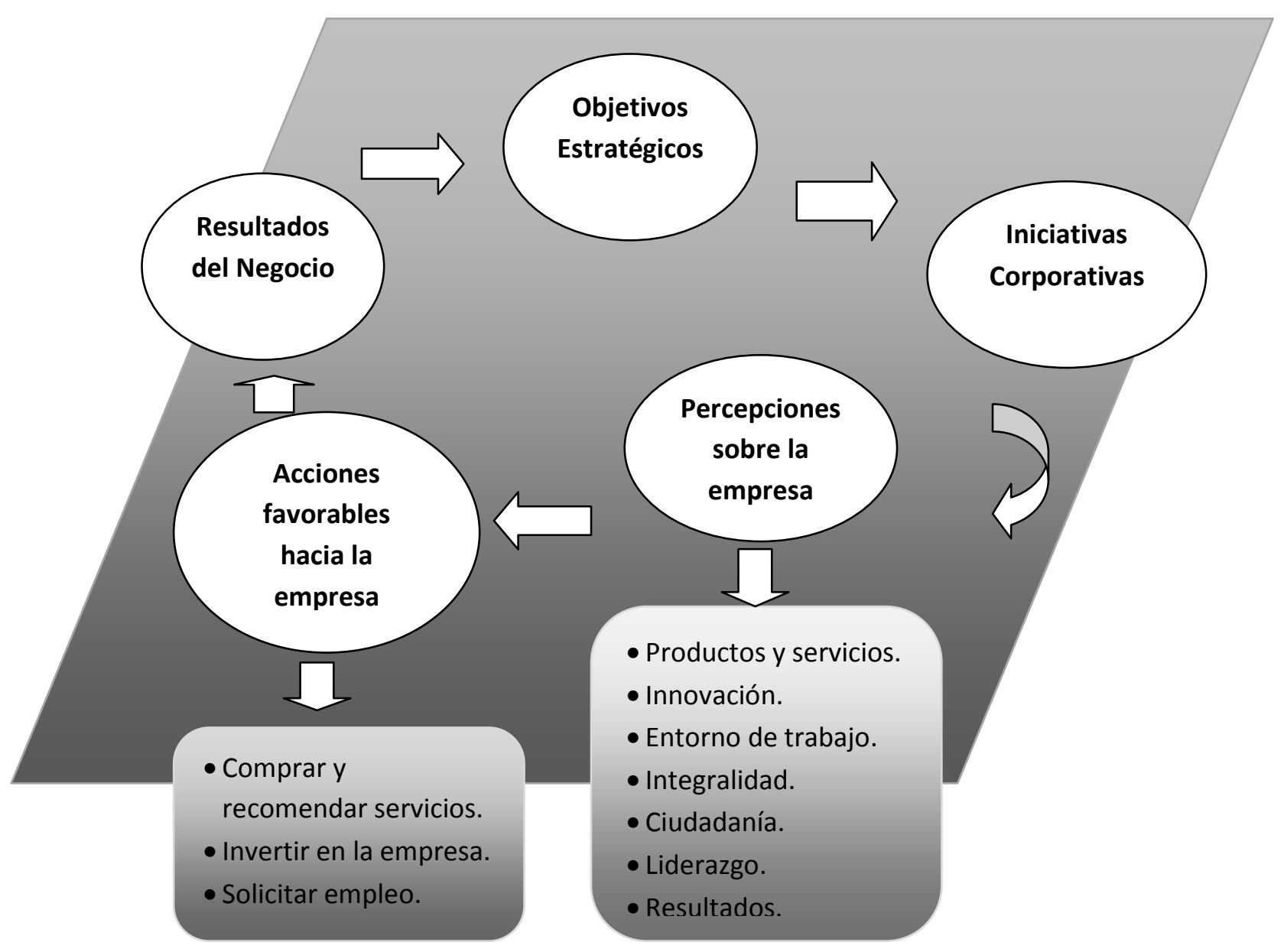

Gráfico 5.1. "El ciclo estratégico de la Comunicación". 


\section{CAPÍTULO V. TÉCNICAS DE MANIPULACIÓN RESEÑABLES EN EL PROCESO COERCITIVO}

DEL MOBBING E INSTRUMENTOS DE EVALUACIÓN DE LAS VÍCTIMAS DE MOBBING.

Así pues, para conseguir que la comunicación entre un Director General y sus subordinados sea realmente eficaz, y alcance sus objetivos, ésta debe ser:

\section{Clara.}

Los mensajes que se transmitan serán claros, comprensibles y accesibles a los diferentes grados de instrucción y madurez de las personas a quien van dirigidos.

\section{Precisa.}

Es necesario que la información transmitida sea completa y precisa, sin lagunas que hagan difícil su comprensión o creen en los destinatarios desconfianza.

\section{Objetiva y Verídica.}

La información debe ser verdadera, imparcial y esencialmente objetiva, independientemente de que se persiga con ella.

\section{Oportuna.}

El mensaje ha de llegar a los receptores en el momento en que es útil y necesario para sus funciones diarias.

\section{Interesante.}

La comunicación debe provocar en recibe el mensaje una reacción positiva, una orientación favorable al cambio de opinión, actitud o comportamiento.

\section{Difundida.}

La información debe llegar y estar disponible a todos los interesados, con el fin de mantenerlos puntualmente informados. 


\section{CAPÍTULO V. TÉCNICAS DE MANIPULACIÓN RESEÑABLES EN EL PROCESO COERCITIVO \\ DEL MOBBING E INSTRUMENTOS DE EVALUACIÓN DE LAS VÍCTIMAS DE MOBBING.}

Además de estos aspectos Pentland (2012) ha identificado en sus investigaciones tres aspectos de la comunicación que afectan en el rendimiento de un equipo.

El primero es la energía, que se mide por el número y la naturaleza de los intercambios entre los miembros del equipo. Un simple intercambio se define como un comentario y algún reconocimiento, por ejemplo, un "sí" o un gesto con la cabeza. Las conversaciones normales a menudo se componen de estos intercambios y en un entorno de equipo más de un intercambio se puede alejar en un momento.

La forma más valiosa de la comunicación es "cara a cara", la siguiente más valiosa es la comunicación por teléfono o videoconferencia, pero con una excepción: las tecnologías se convierten en menos eficaces cuando más personas participan en la llamada o conferencia. Las formas menos valiosas de comunicación son los mensajes de texto y el correo electrónico.

Si se le preguntase a muchos trabajadores de centros sociosanitarios que significan las instrucciones, ellos responden que es "decirle a la gente lo que quiere que hagan", y tal vez algunas indicaciones de cómo se quiere que lo hagan, (Klain, 2000).La lógica es que si hacemos esto, cada miembro del equipo será capaz de seguir las instrucciones y el equipo trabajara como una máquina bien aceitada. Cabe recordar que en un centro residencial o sociosanitario es de vital importancia la coordinación entre los diferentes departamentos que lo componen ya que en el proceder del día a día en el centro, unas actividades van coordinadas con otras y con los propios horarios inherentes a un centro.

Si estamos preocupados de que podrían surgir algunos elementos impredecibles, le podríamos dar al equipo algunas acciones de contingencia para realizar el trabajo bajo ciertas circunstancias. 


\section{CAPÍTULO V. TÉCNICAS DE MANIPULACIÓN RESEÑABLES EN EL PROCESO COERCITIVO \\ DEL MOBBING E INSTRUMENTOS DE EVALUACIÓN DE LAS VÍCTIMAS DE MOBBING.}

Klain, postula que los líderes capacitados permiten que sus subordinados trabajen de una manera más independiente. Cuando los empleados pueden ver lo que realmente el líder quiere obtener, no necesitan recordar todos los pasos a seguir, así pues pueden hacer sus propios ajustes sin buscar frecuentemente al líder.

Los subordinados que entienden la intención del trabajo reaccionan mejor y emplean su propio criterio, sin esperar tener un permiso. Pueden reconocer las oportunidades que no eran parte del plan original y pueden continuar en lugar de simplemente terminar el trabajo y esperar a que se les asigne la siguiente tarea. Pueden reconocer errores, inconsistencias puntuales y anticiparse a los problemas. En corto tiempo, serán capaces de improvisar en lugar de nerviosamente tratar de continuar con cada pequeña tarea.

Por el contrario, cuando un líder no tiene claridad en sus explicaciones, los empleados se confunden en por qué hacer ese tipo de tareas, y dudan sobre la lógica del plan. Estos empleados deben esperar que los guie el líder cada vez que la situación cambie o que algo inesperado suceda.

Esta es la visión que utiliza el acosador; utiliza la comunicación como medio para la práctica de su acoso hacia la víctima. La parte innata de la comunicación de un Director General es la imagen, el lugar, y los movimientos del cuerpo que emplea.

El acosador vive de su imagen, pero como medio básico para crear esa imagen usa la comunicación, el lenguaje es el medio elegido para amedrentar a sus víctimas y conseguir sus objetivos.

De entre los diferentes medios de establecer relaciones según Pentland el que más le gusta es el "cara a cara", ya que es el único que no deja rastro de lo que él está comunicando, tanto a la víctima como a sus subordinados, con el fin de aislarla a esta socialmente en su medio laboral. 


\section{CAPÍTULO V. TÉCNICAS DE MANIPULACIÓN RESEÑABLES EN EL PROCESO COERCITIVO \\ DEL MOBBING E INSTRUMENTOS DE EVALUACIÓN DE LAS VÍCTIMAS DE MOBBING.}

Y lo hace mediante las siguientes conductas referidas todas ellas al lenguaje y la expresión que a continuación se enumeran:

\section{- 1. Repetición del mensaje.}

Trata de repetir reiteradamente el mismo mensaje contra su víctima como si de un eslogan se tratara. El acosador se ha creído su propia historia, y ahora crea la historia de su "elegido". Este mensaje se lo repite a los subordinados de la víctima, a sus allegados, a sus amigos y a la propia víctima con el fin de intentar dar veracidad a algo que no la tiene.

- 2. Prohibición de hablar con otros compañeros directores del grupo.

Prohíbe taxativamente tanto a la víctima como al resto de compañeros directores de centros residenciales, intercambiar información entre ellos. Él acosador da de manera individual a cada director su versión de los hechos, haciendo creer que el único culpable de la situación es la propia víctima. Lo culpabiliza ante sus compañeros cuando el único culpable en realidad es él mismo.

\section{- 3. Prohibición de dirigirse a sus subordinados.}

No solo prohíbe a la víctima hablar con sus compañeros de dirección, sino que además relega prácticamente en su totalidad a la víctima de sus funciones. Le prohíbe dirigirse a sus trabajadores, lo cual crea un mal estar, un desasosiego en estos, ya que no comprenden que está sucediendo. Nadie les explica que está ocurriendo.

- 4. Omisión de parte de la información.

Como norma general el acosador manipula la información, así omite numerosa información de relevancia a su víctima. 


\section{CAPÍTULO V. TÉCNICAS DE MANIPULACIÓN RESEÑABLES EN EL PROCESO COERCITIVO \\ DEL MOBBING E INSTRUMENTOS DE EVALUACIÓN DE LAS VÍCTIMAS DE MOBBING.}

\section{- 5. Creación de informaciones falsas.}

No se conforma con omitir parte de la información relevante sino que además de eso se encarga de crear informaciones y documentación falsa, que en muchas ocasiones muestra al resto de directores del Grupo con el fin de convencer a estos de que todo lo que les está transmitiendo es cierto.

Esta documentación puede que en ocasiones también se la muestre a algunos subordinados, sobre todo si estos mantienen una buena relación con la víctima, con el fin de crear en ellos una imagen errónea y equívoca de su superior.

\section{- 6. Falseado de documentaciones.}

Además de crear numerosa información falsa con tal de perjudicar a su víctima, se encarga de falsear la documentación existente, sobre todo en los registros más importantes que se pueden tener un centro residencial como pueden ser los relativos a los residentes o a los relacionados con el personal. Suele acusar a la víctima de no tenerlos debidamente cubiertos o de tenerlos desactualizados

\section{- 7. Selección de una parte de la información.}

Debido a la gran cantidad de registros que maneja un director de un centro residencial el acosador selecciona partes de la información que saca de contexto como pruebas inequívocas contra su víctima. En este caso los documentos más utilizados suelen ser los correos electrónicos ya que son fácilmente manipulables.

En algunas ocasiones incluso muestra esta "parte de información" a algunos trabajadores como prueba para hacerles ver, que lo que les transmite es real, y que posee documentación que así lo acredita. 


\section{CAPÍTULO V. TÉCNICAS DE MANIPULACIÓN RESEÑABLES EN EL PROCESO COERCITIVO}

DEL MOBBING E INSTRUMENTOS DE EVALUACIÓN DE LAS VÍCTIMAS DE MOBBING.

- 8. Uso de fragmentos de conversaciones.

Es tal su afán de manipulación de la información que es capaz de fragmentar algunas de las conversaciones que ha mantenido la víctima con él con el fin de dañar su labor profesional.

\section{- 9. Trasmisión de información vaga y confusa.}

Con asiduidad este sujeto muestra o da información poco detallada y confusa acerca del funcionamiento del Grupo o de los objetivos marcados en el plan estratégico.

Con esto crea una incertidumbre en su víctima de tal manera que esta nunca está informada debidamente para poder actuar en consecuencia.

- 10. Trasmisión imprecisa de la información.

Busca medios, normalmente mandos intermedios para hacer llegar a la víctima información de relevancia. Muestra imprecisiones en la información que hace llegar de tal forma que el contenido se muestre incompleto para poder realizar el trabajo de una manera exitosa.

\section{- 11. Expresión en términos de todo o nada.}

Acusa a la víctima con expresiones tales como "el culpable de todo eres tú", o "lo firmas tú como no puede ser de otra manera", ello denota el autoritarismo que le caracteriza y que de manera tan sutil esconde tras de sí.

Para el acosador no existen "los grises", todo es "blanco o negro". Esto se debe en gran parte a que en la mayoría de los casos no posee los recursos necesarios como para poder interpretar ciertos matices, lo que le hace que radicalice sus decisiones hasta límites insospechados. 


\section{CAPÍTULO V. TÉCNICAS DE MANIPULACIÓN RESEÑABLES EN EL PROCESO COERCITIVO \\ DEL MOBBING E INSTRUMENTOS DE EVALUACIÓN DE LAS VÍCTIMAS DE MOBBING.}

\section{- 12. Interrupción reiterada en el discurso de la víctima.}

Interrumpe contantemente el discurso de su víctima. Suele llevarlo a cabo en reuniones de equipo, bien ante sus directores compañeros, bien ante sus subordinados, con el propósito de hacer ver a su víctima que su discurso y manera de pensar y proceder no es válido y que está totalmente equivocado en su forma de entender la dirección del centro. Con ello trata de menospreciar su valía.

- 13. Trasmisión de información irrelevante.

El acosador da información que para nada tiene que ver con el puesto de trabajo de la víctima a los subordinados de esta. Con ello pretende dejar en entre dicho las funciones y la labor de su superior.

Los subordinados caerán en contradicciones y malestar generalizado puesto que ya no saben a quién creer y comienzan a desconfiar de su superior, situación ideal y buscada por el Director General, escenario previo al acoso al que se verá sometido el Director del Centro Residencial.

- 14. Transmisión de abundancia de información.

Da numerosa información, en la mayoría de los casos inabarcable para el director del centro. Con ello busca que el director se vea superado. La víctima comienza a creer que no posee recursos suficientes para afrontar las diversas situaciones que se le planteen en el día a día en su puesto de trabajo.

Por tanto comienza a sentirse poco útil, y a generarse cierta ansiedad en su organismo, además su jornada laboral se ve incrementada fruto de un incremento sustancial de sus funciones y al manejo de la diversidad de situaciones en las que se ve inmerso. 


\section{CAPÍTULO V. TÉCNICAS DE MANIPULACIÓN RESEÑABLES EN EL PROCESO COERCITIVO \\ DEL MOBBING E INSTRUMENTOS DE EVALUACIÓN DE LAS VÍCTIMAS DE MOBBING.}

Comienzan además problemas fuera del trabajo a consecuencia de este, tales como malestar con los amigos, pues no dispone de tiempo ni para tomar un café, situaciones tensas con sus familiares más cercanos, ya que este presenta un alto grado de irritabilidad y falta de concentración ya que la víctima cree que está perdiendo ciertas habilidades que antes poseía para realizar sus tareas de manera exitosa.

\section{- 15. Falta de información.}

El acosador como ya hemos visto en líneas anteriores, da información irrelevante, da numerosa información pero además de esto debemos de decir que no informa correctamente ni a al director del centro ni a sus subordinados. No comunica y omite información necesaria para desempeñar eficazmente las funciones encomendadas tanto a la dirección del centro como a sus subordinados.

Con ello pretende enfrentar a los trabajadores con la dirección, ya que estos creen que esta falta de información es fruto de una mala gestión del centro por parte de su superior más inmediato, su director, sin caer en la cuenta de que este no posee más información de la que les transmite.

Ello genera numerosos enfrentamientos entre los propios trabajadores del centro, dando lugar a situaciones de malestar, ansiedad y falta de confianza, creando un clima de hostilidad en la propia residencia. Los problemas se suceden sin que nadie les dé una explicación.

El Director General estudia detenidamente cada situación y observa poco a poco como va consiguiendo su objetivo, la víctima cada vez está más cerca de abandonar su puesto de trabajo y nadie sospechara los motivos excepto él, que disfruta día a día de ver cómo se van dando el escenario perfecto. 


\section{CAPÍTULO V. TÉCNICAS DE MANIPULACIÓN RESEÑABLES EN EL PROCESO COERCITIVO \\ DEL MOBBING E INSTRUMENTOS DE EVALUACIÓN DE LAS VÍCTIMAS DE MOBBING.}

\section{- 16. Creación de contradicciones falaces en el otro.}

Pone en boca de su víctima afirmaciones que esta nunca antes pronuncio. Intenta manipular la información que el Director en ocasiones le ha trasladado, algunas incluso de índole personal con el fin de crear contradicciones en el discurso del otro. Para ello con asiduidad utiliza fragmentos de textos, de conversaciones vía email, e incluso haciendo abuso de la memoria, se refiere a diálogos que poco tienen que ver con la realidad.

Intenta que el Director caiga en contradicciones que no son tales sino solamente falsas invenciones por parte del Director General.

Con frecuencia proyecta en el otro sus cualidades psicológicas, acusándole de las mismas y haciéndole creer que él si las posee a diferencia de su víctima él cual se queda atónito ante la situación que se le plantea.

\section{- 17. Información falsa sobre objetivos empresariales.}

Posee ideas de grandiosidad, ya que lo que realmente quiere es vivir la vida que nunca ha podido llegar a vivir, y que realmente desea. Por ello es capaz de transmitir sus ideas de grandeza a sus directores. Esta información es totalmente falaz, ya que no posee ni la estructura empresarial necesaria, ni los recursos económicos, ni las estrategias laborales para que se den los resultados esperados.

Crea por tanto falsas expectativas a su víctima, y cuando estas no se llevan a cabo la acusa reiteradamente de ser la culpable de obtener unos resultados muy inferiores a los planteados inicialmente. Sistemáticamente trata de culpabilizar a la víctima, creando en ella sentimientos negativos de responsabilidad y de autovalía, con la finalidad de minar su autoestima y motivación para el puesto. 


\section{CAPÍTULO V. TÉCNICAS DE MANIPULACIÓN RESEÑABLES EN EL PROCESO COERCITIVO \\ DEL MOBBING E INSTRUMENTOS DE EVALUACIÓN DE LAS VÍCTIMAS DE MOBBING.}

\section{- 18. Sugerencia de percepciones erróneas.}

Sugiere a los subordinados de sus directores visiones y percepciones personales acerca de su superior. Habitualmente los trabajadores tienen una gran imagen tanto laboral como personal de su superior, lo cual desquicia al acosador, ya que no soporta que hablen bien de él, de sus valores, de su ética, de su rigor, y de su trabajo, lejos de la percepción que esos mismos trabajadores tienen de él.

Necesita destruir la imagen de su víctima, para lo cual se reúne periódicamente e individualmente con sus trabajadores e intenta mediante discursos mediocres, sutilmente analizados, carentes de sentido y ambiguos mediatizarles.

Como último recurso aboga por crear miedo en ellos, incluso puede llegar a amenazarles con la pérdida de empleo con tal de que estos le den la razón. Ante tal situación a los trabajadores no les queda más remedio que apoyarle o al menos parecer que se creen lo que él les trasmite y así se lo hacen creer mediante conductas de aislamiento con su director.

\section{- 19. Falseado de resultados.}

Trata de manipular y falsear los resultados obtenidos por su víctima, fruto de un trabajo eficaz y de calidad al frente del centro residencial. Para ello recurre al sistema informático y a protocolos de diversa índole que en él se encuentran, destacando los archivos de ocupación y facturación, por encima de otros.

Acusa con asiduidad a la víctima de tenerlos incorrectos, incompletos, desactualizados o de ni tan siquiera tenerlos. Pero no solo se lo transmite a la propia víctima, sino que se encarga de divulgarlo al resto de trabajadores que componen el centro. 


\section{CAPÍTULO V. TÉCNICAS DE MANIPULACIÓN RESEÑABLES EN EL PROCESO COERCITIVO \\ DEL MOBBING E INSTRUMENTOS DE EVALUACIÓN DE LAS VÍCTIMAS DE MOBBING.}

Es la excusa perfecta para asignar a la víctima tareas que estarían fuera de su radio de acción y de lo que son sus propias tareas de dirección, tales como buzonear publicidad de puerta en puerta, consiguiendo así aislarle de sus trabajadores y de la propia actividad del centro, así como de las propias familias que le visitan diariamente bien para interesarse por la residencia para futuros ingresos, bien de propios familiares que ya tienen a un familiar internado en el centro y simplemente quieren intercambiar algún tipo de información con la dirección.

La víctima sorprendida no sabe cómo actuar para complacer a su superior y suele ceder a las pretensiones de su Director General. Este le transmite constantemente su malestar.

\section{- 20. Trasmisión de información manipulada a los subordinados.}

No solo trasmite información falsa o manipulada al propio director, sino que reúne a los trabajadores para trasladarles su preocupación por la falta de rigor y las acciones que él dice estar cometiendo su víctima.

Le acusa de cometer una serie de barbaridades, de decisiones inconscientes, carentes de profesionalidad, de ética, saltándose absolutamente todas las responsabilidades como director del centro... nada más lejos de la realidad que vive el propio centro.

Con todo ello la víctima comienza a sentirse acorralada, por un lado entiende que hasta hace tan solo unos días él era capaz de resolver eficazmente las tareas que se le encomendaban e incluso le llegaban a felicitar algunos de sus superiores por el trabajo bien hecho. Por otro lado comienza a perder la confianza en sí mismo, en sus decisiones y en su proceder diario al frente del centro ya que ve como todo se le pone en contra y no encuentra el apoyo de nadie, se encuentra solo ante una situación hostil y denigratoria. 


\section{CAPÍTULO V. TÉCNICAS DE MANIPULACIÓN RESEÑABLES EN EL PROCESO COERCITIVO \\ DEL MOBBING E INSTRUMENTOS DE EVALUACIÓN DE LAS VÍCTIMAS DE MOBBING.}

\section{- 21. Apariencia de escucha activa del mensaje del otro.}

El acosador posee un encanto superficial que hace que el receptor sienta que lo que le transmite es importante para él, que tiene un valor, un sentido, una importancia relevante y que se va a tener en cuenta en decisiones futuras con el fin de mejorar la calidad asistencial del centro. Nada más lejos de la realidad. Nunca incorporara ninguna de las medidas o mejoras propuestas por ninguno de sus trabajadores y menos aún de su víctima. Suele acusar a esta de sugerir medidas absurdas e intenta negarle siempre la valía de las mejoras planteadas.

Solo toma como bueno y válido sus propios pensamientos y decisiones. Realmente no admite sugerencias ni consejos ni observaciones para futuras mejoras de nadie, ya que los considera inferiores a él y a su propia manera de proceder. Anula permanentemente cualquier tipo de procedimiento que rompa con sus esquemas de trabajo.

\section{- 22. Lenguaje cuidado.}

Parte de ese encanto superficial lo consigue gracias al lenguaje que emplea para dirigirse a los demás. Trata de parecer una persona culta, refinada, muy técnica y cultivada socialmente. Intenta mostrarse como alguien poco común y de un status social elevado. Para ello recurre fácilmente a su vestimenta, de reconocidos diseñadores y siempre impecable. Si algo le preocupa al acosador es la imagen que pueda dar a los demás y el lenguaje forma parte de ella y de su engaño.

Suele parecer un verdadero "encantador de serpientes", con una gran oratoria y discurso, capaz de hacer ver cosas donde no las hay. 


\section{CAPÍTULO V. TÉCNICAS DE MANIPULACIÓN RESEÑABLES EN EL PROCESO COERCITIVO \\ DEL MOBBING E INSTRUMENTOS DE EVALUACIÓN DE LAS VÍCTIMAS DE MOBBING.}

\section{- 23. Robo intelectual del discurso de la víctima.}

Realmente el acosador admira a su víctima, esta representa lo que él quiso ser y nunca ha llegado a poder ser. Intelectualmente es muy inferior a ella, por ello trata de hacer suyas las ideas del otro. Merma así intelectualmente a sus directores y consigue numerosos méritos gracias a ellos.

No solo trata de hacer suyas esas ideas, robándoselas sino que además es frecuente que incluso culpabilice a su presa por esa falta de ideas y de actitud que él no tiene.

Por tanto trata de aparentar un cambio de roles, de características y perfiles psicológicos, él atribuye sus cualidades a su víctima y hace suyas las de él, proyectando así sus déficits y carencias en él.

\section{- 24. Uso de lenguaje técnico.}

Como medida disuasoria de duda, acude al uso de un argot muy complejo y técnico, muy lejano al utilizado por la mayoría de trabajadores del centro. Con ello pretende hacer ver a los demás que posee un elevado conocimiento del sector y de las situaciones ante las que se puede encontrar el centro.

Este argot le va a ser de utilidad con la mayoría de los trabajadores del centro, no así con sus directores, los cuales poco a poco y con paso del tiempo denotan carencias incomprensibles de alguien que ostenta el puesto de un Director General.

Puede incluso llegar a inventarse a algunos términos para hacer referencia a situaciones que se puedan vivir en el centro, o sugerir a los empleados el uso de ellas, para transmitir de nuevo una imagen irreal del mundo en el que vive $y$ que dista bastante, de él que le gustaría llegar a vivir. Con todo ello tenemos ya un alto uso de la comunicación como mecanismo de persuasión. 


\section{CAPÍTULO V. TÉCNICAS DE MANIPULACIÓN RESEÑABLES EN EL PROCESO COERCITIVO \\ DEL MOBBING E INSTRUMENTOS DE EVALUACIÓN DE LAS VÍCTIMAS DE MOBBING.}

\section{- 25. Incoherencias lingüísticas.}

Fruto de ese abuso del lenguaje ante el cual nos encontramos, con frecuencia el acosador comete faltas de ortografía impropias de un cargo de tanta relevancia y que van a llamar la atención por su gravedad lingüística.

\section{- 26. Uso de un lenguaje corto y repetido.}

Es una de las medidas más utilizadas por el acosador; utiliza un mensaje breve, corto, como si de un eslogan se tratase el cual no duda en reiterar las veces que sea necesario hasta hacer interiorizar a su víctima y a sus propios trabajadores. Aboga por la reiteración como medida coercitiva para con los demás.

Suele acusar a su presa de hacer lo que realmente está haciendo él, manipular a los trabajadores del centro, en contra de él, con el fin de crear un clima negativo y poco apto para desarrollar diariamente una labor eficaz y eficiente en un lugar tan personal como lo es un Centro Residencial, en el cual el clima laboral es un factor determinante para el buen funcionamiento del mismo, ya que se trabaja con personas, personas en la mayoría de los casos altamente dependientes.

- 27. Discurso con alto componente emocional y afectivo.

En este lenguaje técnico, corto y repetido que utiliza destaca un componente principal por encima de los demás, el componente emocional y afectivo, que el acosador usa en sus acciones como medida de apoyo a sus estrategias.

Acude reiteradamente a él para tratar de convencer a los subordinados del mensaje que les está lanzando, a sabiendas que es un elemento esencial para convencerles. 


\section{CAPÍTULO V. TÉCNICAS DE MANIPULACIÓN RESEÑABLES EN EL PROCESO COERCITIVO \\ DEL MOBBING E INSTRUMENTOS DE EVALUACIÓN DE LAS VÍCTIMAS DE MOBBING.}

- 28. Inmediatez en el procesamiento de la información.

Si algo caracteriza al acosador es sin duda su gran capacidad para captar las necesidades del otro, tanto las fortalezas como las debilidades. Es capaz de procesar rápidamente la información que le llega, dando además una respuesta en cuestión de segundos a cualquier situación que se le plantee. Esto es un elemento clave en su identidad.

Esta habilidad va a hacer que su imagen se vea favorecida, puesta aparenta ser una persona dotada de numerosos recursos, tanto para su vida personal como para su vida profesional.

\section{- 29. Gran capacidad en el tratamiento al "otro".}

Cuida con minuciosidad el trato que da a los demás, ya que forma parte del encanto superficial que describíamos en líneas anteriores. El sujeto se presenta ante los demás con una trato inicial exquisito, más aún si la persona que tiene ante sí pertenece a un status social elevado u ocupa un cargo del cual él crea pueda salir beneficiado.

\section{- 30. Uso eficaz de los silencios.}

A lo largo de su discurso maneja hábilmente los denominados "silencios", trata de buscar respuesta en el otro con ellos, intimidarlos, dejarlos en numerosas acosasiones llevar la iniciativa, para él solapar las informaciones y dar la respuesta que más le convenga en cada situación.

Trata con ello de provocar diversidad de reacciones en el otro, estudiar la ansiedad que pueda crear con ello, e incluso el clima hostil y lejano que en algunas ocasiones utiliza sutilmente para destacar su figura en la empresa. 


\section{CAPÍTULO V. TÉCNICAS DE MANIPULACIÓN RESEÑABLES EN EL PROCESO COERCITIVO \\ DEL MOBBING E INSTRUMENTOS DE EVALUACIÓN DE LAS VÍCTIMAS DE MOBBING.}

\section{- 31. Eliminación de fuentes alternativas de comunicación.}

La comunicación como hemos venido viendo a lo largo de este capítulo es fundamental para que se lleva a cabo la manipulación en un proceso de mobbing o acoso laboral en puestos directivos de centros residenciales. El acosador trata de aislar a su víctima y para ello es necesario eliminar cualquier tipo de comunicación que este pueda establecer, bien sea con los otros compañeros directores, bien sea con subordinados, con los proveedores, o bien se dé con los residentes y familiares. Esto lo consigue prohibiendo taxativamente cualquier tipo de relación verbal que pueda tener su presa.

Para ello en la mayoría de las ocasiones rebaja de sus funciones al director, elimina tareas propias de dirección y lo relega a un segundo plano, es capaz incluso hasta de denegarle la propia firma oficial como director del centro, tareas que de ahora en adelante asume el mismo, con el afán de tomarse en protagonista y de aislar y marginar al Director.

Esto supone además un gran impacto emocional y motivacional para la víctima, lo que conlleva una negatividad y una sensación de "no servir para nada" dentro de la propia empresa, lo cual le hace pensar en poder abandonar su puesto de trabajo. Justo lo que desea su Director General.

\section{- 32. Elevado tono de voz.}

Como último recurso, y solo en caso de que su "encanto aparente" no de sus frutos eleva el tono de voz en su dialéctica con el fin de intentar dar relevancia al mensaje que lanza y atemorizar así al receptor del mensaje. Esto suele llevarlo a cabo de una manera metódica y normalmente sin presencia de público objetivo que pueda desenmascararle en algunas de estas acciones. 


\section{CAPÍTULO V. TÉCNICAS DE MANIPULACIÓN RESEÑABLES EN EL PROCESO COERCITIVO}

DEL MOBBING E INSTRUMENTOS DE EVALUACIÓN DE LAS VÍCTIMAS DE MOBBING.

\section{- 33. Uso de metáforas.}

A menudo en sus discursos utiliza similes, metáforas y frases célebres de los autores más relevantes de la historia, con el fin de transmitir a los demás su aparente cultura.

\section{- 34. Inmadurez afectiva en su lenguaje.}

De su lenguaje se desprende una gran inmadurez afectiva. Como hemos mencionado en el capítulo anterior son personas que "conocen la letra pero no la música", es decir aparentan conocer situaciones, pero realmente son incapaces de vivenciarlas como una persona "normal".

El acosador idealiza cada situación e imagina los rasgos característicos que a su entender se pueden llegar a dar en ella y así la interpretan sin caer en la cuenta de que hay numerosos matices que denotan y caracterizan cada acto.

\section{- 35. Gran orador.}

Por último y como culmen a esta serie de características básicas en la comunicación del sujeto, resaltar como ya hemos venido haciendo su gran capacidad de oratoria, de convencer al otro, de invertir las situaciones hacia lo que más le convenga en ese momento.

Es un orador nato, tiene grandes dotes para el lenguaje, para expresar, para comunicar, para llegar de manera clara y directa al receptor, de transmitir exactamente el mensaje que quiere, de influir en el otro de manera constante y determinante y en definitiva de alcanzar sus logros mediante la comunicación con el otro, lo cual lo convierte en una gran amenaza para sus víctimas. 


\section{CAPÍTULO V. TÉCNICAS DE MANIPULACIÓN RESEÑABLES EN EL PROCESO COERCITIVO \\ DEL MOBBING E INSTRUMENTOS DE EVALUACIÓN DE LAS VÍCTIMAS DE MOBBING.}

Una vez repasado en profundidad la importancia de la comunicación, estudiaremos la violencia psicológica en las organizaciones, la diversidad de situaciones posibles y los tipos de acoso que se pueden dar.

\subsubsection{Violencia Psicológica en las Organizaciones.}

El diseño de la organización formal, los procesos que la regulan, las normas, las prácticas de recursos humanos, y la cultura interna tienen un considerable impacto en la productividad, satisfacción y salud de los empleados.

Entre los factores que pueden provocar estos efectos podemos señalar la comunicación, el estilo de dirección, la participación en la toma de decisiones y otros elementos organizativos tales como la promoción interna, la formación o la estabilidad en el empleo.

Como hemos visto a lo largo de este capítulo la comunicación es esencial para el funcionamiento eficaz de cualquier grupo u organización siendo esta de la índole que fuere. Cumple básicamente cuatro grandes objetivos, además de los que ya hemos visto; control, motivación, expresión emocional e información.

Los problemas habituales de la comunicación, las distorsiones, las ambigüedades o las incongruencias, son "el caldo de cultivo" para los conflictos interpersonales, la insatisfacción del empleado y la reducción de su bienestar. Por lo que una revisión y mejora de los canales de comunicación (horizontales y verticales), fomentar habilidades como saber escuchar y dar retroalimentación son elementos que favorecen una comunicación eficaz (Robbins, 2004).

El estilo de dirección cumple una función central para comprender el funcionamiento de un grupo, puesto que implica la elección de unos métodos y prácticas de supervisión para conseguir los objetivos empresariales. 


\section{CAPÍTULO V. TÉCNICAS DE MANIPULACIÓN RESEÑABLES EN EL PROCESO COERCITIVO \\ DEL MOBBING E INSTRUMENTOS DE EVALUACIÓN DE LAS VÍCTIMAS DE MOBBING.}

El ejercicio de determinados estilos de dirección está en la base de numerosos problemas de relación en el trabajo.

Misumi (1985) y Bass (1992) mostraron que los líderes basados exclusivamente en la producción provocaban mayores síntomas de estrés, ansiedad y hostilidad. Por el contrario los líderes carismáticos contribuían a reducir en nivel de estrés de los subordinados (Cooper y Smith, 2001).

La participación en la toma de decisiones contribuye a la formación y al crecimiento personal de quienes lo hacen, puesto que suele fomentar el aprendizaje de técnicas de resolución de problemas, el análisis de la situación, la búsqueda de alternativas, el trabajo en equipo y la mejora de la comunicación. La falta de participación, en la medida en que el empleado percibe una falta de control sobre sus propias condiciones laborales provoca afecciones de naturaleza psicosomática (Cuenca, 1996).

Por tanto podemos decir que la violencia laboral implica todas aquellas acciones que, durante un tiempo prolongado, afectan a la dignidad del trabajador, su derecho a no ser discriminado, el respeto de su honra y su integridad física, psíquica y moral. En casos extremos como el que nos ocupa pueden desencadenarse daños psicológicos graves, pérdida de empleo y suicidios.

En cualquier caso parece evidente que tanto la empresa como la sociedad pierden a una persona capacitada para desempeñar su puesto de trabajo. La violencia psicológica en las organizaciones se manifiesta en ataques permanentes contra la persona, persecuciones tendientes a provocar aislamiento, pérdida de autoestima, descalificación, desmerecimiento, violación de la intimidad, difamación, supresión de derechos, intimidación, falsa denuncia, afectación a tareas irrelevantes, quita de personal, utilización de influencias e indiferencia a sus peticiones y/o reclamos. 


\section{CAPÍTULO V. TÉCNICAS DE MANIPULACIÓN RESEÑABLES EN EL PROCESO COERCITIVO DEL MOBBING E INSTRUMENTOS DE EVALUACIÓN DE LAS VÍCTIMAS DE MOBBING.}

A sí pues, cuando hablamos de acoso en las organizaciones nos estamos refiriendo a acciones persistentes y reiteradas realizadas con el fin de incomodar con palabras o gestos, al trabajador.

El psicólogo alemán Heinz Leyman, resalto que el acosador "le asigna a la víctima tareas inútiles, absurdas, peligrosas y humillantes; no le permite comunicarse; le interrumpe continuamente cuando habla; le critica su trabajo; se burla de su vida privada; le niega el contacto mediantes gestos de rechazo o menosprecio; ignora su presencia; la aísla de sus compañeros; le grita, la amenaza, la injuria; le atribuye una enfermedad mental".

Hablamos de maltrato psicológico, psíquico y social, porque se manifiesta como una hostilidad continua y repetida en forma de hostigamiento psicológico, desprecio y crítica. Como ejemplo podemos tomar algunas de las siguientes conductas:

-Cambio de funciones y horarios.

-Sobrecarga de trabajo.

-Demanda de una tarea para la que no se está capacitado.

-Indicaciones contradictorias y ambiguas.

-Sanciones injustificadas, como expedientes o negación de permisos.

-Bloqueo constante de iniciativas de interacción generando aislamiento en el trabajador.

-Prohibición de comunicación.

-Reprobar constantemente las tareas realizadas.

-Juzgar de manera ofensiva el desempeño de su labor.

-Amenazas infundadas de despido inmediato.

-Obligar a realizar tareas impropias del cargo que ocupa. 


\section{CAPÍTULO V. TÉCNICAS DE MANIPULACIÓN RESEÑABLES EN EL PROCESO COERCITIVO \\ DEL MOBBING E INSTRUMENTOS DE EVALUACIÓN DE LAS VÍCTIMAS DE MOBBING.}

Una vez hemos visto la importancia de la comunicación en el acoso y la violencia psicológica en las organizaciones hablaremos de la diversidad de situaciones posibles de acoso y los diferentes tipos de acoso que se pueden dar.

\subsubsection{Diversidad de situaciones posibles y tipos de acoso.}

En España, durante la década de los noventa se produjeron una serie de modificaciones de la legislación laboral y de protección social.

En el ámbito de la contratación, aparece un sinfín de modalidades de contratos que hasta no hacía mucho no existían: a tiempo parcial, por obra o servicios, por acumulación de tareas, por sustitución, etc.

Las subvenciones a las empresas para la contratación y para las prejubilaciones aumentan en cantidad y en modalidad, según dicen con el objetivo de ayudar a las empresas a que flexibilicen sus plantillas y se hagan más competitivas. El recurso a las subcontratas aumentan por parte de las empresas mayores.

Se comienza a legislar sobre la movilidad funcional y geográfica con una finalidad y se aplica con otra, generando una total inseguridad y ausencia de perspectivas de futuro.

Se empieza a hablar con insistencia de competitividad, de productividad y de calidad, muchas veces incluso fuera de contexto. Frecuentemente estos términos son utilizados realmente para reducir salarios, para realizar despidos de los más antiguos, o para romper la estructura del salario buscando un mayor poder coactivo, etc.

La jornada y el horario laboral se ven alterados, fraccionados en formas diversas, en muchas ocasiones aumentando, desaparece la nítida separación entre tiempo de 


\section{CAPÍTULO V. TÉCNICAS DE MANIPULACIÓN RESEÑABLES EN EL PROCESO COERCITIVO \\ DEL MOBBING E INSTRUMENTOS DE EVALUACIÓN DE LAS VÍCTIMAS DE MOBBING.}

trabajo y tiempo libre o de ocio. Los directivos comienzan a cobrar "por objetivos", en la mayoría de los casos inalcanzables.

Con todo ello las nuevas reglas del juego son que sólo se puede mejorar o prosperar a costa de otro. Todo vale, convirtiéndose la competitividad depredadora en el hacer cotidiano y desapareciendo lo que se llamaba compañerismo o solidaridad entre compañeros de trabajo.

Nos vemos así ante una sociedad desesperanzada, insegura, que sólo le cabe vivir la inmediatez, poniéndose de moda la filosofía de disfrutar del momento, sin cuestionarse el futuro, ya que el futuro es incierto.

A pesar de esto, las sociedades democráticas modernas aspiran a la inserción laboral de todos sus ciudadanos.

Así pues podemos afirmar que para que el acoso moral se produzca en una organización, ha de darse un requisito básico: la existencia de un poder asimétrico entre agresor y agredido. El mismo no tendrá por qué ser necesariamente jerárquico, pero irá siempre precedido de una dominación psicológica de una de las partes y una sumisión forzada de la otra (Hirigoyen, 2001).

El Instituto Nacional de Seguridad e Higiene en el Trabajo asume plenamente esta perspectiva cuando plantea la siguiente definición: "ejercicio de violencia psicológica extrema que se realiza por una o más personas sobre otra en el ámbito laboral, respeto de la que existe una relación asimétrica de poder".

El acoso moral en las organizaciones puede darse de dos formas principales: vertical y horizontal. Según el sentido, divide también la primera en ascendente o descendente, y contempla así mismo la posibilidad de una combinación de aquellas.

El tipo más frecuente sería, de acuerdo con la práctica totalidad de los autores, el hostigamiento de arriba abajo. 


\section{CAPÍTULO V. TÉCNICAS DE MANIPULACIÓN RESEÑABLES EN EL PROCESO COERCITIVO DEL MOBBING E INSTRUMENTOS DE EVALUACIÓN DE LAS VÍCTIMAS DE MOBBING.}

Se produciría entre el $65 \%$ y el $75 \%$ de los casos, y se ejercería por los mandos jerárquicos, que aprovecharían su posición de autoridad para hacer uso de esta clase de procedimientos. En este ratio se encuentra este estudio de investigación. Estaríamos ante el acoso laboral de un Director General a uno de los Directores que se encuentran dirigiendo uno de los centros del Grupo.

A continuación se situarían las presiones provenientes de los propios compañeros, en conjunción o no con los niveles superiores de la organización (entre el 20 y el 30\% de las veces) y finalmente las agresiones de abajo arriba (entre el 1 y el $9 \%$ de las ocasiones).

Así pues en las siguientes líneas describiremos los diferentes tipos de acoso; el acoso vertical descendente o "bossing", el acoso horizontal o de "iguales", el acoso mixto, el acoso vertical descendente y otros tipos de acoso que se puedan dar.

\subsubsection{Acoso vertical descendente o "bossing".}

Hablamos de acoso vertical descendente o "bossing" para referirnos al acoso moral en el trabajo perpetrado por un empresario o directivo, o por otros altos cargos de la empresa que actúan bajo su supervisión.

En el caso que nos ocupa estaríamos ante una situación de un Grupo empresarial, encargado de dirigir y gestionar centros residenciales, en el que el Director General del Grupo acosa a uno de sus directores de centro, con el fin de que este abandone su puesto de trabajo.

Así pues, la acción se desarrolla exclusivamente en una dirección, vertical, y en un único sentido, descendente. El superior explota las ventajas de una relación desigual y asimétrica y el entorno colabora desempeñando habitualmente un papel relevante. 


\section{CAPÍTULO V. TÉCNICAS DE MANIPULACIÓN RESEÑABLES EN EL PROCESO COERCITIVO \\ DEL MOBBING E INSTRUMENTOS DE EVALUACIÓN DE LAS VÍCTIMAS DE MOBBING.}

Por tanto por "bossing" entendemos un comportamiento que no sucede entre iguales, sino que la víctima tiene una categoría o jerarquía inferior a la del acosador en el organigrama empresarial, o bien en la práctica se sitúa debajo de él.

Mediante un uso desmesurado de poder y con maniobras perversas, el superior consigue fragmentar, y romper, la red de relaciones del empleado en cuestión, reducir al mínimo su influencia social, aislarlo de su entorno laboral (compañeros, otros jefes, departamento de recursos humanos...), y en ocasiones, eliminarlo físicamente de éste, obligándolo al abandono temporal de su puesto de trabajo, a través de un cambio de departamento o una baja laboral, o al abandono definitivo con su salida de la empresa, por iniciativa de esta a través del despido o, por el cese y renuncia "voluntaria" de la persona hostigada.

Hirigoyen (2001) habla de tres subgrupos dentro de esta modalidad de acoso: perverso, institucional y estratégico.

\section{1) Perverso.}

Estaríamos ante un acoso perverso, cuando lo que se pretende es básicamente la destrucción de otra persona o la valorización del propio poder. Es uno de los tipos de acoso más crueles que se pueden dar.

Hirigoyen relaciona el calificativo "perverso" con "una manera sinuosa de comunicarse para manipular al otro con el fin de obtener algo de él sin que lo sepa".

Si bien, afirma, todo el mundo puede comportarse perversamente en determinados contextos o con algunas personas, lo verdaderamente determinante es cuando el concepto se asocia al modo continuo de obrar del acosador. 


\section{CAPÍTULO V. TÉCNICAS DE MANIPULACIÓN RESEÑABLES EN EL PROCESO COERCITIVO}

DEL MOBBING E INSTRUMENTOS DE EVALUACIÓN DE LAS VÍCTIMAS DE MOBBING.

\section{2) Institucional.}

El acoso "institucional" se produciría cuando una persona se convierte en "objeto de agresión por los miembros del propio grupo social", en ocasiones como consecuencia de la aplicación de técnicas de gestión por estrés.

Cumpliría unas funciones muy determinadas "de (discutible y perversa) utilidad social, tales como mantener el grupo unido y homogéneo, preservar la identidad colectiva, garantizar el control y la permanencia del subgrupo dominante, e inculcar en los futuros líderes los valores y criterios jerárquicos propios de la institución "(González de Rivera, 2002), y operaría como una advertencia o amenaza para los demás empleados, a quienes de querría impresionar o escarmentar.

\section{3) Estratégico}

El acoso "estratégico", por último, haría referencia al maltrato psicológico tendende a "invitar" o conminar a un asalariado a renunciar a su puesto de trabajo y dejar voluntariamente la empresa, con el fin de evitar el desembolso económico al que obliga la ley en casos de despido improcedente.

Aislamiento o negación de toda información, pérdida progresiva de los derechos adquiridos o reconocidos legalmente, empleo del rumor malintencionado, son algunos de los procedimientos utilizados para acabar con la resistencia vital del acosado y conseguir que éste acceda a pactar una rescisión de contrato en condiciones muy ventajosas para el empresario (Nazare-Aga, 2002).

Por tanto podemos afirmar que el acoso vertical descendente suele tener consecuencias más graves para la víctima que los otros tipos de hostigamiento. 


\section{CAPÍTULO V. TÉCNICAS DE MANIPULACIÓN RESEÑABLES EN EL PROCESO COERCITIVO \\ DEL MOBBING E INSTRUMENTOS DE EVALUACIÓN DE LAS VÍCTIMAS DE MOBBING.}

Seguidamente desmenuzaremos en qué consiste el acoso horizontal o "de iguales".

\subsubsection{Acoso horizontal o "de iguales".}

Es el acoso que acontece entre posiciones jerárquicas iguales o similares, desde el punto de vista del organigrama empresarial.

El ataque puede producirse por problemas puramente personales, o bien porque alguno de los miembros del grupo sencillamente no acepta las pautas de funcionamiento tácitamente o expresamente aceptadas por el resto.

Otra circunstancia que da lugar a este comportamiento es la existencia de personas físicas o psíquicamente débiles o distintas, y estas diferencias son explotadas por los demás simplemente para pasar el rato o mitigar el aburrimiento, siendo también frecuente cuando dos asalariados rivalizan por un puesto (Hirigoyen, 2001; Rodríguez López, 2004).

Por consiguiente, se produce entre compañeros de la misma escala laboral o nivel jerárquico, si bien es frecuente que uno de ellos ocupe en la práctica un puesto superior, tenga más mando de hecho. (Leymann, 1996).

Para Leymann (1996), las causas de este tipo de acoso se resumen fundamentalmente en:

a) Un grupo de trabajadores intenta forzar a otro reticente a conformarse a las normas implícitas fijadas por la mayoría.

b) Enemistad personal.

c) Un grupo de trabajadores la toma con un compañero debido a la mera falta de trabajo o aburrimiento. 


\section{CAPÍTULO V. TÉCNICAS DE MANIPULACIÓN RESEÑABLES EN EL PROCESO COERCITIVO \\ DEL MOBBING E INSTRUMENTOS DE EVALUACIÓN DE LAS VÍCTIMAS DE MOBBING.}

d) El acoso se desencadena por la discriminación hacia la víctima por alguna diferencia.

Algunos expertos han identificado diversas situaciones como potenciadores causantes de este tipo de agresión:

a- Existencia de enemistades personales o mala voluntad. (Hirigoyen, 1999).

b- Asalariados rivalizan para la obtención de un puesto o un ascenso (Ibid, 2001).

c- Se pretende eliminar a un posible competidor que pueda resultar molesto o que no participe de comportamientos antiéticos (Piñuel, en López Cabarcos y Vázquez Rodríguez, 2003).

d- Envidia de algo que el otro tiene, cualidades destacadas, bienes materiales, encanto, belleza... (Mena Usúa, 2000).

e- No se soportan o no se admiten las diferencias del otro, aspecto físico o psíquico, raza, nacionalidad, religión, procedencia social, sexo, etc... (Ibid, 2001).

f- Un miembro del grupo no acata las normas de funcionamiento del mismo, aceptadas por la mayoría expresa o tácitamente (López Cabarcos y Vázquez Rodríguez, 2003)

g- Se produce una discusión sin importancia entre compañeros, a la que le siguen pulas, indirectas y críticas delante del jefe (Ausfelder, 2002).

Algo que parece que caracteriza a este tipo de acoso es que no duraría mucho tiempo como tal, sino que lo normal es que se transforme en uno de carácter vertical descendente en algún momento del proceso. Esto sucedería, sobre todo, cuando "la jerarquía no hace nada y deja hacer", es decir cuando actúa como cómplice, en cuyo caso nos encontramos con un acoso mixto (Hirigoyen, 2001).

Una vez analizado en qué consiste el acoso vertical descendente o "Bossing" y el acoso horizontal o "de iguales" veremos a continuación en qué consiste el denominado acoso mixto. 


\section{CAPÍTULO V. TÉCNICAS DE MANIPULACIÓN RESEÑABLES EN EL PROCESO COERCITIVO \\ DEL MOBBING E INSTRUMENTOS DE EVALUACIÓN DE LAS VÍCTIMAS DE MOBBING.}

\subsection{Acoso Mixto.}

Hablaríamos de acoso mixto para referirnos a un combinado de los dos tipos de acoso anteriormente descritos, ya que con frecuencia y en numerosas ocasiones, uno suele dar lugar a otro.

Por tanto podemos decir que es inusual que el acoso horizontal persista como tal, de modo que es habitual que en algún momento se convierta en vertical descendente porque la jerarquía no hace nada al respecto o deja hacer que continúe la situación de acoso (escudero y Poyatos, 2004: Soria y Garrido, 2005).

\subsubsection{Acoso Vertical ascendente.}

Por acoso vertical ascendente se entiende la agresión de uno o más subordinados a un superior jerárquico. Existe un consenso en señalar que se trata del tipo de acoso menos frecuente, por lo que podríamos decir que representa entre un 1 y un $9 \%$ de los casos de acoso psicológico.

La rareza de esta clase de hostigamiento haría que se tenga menos en cuenta que las otras modalidades, pero todo indica que puede resultar igual de violenta $y$ destructiva (Hirigoyen, 2001).

Generalmente se produce cuando se incorpora a la empresa una persona del exterior con un rango jerárquico superior y sus métodos no son aceptados por los trabajadores que se encuentran bajo su dirección, o porque ese puesto es ansiado por alguno de ellos (Escudero y Poyatos, 2004; Rodríguez-López, 2004).

La reacción grupal contra un superior ocurriría con especial frecuencia en el caso de fusión o compra de un conglomerado empresarial por otro; "a nivel de dirección hay un acuerdo para entremezclar el personal directivo procedente de distintas 


\section{CAPÍTULO V. TÉCNICAS DE MANIPULACIÓN RESEÑABLES EN EL PROCESO COERCITIVO DEL MOBBING E INSTRUMENTOS DE EVALUACIÓN DE LAS VÍCTIMAS DE MOBBING.}

empresas, y la repartición se hace únicamente en base a criterios políticos o estratégicos, sin tener en cuenta la opinión de los asalariados" (Hirigoyen, 2001).

Esta es hoy en día una de las fórmulas más utilizadas en las empresas españolas, puesto que la actual situación económica del país hace que numerosos holdings y conglomerados de grandes multinacionales y bancos se fusionen con el fin de intentar salvar o reflotar la organización, y ahorrarse duplicidades salariales con el fin de ahorrar en costes financieros y salarios.

Esto toma especial relevancia en el tema que tratamos ya que los directivos ante estas situaciones tienden a solaparse y son cargos habitualmente altamente remunerados económicamente y especialmente deseados para muchos empleados, que son capaces de casi todo por obtener un alto status social y económico dentro de la organización.

Cabe reseñar que cuando hablamos de puestos directivos en la mayoría de los casos hablamos de "puestos de confianza", los centros residenciales no son una excepción.

Por tanto, los directivos de los centros residenciales, suelen ser personas muy cercanas a la Dirección General del Grupo en los cuales se tienen depositadas numerosas esperanzas de éxito en la gestión y sobre los cuales se tienen altas expectativas en la consecución de los objetivos planteados.

Para Hirigoyen (1999) otra situación generadora de este tipo de ataques sería que un empleado de la plantilla de la empresa sea ascendido o promocionado y, entre sus nuevas responsabilidades se encuentra la de dar órdenes a sus antiguos compañeros.

Estos son los tipos de acoso laboral más frecuentes en la actualidad, no obstante existen otros tipos de acoso que a continuación analizaremos. 


\section{CAPÍTULO V. TÉCNICAS DE MANIPULACIÓN RESEÑABLES EN EL PROCESO COERCITIVO \\ DEL MOBBING E INSTRUMENTOS DE EVALUACIÓN DE LAS VÍCTIMAS DE MOBBING.}

\subsubsection{Otros tipos de acoso.}

Además de los tipos de acoso, existen otros tipos de acoso, el más emergente en la actualidad es el denominado acoso o mobbing maternal.

El mobbing maternal ${ }^{13}$ es al acoso que sufre la mujer por el hecho de ser madre, en su entorno laboral.

Comienza por el enfriamiento de las relaciones, con ruptura de la comunicación, realizando la misma, única y exclusivamente a los temas imprescindibles y con una hipotética modificación de las condiciones laborales dentro del puesto que desempeñe la mujer.

Además, en el supuesto del mobbing maternal, existe en la mayoría de los casos, una presión psicológica ejercida por la empresa que se fundamenta en la inestabilidad laboral de las mujeres que contrata, negando siempre contratos indefinidos e impidiendo la estabilidad necesaria que necesita cualquier persona para desarrollar con plenitud su profesión.

El perfil ${ }^{14}$ de la mujer que sufre este tipo de acoso, es embarazada o con un menor inferior al año, tiene entre 25 y 35 años, con cualificación media, media-baja, la mayoría es española.

La regularización y la crisis económica están haciendo crecer ostensiblemente la mujer afectada por mobbing maternal laboral con origen inmigrante, iberoamericano y de países del este de Europa.

El $90 \%$ de los casos de mobbing maternal laboral nunca llega a juicio motivado por el abandono anticipado del mercado laboral de la mujer trabajadora y la temporalidad

\footnotetext{
${ }^{13}$ Boletín del Ministerio de Justicia, "Estudio Doctrinal", "Diversos Tipos de Mobbing y conceptos relacionados". Autora: Carmen Soto Suárez.

2Datos de la "Fundación Madrina", entidad independiente de carácter "benéfico asistencial".
} 


\section{CAPÍTULO V. TÉCNICAS DE MANIPULACIÓN RESEÑABLES EN EL PROCESO COERCITIVO DEL MOBBING E INSTRUMENTOS DE EVALUACIÓN DE LAS VÍCTIMAS DE MOBBING.}

de los contratos, en un $80 \%$. La mujer suele estar contratada temporalmente en Pymes.

Últimamente, se percibe un crecimiento de los casos de despido y readmisión por improcedencia reiterada de hasta tres veces, generando un proceso de acoso hasta conseguir la baja voluntaria. En esta "mala praxis laboral" se observa la ampliación del círculo de presión hacia la pareja si trabaja en la misma empresa. Madrid, Cataluña y Andalucía, centran las Comunidades de este tipo de acoso, con más del $60 \%$ de los casos.

Además de este tipo de acoso podemos destacar también el "gang mobbing" si el acoso es contra un grupo definido de trabajadores (Field, 2000) ,el "acoso laboral aleatorio" caracterizado porque el acosador elige periódicamente una víctima con la que abusar durante algún tiempo hasta lograr su control, para después pasar a otra (Piñuel, 2001) , el "acoso por razón de género", siendo este una manera discriminatoria de acoso hacia la mujer (Rivas, 2005), y el "acoso discriminatorio", dirigido hacia un trabajador por motivos religiosos (Velázquez, 2005).

En definitiva podemos decir que el acoso psicológico en el lugar de trabajo es una realidad sociolaboral, que puede sufrir cualquier persona, independientemente de que sea mujer u hombre e independientemente del puesto que ocupe, la labor que realice o la empresa en la que se encuentre.

Heinz Leymann en su obra "Mobbing, la persecution au travail" postula que:

"Todo acoso se puede abortar y todo aquél que pudiendo hacerlo no hace nada, es culpable". 


\section{CAPÍTULO V. TÉCNICAS DE MANIPULACIÓN RESEÑABLES EN EL PROCESO COERCITIVO \\ DEL MOBBING E INSTRUMENTOS DE EVALUACIÓN DE LAS VÍCTIMAS DE MOBBING.}

\subsubsection{El Aislamiento y la Soledad del Directivo acosado.}

La percepción general que se tiene de los directivos impide a veces reconocer que se trata de seres humanos, regidos por emociones y susceptibles de sentir angustias y temores; esto además, se verá agudizado en el caso de que un directivo sufra acoso laboral. Debemos de recordar que un alto mando de una empresa debe de mostrar seguridad, firmeza y solidez en su toma de decisiones, algo muy complicado de hacer cuando un directivo está siendo sometido por otro a un hostigamiento constante, y sistemático.

En la ardua labor de gestionar equipos en centros residenciales, los líderes pueden sentirse acompañados de otras personas, que los buscan, les obedecen, le sugieren ideas e incluso les adulan, pero no así cuando denotan incertidumbre en torno a la continuidad de ese líder en el centro.

Es muy común en los casos de mobbing, en el ámbito empresarial, el llamado "doble juego del alto directivo"; el acosador delega en el acosado la toma de decisiones pero no le confiere la autonomía para tomarlas, sino que se las impone, haciéndolas pasar como si vinieran de ellos. De ese modo, el manipulador evade las eventuales responsabilidades que pudieran surgir y así puede culpar a otros de las posibles consecuencias negativas.

Ante todo ello, el directivo acosado se sentirá solo, vivirá en soledad, no solo las decisiones referentes a su propio cargo, sino el propio acoso que está sufriendo. Se encuentra ante una soledad que discurre entre la muchedumbre que le rodea, trabajadores, compañeros de otros centros, familia, amigos, colaboradores... La aparente calidez de la presencia de otros y la supuesta compañía que proporcionan no son suficientes para hacer frente a la soledad que le invade. 


\section{CAPÍTULO V. TÉCNICAS DE MANIPULACIÓN RESEÑABLES EN EL PROCESO COERCITIVO}

DEL MOBBING E INSTRUMENTOS DE EVALUACIÓN DE LAS VÍCTIMAS DE MOBBING.

Su vida social transcurrirá entre aparentes diálogos, que en realidad no son sino monólogos de uno consigo mismo, intentando darse para sí, una explicación capaz de hacer cobrar de nuevo sentido a su propia vida y a su propio puesto de trabajo. La necesidad de compartir su mundo interior crece cuando crecen sus responsabilidades, y en este caso se encuentra inmerso en un gran dilema interno sin salida.

Su gestión ordinaria en la toma de decisiones, puede verse reflejada en el gráfico 5.2, que se ilustra a continuación;

DIRECCIÓN VS TOMA DE DECISIONES ${ }^{15}$

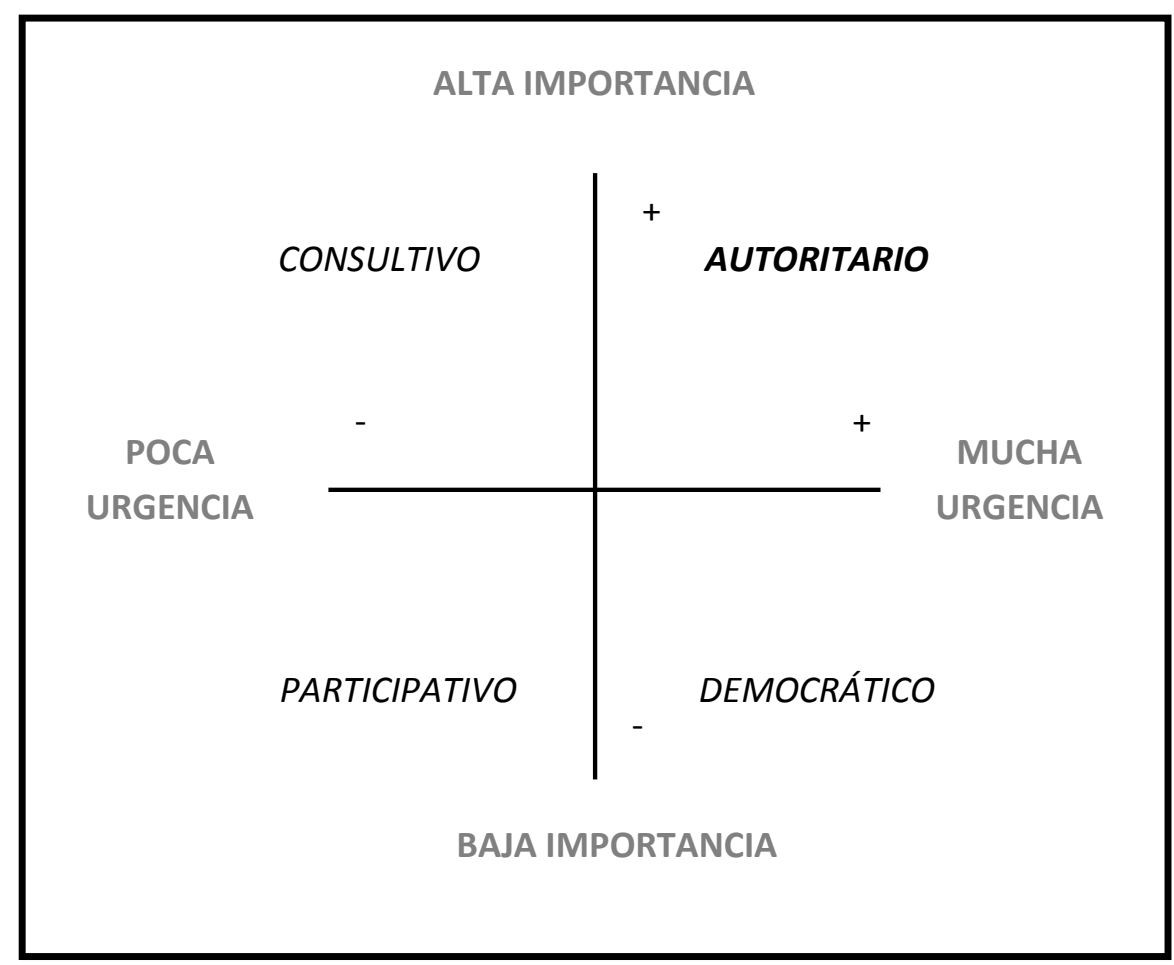

Gráfico 5.2. "Dirección vs Toma de Decisiones".

\footnotetext{
${ }^{15}$ Paradójicamente, en las relaciones comerciales y en los negocios, como puede considerase un centro residencial, la racionalidad y los cálculos suelen quedarse cortos para llevar a cabo una gestión integral de la dirección. Por ello ningún directivo, debe desconocer que la propia gestión de personas lleva inmersa una gran dimensión emocional; las personas tienen creencias, aspiraciones, temores, arrebatos y todo tipo de sentimientos que han de ser gestionados.
} 


\section{CAPÍTULO V. TÉCNICAS DE MANIPULACIÓN RESEÑABLES EN EL PROCESO COERCITIVO \\ DEL MOBBING E INSTRUMENTOS DE EVALUACIÓN DE LAS VÍCTIMAS DE MOBBING.}

En su necesidad de mostrarse fuerte, el directivo acosado experimenta enormes dificultades para buscar apoyo en los demás, para comunicarse con otros y para expresar su propia angustia, ante la situación vivenciada. Renuncia así, a los llamados "refugios afectivos" a los que el resto de personas acudimos en los momentos en que los necesitamos. El apoyo emocional suele verse reprimido por cuanto se le percibe por el acosado como un símbolo de debilidad. No obstante el ejecutivo acosador utiliza esta soledad a sabiendas para exigir aún más si cabe a alguien a quien confiaron su empresa, y su gestión, ahondando aún más en el acoso y debilitando así la fortaleza y seguridad restante del acosado para el desempeño de su trabajo. En cierta manera, esta exigencia le implicara desconocer su faceta humana, recrudeciendo el peso de su soledad.

Se debe poner en relieve, la necesidad que tiene el ejecutivo acosador de ser adulado, de recibir afecto y admiración de quienes le rodean aún siendo está en la mayoría de los casos superficial e hipócrita. Les gusta así rodearse solamente de aquellos que continuamente lo adulan, lo engrandecen y lo toman como modelo de referencia continuamente. Esto no hace más que mediocrizar la organización que dirigen, careciendo de innovación y profesionalización entre otras cualidades que se le han de exigir a un centro residencial.

Así, hemos de afirmar que quienes son sometidos a un acoso laboral, en un centro residencial, se enfrentan a una serie de circunstancias particulares que acentúan la soledad del directivo, y que le acercan a la angustia y a la tristeza, pues de una parte, los directivos no pueden delegar su responsabilidad, por más que si puedan delegar algunas tareas; esto significa que, en una gran parte de sus funciones, son solo ellos quienes pueden tomar decisiones que involucren la suerte de otras personas. De otra parte, la confianza que otros han depositado en ellos les exige mostrarse fuertes. 


\section{CAPÍTULO V. TÉCNICAS DE MANIPULACIÓN RESEÑABLES EN EL PROCESO COERCITIVO}

DEL MOBBING E INSTRUMENTOS DE EVALUACIÓN DE LAS VÍCTIMAS DE MOBBING.

Si bien la soledad presenta un aspecto positivo, pues permite el recogimiento y la reflexión necesarias para tomar decisiones calculadas y consistentes, ésta misma puede volverse patológica al imposibilitar que la persona establezca vínculos con la sociedad y el entorno que le rodea. De esta soledad infundada por el acosador, surgen diferentes trastornos psicológicos como hemos visto en el anterior capítulo de esta tesis, tal como la fragmentación de la personalidad de la víctima para asumir comportamientos muy diversos en los diferentes ámbitos, llegando incluso a perder el control sobre sí mismos.

Por tanto en el caso que nos ocupa debemos saber discernir entre la soledad razonable, que acompaña habitualmente a las labores directivas, innatas en el propio cargo de dirección de un centro residencial, y la soledad infundada, ocasionada por el acosador, que no hace más que tratar de perturbar la razón del directivo acosado, alejarlo de los demás y llevarlo a tomar decisiones precipitadas, erróneas y arbitrarias, con el único fin de destruirlo. Así, pues la soledad del directivo acosado se caracteriza por:

\section{1) No poder compartir ningún tipo de información con nadie.}

El líder acosado, ve coartadas sus vías de expresión con los demás, (familiares, amigos, compañeros, etc...), esto se debe en gran parte a la contrariedad, incertidumbre, desigualdad situacional, y falta de autoestima que sufre debido a la acción del acosador sobre su figura. Tiene miedo a emitir su juicio sobre la situación que está viviendo, a los demás, ya que estos pueden no entender qué es lo que le está sucediendo, o lo que es peor, que den la razón a la persona que le está hostigando, lo cual no haría más que alimentar su propio sufrimiento interno.

Esto como hemos visto a lo largo del Capítulo IV de esta tesis conllevará a unas consecuencias nefastas y devastadoras para la propia víctima, ya que está internalizando el sufrimiento. 


\section{CAPÍTULO V. TÉCNICAS DE MANIPULACIÓN RESEÑABLES EN EL PROCESO COERCITIVO}

DEL MOBBING E INSTRUMENTOS DE EVALUACIÓN DE LAS VÍCTIMAS DE MOBBING.

2) Sentirse presionado por el consejo de administración de la propia empresa o por su presidente.

Un centro residencial, no es más, sino que una empresa dedicada al cuidado integral del anciano, o persona dependiente que en ella decida institucionalizarse. Este es un concepto que muchas personas, obvian; como empresa que se precie, está constituida por un organigrama claramente definido y en el cual, podemos distinguir las figuras que se muestran en el gráfico 5.3 que a continuación de muestra:

ORGANIGRAMA ESTANDART DE UN CENTRO RESIDENCIAL

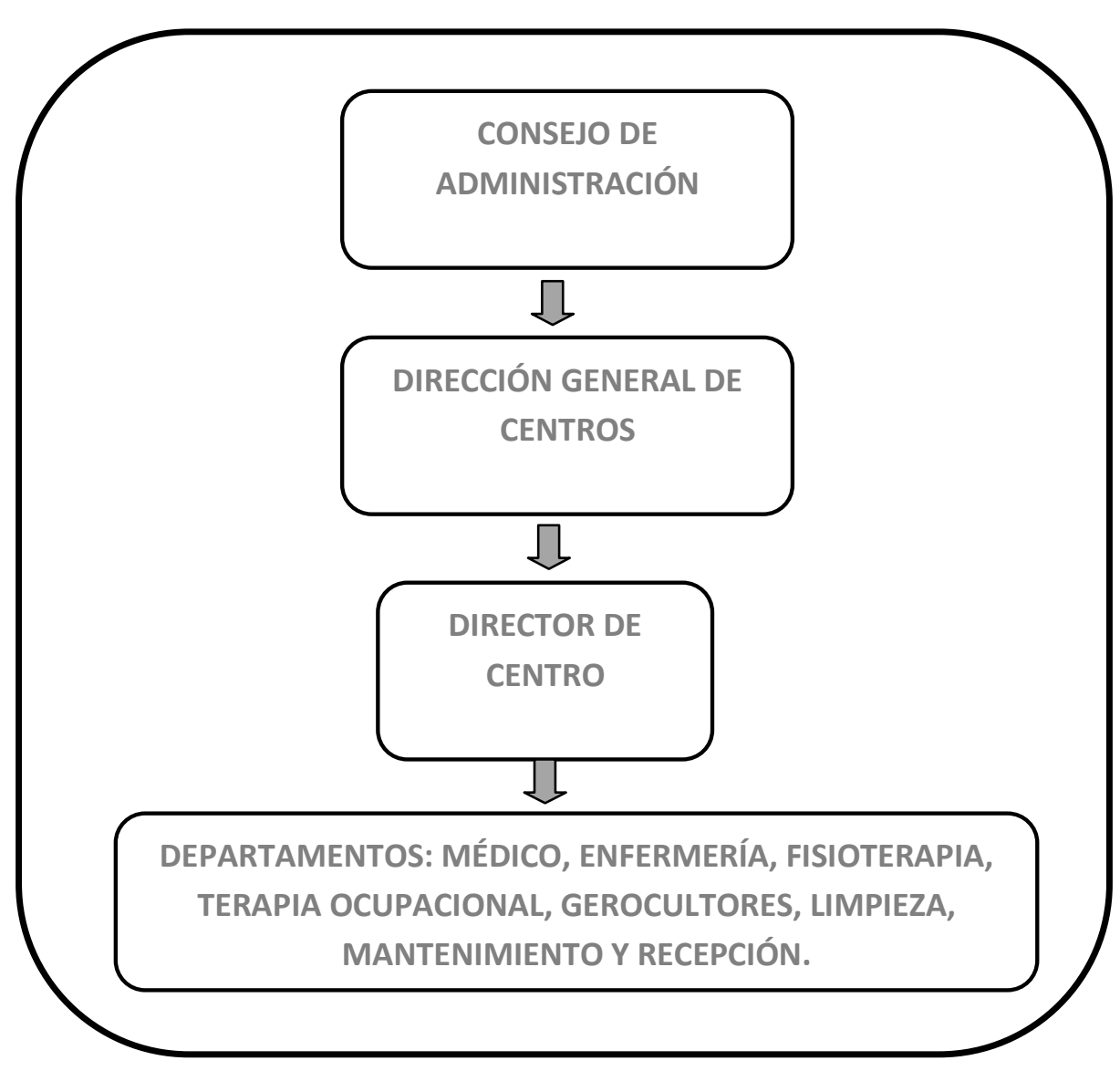

Gráfico 5.3. "Organigrama Estándar de un Centro Residencial". Fuente: elaboración propia. 


\section{CAPÍTULO V. TÉCNICAS DE MANIPULACIÓN RESEÑABLES EN EL PROCESO COERCITIVO}

DEL MOBBING E INSTRUMENTOS DE EVALUACIÓN DE LAS VÍCTIMAS DE MOBBING.

Lejos de comprender un fenómeno tan complejo, como es el del mobbing directivo, el consejo de administración de la empresa, encabezado normalmente por su presidente, suele presionar al directivo acosado con la consecución de los objetivos planteados en el año en curso.

\section{3) Tomar decisiones impopulares.}

La persona hostigada suele ser, alguien muy popular dentro de la propia empresa, que como hemos visto en capítulos anteriores goza del éxito y de la confianza de los demás, hasta que comienza el acoso, momento en el cual sus medidas son vistas como "impopulares" por sus trabajadores. Debemos de recordar que liderar equipos es tremendamente complejo, ya que a veces se tienen que tomar decisiones difíciles para el director del centro, con el fin de dar viabilidad al proyecto.

\section{4) Cambio de rol en la propia empresa.}

Sin duda es uno de los fenómenos que mayor soledad produce en el acosado. Los trabajadores, compañeros de dirección, amigos... al producirse el acoso, y ante la incertidumbre que otean se alejan de la víctima, haciéndole sentirse muy solo. Lo que antes eran alabanzas, reconocimientos, compañerismo, etc... se transforma en distancia, lejanía, indiferencia e incluso en desprecio.

Esto es percibido además de manera muy negativa por la víctima, quien ya no solo tendrá que sufrir el acoso, sino que lo hará sin la compañía de los que hasta el momento eran sus compañeros e incluso amigos en algunos casos.

Todo ello conformaría una gran soledad vital para el directivo acosado. A continuación procederemos a analizar y describir los instrumentos existentes, para evaluar a las víctimas del mobbing. 


\section{CAPÍTULO V. TÉCNICAS DE MANIPULACIÓN RESEÑABLES EN EL PROCESO COERCITIVO \\ DEL MOBBING E INSTRUMENTOS DE EVALUACIÓN DE LAS VÍCTIMAS DE MOBBING.}

\subsection{Descripción de los Instrumentos existentes para evaluar a las víctimas del mobbing.}

En la actualidad existen diferentes instrumentos para evaluar a las víctimas del acoso laboral; podemos afirmar que son numerosos en cuanto a cantidad de cuestionarios se refiere, diferenciando entre aquellos que miden las incidencias y los que se encargan de la medida de las consecuencias que en la víctima se reflejan. Desde el punto de vista directivo, y en consonancia con la línea de investigación que estamos siguiendo en esta investigación, nos debemos de central principalmente es estos últimos, puesto que nos es de especial significación tratar de evaluar la sintomatología psicosomática generada en el proceso de acoso al directivo de un centro residencial, para posteriormente, en minucia estudiar los diferentes aspectos observados.

Antes de comenzar a describir algunos de los instrumentos más importantes, debemos de señalar, que los cuestionarios pueden no ser el medio más adecuado para el estudio de toda la sintomatología, pues denotan algunas de las siguientes cuestiones a tratar:

1) El denominado "mobbing en tiempos de crisis"; en la actualidad económica que nos encontramos, y ante el panorama laboral que nos rodea, es muy común el temor al desempleo, la amenaza de estar parado, (que constantemente frecuenta las empresas y que en muchas de ellas es una herramienta directiva para la consecución de objetivos de los ejecutivos), la competitividad existente ante la incertidumbre de un posible expediente de regulación de empleo en la empresa y el mal presagio que se puede observar día a día de lo que la Unión Económica Europea, denomina el "enlentecimiento del crecimiento de la economía española", hacen que los trabajadores se invadan de pesimismo, lo cual hará que se vean así reflejados en la actual coyuntura económica que atraviesa nuestro país. 


\section{CAPÍTULO V. TÉCNICAS DE MANIPULACIÓN RESEÑABLES EN EL PROCESO COERCITIVO}

DEL MOBBING E INSTRUMENTOS DE EVALUACIÓN DE LAS VÍCTIMAS DE MOBBING.

2) La problemática "cultural"; la cultura, en la cual estamos inmersos hace que exista una gran burocracia y que haya una gran jerarquía dentro de las empresas, jerarquía en el caso que nos ocupa discretamente definida, poco clara y precisa, con fines puramente económicos, que impiden establecer generalizaciones a la hora de emprender investigaciones al respecto, como es la que pretendemos llevar a cabo en esta tesis doctoral. Estos diferentes niveles de categorización empresarial, harán que la recogida de datos se vea mermada en cuanto a cantidad y precisión se refiere.

3) La problemática entre "lo subjetivo y lo objetivo"; dotar de realidad la investigación, es uno de los retos que se nos plantearon cuando decidimos abordar la temática de esta investigación, ya que, son bien conocidas las discrepancias entre las percepciones subjetivas de quienes se consideran afectados de mobbing en los puestos directivos de centros residenciales. Es muy difícil, tratar de objetivar lo subjetivo, por lo que abordaremos los datos obtenidos de la manera menos sesgada para su buen uso, con el fin de establecer las conclusiones que de ellos se convengan.

4) La "consideración de terceros"; no siempre es fácil, denunciar, hablar, contar, pensar, recordar lo que nos ha ocurrido o lo que nos está ocurriendo, puesto que ello, implícitamente afecta a la familia, compañeros, amigos, y allegados de las víctimas. Cabe recordar como en el capítulo anterior, capítulo 4, se hacía mención a las diferentes consecuencias que para cada uno de ellos tenía el fenómeno del mobbing, ya que no afecta únicamente a la víctima. Está "consideración" que tiene la víctima con su entorno más cercano, hace más difícil si cabe el arrojo de datos, datos que en la mayor parte de las ocasiones son de especial significación para el estudio y explicación de un fenómeno de tales dimensiones, y que se silencia con mayor frecuencia de la deseada. 


\section{CAPÍTULO V. TÉCNICAS DE MANIPULACIÓN RESEÑABLES EN EL PROCESO COERCITIVO}

DEL MOBBING E INSTRUMENTOS DE EVALUACIÓN DE LAS VÍCTIMAS DE MOBBING.

5) Lo "poco visible y lo sutil"; lo verdaderamente complicado en el estudio de casos de acoso laboral en puestos directivos de centros residenciales es hacer "visible lo invisible". La sutileza con la que actua el ejecutivo acosador es tal, que difícilmente el propio hostigado será capaz de reconocer el acoso al que está siendo sometido hasta no bien entrado en él, lo cual será ya inabarcable para alguien desconocedor de la materia.

6) La "frecuencia"; por norma el acoso se perpetua durante meses e incluso durante años. La frecuencia con la que una víctima de acoso, lo reconoce como tal, es altamente preocupante. A menudo las personas tienden a ocultar que están siendo objeto de acoso, o que en algún momento de su vida laboral lo han sido, por lo que este indicador suele estar sesgado por la muestra de estudio escogida.

7) El "reconocimiento de conductas degradantes con el otro"; reconocer que estas siendo sometido no es tarea baladí para el acosado, en tanto en cuanto ello implica hacer ver al otro, que él está siendo el autor de tales conductas degradantes y por lo tanto, el culpable de lo que te está ocurriendo. Ello implica además que comienzas a ser consciente de la situación que estás viviendo y que estas reconociendo el acoso como tal, algo totalmente perjudicial para quien lleva a cabo el acoso, el cual precisamente trata de evitar que el acoso sea notorio y público.

Todos estos aspectos, han de ser considerados a la hora de emprender el estudio del acoso laboral en puestos directivos de centros residenciales, ya que el tenerlos presentes será de especial importancia a la hora de objetivar al máximo los resultados obtenidos. A continuación describiremos algunos de los cuestionarios más representativos. 


\section{CAPÍTULO V. TÉCNICAS DE MANIPULACIÓN RESEÑABLES EN EL PROCESO COERCITIVO \\ DEL MOBBING E INSTRUMENTOS DE EVALUACIÓN DE LAS VÍCTIMAS DE MOBBING.}

\subsubsection{LIPT (“Leymann Inventory Of Psychological Terrorization”.}

En 1984, Heinz Leymann, psiquiatra alemán afincado en Suecia, publicó su primer estudio piloto sobre la violencia psicológica en el trabajo, fenómeno ya mencionado a lo largo de esta investigación, pero no solo sus estudios se basaron en esto, sino que además creó el concepto de violencia psicológica en el trabajo, abrió el campo de estudio y realizó los primeros estudios clínicos y epidemiológicos, para lo cual describió de manera operativa y objetivamente demostrable 45 actividades características del mobbing. La lista de estas actividades en forma de cuestionario es lo que se denomina LIPT (Leymann Inventory Of Psychological Terrorization) (González de Rivera, 2002).

Conceptualmente, Leymann clasifica las estrategias de acoso en cinco grandes apartados:

1) Limitar su comunicación: el acosador impone con su autoridad lo que puede decirse y lo que no. A la víctima se le niega el derecho a expresarse o a hacerse oír. Estaríamos refiriéndonos a los ítems 1-11 del LIPT. (ej. Ítem 1. -"Sus superiores no le dejan expresarse o decir lo que tiene que decir-"--

2) Limitar su contacto social: no se dirige la palabra a la víctima, procurando además que nadie lo haga. Se le cortan las fuentes de información, se le aísla físicamente de sus compañeros. Estaríamos refiriéndonos a los ítems 12-16 del LIPT. (ej. Ítem 13. -“No consigue hablar con nadie, todos le evitan-”).

3) Desprestigiar su persona ante sus compañeros: bromas y burlas sobre la víctima, su familia, orígenes, antecedentes y entorno. Estaríamos haciendo referencia a los ítems 17-31 del LIPT. (ej. Ítem23. -“Imitan su forma de andar, su voz, sus gestos para ponerle en ridículo"-). 


\section{CAPÍTULO V. TÉCNICAS DE MANIPULACIÓN RESEÑABLES EN EL PROCESO COERCITIVO}

DEL MOBBING E INSTRUMENTOS DE EVALUACIÓN DE LAS VÍCTIMAS DE MOBBING.

4) Desacreditar su capacidad profesional y laboral: se asigna a la víctima tareas muy por debajo o muy por encima de su capacidad, o no se le permite hacer nada; se le critican los más mínimos errores o defectos; se desprecia su trabajo y sus capacidades profesionales. Estaríamos haciendo referencia a los Ítems 32-38 del LIPT. (ej. Ítem 34. -“Le obligan a hacer tareas absurdas o inútiles”-).

5) Comprometer su salud: aparte de ataques directos, el mero sometimiento a un régimen de acoso psicológico ya tiene efectos negativos, psicológicos y psicosomáticos, pero lo que se evalúa en este cuestionario son las conductas del acosador o acosadores, no su repercusión en el acosado. Estaríamos haciendo referencia a los Ítems 39-45 del LIPT. (ej. Ítem 39. -“Le obligan a hacer trabajos nocivos o peligrosos"-).

EI LIPT, por tanto podemos afirmar que es el instrumento de medida de acoso psicológico más utilizado en investigación. En España, desde el estudio de los primeros casos, se detectaron estrategias de acoso, relativamente frecuentes, que no se encontraban en la lista original de Leymann (González de Rivera, 2006), por lo que se decidió añadir quince de estas conductas al cuestionario original, a continuación de las 45 ya descritas, surgiendo así el LIPT-60, versión traducida al castellano, modificada y recientemente adaptada. EI LIPT-60 es un cuestionario escalar autoadministrado que objetiva y valora sesenta diferentes estrategias de acoso psicológico, derivadas del LIPT original, dicotómico, de cuarenta y cinco ítems. EI LIPT-60, modifica además, las posibilidades de respuesta del cuestionario, inicialmente de tipo dicotómico, para permitir la valoración por el sujeto de la intensidad con que es afectado por cada una de las estrategias de acoso. Surgen así dos versiones españolas del LIPT:

a) La dicotómica, en la que se añaden quince ítems a los cuarenta y cinco originales de Leymann, conservando las mismas instrucciones de administración y la misma metodología de respuesta. 


\section{CAPÍTULO V. TÉCNICAS DE MANIPULACIÓN RESEÑABLES EN EL PROCESO COERCITIVO \\ DEL MOBBING E INSTRUMENTOS DE EVALUACIÓN DE LAS VÍCTIMAS DE MOBBING.}

b) La escalar, igual en cuanto a la descripción de los ítems, pero en la que se amplían las posibilidades de respuesta para incluir en ella una valoración tipo Likert de la intensidad con que cada una de las conductas de acoso ha afectado al sujeto, desde cero (la conducta no ha tenido lugar) hasta cuatro (conducta de intensidad máxima).

Para la corrección del LIPT escalar, por analogía con el procedimiento seguido en otros instrumentos de medida, se establecieron tres parámetros de evaluación globales: a) el número total de estrategias de acoso psicológico percibido (NEAP), b) el índice global de acoso psicológico (IGAP), y c) el índice medio de acoso psicológico (IMAP), efectuándose el cálculo de dichos parámetros globales del modo siguiente:

-NEAP: contaje simple de todas las respuestas distintas de cero. Esta medida es conceptualmente la misma que el LIPT total calculado con el cuestionario dicotómico, aunque presenta diferencias de orden metodológico que posteriormente serán discutidas.

-IGAP: índice global, obtenido sumando los valores asignados a cada estrategia de acoso psicológico y dividiendo esta suma entre el número total de estrategias consideradas en el cuestionario, es decir, entre sesenta.

-IMAP: índice medio de intensidad de las estrategias de acoso psicológico experimentadas, obtenido dividiendo la suma de los valores asignados a cada estrategia entre el número total de respuestas positivas. Este número es variable, y viene determinado por el NEAP, ya que se obtiene mediante el cociente entre la suma de valores asignados a cada estrategia y el NEAP.

Además de la obtención de estos tres parámetros globales, se pueden obtener puntuaciones pertenecientes a seis subescalas de acoso laboral (González de Rivera y Rodríguez-Abuín, 2005: 


\section{CAPÍTULO V. TÉCNICAS DE MANIPULACIÓN RESEÑABLES EN EL PROCESO COERCITIVO \\ DEL MOBBING E INSTRUMENTOS DE EVALUACIÓN DE LAS VÍCTIMAS DE MOBBING.}

1) Subescala de desprestigio laboral (DL) = ítems $5,10,17,18,28,49,50,54,55$, $56,57,58,59$ y 60 . La constituyen aquellas estrategias de acoso en el trabajo en las que se produce un descrédito o desprestigio en el trabajo, bien a través de distorsión en la comunicación, como rumores o calumnias, o con medidas restrictivas o de agravio comparativo con el resto de los trabajadores, minimizando u ocultando sus logros.

\section{Ítems Subescala DL:}

\section{Critican su trabajo}

10. No le miran, o le miran con desprecio o gestos de rechazo.

17. Le calumnian y murmuran a sus espaldas.

18. Hacen circular rumores falsos o infundados sobre usted......

28. Se evalúa su trabajo de manera parcial, injusta y malintencionada

49.Se someten informes confidenciales y negativos sobre usted, sin notificarle ni darle la oportunidad de defenderse.

50.Las personas que le apoyan reciben amenazas, o presiones para que se aparten de usted

54. Callan o minimizan sus esfuerzos, logros y aciertos.

55. Ocultan sus habilidades y competencias especiales.

56. Exageran sus fallos y errores

57. Informan mal sobre su permanencia y dedicación

58. Controlan de manera muy estricta su horario.

59. Cuando solicita un permiso o actividad a la tiene derecho se lo niegan o le ponen pegas y dificultades

60 . Se le provoca para obligarle a reaccionar emocionalmente.

Tabla 5.1. "Items que componen la Subescala de Desprestigio Laboral". 


\section{CAPÍTULO V. TÉCNICAS DE MANIPULACIÓN RESEÑABLES EN EL PROCESO COERCITIVO \\ DEL MOBBING E INSTRUMENTOS DE EVALUACIÓN DE LAS VÍCTIMAS DE MOBBING.}

2) Subescala de entorpecimiento del progreso (EP) = ítems 14, 27, 32, 33, 34, 35 y 37. La constituyen ítems que se refieren a un bloqueo sistemático de la actividad laboral, degradando al trabajador con tareas inapropiadas en la forma o en el contenido, de acuerdo con sus competencias.

\section{Ítems Subescala EP:}

14. Le asignan un lugar de trabajo que le mantiene aislado del resto de sus compañeros.

27. Le asignan un trabajo humillante.

32. No se le asignan nuevas tareas, no tiene nada que hacer

33. Le cortan sus iniciativas, no le permiten desarrollar sus ideas

34. Le obligan a hacer tareas absurdas o inútiles.

35. Le asignan tareas muy por debajo de su competencia.

37. Le obligan a realizar tareas humillantes

Tabla 5.2. "Items que componen la Subescala de Entorpecimiento del Progreso".

3) Subescala de incomunicación o bloqueo de la comunicación (BC) = ítems 3, 11, $12,13,15,16,51,52$ y 53. La constituyen ítems referidos a un bloqueo de la comunicación intraorganizacional (dentro de la organización) y extraorganizacional (con el exterior de la organización).

Ítems Subescala BC:

3. Sus compañeros le ponen pegas para expresarse o no le dejan hablar

11. Ignoran su presencia, no responden a sus preguntas

12. La gente ha dejado o está dejando de dirigirse o de hablar con usted.

13. No consigue hablar con nadie, todos le evitan. 


\section{CAPÍTULO V. TÉCNICAS DE MANIPULACIÓN RESEÑABLES EN EL PROCESO COERCITIVO \\ DEL MOBBING E INSTRUMENTOS DE EVALUACIÓN DE LAS VÍCTIMAS DE MOBBING.}

Ítems Subescala BC (continuación):

15. Prohíben a sus compañeros que hablen con usted.

16. En general, se le ignora y se le trata como si fuera invisible.....

51. Devuelven, abren o interceptan su correspondencia.

52. No le pasan las llamadas, o dicen que no está.....

53. Pierden u olvidan los encargos para usted.

Tabla 5.3. "Items que componen la Subescala de Incomunicación o Bloqueo de la Comunicación".

4) Subescala de intimidación encubierta (IE) = ítems 7, 9, 43, 44, 46, 47 y 48. La constituyen ítems referidos a amenazas y daños encubiertos, que predominantemente no dejan "huella" o se realizan de manera "limpia", sin que se puedan delimitar responsables específicos.

\section{Ítems Subescala IE:}

7. Recibe llamadas telefónicas amenazantes, insultantes o acusadoras..

9. Recibe escritos y notas amenazadoras.

43. Le ocasionan a propósito gastos para perjudicarle.

44. Le ocasionan daños en su domicilio o en su puesto de trabajo.....

46. Ocasionan daños en sus pertenencias o en su vehículo...

47. Manipulan sus herramientas (por ejemplo, borran archivos de su ordenador).

48. Le sustraen algunas de sus pertenencias, documentos o herramientas de trabajo.

Tabla 5.4. "Ítems que componen la Subescala de Intimidación Encubierta". 


\section{CAPÍTULO V. TÉCNICAS DE MANIPULACIÓN RESEÑABLES EN EL PROCESO COERCITIVO \\ DEL MOBBING E INSTRUMENTOS DE EVALUACIÓN DE LAS VÍCTIMAS DE MOBBING.}

5) Subescala de intimidación manifiesta (IM) = ítems 1, 2, 4, 8, 19 y 29. En este caso, los ítems se refieren a amenazas o restricciones que se le imponen de forma directa, no disimulada incluso en público, tales como amenazas verbales, gritos o ponerle en ridículo.

\section{Ítems Subescala IM:}

1. Sus superiores no le dejan expresarse o decir lo que tiene que decir

2. Le interrumpen cuando habla.

4. Le gritan o le regañan en voz alta.

8. Se le amenaza verbalmente

19. Le ponen en ridículo, se burlan de usted.....

29. Sus decisiones son siempre cuestionadas o contrariadas.

Tabla 5.5. "Items que componen la Subescala de Intimidación Manifiesta".

6) Subescala de desprestigio personal (DP) = ítems 6, 20, 21, 24, 25, 30 y 31. Está compuesta por ítems que se refieren a un descrédito o desprestigio de su vida personal y privada (no la laboral), mediante la crítica, burla y denuesto de su forma de ser, vivir y pensar.

\section{Ítems Subescala DP:}

6. Critican su vida privada.

20. Le tratan como si fuera un enfermo mental o lo dan a entender.

21. Intentan obligarle a que se haga un examen psiquiátrico o una evaluación psicológica.

24. Atacan o se burlan de sus convicciones políticas o de sus creencias religiosas. 


\section{CAPÍTULO V. TÉCNICAS DE MANIPULACIÓN RESEÑABLES EN EL PROCESO COERCITIVO \\ DEL MOBBING E INSTRUMENTOS DE EVALUACIÓN DE LAS VÍCTIMAS DE MOBBING.}

\section{Ítems Subescala DP (continuación):}

25. Ridiculizan o se burlan de su vida privada.

30. Le dirigen insultos o comentarios obscenos o degradantes

31. Le hacen avances, insinuaciones o gestos sexuales

Tabla 5.6. "Ittems que componen la Subescala de Desprestigio Personal".

7) Ítems no incluidos en las seis subescalas: además de estos ítems, existen otros 10 más que no se pueden agrupar en estas dimensiones apropiadamente, aunque si se tienen en cuenta para la obtención de los indicadores globales NEAP, IMAP, e IGAP y para el análisis cualitativo. Estos ítems, serían los que se muestran a continuación:

Ítems no incluidos:

22. Se burlan de alguna deformidad o defecto físico que puedan tener.

23. Imitan su forma de andar, su voz, sus gestos para ponerle en ridículo.....

26. Se burlan de su nacionalidad, procedencia o lugar de origen

36. Le sobrecargan sin cesar con tareas nuevas y diferentes.

38. Le asignan tareas muy difíciles o muy por encima de su preparación, en las que es muy probable que fracase.

39. Le obligan a realizar trabajos nocivos o peligrosos.

40. Le amenazan con violencia física.

41. Recibe ataques físicos leves, como advertencia.

42. Le atacan físicamente sin ninguna consideración.

45. Recibe agresiones sexuales físicas directas.

Tabla 5.7. "Ítems no incluidos en las diferentes dimensiones".

A continuación se muestran íntegramente los ítems del LIPT original y del LIPT-60. 
CAPÍTULO V. TÉCNICAS DE MANIPULACIÓN RESEÑABLES EN EL PROCESO COERCITIVO

DEL MOBBING E INSTRUMENTOS DE EVALUACIÓN DE LAS VÍCTIMAS DE MOBBING.

\section{ÍTEMS LIPT ORIGINAL}

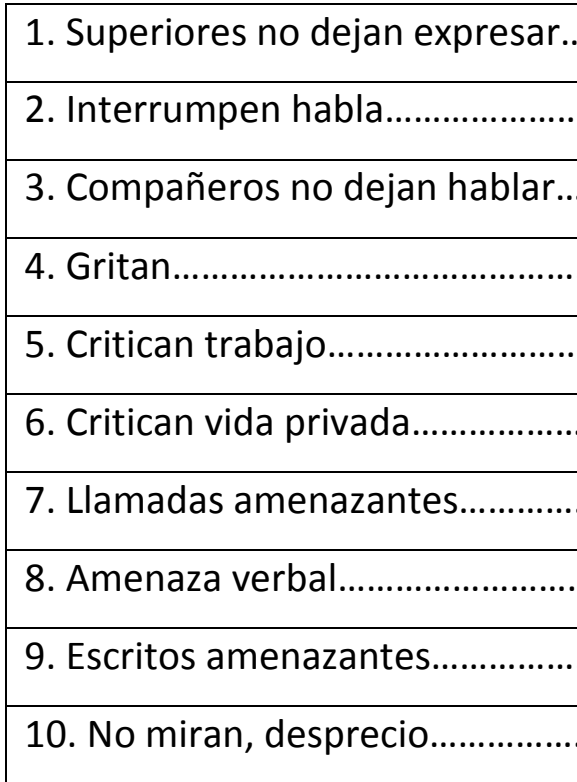

11. Ignorarle.

12. No dirigirse a usted

13. Le evitan.

14. Lugar trabajo aislado

15. Prohibir al resto hablarle.

16. Trato como invisible.

17. Calumnias, murmurar.

18. Rumores falsos.

19. Burlas, ridículo

20. Trato enfermo mental

21. Obligar examen psicológico.

22. Burlas defecto físico.

23. Imitación para ridículo.

24. Burlas religión, política.

25. Burlas vida privada 


\section{CAPÍTULO V. TÉCNICAS DE MANIPULACIÓN RESEÑABLES EN EL PROCESO COERCITIVO \\ DEL MOBBING E INSTRUMENTOS DE EVALUACIÓN DE LAS VÍCTIMAS DE MOBBING.}

46. Daños pertenencias.

Tabla 5.9. "Items que conforman el LIPT-60".

A continuación procederemos a estudiar el NAQ (Negative Acts Questionnaire), otra de las pruebas psicométricas destacadas en el ámbito de la investigación del acoso psicológico en el puesto de trabajo.

\subsubsection{NAQ ("Negative Acts Questionnaire").}

EI NAQ (Einarsen y Raknes, 1997), es uno de los cuestionarios más relevantes internacionalmente para el estudio del acoso psicológico en el puesto de trabajo. Es junto con el LIPT, una de las pruebas con mayor fiabilidad, en lo que a la psicometría interna se refiere. 


\section{CAPÍTULO V. TÉCNICAS DE MANIPULACIÓN RESEÑABLES EN EL PROCESO COERCITIVO}

DEL MOBBING E INSTRUMENTOS DE EVALUACIÓN DE LAS VÍCTIMAS DE MOBBING.

Goza así de gran admiración entre los investigadores, siendo considerablemente más breve que el LIPT (Cowie et al., 2002). El desarrollo de métodos específicos de medida del acoso laboral ha constituido un área de investigación destacada hasta la fecha. El NAQ, creado por Einarsen y Raknes, en 1997, es posiblemente el instrumento más fiable para evaluar las diferentes formas de comportamientos negativos en el lugar de trabajo (Nielsen, Notelaers y Einarsen, 2011). El NAQ original, desarrollado en la Universidad de Bergen (Noruega) está compuesto por 24 ítems que recogen información sobre experiencias conductuales no catalogadas como acoso, que evaluaban la frecuencia con la que los sujetos habían sido sometidos a distintas conductas acosadoras en los últimos seis meses.

Los ítems del NAQ miden la frecuencia de exposición en los últimos seis meses, a conductas negativas y a conductas que pueden conceptualizarse como acoso en una escala Likert de cinco puntos: 1 nunca, 2 a veces, 3 mensualmente, 4 semanalmente, 5 a diario. Según los diversos autores que investigaron acerca de la escala, la ventaja de utilizar listas con conductas consiste en que no es necesario que quienes responden realicen un juicio previo sobre si han sido víctimas o no de acoso, por lo que podría considerarse como un método más objetivo. Sin embargo, tras responder a estos ítems, se introduce una definición de acoso y los sujetos deben indicar si se consideran víctimas de acoso psicológico de acuerdo con la definición dada. Se trata de un instrumento de fácil y bajo coste de aplicación (Einarsen y Hoel, 2001).

EI NAQ desglosa las conductas percibidas en el lugar de trabajo en dos subescalas: el acoso personal (compuesto por doce elementos que describen una exposición a conductas tales como cotilleo, insultos, y críticas constantes y el acoso laboral (compuesto por ocho elementos que describen la solicitud de tareas inalcanzables, excesiva carga de trabajo, supervisión exagerada, o ausencia de información para desempeñar correctamente su trabajo) (Einarsen y Hoel, 2001). 


\section{CAPÍTULO V. TÉCNICAS DE MANIPULACIÓN RESEÑABLES EN EL PROCESO COERCITIVO DEL MOBBING E INSTRUMENTOS DE EVALUACIÓN DE LAS VÍCTIMAS DE MOBBING.}

A pesar de existir suficiente evidencia empírica acerca de su validez, se han desarrollado posteriores revisiones en las que se han añadido o suprimido ítems pero siempre teniendo en cuenta que no debe aparecer el término acoso laboral en ninguno de ellos (Cowie et al., 2002).

Entre todas las revisiones hechas, podemos destacar el NAQ-R, que consta de 22 ítems, todos ellos descritos en términos conductuales que no incluyen el término acoso laboral, tras los cuales se incluye una pregunta adicional $(22+1)$ en la que se cuestiona directamente sobre el acoso percibido (Einarsen et al., 2009).

EI NAQ se encuentra adaptado a diversos idiomas. En España disponemos de tres versiones diferentes del instrumento: por una parte el NAQ.RE (García-Izquierdo, Sáez y Llor, 2003) que se deriva del NAQ original: una versión reducida del instrumento (NAQ-14) (Moreno-Jiménez, Rodríguez-Muñoz, Martínez-Gamarra y Gálvez-Herre, 2007): y una adaptación del cuestionario para acosadores (NAQ-P) (Escartin, Sora, Rodríguez-Muñoz y Rodríguez-Carballeira, 2012).

A continuación se muestra el modelo de NAQ-R:

\section{Cuestionario de Conductas Negativas - Revisado (NAQ-R)}

Las siguientes conductas sirven como ejemplo de conductas negativas en el LUGAR DE TRABAJO. Durante los últimos 6 meses, puede indicar ¿cuántas veces se ha visto sometido a las siguientes conductas negativas en el trabajo?. Por favor señale con un círculo o con una " $X$ " el número que mejor se corresponda con su experiencia personal durante los últimos 6 meses:

$$
\mathbf{1}=\text { Nunca } \mathbf{2}=\text { A veces } \mathbf{3}=\text { Mensualmente } \mathbf{4}=\text { Semanalmente } \mathbf{5}=\text { A diario }
$$




\section{CAPÍTULO V. TÉCNICAS DE MANIPULACIÓN RESEÑABLES EN EL PROCESO COERCITIVO}

DEL MOBBING E INSTRUMENTOS DE EVALUACIÓN DE LAS VÍCTIMAS DE MOBBING.

\begin{tabular}{|c|c|c|c|c|c|}
\hline $\begin{array}{l}\text { 1. Alguien le ha ocultado información que ha afectado a su } \\
\text { rendimiento. }\end{array}$ & 1 & 2 & 3 & 4 & 5 \\
\hline 2. Ha sido humillado o ridiculizado en relación a su trabajo & 1 & 2 & 3 & 4 & 5 \\
\hline $\begin{array}{l}\text { 3. Le han ordenado realizar un trabajo que está por debajo de } \\
\text { su nivel de competencia }\end{array}$ & 1 & 2 & 3 & 4 & 5 \\
\hline $\begin{array}{l}\text { 4. Le han cambiado de realizar tareas de responsabilidad por } \\
\text { otras más triviales o desagradables }\end{array}$ & 1 & 2 & 3 & 4 & 5 \\
\hline 5. Se han extendido rumores sobre usted & 1 & 2 & 3 & 4 & 5 \\
\hline 6. Ha sido ignorado, excluido o le han dejado de hablar & 1 & 2 & 3 & 4 & 5 \\
\hline $\begin{array}{l}\text { 7. Le han insultado con comentarios sobre usted, sus actitudes } \\
\text { o su vida privada }\end{array}$ & 1 & 2 & 3 & 4 & 5 \\
\hline 8. Le han gritado o ha sido objeto de enfados espontáneos & 1 & 2 & 3 & 4 & 5 \\
\hline $\begin{array}{l}\text { 9. Ha sufrido conductas intimidatorias como ser apuntado con el } \\
\text { dedo, la invasión de su espacio personal, empujones, que no le } \\
\text { dejen pasar, etc... }\end{array}$ & 1 & 2 & 3 & 4 & 5 \\
\hline $\begin{array}{l}\text { 10. Ha visto detalles o indirectas de otros que le sugieran abandonar } \\
\text { su trabajo }\end{array}$ & 1 & 2 & 3 & 4 & 5 \\
\hline 11. Le han recordado continuamente sus errores y fallos & 1 & 2 & 3 & 4 & 5 \\
\hline $\begin{array}{l}\text { 12. Ha sido ignorado o ha recibido una reacción hostil cuando se ha } \\
\text { acercado a alguien }\end{array}$ & 1 & 2 & 3 & 4 & 5 \\
\hline 13. Ha recibido críticas persistentes sobre su trabajo y esfuerzo & 1 & 2 & 3 & 4 & 5 \\
\hline 14. Sus opiniones y puntos de vista han sido ignorados & 1 & 2 & 3 & 4 & 5 \\
\hline 15. Ha recibido bromas pesadas de gente con la que no se lleva bien & 1 & 2 & 3 & 4 & 5 \\
\hline 16. Le han asignado tareas u objetivos inalcanzables & 1 & 2 & 3 & 4 & 5 \\
\hline 17. Ha recibido alegaciones en su contra & 1 & 2 & 3 & 4 & 5 \\
\hline 18. Ha sido excesivamente supervisado en su trabajo & 1 & 2 & 3 & 4 & 5 \\
\hline 19. Ha sido presionado para no reclamar algo a lo que tiene derecho & 1 & 2 & 3 & 4 & 5 \\
\hline 20. Ha sido objeto de numerosas tomaduras de pelo y sarcasmos & 1 & 2 & 3 & 4 & 5 \\
\hline
\end{tabular}




\section{CAPÍTULO V. TÉCNICAS DE MANIPULACIÓN RESEÑABLES EN EL PROCESO COERCITIVO}

DEL MOBBING E INSTRUMENTOS DE EVALUACIÓN DE LAS VÍCTIMAS DE MOBBING.

21. Ha sido expuesto a una excesiva carga de trabajo

22. Ha recibido amenazas de violencia o abusos físicos

\begin{tabular}{|l|l|l|l|l|}
\hline 1 & 2 & 3 & 4 & 5 \\
\hline 1 & 2 & 3 & 4 & 5 \\
\hline
\end{tabular}

23. ¿Le han acosado en el trabajo? Definimos el acoso como una situación en la que uno o varios individuos perciben continuamente durante un periodo de tiempo, que reciben conductas negativas de una o varias personas, en una situación donde el sujeto víctima del acoso tiene dificultad para defenderse de estas acciones. No nos referimos al acoso como un incidente puntual. Según la definición anterior, por favor indique si ha sido acosado en el trabajo durante los últimos 6 meses.

1. No.

2. Sí pero pocas veces.

3. $\mathrm{Si}$, pero de vez en cuando.

4. Sí, varias veces por semana.

5. Sí, prácticamente a diario.

Una vez analizado en minucia, el NAQ y el NAQ-R., procederemos a estudiar el WHS (Work Harassment Scale).

\subsubsection{WHS ("Work Harassment Scale").}

El WHS, es un cuestionario breve, creado por Björkqvist y sus colaboradores en el año 1992, con el fin de estudiar el nivel de agresión existente entre empleados universitarios (Björkqvist et al., 1994). Es una prueba de menor reconocimiento internacional que el LIPT, o el NAQ, menos utilizada en investigaciones clínicas y de menor repercusión entre los investigadores, pero no por ello de menor relevancia en cuanto al estudio del acoso laboral se refiere. El WHS consta de veinticuatro ítems que valoran distintos tipos de conductas degradantes y de opresión cometidas entre compañeros en el último medio año, correlacionando de forma positiva las puntuaciones elevadas en WHS, con la ansiedad y agresividad experimentada por el 


\section{CAPÍTULO V. TÉCNICAS DE MANIPULACIÓN RESEÑABLES EN EL PROCESO COERCITIVO}

DEL MOBBING E INSTRUMENTOS DE EVALUACIÓN DE LAS VÍCTIMAS DE MOBBING.

sujeto acosado (Cowie et al., 2002; Hubert, 2004).

A continuación se muestra el modelo de WHS:

\section{Work Harassment Scale}

How often you been esposed to degrading or oppressing by your colleagues at Work during the last six months? The activities clearly must have been experienced as a means of harassment, not as normal communication, or as exceptional occasions.

Your age:__years Your sex: female___ male

Answer by marking the alternative that comes closet to your own experience.

$$
\mathbf{0}=\text { never } \mathbf{1}=\text { seldom } \mathbf{2}=\text { occasionally } \mathbf{3}=\text { often } \mathbf{4}=\text { very often }
$$

\section{Have you been exposed to}

1.Unduly reduced opportunities to express yourself? .01234

2.Lies about you told to others?.

3.Being unduly disrupted?

4.Being shouted at loudly? 01234

5.Being unduly critized? 1234

6.Insulting comments about your prívate life? 01234

7.Being isolated? 01234

8. Having sensitive details about your prívate life revealed? 01234

9.Direct threats? .01234

10.Insinuative glances and/ or negative gestures? .01234

11.Accusations?. .01234 


\section{CAPÍTULO V. TÉCNICAS DE MANIPULACIÓN RESEÑABLES EN EL PROCESO COERCITIVO \\ DEL MOBBING E INSTRUMENTOS DE EVALUACIÓN DE LAS VÍCTIMAS DE MOBBING.}

13. Refusal to speak with you?

14.Belittling of your opinions?

15. Refusal to hear you?.

16. Being treated as non-existent?.

17.Words aimed at hurting you?.... 012234

18. Being given meaningless tasks?. 01234

19. Being given insulting tasks?. 01234

20. Having malicius rumors spread behind your back? 01234

21.Being ridiculed in front of others? 01234

22. Having your Work judged in an incorrect and insulting manner?.... 01234

23. Having your sense of judgement questioned? 01234

24.Accusations of being mentally disturbed? 01234

A continuación analizaremos la Escala Cisneros, el instrumento de medida elegido además para la realización de la metodología empírica de esta investigación como analizaremos en los capítulos VII y VIII, de esta tesis.

\subsubsection{Escala "Cisneros".}

La escala Cisneros es un cuestionario desarrollado por el profesor Iñaki Piñuel de carácter autoadministrado, compuesto por 43 ítems que objetivan y valoran 43 conductas de acoso psicológico. Dicho cuestionario forma parte del Barómetro Cisneros (Cuestionario Individual sobre Psicoterror, Negación, Estigmatización Y Rechazo en Organizaciones Sociales), integrado por una serie de escalas cuyo objetivo 


\section{CAPÍTULO V. TÉCNICAS DE MANIPULACIÓN RESEÑABLES EN EL PROCESO COERCITIVO}

DEL MOBBING E INSTRUMENTOS DE EVALUACIÓN DE LAS VÍCTIMAS DE MOBBING.

es sondear el estado, y las consecuencias de la violencia en el entorno laboral de las organizaciones. Lo analizaremos en detalle en los capítulos VII y VIII de esta investigación. A continuación se muestra el modelo Cisneros:

\section{ESCALA CISNEROS}

¿Cuáles de las siguientes formas de maltrato psicológico (ver lista de preguntas 1 a 43) se han ejercido contra Ud.?

Señale, en su caso, quiénes son el/los autores de los hostigamientos recibidos

1 Jefes o supervisores

2 Compañeros de trabajo

3 Subordinados

Señale, en su caso, el grado de frecuencia con que se producen esos hostigamientos

0 Nunca

1 Pocas veces al año o menos

2 Una vez al mes o menos

3 Algunas veces al mes

4 Una vez a la semana

5 Varias veces a la semana

6 Todos los días

\begin{tabular}{|l|c|c|c|c|c|c|c|c|}
\hline Comportamientos & \multicolumn{2}{|c|}{ Autor } & \multicolumn{5}{|c|}{$\begin{array}{c}\text { Frecuencia del } \\
\text { comportamiento }\end{array}$} \\
\hline $\begin{array}{l}\text { 1.Mi superior restringe mis posibilidades de } \\
\text { comunicarme, hablar o reunirme con él. }\end{array}$ & [ ] ] & 0 & 1 & 2 & 3 & 4 & 5 & 6 \\
\hline $\begin{array}{l}\text { 2.Me ignoran. Me excluyen o me hacen el } \\
\text { vacío, fingen no verme o me hacen "invisible". }\end{array}$ & [ ] ] & 0 & 1 & 2 & 3 & 4 & 5 & 6 \\
\hline $\begin{array}{l}\text { 3.Me interrumpen continuamente impidiendo } \\
\text { expresarme. }\end{array}$ & [ ] & 0 & 1 & 2 & 3 & 4 & 5 & 6 \\
\hline
\end{tabular}




\section{CAPÍTULO V. TÉCNICAS DE MANIPULACIÓN RESEÑABLES EN EL PROCESO COERCITIVO}

DEL MOBBING E INSTRUMENTOS DE EVALUACIÓN DE LAS VÍCTIMAS DE MOBBING.

\begin{tabular}{|c|c|c|c|c|c|c|c|c|}
\hline $\begin{array}{l}\text { 4.Me fuerzan a realizar trabajos que van } \\
\text { contra mis principios o mi ética. }\end{array}$ & [ ] & 0 & 1 & 2 & 3 & 4 & 5 & 6 \\
\hline $\begin{array}{l}\text { 5.Evalúan mi trabajo de manera inequitativa o } \\
\text { de forma sesgada. }\end{array}$ & {$\left[\begin{array}{ll} & ]\end{array}\right]$} & 0 & 1 & 2 & 3 & 4 & 5 & 6 \\
\hline $\begin{array}{l}\text { 6. Me dejan sin ningún trabajo que hacer, ni } \\
\text { siquiera a iniciativa propia. }\end{array}$ & [ ] & 0 & 1 & 2 & 3 & 4 & 5 & 6 \\
\hline $\begin{array}{l}\text { 7.Me asignan tareas o trabajos absurdos o sin } \\
\text { sentido. }\end{array}$ & {$\left[\begin{array}{ll} & \end{array}\right]$} & 0 & 1 & 2 & 3 & 4 & 5 & 6 \\
\hline $\begin{array}{l}\text { 8. Me asignan tareas o trabajos por debajo de } \\
\text { mi capacidad profesional o mis competencias. }\end{array}$ & {$\left[\begin{array}{ll} & ]\end{array}\right.$} & 0 & 1 & 2 & 3 & 4 & 5 & 6 \\
\hline $\begin{array}{l}\text { 9. Me asignan tareas rutinarias o sin valor o } \\
\text { interés alguno. }\end{array}$ & {$\left[\begin{array}{ll} & ]\end{array}\right.$} & 0 & 1 & 2 & 3 & 4 & 5 & 6 \\
\hline $\begin{array}{l}\text { 10.Me abruman con una carga de trabajo } \\
\text { insoportable de manera mal intencionada. }\end{array}$ & {$\left[\begin{array}{ll} & ]\end{array}\right]$} & 0 & 1 & 2 & 3 & 4 & 5 & 6 \\
\hline $\begin{array}{l}\text { 11.Me asignan tareas que ponen en peligro mi } \\
\text { integridad física o mi salud a propósito. }\end{array}$ & {$[\quad]$} & 0 & 1 & 2 & 3 & 4 & 5 & 6 \\
\hline $\begin{array}{l}\text { 12.Me impiden que adopte las medidas de } \\
\text { seguridad necesarias para realizar mi trabajo } \\
\text { con la debida seguridad. }\end{array}$ & {$\left[\begin{array}{ll} & ]\end{array}\right]$} & 0 & 1 & 2 & 3 & 4 & 5 & 6 \\
\hline $\begin{array}{l}\text { 13.Se me ocasionan gastos con intención de } \\
\text { perjudicarme económicamente. }\end{array}$ & {$\left[\begin{array}{ll} & ]\end{array}\right]$} & 0 & 1 & 2 & 3 & 4 & 5 & 6 \\
\hline $\begin{array}{l}\text { 14.Prohiben a mis compañeros o colegas } \\
\text { hablar conmigo. }\end{array}$ & {$[\quad]$} & 0 & 1 & 2 & 3 & 4 & 5 & 6 \\
\hline
\end{tabular}




\section{CAPÍTULO V. TÉCNICAS DE MANIPULACIÓN RESEÑABLES EN EL PROCESO COERCITIVO}

DEL MOBBING E INSTRUMENTOS DE EVALUACIÓN DE LAS VÍCTIMAS DE MOBBING.

\begin{tabular}{|c|c|c|c|c|c|c|c|c|}
\hline $\begin{array}{l}\text { 15. Minusvaloran y echan por tierra mi trabajo, } \\
\text { no importa lo que haga. }\end{array}$ & {$\left[\begin{array}{ll} & ]\end{array}\right]$} & 0 & 1 & 2 & 3 & 4 & 5 & 6 \\
\hline $\begin{array}{l}\text { 16.Me acusan injustificadamente de } \\
\text { incumplimientos, errores, fallos, inconcretos y } \\
\text { difusos. }\end{array}$ & {$\left[\begin{array}{ll} & ]\end{array}\right]$} & 0 & 1 & 2 & 3 & 4 & 5 & 6 \\
\hline $\begin{array}{l}\text { 17.Recibo críticas y reproches por cualquier } \\
\text { cosa que haga o decisión que tome en mi } \\
\text { trabajo. }\end{array}$ & {$\left[\begin{array}{ll} & ]\end{array}\right.$} & 0 & 1 & 2 & 3 & 4 & 5 & 6 \\
\hline $\begin{array}{l}\text { 18.Se amplifican y dramatizan de manera } \\
\text { injustificada errores pequeños o } \\
\text { intrascendentes. }\end{array}$ & [ ] & 0 & 1 & 2 & 3 & 4 & 5 & 6 \\
\hline $\begin{array}{l}\text { 19.Me humillan, desprecian o minusvaloran } \\
\text { en público ante otros colegas o ante terceros. }\end{array}$ & {$\left[\begin{array}{ll} & ]\end{array}\right]$} & 0 & 1 & 2 & 3 & 4 & 5 & 6 \\
\hline $\begin{array}{l}\text { 20.Me amenazan con usar instrumentos } \\
\text { disciplinarios (rescisión de contrato, } \\
\text { expedientes, despido, traslados, etc.) }\end{array}$ & {$\left[\begin{array}{ll} & ]\end{array}\right]$} & 0 & 1 & 2 & 3 & 4 & 5 & 6 \\
\hline $\begin{array}{l}\text { 21.Intentan aislarme de mis compañeros } \\
\text { dándome trabajos o tareas que me alejan } \\
\text { físicamente de ellos. }\end{array}$ & {$\left[\begin{array}{ll} & ]\end{array}\right]$} & 0 & 1 & 2 & 3 & 4 & 5 & 6 \\
\hline $\begin{array}{l}\text { 22.Distorsionan malintencionadamente lo que } \\
\text { digo o hago en mi trabajo. }\end{array}$ & [ ] & 0 & 1 & 2 & 3 & 4 & 5 & 6 \\
\hline $\begin{array}{l}\text { 23.Se intenta buscarme las cosquillas para } \\
\text { "hacerme explotar". }\end{array}$ & {$\left[\begin{array}{ll} & ]\end{array}\right]$} & 0 & 1 & 2 & 3 & 4 & 5 & 6 \\
\hline $\begin{array}{l}\text { 24.Me menosprecian personal o } \\
\text { profesionalmente. }\end{array}$ & {$\left[\begin{array}{ll}{[} & ]\end{array}\right.$} & 0 & 1 & 2 & 3 & 4 & 5 & 6 \\
\hline $\begin{array}{l}\text { 25. Hacen burla de mí o bromas intentando } \\
\text { ridiculizar mi forma de hablar, de andar, etc. }\end{array}$ & {$\left[\begin{array}{ll}1 \\
\end{array}\right]$} & 0 & 1 & 2 & 3 & 4 & 5 & 6 \\
\hline
\end{tabular}




\section{CAPÍTULO V. TÉCNICAS DE MANIPULACIÓN RESEÑABLES EN EL PROCESO COERCITIVO}

DEL MOBBING E INSTRUMENTOS DE EVALUACIÓN DE LAS VÍCTIMAS DE MOBBING.

\begin{tabular}{|c|c|c|c|c|c|c|c|c|}
\hline $\begin{array}{l}\text { 26.Recibo feroces e injustas críticas acerca de } \\
\text { aspectos de mi vida personal. }\end{array}$ & {$\left[\begin{array}{ll}{[} & ]\end{array}\right.$} & 0 & 1 & 2 & 3 & 4 & 5 & 6 \\
\hline $\begin{array}{l}\text { 27.Recibo amenazas verbales o mediante } \\
\text { gestos intimidatorios. }\end{array}$ & {$\left[\begin{array}{ll}{[} & ]\end{array}\right.$} & 0 & 1 & 2 & 3 & 4 & 5 & 6 \\
\hline $\begin{array}{l}\text { 28.Recibo amenazas por escrito o por teléfono } \\
\text { en mi domicilio. }\end{array}$ & {$\left[\begin{array}{ll}{[} & ]\end{array}\right.$} & 0 & 1 & 2 & 3 & 4 & 5 & 6 \\
\hline $\begin{array}{l}\text { 29.Me chillan o gritan, o elevan la voz de } \\
\text { manera a intimidarme. }\end{array}$ & {$\left[\begin{array}{ll}{[} \\
\end{array}\right.$} & 0 & 1 & 2 & 3 & 4 & 5 & 6 \\
\hline $\begin{array}{l}\text { 30.Me zarandean, empujan o avasallan } \\
\text { físicamente para intimidarme. }\end{array}$ & {$\left[\begin{array}{ll}\text { [ } \\
\text { ] }\end{array}\right.$} & 0 & 1 & 2 & 3 & 4 & 5 & 6 \\
\hline $\begin{array}{l}\text { 31.Se hacen bromas inapropiadas y crueles } \\
\text { acerca de mí. }\end{array}$ & {$\left[\begin{array}{ll}{[} & ]\end{array}\right.$} & 0 & 1 & 2 & 3 & 4 & 5 & 6 \\
\hline $\begin{array}{l}\text { 32.Inventan y difunden rumores y calumnias } \\
\text { acerca de mí de manera malintencionada. }\end{array}$ & {$\left[\begin{array}{l}1 \\
\end{array}\right.$} & 0 & 1 & 2 & 3 & 4 & 5 & 6 \\
\hline $\begin{array}{l}\text { 33.Me privan de información imprescindible y } \\
\text { necesaria para hacer mi trabajo. }\end{array}$ & {$\left[\begin{array}{ll}] & ]\end{array}\right.$} & 0 & 1 & 2 & 3 & 4 & 5 & 6 \\
\hline $\begin{array}{l}\text { 34.Limitan malintencionadamente mi acceso a } \\
\text { cursos, promociones, ascensos, etc. }\end{array}$ & {$\left[\begin{array}{l}{[} \\
{[}\end{array}\right]$} & 0 & 1 & 2 & 3 & 4 & 5 & 6 \\
\hline $\begin{array}{l}\text { 35.Me atribuyen malintencionadamente } \\
\text { conductas ilícitas o antiéticas para perjudicar } \\
\text { mi imagen y reputación. }\end{array}$ & {$\left[\begin{array}{ll}{[} & ]\end{array}\right.$} & 0 & 1 & 2 & 3 & 4 & 5 & 6 \\
\hline $\begin{array}{l}\text { 36. Recibo una presión indebida para sacar } \\
\text { adelante el trabajo. }\end{array}$ & {$\left[\begin{array}{ll}{[} & ]\end{array}\right]$} & 0 & 1 & 2 & 3 & 4 & 5 & 6 \\
\hline
\end{tabular}


CAPÍTULO V. TÉCNICAS DE MANIPULACIÓN RESEÑABLES EN EL PROCESO COERCITIVO

DEL MOBBING E INSTRUMENTOS DE EVALUACIÓN DE LAS VÍCTIMAS DE MOBBING.

\begin{tabular}{|c|c|c|c|c|c|c|c|c|}
\hline $\begin{array}{l}\text { 37.Me asignan plazos de ejecución o cargas de } \\
\text { trabajo irrazonables. }\end{array}$ & [ ] & 0 & 1 & 2 & 3 & 4 & 5 & 6 \\
\hline $\begin{array}{l}\text { 38.Modifican mis responsabilidades o las } \\
\text { tareas a ejecutar sin decirme nada. }\end{array}$ & [ ] & 0 & 1 & 2 & 3 & 4 & 5 & 6 \\
\hline $\begin{array}{l}\text { 39.Desvaloran continuamente } \mathrm{mi} \text { esfuerzo } \\
\text { profesional. }\end{array}$ & [ ] & 0 & 1 & 2 & 3 & 4 & 5 & 6 \\
\hline 40.Intentan persistentemente desmoralizarme. & [ ] & 0 & 1 & 2 & 3 & 4 & 5 & 6 \\
\hline $\begin{array}{l}\text { 41.Utilizan varias formas de hacerme incurrir } \\
\text { en errores profesionales de manera } \\
\text { malintencionada. }\end{array}$ & [ ] & 0 & 1 & 2 & 3 & 4 & 5 & 6 \\
\hline $\begin{array}{l}\text { 42.Controlan aspectos de mi trabajo de forma } \\
\text { malintencionada para intentar "pillarme en } \\
\text { algún renuncio". }\end{array}$ & [ ] & 0 & 1 & 2 & 3 & 4 & 5 & 6 \\
\hline $\begin{array}{l}\text { 43.Me lanzan insinuaciones o proposiciones } \\
\text { sexuales directas o indirectas. }\end{array}$ & {$\left[\begin{array}{ll}{[} & ]\end{array}\right.$} & 0 & 1 & 2 & 3 & 4 & 5 & 6 \\
\hline $\begin{array}{l}\text { 44.En el transcurso de los últimos } 6 \text { meses, } \\
\text { ¿ha sido UD víctima de por lo menos alguna de } \\
\text { las anteriores formas de maltrato psicológico } \\
\text { de manera continuada (con una frecuencia de } \\
\text { más de una vez por semana)? } \\
\text { (ver lista de preguntas la } 43 \text { ) }\end{array}$ & 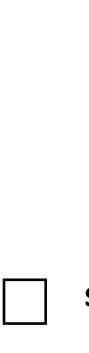 & & & & & & & \\
\hline
\end{tabular}

Por último, para finalizar este capítulo $V$, analizaremos la Escala ISTAS 21 (Escala Psicosocial de Copenhague). 


\section{CAPÍTULO V. TÉCNICAS DE MANIPULACIÓN RESEÑABLES EN EL PROCESO COERCITIVO}

DEL MOBBING E INSTRUMENTOS DE EVALUACIÓN DE LAS VÍCTIMAS DE MOBBING.

\subsubsection{ISTAS 21 ("Escala Psicosocial de Copenhague").}

Entre los instrumentos más utilizados y útiles en la evaluación psicosocial del acoso laboral en el puesto de trabajo, se encuentra el Cuestionario Psicosocial de Copenhague, (COPSOQ), lo que vulgarmente algunos autores denominan la "Escala Psicosocial de Copenhague". Es una de las escalas más recientes, elaborada por el Instituto Nacional de Seguridad y Salud Laboral de Dinamarca (AMI).

El Cuestionario Psicosocial de Copenhague, se caracteriza por ser un cuestionario individual y anónimo, del cual existen tres versiones diferenciadas, larga (para investigación), media (para evaluación de riesgos en empresas con más de 30 trabajadores) y corta (para empresas con menos de 30 trabajadores y para autoevaluación), es una escala aplicable a cualquier tipo de trabajo, ocupación o actividad económica, sea este de la índole que fuere, está basada en un marco conceptual de demanda-control-apoyo social- incluyendo solamente las dimensiones para las que existe evidencia científica razonable de que afecten a la salud, está orientado a la participación y acción (rol de liderazgo del grupo de trabajo dirección-técnicasrepresentantes de los trabajadores), combina además métodos cualitativos (grupos de trabajo) y cuantitativos (cuestionario) y triangulación de los resultados (interpretación grupal), comparando las mediciones obtenidas con valores de referencia poblacionales, obtenidos mediante una encuesta representativa de la población ocupada, presentando los resultados de forma gráfica y comprensible para todos los agentes sociales. Usa puntuaciones estandarizadas (que oscilan entre 0 y 100) para cada dimensión psicosocial y unidad de análisis, para la detección de las áreas de mejora, poseyendo una elevada validez y fiabilidad contrastadas.

En España, resulta habitual en estudios científicos, como instrumento de medida del mobbing, el uso del ISTAS 21. El ISTAS 21, es la adaptación española desarrollada en 2002, del Cuestionario Psicosocial de Copenhague. 


\section{CAPÍTULO V. TÉCNICAS DE MANIPULACIÓN RESEÑABLES EN EL PROCESO COERCITIVO DEL MOBBING E INSTRUMENTOS DE EVALUACIÓN DE LAS VÍCTIMAS DE MOBBING}

La característica fundamental del ISTAS 21, es su universalidad, ya que está diseñado para cualquier tipo de trabajo, es un instrumento autoadministrado e identifica y mide todos aquellos factores psicosociales para los que afecte evidencia científica (veinte dimensiones psicosociales y siete dimensiones de efectos sobre la salud) (González, 2002). Moncada, Llorens y Kristensen lo definen como "un instrumento de evaluación de riesgos psicosociales que identifica y evalúa aquellas condiciones de la organización del trabajo, que pueden suponer un riesgo para la salud e los trabajadores". Por ello, el ISTAS 21, es un instrumento de evaluación orientado principalmente a la prevención (Moncada et al., 2002).

A continuación se muestran los ítems de las 21 dimensiones psicosociales incluidos en la versión larga del ISTAS 21 (COPSOQ):

\section{DIMENSIONES E ÍTEMS}

\section{-Doble presencia.}

¿Qué parte del trabajo familiar y doméstico haces tú?

Si faltas algún día de casa ¿las tareas domésticas que realizas se quedan sin hacer?

Cuando estás en la empresa, ¿piensas en las tareas domésticas y familiares?

¿Hay momentos en los que necesitarías estar en la empresa y en casa a la vez?

\section{-Exigencias psicológicas cuantitativas.}

¿Tienes que trabajar muy rápido?

¿La distribución de tareas es irregular y provoca que se te acumule el trabajo?

¿Tienes tiempo de llevar al día tu trabajo?

$¿$ ¿Te retrasas en la entrega de tu trabajo?

¿Puedes tomarte tranquilamente tu trabajo y tenerlo al día?

¿Tienes tiempo suficiente para hacer tu trabajo?

¿Tienes que quedarte después de la hora establecida de salida?

\section{-Exigencias psicológicas cognitivas.}

¿Tu trabajo requiere que controlas muchas cosas a la vez?

¿Tu trabajo requiere memorizar muchas cosas?

¿Tu trabajo requiere que seas capaz de proponer nuevas ideas?

¿Tu trabajo requiere que tomes decisiones de forma rápida?

¿Tu trabajo requiere que tomes decisiones difíciles?

¿Tienes que tomar decisiones de gran importancia para tu centro de trabajo? 


\section{CAPÍTULO V. TÉCNICAS DE MANIPULACIÓN RESEÑABLES EN EL PROCESO COERCITIVO}

\section{DEL MOBBING E INSTRUMENTOS DE EVALUACIÓN DE LAS VÍCTIMAS DE MOBBING}

¿El trabajo que tú haces puede tener repercusiones importantes sobre los compañeros, clientes, usuario, maquinaria o instalaciones?

¿Tu trabajo requiere manejar muchos conocimientos?

\section{-Exigencias emocionales.}

¿Se producen en tu trabajo momentos o situaciones desgastadoras emocionalmente?

¿Tu trabajo, en general, es desgastador emocionalmente?

¿Te cuesta olvidar los problemas del trabajo?

\section{-Exigencias de esconder emociones.}

¿Tu trabajo requiere que te calles tu opinión?

¿Tu trabajo requiere que escondas tus emociones?

\section{-Exigencias psicológicas sensoriales.}

¿Tu trabajo requiere mucha concentración?

¿Tu trabajo requiere mirar con detalle?

¿Tu trabajo requiere atención constante?

¿Tu trabajo requiere un alto nivel de precisión?

\section{-Influencia.}

¿Otras personas toman decisiones sobre sus tareas?

¿Tienes mucha influencia sobre las decisiones que afectan a tu trabajo?

¿Tienes influencia sobre el ritmo al que trabajas?

¿Puedes escoger a quién tienes como compañero/a de trabajo?

¿Tienes influencia sobre la cantidad de trabajo que se te asigna?

¿Tienes influencia sobre el horario en el que trabajas (turno, días de la semana, hora a la que entras y sales, etc.)?

¿Tienes influencia sobre los métodos de trabajo?

¿Se tiene en cuenta tu opinión cuando se te asignan tus tareas?

¿Tienes influencia sobre tus condiciones de trabajo (exposición a productos tóxicos, ruido, condiciones ergonómicas...)?

¿Tienes influencia sobre la calidad del trabajo que tú haces?

¿Se tiene en cuenta tu opinión si te cambian de ubicación (de centro de trabajo, unidad, departamento, sección...?

¿Tienes influencia sobre el orden en el que realizas las tareas?

\section{-Posibilidades de desarrollo en el trabajo.}

¿Tu trabajo es variado?

$¿$ ¿Tu trabajo requiere un alto nivel de profesionalidad (habilidades y conocimientos

específicos, experiencia...)?

¿Tienes que hacer lo mismo una y otra vez?

¿Tu trabajo requiere que tengas iniciativa?

¿Tu trabajo te permite que aprendas cosas nuevas?

¿La realización de tu trabajo permite que apliques tus habilidades y conocimientos? ¿Tu trabajo te da la oportunidad de mejorar tus habilidades profesionales? 


\section{CAPÍTULO V. TÉCNICAS DE MANIPULACIÓN RESEÑABLES EN EL PROCESO COERCITIVO \\ DEL MOBBING E INSTRUMENTOS DE EVALUACIÓN DE LAS VÍCTIMAS DE MOBBING}

\section{-Control sobre los tiempos de trabajo.}

¿Puedes decidir cuándo haces un descanso?

¿Puedes coger las vacaciones más o menos cuando tú quieres?

¿Puedes dejar tu trabajo para charlar con un compañero o compañera?

Si tienes algún asunto personal o familiar, ¿puedes dejar tu puesto de trabajo al menos una hora, sin tener que pedir un permiso especial

\section{-Sentido del trabajo.}

¿Tienen sentido tus tareas?

¿Las tareas que haces te parecen importantes?

¿Te sientes comprometido con tu profesión?

\section{-Integración en la empresa.}

¿Te gustaría quedarte en la empresa en la que estás para el resto de tu vida laboral?

¿Hablas con entusiasmo de tu empresa a otras personas?

¿Sientes que los problemas en tu empresa son también tuyos?

¿Sientes que tu empresa tiene una gran importancia para ti?

\section{-Previsibilidad.}

¿En tu empresa se te informa con suficiente antelación de los cambios que pueden afectar tu futuro?

¿Recibes toda la información que necesitas para realizar bien tu trabajo?

\section{-Claridad de rol.}

¿Sabes exactamente qué margen de autonomía tienes en tu trabajo?

¿Tu trabajo tiene objetivos claros?

¿Sabes exactamente qué tareas son de tu responsabilidad?

¿Sabes exactamente qué se espera de ti en el trabajo?

\section{-Conflicto de rol.}

¿Haces cosas en el trabajo que son aceptadas por algunas personas y no por otras?

¿Se te exigen cosas contradictorias en el trabajo?

¿Tienes que hacer tareas que tú crees deberían hacerse de otra manera?

¿Tienes que realizar tareas que parecen innecesarias?

\section{-Calidad de liderazgo.}

Tus jefes inmediatos:

¿Se aseguran de que cada uno de los trabajadores/as tiene buenas oportunidades de desarrollo profesional?

¿Dan una gran prioridad a que los trabajadores/as estén a gusto en el trabajo?

¿Planifican bien el trabajo?

¿Asignan bien el trabajo?

¿Resuelven bien los conflictos?

¿Se comunican bien con los trabajadores y trabajadoras? 


\section{CAPÍTULO V. TÉCNICAS DE MANIPULACIÓN RESEÑABLES EN EL PROCESO COERCITIVO \\ DEL MOBBING E INSTRUMENTOS DE EVALUACIÓN DE LAS VÍCTIMAS DE MOBBING}

\section{-Refuerzo.}

¿Hablas con tu superior sobre cómo llevas a cabo tu trabajo?

¿Hablas con tus compañeros o compañeras sobre cómo llevas a cabo tu trabajo?

\section{-Apoyo social en el trabajo.}

¿Recibes ayuda y apoyo de tus compañeras o compañeros?

¿Tus compañeros o compañeras están dispuestos a escuchar tus problemas en el trabajo?

¿Recibes ayuda y apoyo de tu inmediato o inmediata superior?

¿Tu inmediato o inmediata superior está dispuesto a escuchar tus problemas en el trabajo?

\section{-Posibilidades de relación social.}

¿Tu puesto de trabajo se encuentra aislado del de tus compañeros o compañeras? ¿Puedes hablar con tus compañeros o compañeras mientras estás trabajando?

\section{-Sentimiento de grupo.}

¿Hay un buen ambiente entre tú y tus compañeros/as de trabajo? Entre compañeros y compañeras ¿Os ayudáis en el trabajo?

En el trabajo ¿sientes que formas parte de un grupo?

\section{-Inseguridad en el trabajo.}

¿Estás preocupado por...:

...si te despiden o no te renuevan el contrato?

.... do difícil que sería encontrar otro trabajo en el caso de que te quedaras en paro?

...si te trasladan a otro centro de trabajo, unidad, departamento o sección contra tu voluntad?

...si te cambian de tareas contra tu voluntad?

...si te cambian el horario (turno, días de la semana, horas de entrada y salida) contra tu voluntad?

...por si te varían el salario (que no te lo actualicen, que te lo bajen, que introduzcan el salario variable, que te paguen en especie, etc..)?

...si no te hacen fijo/a?

...si no te promocionan?

\section{-Estima.}

Mis superiores me dan el reconocimiento que merezco

Mis compañeros de trabajo me dan el reconocimiento que merezco

En las situaciones difíciles en el trabajo recibo el apoyo necesario

En mi trabajo me tratan injustamente

Si pienso en todo el trabajo y esfuerzo que he realizado, el reconocimiento que recibo en mi trabajo me parece adecuado.

Seguidamente se presenta, un resumen-abstract, en el que se recogen los aspectos principales abordados a lo largo del Capítulo. 


\section{CAPÍTULO V. TÉCNICAS DE MANIPULACIÓN RESEÑABLES EN EL PROCESO COERCITIVO}

DEL MOBBING E INSTRUMENTOS DE EVALUACIÓN DE LAS VÍCTIMAS DE MOBBING

\section{RESUMEN - ABSTRACT}

\section{CAPÍTULO V.}

"Técnicas de Manipulación reseñables en el proceso coercitivo del mobbing e instrumentos de evaluación de las víctimas de mobbing”.

A lo largo del Capítulo $V$, se han recogido los diferentes análisis de estudio acerca de las técnicas de manipulación existentes en el fenómeno del mobbing directivo y los instrumentos de evaluación más relevantes en la actualidad para evaluar a las víctimas.

En él se detallan las diferentes estrategias de manipulación coexistentes (influencia intensa, doble intencionalidad, seducción, informidad, nebulosidad, simulación, familiaridad, autorrevelación, proyección de honestidad, manipulación de sentimientos y secretismo), los principales mecanismos psicológicos que interfieren e intervienen (selección, dramatización, generalización, atribución, proyección, evitación, racionalización, negación, equipo forzado, giro y triangulación), la comunicación interpersonal como medida de coacción de la víctima (estudiando en minucia el ciclo estratégico de la comunicación y la comunicación eficaz entre otros aspectos destacables), la violencia psicológica existente en las organizaciones (situación previa a la aparición del acoso), la diversidad de situaciones que puedan presentarte y los tipos de acoso que se pueden llegar a dar (acoso vertical descendente o "bossing", acoso horizontal o "de iguales", acoso mixto, acoso vertical ascendente y algunos tipos de acoso emergentes, diferenciados de estos) y la soledad y el aislamiento que vivencia la persona acosada, el directivo acosado.

Por último se describen las diferentes pruebas, e instrumentos existentes en la actualidad para evaluar a quienes han sido objeto de acoso laboral, realizando un 


\section{CAPÍTULO V. TÉCNICAS DE MANIPULACIÓN RESEÑABLES EN EL PROCESO COERCITIVO DEL MOBBING E INSTRUMENTOS DE EVALUACIÓN DE LAS VÍCTIMAS DE MOBBING}

análisis exhaustivo del LIPT (Leymann Inventory Of Psychological Terrozization), el NAQ (Negative Acts Questionnaire) el WHS (Work Harassment Scale) , la Escala Cisneros, y el ISTAS 21 (Escala Psicosocial de Copenhague). Todos ellos se analizan en profundidad, intentando además mostrar un modelo de cada uno de ellos, que muestren de manera descriptiva en qué consiste cada uno, poniendo énfasis en cuáles son los aspectos que miden o tratan de medir y en qué casos es más importante el uso de unos u otros en función de la situación que se presente.

A continuación abordaremos el Capítulo VI, centrado en la identificación y tratamiento del acoso laboral. 


\section{CAPÍTULO VI}

"Identificación y Tratamiento del Acoso Laboral"

VNIVERSITAS STVDII SALAMANTINI

"Execrábale sobremanera, y, deseoso de encima, en interés de la propia reputación, hízole blanco de sus ataques, en los que descubría lo tortuoso de su inteligencia, su malignidad y su perversidad".

Gustave Flaubert. 


\section{CAPÍTULO VI.}

"Identificación y Tratamiento del Acoso Laboral".

\section{Identificación y Tratamiento del Acoso Laboral.}

"Debes irte justo en el momento en el que empiezas a preguntarte si deberías irte o quedarte..."

Anónimo.

Como hemos visto a lo largo de los cinco capítulos anteriores, el acoso laboral o mobbing no distingue del nivel cultural, de la idiosincrasia, del idioma, de la religión, del nivel de desarrollo educacional, del país, de su gente, de la historia, de las costumbres y de ninguno de los diferentes parámetros vinculados con el desarrollo humano, puesto que como hemos analizado es una verdadera pandemia que afecta a las personas tanto física como moral y psicológicamente, comenzando por hechos insignificantes, que pasan inadvertidos, hasta llegar al verdadero psicoterror laboral en los centros residenciales.

Por tanto debemos señalar que el acoso laboral en puestos directivos de centros residenciales, ha de abordarse de manera interdisciplinar, aplicando diversas medidas para su diagnóstico y con un enfoque eminentemente preventivo. Los diferentes investigadores de la materia, coinciden en la importancia de adoptar medidas de concienciación y prevención en fases tempranas para evitar un entorno de trabajo tóxico y destructivo.

Rodríguez Copé (2006), señala que la empresa debe ser el primer campo de actuación contra el acoso, porque es el escenario donde se suceden los hechos, de tal forma que debe adoptar pautas orientadas a evitar la aparición de conflictos y su 


\section{CAPÍTULO VI. IDENTIFICACIÓN Y TRATAMIENTO DEL ACOSO LABORAL}

estigmatización, lo que se conseguirá a través de una adecuada organización del trabajo y de la puesta en práctica de los instrumentos necesarios para prevenir, regular y sancionar si es preciso.

Gimeno (2008), destaca tres aspectos a tener en cuenta en el desarrollo de las acciones preventivas:

1-El ámbito en el que se circunscribe la intervención (individual, grupal, organizacional y social); según el nivel sobre el que se trabaje, la actividad preventiva se centrara en unos elementos u otros. En el ámbito individual se puede trabajar sobre la personalidad, las motivaciones, las actitudes, las aptitudes, las conductas, las habilidades sociales y los recursos personales y sociales. En el ámbito grupal se tratarían aspectos tales como el desempeño de roles, el estatus, las normas grupales, el reparto de tareas, la pertenencia, el establecimiento de las relaciones, la cooperación grupal y sobre todo el liderazgo formal. En el ámbito organizacional resultan determinantes elementos esenciales como son la estructura jerárquica, el reparto de poder, los canales de información y comunicación, las relaciones personales, las promociones y desarrollos profesionales, el tipo de jornada, las pautas de trabajo, el tipo de relaciones sociolaborales, el estilo de mando, la cultura o el clima organizacional entre otros. En el ámbito social son destacables aspectos tales como desarrollos jurídicos, mecanismos sociosanitarios, recursos técnicos, percepciones sociales, o la calidad de vida entre otros.

2-La fase en la que se debe intervenir dentro del proceso de evolución del acoso; es evidente que no es lo mismo trabajar en paliar la situación que en evitar su aparición. Debemos reseñar que la prevención responde a una visión proactiva del fenómeno, mientras que la paliación nace de una perspectiva reactiva, más compleja y con mayores consecuencias sobre la salud de los trabajadores. 


\section{CAPÍTULO VI. IDENTIFICACIÓN Y TRATAMIENTO DEL ACOSO LABORAL}

3-La creencia que tienen las empresas, sus miembros y el contexto social acerca del acoso laboral; una interpretación errónea que hacen la mayoría de las empresas en las que se produce el fenómeno, es considerarlo un problema individual, centrado en la personalidad o incapacidad para adaptarse de la víctima. Esta postura imposibilita cualquier tipo de acción preventiva, puesto que no reconocen el acoso como tal, sino que tan solo lo consideran como un problema personal del trabajador afectado, resolviendo la situación considerándola como riesgo laboral. Puede incluso que lo consideren como una incompatibilidad interpersonal (normalmente entre dos personas, miembros de la empresa), que por razones "desconocidas para ellos", no lograr conciliar el trabajo conjunto, en equipo.

Rojas Rivero (2005), alude a dos aspectos de máxima relevancia al hablar de prevención:

1) La evaluación de los riesgos en el desarrollo habitual de la actividad laboral, evaluación de los aspectos organizativos, estructurales y relacionales, en este caso que nos ocupa estaríamos hablando de realizar dicha evaluación en los centros residenciales, con la colaboración de los diferentes departamentos y el permiso de los directivos.

2) La planificación, que debe ir acompañada de tareas formativas y de vigilancia; en este caso la política que se ha de seguir debe comenzar por educar a los directivos de los centros, a los máximos responsables, en crear códigos de conductas, de buena praxis profesional, protocolos de buenas prácticas que se lleven a efecto y que sean conocidos por todos los trabajadores que compongan el centro en la actualidad, donde además de verifiquen conductas y pautas y se controlen con eficacia los mecanismos de trabajo, y la ética empresarial del centro, y del grupo gestor del mismo. 


\section{CAPÍTULO VI. IDENTIFICACIÓN Y TRATAMIENTO DEL ACOSO LABORAL}

Por tanto para hablar de ambientes de trabajo "saludables" y con niveles de calidad de vida laboral oportunos, debemos hablar de (Alcover de la Hera, 2007):

\section{1) Multidimensionalidad.}

El bienestar laboral de una persona no solo se manifiesta en su estado físico, sino que se manifiesta en diferentes ámbitos, individuales y colectivos, por lo que determinar el bienestar ha de conllevar evaluar su salud física, evaluar la calidad de sus relaciones sociales y evaluar sus posibilidades de desarrollo intelectual y emocional entre muchas otras que podríamos nombrar. Estos podrían ser indicadores de un ambiente de trabajo saludable.

\section{2) Pluralidad de niveles.}

Una de las principales dificultades en el estudio del comportamiento laboral en un centro residencial, es la presencia de distintos niveles de análisis que interactúan entre sí. La tensión experimentada puede ser el resultado de una evaluación ineficaz de las necesidades de formación, por lo que la evaluación ha de ser muy exhaustiva y prudente, tratando los datos con suma cautela, considerando además que en numerosos casos la tensión reflejada en los trabajadores es fruto del ambiente competitivo que impera en la actualidad en las empresas.

\section{3) Congruencia e integración.}

En un centro residencial, la integración de los diferentes departamentos es un elemento esencial para el buen funcionamiento del mismo, ya que interactúan constantemente los unos con los otros. Debemos resaltar la importancia del ajuste entre la persona y el contexto de trabajo: los valores, las necesidades y las capacidades de la persona deben sincronizarse con los de la empresa. 


\section{CAPÍTULO VI. IDENTIFICACIÓN Y TRATAMIENTO DEL ACOSO LABORAL}

\section{4) Acciones para la promoción del bienestar y la salud en el trabajo.}

Cuando una organización se plantea la necesidad de abordar cuestiones relacionadas con la promoción del bienestar, es necesario determinar cuál será el alcance de las mismas, puede que la organización se limite a poner en marcha programas específicos para atajar algún problema concreto ya presente o aquellos que se estimen posibles en un futuro no muy lejano.

\section{5) Autoevaluación y adaptabilidad.}

Un centro residencial es un ente dinámico por definición, está en continuo cambio, tanto por la interacción con los agentes sociales del entorno, como por los diferentes residentes que se encuentran en cada momento concreto, como por los trabajadores que conforman la plantilla del centro. Por tanto se debe tratar de encontrar un equilibrio dinámico, es decir se deben producir cambios constantes en la gestión del centro, que exigirán una readaptación del sistema laboral hasta alcanzar una nueva condición de estabilidad.

El centro, y en su lugar los directivos del mismo, han de ser capaces de detectar los cambios, evaluar su impacto sobre el bienestar y la salud de sus miembros y poner en marcha acciones que prevengan o amortigüen las consecuencias negativas. Además se ha de tener en cuenta que cuando un grupo empresarial realiza nuevas aperturas de centros, o remodelaciones profundas en los departamentos de los mismos, deberá planificar los aspectos relacionados con las nuevas estructuras y su funcionalidad, además de estimar y prever acciones que faciliten la adaptación de los trabajadores y la nueva configuración de los equipos de trabajo.

\section{6) Conciencia de las tensiones.}

Una de las primeras cuestiones a tener en cuenta al afrontar el estudio del bienestar laboral, es que las organizaciones nunca alcanzan un estado de 


\section{CAPÍTULO VI. IDENTIFICACIÓN Y TRATAMIENTO DEL ACOSO LABORAL}

armonía total, sino que siempre atraviesan por una serie de tensiones o conflictos que no pueden resolverse de manera concluyente, aunque si se puede buscar la forma de redefinirlos satisfactoriamente para las partes implicadas. La necesidad de coherencia frente a la diversidad y la necesidad de reestructuración frente a la flexibilidad son dos máximas en los centros residenciales.

Respecto a la coherencia debemos resaltar que el buen funcionamiento de un centro solo es posible si se da un mínimo de uniformidad en las normas, procedimientos y demás elementos comunes necesarios, no obstante y por definición de la diversidad que conforma el centro residencial se hace necesaria e indispensable, cierto grado de autonomía regulada en el cumplimiento de dichas normas.

La conducta ética de cada trabajador en las funciones que caracterizan cada puesto de trabajo, que a su vez conforman cada departamento, que componen un centro debe de estar lo más explícita posible, precisando lo que es apropiado y lo que no lo es, lo que se ha de hacer y lo que no, debiendo quedar lo suficientemente claro para todos los trabajadores lo aceptable, lo inaceptable, lo justo, lo injusto, lo tolerable y lo intolerable.

A continuación enumeraremos una serie de mitos existentes en la actualidad entorno al acoso laboral o mobbing, con el fin de poder desmitificar su falsedad mediante un análisis y argumentación lógica:

MITO 1. "En el caso de la víctima, se dice que ella lo provoco".

Este mito es el que sustenta las afirmaciones que hacen a la persona afectada de acoso laboral la responsable del hostigamiento. Se manifiesta con expresiones que se centran en las características personales del acosado, llegando a decir que "se lo merece", "algo habrá hecho", "se veía venir", "si es que no se puede ser asi", "eso le pasa por trepa"...Se produce así un error de 


\section{CAPÍTULO VI. IDENTIFICACIÓN Y TRATAMIENTO DEL ACOSO LABORAL}

atribución, y no es otra cosa más que la manifestación de un mecanismo defensivo. A las personas las provoca pánico pensar en la existencia de la violencia gratuita, de ahí que necesiten una "explicación lógica" ante los hechos que ellos observan día a día, en el trabajo, ocurren a sus compañeros. Por todo ello debemos resaltar que el hostigamiento, no es provocado por la víctima ya que ninguna persona quiere ser objeto de violencia, de acoso laboral.

MITO 2. "No es un problema grave".

Esta negación de los hechos, evita observar atentamente la gravedad de lo ocurrido, ya que intenta aparentar normalidad, cuando la realidad es otra. Encubre así las graves repercusiones que el acoso ejerce sobre la víctima, su familia, sus amigos, sus compañeros de trabajo, su empresa y la sociedad en su conjunto, ya que como hemos visto en capítulos anteriores, es un fenómeno con numerosas consecuencias para todos ellos. Se tiende así a decir, que la víctima está exagerando la situación. La realidad es que es un grave problema psicosocial que está ampliamente estudiado, y que tras la actual crisis económica que atraviesa España, aumenta día tras día.

MITO 3. "Las personas que hostigan son enfermos mentales".

Es necesario reconocer, que las personas que ejercen de hostigadores no son enfermos mentales. Tradicionalmente se ha utilizado la enfermedad mental como eximente de responsabilidad, cuando es bien sabido que nuestro código penal contempla muy pocas enfermedades mentales como eximentes en un proceso judicial, siendo estas aquellas que cursan con desconocimiento entre el bien y el mal. Todos los estudios realizados hasta día de hoy, denotan que los acosadores, tienden a ver a su víctima como objeto o medio, para alcanzar su satisfacción personal y están dispuestos a llevar a cabo cualquier tipo de conducta para alcanzar su propósito. 


\section{CAPÍTULO VI. IDENTIFICACIÓN Y TRATAMIENTO DEL ACOSO LABORAL}

> MITO 4. "El hostigamiento sólo afecta a algunas personas".

Debemos de tener siempre la firmeza de que cualquier persona puede ser víctima de acoso laboral, independientemente de cualquier circunstancia que la rodee. Esta afirmación, pretende justificar el hostigamiento que se produce, siendo interpretada como un castigo hacia la víctima, por no someterse o no cumplir las tareas encomendadas por quien violenta y hostiga. Lo único que verdaderamente podemos afirmar es que si existe un perfil de acosador.

MITO 5. "El hostigamiento complace a las víctimas".

Es uno de los mitos más estudiados en investigaciones recientes. Esta afirmación sugiere que el acoso, tan solo son simples formas de relacionarse entre las personas, justificando la falta de empatía o habilidades sociales de la víctima para relacionarse con sus superiores, nada más lejos de la realidad. El hostigamiento nunca puede complacer a la víctima, ya que con ello tan solo encuentra sufrimiento y dolor. El hostigamiento se da en contra de la víctima, ninguna persona se quiere sentir como tal, humillada, violentada, deprimida, sola, etc...

MITO 6. "El hostigador no puede, por naturaleza, controlar su agresividad".

Las expresiones que justifican este mito, son tales como "es que él es asi", "es su manera de hacer las cosas", "siempre trata así a los trabajadores", refiriéndose al acosador. Por norma un abuso, u hostigamiento que no cesa, siempre va a más, siendo frecuente en investigaciones afirmar que "el hostigador llega hasta donde la víctima lo deje", es decir el abuso va increscendo. Debemos siempre saber, que el hostigador no trata a todos por igual, sino que sabe muy bien cómo y con quien hacer uso de su violencia, incluso llega a mostrarse como una persona encantadora, para quienes le rodean. 


\section{CAPÍTULO VI. IDENTIFICACIÓN Y TRATAMIENTO DEL ACOSO LABORAL}

MITO 7. "Si quisieran, las víctimas podrían detener el hostigamiento".

Es un mito basado, en que el control de la situación la tiene la víctima, cuando en realidad la persona que controla lo que está ocurriendo es el hostigador. Sirve a todos aquellos que aún pudiendo hacer algo para detener el acoso no lo hacen. Todos los estudios llevados a cabo arrojan datos y demuestran que las víctimas del acoso laboral, hacen todo cuanto está en su mano por cambiar la situación. La asimetría existente en esta situación hace que el acoso solo pueda detenerlo quien lo lleva a cabo, ya que la víctima siempre estará en desventaja.

MITO 8. "La mayoría de las víctimas denuncian falsamente".

Esta afirmación, no hace sino más que estigmatizar a las víctimas de acoso laboral. Siempre se ha de poner el acento y la atención en quienes sufren el mobbing, no en quienes lo denuncian sin certeza, pues de lo contrario se pondrá en duda a quienes lo padecen realmente. Todo ello producirá más indefensión en la víctima, lo cual agudizará más su situación de hostilidad y de soledad. Esta creencia de que se denuncia falsamente es a menudo utilizada por los acosadores, para descalificar a la víctima que denuncia y con ello pretende desacreditar su versión mediante la creación de un ambiente de duda dentro del proceso judicial que se pueda estar desarrollando.

MITO 9. "Los hostigadores tienen escasa cultura".

Se tiende a creer que quienes son capaces de llevar a cabo estos actos y estas conductas violentas son personas con un bajo nivel de estudios, de una clase social desfavorecida, etc.. Esto es totalmente falso. Quien hostiga, con frecuencia, es una persona con recursos, estudios e incluso altamente cualificada, o si no lo es, al menos ha sido capaz de optar a puestos de responsabilidad dentro de su empresa y del mundo laboral actual. 


\section{CAPÍTULO VI. IDENTIFICACIÓN Y TRATAMIENTO DEL ACOSO LABORAL}

MITO 10. "Los que acosan laboralmente han tenido una infancia difícil".

Estamos ante una afirmación suspicaz y controvertida en investigación; ni todos los hostigadores han sido maltratados, acosados, o han tenido una infancia difícil, ni podemos afirmar que algunos casos no lo hayan sido. Las estadísticas lo que confirman es que si son personas con algunos déficits sociales, con carencias de reconocimiento de éxito, éxito que persiguen a costa de quienes hostigan, con el fin de sentirse plenos, tanto en su vida personal y afectiva, como en su carrera profesional.

MITO 11. "Los trabajadores también maltratan a los directivos".

Esta sin lugar a duda es una de las estrategias más utilizadas por el acosador cuando es descubierto por quien está siendo su víctima. Negará ser el autor de lo que está ocurriendo y de lo que ya, ha ocurrido, acusando a su víctima de ser ella quien realmente está maltratándole como directivo, debido dice, a no querer llevar a cabo las instrucciones que se le dan como trabajador de la empresa. En el caso de que la víctima denuncie los hechos, y el procedimiento se vea sometido a ser juzgado por la justicia, incluso será uno de los argumentos del acusado para intentar desfocalizar la atención de los jueces en su persona.

MITO 12. "Los casos de acoso laboral, son casos puntuales, aislados".

Es una clara falacia pensar que hoy en día el acoso laboral se dé aisladamente. Cada vez son más quienes desafortunadamente padecen y se ven inmersos en este tipo de situaciones, agudizadas aún más si cabe por el actual momento laboral que viven los trabajadores, quienes se ven amenazados por el paro y las largas estancias en desempleo que se están produciendo día tras día. 


\section{CAPÍTULO VI. IDENTIFICACIÓN Y TRATAMIENTO DEL ACOSO LABORAL}

Seguidamente analizaremos en detalle, las diferentes fases que se suceden para que una persona víctima de acoso laboral en su puesto de trabajo, pueda ser capaz de regresar al estado anterior al de sufrir el acoso.

\subsection{Fases en la Superación del Acoso en el Trabajo.}

Una organización de trabajo, implica la reunión de un grupo de personas, más o menos grande, con un fin común, lo que la convierte en una organización social. En las organizaciones de trabajo, como es un centro residencial, suelen estar contempladas las relaciones que deben establecerse entre los distintos individuos y grupos para la realización de las tareas encomendadas. Sin embargo, como hemos visto a lo largo del desarrollo de esta tesis, la existencia de otros tipos de relaciones, distintas de las meramente productivas, entre los distintos componentes de una empresa, no se contempla en ningún manual, ni en ningún departamento de la empresa. Como consecuencia, es posible que se dé un funcionamiento anormal de la organización social, cuando emerjan casos de acoso laboral, lo que puede traducirse en consecuencias bastante más amplias que simples discusiones o problemas personales entre los miembros que la componen.

A pesar de que el acoso laboral es un problema que no puede superarse sin apoyo familiar, social y sin la ayuda de un profesional cualificado, hay una serie de estrategias que pueden ponerse en marcha a nivel personal para superar este problema. Es sabido, que a lo largo de la vida, nos enfrentamos a diversas situaciones que comprometen nuestra integridad y nuestro pensamiento, como es el caso ante el que nos encontramos, pero no es menos cierto que el ser humano, dispone de mecanismos de defensa, capaces de hacer frente a tales situaciones.

El afrontamiento supone para el acosado una elección que no siempre es adoptada, por varias razones. Suele ser frecuente que la víctima se deje llevar por 


\section{CAPÍTULO VI. IDENTIFICACIÓN Y TRATAMIENTO DEL ACOSO LABORAL}

sutiles mecanismos psicológicos de defensa, en lugar de elaborar una racional, meditada e inteligente respuesta asertiva. Por ello las estrategias para afrontar y enfrentar al acosador laboral, exigen el despliegue de un intenso trabajo personal, Ileno de autodisciplina (Piñuel, 2003).

La principal reacción del organismo, ante los hechos sufridos en la inseguridad, esta inseguridad viene caracterizada por:

Malestar emocional.

En las fases iniciales del comienzo del acoso, la persona siente una inquietud vital que le invade. No es capaz de reconocer que está ocurriendo, pero si siente que no está bien. Se irrita con facilidad, ante cualquier situación y siente sentimientos de negatividad ante la vida.

Nerviosismo.

Este malestar emocional hace que su sistema límbico y su neocortex, transmitan mayor número de impulsos nerviosos. El sujeto siente mayor reactividad en su cuerpo de la deseada, él consciente de ello trata de ocultar este nerviosismo que se apodera de él, consiguiendo el efecto contrario al deseado, lo cual intenta ocultar a quienes le rodean.

Falta de confianza en la valía y las capacidades.

Este malestar emocional y nerviosismo inicial, merman la confianza en sí mismo, que hasta ahora tenía la persona. Sus capacidades intelectuales y ante la propia vida, se ven coartadas, y la víctima, comienza a ser consciente de ello, lo cual no hará más que agravar su situación.

Desconfianza hacia el otro.

Fruto de todo ello, y ante las condiciones que imperan sobre su organismo, la víctima, desconfía de todo y todos cuanto le rodean. 


\section{CAPÍTULO VI. IDENTIFICACIÓN Y TRATAMIENTO DEL ACOSO LABORAL}

Arrogancia reactiva.

Es una conducta que se produce como respuesta, ante la situación injusta que el acosado comienza a sentir que padece. Responde así de manera abrupta, ante cualquier situación, que él considere injusta o desmedida, llegándose a mostrar arrogante ante algunos hechos y situaciones. Muestra así una analogía entre su situación y la que observa en los demás como tal.

Aislamiento.

Ante todo ello, y como hemos relatado a lo largo de toda la tesis, el sujeto decide estar solo, es un aislamiento patológico, no elegido voluntariamente, sino que la persona afectada decide que la mejor medida a adoptar es alejarse de todo y de todos. El bloqueo que experimenta es tal, que es incapaz de describir lo que está viviendo. Ante esa falta de capacidad, decide no mostrarse ante nadie.

Percepción de vulnerabilidad.

A la vez que se aisla de los demás, comienza a tener conciencia de que lo que le está ocurriendo, lo cual, le hace más débil, le debilita, de tal manera que él mismo se ve como alguien a quien le pueden ocurrir más cosas. Se percibe a sí mismo como inferior a los demás, con menos capacidad de afrontamiento de la propia vida.

Nuevas formas de entender la propia conciencia.

El sujeto, comenzará así a sentirse diferente, interioriza y hace suya la culpa de lo acontecido, y su sentimiento de fracaso laboral. Siente que tiene "mala conciencia" ante lo ocurrido, pues se siente culpable de no haber sido capaz de desarrollar óptimamente su trabajo. 


\section{CAPÍTULO VI. IDENTIFICACIÓN Y TRATAMIENTO DEL ACOSO LABORAL}

Cambios bruscos de opinión.

Esta situación, ante la cual se encuentra hace que tenga una vaga opinión, lo cual le lleva a tomar decisiones contradictorias. Cabe recordar que la dirección de un centro residencial implica una toma de decisiones constantes para el buen devenir del centro, lo que no ayudará en el proceso de acoso laboral.

Falta de decisión, a la hora de asumir riesgos.

Las personas que dirigen centros residenciales han de ser líderes, líderes que como tales, además de ceñirse a los objetivos de la propia empresa, han de ser capaces de asumir riesgos en la toma de decisiones de la dirección del centro. La falta de decisión que muestran las víctimas en este estado hará que sean incapaces de asumir dichos riesgos, cayendo en formas vagas $y$ monótonas de gestión.

Análisis exhaustivo de situaciones y factores irrelevantes.

Los directivos que se encuentran ante esta situación, analizan en detalle cualquier situación que se produzca a su alrededor por irrelevante que sea, lo que hará que pierda una gran cantidad de tiempo de su jornada en revisar documentación y en analizar cada circunstancia que se dé, sin obtener conclusión alguna que haga que su situación mejore.

Incapacidad temporal en la resolución de problemas.

Todo buen gestor de equipos que se precie ha de tener una gran capacidad en la resolución de conflictos y problemas que puedan surgir en el desempeño de las tareas del centro. Mientras acontece el mobbing, las capacidades y habilidades sociales e intelectuales del directivo merman, hasta prácticamente su desaparición. La persona es incapaz de dar una solución óptima a situaciones que podemos calificar de cotidianas en su puesto de trabajo. 


\section{CAPÍTULO VI. IDENTIFICACIÓN Y TRATAMIENTO DEL ACOSO LABORAL}

Toma de decisiones irracionales.

El directivo acosado, tiende a no reflexionar acerca de las decisiones tomadas debido en gran parte al bloqueo cognitivo que padece, tras sufrir el acoso. El pensamiento reflexivo queda en un segundo plano a la hora de la toma de decisiones concernientes a su labor como directivo del centro residencial.

Sentimientos contrariados.

Con todo ello, la víctima se siente inmensamente contrariada, siente que ya no es capaz de desempeñar su trabajo como lo venía haciendo hasta antes de comenzar el acoso. Se siente frustrada, confundida, apesadumbrada, y sola. Ve inalcanzable casi cualquier tarea que requiera un alto pensamiento reflexivo como director.

Maximización de lo negativo.

Así pues, la víctima maximiza todo aquello que a su parecer le está ocurriendo negativamente. Generaliza situaciones concretas, y ensombrece todo cuanto evalúa como amenaza para sí.

Dudas y pudor ante determinados temas.

Siente un gran estupor para hablar de algunos temas determinados, normalmente todos aquellos que estén relacionados con el trabajo, y con la manera de proceder en la vida laboral. Siente como una duda generalizada se apodera de su cognición, hasta hacerle dudar incluso en algunos casos acerca de su propia vida.

Indecisión.

Toda esta incertidumbre, lógica, llevará a la víctima a estar indeciso, sobre qué postura tomar, frente a la situación que está vivenciando. 


\section{CAPÍTULO VI. IDENTIFICACIÓN Y TRATAMIENTO DEL ACOSO LABORAL}

En el gráfico que se muestra a continuación, gráfico 6.1 se resumen los indicadores que hemos analizado.

\section{TABLA-RESUMEN:}

INDICADORES DE LA INSEGURIDAD
DIRECTIVA
1-Malestar emocional.
2-Nerviosismo.
3-Falta de confianza en la valía y las capacidades.
4-Desconfianza hacia el otro.
5-Arrogancia reactiva.
6-Aislamiento.
7-Percepción de vulnerabilidad.
8-Nuevas formas de entender la propia conciencia.
9-Cambios bruscos de opinión.
10-Falta de decisión, a la hora de asumir riesgos.
11-Análisis exhaustivo de situaciones y factores
irrelevantes.
12-Incapacidad temporal en la resolución de
problemas.
13-Toma de decisiones irracionales.
14-Sentimientos contrariados.
15-Maximización de lo negativo.
16-Dudas y pudor sobre determinados temas.
17-Indecisión.

Gráfico 6. I. "Indicadores de la Inseguridad de un Directivo".

Una vez superada esta inseguridad, que como hemos visto se apodera de la víctima, se producirá una reacción agresiva contra el acosador o contra sus cooperantes necesarios. La persona acosada tiende a defenderse mediante un comportamiento agresivo, que busca su supervivencia, lo cual resultará altamente perjudicial para su salud. Agredir verbalmente al acosador, no puede sino, empeorar más la situación. La naturaleza perversa y psicopática del acosador aprovechará la reacción agresiva como confirmación de hasta qué punto la víctima es merecedora de su castigo y reprobación. Asimismo, utilizará la reacción agresiva, para desprestigiar y difamar la imagen pública de su víctima (Piñuel, 2003). 


\section{CAPÍTULO VI. IDENTIFICACIÓN Y TRATAMIENTO DEL ACOSO LABORAL}

En el siguiente gráfico, gráfico 6.2, se muestra la reacción de agresividad e ira que se produce hacia el acosador:

\section{PROGRAMACIÓN}

- Los ataques injustos no se deberían producir.

- No se deberían cometer injusticias conmigo.

- Me debo sentir mal si se cometen injusticias conmigo
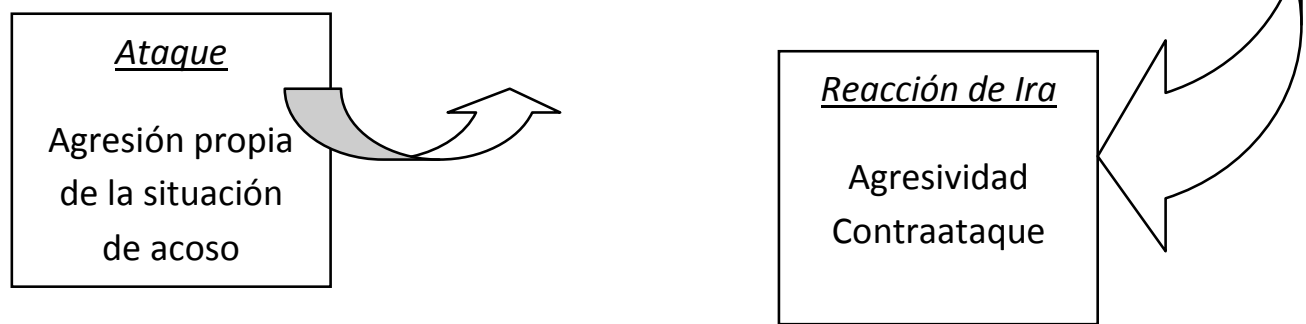

Gráfico 6.2. "Mediación de la Programación de la persona en la reacción de ira después del ataque" (Piñuel, 2003).

Así pues, lo más saludable psicológicamente, y a la vez lo más difícil es aceptar la impotencia que uno siente, y asumir que no tiene elección ni alternativa, el hostigador lo ha elegido a él.

Así pues es necesario que se sucedan una serie de fases para que el sujeto sea capaz de superar el acoso al que ha estado sometido durante los últimos meses e incluso años. Es muy relevante llegado a este punto que el sujeto hostigado, haya sido capaz de canalizar la ira inicial que le invade, fruto de la inseguridad que hemos descrito y que haya superado la agresividad que se produce ante la impotencia que ha vivido.

Las fases que constituyen la superación del acoso en el trabajo son las que se muestran en el siguiente gráfico, gráfico 6.3: 


\section{FASES EN LA SUPERACIÓN DEL ACOSO:}

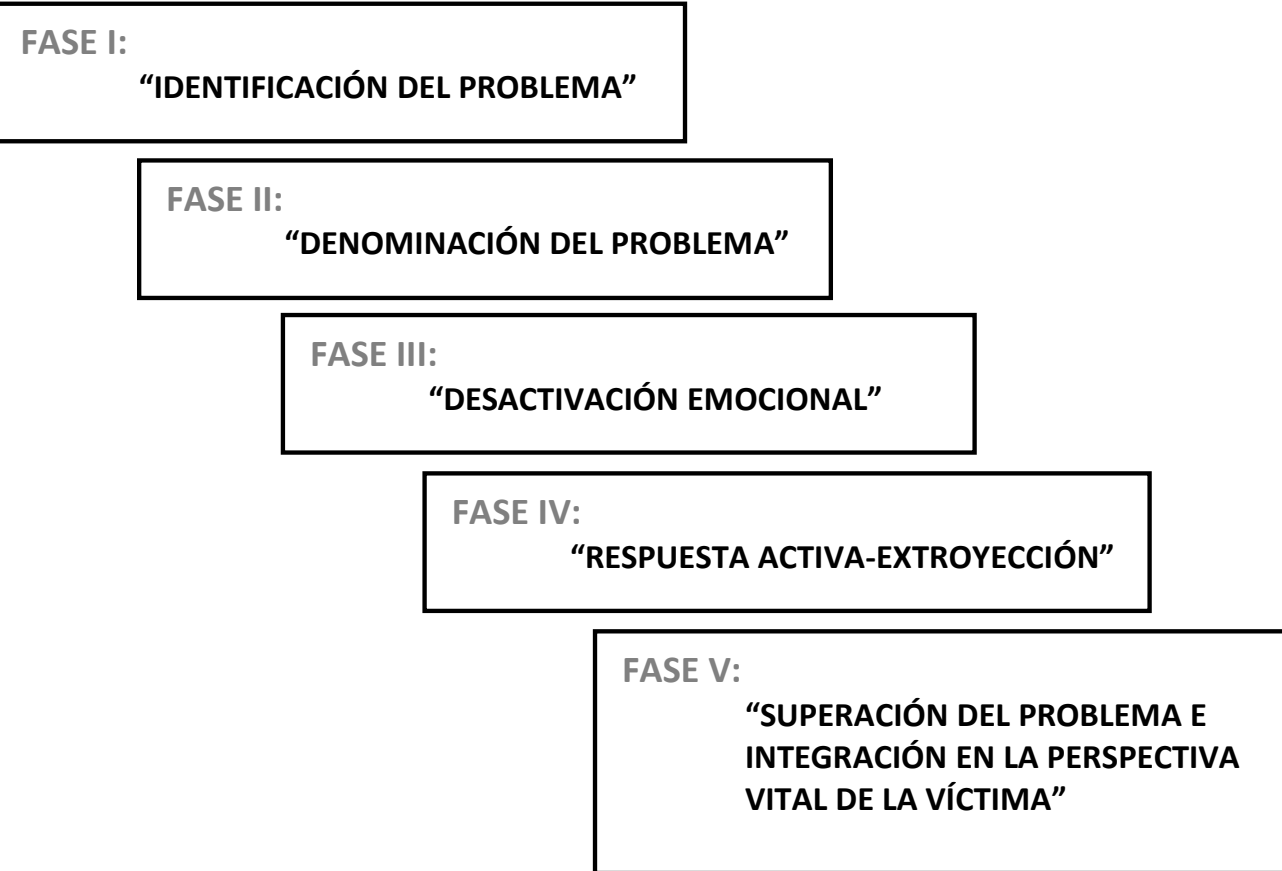

Gráfico 6.3. "Fases en la superación del mobbing o psicoterror laboral" (Piñuel, 2003).

Fase I: Identificación del Problema.

Esta fase inicial consiste en que la víctima supere la negación de los hechos y del problema, de tal manera que logre identificar el acoso, que sea capaz de reconocer lo que le está sucediendo o le ha sucedido. La identificación del problema como tal, hará consciente al acosado del daño que se le está infligiendo, con lo que comenzarán a remitir las somatizaciones, a aclarársele las dudas al respecto del fenómeno que está viviendo. El profesional, le explicará como transcurre el problema, dándole todo tipo de información que requiera, aportándole detalles de la perspectiva correcta de lo que le ha sucedido. Es muy común además que en esta fase inicial, se trabaje con la familia, amigos, allegados o pareja de la víctima y demás personas sobre las que ha tenido consecuencia alguna el acoso, con el fin de esclarecerles a ellos también lo sucedido. De esta manera se les hace participes del proceso. 


\section{CAPÍTULO VI. IDENTIFICACIÓN Y TRATAMIENTO DEL ACOSO LABORAL}

\section{Fase II: Denominación del Problema.}

Esta segunda fase, es sin duda es una de las más duras de afrontar para la víctima; requiere un esfuerzo psicológico adicional puesto que se trata de reconocer qué ha ocurrido y etiquetar los hechos. El acoso laboral en la mayoría de los casos es algo lejano para la víctima, algo que desconoce y que piensa nunca le va a ocurrir a él. Una vez evaluado y denominado, la víctima buscara todo tipo de información al respecto, lo cual desde el punto de vista del profesional, se ha de acotar y leer tan solo aquello que le proporcione el mismo, con el fin de mitigar las posibles lecturas erróneas y falsas que pueda encontrar en el medio.

\section{Fase III: Desactivación Emocional.}

Es un requisito previo que el hostigado comprenda lo que le ha ocurrido, para así poder empezar a trabajar el comportamiento emocional que ha desencadenado el acoso. El sujeto ha de percibir, como la rabia e ira inicial contra el acosador le impiden afrontar de manera eficaz y con una respuesta adecuada la situación. La víctima comienza a tomar conciencia de la magnitud de los daños ocasionados y las secuelas existentes, advierte como el acoso le ha generado una situación de indefensión que ha terminado por paralizar e interferir en su vida laboral y personal, perjudicando gravemente su carrera profesional. De esta manera, comienza a retomar el control sobre sus propias conductas y emociones. Algunas de las víctimas pronuncian afirmaciones tales como "vuelvo a ser yo", "que bien estoy sin ellos", etc...

\section{Fase IV: Respuesta Activa-Extroyección.}

Si algo siente el acosado además de ira y rabia, es culpa, culpa que ha interiorizado y sobre la que se ha de trabajar. Una vez se ha producido la desactivación emocional, y 


\section{CAPÍTULO VI. IDENTIFICACIÓN Y TRATAMIENTO DEL ACOSO LABORAL}

el sujeto es consciente del problema, se podrá trabajar sobre la extroyección de la culpa, invirtiendo el proceso que le ha llevado a interiorizarla. En esta fase se ha de trabajar además sobre la autoestima, el autoconcepto o la motivación, entre otros aspectos destacables.

\section{Fase V: Superación del Problema e Integración en la Perspectiva Vital de la Víctima.}

Perdonar al acosador, supone liberar energía del sistema psíquico que hasta el momento se encargaba de hacerlo presente. Una vez que la persona ha dado una respuesta óptima, independientemente de cuál sea su situación laboral, ha definido el problema, lo ha acotado, tiene suficiente información acerca de él, y posee ayuda de un profesional y el apoyo de su entorno y familia más cercano, es el momento de comenzar la superación del acoso y retomar la perspectiva de vida, anterior a los hechos acontecidos.

La mayoría de los afectados hablan de "pasar página", "de comenzar de nuevo a vivir", de "recuperar la ilusión", "de volver a tener tiempo libre y para la familia", perdiendo así el resentimiento, odio y rencor que pudiera sentir hacia quien él en un principio consideró "le había destrozado la vida".

Es por tanto un proceso largo, que requiere de un gran esfuerzo por parte de la víctima y sus allegados, y en el que se pueden suceder diferentes etapas de evolución dependiendo de las características personas de la víctima.

En las siguientes líneas estudiaremos como existen ciertos factores de defensa ante el mobbing, los enumeraremos y analizaremos en profundidad cada uno de ellos, con la intención de posteriormente hacer un abordaje sobre cuáles son las líneas de acción terapéutica existentes en la actualidad. 


\section{CAPÍTULO VI. IDENTIFICACIÓN Y TRATAMIENTO DEL ACOSO LABORAL}

\subsection{Factores de Resistencia al Mobbing.}

La reacción de la persona que ha estado sometida a hostigamiento, es la de blindarse emocionalmente. Es frecuente que la persona acosada sienta que la privan de la capacidad de disfrutar de aquellas cosas que antes le gustaban; experimentara así una gran dificultad inicial para experimentar placer y gusto, por las cosas que antes lo sentía. Por otra parte, puede darse la reacción de daño, que consiste en la frialdad e insensibilidad ante los problemas ajenos a su realidad. Esta frialdad ante los problemas o el sufrimiento de los demás es una reacción defensiva característica de un organismo acostumbrado al hostigamiento psicológico; a fuerza de repetición y continuidad se irá banalizando.

Si algo parece claro, es que cuando se produce una conducta de acoso moral, en el ámbito laboral, es evidente que la empresa no ha tomado las medidas oportunas de salud y seguridad y que la política de seguridad e higiene seguida en la empresa, tampoco es la adecuada, de tal manera que parece obvio afirmar que se han vulnerado los derechos del trabajador a su integridad física y moral en materia de seguridad e higiene en el trabajo.

El pesimismo de las víctimas de acoso laboral se concreta en expectativas muy negativas hacia su futuro profesional y personal, sentimientos de culpa o de hacerlo todo mal y una actitud muy mermada sobre lo que puede esperar de los demás. A pesar de todo ello existen numerosos factores que sirven para resistir al mobbing, y que hacen que la persona pueda recuperar la normalidad (Piñuel, 2003):

1) La construcción de un pensamiento racional, no tóxico, que evite las distorsiones que produce el pesimismo;

Es muy frecuente que las víctimas de acoso laboral presenten una serie de ideas irracionales tales como (Ellis, 1993) ${ }^{16}$ :

\footnotetext{
${ }^{16}$ Albert Ellis, fundador e investigador de la terapia racional emotiva. Una de sus grandes obras fue "Razón y Emoción en Psicoterapia”.
} 


\section{CAPÍTULO VI. IDENTIFICACIÓN Y TRATAMIENTO DEL ACOSO LABORAL}

- Es necesario para el ser humano, ser querido y aceptado por todo el mundo.

- Uno tiene que ser muy competente y saber resolverlo todo, si quiere considerarse necesario y útil.

- Hay gente mala y despreciable que debe recibir su merecido.

- Es horrible que las cosas no salgan como a uno le gustarían.

- La desgracia humana se debe a causas externas, y las personas no tenemos ninguna o muy pocas posibilidades de controlar nuestros disgustos y trastornos.

- Si algo es o puede ser peligroso o atemorizante, hay que preocuparse mucho al respecto y recrearse constantemente en la posibilidad de que ocurra.

- Es más fácil evitar que hacer frente a algunas dificultades o responsabilidades personales.

- Se necesita siempre de alguien más fuerte que uno en quien poder confiar.

- Un suceso pasado es un determinante importante de la conducta actual. Si algo me afectó mucho, continuará afectándome indefinidamente.

- Uno debe preocuparse continuamente por los problemas de los demás.

Frente a todo ello, la persona hostigada debe de construir su propio pensamiento constructivo, lógico, racional, basándose en premisas tales como, la aceptación social no es generalizada para nadie, la deseabilidad social no siempre es lo más óptimo, la perfección no siempre es sinónimo de éxito, la tolerancia al rencor, la ira y la venganza, la tolerancia hacia la frustración, más aún teniendo en cuenta que está es infundada, la toma de posturas intermedias hacia la solución del conflicto interno, cuidarse, fomentar la responsabilidad e independencia en la toma de decisiones, etc... 


\section{CAPÍTULO VI. IDENTIFICACIÓN Y TRATAMIENTO DEL ACOSO LABORAL}

2) La generación de una autoestima sólida, no basada en la opinión que tengan los demás de la persona afectada.

Uno de los grandes perjuicios que afectan a la víctima, es cómo valorarán los demás su situación, o lo que le ha ocurrido. Este temor, aminora sus condiciones psíquicas, entre las que cabe destacar como hemos visto a lo largo de esta tesis, la autoestima. El hostigado ha de conseguir fomentar su autoestima, día a día. Se debe tener en cuenta que la teoría de la disonancia cognoscitiva, establece cómo dos ideas o cogniciones disonantes entre sí, no pueden coexistir simultáneamente en el ser de una persona, por lo que optará por eliminar una de ellas.

3) El estado físico y el sueño.

El acoso laboral afecta al organismo de manera directa, así pues el cuerpo somatiza el cuadro, produciendo graves alteraciones en el estado de salud físico, entre las que cabe destacar el sueño. El objetivo del acosador, no es otro más que el de minar al acosado, tanto en su salud psíquica como física. Mantener el estado físico, en un proceso de estas características, supone tonificar el organismo, favorecer la oxigenación, especialmente la del cerebro, canalizar las tensiones acumuladas y evitar el estrés, incrementar la producción de endorfinas, protectoras de otros problemas psíquicos, aumenta la autoeficacia de la persona, ayuda en la creación de expectativas vitales respecto al futuro más inmediato, evitar en su medida la agresividad acumulada, evita pensamientos tóxicos e incluso ideaciones suicidas, ayuda a la reflexión y toma de decisiones elaboradas, etc.

Tan frecuentes son los casos en los que las víctimas adelgazan como aquellos en los que las víctimas acumulan un exceso de peso, por lo que se ha de intentar mantener una dieta equilibrada.

Además del estado físico, el acoso afecta gravemente al sueño, desestabilizándolo por completo. Como hemos visto en capítulos anteriores 


\section{CAPÍTULO VI. IDENTIFICACIÓN Y TRATAMIENTO DEL ACOSO LABORAL}

son frecuentes las pesadillas, el sueño ligero, o incluso el insomnio. Ello concluye con una falta de descanso óptimo, afectado así de nuevo, a su estado de salud, generando un estado de fatiga y cansancio que pueden llegar a cronificarse en el tiempo y que no hacen más que empeorar la situación. De ahí la importancia que la persona descanse las horas necesarias y acuda a profesionales (médicos, psicólogos, psiquiatras, etc...) que valoren, supervisen y mejoren su estado de salud y su sueño. En el gráfico 6.4, se puede observar la retroalimentación entre el insomnio que se genera y la fatiga crónica:

\section{INSOMNIO VS FATIGA CRÓNICA}

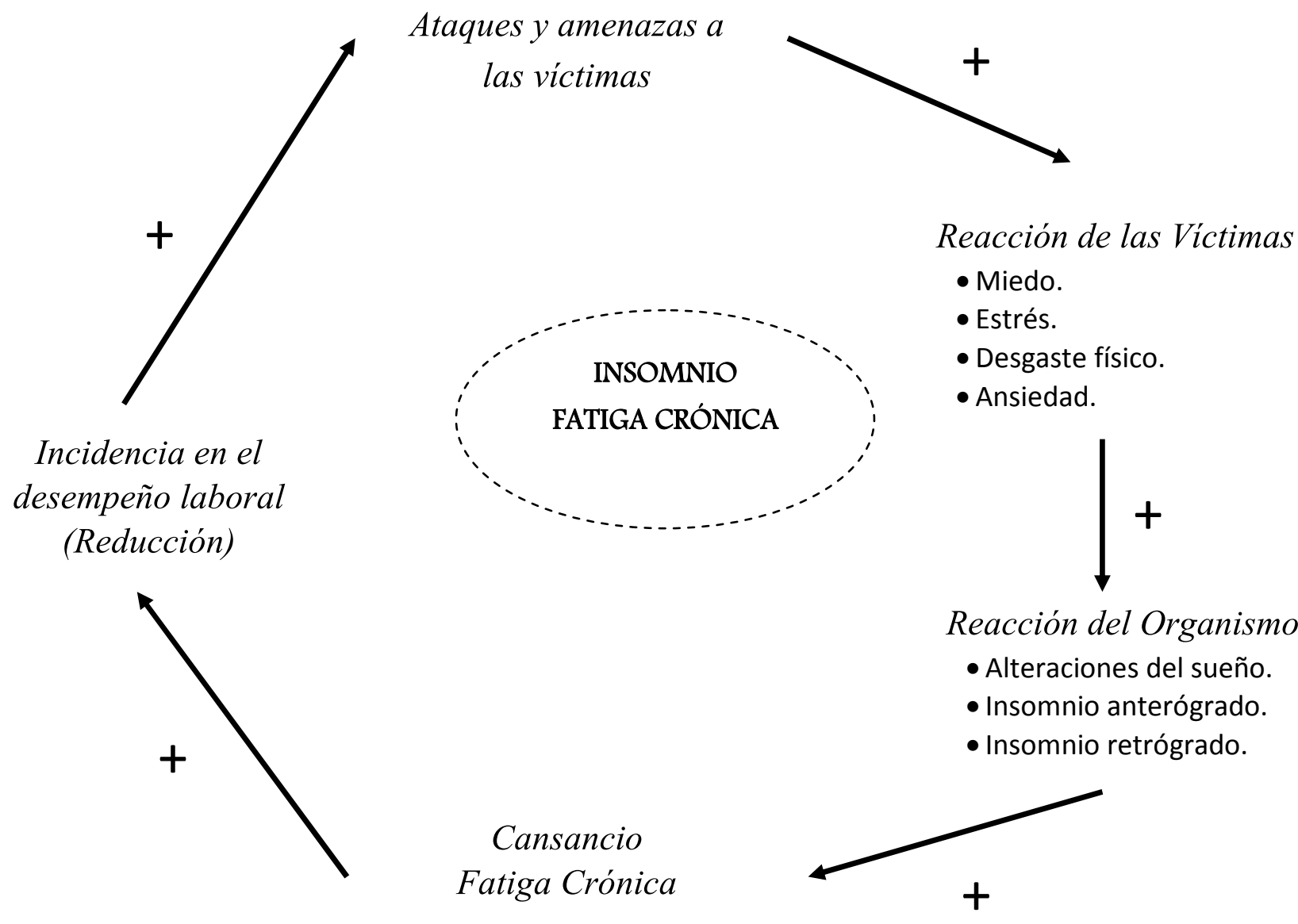




\section{CAPÍTULO VI. IDENTIFICACIÓN Y TRATAMIENTO DEL ACOSO LABORAL}

4) La confianza en uno mismo.

Uno de los factores más determinantes que ayudan a la superación del acoso es afrontar y superar el miedo generado, miedo generado por la falta de confianza, falta de asertividad, y la incertidumbre creada en la atmósfera en la que se desenvuelve la víctima.

La confianza por tanto, implica conocerse aún más si cabe uno mismo, conocer sus propias destrezas, sus propias fortalezas, ahondar en el conocimiento propio y consolidar un estado emocional positivo, firme, estable y duradero.

El gráfico adjunto, gráfico 6.5, muestra el proceso necesario para alcanzar la confianza, superando el miedo:

\section{MIEDO VS CONFIANZA}

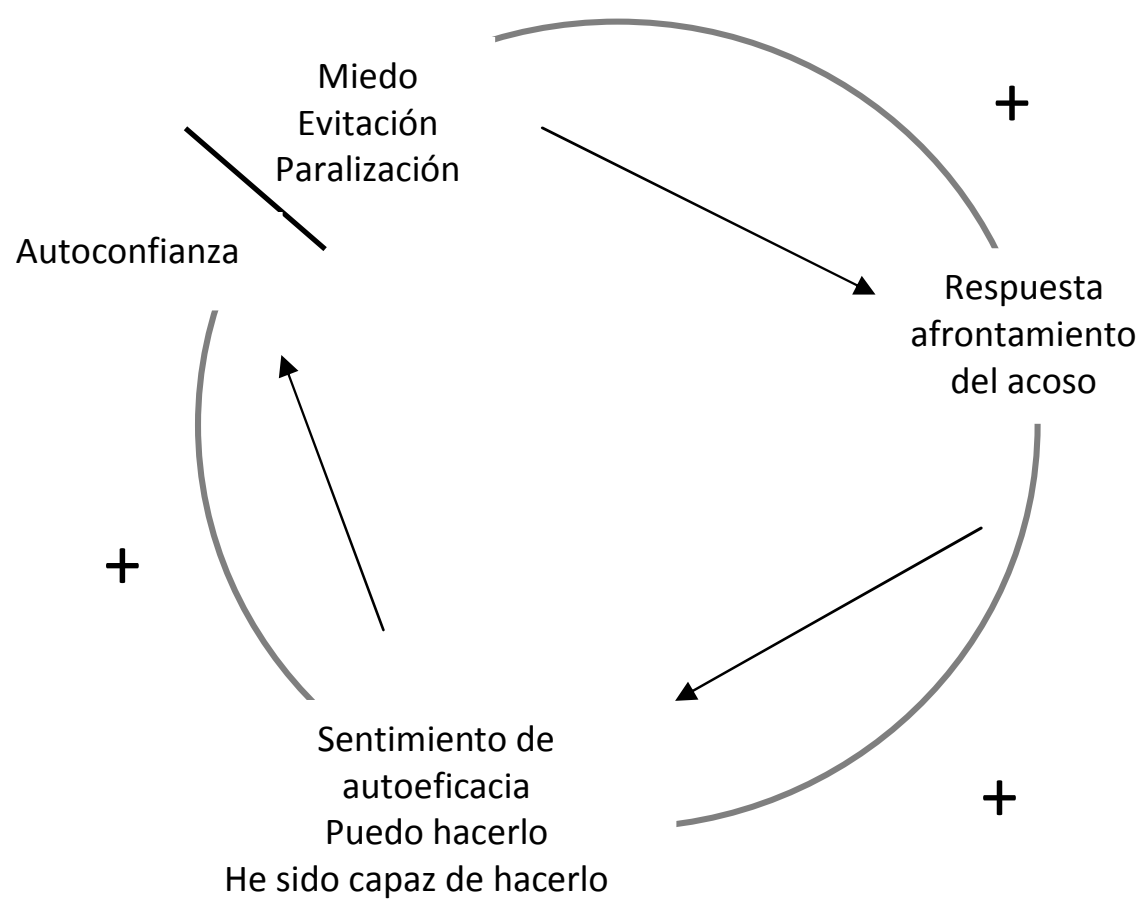

Gráfico 6.5. "Mecanismo de refuerzo de la confianza a través de la elaboración de la respuesta" (Piñuel, 2003). 


\section{CAPÍTULO VI. IDENTIFICACIÓN Y TRATAMIENTO DEL ACOSO LABORAL}

5) El conocimiento y la aceptación incondicional de las propias limitaciones, debilidades y errores.

El conocimiento y la aceptación, suponen asumir que no existe la posibilidad de transformar el comportamiento, la manera de ser, de actuar, y de pensar del hostigador. En la mayoría de los casos significa comprender las dificultades lógicas para contener la ira, la rabia, el rencor y el ánimo de venganza que invade a la víctima tras el acoso. Todo ello conlleva la implicación y aceptación, de no poder hacer nada ante el daño recibido por el acosador y afrontar de manera positiva que no hay nada, absolutamente nada capaz de compensar el daño ocasionado.

6) El mantenimiento de la consideración del entorno.

Si algo le importa al acosador es la opinión que los demás interiorizan de él. El público objetivo del acoso, es decir los trabajadores más cercanos del directivo y las personas que trabajen de manera directa e indirecta con el centro, en principio manipulados, sino ajenos al hostigamiento, suelen desarrollar una intensa disonancia en el comportamiento del acosador, pues, este siempre teme ser descubierto, quedando así desenmascarado su comportamiento y con ello su manera de ser. En la mayoría de las ocasiones, la persona acosada es una persona íntegra e intachable, tanto en su vida laboral, como en su vida personal, lo cual minará al acosador, de manera que cese su acoso, o al menos lo aminore. Este comportamiento puede evitar que la víctima sea estigmatizada por su entorno más cercano, lo cual ayudara positivamente en el afrontamiento del acoso.

Según el profesor Iñaki Piñuel (2003), deberán evitarse de manera especial:

Las explosiones de ira.

Los llantos, gritos e improperios.

Las justificaciones. 


\section{CAPÍTULO VI. IDENTIFICACIÓN Y TRATAMIENTO DEL ACOSO LABORAL}

Las salidas de tono.

Las quejas y lamentaciones.

Parecer frustrado, tenso, molesto.

La conducta agresiva, violenta o amenazadora.

La maledicencia, insultos, palabrotas.

La manipulación.

Las maquinaciones, complots i coaliciones.

Por el contrario, indica Piñuel (2003), resultarán especialmente útiles:

La serenidad y paz consigo mismo.

El aplomo personal.

La educación y elegancia en las formas.

Cuidar la forma de expresión.

Mostrar elevada autoconfianza (sin prepotencia).

La benevolencia (no devolver mal por mal).

La honradez y sinceridad.

La apertura.

La cordialidad.

La transparencia.

La calma y tranquilidad.

La asertividad.

7) El apoyo del entorno familiar y social.

La armonía en el entorno familiar y social más cercano a la víctima, es una condición sine qua non para superar el acoso. Uno de los aspectos que más preocupa al hostigado, es "qué va a pensar mi familia y mis amigos de todo esto". Una vez el sujeto reconoce el acoso como tal, y da cabida a su recuperación, la familia y seres cercanos han de estar debidamente informados de lo que ha ocurrido. 


\section{CAPÍTULO VI. IDENTIFICACIÓN Y TRATAMIENTO DEL ACOSO LABORAL}

8) El reconocimiento de que no siempre las cosas salen bien, o como uno desea, mejorando la tolerancia a la frustración.

La frustración es una respuesta emocional del organismo, que actúa como mecanismo de defensa psicológico, fruto de un conflicto, ante un hecho o situación no gestionada o ante una vivencia no deseada, como es el caso en el que nos encontramos. El impacto a la frustración y la tolerancia mostrada ante ella, dependerán de diversos factores personales de la persona acosada, además de numerosas variables difíciles de controlar.

La relatividad de la frustración, hace muy diversa la respuesta del organismo; en el caso del acoso laboral, nos encontramos ante la denominada "frustración por conflicto", entendiendo por este, la situación creada voluntariamente y de manera unilateral por el hostigador.

En la sociedad actual, el deseo por el éxito surge como una necesidad vital. Por lo tanto, la persona acosada, debe evitar la idea de perfección e inflexibilidad, que la ocupa y que hace que no sea capaz de afrontar la situación de manera positiva para su recuperación.

9) La mejora de las habilidades sociales.

Uno de los ataques más perversos que realiza el acosador, tiene precisamente como objetivo mermar las habilidades sociales del directivo. $\mathrm{Si}$ algo caracteriza a la dirección de un centro residencial, es el continuo contacto social que se lleva a cabo, para lo cual son imprescindibles las formas de comunicarte con los demás. Debemos recordar que tomamos como habilidades sociales, a todas aquellas conductas basadas en el dominio de la comunicación y el autocontrol emocional, de ahí la importancia de la rehabilitación psicosocial de la que hablaremos a lo largo del capítulo. La popularidad de la que se hace eco el ejecutivo acosador, está correlacionada positivamente con el éxito profesional y a su vez, con las habilidades sociales. 


\section{CAPÍTULO VI. IDENTIFICACIÓN Y TRATAMIENTO DEL ACOSO LABORAL}

10) La aceptación del dolor que genera el acoso.

Intentando cumplir con el objetivo de "encontrarse bien", la víctima no aceptará la situación que está viviendo o que ha vivido, lo cual la provocará más sufrimiento aún. Por tanto, será determinante la actitud que muestre el hostigado ante el dolor emergente; si es de resistencia o de negación de sus propios pensamientos, emociones, sensaciones o recuerdos que vienen acompañados de malestar, solo estará centrándose aún más en el mismo dolor, no consiguiendo encauzar la situación hacia una fase que promueva la recuperación.

La aceptación, implica además favorecer el crecimiento personal, lo que significara mayor autocontrol emocional, control de pensamientos negativos que interfieren en la vida de la persona, y aceptación de cada matiz que nos define como tales, sin necesidad de que la víctima se juzgue constantemente.

11) La afectividad social del entorno.

La susceptibilidad de la persona que ha sido objeto de acoso, varía en grado, quedando altamente afectada durante el proceso de mobbing. La diversidad de reacciones emocionales que se producen en su entorno más próximo, hace que esta susceptibilidad alcance valores aún mayores, o por el contrario se vea favorecida y disminuya hasta valores entendidos como homeostáticos. Esta variabilidad se verá reflejada en el estado general que caracteriza con asiduidad al sujeto. Algunos autores, como Antonio Damasio ${ }^{17}$, consideran que mientras la emoción es un proceso individual, el afecto es un proceso interactivo, que involucra a dos o más personas, si bien no existe una división estricta entre ambos conceptos.

\footnotetext{
${ }^{17}$ Antonio Damasio, es neurólogo de profesión, e investigador y profesor de la Universidad de California. Miembro de la Academia Europea de Ciencias y Artes y de la Academia Estadounidense de las Artes y las Ciencias.
} 


\section{CAPÍTULO VI. IDENTIFICACIÓN Y TRATAMIENTO DEL ACOSO LABORAL}

12) La conexión con los propios sentimientos y su verbalización.

Con frecuencia, la víctima sufre una incapacidad temporal para expresar y verbalizar sus sentimientos y emociones (alexitimia temporal), debido a que no es capaz de identificar lo que siente, entenderlo, describirlo ni hacérselo saber a los demás; no saben si sienten miedo o ira, no diferencian una emoción de otra, ni un sentimiento de otro, les resulta imposible describir a otra persona todo lo referente al ámbito subjetivo, de los afectos, presentan un pensamiento concreto, con problemas para el manejo simbólico de las emociones, somatizan la intensidad afectiva con manifestaciones fisiológicas, tales como sudoración, aumento del ritmo cardiaco etc.. Muestran así preocupación por los detalles y acontecimientos externos. Apenas introducen cambios en su tono de voz, siendo rígidos en sus formas.

La superación de esta tipología de alexitimia, es determinante para la recuperación de la víctima, saber qué ha ocurrido, qué ha podido sentir y experimentar, qué siente en la actualidad, verbalizarlo, y saber expresarlo a los demás. Todo ello ayudará a superar el estado emocional en el que se encuentra.

13) El apoyo de compañeros de los compañeros de trabajo.

El trabajo en un centro residencial, es un trabajo en equipo, todos los departamentos que lo conforman son interdependientes entre sí, incluyendo el departamento directivo. Como hemos visto a lo largo del desarrollo de esta tesis, es muy común que los compañeros de trabajo de la víctima, no sean capaces de reconocer el acoso y quienes lo hacen rara vez se posicionan a su favor. Será pasado un periodo de tiempo estimado de entre 12 y 24 meses, cuando la mayoría de los trabajadores, compañeros de la víctima, sean capaces de reconocer el acoso, y apoyar a la víctima como tal, ofreciéndole reconocimiento y afecto social, apoyo que aún tardío, será fundamental para el sentir del hostigado. 


\section{CAPÍTULO VI. IDENTIFICACIÓN Y TRATAMIENTO DEL ACOSO LABORAL}

En el siguiente apartado, desarrollaremos algunas de las aportaciones terapéuticas más afectivas en el abordaje del mobbing directivo, resaltando las de mayor complejidad y relevancia.

\subsection{Líneas de Actuación terapéutica.}

Durante el periodo del tratamiento del acoso laboral en puestos directivos, se debe garantizar que la persona afectada no vuelva a padecer situaciones similares en el ámbito laboral. El período de recuperación física es estimable, no así el tiempo para la recuperación psíquica, el cual es muy variable; dependerá de la adecuación del enfoque terapéutico, así como de la constitución psicológica y los recursos personales de la persona hostigada. Son elementos decisivos en el pronóstico y en la evolución terapéutica el tipo de hostigamiento psicológico padecido, su duración, sus modalidades y el apoyo organizativo, social y personal que recibe la persona. En ningún caso debe tratarse el acoso mediante un tratamiento sintomático o exclusivamente farmacológico, siendo relevante la especial vigilancia que ha de tenerse de la víctima. De este modo se ha de trabajar especialmente en la recuperación de la asertividad, la autoestima y la confianza entre otras áreas afectadas (Piñuel, 2003).

Cualquier estrategia terapéutica correcta que trate un problema de mobbing debe dirigirse a que el paciente termine afrontando la situación de hostigamiento y violencia psicológica creada, buscando romper el proceso de indefensión que se ha generado. Pretender que la víctima se aclimate al hostigamiento, que huya o que abandone su lugar de trabajo son estrategias incorrectas (Piñuel, 2003).

Resulta pues, fundamental desde el punto de vista del profesional, la aceptación incondicional y el apoyo a la víctima; cualquier duda, matiz, suposición infundada, creencia errónea, teoría...etc, que ponga en duda la ética del directivo deteriorara la terapia a poner en práctica. 


\section{CAPÍTULO VI. IDENTIFICACIÓN Y TRATAMIENTO DEL ACOSO LABORAL}

Las líneas de la actuación terapéutica deberán incidir en los aspectos que a continuación se enuncian:

\section{1) Eliminación del sentimiento de culpa.}

Sentimientos como la culpa, hacen que la víctima tenga la necesidad de cambiar de trabajo, e ir en busca de nuevos retos profesionales; considera que es un área, o un trabajo en el que ha fracasado, ya que no ha sido reconocido como un trabajador eficaz en el desempeño de sus tareas. Abandona así una temática laboral, en la que él considera no ha desarrollado al cien por cien sus cualidades profesionales. La eliminación paulatina de este sentimiento de culpabilidad, hará que la víctima se sobreponga a la situación de acoso, buscando nuevos retos profesionales en el mismo ámbito y puesto de trabajo que venía desempeñando hasta el momento.

\section{2) Entrenamiento en asertividad.}

La asertividad, está íntimamente ligada con la emotividad de la persona. El estado emocional influye además en la respuesta que se pueda dar en un momento concreto y ante una situación determinada. Una alta carga de estrés y ansiedad puede provocar una conducta excesivamente agresiva o pasiva, generando en ocasiones un mayor estadio ansioso debido al propio rechazo que la propia respuesta genera en los demás. Un entrenamiento adecuado de la asertividad puede hacer que el sujeto no cambie de área profesional, e incluso que incremente sus retos profesionales y sus metas personales.

\section{3) Mejora de la Autoestima.}

Un profesional de la dirección de centros, acudirá a terapia sintiéndose infravalorado, convencido de que sus habilidades no están acorde con las tareas que podría realizar, preguntándose a qué se deben estas circunstancias. Durante su tratamiento se debe intentar restaurar el sistema de equilibrio 


\section{CAPÍTULO VI. IDENTIFICACIÓN Y TRATAMIENTO DEL ACOSO LABORAL}

anterior a que aconteciera el acoso, focalizando su atención en las fuentes de éxito de las que ha disfrutado en años anteriores a producirse el acoso, así como el éxito obtenido en otras áreas de su vida personal.

\section{4) Mejora de los recursos personales.}

Los recursos personales delimitan un conjunto de variables importantes para conocer y predecir las fuentes de resistencia al desgaste profesional, esto es la personalidad resistente, el optimismo, la autoestima y la competencia emocional entre otras. La evolución de este constructo parte de una concepción de la personalidad como un conjunto de procesos cognitivos, emocionales y conductuales que interactúan entre sí, cambiando continuamente, pero manteniendo cierta autonomía (González, 2007).

\section{5) Fomento de los procesos emocionales.}

Educar las emociones de la persona hostigada, implica trabajar sobre la personalidad resistente creada, con el fin de impulsar una actitud ante la propia vida que pueda manifestarse en actitudes tales como compromiso, control, reto u oportunidad, frente a las actitudes negativas que posee la víctima cuando acude a terapia fruto del acoso vivenciado.

\section{6) Aumento de la autorregulación del optimismo.}

Maximizar el optimismo implica ser capaz de autorregularlo, de tal manera que la persona lo utilice para conseguir sus metas, descubrir los impedimentos que puedan surgir para la consecución de dichas metas y elegir las estrategias adecuadas para su consecución. Los planteamientos negativos que invaden a la persona hostigada conllevan un pesimismo que hacer desarrollar un menor compromiso con las metas y una mayor probabilidad del aumento del abondo durante su consecución. 


\section{CAPÍTULO VI. IDENTIFICACIÓN Y TRATAMIENTO DEL ACOSO LABORAL}

\section{7) Entrenamiento de habilidades sociales y solución de problemas.}

La persona afectada en la mayoría de las ocasiones, es una persona con grandes habilidades sociales y dotes para la gestión; durante el tiempo que permanece el acoso, la víctima, no hace más sino que perder cualitativamente y cuantitativamente estos recursos, hasta incluso llegar a ser incapaz de resolver un mínimo conflicto. Por ello es de especial importancia, trabajar y entrenar de nuevo al individuo en habilidades sociales y en la solución de problemas. Este entrenamiento, tiene como objetivo enseñar a las personas a resolver los problemas laborales en los que están implicadas dos o más personas, utilizando para ello una serie de estrategias cuyo fin sea la obtención de ganancias para todas las partes implicadas. Con ello se conseguirá que la víctima no vea al otro como un enemigo dentro de una batalla que ha de ganar.

Además de los aspectos descritos, para llevar a cabo una terapia eficaz se debe realizar una evaluación psicológica adecuada, para lo cual nos basaremos en la propuesta realizada por la profesora e investigadora Rocío Fernández Ballesteros, compuesta por nueve fases bien diferenciadas. El proceso ha de realizarse de manera flexible, dinámica e interactiva entre las distintas fases y momentos, y siempre teniendo en cuenta la situación vivida por la víctima. Nunca se deben intentar formulas hipótesis en los primeros minutos del proceso terapéutico, ni sorprenderse ante el relato del paciente. Por tanto se deberá intentar refutar las hipótesis de manera ética y profesional, haciendo que la víctima sienta que está siendo tratado así. Las fases que propone Ballesteros serían las siguientes:

- Fase 1. Recogida de la Información.

Los objetivos de esta primera fase son especificar la demanda, clarificarla, fijar los objetivos sobre el caso y establecer las condiciones históricas y actuales potencialmente relevantes. Consiste en una primera toma de contacto con el 


\section{CAPÍTULO VI. IDENTIFICACIÓN Y TRATAMIENTO DEL ACOSO LABORAL}

paciente, en la cual se debe averiguar el motivo de la consulta, las principales conductas-problema y cuáles son las expectativas que el cliente tiene puestas en la terapia. Se trata así de analizar la demanda de la víctima de acoso y la meta que se plantea. La persona hostigada suele acudir a terapia con numerosas dudas, por lo que puede solicitar la descripción, clasificación y explicación del comportamiento de su acosador, con la finalidad de disuadir la incertidumbre que la invade. Resulta imprescindible además la información que puedan dar al terapeuta sus familiares más cercanos, por lo que en algunos casos en los que la víctima acude a terapia "obligada", conviene tomar contacto con ellos, de tal manera que sirvan como fuente de información.

- Fase 2. Formulación de Hipótesis y deducción de enunciados verificables.

En esta segunda fase se han de plantear los supuestos y las deducciones verificables. La información recogida en la fase inicial, servirá ahora para conseguir los objetivos, que resultarán más fiables cuanta más información se tenga de la problemática. Pueden formularse hasta cuatro tipos de hipótesis diferentes: hipótesis de cuantificación, de semejanza, de asociación predictiva y de relación funcional o explicativa; las de cuantificación se formularán para verificar la frecuencia con la que se da la conducta acosadora, las de semejanza harán que podamos comparar las conductas observadas con otras de otros sujetos, las de asociación predictiva presupondrán relaciones entre antecedentes y consecuentes conductuales y las de relación funcional o explicativa, harán que se puedan relacionar aspectos funcionales.

Con el fin de comprobar las hipótesis se establecerán los enunciados que puedan ser verificables. Los instrumentos de evaluación deberán ser susceptibles de cuantificación y por lo tanto han de ser específicos para la temática que nos mueve, el acoso laboral; se pueden complementar además 


\section{CAPÍTULO VI. IDENTIFICACIÓN Y TRATAMIENTO DEL ACOSO LABORAL}

con instrumentos que evalúen otros aspectos que puedan incidir directa o indirectamente con el problema.

- Fase 3. Contrastación inicial de hipótesis.

Los objetivos en esta tercera fase son contrastar las hipótesis y los anunciados formulados en la fase anterior. Las tareas a realizar, por tanto serían la preparación del material y del procedimiento de administrarlo, preparar al paciente, y en su caso a los allegados más cercanos, y aplicar los procedimientos de recogida de información. En cuanto a la preparación del material, es importante resaltar la elaboración de autorregistros o registros observacionales específicos. En cuanto al procedimiento de administración de las técnicas seleccionadas se deberá tener en cuenta tanto el orden de aplicación de las mismas como las sesiones necesarias. La preparación del paciente, se realiza con el fin de conseguir una actitud activa frente a la evaluación. En cuanto a la aplicación de los procedimientos de recogida de la información, supone uno de los gruesos de la evaluación y se deben emplear distintas sesiones hasta recopilar la información necesaria para poder contrastar las hipótesis y enunciados formulados.

- Fase 4. Resultados.

Los objetivos principales es esta cuarta fase serían la corrección, valoración, análisis de la información y la comunicación de los resultados del proceso evaluativo. Si el objetivo de la demanda por parte del paciente, es solamente el diagnóstico, o la orientación, el proceso psicológico terminará en este momento, mientras que si se solicita un programa de intervención psicológica específico, como es el caso del acoso laboral en puestos directivos de centros residenciales, el proceso ha de continuar en las siguientes fases que se detallan a continuación. 


\section{CAPÍTULO VI. IDENTIFICACIÓN Y TRATAMIENTO DEL ACOSO LABORAL}

- Fase 5. Formulación de Hipótesis Funcionales.

Una vez hemos obtenido la valoración del sujeto, deberemos establecer los supuestos funcionales sobre el caso concreto, específico y deducir las predicciones verificables. En esta fase las hipótesis que se establezcan tendrán relación con la propuesta de intervención o tratamiento propuesto. Se seleccionaran además tanto las variables dependientes como las independientes.

- Fase 6. Recogida de datos referentes a las hipótesis funcionales.

En esta sexta fase, los objetivos son el establecimiento del diseño de intervención y valoración, le control de posibles variables potencialmente contaminadoras y la aplicación del tratamiento. Para conseguir estos objetivos, se deben realizar seis tareas fundamentales:

1) Elección del diseño apropiado.

2) Selección y aplicación de las técnicas de evaluación y control de posibles variables contaminadoras de los efectos del tratamiento.

3) Preparación del paciente.

4) Aplicación del tratamiento.

5) Evaluación continúa del progreso del tratamiento.

6) Finalización del tratamiento.

- Fase 7. Valoración de resultados.

Una vez completa la fase anterior, en esta, se valorará el tratamiento aplicado, valorando si se han alcanzado las metas establecidas al comienzo de la psicoterapia. Para ello, se hará un análisis exhaustivo de los datos obtenidos tanto cualitativo como cuantitativo, comprobando las hipótesis formuladas y el estado psicológico del hostigado tras la terapia. 


\section{CAPÍTULO VI. IDENTIFICACIÓN Y TRATAMIENTO DEL ACOSO LABORAL}

- Fase 8. Resultados.

El objetivo es esta octava fase es comunicar los resultados obtenidos después del tratamiento. El informe de evaluación en el caso de acoso laboral, ha de contemplar además de la evaluación post-tratamiento, otros posibles cambios que puedan producirse en un futuro próximo que puedan afectar a la víctima de manera significativa.

- Fase 9. Seguimiento.

Conforman aspectos esenciales en esta última fase, una nueva recogida de datos y de la comprobación de si se mantiene los resultados del tratamiento, para lo cual es necesario algunas tareas, que se deben realizar en diferentes momentos, como puedan ser una nueva toma de contacto con la víctima, una nueva evaluación de las conductas objetivo, un nuevo análisis exhaustivo de datos comparándolos con los anteriores, una comprobación de la estabilidad y mantenimiento de los resultados del tratamiento y, en su caso, elaborar un nuevo informe tanto al paciente como a sus allegados.

El profesor e investigador Iñaki Piñuel, propone el siguiente modelo de intervención del psicólogo en los casos de acoso psicológico en el puesto de trabajo:

\section{Fase de Diagnosis y Evaluación de la Víctima de Acoso Psicológico.}

Aplicación de baterías clínicas.

- Pruebas aptitudinales.

- Pruebas de personalidad.

- Escalas de ansiedad.

- Escalas de depresión.

- Escalas específicas de estrés postraumático.

- Test proyectivos. 


\section{CAPÍTULO VI. IDENTIFICACIÓN Y TRATAMIENTO DEL ACOSO LABORAL}

Aplicación de instrumentos de medida de comportamientos de hostigamiento psicológico.

- Cisneros.

- $\quad$ LIPT.

Entrevista de Evaluación.

- Anamnesis familiar y social.

- Evaluación de los recursos psicológicos de afrontamiento (COPING).

- Evaluación de las redes sociales de la organización.

- Evaluación de los daños sobre la empleabilidad del sujeto.

- Análisis de la evolución de la carrera profesional y proyección.

- Monitorización específica de la ideación autolítica.

2. Fase de Tratamiento Psicológico y Entrenamiento de tipo CognitivoConductual.

Tratamiento Psicológico de la sintomatología Cínica.

- Ansiedad.

- Distimia.

- Estrés Postraumático.

- Fobia Social.

- Comportamientos Obsesivos.

- Hipervigilancia.

Desarrollo de Habilidades de Coping o Afrontamiento.

- Recuperación y desarrollo de la autoestima.

- Desarrollo de recursos de afrontamiento.

- Entrenamiento específico en asertividad y habilidades sociales. 


\section{CAPÍTULO VI. IDENTIFICACIÓN Y TRATAMIENTO DEL ACOSO LABORAL}

Intervención a nivel familiar y de pareja.

\section{Fase de Acompañamiento en la Reintegración Laboral de la Víctima.}

Entrenamiento en habilidades de búsqueda activa de empleo (en su caso).

$>$ Entrenamiento en habilidades y manejo de entrevistas de selección (en su caso).

Desarrollo de recursos de manejo del estrés.

$>$ Gestión de incidentes críticos y de afrontamiento de conductas de acoso.

Desarrollo de habilidades de comunicación.

4. Fase de Prevención y Desarrollo de los Recursos Humanos: COACHING.

Evaluación de las capacidades y recursos actualmente en uso del sujeto.

$>$ Terapia de mantenimiento en afrontamiento y habilidades sociales.

Acompañamiento y revisión periódica de la evolución en la sintomatología clínica.

Una vez analizadas las posibles líneas de actuación terapéutica, con las víctimas de acoso laboral es puestos directivos, describiremos cómo es el regreso a un nuevo trabajo.

\subsection{El regreso a un nuevo Trabajo.}

Uno de los retos más importantes para la víctima es regresar de nuevo al mundo laboral, bien sea al puesto que venía desarrollando hasta que se produjo el acoso o iniciando una nueva andadura profesional. La gran mayoría de los directores de centros residenciales que han sufrido acoso laboral, no regresan de nuevo al puesto de trabajo que ostentaban; se enfrentan además a ver como el hostigador continua en su 


\section{CAPÍTULO VI. IDENTIFICACIÓN Y TRATAMIENTO DEL ACOSO LABORAL}

puesto de trabajo, mientras ellos se encuentran en una situación de desempleo, lo que conlleva un desgaste psicológico implícito, sin expectativas próximas de acceder a un puesto similar al que desarrollaba, sintiendo "que ya no es la misma persona que antes".

El acosador tras protagonizar el acoso, además trata de promover todo aquello que no hace, que no ha hecho y que sabe nunca podrá llegar a hacer: cumplir con pulcritud los requisitos que establece el convenio, elaborar planillas de trabajo flexibles, crear cuadros de mando funcionales, establecer una evaluación continua de las competencias profesionales de los trabajadores, analizar exhaustivamente el clima laboral, detectar las necesidades formativas de los trabajadores, ofrecer formación y desarrollo de itinerarios formativos, elaborar planes de acogida del personal de nuevo ingreso en la empresa, facilitar la conciliación laboral-personal y social, establecer una organización por procesos que promueva la colaboración, definir claramente la estructura organizativa del centro, crear áreas funcionales, promover los equipos interdisciplinares, crear comisiones de trabajo, cumplir los ratios de personales adecuados, contratar personal cualificado para las tareas encomendadas pese a ser más costoso en algunas ocasiones, supervisar las funciones de los profesionales, crear un departamento de recursos humanos o subcontratarlo, promover las relaciones interpersonales entre los trabajadores que conforman el centro, crear programas específicos que capaciten aún más a los profesionales, establecer protocolos que faciliten la actividad profesional, desarrollar un proceso dinámico en lo que a la toma de decisiones se refiere, planificar la gestión económica, organizar la información financiera realizando una evaluación, un control y un seguimiento que permita el funcionamiento óptimo de la empresa, con el fin de ser eficientes y eficaces, anticipándose a posibles problemas.

En algunos casos, que podríamos definir como "extremos" promueven incluso servicios de consultoría para facilitar el apoyo funcional a aquellas personas que 


\section{CAPÍTULO VI. IDENTIFICACIÓN Y TRATAMIENTO DEL ACOSO LABORAL}

decidan comenzar su andadura como directivos de centros, y formación específica, tanto técnica como funcional, todo una paradoja. Así es el hostigamiento.

Como estamos viendo a lo largo de esta tesis de investigación, las víctimas de acoso laboral en puestos directivos quedan muy afectadas por los hechos acontecidos, por tanto una vez que tienen claro qué ha ocurrido, cómo ha podido ocurrir ese acoso al que han estado sometidas, por qué, a qué se deben ese tipo de conductas hostiles, desde cuándo se han producido y dónde han surgido, pueden comenzar a desarrollar de nuevo su vida ordinaria.

Autores como Carbonell (2008), plantean la reincorporación al mundo laboral de las víctimas, como la última fase de su recuperación, sirviéndose de principios psicológicos caracterizados por la delimitación del propio acoso, la atribución externa de la responsabilidad de sus dolencias, la atribución de la culpa al acosador y el convencimiento por parte del hostigado de que deje de considerarse como víctima lo antes posible. Las víctimas por norma no desean volver al mismo lugar donde se produjeron los hechos ya que existen demasiados elementos de la situación que le recuerdan la experiencia, incluso aunque ya no esté el acosador se recuerda por ejemplo, la falta de apoyo; de ahí que abandonar el papel de víctima sea un elemento esencial para el regreso a un nuevo trabajo, ya que el acosador considera como un triunfo personal que la víctima abandone la actividad laboral.

Así pues para la víctima el regresar a un nuevo trabajo debe suponer:

\section{1) Haber superado la situación vivida.}

El regreso al trabajo, es la mejor manera de hacer que no triunfe el acosador. Debemos de tener siempre muy presente que el único objetivo que persigue el mismo, es el abandono de la vida laboral y la destrucción de la persona. Ser capaces de volver a desarrollar un nuevo puesto de trabajo, es señal de que hemos fortalecido nuestras capacidades y recursos personales y 


\section{CAPÍTULO VI. IDENTIFICACIÓN Y TRATAMIENTO DEL ACOSO LABORAL}

profesionales, lo cual hará que podamos tener mayores posibilidades de éxito en el futuro próximo.

2) La tenencia de nuevas expectativas profesionales.

Cabe resaltar que por lo general, la expectativa se asocia con el procedimiento razonable de que algo se concrete. Surge además después de haber atravesado un período continuado en el tiempo de gran incertidumbre. Con ello lo que logra la víctima es depositar confianza en aquello que considera, tiene más posibilidades de que ocurra.

3) La confianza que ha generado en nuevos profesionales del sector.

El hecho de ser contratado por una nueva empresa, significa para la persona hostigada que alguien vuelve a confiar tanto en su persona, como en sus cualidades y capacidades profesionales. Esto hará que su motivación y autoestima aumenten de manera notoria y observable.

4) Enfrentarse a los propios miedos.

Comenzar un nuevo trabajo siempre supone enfrentarte a nuevos miedos; miedo a fracasar, miedo a no estar a la altura de lo esperado, miedo a arrepentirte de desempeñar este nuevo trabajo, miedo a las críticas de los demás, etc... Por tanto lo que debe de tener siempre claro la víctima, es que este nuevo empleo debe de servir como "motor de cambio" en su vida, generándole así nuevas ilusiones, nuevas esperanzas y nuevos motivos para recuperar la alegría perdida.

5) Afianzar la creencia que nunca se debe perder de que posee recursos personales y profesionales.

En definitiva lo más relevante en el regreso a un nuevo trabajo ha de ser la perseverancia; la constancia en la búsqueda de un nuevo empleo y el saber 


\section{CAPÍTULO VI. IDENTIFICACIÓN Y TRATAMIENTO DEL ACOSO LABORAL}

reconocer las oportunidades para empezar algo nuevo, distinto, positivo para la persona hostigada, ya que así se abrirán de nuevo las posibilidades de conocer gente nueva y se desarrollará una gran satisfacción personal.

\subsection{Hipótesis de Estudio.}

Tras la revisión de la literatura, abordada en los capítulos anteriores, que profundizan en los aspectos relacionados con el acoso laboral a directivos de centros residenciales y analizan sus antecedentes y consecuentes y los efectos moderadores de este, en este apartado se plantean las hipótesis de investigación y se formula el modelo teórico de antecedentes y consecuentes del acoso laboral en puestos directivos de centros residenciales, basado en el modelo de ecuaciones estructurales que a continuación se presenta en el gráfico 6.6, el cual ilustra además el modelo teórico de investigación propuesto que recoge las relaciones postuladas y representa el punto de partida para la realización de la investigación empírica de esta tesis doctoral.

\section{MODELO EXPERIMENTAL}

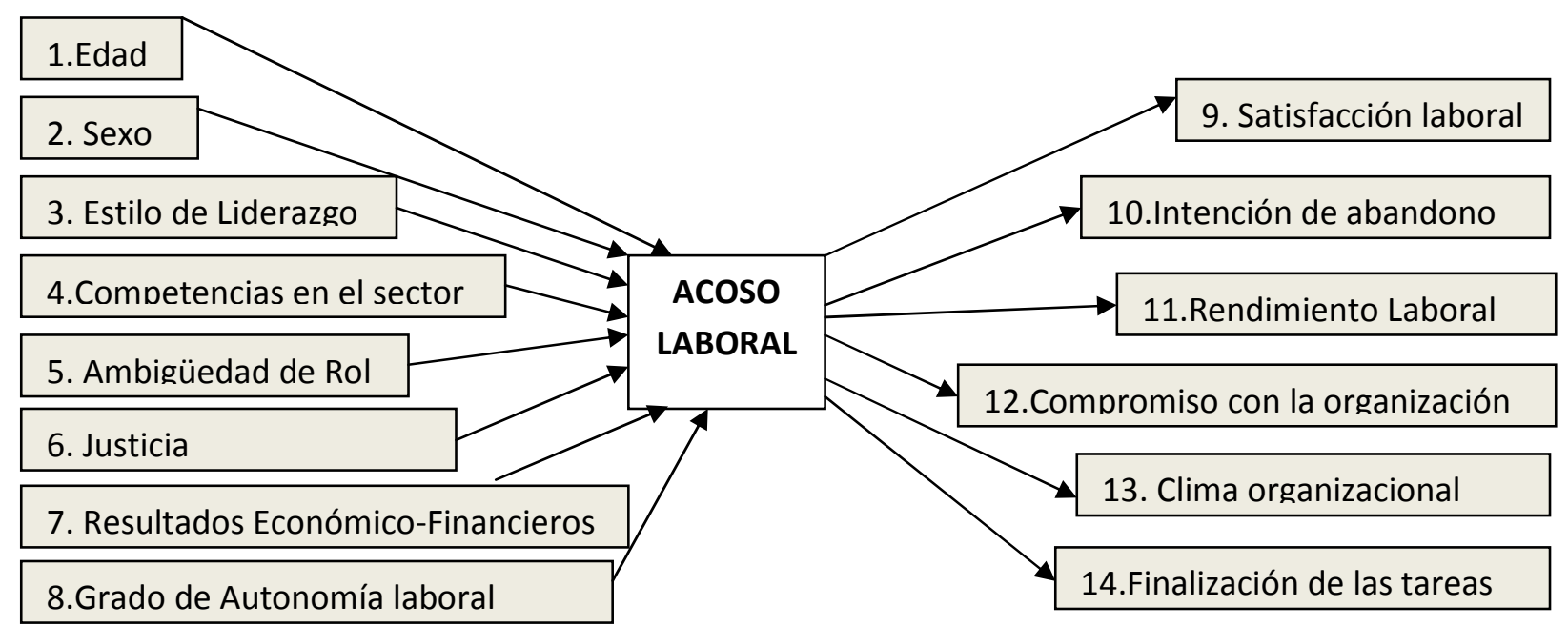

Gráfico 6.6. "Modelo inicial de relaciones entre el Acoso Laboral, antecedentes y consecuentes" 


\section{CAPÍTULO VI. IDENTIFICACIÓN Y TRATAMIENTO DEL ACOSO LABORAL}

Como hemos visto a lo largo del desarrollo de esta tesis doctoral, el acoso laboral es un fenómeno que se ha enfocado desde diferentes perspectivas; europeas, escandinavas especialmente y estadounidenses. Cada una de ellas ha dado lugar a numerosos estudios; algunos de ellos han puesto el acento en la importancia de los factores personales de la víctima, mientras que la gran mayoría se centran en los factores organizaciones, como factores explicativos. Por tanto podemos decir que la revisión de la literatura, pone de manifiesto que históricamente se ha recurrido a dos tipos de modelos explicativos, uno de ellos centrado en la vulnerabilidad de las víctimas, fundado en su patrón de personalidad, poniendo de manifiesto los estudios que las mujeres, los jóvenes o los empleados inexpertos son acosados con mayor frecuencia, y otro modelo explicativo centrado en las características del ambiente organizacional, insistiendo y reflejando la importancia que tienen los valores predominantes en una organización. Desde este punto de vista, las condiciones organizacionales y de trabajo, se consideran factores ambientales que pueden fomentar conflictos interpersonales, dando lugar al acoso laboral; los investigadores Einarsen y Zapf (1999) a partir de entrevistas realizadas con víctimas, evaluadas en aspectos tales como las deficiencias en la delegación de funciones y conductas de liderazgo, concluyen que estos factores ambientales en la organización propician el hostigamiento laboral.

Muchos de estos estudios asumen implícitamente, que la cultura organizacional podría configurar las respuestas conductuales a través del mecanismo psicológico de la congruencia entre el individuo y la organización.

Sobre la base de la literatura revisada, en la presente investigación se espera que ambas dimensiones, tanto la personal, como la organizacional tengan poder predictivo sobre las conductas de acoso laboral, comenzando esta exposición de supuestos e hipótesis por el análisis de los factores personales, tales como la edad, el sexo, el estilo de liderazgo y las competencias en el sector. 


\section{CAPÍTULO VI. IDENTIFICACIÓN Y TRATAMIENTO DEL ACOSO LABORAL}

Comenzaremos abordando el primer parámetro establecido: la edad. Los países desarrollados, como España, se enfrentan a la necesidad de gestionar todos los aspectos relacionados con la edad, en las organizaciones; la idea de que nos encontramos ante un mundo cada vez más globalizado constituye, probablemente, el mensaje más comúnmente utilizado en el mundo empresarial. Cada empresa debería encontrar un adecuado equilibrio intergeneracional; diferentes estudios han puesto de manifiesto la tardía incorporación de las personas al mundo laboral, no obstante en el sector sociosanitario encontramos elevadas tasas de directivos de centros de edades comprendidas entre los 32 y los 45 años, lo cual les hace a priori más vulnerables en lo que al acoso laboral se refiere. Desde algunos foros europeos como la European Foundation for the Improvement of Living and Working Conditions se ha planteado también la preocupación por el problema del envejecimiento y el trabajo, haciendo hincapié en la problemática de las personas con mayor antigüedad en la empresas. Las instituciones y agencias gubernamentales de los diversos países de Europa, conscientes de las consecuencias que ello pueda tener, invitan a la toma de conciencia y a la adopción, tanto a nivel nacional como empresarial de una política de gestión del empleo y de la edad.

Conviene además mencionar que la mayoría de los consejos de administración y direcciones generales, de las grandes y medianas empresas del sector residencial, están constituidos por los denominados activos de gran experiencia (AGE), personas que suelen tener más de 25 años de vida laboral, con lo que superan los 50 años de edad. Ello supone que, lejos de ver a algunos de sus directivos como complementarios, los ven como rivales. Cabe así la necesidad de resaltar los actuales prejuicios existentes en torno a la edad, y la falta de políticas que promuevan el fomento de la intergeneracionalidad. Así proponemos la primera hipótesis de estudio:

$H_{1}$ : Cuanto menor es la edad del directivo, mayor acoso laboral se produce. 


\section{CAPÍTULO VI. IDENTIFICACIÓN Y TRATAMIENTO DEL ACOSO LABORAL}

El segundo factor a estudio es el sexo. Históricamente se ha estudiado el sexo o el género como un alto predictor del acoso laboral. El estudio de Hoel y Cooper (2000), arroja un efecto de interacción entre el acoso laboral y el sexo o género de los acosados: los hombres resultaban acosados en mayor medida que las mujeres, pero en los niveles jerárquicos directivos más altos, las mujeres lo eran en mayor medida que los hombres; este resultado puede verse mermado por los prejuicios existentes contra las mujeres en las posiciones de liderazgo. Las investigaciones de Zapf (2003) en cuanto al género, sugieren que alrededor de un tercio de los acosados en el puesto de trabajo son hombres y dos tercios son mujeres, dando para esta mayor vulnerabilidad de la mujer varias explicaciones: 1)las mujeres suelen trabajar en mayor medida que los hombres en sectores ocupacionales, tales como el de la sanidad o educación, en los que como hemos visto a lo largo de la revisión de la literatura específica, se registra un mayor número de casos de mobbing (Di Martino, 2003), 2)las mujeres ocupan en mayor medida que los hombres un status de subordinación en la jerarquía laboral, 3) las mujeres han sido educadas a ser menos asertivas (Björkvist, 1994), y 4)la posibilidad de que las mujeres duden menos que los hombres a la hora de etiquetarse como víctimas (Salin, 2001), así, cuando se analizan las explicaciones que se dan sobre el acoso laboral en puestos directivos, los hombres subrayan el papel y responsabilidad de la víctima, mientras que las mujeres lo explican basándose en las características del acosador y la dinámica del grupo, lo que puede tener que ver con la menor voluntariedad de los hombres a la hora de etiquetarse a sí mismos como víctimas de acoso. Por ello, la mayor tasa de mujeres encontrada en los estudios entre las víctimas de mobbing podría deberse al menor rechazo a clasificar el acoso como tal.

En cuanto a la dirección de centros residenciales se refiere, encontramos estudios que reflejan como normalmente las mujeres suelen ser acosadas por mujeres (aunque también hay un gran número de mujeres acosadas por varones) y los hombres suelen ser acosados por hombres. En estos casos si el acosador es hombre se le atribuye un 


\section{CAPÍTULO VI. IDENTIFICACIÓN Y TRATAMIENTO DEL ACOSO LABORAL}

acoso más directo, mientras que si la que acosa es una mujer podríamos hablar de conductas más sutiles e indirectas. Además el estudio presentado recientemente por Rosa María Peris, (Directora General del Instituto de la Mujer), "Acoso psicológico y sexual en el trabajo", refleja una tasa de acoso laboral del 9\% en las mujeres y del $7 \%$ en los hombres, siendo de mayor gravedad el acoso sufrido por los varones $58 \%$ frente a las mujeres, $45 \%$. Consideramos así necesario reflejar la siguiente hipótesis de esta investigación:

\section{$\mathrm{H}_{2}$ : El sexo del directivo promueve la aparición del acoso laboral.}

A continuación analizaremos el estilo de liderazgo. Los estilos de liderazgo, nos permiten categorizar adecuadamente la conducta de los líderes, predecir numerosos aspectos empresariales, así como abordar la conducta exhibida por los mismos. El liderazgo adquiere un papel preponderante en el estudio del acoso laboral, pues de los líderes dependerán en gran medida que se diseñen e implementen prácticas socialmente responsables en el interior de la organización, y que estas se reflejen en el bienestar de sus trabajadores; corresponde a quienes lideran procesos en las organizaciones asumir este compromiso, dado que como plantea Drucker (2001), son ellos quienes desarrollan una visión de futuro, y fomentan el entusiasmo. Por tanto, los estilos de dirección involucran una serie de comportamientos que ejercen algunos individuos sobre otros debido a la posición que ocupan en la organización; los directivos que ejercen un liderazgo efectivo serían aquellos que tienen en cuenta las características de las situaciones, que logran persuadir a sus colaboradores para el logro de las metas y objetivos comunes, generando compromiso y satisfacción en los equipos de trabajo, a diferencia de aquellos que dirigen procesos centrados en el puro cumplimiento de objetivos organizacionales, descuidando aspectos fundamentales, relacionados con la satisfacción y el bienestar del trabajador (Conger, Kanungo y Menon, 2000). 


\section{CAPÍTULO VI. IDENTIFICACIÓN Y TRATAMIENTO DEL ACOSO LABORAL}

Así, numerosas investigaciones ponen de manifiesto cómo la efectividad del liderazgo no ha de basarse únicamente en la productividad, sino también en la calidad de vida de las personas y en la satisfacción laboral. Autores como Austin, Garriga o Mele (2004) plantean la importancia de lo que ellos denominan la responsabilidad social empresarial (RSE) dentro del liderazgo; esta perspectiva, no resta importancia a los intereses financieros de las organizaciones sino que asume el efecto favorable que ésta puede tener sobre la productividad empresarial, armonizando los intereses de la organización con los de las personas que la conforman. Formulamos así, la siguiente hipótesis de esta investigación:

$H_{3}$ : Cuanto menor sea el liderazgo, mayor es el acoso laboral que se produce.

El cuarto factor a estudio serán las competencias en el sector. El curriculum a la hora de ocupar un puesto de directivo presenta ciertas particularidades. El puesto de trabajo como tal, en la dirección de un centro residencial, requiere de una amplia experiencia en puestos de menor a mayor responsabilidad, grandes dotes en lo que a gestión de equipos se refiere, además de un profundo conocimiento del sector sociosanitario. Los efectos de la experiencia se basan en la llamada "curva de aprendizaje"; la curva de aprendizaje se fundamenta en la noción de que a medida que un trabajador aprende cómo realizar mejor y más rápido su trabajo, mejora su productividad, y a su vez el conocimiento acerca del puesto que desempeña y del sector en el que se encuentra inmerso. Así pues, podemos decir que la experiencia subjetiva de cada persona le permite establecer predicciones o expectativas respecto a su propia conducta, y esto ocurre no porque el sujeto considere que al poder elegir entre distintos cursos de acción está en posición de anticipar lo que hará o le ocurrirá en el futuro, sino porque tiene la evidencia de que cree saber cómo se comportará en el tiempo venidero, al margen de las decisiones arbitrarias que como veremos a continuación se producen en el caso del acoso laboral a directivos de centros residenciales. 


\section{CAPÍTULO VI. IDENTIFICACIÓN Y TRATAMIENTO DEL ACOSO LABORAL}

Algunos autores como Maslow (1954) y Murray (1938) mantienen que si consigue identificar con seguridad las necesidades del sujeto y la forma en que la persona ve el mundo en función de esas necesidades, se puede anticipar su conducta. Partiendo de estas premisas consideramos oportuno formular está nuestra cuarta hipótesis de estudio:

$\mathrm{H}_{4}$ : Cuantas menos competencias se tengan en el sector mayor será la probabilidad de sufrir acoso.

Seguidamente haremos hincapié en la ambigüedad de rol. Las funciones, papeles o roles que en una organización se atribuyen a un puesto de trabajo constituyen el conjunto de comportamientos y actividades que deben ser adoptados por la persona que ocupa esa posición (Kaltz y Kahn, 1978). Davis y Newstrom (1991), definen el rol como un patrón de conducta esperada de una persona al desarrollar actividades relacionadas con los otros. Las actividades de los directivos y sus trabajadores están guiadas por sus percepciones del rol, es decir, la manera en que piensan que deben actuar en sus propios puestos de trabajo y cómo otros lo deberían hacer en los suyos. Cuando los roles se definen de forma inadecuada o se desconocen sustancialmente, se produce lo que se ha denominado ambigüedad de rol, debido a que las personas no sienten seguridad en la forma en que deben actuar; los empleados no poseen entonces la información suficiente como para realizar adecuadamente las funciones propias de su puesto, mostrando así serias dudas respecto a lo que los ejecutivos esperan de ellos, y sobre cómo satisfacer sus expectativas laborales, lo que conlleva a una incertidumbre propia de no saber cómo serán evaluados, ni entorno a que parámetros se verán recompensadas sus actuaciones.

En la actualidad es muy común que en las organizaciones surjan conflictos entre las expectativas de la empresa y las expectativas de sus directivos; una causa final de estos conflictos funcionales es un puesto de trabajo ambiguo, y normalmente sobrecargado de tareas inexactas e inespecíficas. 


\section{CAPÍTULO VI. IDENTIFICACIÓN Y TRATAMIENTO DEL ACOSO LABORAL}

Así, podemos afirmar, que la ambigüedad de rol, produce en los directivos de centros residenciales gran incertidumbre, ya que no son capaces de establecer qué se espera de ellos, no tienen una configuración psicológica clara sobre cuál ha de ser su función y papel en la empresa, no poseen referencias específicas para desempeñar su labor al frente del centro, o bien se les presentan referencias incongruentes e inespecíficas. En definitiva no posee la información que debería tratar sobre el propósito u objetivos de su trabajo, las delimitaciones de su autoridad, sus responsabilidades, su estilo de relación, su comunicación con los demás, etc. Con ello establecemos la siguiente hipótesis de esta tesis doctoral:

H5: Cuanto menor sea la ambigüedad de rol, menor acoso se producirá.

A continuación como sexta variable de estudio, estableceremos la justicia, entendida como justicia organizacional. La justicia organizacional, hace referencia a las percepciones que los empleados tienen sobre lo justo y lo injusto dentro de la organización a la que pertenecen. Las diferentes investigaciones realizadas al respecto tienen como base fundamental el tratamiento que el empleado cree que recibe, así si percibe que está siendo justamente tratado, tendrá una actitud positiva hacia el trabajo siendo esta negativa en el caso contrario. Los estudios que se han hecho hasta el momento referentes a la justicia organizacional se han dividido en tres grandes ejes, los cuales pueden a su vez ser estudiados de manera independiente o articulada: 1) justicia distributiva, referida al contenido de las distribuciones y a la justicia de los fines y resultados alcanzados, 2) justicia procedimental, definida como la justicia de los medios utilizados para determinar las distribuciones, y 3) la justicia interaccional, asociada a la calidad del tratamiento interpersonal entre quienes toman las decisiones y los empleados afectados por sus decisiones; de acuerdo con la nueva nomenclatura jurídica, los elementos sociales presentes en la justicia interaccional se dividen en justicia interpersonal y justicia informacional; la justicia interpersonal, incluye la sensibilidad social, que hace referencia al grado con el que el gestor adopta un trato 


\section{CAPÍTULO VI. IDENTIFICACIÓN Y TRATAMIENTO DEL ACOSO LABORAL}

digno y de respeto con las personas afectadas por las decisiones distributivas y procedimientos. La justicia informacional consta de las informaciones y la explicación de las decisiones tomadas. En el caso de la justicia interpersonal se esperaría que cuanto más justo sea el trato, mayor será la percepción de la justicia y mayor el grado de aceptación de las decisiones por parte de los empleados. Por su parte en la justicia informacional, se presume que las explicaciones y justificaciones atenúen las reacciones negativas de los empleados a las percepciones de injusticia o desfavorabilidad de los resultados obtenidos (Wayne y Cols, 2002).

Autores como Sharlicki y Kulick (2005), afirman que al evaluar un hecho como justo o injusto, el sujeto valora otros alternativas posibles imaginando como debería ser la situación; cuando se es testigo de cualquier tipo de acoso, al imaginar una alternativa mejor, se percibe mayor injusticia. Si la conclusión es que la víctima sufrió un impacto negativo, se valorará de forma consecuente la culpabilidad de la organización, ponderando si esta pudo haber hecho las cosas mejor, resultando así una atribución interna y externa de la organización(Topa, Moriano y Morales, 2009). De esta manera, será clave la relación de la tercera persona con la víctima, ya que cuanto mayor similitud perciba con ella, más probable será que culpabilice a la organización de lo ocurrido.

Así diferentes estudios e investigadores, promueven lo que denominan la conducta cívica organizacional, entendida como todas aquellas acciones realizadas por los empleados, encaminadas a beneficiar a la organización y que no están explícitas en los deberes propios de su cargo o puesto, lo cual sugiere un gran desafío para las empresas del siglo $\mathrm{XXI}$, en términos de entender las formas de comunicación $\mathrm{Y}$ liderazgo existentes (Moorman, 1991).En consecuencia estableceremos la hipótesis siguiente:

H6: A menor justicia organizacional, mayor acoso laboral. 


\section{CAPÍTULO VI. IDENTIFICACIÓN Y TRATAMIENTO DEL ACOSO LABORAL}

La siguiente variable a estudiar serán los llamados resultados económicosfinancieros. En la actualidad, la toma de decisiones en la empresa, no es una actividad estrictamente racional, de hecho, en el mejor de los casos, muchas de las decisiones empresariales, incluso de gran alcance, lo son sólo en parte; con frecuencia, las elecciones estratégicas se basan en informaciones muy poco seguras, mientras que la toma de decisiones a nivel operacional está respaldada y motivada por análisis económicos. Algunos investigadores postulan que la salud laboral del trabajadordirectivo, tiene la importancia que las instancias decisorias creen que tienen; la información y las percepciones sobre los efectos futuros de las decisiones, expresadas en términos financieros, "ayudan" a los empresarios en el proceso de toma de decisiones, de tal manera que el análisis económico está influyendo en el pensamiento de los responsables de tomar decisiones y elaborar políticas de empresa. La mayoría de los economistas, consideran que realizar análisis de costo- beneficio es predecir el futuro.

Así, podemos decir que para la gran mayoría de las organizaciones del sector sociosanitario, la referencia última en términos de rendimiento de la empresa es el balance financiero, ya que incluso las fundaciones, gestionadas por patronatos locales, (organizaciones sin ánimo de lucro) deben llegar al umbral de la rentabilidad.

Un buen análisis exhaustivo del sector residencial que se precie, debería concentrar su visión, en la contribución de la salud laboral a la competitividad de la empresa. No podemos obviar la actual situación financiera internacional, lo que de alguna manera, obliga a las empresas a administrar adecuadamente los recursos, con vistas a lograr la eficiencia en la productividad empresarial; se obvia así en multitud de ocasiones la evaluación del desempeño directivo, primando el resultado de las operaciones contables, realizadas en un periodo de tiempo determinado. Resulta así determinante establecer la siguiente hipótesis de estudio:

H7: A menor resultado económico, mayor acoso laboral se produce. 


\section{CAPÍTULO VI. IDENTIFICACIÓN Y TRATAMIENTO DEL ACOSO LABORAL}

El octavo elemento que analizaremos será, el grado de autonomía laboral. Alles, (2004) describe la autonomía como una competencia, siendo ésta la rápida ejecutividad ante las pequeñas dificultades o problemas que surgen en el día a día de la actividad; supone actuar proactivamente cuando ocurren desviaciones o dificultades sin esperar a consultar a toda la línea jerárquica de la empresa u organización, evitando así el agravamiento de problemas menores. También implica la posibilidad de proponer mejoras aunque no haya un problema concreto que deba ser solucionado. Para otros investigadores tales como Silva, (1996), la autonomía viene definida por la responsabilidad, independencia y poder de decisión de que goza el sujeto en su organización. Amorós, (2007), define la autonomía como el grado en el cual el puesto proporciona libertad, independencia y discrecionalidad, sustanciales para que el individuo programe el trabajo y determine los procedimientos que deberán ser utilizados para llevarlo a cabo; asimismo afirma que involucrar a los trabajadores en las decisiones hace que se incremente su autonomía y su autocontrol, lo que a su vez, hará que se sientan más motivados y comprometidos con la organización, presentando un mayor desempeño en la realización con éxito de sus funciones, siendo más productivos en su puesto de trabajo. La autonomía laboral está ligada a las características centrales del puesto; Hackman y Oldham (2003), proponen como tales las siguientes:

- Variedad de habilidades: el grado en que el puesto requiera que el individuo desempeñe tareas diversas en que usa capacidades y habilidades distintas.

- Identidad de tarea: la medida en que el puesto precisa que el individuo realice una tarea completa o identificable en su totalidad (la identidad de la tarea es alta cuando la persona trabaja en un producto o proyecto desde su principio hasta su fin y ve un resultado tangible).

- Importancia de la tarea: el grado en que el puesto afecta la vida de otras personas dentro o fuera de la organización. 


\section{CAPÍTULO VI. IDENTIFICACIÓN Y TRATAMIENTO DEL ACOSO LABORAL}

- Autonomía: la medida en que el puesto permite que el individuo experimente libertad, independencia y discreción en la programación y determinación de los procedimientos usados para realizar el trabajo. La responsabilidad experimentada se genera con la característica de autonomía.

- Retroalimentación: el grado en que la persona recibe información directa y clara acerca de la efectividad con que se realiza su trabajo.

Basándose en este modelo, ambos autores definen la autonomía laboral como el grado en que un trabajador tiene libertad e independencia para programar el trabajo y tomar decisiones, así como la libertad de elegir el método más adecuado para la realización de sus actividades. Cabe recordar además que el puesto directivo en un centro residencial, está caracterizado por una continua toma de decisiones, decisiones ante situaciones en su mayoría imprevisibles, que surgen día a día como consecuencia del trabajo en equipo y del trabajo "con personas", ante las cuales el directivo debe tomar las medidas más adecuadas, con el fin de elegir la mejor opción, la cual debe satisfacer las necesidades demandadas. Basándonos en ello, creemos oportuno formular la siguiente hipótesis de trabajo:

\section{H8: Cuanto menor es el grado de autonomía laboral, mayor es el acoso laboral}

Como noveno elemento de estudio enunciaremos la satisfacción laboral. La satisfacción laboral es un aspecto que ha sido ampliamente estudiado desde que Hoppock en 1935, desarrollará los primeros estudios abarcando grandes grupos de población; Locke, en 1976 definió la satisfacción laboral como "un estado emocional positivo o placentero de la percepción subjetiva de las experiencias ${ }^{18}$ laborales del sujeto".

\footnotetext{
${ }^{18}$ Entendiendo el concepto de "experiencias", como las vivencias experimentadas, no como años de trabajo en la misma organización.
} 


\section{CAPÍTULO VI. IDENTIFICACIÓN Y TRATAMIENTO DEL ACOSO LABORAL}

La satisfacción laboral, históricamente, también se ha concebido como el cumplimiento de determinadas necesidades y aspiraciones del trabajador, sean de tipo económico, social, organizativo, de desarrollo etc... que pueden verse reflejadas en cinco factores: 1) el carácter intrínseco del trabajo, 2) la remuneración, 3) la promoción, 4) la seguridad del empleo, y 5) las condiciones de trabajo (Bravo, Peiró y Rodríguez, 1996). Hoel, Einarsen y Cooper (2003), ratifican en diferentes investigaciones la relación existente entre el acoso psicológico, entendido este como agresión laboral, y la satisfacción laboral, indicando asimismo, que los problemas de salud que suelen ir asociados al acoso psicológico, pueden a su vez desmotivar y reducir la satisfacción de los trabajadores.

En un informe reciente de la Agencia Europea de Seguridad y Salud en el Trabajo (European Agency for Safety and Health at Work, 2010), se indica que entre un 5 y un $20 \%$ de los trabajadores europeos son víctimas de agresión laboral, y aunque el $40 \%$ del personal directivo-ejecutivo de las empresas se muestra preocupado, sólo el $25 \%$ ha implantado medidas correctivas, incidiendo además a posteriori en que uno de los sectores más afectados y con mayor número de casos emergentes es el sector sociosanitario.

Podemos así afirmar que por satisfacción laboral hoy en día se entiende el grado de conformidad de la persona respecto a su entorno de trabajo, incidiendo en la actitud del trabajador hacia sus obligaciones, surgiendo así una correspondencia entre el trabajo real y las expectativas del trabajador. Acorde con ello, se formula la novena hipótesis de investigación:

H9: A mayor acoso laboral, menor satisfacción laboral.

El siguiente fundamento a estudio es la intención de abandono de la organización. Podemos afirmar que la intención de abandono es una de las consecuencias organizacionales más estudiadas en la psicología del trabajo. Ha sido entendida como la voluntad consciente y deliberada de dejar la organización; suele 


\section{CAPÍTULO VI. IDENTIFICACIÓN Y TRATAMIENTO DEL ACOSO LABORAL}

medirse con referencia a un intervalo de tiempo específico, y se considera como el último paso de una secuencia de pensamientos, que han llevado al empleado a plantearse abandonar el empleo e intentar buscar uno alternativo (Mobley, Horner y Hollinsworth, 1978). Otros autores como Lee (2007), definen la intención de abandono como la probabilidad de que el empleado cambie de trabajo en un periodo determinado de tiempo. La intención de abandono es además un predictor del posible retiro definitivo del trabajo (Nielsen, 2004), y como tal un factor relevante a tener en cuenta dentro de la organización. Así pues el acoso laboral es una de las situaciones que afecta de manera negativa a los sentimientos de los empleados hacia su trabajo (Hershcovis, 2010). Cortina y Lim (2005) encontraron que los empleados que han experimentado frecuentemente actos de incivismo laboral, tienen una mayor probabilidad de pensar en dejar sus trabajos. Por otra parte, Pearson, Anderson y Porath (2000), identificaron que el $46 \%$ de las víctimas de incivismo consideraron esta opción de renuncia y el $12 \%$ de estos empleados de hecho, lo hicieron. Uno de los estudios más relevantes al respecto es el propuesto por Hershcovis y Barling (2010), en el cual se concluye que los trabajadores afectados por situaciones de acoso laboral suelen tener reacciones que pueden afectar a la organización.

De igual manera los resultados de los estudios realizados entre el acoso psicológico y la intención de abandono, arrojan datos altamente preocupantes. De todo ello surge esta nuestra décima hipótesis de estudio:

H10: A mayor acoso laboral, mayor intención de abandono.

El siguiente constructo que analizaremos será el rendimiento laboral. Uno de los autores más destacados en el estudio del rendimiento laboral es Motowidlo (2003); lo concibe como el valor total que la empresa u organización espera con respecto a los episodios que un trabajador lleva a cabo en un periodo de tiempo determinado. Ese valor, que puede ser positivo o negativo, supone la contribución que ese empleado hace a la consecución de la eficacia de su organización. 


\section{CAPÍTULO VI. IDENTIFICACIÓN Y TRATAMIENTO DEL ACOSO LABORAL}

Analizando en profundidad el término, encontramos que existe una doble perspectiva en su conceptualización; por un lado algunos autores consideran el rendimiento en términos de resultado $u$ outputs del trabajador (como por ejemplo el número de clientes conseguidos, en el caso que nos ocupa, ancianos), y por otro lado existe otro grupo de especialistas y autores para los que lo correcto es considerar el rendimiento como un conjunto de conductas en el entorno laboral, en lugar de definirlo como el resultado de las mismas. Por esto, se podría decir que medir el rendimiento es cuantificar lo que el empleado ha hecho y su evaluación consiste en asignar un juicio de valor o la calidad de esa medida cuantificada del rendimiento. De estas dos interpretaciones, a lo largo de la historia de la evaluación del rendimiento, se han generado numerosas investigaciones.

De manera operativa, también se suele definir el rendimiento laboral como una función de la capacidad y la motivación del trabajador (Moorhead y Griffin, 1998), en este sentido, si la motivación es el estado psicológico de activación hacia el trabajo, su resultado conductual, y por esto observable, es el rendimiento. En cualquier caso, independientemente de la conceptualización que se puede hacer del constructo, y sea cual sea el objetivo perseguido, el rendimiento necesariamente ha de estar ligado a los objetivos estratégicos de la empresa u organización. En la actualidad, en los puestos directivos de centros residenciales, es muy frecuente encontrarnos una medición del rendimiento por objetivos, entendidos estos en el caso que nos ocupa, como la captación de nuevos clientes, el grado de ocupación del centro, el nivel de calidad obtenido en las certificaciones auditoras, la facturación...etc. a partir de los cuales la empresa establece unos criterios claros, medibles, y específicos. En la fecha establecida por la misma, se evalúa en qué medida se han conseguido estos objetivos planteados. Así, pues la hipótesis que formulamos es la siguiente:

$H_{11}$ : A mayor acoso laboral, menor rendimiento. 


\section{CAPÍTULO VI. IDENTIFICACIÓN Y TRATAMIENTO DEL ACOSO LABORAL}

Seguidamente abordaremos el compromiso con la empresa u organización del directivo; para dar lo mejor de sí todos los días, los trabajadores deben sentir que forman parte del éxito de la empresa, y el director no es una excepción. El compromiso del empleado proviene en parte del conocimiento de la empresa y de la importancia de la función del empleado a la hora de ayudar a cumplir sus objetivos. El compromiso refleja además la implicación intelectual y emocional del trabajador, lo cual les lleva a compartir una serie de creencias y actitudes que vistas en su conjunto reflejan un aspecto clave del estado de la empresa. Algunos autores definen el compromiso laboral, como aquel vínculo de lealtad por el cual el trabajador desea permanecer en la organización, debido a su motivación implícita.

Meyer y Allen, definen el compromiso como una actitud que se expresa, como el vínculo psicológico del empleado hacia la organización que hace sea poco probable que el empleado abandone la organización. Este vínculo psicológico se puede alcanzar relatan, mediante tres componentes diferenciados:

1) Compromiso afectivo o de deseo: es la identificación psicológica del trabajador con los valores y la filosofía de la empresa, mostrando una fuerte convicción y aceptación de los objetivos y valores de la organización, una clara disposición para ejercer un esfuerzo en beneficio de la organización, una preocupación por los problemas de la empresa y un fuerte deseo de permanecer en ella.

2) Compromiso de continuidad o de necesidad: se trata del apego que tiene el trabajador con la empresa, es de carácter material, su continuidad en la misma depende de la percepción que tiene con lo que recibe como contraprestación a su trabajo.

3) Compromiso normativo o moral; es un modo motivado por ciertas presiones de tipo cultural o familiar. 


\section{CAPÍTULO VI. IDENTIFICACIÓN Y TRATAMIENTO DEL ACOSO LABORAL}

Así pues creemos necesario abordar la siguiente hipótesis:

H12: A mayor acoso laboral, menor compromiso con la organización.

El decimo tercer factor a analizar en este trabajo de investigación, es el denominado clima organizacional. Cuando se estudia este parámetro se evidencia que no existe una unificación teórica sobre su conceptualización. Autores como Robbins (1999) y Gibson, Ivancevich \& Donnelly (1996) plantean que clima y cultura organizacional son lo mismo cuando los definen como la personalidad y el carácter de una organización. El concepto de clima organizacional fue introducido por primera vez en psicología organizacional por Gellerman en 1960; nace de la idea de que el hombre vive en ambientes complejos y dinámicos, puesto que las organizaciones están compuestas de personas, grupos y colectividades que generan diversidad de comportamientos que a su vez afectan a ese ambiente. Autores como Méndez (2006) manifiestan que el origen del clima organizacional está en los posos de la sociología, donde el concepto de organización dentro de las teorías de las relaciones humanas enfatiza la importancia del hombre en su función del trabajo y por su participación en un sistema social. Para Dessler (1976) la importancia del concepto está en la función que cumple como vínculo entre aspectos objetivos de la organización y el comportamiento subjetivo de los trabajadores, es por ello que su definición se basa en el enfoque objetivo de Forehand y Gilmer (1964) que plantean el clima organizacional como el conjunto de características permanentes que describen una organización, la distinguen de otra, e influyen en el comportamiento de las personas que la forman.

Por tanto podemos decir que el clima organizacional, ocupa un lugar destacado en la gestión de las personas, tomando en los últimos años un rol protagónico como objeto de estudio en diferentes sectores.

En el caso que nos ocupa, el clima organizacional estaría conformado por el ambiente donde el directivo del centro residencial desempeña su trabajo diariamente, el trato que puede tener con sus superiores y subordinados, la relación entre el 


\section{CAPÍTULO VI. IDENTIFICACIÓN Y TRATAMIENTO DEL ACOSO LABORAL}

personal de atención indirecta de la empresa e incluso la relación con los proveedores y clientes. En suma, podríamos concluir que es la expresión personal de la "percepción" que el sujeto tiene de la organización a la que pertenece y que va a incidir de manera directa sobre el desempeño de su trabajo, de ahí, nuestra siguiente hipótesis de estudio:

\section{$H_{13}$ : A mayor acoso laboral, peor clima organizacional.}

Por último finalizaremos con el estudio de la finalización de las tareas. Como hemos visto a lo largo de esta tesis de investigación, la función directiva en la empresa es un factor crítico para el éxito, el crecimiento y el desarrollo integral de la organización. Dirigir un centro residencial es una tarea sumamente ardua, una suma de tareas cada una de ellas de gran complejidad; los ejecutivos de estas organizaciones a menudo obvian la dificultad que sus directivos tienen para afrontar las tareas con éxito, ya que fijan los objetivos de los trabajadores, planifican con anticipación los recursos, organizan las estructuras de trabajo, coordinan todos los departamentos del centro, gestionan los recursos humanos, controlan el gasto económico, evalúan los resultados periódicamente, elaboran estrategias a corto y largo plazo, gestionan al personal del centro, y ejecutan las acciones correctoras correspondientes en caso de haber desviaciones.

Con todo ello podemos afirmar que un directivo de un centro residencial tiene numerosas tareas a desarrollar en su jornada laboral, tareas que rara vez puede abordar en el tiempo estipulado en su jornada, ya que desde la dirección general, no han sido planificadas correctamente con lo que ello conlleva tanto para el directivo del centro, como para los trabajadores y la propia organización, y todo ello por norma, debido a factores puramente económicos, que merman la realidad de la situación del centro. La ejecutiva de la empresa debe tener en cuenta el equipo disponible, los recursos materiales, el espacio arquitectónico, el orden de las tareas, la urgencia que 


\section{CAPÍTULO VI. IDENTIFICACIÓN Y TRATAMIENTO DEL ACOSO LABORAL}

suponen y el grado de relevancia entre otros factores; de la necesidad de abordar está temática, se formula la última hipótesis de esta investigación:

H14: A mayor acoso laboral, menor finalización de las tareas.

Estableciendo las hipótesis de estudio, concluimos la primera parte de esta tesis doctoral, la fundamentación teórica, en la que se basa la investigación empírica que a continuación comenzaremos a detallar.

En la segunda parte de este trabajo de estudio, abordaremos con profundidad el diseño empírico, profundizando en la fundamentación metodológica, los objetivos establecidos, los participantes, el diseño experimental, los instrumentos de evaluación necesarios, las variables de estudio, el procedimiento seguido, el análisis exhaustivo de los datos recogidos en la muestra de estudio, las propiedades psicométricas de las escalas y cuestionarios utilizados, la descripción exhaustiva de estas escalas y cuestionarios, el estudio crítico de los instrumentos de medida, el estudio de la muestra, los perfiles victimológicos y las líneas futuras de investigación. 
RESUMEN - ABSTRACT

CAPÍTULO VI.

"Identificación y Tratamiento del Acoso Laboral".

En el desarrollo del Capítulo VI, hemos estudiado en minucia la identificación y el tratamiento del acoso laboral, comenzando por la identificación de los aspectos destacados en la acción preventiva y la desmitificación y consiguiente argumentación lógica de algunos mitos "sociales" indebidamente preestablecidos en nuestra sociedad.

Una vez introducida la temática de análisis, se recogen las diferentes fases que se suceden en la superación del acoso; identificación del problema, denominación del problema, desactivación emocional, respuesta activa-extroyección y superación del problema e integración en la perspectiva vital de la víctima, además de incidir en los diferentes indicadores que reflejan la inseguridad vivida por un directivo de un centro residencial; malestar emocional, nerviosismo, falta de confianza en su valía y sus capacidades, desconfianza hacia el otro, arrogancia reactiva, aislamiento, percepción de vulnerabilidad, nuevas formas de entender la propia conciencia, cambios bruscos de opinión, falta de decisión a la hora de asumir riesgos, análisis exhaustivo de situaciones y factores irrelevantes, incapacidad temporal en la resolución de problemas, toma de decisiones irracionales, sentimientos contrariados, maximización de lo negativo, dudas y pudor sobre determinados temas e indecisión.

Seguidamente, se identifican los factores de resistencia al mobbing; la constitución de un pensamiento racional, la generación de una autoestima sólida, el estado físico y el sueño, la confianza en uno mismo, el conocimiento y la aceptación de las propias limitaciones, el mantenimiento de la consideración del entorno, el apoyo familiar y social, la mejora de la tolerancia a la frustración, la mejora de las habilidades sociales, la aceptación del dolor generado, la afectividad social del entorno, la 


\section{CAPÍTULO VI. IDENTIFICACIÓN Y TRATAMIENTO DEL ACOSO LABORAL}

conexión con los propios sentimientos y su verbalización, y el apoyo de los compañeros de trabajo.

A continuación se delimitan las líneas de actuación terapéutica; la eliminación del sentimiento de culpa, el entrenamiento en asertividad, la mejora de la autoestima, la mejora de los recursos personales, el fomento de los procesos emocionales, el aumento de la autorregulación del optimismo, el entrenamiento de habilidades sociales y solución de problemas. Para todo ello, se propone un modelo de evaluación psicológica y un modelo de intervención psicológica.

Una vez estudiados todos los factores anteriores, se detalla cómo es el regreso a un nuevo puesto de trabajo, finalizando el Capítulo con la formulación de las hipótesis de investigación de esta tesis doctoral. 
SEGUNDA PARTE: INVESTIGACIÓN EMPÍRICA

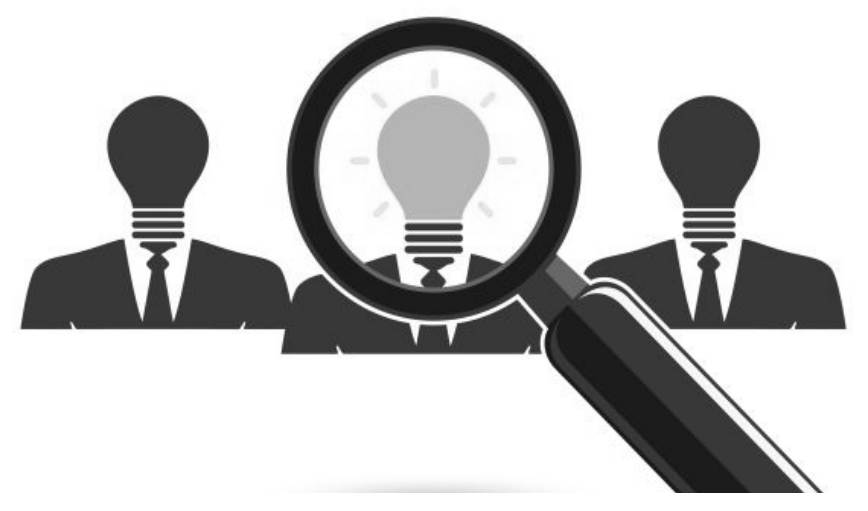

\section{SEGUNDA} PARTE

\section{INVESTIGACIÓN EMPÍRICA}

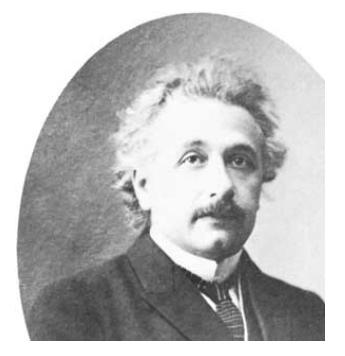

"Si supiese qué es lo que estoy haciendo, no le Ilamaría investigación, verdad?".

Albert Einstein (físico alemán). 


\section{CAPÍTULO VII}

“Metodología Empírica y Proceso"

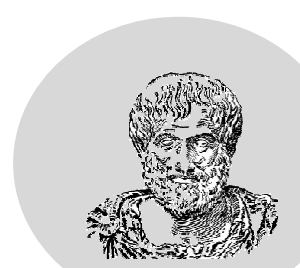

"Es de importancia para quien desee alcanzar una certeza en su investigación, el saber dudar a tiempo ".

\section{Aristóteles (filósofo griego).}




\title{
CAPÍTULO VII.
}

\author{
"Metodología Empírica y \\ Proceso".
}

\section{Metodología Empírica y Proceso.}

La investigación empírica se define como el proceso que conduce a la búsqueda de conocimiento mediante la aplicación de métodos y técnicas. La metodología empírica conlleva toda una serie de procedimientos prácticos con el objeto y los medios de investigación que permiten revelar las características fundamentales y relacionales (antecedentes-consecuentes) esenciales del objeto de estudio que se plantea, los cuales a su vez son accesibles a la contemplación sensorial existente. Así, los métodos de investigación empírica, representan un nivel en el proceso de investigación, cuyo contenido, procede fundamentalmente de la experiencia, el cual es sometido a cierta elaboración racional y expresado en un lenguaje determinado.

Mediante la observación científica, recogida esta mediante la técnica del cuestionario, obtendremos una visión directa del objeto de esta investigación, el acoso laboral experimentado en puestos directivos de centros residenciales, así intentaremos conocer la realidad mediante la percepción directa del fenómeno.

Este tipo de observación, presenta diferentes cualidades, que la diferencian de lo casual y espontáneo; es una percepción consciente, orientada hacia un objetivo muy definido y bien determinado, metódica y altamente especializada (el investigador debe tener un conocimiento muy amplio del proceso, fenómeno y objeto de estudio), para ser capaz dentro del conjunto de diferentes características que lo conforman, de seleccionar aquellos aspectos susceptibles de estudio que contribuyan a la corroboración o no de las hipótesis establecidas a lo largo del desarrollo de la investigación. 


\section{CAPÍTULO VII. METODOLOGÍA EMPÍRICA Y PROCESO}

La metodología empleada en esta tesis, estará cuidadosamente planificada, teniendo en cuenta la sensibilidad de la materia a estudio, los objetivos a alcanzar, el objeto de estudio, los sujetos que participarán en la investigación, los medios con los que se realizará, las condiciones o contexto social donde se produce el fenómeno, así como las cualidades de estudio de los participantes. Cabe recordar cómo la función directiva desempeñara un rol fundamental en la recogida de datos de la muestra de estudio, recabando así la información necesaria para llevar a cabo el desarrollo de este estudio.

Por tanto, el trato de la información será objetivo, despojado lo más posible de todo elemento de subjetividad que se precie, evitando posibles perjuicios valorativos que puedan darse en la información facilitada, para lo cual, recogeremos información concreta y específica de cada una de las variables definidas en las hipótesis de trabajo, intentando conseguir así la mayor validez de estudio posible, ponderando de manera adecuada el trato estadístico de la información.

La recogida de datos será confiable, es decir, el cuestionario guía de la observación aplicado, será lo suficientemente preciso y claro, como para garantizar que los diferentes directivos, lo entiendan y apliquen de la misma manera, garantizando así la equidad en las respuestas de los mismos. Todo ello nos permitirá obtener conocimiento acerca del comportamiento del objeto de estudio de la investigación tal y como éste se da en la realidad, accediendo de manera directa e inmediata al fenómeno que está siendo investigado en esta tesis.

Conseguiremos así, investigar el fenómeno en su manifestación más visible, externa y ajena en su desarrollo, tratando de constatar las diferentes hipótesis de las que consta este estudio, de forma consciente, desprejuiciada e inclusive garantizando la uniformidad de los resultados obtenidos, garantizando las condiciones necesarias para el esclarecimiento de las relaciones con el objeto de estudio. 


\section{CAPÍTULO VII. METODOLOGÍA EMPÍRICA Y PROCESO}

La actividad empírica que llevaremos a cabo presentará así las siguientes características:

1) Aislara al objeto de estudio de la influencia de otros factores no esenciales que puedan enmascarar la esencia del mismo.

2) Reproducirá el objeto de estudio en condiciones controladas.

3) Describirá de la manera más fielmente posible, las condiciones y factores que tienen lugar en el proceso de estudio.

4) Esclarecerá en lo posible las leyes y relaciones existentes entre las variables recogidas en la formulación de las hipótesis y el objeto de estudio.

5) Estará indisolublemente unido a la teoría recogida previamente, en el estudio pormenorizado recogido a lo largo del desarrollo de esta tesis.

6) Inferirá los resultados obtenidos a través de un razonamiento hipotético deductivo lógico, tratando de clarificar las conclusiones recogidas a través del estudio informático y estadístico.

7) Considerara el acoso laboral en puestos directivos, como un fenómeno dinámico, en continua interacción con las estructuras sociales que le rodean y que le pueden incluso retroalimentar.

8) Formulará de manera precisa y concreta la materia objeto de estudio, especificando con exactitud qué se pretende investigar.

9) Propondrá las hipótesis formuladas bien definidas, recogiendo cada variable en el cuestionario empleado.

10) Someterá a todas y cada una de las hipótesis recogidas, a una contrastación rigurosa y pormenorizada.

11) Analizará las diferentes relaciones existentes entre las variables seleccionadas en el modelo tomado, y definido como modelo de ecuaciones estructurales, el cual tratará de ser fiel reflejo del planteamiento teórico que sustenta esta investigación. 


\section{CAPÍTULO VII. METODOLOGÍA EMPÍRICA Y PROCESO}

12) Tenderá a alcanzar la mayor relevancia científica posible.

13) Delimitada, para alcanzar la mayor precisión posible a la hora de concluir los factores estudiados.

14) Abarcará factores humanos, intentado mejorar la vida social de las personas y su problemática actual.

15) Su objeto de estudio poseerá un valor didáctico, intentando ahondar en determinados parámetros que a su vez puedan ser origen de diversos problemas.

16) No axiológica, evitando circunstancias que guarden alguna relación con pronunciamientos políticos, religiosos, morales o con filosofías de vida.

17) Conmensurable, analizando la temática expuesta, en función de diferentes variables que varían en cantidad y que exhiben una intensidad diferenciadora.

18) Medible, precisando y estimando desde las diferentes hipótesis planteadas, la extensión del fenómeno acontecido.

19) Contextualizada, avanzando en el conocimiento científico desde lo general a lo específico.

20) Prognosica, estudiando el fenómeno en los escenarios en que se produce, desde el menos favorable, hasta el más favorable.

21) Descriptiva, realizando un esbozo del camino y método seguido para dar respuesta al planteamiento inicial.

22) Focalizada en el área específico del fenómeno, donde ocurre el hecho investigado.

23) Minuciosa, sirviéndose de un procedimiento claro, optimizando los recursos, tales como el cuestionario.

24) Continua, tomando permanentemente decisiones, que se derivan de manera inevitable del desarrollo de la investigación.

25) Diferenciada, diferenciando el objeto de estudio, de las variables intervinientes en el mismo. 


\section{CAPÍTULO VII. METODOLOGÍA EMPÍRICA Y PROCESO}

A continuación se expone el análisis de los datos obtenidos a lo largo del desarrollo de este estudio de investigación.

\subsection{Análisis de datos.}

Para el análisis de los datos se ha utilizado el programa informático SPSS 19 para Windows 7, el cual es un programa estadístico muy usado en el estudio de las ciencias aplicadas. Originalmente SPSS fue creado como el acrónimo de Statistical Package for the Social Sciences aunque también se ha referido como Statistical Product and Service Solutions. Sin embargo, en la actualidad toma su nombre del software IBM SPSS. Su característica más notable es que es capaz de trabajar con grandes bases de datos, ya que se podrían realizar análisis con hasta dos millones de registros y 250.000 variables. Por tanto su eficacia es altamente reconocida en el mundo científico y de la investigación.

El programa consiste así en un módulo base y módulos externos. Originalmente fue creado por Normal H. Nie, C. Hadlai Hull y Dale H. Bent en 1968. Entre 1969 y 1975 la Universidad de Chicago por medio de su National Opinion Research Center estuvo a cargo del desarrollo del programa. En 1970 se publica el primer manual de usuario del SPSS; este manual populariza el programa entre algunas de las instituciones más prestigiosas de Estados Unidos, saliendo así en 1984 la primera versión para ordenadores personales. Desde la versión 14, pero más específicamente desde la versión 15 se implanta la posibilidad de hacer uso de las librerías de objetos del SPSS desde diversos lenguajes de programación.

Por todo ello se ha creído como el medio informático estadístico más adecuado para esta investigación. Así se obtienen los resultados que en las líneas siguientes se analizan con el fin de dar respuesta a las hipótesis y objetivos propuestos en esta tesis doctoral. 


\section{CAPÍTULO VII. METODOLOGÍA EMPÍRICA Y PROCESO}

En las siguientes líneas, haremos una descripción fiel y exhaustiva de los directivos de centros residenciales, que han formado parte de nuestra muestra de estudio.

\subsection{Participantes.}

En el desarrollo de esta investigación, se contó con la participación de un total de 59 sujetos pertenecientes a la población activa española seleccionados, todos ellos directores de centros residenciales privados y/o concertados, con capacidad para al menos 50 residentes, del territorio nacional. Inicialmente fueron entregados un total de 75 cuestionarios, compuestos por 150 escalas, 75 escalas Cisneros y 75 escalas de Perfil Profesional, resultando la tasa de respuesta del 92\%, es decir un total de 69 cuestionarios resultaron devueltos, de los cuales fueron rechazados inicialmente un total de 10, por tratarse de cuestionarios con datos defectuosos, o contestados al azar. Así, por ejemplo, los cuestionarios donde no aparecía el sexo, la edad, el nivel de estudios, los años de experiencia ó el puesto o puestos ocupados con anterioridad, fueron eliminados. Independientemente de la complejidad de los datos disponibles y del procedimiento estadístico que se tenga la intención de utilizar, se realizó una exploración minuciosa de los datos recogidos previa al inicio de cualquier análisis estadístico, ya que esta permite identificar, entre otros aspectos:

1) Posibles errores (p. ej., datos mal introducidos o respuestas mal codificadas por los sujetos).

2) Valores señalados, incorrectamente (p. ej., duplicidad a la hora de emitir los juicios).

3) Posibles pautas extrañas en los datos ( $p$. ej., valores que se repiten demasiado o que no aparecen nunca).

4) Variabilidad no esperada (p. ej., demasiada concentración en torno a determinados parámetros). 


\section{CAPÍTULO VII. METODOLOGÍA EMPÍRICA Y PROCESO}

De este modo, la muestra definitiva para la realización de esta investigación consistió en 59 sujetos pertenecientes a la población activa española. Todos los sujetos partícipes en el estudio propuesto respondieron al protocolo de recogida de datos previamente elaborado (cuestionario, formado por, formulario de datos socio demográficos y socio laborales, Escala Cisneros y Escala de Perfil Profesional).

Por otra parte, los sujetos componentes de la muestra de estudio definitiva, a los que se les facilitó en el propio cuestionario las instrucciones para cumplimentar debidamente cada una de las escalas recogidas en el mismo a modo de introducción, participaron de forma voluntaria y confidencial en el desarrollo de esta investigación, en la que se trataran los cuestionarios de manera anónima. A continuación se facilitan los datos descriptivos y algunas frecuencias y porcentajes sobre las variables y parámetros sociodemográficos y sociolaborales y de percepción de acoso psicológico en puestos directivos de centros residenciales, obtenidos a partir del cuestionario elaborado a los efectos para la presente investigación.

Así, respecto a las variables sociodemográficas y sociolaborales, se han tenido en consideración los siguientes aspectos a la hora de describir la muestra de estudio:

a) La edad, siendo la media de los sujetos participantes en el presente estudio de 44 años y oscilando la misma desde los 20 años hasta los 65 años o más. (Véase el gráfico 7.1).

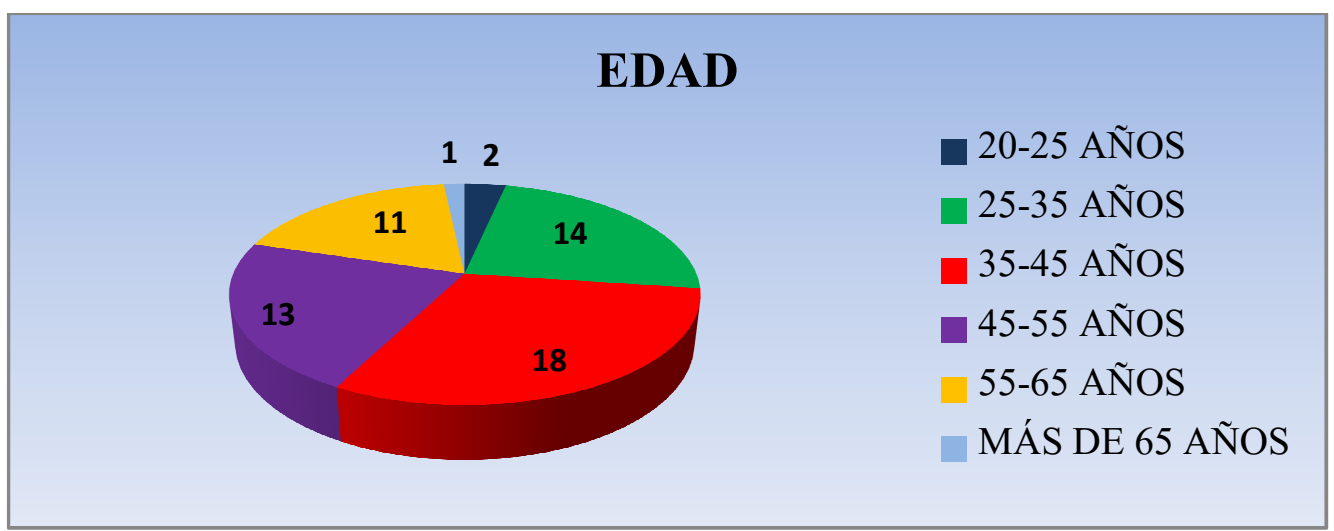

Gráfico 7.1. Descriptivos sociodemográficos de la edad. 


\section{CAPÍTULO VII. METODOLOGÍA EMPÍRICA Y PROCESO}

b) El sexo, estableciéndose como variable moduladora y complementaria en la investigación, siendo el 37.28 \% de la muestra recogida hombres y el $62.72 \%$ mujeres. (Véase el gráfico 7.2).

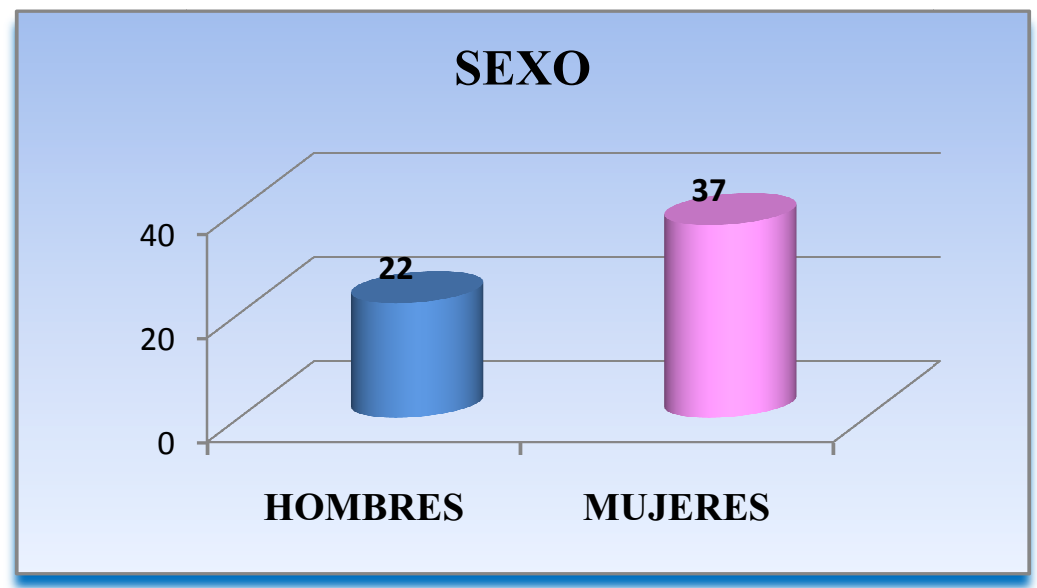

Gráfico 7.2. Descriptivos sociodemográficos del sexo.

c) Los años de experiencia en el sector, diferenciando 6 intervalos; 1) $\sin$ experiencia, 2) una experiencia inferior a un año, 3) experiencia entre 1 y 10 años, 4) experiencia entre 10 y 20 años, 5) experiencia de 20 a 30 años, y 6) más de 30 años de experiencia (Véase el gráfico 7.3).

\section{AÑOS DE EXPERIENCIA EN EL SECTOR}

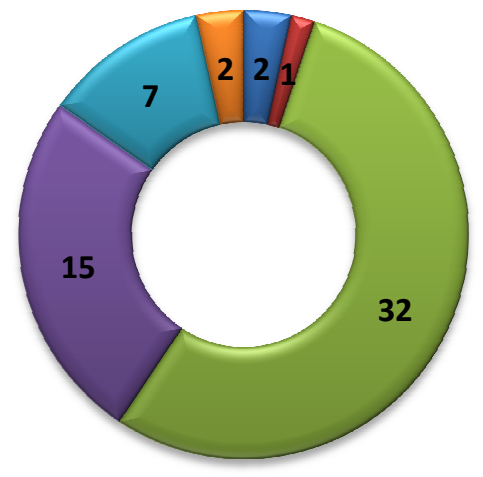

$$
\begin{aligned}
& \square \text { Sin experiencia } \\
& \square \text { Experiencia inferior a } 1 \text { año } \\
& \square \text { De } 1 \text { a } 10 \text { años } \\
& \square \text { De } 10 \text { a } 20 \text { años } \\
& \square \text { De } 20 \text { a } 30 \text { años } \\
& \square \text { Más de } 30 \text { años }
\end{aligned}
$$




\section{CAPÍTULO VII. METODOLOGÍA EMPÍRICA Y PROCESO}

d) El nivel de estudios más alto alcanzado, categorizado en; 1) sin estudios reglados, 2) educación general básica (EGB) considerada como estudios primarios, 3) diplomatura o grado equivalente y 4) licenciatura o equivalente. (Véase el gráfico 7.4).

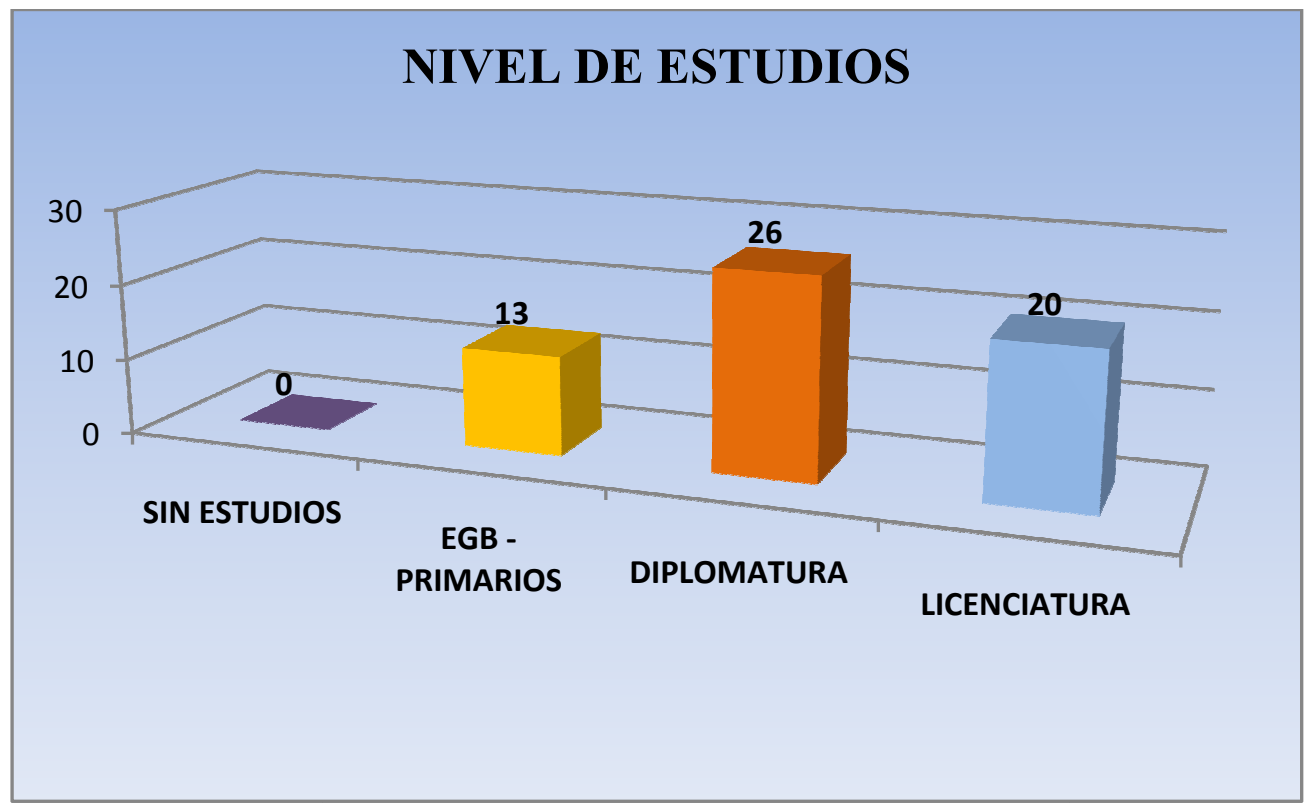

Gráfico 7.4. Descriptivos sociodemográficos del nivel de estudios alcanzado.

c) Los puestos ocupados con anterioridad, diferenciando cada uno de los puestos recogidos en la muestra de estudio, donde se aprecia que el $28.81 \%$ dice no haber ocupado ningún puesto con anterioridad, el $3.38 \%$ dicen haber sido abogados, el 1.69 \% adjuntos a dirección, el 1.69 \% fueron dependientes, el $8.47 \%$ directores, el $1.69 \%$ arquitectos, el $6.77 \%$ técnicos, el $5.08 \%$ terapeutas ocupacionales, el 1.69 \% fisioterapeutas, el $3.38 \%$ auxiliares de enfermería, el $3.38 \%$ administrativos, el $5.08 \%$ se habían dedicado a la enfermería, el 5.08 \% desarrollaron tareas como docentes, el 3.38 \% fueron psicólogos, el $5.08 \%$ se dedicaron a la medicina, el $6.77 \%$ fueron trabajadores sociales, el $1.69 \%$ habían sido antes supervisores, el $1.69 \%$ habían estado de encargados, el 1.69 \% habían sido farmacéuticos y el 3.38 \% 


\section{CAPÍTULO VII. METODOLOGÍA EMPÍRICA Y PROCESO}

habían desarrollado varios puestos con anterioridad (Véase el gráfico 7.5).

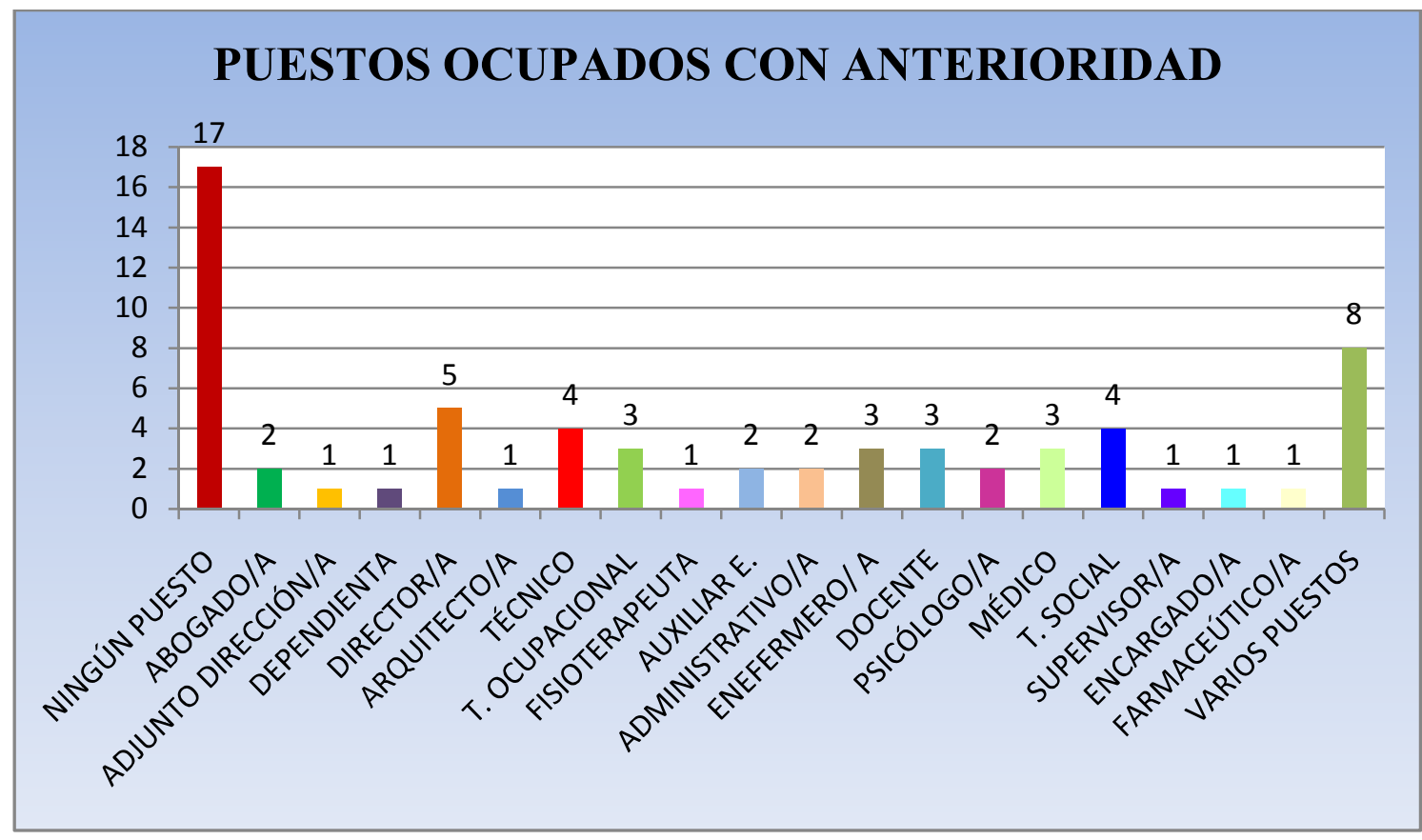

Gráfico 7.5. Descriptivos sociodemográficos de los puestos ocupados con anterioridad.

Así para seleccionar la población y posteriormente la muestra fue necesario definir la llamada unidad de análisis, es decir definir con meridiana claridad "quiénes iban a ser medidos" (Hernández, Fernández y Baptista, 1998); esta unidad de análisis ha sido la que nos ha llevado a delimitar la población objeto de estudio, recogida en las líneas citadas anteriormente. Autores como Sellitz (1965), definen la población como "el conjunto de todos los casos que concuerdan con una serie de especificaciones previamente estudiadas". Cabe recordar que dado lo delicado del objeto de estudio, aún con la confidencialidad dada y la protección de datos establecida, algunos de los participantes escogidos no quisieron participar en el estudio, a pesar de lo cual consideramos la muestra recogida como suficiente para llevar a cabo esta investigación. 


\section{CAPÍTULO VII. METODOLOGÍA EMPÍRICA Y PROCESO}

La tabla 7.1, muestra a continuación las variables descriptivas del informante:

\begin{tabular}{|c|c|c|c|}
\hline VARIABLE & INDICADORES & $\begin{array}{l}\text { NÚMERO DE } \\
\text { SUJETOS (N) }\end{array}$ & $\begin{array}{c}\text { PORCENTAJE } \\
(\%)\end{array}$ \\
\hline EDAD & $\begin{array}{l}>\text { De } 20 \text { a } 25 \text { años. } \\
>\text { De } 25 \text { a } 35 \text { años. } \\
>\text { De } 35 \text { a } 45 \text { años. } \\
>\text { De } 45 \text { a } 55 \text { años. } \\
>\text { De } 55 \text { a } 65 \text { años. } \\
>\text { Más de } 65 \text { años }\end{array}$ & $\begin{array}{c}2 \\
14 \\
18 \\
13 \\
11 \\
1\end{array}$ & $\begin{array}{r}3.38 \% \\
23.72 \% \\
30.50 \% \\
22.03 \% \\
18.64 \% \\
1.69 \%\end{array}$ \\
\hline SEXO & $\begin{array}{l}>\text { Hombres. } \\
>\text { Mujeres. }\end{array}$ & $\begin{array}{l}22 \\
37\end{array}$ & $\begin{array}{l}37.28 \% \\
62.72 \%\end{array}$ \\
\hline $\begin{array}{c}\text { AÑOS DE } \\
\text { EXPERIENCIA EN } \\
\text { EL SECTOR }\end{array}$ & $\begin{array}{l}\text { S Sin experiencia. } \\
>\text { Experiencia inferior a } 1 \text { año. } \\
>\text { Experiencia de } 1 \text { a } 10 \text { años. } \\
>\text { Experiencia de } 10 \text { a } 20 \text { años. } \\
>\text { Experiencia de } 20 \text { a } 30 \text { años. } \\
>\text { Experiencia más de } 30 \text { años. }\end{array}$ & $\begin{array}{c}2 \\
1 \\
32 \\
15 \\
7 \\
2\end{array}$ & $\begin{array}{r}3.38 \% \\
1.69 \% \\
54.23 \% \\
25.42 \% \\
11.86 \% \\
3.38 \%\end{array}$ \\
\hline $\begin{array}{c}\text { NIVEL DE } \\
\text { ESTUDIOS MÁS } \\
\text { ALTO }\end{array}$ & $\begin{array}{l}>\text { Sin estudios } \\
>\text { Estudios EGB-primarios } \\
>\text { Diplomatura. } \\
>\text { Licenciatura. }\end{array}$ & $\begin{array}{c}0 \\
13 \\
26 \\
20\end{array}$ & $\begin{array}{r}0 \% \\
22.03 \% \\
44.06 \% \\
32.20 \%\end{array}$ \\
\hline $\begin{array}{c}\text { PUESTOS } \\
\text { OCUPADOS }\end{array}$ & $\begin{array}{l}>\text { Ningún puesto. } \\
>\text { Abogado/a. } \\
>\text { Adjunto dirección/a. } \\
>\text { Dependienta. } \\
>\text { Director/a. } \\
>\text { Arquitecto/a. } \\
>\text { Técnico. } \\
>\text { Terapeuta Ocupacional. } \\
>\text { Fisioterapeuta. } \\
>\text { Auxiliar de enfermería. } \\
>\text { Administrativo/a. } \\
>\text { Enfermero/a. } \\
>\text { Docente. } \\
>\text { Psicólogo/a. } \\
>\text { Médico. } \\
>\text { Trabajador social/a. } \\
>\text { Supervisor/a. } \\
>\text { Encargado/a. } \\
>\text { Farmacéutico/a. } \\
>\text { Otros puestos. }\end{array}$ & $\begin{array}{l}17 \\
2 \\
1 \\
1 \\
5 \\
1 \\
4 \\
3 \\
1 \\
2 \\
2 \\
3 \\
3 \\
2 \\
3 \\
4 \\
1 \\
1 \\
1 \\
2\end{array}$ & $\begin{array}{c}28.81 \% \\
3.38 \% \\
1.69 \% \\
1.69 \% \\
8.47 \% \\
1.69 \% \\
6.77 \% \\
5.08 \% \\
1.69 \% \\
3.38 \% \\
3.38 \% \\
5.08 \% \\
5.08 \% \\
3.38 \% \\
5.08 \% \\
6.77 \% \\
1.69 \% \\
1.69 \% \\
1.69 \% \\
3.38 \%\end{array}$ \\
\hline
\end{tabular}

Tabla 7.1. Variables descriptivas del informante. 


\section{CAPÍTULO VII. METODOLOGÍA EMPÍRICA Y PROCESO}

Asimismo ha de admitirse la escasez de canales alternativos para llegar al fenómeno, tales como las sentencias judiciales, lo cual nos permitiría obtener información sobre los lugares donde localizar a quienes se han personado como denunciantes en un proceso sociolaboral sobre la materia. Por otro lado cabe destacar la complejidad para acceder a las víctimas, de los acosadores y de la empresa, entidad o unidad donde se produce el acoso. En cuanto a los primeros el acceso es muy limitado y restringido debido a entre otras causas ya mencionadas, el miedo que les invade, referente a los segundos, los acosadores tienen escasa o nula disponibilidad por motivos obvios, y por lo que respecta a la empresas o instituciones donde consta que se ha producido el fenómeno o se pueda estar produciendo, se parte de las dificultades corporativas para reconocer lo sucedido o lo que está sucediendo bajo la categorización de acoso laboral; de hecho, la organización es más que un mero contexto donde se da una relación interpersonal conflictiva, ya que como hemos visto a lo largo del desarrollo teórico de esta investigación, ella misma está implicada de manera directa en esta práctica tan aberrante y vejatoria.

Esto nos lleva a una primera reflexión un tanto periférica, que consiste en una primera evaluación general de los datos obtenidos y de las dificultades para obtenerlos. Hay que mencionar lo que en las propias organizaciones tiende a denominarse la tradición organizativa hoy también llamada "cultura corporativa o institucional", un claro perjuicio a la hora de evitar la aparición de este fenómeno e incluso a la hora de etiquetarlo como tal; es lícito que la empresa entendida como estructura jerárquica adapte sus intereses a la estructura de colectividad, de manera que donde surjan diferencias o situaciones consideradas como negativas, antepongan sus objetivos y prioridades, pero no tanto en casos en los cuales la salud del trabajador este en entredicho. Merece por tanto la pena traer a colación al respecto la importancia en términos de imagen que reviste, por ejemplo, trabajar en organizaciones altamente reputadas, o al contrario el potencial desvalorizado que se deriva de pertenecer a otras determinadas. 


\section{CAPÍTULO VII. METODOLOGÍA EMPÍRICA Y PROCESO}

De esta manera cabe la idea considerar que la institución empresarial no sólo crea a las personas, imponiéndose a ellas como tal, ni es tan sólo un producto de lo que estas realizan, como se cree desde diferentes ambientes sociales y empresariales sino que realmente hace sociedad y es hecha por ella. Así surge lo que en la psicología de las organizaciones se llama "la lucha por el valor". Existen en la actualidad numerosas disputas, que transcurren en el día a día cotidiano de la organización para establecer el valor de cada miembro que compone la organización, en el caso que nos ocupa el centro entendido como sociosanitario. Hoy en día prima "el hacerse importante dentro de la organización" aún acosta de los demás trabajadores que le rodeen e incluso que conformen la propia organización, para lo cual intentan plasmar actuaciones que sean reconocidas y que "se hagan valer" desde las cualidades a las que la cultura de la empresa otorga relevancia, por lo que el hostigamiento laboral o todo lo que pueda relacionar a un trabajador con él, pueda inicialmente entenderse como una de las consecuencias no queridas de semejante pretensión. Seguramente queden por dilucidar múltiples cuestiones al respecto, lo cual dejaré para la interpretación de cada lector, pero sí haré hincapié en una de las principales argumentaciones que creo de importancia, y no es otra más que reconocer que independientemente de sus características, e incluyendo la propia definición de misión, visión, valores y objetivos que toda empresa socio sanitaria argumenta, una compañía o grupo empresarial sea del índole que fuere se distingue únicamente por su función de generar los máximos beneficios a sus propietarios, siendo el esquema interno de valores una subordinación del carácter fundamental que no es otro que la rentabilidad que aporte.

Cabe así destacar la acentuada disonancia existente aún hoy en día entre los fines socialmente deseables y los fines corporativos, siendo seguramente el principal detonador para el surgimiento del acoso la disonancia creada en la víctima entre lo que cree que es la organización o debe ser y la proyección final de la realidad. 


\section{CAPÍTULO VII. METODOLOGÍA EMPÍRICA Y PROCESO}

Véanse a continuación la representación gráfica (gráfico 7.6 y tabla 7.2) del estudio y la ficha técnica de los participantes en esta investigación con los que concluiremos a modo de resumen la descripción de los directivos de centros residenciales que han formado parte de esta muestra necesaria para la investigación.

\section{MUESTRA DE ESTUDIO}

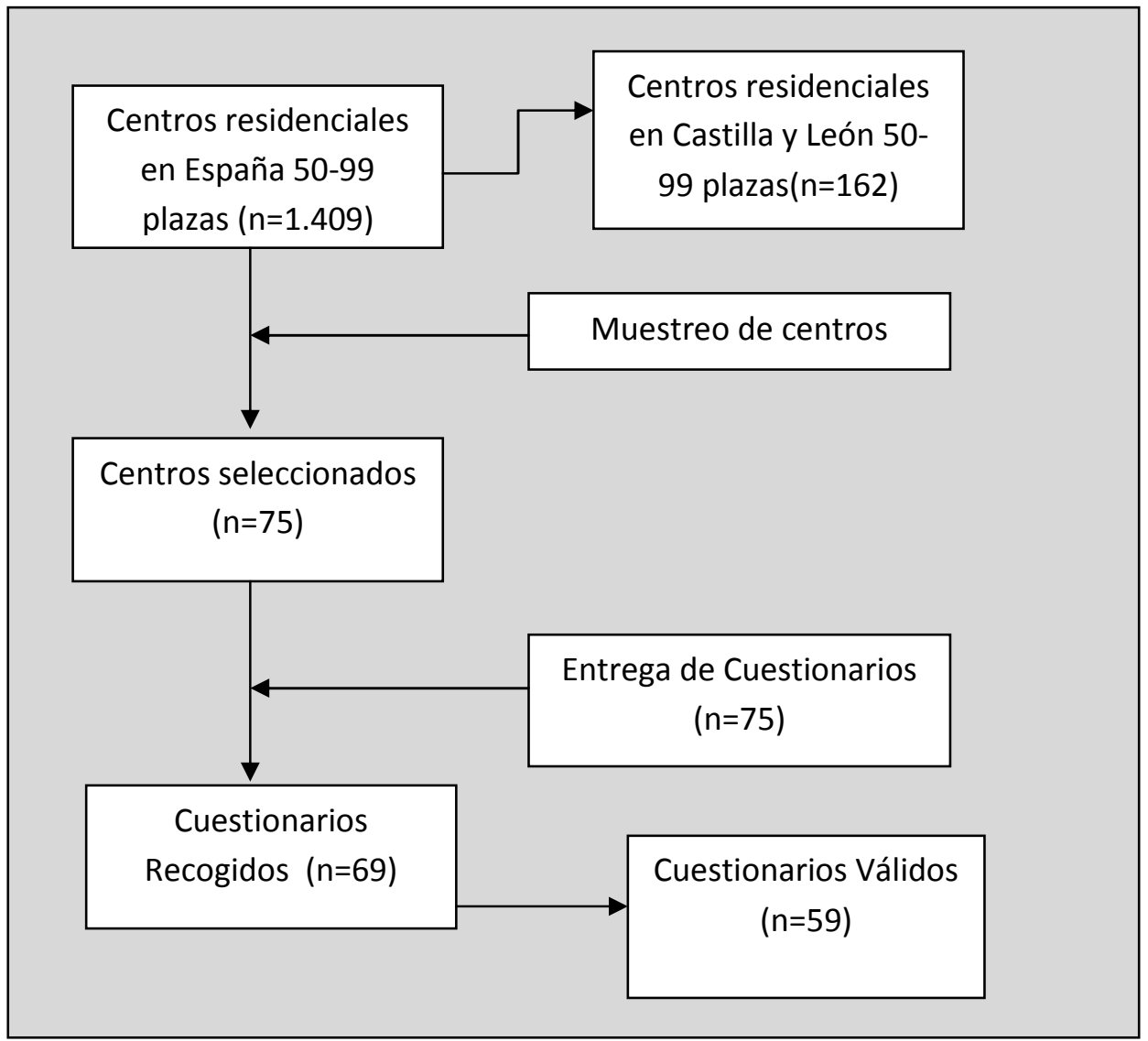

Gráfico 7.6. Esquema del estudio.

La muestra de estudio se recogió durante el año 2016, concretamente los cuestionarios fueron entregados y recogidos desde el 4 de Abril hasta el 30 de Mayo, a los directores de centros residenciales seleccionados de toda España, participando los mismos de forma voluntaria y consentida. 
Así, la ficha técnica resultante sería;

\begin{tabular}{|c|c|}
\hline Naturaleza de la fase metodológica & Cuantitativa \\
\hline Técnica de obtención de la información & Cuestionario auto-administrado. \\
\hline Universo & $\begin{array}{l}\text { Empresas del sector sociosanitario } \\
\text { incluidas en la categoría de centros } \\
\text { residenciales, con sede corporativa en } \\
\text { España y con capacidad para al menos } 50 \\
\text { residentes }\end{array}$ \\
\hline Marco Muestral & $\begin{array}{l}\text { Listado de empresas y grupos del sector } \\
\text { a través de las bases de datos obtenidas } \\
\text { de internet. }\end{array}$ \\
\hline Informante Clave & $\begin{array}{l}\text { Alta dirección de centros residenciales, } \\
\text { concretamente directivos responsables } \\
\text { de centros. }\end{array}$ \\
\hline Ámbitos geográfico & España \\
\hline $\begin{array}{l}\text { Tamaño de la muestra y tasa de } \\
\text { respuesta }\end{array}$ & $\begin{array}{l}59 \text { cuestionarios válidos con un } \\
\text { porcentaje de respuesta del } 92 \% .\end{array}$ \\
\hline Período de recolección de datos & Del 4 de Abril al 30 de Mayo de 2016. \\
\hline
\end{tabular}

Tabla 7.2. Ficha técnica de la investigación.

Una vez hemos detallado con pulcritud el perfil de los directivos participantes en la muestra de este estudio analizaremos a continuación el diseño experimental que se ha llevado a cabo, enfatizando en los aspectos que creemos fundamentales y patognomónicos a la hora de explicar el acoso laboral en puestos directivos de centros residenciales. Para ello, abordaremos con la mayor exactitud posible las cuestiones planteadas a lo largo del desarrollo de la investigación, partiendo de los meta análisis estudiados con anterioridad y de algunos aspectos que algunos autores postularon como fundamentales en el estudio de una materia de esta índole. 


\section{CAPÍTULO VII. METODOLOGÍA EMPÍRICA Y PROCESO}

\subsection{Diseño experimental.}

El diseño experimental de esta investigación, parte de la justificación hecha del tema objeto de estudio, entendiendo así que la temática estaría enmarcada en la psicología de las organizaciones y de los grupos, refiriendo a su vez el acoso como una expresión clara de las formas de las relaciones laborales existentes y esta a su vez llevada al último extremo del acoso laboral en gestión-dirección de centros residenciales, teniendo su expresión máxima en lo que hoy conocemos como mobbing, violando así la tan llamada gestión ética empresarial.

Aunque las organizaciones las componen personas, y aunque el carácter personal de los directores tiene una importancia decisiva, en el perfil ético de las organizaciones las responsabilidades corporativas en numerosas ocasiones no coinciden con las individuales, los métodos de decisión corporativa difieren de los profesionales, estableciéndose así que los principios y objetivos de las organizaciones están por encima de las personas y los valores corporativos.

Así como se formuló desde el punto de partida inicial de esta tesis, se pretende desarrollar y poner de manifiesto la magnitud que en el momento actual está alcanzando el acoso laboral o mobbing en la gestión empresarial, tomando como referencia las variables y parámetros organizacionales y sociales que delimitan la actividad directiva en centros residenciales, considerando además los principios psicológicos que se han de suceder, las conductas que se desarrollan y las consecuencias que se sufren. A día de hoy consideramos que no basta con ser "un gerentes competitivo" sino que se debe experimentar una transformación a "líder", que ante todo sabe o ha de saber que es una persona y que está rodeado de personas, las mismas que a él mismo y a su empresa o a la empresa que él dirige la pueden llevar al éxito o fracaso laboral. 


\section{CAPÍTULO VII. METODOLOGÍA EMPÍRICA Y PROCESO}

No debemos obviar que no es menos cierto que algunas de las grandes empresas de este país, las que menos, proponen un modelo de éxito basando su éxito profesional y económico, en el bienestar de sus trabajadores, preocupándose por ellos, conociendo sus circunstancias personales, laborales, sus expectativas, sus déficits, sus preocupaciones y en definitiva haciendo un gran grupo de "éticas individuales" que juntas conforman "una sola ética" consolidada, funcional y normalmente de muchísimo éxito. Por todo ello el diseño experimental de esta tesis se centra en aunar principios éticos y principios psicológicos estudiando para ello los parámetros organizacionales y sociales más destacables en un puesto directivo.

Los principales objetivos propuestos serían inicialmente analizar el proceso de acoso, sus causas, manifestar la importancia de los parámetros organizacionales y de un clima laboral satisfactorio en la realización del desempeño del trabajo, estudiar las variables psicosociales en las que se produce el fenómeno de mobbing, identificar los factores relacionados con los conflictos interpersonales que se dan en el ámbito directivo de un centro residencial sociosanitario medio, y comprender las vivencias y experiencias significativas de acoso laboral que puede experimentar un directivo en las circunstancias concretas que estamos estudiando en esta investigación.

El estudio pretende por tanto ser una exploración del fenómeno, que en principio intenta responder a las preguntas de qué está sucediendo y cómo sucede un episodio de estas características, sustentadas en las hipótesis previamente planteadas. Así, el diseño empírico podemos afirmar que está diseñado en función de ambos fines, intentando corroborar las hipótesis que se plantean.

Siguiendo a diversos autores tales como Klimovsky (1979), podemos referirnos al diseño experimental y científico, como el conjunto de técnicas empleadas para constituir el conocimiento, por lo que podemos afirmar que la metodología definirá 


\section{CAPÍTULO VII. METODOLOGÍA EMPÍRICA Y PROCESO}

como tal el proceso de conocimiento caracterizado por el uso constante e irrestricto de la capacidad crítica de la razón. De esta forma, la metodología utilizada será un conjunto de procedimientos, instrumentos y también una orientación y actitud hacia el objeto de estudio y su tratamiento, que emitirá a presupuestos teóricos y a formas de explicación concretas.

Es por tanto, como definimos en el prefacio con el que comienza la tesis doctoral, una investigación descriptiva, con carácter cuantitativo y rasgos cualitativos, con el objetivo principal de reconstruir lo más fielmente posible una situación de acoso laboral o mobbing directivo en un puesto de un centro residencial o sociosanitario. La finalidad es obtener respuestas fiables acerca de lo que las personas piensan y sienten, y proporcionar así una mayor comprensión de la magnitud del fenómeno. Así, pues en análisis experimental se lleva a cabo a partir de un marco teórico previo muy examinado, concreto y necesariamente amplio, y de un contexto socio laboral en el cual se produce o puede producirse tal situación.

A partir de este marco teórico se han planteado las diferentes hipótesis, basadas en el modelo teórico (antecedentes-conducta-consecuentes) y objetivos recogidos en el plan de investigación inicial, y se procede al diseño denominado de campo o empírico, basado en recoger datos de una muestra de entre 50 y 100 profesionales de la dirección de centros residenciales en activo, en todo el territorio nacional español, mediante un cuestionario formado por la "Escala Cisneros" subescala que conforma parte de lo que se conoce como el "barómetro Cisneros" y la "Escala de Perfil Profesional", descritas ambas exhaustivamente en el siguiente apartado de este capítulo (variables e instrumentos de evaluación).Los resultados obtenidos del estudio, se analizarán significativamente con su interpretación a la luz del marco teórico planteado previamente arrojando nuevas líneas de investigación que se plasmarán en el capítulo IX de esta investigación, y aportando nuevas sugerencias para afrontar esta problemática con mayor éxito desde la cotidianidad social. 


\section{CAPÍTULO VII. METODOLOGÍA EMPÍRICA Y PROCESO}

Planteados y concretados los objetivos generales y específicos de la investigación se propone un estudio empírico de naturaleza transversal, empleándose para ello un diseño de tipo prospectivo, ya que en el momento de realizar la presente tesis todos los participantes de la muestra de estudio definitiva pertenecen a la población activa española y, por lo tanto, parte de ellos están expuestos a una posible situación de acoso laboral; dicho tipo de estudio además permite la obtención de información sobre diferentes aspectos intervinientes y describe mediante el modelo de ecuaciones estructurales, las relaciones existentes entre un conjunto de variables previamente estudiadas y seleccionadas en el momento determinado de realizar esta investigación.

Dado que es obligación de las empresas conforme al art $15.1 \mathrm{~A}$. de la Ley de Prevención de Riesgos Laborales (1995) evitar los riesgos laborales y entre ellos se encuentran los de carácter psicosocial, donde podría estar enmarcado el acoso laboral, el primer paso ha sido analizar el tipo de empresa frente a la que nos hallamos y establecer así los criterios del envío de cuestionarios adaptándonos al acceso para establecer contacto con ellas, delimitando el canal de comunicación más eficaz y el que nos garantice la mayor probabilidad de respuesta en el menor tiempo posible.

Por otra parte debemos reseñar que el cuestionario será empleado como el instrumento básico de la observación, formulando en él las preguntas que categorizan y describen las variables revisadas.

Su estructura viene delimitada por el contenido de las preguntas, preguntas todas ellas cerradas cuya respuesta como veremos más adelante se establece mediante una escala tipo likert, con el fin de limitar el número de variantes en la confección del estudio. La escala tipo likert utilizada en esta investigación abarca las puntuaciones de 0 "totalmente en desacuerdo" a 6 "totalmente de acuerdo", siendo esta última la de mayor puntuación obtenida en la escala. 


\section{CAPÍTULO VII. METODOLOGÍA EMPÍRICA Y PROCESO}

Así, al igual que cualquier otra teoría propia de los métodos empíricos, el cuestionario elaborado, parte de las hipótesis formuladas y específicamente de los indicadores de las variables definidas en ésta, lo que se traducirá en las preguntas específicas que conformen los ítems del cuestionario, evitando preguntas tendenciosas, de manera que ninguna lleve al individuo a responder de una manera determinada o que le predisponga en contradicción con su sentir ante la pregunta a responder, eludiendo además aspectos controvertidos o embarazosos de forma que no constituyan un conflicto para el sujeto, solventando la monotonía en la variante de la respuesta aspecto que ocurre frecuentemente en este tipo de forma de cuestionario en los que a menudo el sujeto no se siente totalmente motivado a responder. Por todo ello el orden de las preguntas se ha dispuesto con arreglo a las características psicológicas de las mismas, redactando en primer lugar las preguntas relacionadas con los datos denominados sociodemográficos tales como la edad, el sexo, los años de experiencia, el nivel de estudios o la ocupación anterior en otros puestos seguidas de preguntas consideradas generales simples que lo van llevando hasta las preguntas más complejas que conforman el todo que da lugar al formato del cuestionario.

En conclusión podemos afirmar que en la ejecución de esta investigación se han hecho uso de múltiples métodos y procedimientos tratando de ser cada vez más pulcros y esenciales en la caracterización del objeto, con el fin de tratar de investigar aquello que se pretende y no otra cosa, siendo objetivos, evitando todo riesgo de interpretación subjetiva, intentando ser sencillos, claros e interesante para el entrevistado, de tal manera que incluso pueda despertar el interés de quien está siendo objeto de estudio.

A continuación en el gráfico 7.7. se puede observar la hipotetización del modelo establecido en el estudio. 


\section{MODELO EXPERIMENTAL HIPOTETIZADO}

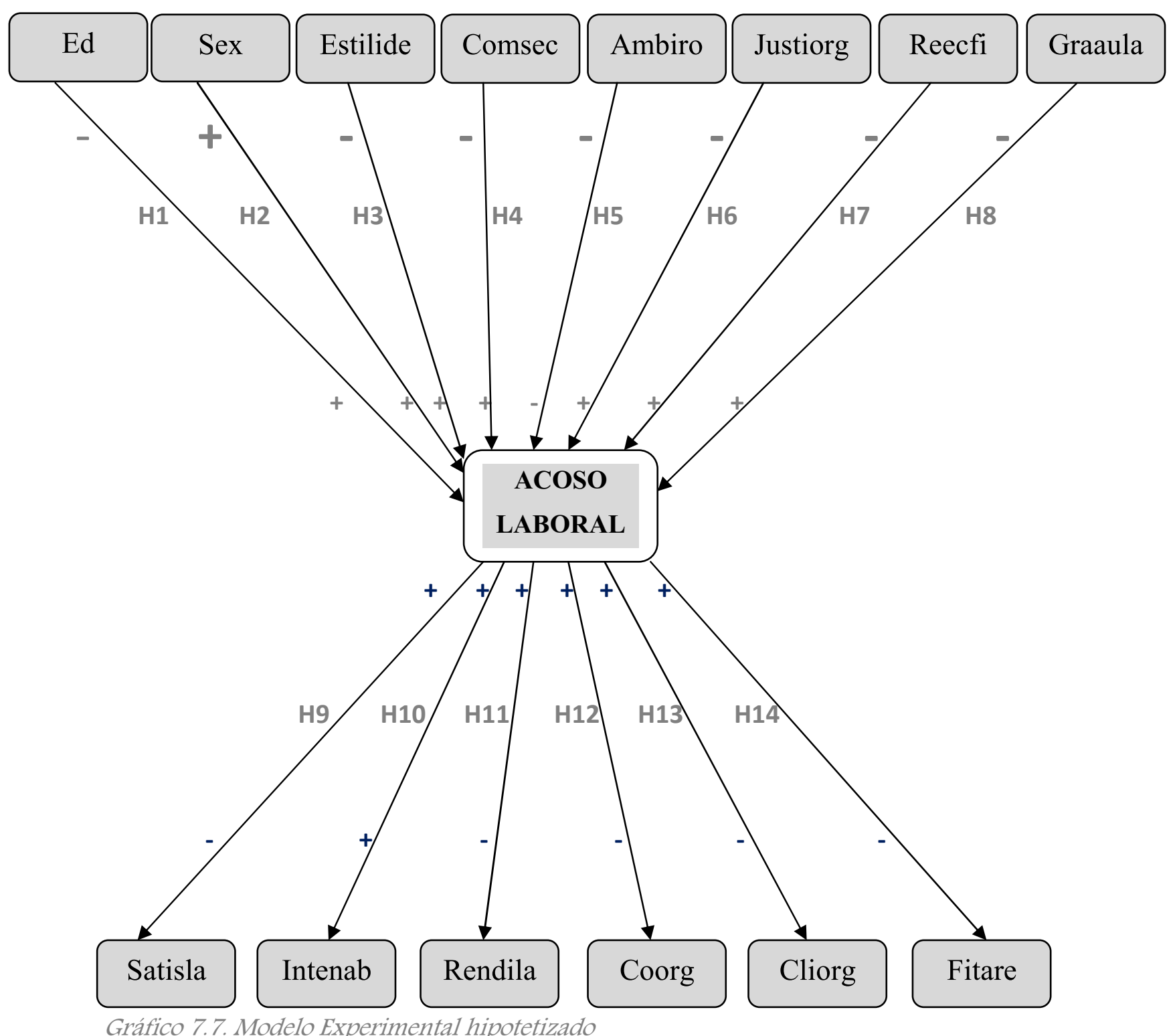

Nota: Ed=Edad; Sex=Sexo; Estilide=Estilo de liderazgo; Comsec=Competencias en el sector; Ambiro= Ambigüedad de rol; Justiorg= Justicia organizacional; Reecfi=Resultados económico financieros; Graaula= Grado de autonomía laboral; Satisla= Satisfacción laboral; Intenab= Intención de abandono; Rendila $=$ Rendimiento laboral; Coorg= Compromiso con la organización; Cliorg= Clima organizacional; Fitare= Finalización de las tareas. 


\section{CAPÍTULO VII. METODOLOGÍA EMPÍRICA Y PROCESO}

Con la hipotetización del estudio concluye la descripción de las escalas. Seguidamente analizaremos las variables establecidas en el objeto de estudio y los instrumentos de evaluación empleados durante el mismo.

\subsection{Variables e instrumentos de evaluación.}

Cuando hablamos de variables estamos haciendo referencia a diferentes propiedades, propiedades que pueden fluctuar y fluctúan y cuya variación es susceptible de adoptar diferentes valores, los cuales como hemos visto a lo largo de esta investigación pueden medirse y observarse a través de diferentes instrumentos de evaluación previamente seleccionados. Las variables adquieren valor cuando se relacionan con otras variables, es decir cuando forman parte de unas hipótesis y por consiguiente de una teoría o tesis (Wikipedia, 2016).

Consecuentemente de los objetivos establecidos en el apartado anterior se derivan necesariamente las variables que a continuación se enumeran:

\section{- Variable 1. La edad.}

La edad, se evaluó mediante la Escala de Perfil Profesional, concretamente con los cinco primeros ítems de la escala, elaborados a partir de recursos propios. Los ítems del estudio de la edad se refieren específicamente a la posibilidad de existir una relación directa entre la edad y la aparición de acoso laboral en puestos directivos de centros residenciales, como queda reflejado en la hipótesis $\mathrm{H}_{1}$ "cuanto menor es la edad del directivo, mayor acoso laboral se produce" que representa al objetivo 01 "examinar si la edad es un elemento determinante a la hora de sufrir acoso laboral es puestos directivos" (ej, ítems "1. Considero que no existe ninguna relación entre la edad y el acoso laboral", "2. La edad es un factor determinante en el acoso laboral", etc....). Los ítems son valorados con una escala likert de 6 grados, que va de 0 "Totalmente es desacuerdo" a 6 "Totalmente de acuerdo". 


\section{CAPÍTULO VII. METODOLOGÍA EMPÍRICA Y PROCESO}

○ Variable 2. El sexo.

El sexo se evaluó mediante la Escala de Perfil Profesional, con el intervalo de ítems del 6 al 10, ambos inclusive, elaborados a partir de recursos propios. Los ítems seleccionados hacen referencia a la determinación de la influencia del sexo como un factor de acoso laboral. Lo esperado según los estudios recabados con anterioridad es que el sexo sea un factor determinante en el surgir del acoso, siendo más acosadas las mujeres que los hombres. Así queda reflejado en la hipótesis correspondiente establecida $\mathrm{H}_{2}$ "el sexo del directivo promueve la aparición del acoso laboral" que representa al segundo objetivo 02 "diagnosticar si existe relación alguna entre el sexo del sujeto y la aparición del acoso laboral" como por ejemplo identifican los ítems, "6. Tengo la creencia de que los hombres son más acosados laboralmente que las mujeres", "7.Considero que las mujeres sufren mayor acoso laboral", etc.... Los ítems son valorados con una escala likert de 6 grados, que va de 0 "Totalmente es desacuerdo" a 6 "Totalmente de acuerdo". Por tanto debemos de hacer hincapié en los resultados que obtengamos de esta variable ya que los resultados encontrados hasta la fecha entre hombres y mujeres en estudios realizados en otros sectores directivos no arrojan significancia en la interpretación.

\section{○ Variable 3. El estilo de liderazgo.}

El estilo de liderazgo se evaluó mediante la Escala de Perfil Profesional, con el intervalo de ítems comprendidos entre el 12 y el 14 ambos inclusive, elaborados a partir de recursos propios. Los ítems mencionados intentan reflejar si el estilo de liderazgo es un factor, que interfiera y fomente la aparición del acoso, de tal manera que los investigadores en estudios anteriores sobre este constructo si identificaron que ciertos modelo de 


\section{CAPÍTULO VII. METODOLOGÍA EMPÍRICA Y PROCESO}

liderazgo propiciaban el acoso laboral. Trataremos por tanto de reflejar si esta cuestión es equiparable en puestos directivos de centros residenciales. Así está reflejado en la $\mathrm{H}_{3}$ "cuanto menor sea el liderazgo, mayor es el acoso que se produce" que representa al 03 "identificar si el estilo de liderazgo es un factor que pueda influir positivamente en el acoso laboral". Algunos ejemplos de los ítems que abordan esta temática son el ítem "12. Considero que mi jefe es un líder participativo", el ítem "13. A menudo, mi superior consensua las decisiones conmigo" etc... Los ítems son valorados con una escala likert de 6 grados, que va de 0 "Totalmente es desacuerdo" a 6 "Totalmente de acuerdo".

\section{- Variable 4. Las competencias en el sector.}

Las competencias en el sector pueden ser también entendidas como la experiencia subjetiva, o el conocimiento aprendido en un puesto anterior de al menos la misma categoría que el que se ostenta en la actualidad. Se evaluaron mediante la Escala de Perfil Profesional, con el intervalo comprendido entre los ítems 17 y 20 ambos inclusive, elaborados a partir de recursos propios. Los ítems seleccionados tratarán de diferenciar si , como demuestran las evidencias empíricas estudiadas hasta el momento, las competencias en el sector son un elemento o posible causa para sufrir acoso laboral. Según lo estimable cuantas menores competencias se tengan, y por tanto menores recursos propios, mayor será la posibilidad de sufrir acoso laboral. Así se menciona en la $\mathrm{H4}$ "cuantas menos competencias se tengan en el sector mayor será la probabilidad de sufrir acoso" que a su vez representa al 04 "constatar como aquellos directivos con menores competencias en el sector sociosanitario sufren un mayor acoso laboral". Algunos ejemplos de los ítems que abordan esta temática serían "17. Poseo conocimientos y habilidades aprendidas para un 


\section{CAPÍTULO VII. METODOLOGÍA EMPÍRICA Y PROCESO}

óptimo desarrollo de mi trabajo" "18.Conozco las tareas específicas, que implica mi puesto de trabajo" etc... Los ítems son valorados con una escala likert de 6 grados, que va de 0 "Totalmente es desacuerdo" a 6 "Totalmente de acuerdo".

\section{○ Variable 5. La ambigüedad de rol.}

La ambigüedad de rol se evaluó mediante la Escala de Perfil Profesional, con el intervalo de ítems comprendidos entre el 21 y 25 inclusive, elaborados a partir del "Cuestionario de Ambigüedad de Rol" de Rizzo, House y Litzman. Los ítems escogidos, tratarán de identificar si la ambigüedad en el rol desempeñado por los directivos puede ser motivo para sufrir acoso laboral con mayor probabilidad. Por tanto se trata de comprender si los directivos tienen lo suficientemente claro cuáles son sus funciones, dónde están los límites de su actividad directiva, la claridad en la realización de sus tareas, sus responsabilidades o los objetivos que se les exige desde la ejecutiva de la organización a la que pertenecen y la relación existente de todo esto con el acoso laboral. De todo ello estimamos que los resultados esperados si denotarían una clara relación entre la ambigüedad de rol y la aparición del acoso laboral. Así se deriva de la $\mathrm{H}_{5}$ "cuanto menor sea la ambigüedad de rol, menor acoso se producirá", que a su vez representa al 05 "inferir si la ambigüedad de rol puede considerarse como una de las causas del surgir el acoso". Ejemplos de algunos de estos ítems serían los ítems "21. Sé exactamente que se espera de mi", "22. Sé cuáles son mis responsabilidades", etc... Estos ítems son valorados con una escala likert de 6 grados, que va de 0 "Totalmente es desacuerdo" a 6 "Totalmente de acuerdo". 


\section{CAPÍTULO VII. METODOLOGÍA EMPÍRICA Y PROCESO}

○ Variable 6. La justicia organizacional.

Es sin duda uno de los aspectos más percibidos por los trabajadores de un centro residencial. Específicamente en lo psicológico, la justicia organizacional hace hincapié en las percepciones que los empleados tienen sobre lo que creen es justo e injusto dentro de su propia empresa. Estas percepciones son las que harán que se mantengan actitudes positivas o negativas hacia su trabajo.

Así se espera que cuanto más justa sea la percepción del trato recibido, más elevadas sean las percepciones de justicia, mayor grado de aceptación de las decisiones habrá y mayor el compromiso del trabajador. Por tanto, las expectativas que esperamos de esta investigación serían que cuanto mayor sea la justicia organizacional percibida, menor acoso existirá. La justicia organizacional se midió mediante la Escala de Perfil Profesional, con el intervalo de los ítems comprendidos entre los ítems 26 y 30, ambos inclusive, elaborados a partir de la Escala de Justicia Organizacional de Niehoff y Moorman. Así los ítems escogidos trataran de identificar si los sujetos creen justa su organización, lo cual plasmamos en la $\mathrm{H}_{6}$ "a menor justicia organizacional, mayor acoso laboral" que representa al 06 "considerar si la justicia organizacional puede ser un factor desencadenante del acoso". Ejemplos de algunos de estos ítems seleccionados, serían "26. Me parece justo el sueldo que percibo", "27.Las decisiones de trabajo son tomadas por mi superior de una manera imparcial", etc.... Estos ítems son valorados con una escala likert de 6 grados, que va de 0 "Totalmente es desacuerdo" a 6 "Totalmente de acuerdo".

\section{- Variable 7. Los resultados económico - financieros.}

En cuanto a los resultados económicos financieros podemos afirmar que en la actualidad existe una gran controversia. El actual panorama financiero internacional junto con la dura crisis económica que atraviesa España, hacen 


\section{CAPÍTULO VII. METODOLOGÍA EMPÍRICA Y PROCESO}

que el balance de la empresa en muchos casos sea lo único válido; poco importa si para ello es necesario tomar decisiones de cualquier índole e incluso si se tiene que despedir a alguien sin causa justificada. Parece obvio entonces pensar que pueda existir una relación clara y proporcional entre el resultado económico de la empresa y la aparición del acoso laboral. Esto es lo que se pretende determinar mediante la Escala de Perfil Profesional con la que se evaluó, concretamente con el ítem 31, elaborado a partir de recursos propios. Lo esperado de esta manera es que exista cierto grado de relación entre los resultados económicos de la empresa y la aparición del acoso laboral. Así se deriva de la $\mathrm{H7}$ "a menor resultado económico, mayor acoso laboral se produce", lo que a su vez representa y queda reflejado en el 07 "establecer si puede existir una relación directa entre los resultados económicos de la empresa y el acoso laboral" emergente. El enunciado reflejo del mismo es el ítem "31. Considero que el acoso laboral se produce en gran medida debido a las pérdidas económicas de la empresa". Este ítem es valorado con una escala likert de 6 grados, que va de 0 "Totalmente es desacuerdo" a 6 "Totalmente de acuerdo".

\section{○ Variable 8. El grado de autonomía laboral.}

La autonomía laboral referida en esta investigación hace referencia a la libertad que pueda tener el directivo, libertad en cuanto a la toma de ciertas decisiones no reguladas se refiere, siempre y cuando sean tomadas desde una óptica positiva por parte del trabajador, y con el fin de solventar de una manera eficaz una situación determinada. Para evaluar este aspecto se ha utilizado la Escala de Perfil Profesional, elaborada a partir de la Escala de Satisfacción Laboral de War, Cook y Wall, específicamente para ello el intervalo de ítems comprendidos entre el 36 y el 39, ambos inclusive. 


\section{CAPÍTULO VII. METODOLOGÍA EMPÍRICA Y PROCESO}

Se estima que deberá existir un menor acoso laboral en aquellos casos en los que el directivo posee ese cierto grado de autonomía laboral, necesario para el buen hacer en el día a día cotidiano de un centro residencial.Así lo recoge la $\mathrm{H}_{8}$ "cuanto menor es el grado de autonomía laboral, mayor es el acoso laboral" existente, que a su vez recoge lo planteado en el O8 "confrontar como, cuanto mayor es el grado de autonomía laboral del que dispone el directivo del centro residencial, menor es el grado de acoso laboral". Ejemplos de algunos de estos ítems serían "36. Poseo libertad para elegir el método de trabajo que creo más adecuado", "37.Las actividades que me encomiendan son de una gran responsabilidad", etc.... Estos ítems son valorados con una escala likert de 6 grados, que va de 0 "Totalmente es desacuerdo" a 6 "Totalmente de acuerdo".

\section{○ Variable 9. La satisfacción laboral.}

Cuando hablamos de satisfacción laboral, no estamos hablando únicamente de la remuneración económica percibida en el puesto de trabajo, sino que el concepto abarcara cuestiones tales como el grado de conformidad de la persona respecto a su entorno de trabajo, las relaciones humanas entre los compañeros, la seguridad laboral, la remuneración económica, la actitud en el puesto de trabajo, etc. Estas expectativas por otra parte, se forman a través de las comparaciones con otros empleados o con empleos previos; si una persona nota o cree que está en desventaja respecto a sus compañeros, su nivel de satisfacción laboral desciende, al igual que si considera que su trabajo anterior le ofrecía mejores condiciones.

El concepto se evaluó con la Escala de Perfil Profesional, elaborada a partir de la Escala de Satisfacción Laboral de War, Cook y Wall, concretamente con el intervalo de ítems comprendidos entre los ítems 41 y 45 ambos inclusive. 


\section{CAPÍTULO VII. METODOLOGÍA EMPÍRICA Y PROCESO}

Se estima que cuanto mayor sea la satisfacción laboral menor acoso existirá. De ello se deriva la $\mathrm{H}_{9}$ "a mayor acoso laboral, menor satisfacción laboral", que recoge el 09 "determinar si el acoso laboral tiene menor incidencia en aquellos directivos que experimentan una mayor satisfacción laboral". Ejemplos de algunos de estos ítems serían los ítems " 41 .Obtengo reconocimiento por el trabajo bien hecho", "42.Se presta atención a las sugerencias que realizo", etc... Estos ítems son valorados con una escala likert de 6 grados, que va de 0 "Totalmente es desacuerdo" a 6 "Totalmente de acuerdo".

\section{Variable 10. La intención de abandono.}

La intención de abandono, según la literatura analizada sobre el tema, no predice directamente el abandono de la empresa (Maertz, Jr. \& Campion, 1998). Existen modelos, tales como el modelo de la adaptación, que postula cómo si surge un desinterés por la organización, sugiriendo que las personas se distancian de la organización manifestando un patrón de conductas adaptativas negativas como pueden ser aumentar el absentismo, disminuir su esfuerzo, perder el tiempo, etc (Hulin, 1991). Por el contrario la teoría de la acción razonada sugiere que la intención que la intención predice una serie de conductas contingentes relacionadas con la actitud subyacente (Fishbein \& Azjen, 1975). De ahí la conveniencia de identificar en esta variable si la existencia de acoso laboral hace que aumente en la organización la intención de abandono. Para su evaluación se utilizó la Escala de Perfil Profesional, elaborada a partir de la Escala de Intención de Abandono de Porter, Crampon y Smith ,concretamente los ítems 47 y 50. Así se deriva de la $\mathrm{H}_{10}$ "a mayor acoso laboral, mayor intención de abandono", que representa al 010 "confirmar como el directivo acosado no tiene ninguna intención previa de abandonar su puesto de trabajo". 


\section{CAPÍTULO VII. METODOLOGÍA EMPÍRICA Y PROCESO}

Los enunciados que representan ambos ítems son los que se mencionan a continuación; "47. Me gustaría continuar el resto de carrera profesional en esta organización" y "50. Creo que no estaría bien dejar esta organización aunque me beneficiase el cambio" etc....Estos dos ítems son valorados con una escala likert de 6 grados, que va de 0 "Totalmente es desacuerdo" a 6 "Totalmente de acuerdo".

\section{- Variable 11. El rendimiento laboral.}

En la actualidad la productividad empresarial es uno de los factores más determinantes para las organizaciones y no se puede hablar de productividad sin tener en cuenta el rendimiento laboral. Los diversos estudios revisados hasta el momento inciden y sugieren que cuanto mayor es el acoso laboral o la percepción del mismo, menor es el rendimiento laboral del trabajador. Es frecuente encontrar una evolución del término mencionándose como desempeño laboral y siendo definido por autores tales como Bohórquez, como el nivel de ejecución alcanzado por el trabajador en el logro de las metas dentro de la organización en un tiempo determinado (citado en Araujo y Guerra, 2007). Para su evaluación en el estudio se utilizó la Escala de Perfil Profesional, elaborada a partir de recursos propios, concretamente los ítems comprendidos entre el ítem 51 y el ítem 55 ambos inclusive. Así se deriva de la H11 "a mayor acoso laboral, menor rendimiento", que representa al 011 "verificar la relación existente entre el rendimiento y el acoso laboral, en puestos directivos de centros residenciales". Ejemplos de algunos de estos ítems serían los ítems "51.En esta organización las tareas están claramente definidas", "52.La empresa, posibilita un rendimiento laboral elevado", etc... Estos ítems son valorados con una escala likert de 6 grados, que va de 0 


\section{CAPÍTULO VII. METODOLOGÍA EMPÍRICA Y PROCESO}

"Totalmente es desacuerdo" a 6 "Totalmente de acuerdo".

\section{Variable 12. El compromiso con la organización.}

Porter, Steers, Mowday y Boulain (1974) consideran el compromiso organizacional como la creencia en las metas y valores de la organización aceptándolas, y teniendo la voluntad de ejercer un esfuerzo considerable en beneficio de la organización y, en definitiva, desear seguir siendo miembro de la misma. El compromiso organizacional ha sido objeto de estudio extenso, debido a la importancia que tiene para las empresas. A partir de finales de 2008, tras la grave recesión económica vivida el compromiso toma aún más relevancia en el ámbito empresarial, siendo para muchos empresarios y académicos cuestión capital. Con este estudio pretendemos aportar luz a la relación existente entre el acoso laboral y el compromiso del trabajador con la organización, para lo cual hemos revisado la literatura científica a nuestro juicio más relevante que nos permitiera una adecuada comprensión del término desde un sólido marco conceptual y tratar de ofrecer propuestas que sirvan para una posible aplicación práctica en un futuro inmediato. Para su evaluación en el estudio se utilizó la Escala de Perfil Profesional, elaborada a partir del Cuestionario de Compromiso Organizacional de Meyer y Allen, concretamente los ítems comprendidos entre el ítem 56 y el ítem 60 ambos inclusive. Así se deriva de la $\mathrm{H}_{12}$ "a mayor acoso laboral, menor compromiso con la organización", que representa al 012 "mostrar como la existencia de un mayor compromiso del directivo con la organización en la que desempeña su actividad laboral no es sinónimo de no ser objeto de acoso laboral". Ejemplos de algunos de estos ítems serían los ítems "56.Sugiero mejoras organizacionales, administrativas o de procedimientos", "57.Permanecería en esta organización a pesar de privaciones o condiciones difíciles", etc... Estos ítems son valorados con una escala likert de 6 grados, que va de 0 "Totalmente es desacuerdo" a 6 


\section{CAPÍTULO VII. METODOLOGÍA EMPÍRICA Y PROCESO}

"Totalmente de acuerdo".

- Variable 13. El clima organizacional.

El concepto de clima organizacional proviene originalmente del trabajo de Lewin (1936), quien demostró que el comportamiento humano depende de la situación global donde concurre la conducta; el término "situación global", se refiere a la persona y su ambiente psicológico (o de comportamiento), el cual es percibido e interpretado por la persona, es decir la conducta será una función de la interacción entre la persona y el ambiente. Con el paso de los años el concepto ha sido ampliamente estudiado por autores tales como Tagiuri y Litwin (1968), Campbell (1970), Jonhson (1972), Lawler y Weik (1970), Berman (1975), Fincher y Nasch (1983) o (Gant). El concepto más preciso de los existentes en la literatura lo encontramos en los estudios de Chiavenato (2009), el cual estima que el clima organizacional se refiere al ambiente existente entre los diferentes miembros que componen una organización, estando estrechamente ligado al grado de motivación de los empleados e indica además de manera específica las propiedades motivacionales del ambiente organizacional. Con la investigación que se ha llevado a cabo se pretende conocer la relación existente entre el acoso laboral en puestos directivos de centros residenciales y el clima organizacional. Se estima que cuanto mayor sea el acoso laboral peor clima organizacional existirá. Para su evaluación en el estudio se utilizó la Escala de Perfil Profesional, elaborada a partir de la Escala de Clima Organizacional (EDCO) de Lorenz, concretamente los ítems comprendidos entre el ítem 62 y el ítem 65 ambos inclusive. Así se deriva de la H13 "a mayor acoso laboral, peor clima organizacional", que representa al 013 "corroborar como un clima organizacional positivo hace que se reduzca el número de casos 


\section{CAPÍTULO VII. METODOLOGÍA EMPÍRICA Y PROCESO}

de acoso laboral en puestos directivos de centros residenciales". Ejemplos de algunos de estos ítems serían los ítems "62.Las relaciones con mis compañeros tienden a ser agradables", "63.Los distintos departamentos tienen una comunicación fluida", etc... Estos ítems son valorados con una escala likert de 6 grados, que va de 0 "Totalmente es desacuerdo" a 6 "Totalmente de acuerdo".

\section{- Variable 14. La finalización de las tareas.}

Una de las estrategias más frecuentes que sin duda señalan la mayoría de los estudios recientes sobre acoso laboral, es el ataque del acosador a la imagen profesional del directivo; para ello el acosador suele utilizar dos tipos de acciones: sobrecargar de tareas a la víctima o no encomendarle ninguna, e incluso en algunas ocasiones le trataría de asignar tareas de menor responsabilidad. Así, bajo el estudio de esta variable podríamos encontrar si existe una asignación de objetivos y plazos imposibles de cumplir, si existe una sobrecarga selectiva de trabajo, si se da una eliminación de responsabilidades, si se asignan tareas rutinarias o sin interés, o si el directivo experimenta un control exhaustivo y continuo de sus tareas, sin objeto estimable alguno. Para su evaluación en el estudio se utilizó la Escala de Perfil Profesional, elaborada a partir del Cuestionario de Finalización de las Tareas de Litwin y Stringer, concretamente los ítems comprendidos entre el ítem 66 y el ítem 69 ambos inclusive. Así se deriva de la $\mathrm{H}_{14}$ "a mayor acoso laboral, menor finalización de las tareas", que representa al 014 "analizar como el acoso laboral incide directamente en la finalización de las tareas en la dirección de un centro residencial". Ejemplos de algunos de estos ítems serían los ítems "66.Nuestros jefes muestran interés porque las normas, métodos y procedimientos estén claros y se cumplan", "67.Mis compañeros me ayudan cuando tengo una labor 


\section{CAPÍTULO VII. METODOLOGÍA EMPÍRICA Y PROCESO}

difícil", etc... Estos ítems son valorados con una escala likert de 6 grados, que va de 0 "Totalmente es desacuerdo" a 6 "Totalmente de acuerdo".

- Variable 15. El número total de estrategias de acoso sufridas (NEAP).

El número total de estrategias sufridas (NEAP), representa al acoso laboral sufrido. Para su evaluación en el estudio se utilizó la Escala Cisneros, cuestionario desarrollado por el profesor Iñaki Piñuel compuesto por 43 ítems que objetivan y valoran 43 conductas de acoso psicológico. Se estima previamente al estudio que la mayor parte de la población estudiada no sea víctima de acoso, puesto que estamos trabajando con una muestra de población no patológica, por lo que el acoso psicológico debería presentarse inicialmente como un caso excepcional. Ejemplos de algunos de estos ítems serían los ítems "1.Mi superior restringe mis posibilidades de comunicarme, hablar o reunirme con él", "2.Me ignoran, me excluyen o me hacen el vacío, fingen no verme o me hacen "invisible", "3.Me interrumpen continuamente impidiendo expresarme", "4.Me fuerzan a realizar trabajos que van contra mis principios o mi ética", "5. Evalúan mi trabajo de manera equitativa o de forma sesgada", "6. Me dejan sin ningún trabajo que hacer, ni siquiera a iniciativa propia", "7. Me asignan trabajos absurdos o sin sentido" etc... Estos ítems son valorados con una escala likert de 6 grados, que va de 0 "Nunca" a 6 "Todos los días", además se pide al directivo que señale en su caso el autor o autores de los hostigamientos mediante una escala pormenorizada para ello, indicando si el autor es el jefe o supervisor, son los compañeros de trabajo, o son los subordinados. 


\section{CAPÍTULO VII. METODOLOGÍA EMPÍRICA Y PROCESO}

Seguidamente llevaremos a cabo una descripción del cuestionario utilizado para este estudio, compuesto por dos escalas como hemos visto en líneas anteriores; la Escala Cisneros y la Escala de Perfil Profesional. Para ello haremos hincapié en la estructura de ambas escalas, describiendo de la manera más adecuada posible cada una de las mismas, relatando además la importancia y significación del uso que se hace de ellas en esta tesis como elemento facilitador en la obtención de los resultados necesarios para dar respuesta a las hipótesis planteadas.

\subsection{Descripción del cuestionario: La Escala Cisneros y la Escala de Perfil Profesional.}

Para la realización de este estudio se emplearon distintas escalas que compusieron el protocolo de recogida de datos definitivo, denominado así cuestionario, que consistió en un total de cinco páginas y que se facilita en el apartado de anexos, concretamente en el anexo 1, de la presente tesis doctoral. La selección de estos instrumentos fue motivada fundamentalmente por la calidad psicométrica que posee cada uno de ellos, ampliamente contrastada así como por la cantidad de datos recogidos (Einarsen, 1997). Asimismo fueron seleccionados, porque como pruebas de autoinforme que son, proporcionan la suficiente información, de forma sencilla, concisa y clara para cumplir con los objetivos propuestos a lo largo de esta investigación. Seguidamente describiremos estos instrumentos de evaluación.

Primeramente el cuestionario recoge una breve descripción del estudio a modo de lo que hemos considerado introducción, en la cual se matiza quién es la universidad que realiza el estudio, desde qué departamento de la misma se va a llevar a cabo, y cuáles son los fines que se persiguen, en el caso que nos ocupa el estudio sobre los parámetros organizacionales y sociales que delimitan la actividad directiva en centros residenciales. A continuación se recogen en él 5 parámetros sociodemográficos: la edad de quien lo realiza, el sexo, los años de experiencia, el nivel de estudios más alto alcanzado y los puestos ocupados con anterioridad. Una vez hemos introducido la 


\section{CAPÍTULO VII. METODOLOGÍA EMPÍRICA Y PROCESO}

temática, y hemos recogido los datos demográficos necesarios para el estudio, comenzamos a presentar en el cuestionario las escalas seleccionadas, comenzando por presentar la Escala Cisneros.

Antes de dar comienzo a la cumplimentación de la escala, se presentan las instrucciones necesarias para dar respuesta de manera adecuada a los ítems que componen la escala; posteriormente el individuo comenzará a responder a los ítems. La Escala Cisneros es un cuestionario desarrollado por el profesor Iñaki Piñuel, (profesor de la universidad de Alcalá) de carácter autoadministrado compuesto por 43 ítems que objetivan y valoran 43 conductas de acoso psicológico. Dicho cuestionario forma parte del conocido Barómetro Cisneros (Cuestionario Individual sobre Psicoterror, Negación, Estigmatización y Rechazo en Organizaciones Sociales), cuyo objetivo es sondear el estado, y las consecuencias, de la violencia en el entorno laboral de las organizaciones. La Escala Cisneros, tiene una elevada fiabilidad (.96), y una estructura bidimensional que permite ordenar sus ítems a lo largo de dos dimensiones (ámbito de la conducta de acoso y tipo de conducta de acoso). Presenta demás como característica principal relaciones elevadas teóricamente esperables con otro tipo de escalas que puedan medir indicadores de hecho del acoso laboral. Los estudios realizados de la misma hasta el momento muestran una buena capacidad para discriminar entre diversos grados de acoso, y por consiguiente, la utilidad de la escala como indicador de la gravedad e intensidad del daño infligido a la víctima.

Como ya hemos mencionado en líneas anteriores, esta escala objetiva 43 conductas de acoso psicológico solicitando de la persona que responde que valore en una escala likert, de 0 (nunca) a 6 (todos los días) el grado en que es afectada por cada una de las conductas de acoso enumeradas. En cuanto a la corrección de la escala, debemos decir que es muy similar a la propuesta para el cuestionario LIPT-60 (González de Rivera y Rodríguez-Abuín, 2003), se puede así realizar atendiendo a tres índices; el primero, el número total de estrategias de acoso (NEAP), es un simple recuento de las respuestas diferentes de cero, que nos informa del número total de 


\section{CAPÍTULO VII. METODOLOGÍA EMPÍRICA Y PROCESO}

estrategias de acoso sufridas (es el elegido en la investigación). El segundo, será el índice global de acoso psicológico (IGAP), que es igual a la suma de la puntuación de los ítems dividida del número de ítems, es por tanto el índice global del grado de acoso sufrido; este índice ofrece la misma información que obtendríamos de utilizar la puntuación total del test ( en una escala de 0 a 258 puntos), con la ventaja de que dicha información se expresa ahora en la misma escala en la que se responden los ítems ( de 0 a 6 ).

El tercero, es el índice medio de la intensidad de las estrategias de acoso (IMAP), que es igual a la suma de la puntuación en los ítems dividida entre el valor del índice NEAP; este índice nos indica la intensidad promedio de las estrategias de acoso sufridas. El sentido de los dos últimos índices queda más claro cuando se consideran conjuntamente. El valor en IMAP es siempre mayor o igual que IGAP, ya que el primero divide el sumatorio de la puntuación en los ítems por el número de respuestas positivas, en tanto el segundo divide siempre por el número total de ítems (43). De esta forma podemos afirmar que diferencias muy grandes entre IMAP e IGAP indican que el sujeto sufre pocas conductas de acoso, pero que las que experimenta son muy intensas (Fidalgo y Piñuel, 2004).

Una vez el sujeto a respondido a la Escala Cisneros se le presentará la Escala de Perfil Profesional. Antes de comenzar a responder a la misma, el sujeto encontrará unas breves instrucciones de cómo ha de contestar a los ítems correctamente. Está es una escala de elaboración propia compuesta por 70 ítems, a los que se valoran dando la opinión del directivo en una escala likert desde 0 (totalmente en desacuerdo) hasta 6 (totalmente de acuerdo). Para su composición se ha estudiado diversa literatura científica al respecto tomando así como referencia para su estructura las variables de estudio; de esta forma los ítems comprendidos entre el 1 y el 5 ambos inclusive se corresponden con el análisis de la variable edad, tomada esta como un antecedente 


\section{CAPÍTULO VII. METODOLOGÍA EMPÍRICA Y PROCESO}

personal, y siendo todos los ítems de elaboración propia. Los ítems comprendidos entre el ítem 6 al ítem 10 ambos incluidos, representan a la variable sexo, entendida como un antecedente personal siendo nuevamente todos los ítems de elaboración propia. Los ítems comprendidos entre el 11 y el 15 ambos inclusive, representan a la variable estilo de liderazgo, referenciada esta como antecedente personal elaborando una vez más de manera propia cada uno de ellos. Los ítems que le siguen del 16 al 20 ambos inclusive reflejan la variable competencias en el sector, tomada como el último antecedente personal que recogen una vez más los ítems de elaboración propia del autor.

Los ítems comprendidos entre el 21 y el 25 ambos inclusive representan a la variable ambigüedad de rol, tomada como un antecedente organizacional y para cuya elaboración de los ítems se ha tomado como referencia el Cuestionario de Ambigüedad de Rol de Rizzo, House y Litzman. Seguidamente en los ítems comprendidos entre el 26 y el 30 ambos inclusive se analiza la variable denominada justicia organizacional, entendida como un antecedente organizacional, para lo cual se ha tomado de modelo la Escala de Justicia Organizacional de Niehoff y Moorman. El intervalo de ítems comprendidos entre el ítem 31 y el 35 ambos inclusive, refiere como antecedente organizacional la variable definida como los resultados económicos y financieros, elaborados como elaboración propia del autor de esta tesis. Los ítems comprendidos entre el ítem 36 y el ítem 40, definen el antecedente organizacional delimitado como la variable grado de autonomía laboral del directivo, para los cuales se ha tomado como modelo la Escala de Satisfacción Laboral de War, Cook y Wall, siendo esta la última variable analizada como antecedente. El siguiente intervalo de ítems, los comprendidos entre el ítem 41 y 45 ambos inclusive, hacen referencia al primer consecuente analizado como tal, refiriéndose a la variable satisfacción laboral para lo cual al igual que en la variable anterior se ha tomado como referencia la Escala de Satisfacción Laboral de War, Cook y Wall. Los ítems comprendidos entre el 46 y el 50 ambos inclusive hacen hincapié en la variable denominada intención de abandono 


\section{CAPÍTULO VII. METODOLOGÍA EMPÍRICA Y PROCESO}

tomada como el segundo consecuente a analizar, para lo cual se ha tenido en cuenta la Escala de Intención de Abandono de Porter, Lampon y Smith. El siguiente intervalo de ítems son los comprendidos entre el ítem 51 y el 55 ambos inclusive, en los cuales se define el análisis del rendimiento laboral como consecuente del acoso, para lo cual se han redactado los ítems de manera propia. Los ítems comprendidos entre el ítem 56 y el 60 ambos inclusive analizan la variable compromiso con la organización, tomada esta como el tercer consecuente de análisis, para lo cual se ha tomado como referencia el Cuestionario de Compromiso Organizacional de Meyer y Allen.

El intervalo de ítems comprendido a continuación son los ítems delimitados entre el ítem 61 y 65 ambos inclusive, los cuales analizan la variable denominada como clima organizacional tomada como cuarto consecuente, para lo cual se ha tomado en consideración la Escala de Clima Organizacional de la EDCO.

Finalmente para concluir la escala nos encontramos con los ítems recogidos entre el ítem 66 y 70 ambos inclusive, los cuales reflejan la última variable tomada como consecuente, la finalización de las tareas, para lo cual se ha tomado como modelo el Cuestionario de Litwin y Stringer.

En la Tabla 7.8 que se presenta a continuación se refleja un cuadro resumen de la estructura de la Escala Cisneros:

\section{ESTRUCTURA ESCALA CISNEROS}

\begin{tabular}{|c|c|c|}
\hline ÍNDICES & ¿QUÉ OBTENEMOS? & ¿CÓMO LO OBTENEMOS? \\
\hline $\begin{array}{l}\text { NEAP } \\
\text { IGAP }\end{array}$ & $\begin{array}{l}\text { Número de estrategias de acoso sufridas } \\
\text { Índice global del grado de acoso sufrido }\end{array}$ & $\begin{array}{l}\text { Recontando las respuestas que no son cero } \\
\text { Suma de la puntuación de todos los ítems } \\
\text { dividida entre el número de ítems (43) }\end{array}$ \\
\hline IMAP & $\begin{array}{l}\text { Intensidad promedio de las estrategias de } \\
\text { acoso sufridas }\end{array}$ & $\begin{array}{c}\text { Suma de la puntuación de los } 43 \text { ítems } \\
\text { dividida entre el NEAP }\end{array}$ \\
\hline
\end{tabular}




\section{CAPÍTULO VII. METODOLOGÍA EMPÍRICA Y PROCESO}

En la Tabla 7.9 que se presenta a continuación se presentará la estructura de la Escala de Perfil Profesional elaborada con recursos propios, como hemos visto en líneas anteriores en detalle, la cual será determinante para recoger la evaluación hecha por los diferentes directivos participantes en la muestra de estudio. El gráfico recoge a modo de resumen las variables estudiadas, los ítems que así las definen y la escala que se ha tomado como referencia, además de definir claramente si son antecedentes siendo estos de la índole que fueren o consecuentes.

\section{ESTRUCTURA ESCALA DE PERFIL PROFESIONAL}

\begin{tabular}{|c|c|c|}
\multicolumn{2}{|c|}{ ANTECEDENTES PERSONALES } \\
VARIABLE & ÍTEMS & ESCALA \\
EDAD & $1-5$ & PROPIA \\
SEXO & $6-10$ & PROPIA \\
ESTILO DE LIDERAZGO & $11-15$ & PROPIA \\
COMPETENCIAS EN EL SECTOR & $16-20$ & PROPIA \\
\hline
\end{tabular}

\begin{tabular}{|c|c|c|}
\hline \multicolumn{3}{|c|}{ ANTECEDENTES ORGANIZACIONALES } \\
VARIABLE & ÍTEMS & ESCALA \\
\hline AMBIGUEDAD DE ROL & $21-25$ & Rizzo, House y Litzman \\
JUSTICIA ORGANIZACIONAL & $26-30$ & Niehoff y Moorman \\
RESULTADOS ECONÓMICOS & $31-35$ & PROPIA \\
GRADO DE AUTONOMÍA LABORAL & $36-40$ & War, Cook y Wall \\
\hline
\end{tabular}

\begin{tabular}{|c|c|c|}
\multicolumn{3}{c|}{ CONSECUENTES } \\
VARIABLE & ÍTEMS & ESCALA \\
\hline SATISFACCIÓN LABORAL & $41-45$ & War, Cook y Wall \\
INTENCIÓN DE ABANDONO & $46-50$ & Porter, Lampon y Smith \\
RENDIMIENTO LABORAL & $51-55$ & PROPIA \\
COMPROMISO CON LA ORGANIZACIÓN & $56-60$ & Meyer y Allen \\
CLIMA ORGANIZACIONAL & $61-65$ & EDCO \\
FINALIZACIÓN DE LAS TAREAS & $66-70$ & Litwin y Stringer \\
\hline
\end{tabular}




\section{CAPÍTULO VII. METODOLOGÍA EMPÍRICA Y PROCESO}

\subsection{Procedimiento.}

El presente estudio, está dirigido a trabajadores, directivos de centros residenciales pertenecientes a la población activa española, de centros privados y/o concertados de al menos 50 plazas residenciales, que cumplimentaron el cuestionario elaborado para la propia investigación, formado como hemos visto con anterioridad por la Escala Cisneros y la Escala de Perfil Profesional, en el que se estudian variables antecedentes del acoso laboral, el acoso laboral identificado a tal efecto en el estudio como NEAP, y las variables consecuentes del mismo. Así pues se describe a continuación las etapas de que se suceden para alcanzar tales fines:

\section{- Etapa 1: Identificación de la muestra.}

A lo largo del año 2015, tomando como referencia el directorio de residencias todoresidencias.com, se seleccionaron mediante muestreo aleatorio, 75 centros para personas de la tercera edad del territorio nacional.

La selección se realizó considerando aquellos centros de titularidad privada y/o concertada de al menos 50 plazas residenciales, independientemente de si tuvieran o no plazas de centro de día o plazas psicogeriátricas. Se excluyeron así fundaciones, centros menores o nuevas formas existentes como son actualmente las cooperativas o viviendas con servicios sociosanitarios. El número de personas que se estima trabajan en estos centros es de entorno a 1725, según los baremos establecidos para tales centros, este número puede variar en función de la temporalidad de los contratos.

\section{- Etapa 2: Contacto con las organizaciones para la recogida de datos.}

Realizada la selección de centros se procedió a contactar con los directores de los mismos, vía telefónica con el propósito de explicarles los objetivos del proyecto, su origen y la finalidad del mismo. 


\section{CAPÍTULO VII. METODOLOGÍA EMPÍRICA Y PROCESO}

En algunos casos se les adjunto mediante email el instrumento con el que se recogerían los datos para que el director/a valorase, en el momento de tomar la decisión de participar en la investigación. Tras esta primera toma de contacto, se procedió a elaborar la lista-borrador de aquellos directivos de centros dispuestos a participar en la investigación. Pasados 15 días tras la primera toma de contacto se procedió a telefonear a aquellos directivos que inicialmente estaban comprometidos a colaborar en la investigación, explicándoles nuevamente y de manera más exhaustiva si cabe, el objetivo del estudio, y el procedimiento de entrega de cuestionarios y de recogida de datos. Una vez que el director/a confirmaba la participación en el estudio, se reflejaba en la lista definitiva de centros.

Del total de centros seleccionados inicialmente, seis declinaron participar en el estudio alegando diferentes motivos, tales como que los socios o la entidad gestora no deseaban participar en la investigación. Algo entendido como normal dentro de la sensibilidad de la temática tratada en esta investigación.

\section{- Etapa 3: Distribución de cuestionarios.}

Como paso previo al inicio de la recogida de datos, se pretendía tener una entrevista con los directivos seleccionados, al menos con los de mayor cercanía, siendo esta declinada en la mayor parte de los casos. Así pues se procedió vía telefónica a explicarles algunas características del estudio con el fin de disponerles positivamente hacia la colaboración. Además se les trasladaron algunas cuestiones de relevancia: a) el estudio era una iniciativa de un doctorando del Departamento de Psicología Social de la Universidad de Salamanca, b) el estudio era meramente estadístico y con fines universitarios, c) la organización para la que trabajaban no estaba implicada en el estudio, d) los datos serían plenamente confidenciales y las respuestas anónimas, de manera que la información reflejada en el cuestionario que potencialmente 


\section{CAPÍTULO VII. METODOLOGÍA EMPÍRICA Y PROCESO}

podría ser utilizada para identificar al individuo sólo sería accesible para el propio doctorando y el director del proyecto, y con fines de investigación y de agrupación de datos. En ningún caso la información sería utilizada para tratar de identificar al participante y sus respuestas.

Las escalas utilizadas para evaluar las variables del estudio se integraron en un instrumento que se denominó Cuestionario. Este cuestionario constaba de una introducción en la que se explicaba el objetivo del estudio y las instrucciones para cumplimentar correctamente el mismo, además de las escalas ya mencionadas, primeramente la Escala Cisneros y posteriormente la Escala de Perfil Profesional. Junto con el cuestionario se entregó un sobre de respuesta franqueado para que el cuestionario respondido se enviara al autor del proyecto, el doctorando.

Los cuestionarios fueron así enviados a la atención del director del centro, o en su defecto a la persona responsable del correo del centro.

\section{- Etapa 4: Recogida de datos.}

El proceso de recogida de datos se extendió desde el 4 de Abril de 2016, hasta el 15 de Junio de 2016. Durante este periodo de tiempo se realizaron numerosas llamadas telefónicas y numerosos viajes a los centros seleccionados más cercanos, para animar a los directivos a participar en el estudio, especialmente a aquellos que aún estaban dubitativos. En el caso de algunos centros concretamente 7, la devolución de los datos se realizó mediante correo electrónico, pues preferían este procedimiento al envío por correo postal.

La participación en el estudio fue totalmente voluntaria, de tal manera que se evitara así el falseado de respuestas. Si algún centro hubiese cambiado de director/a del centro, se le explicaba al nuevo director/a el proyecto de investigación, y se le remitía cuanta información al respecto fuera necesaria. 
RESUMEN - ABSTRACT

\author{
CAPÍTULO VII. \\ "Metodología Empírica y Proceso".
}

En el Capítulo VII, se ha realizado una descripción exhaustiva de la metodología empírica llevada a cabo en la investigación y su proceso, desarrollando en profundidad entre otros aspectos de especial relevancia, las características de la actividad experimental realizada. En él además se hace una exposición concisa de la muestra de estudio recogida, de los participantes, tomando como referencia los 59 cuestionarios, reflejando así parámetros tales como la edad, el sexo, los años de experiencia en el sector, el nivel de estudios previo a la ostentación del cargo, o los puestos ocupados con anterioridad al desempeño directivo, junto con las tablas y gráficos descriptivos correspondientes, y el esquema longitudinal del estudio y la ficha técnica resultante.

Seguidamente se abordan los objetivos principales o generales del estudio, y los objetivos específicos o concretos, junto con la hipotetización del modelo experimental planteado inicialmente. Una vez detallado el modelo, y planteados los objetivos, se especifican cuáles son las variables y los instrumentos de evaluación planteados, enumerando cada variable participe en el estudio, haciendo una reseña en minucia de la misma, reflejando además cómo se recoge, detallando alguno de los ítems que la predicen, y delimitando la fiabilidad obtenida para tal fin mediante la obtención estadística del Alfa de Cronbach. Así, estimamos lo esperado en el estudio de cada variable bajo la base de los estudios existentes hasta el momento. Las variables analizadas son, la edad, el sexo, el estilo de liderazgo, las competencias en el sector, la ambigüedad de rol, la justicia organizacional, los resultados económico financieros, el grado de autonomía laboral, la satisfacción laboral, la intención de abandono, el rendimiento laboral, el compromiso con la organización, el clima organizacional, la finalización de las tareas y el número total de estrategias de acoso sufridas (NEAP). 


\section{CAPÍTULO VII. METODOLOGÍA EMPÍRICA Y PROCESO}

Se ha procedido además, a la descripción del cuestionario utilizado en la recogida de los datos, describiéndose así las escalas que lo conforman: la Escala Cisneros y la Escala de Perfil Profesional. Cabe recordar que el empleo y manejo de las mismas se debe a la elevada calidad psicométrica que presentan, obteniéndose de esta manera las estructuras y los componentes que conforman cada una de ellas, analizándose así los ítems que reflejan cada variable objeto de estudio.

Junto con todo ello, en el mismo capítulo se recoge el procedimiento llevado a cabo, reflejando así las diferentes etapas que componen el mismo; 1)identificación de la muestra, en el que se detalla cómo se obtiene la muestra, cuáles son las fuentes para tal fin, 2)el contacto con las organizaciones para la recogida de datos, en la que se detalla la vía de comunicación con los centros y los directivos seleccionados, 3)la distribución de los cuestionarios, delimitando claramente la manera de hacer llegar el cuestionario de tal forma que garantice la total confidencialidad de la identidad de los directivos participes en la investigación y 4)la recogida de datos, reflejando en detalle cuál ha sido el procedimiento más eficaz y funcional para el proceso.

Una vez finalizamos este Capítulo VII, comenzaremos a analizar en el capítulo siguiente los resultados obtenidos; resultados de los análisis referidos a las escalas (Escala Cisneros y Escala de Perfil Profesional), resultados de los análisis referidos a las hipótesis donde destacan el análisis de la prueba " $t$ " de diferencias de medias entre hombres y mujeres, los resultados del análisis correlaccional de los antecedentes, y los resultados del análisis correlaccional de los consecuentes. Además analizaremos los resultados referidos al modelo de los análisis predictivos, o lo que es lo mismo los análisis de regresión pertinentes. Con todo ello, podremos extraer las conclusiones pertinentes que den respuesta a las cuestiones previas planteadas en el estudio. 


\title{
CAPÍTULO VIII
}

\author{
“Resultados Obtenidos"
}

VNIVERSITAS STVDII SALAMANTINI

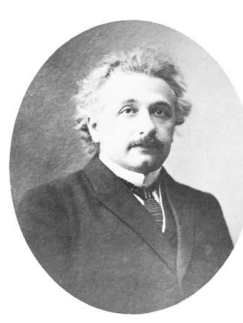

"Si quieres entender a una persona, no escuches sus palabras, observa su comportamiento".

Albert Einstein (físico alemán). 


\section{CAPÍTULO VIII.}

"Resultados Obtenidos".

\section{Resultados Obtenidos.}

En este capítulo se pretende facilitar los principales resultados obtenidos en el estudio desarrollado. Dada la magnitud del fenómeno y la abundante información obtenida únicamente se expondrán aquellos datos que sean más significativos, relacionados con los distintos objetivos planteados en el comienzo de esta investigación. Para dar respuesta y obtener unas conclusiones y resultados fiables al respecto, se han enunciado a lo largo del desarrollo de esta tesis los diferentes enfoques teóricos y marcos referentes a la literatura científica encontrada, sintetizando las principales teorías del estudio del acoso laboral.

Debemos recordar que esta tesis plantea un enfoque desde la perspectiva de la psicología social y laboral o de las organizaciones, con la intención de marcar una línea de estudio novedosa, por lo que se ha pretendido realizar una serie de aportaciones que hasta el momento no se habían apenas trabajado, como es el estudio de aquellas variables organizacionales y sociales que influyen o determinan de manera alguna el posible acoso laboral al directivo de un centro residencial por sus superiores. El valor por tanto científico radica en quien ejerce el acoso y quien le recibe, ya que hasta el momento los estudios encontrados sobre temáticas similares hacen hincapié en el estudio del acoso laboral de los superiores a sus trabajadores. Para ello se han tenido en cuenta variables hasta ahora escasamente estudiadas, como son el estilo de liderazgo, las competencias en el sector, la ambigüedad directiva de rol, la justicia organizacional, los resultados económico-financieros de la empresa, el grado de autonomía laboral, la satisfacción laboral del directivo, la intención de abandono del puesto de trabajo, el rendimiento laboral, el compromiso organizacional para con la empresa, el clima laboral o la finalización de las tareas encomendadas. 


\section{CAPÍTULO VIII. RESULTADOS OBTENIDOS}

\subsection{Resultados de los análisis referidos a las Escalas.}

Realizaremos por tanto un análisis del cuestionario elaborado por escalas, comenzando por analizar los resultados obtenidos en la Escala Cisneros, para posteriormente analizar los datos de la Escala de Perfil Profesional.

\subsubsection{Escala Cisneros.}

Así, en cuanto a la Escala Cisneros obtendremos:

\section{1) Los estadísticos descriptivos.}

Toman su denominación de aquellos algoritmos que facilitan una cuantificación inicial de la muestra de estudio tomada y de las variables asociadas, previamente definidas con claridad. En numerosas ocasiones suelen incluirse entre ellos a los llamados histogramas o gráficos de barras histológicos que tratan de cuantificar la distribución de las variables estudiadas en sucesivos intervalos denominados de clase. Así, a continuación presentamos la tabla cuyo contenido es el resultado de la aplicación sistemática de estas técnicas descriptivas. De esta manera tendremos una referencia inicial que utilizaremos posteriormente en el análisis global de las variables, objetivos e hipótesis planteadas. Por tanto, seguidamente se muestran los estadísticos descriptivos (media y desviación típica) tanto de los índices del mismo (véase tabla 8.1), como de cada uno de los ítems que compusieron la escala definitiva (véase tabla 8.2)

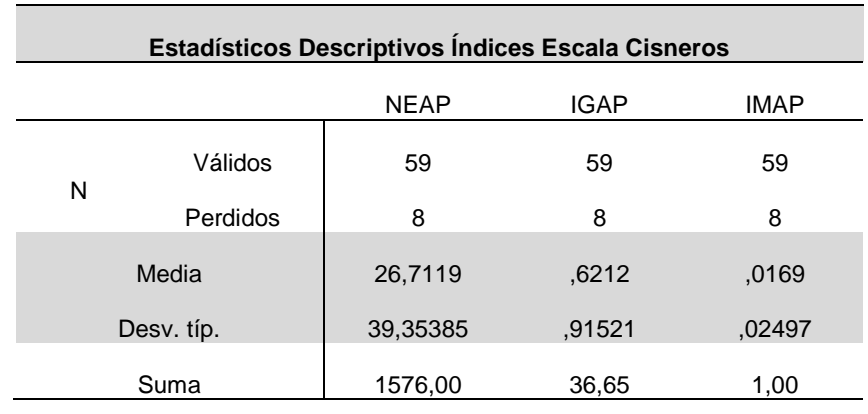




\section{CAPÍTULO VIII. RESULTADOS OBTENIDOS}

La tabla 8.1. refleja un primer análisis descriptivo de la muestra utilizada en la Escala Cisneros, obteniendo así de los índices, en relación al número total de estrategias de acoso (NEAP), al índice global de acoso psicológico (IGAP) y al índice medio de la intensidad de las estrategias de acoso (IMAP), siendo la media de cada uno respectivamente $26,71,0,6212$ y 0.0169 , y cuya desviación típica refiere en el mismo orden $39,35,0,9152$ y 0,2497. En la siguiente tabla, tabla 8.2, podemos observar los estadísticos descriptivos de cada ítem que componen la escala:

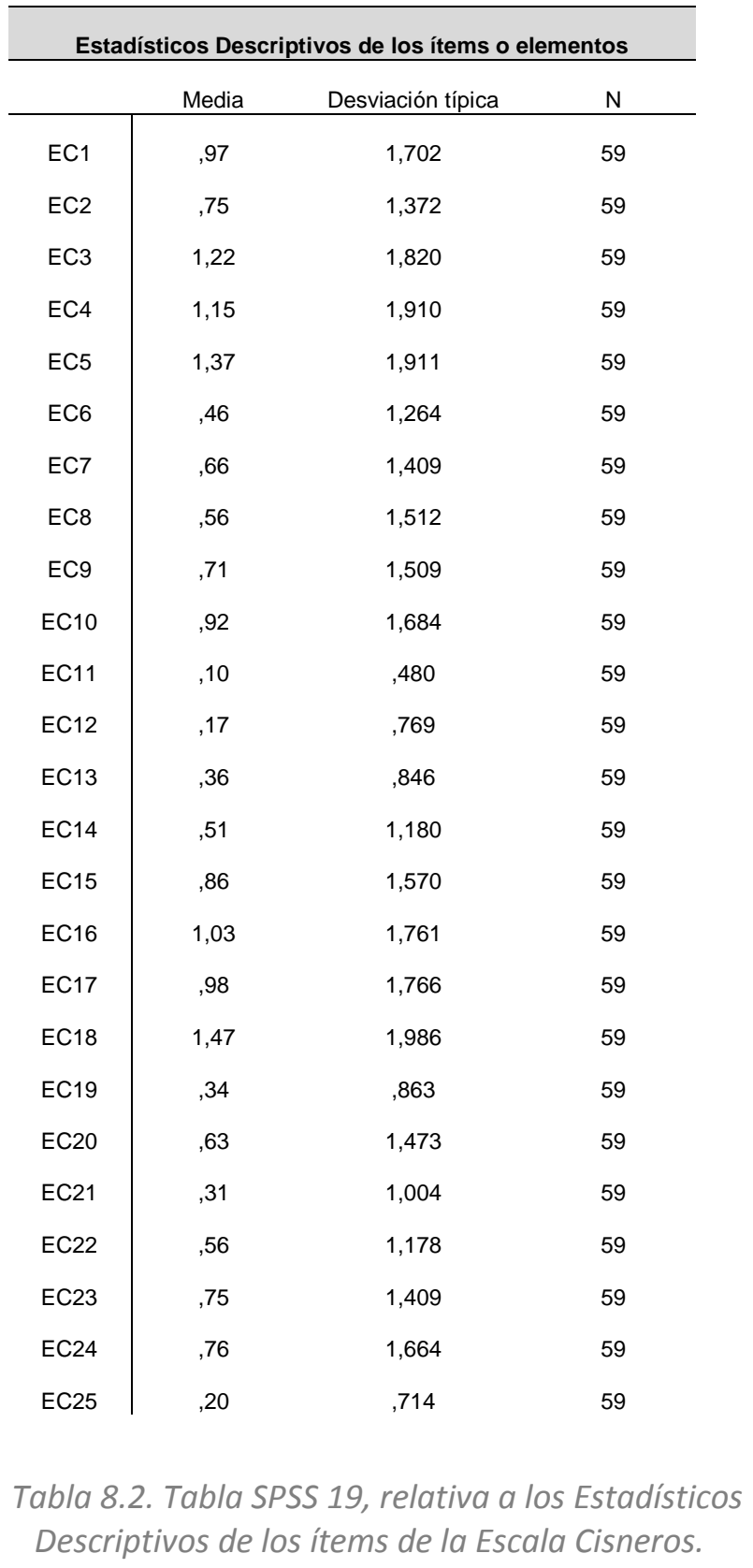




\section{CAPÍTULO VIII. RESULTADOS OBTENIDOS}

\begin{tabular}{l|ccc} 
EC26 &, 19 &, 730 & 59 \\
EC27 &, 19 &, 840 & 59 \\
EC28 &, 05 &, 222 & 59 \\
EC29 &, 75 & 1,646 & 59 \\
EC30 &, 03 &, 260 & 59 \\
EC31 &, 24 & 1,040 & 59 \\
EC32 &, 42 &, 986 & 59 \\
EC33 &, 63 & 1,299 & 59 \\
EC34 &, 68 & 1,420 & 59 \\
EC35 &, 17 &, 530 & 59 \\
EC36 & 1,53 & 2,246 & 59 \\
EC37 & 1,32 & 2,208 & 59 \\
EC38 &, 46 &, 971 & 59 \\
EC39 &, 73 & 1,659 & 59 \\
EC40 &, 66 & 1,582 & 59 \\
EC41 &, 34 & 1,010 & 59 \\
EC42 &, 49 & 1,382 & 59 \\
EC43 &, 05 &, 391 & 59 \\
\hline
\end{tabular}

Tabla 8.2. (continuación) Tabla SPSS 19, relativa a los Estadísticos Descriptivos de los ítems o elementos de la Escala Cisneros.

El ítem que presenta una media más elevada es el EC36 ("recibo una presión indebida para sacar adelante el trabajo"), 1,53, que presenta una desviación típica de 2,246, mientras que el ítem que presenta la menor media es el EC43 ("me lanzan insinuaciones o proposiciones sexuales directas o indirectas"), 0,05 y cuya desviación típica es de 0,391. En cuanto a la mayor desviación típica la podemos encontrar también en el ítem EC36, siendo el ítem que presenta la menor desviación típica el EC28 ("recibo amenazas por escrito o por teléfono en mi domicilio"), 0,222, cuya media es 0,05.

Tal y como se puede comprobar en la anterior tabla, el segundo ítem con una puntuación media más alta resultó ser el EC18 ("se amplifican y dramatizan de manera injustificada errores pequeños o intrascendentes"), 1,47, cuya desviación típica es de 1,98. 


\section{CAPÍTULO VIII. RESULTADOS OBTENIDOS}

Una vez calculados los estadísticos descriptivos de los ítems o elementos de la Escala Cisneros, obtenemos además el llamado índice de homogeneidad corregido de los ítems, (véase la tabla 8.3), definiéndose como la correlación existente entre cada ítem y el resto del test. Dicho índice indica la discriminación de los ítems o elementos evaluada a partir de su relación con el resto de los ítems que componen el test, obteniéndose resultados entre -1 y 1 , considerándose adecuado a partir de 0,20. Así se obtiene:

\begin{tabular}{|c|c|}
\hline \multicolumn{2}{|c|}{$\begin{array}{l}\text { Índice de Homogeneidad } \\
\text { Corregido de la Escala Cisneros }\end{array}$} \\
\hline & $\begin{array}{c}\text { Correlación elemento- } \\
\text { total corregida }\end{array}$ \\
\hline EC1 & 689, \\
\hline EC2 & 855 \\
\hline EC3 & 684 \\
\hline EC4 & ,641 \\
\hline EC5 & 497, \\
\hline EC6 & 647, \\
\hline EC7 & 768, \\
\hline EC8 & 581, \\
\hline EC9 & 704, \\
\hline EC10 & 722, \\
\hline EC11 & 680 \\
\hline EC12 & 693, \\
\hline EC13 & 617, \\
\hline EC14 & ,767 \\
\hline EC15 & 816 \\
\hline EC16 & 775, \\
\hline EC17 & 811 \\
\hline EC18 & ,569, \\
\hline EC19 & 813, \\
\hline EC20 & 762 \\
\hline EC21 & 670, \\
\hline EC22 & 842 \\
\hline EC23 & ,715 \\
\hline EC24 & 857, \\
\hline
\end{tabular}




\section{CAPÍTULO VIII. RESULTADOS OBTENIDOS}

\begin{tabular}{l|l} 
EC25 &, 728 \\
EC26 &, 483 \\
EC27 &, 630 \\
EC28 &, 442 \\
EC29 &, 486 \\
EC30 &, 521 \\
EC31 &, 707 \\
EC32 &, 688 \\
EC33 &, 780 \\
EC34 &, 488 \\
EC35 &, 333 \\
EC36 &, 740 \\
EC37 &, 653 \\
EC38 &, 813 \\
EC39 &, 813 \\
EC40 &, 839 \\
EC41 &, 756 \\
EC42 &, 712 \\
EC43 &, 109 \\
\hline
\end{tabular}

Tabla 8.3. Índice de Homogeneidad Corregido de la Escala Cisneros (continuación).

Siguiéndose el criterio anteriormente planteado, serían adecuados todos los elementos presentando el ítem EC2 ("me ignoran, me excluyen o me hacen el vacío, fingen no verme o me hacen invisible") el mayor índice de homogeneidad 0,855, siendo el ítem que menor índice presenta el EC43 ("me lanzan insinuaciones o proposiciones sexuales directas o indirectas"), 0,109.

Los resultados así expresados resultan ser ampliamente satisfactorios, aportando evidencia empírica acerca de la adecuación de la prueba al modelo de estudio planteado en esta tesis doctoral, si bien se ha de anotar que uno de los ítems presentó una puntuación ligeramente inferior al esperado. No obstante, los criterios utilizados para definir la puntuación aceptable estadísticamente fueron elevados, proponiendo así un modelo altamente estimado. A continuación analizaremos la fiabilidad y validez de la Escala Cisneros, planteada en esta investigación. 


\section{CAPÍTULO VIII. RESULTADOS OBTENIDOS}

\section{2) La fiabilidad y validez.}

Una vez expuestos los estadísticos descriptivos básicos del instrumento diseñado se pasó a determinar su índice de fiabilidad y validez, para lo cual se calculó el coeficiente de fiabilidad Alfa de Cronbach y la fórmula de SpearmanBrown, coeficientes que, considerando el número de ítems que componen la escala, pueden considerarse suficientes a efectos de la estimación o medición experimental realizada (véase tabla 8.4).

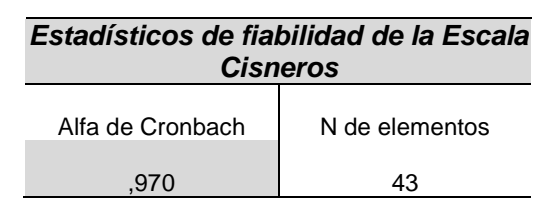

Tabla 8.4. Estadísticos Alfa de Cronbach

El Alfa de Cronbach, por tanto indica la proporción de varianza de las puntuaciones de los sujetos, explicada por sus verdaderas diferencias en el atributo medido. Este coeficiente desarrollado por J.L. Cronbach requiere una sola administración del instrumento de medición y produce valores que oscilan entre 0 y 1 . Su ventaja reside en que no es necesario dividir en dos mitades a los ítems del instrumento de medición, simplemente se aplica la medición y se calcula el coeficiente. No obstante, cuanto más se aproxime a su valor máximo, 1, mayor será la fiabilidad de la escala, además en determinados contextos y por tácito convenio, se considera que valores del Alfa superiores a 0,7 0 0,8, son suficientes para garantizar la fiabilidad de la escala. Tal y como se observa en la tabla anterior, el coeficiente de fiabilidad Alfa de Cronbach obtenido resultó satisfactorio (.970).

Debemos recordar además que el Alfa de Cronbach no deja de ser una media ponderada de las correlaciones entre las variables o ítems que forman parte de la escala utilizada. 


\section{CAPÍTULO VIII. RESULTADOS OBTENIDOS}

Seguidamente calcularemos la fórmula de Spearman Brown (véase tabla 8.5), la cual permite pronosticar el aumento de fiabilidad obtenida tras el incremento de la longitud de un test. Normalmente se asume, que, en ausencia de otros condicionantes, cuantos más ítems tenga un test más fiable será, aunque no siempre esto es así, por ello hemos creído conveniente calcular esta fórmula. Debemos resaltar que la precisión de un test es nula cuando la longitud es 0, y va aumentando a medida que aumenta la longitud aunque el aumento es relativamente menor a medida que la longitud de que se parte es mayor. Esto significa, que la precisión crecerá mucho al principio y relativamente menos después. Cuando la longitud tiende a infinito, el coeficiente de fiabilidad tiende a 1. Por ello decimos que al aumentar la longitud de un test, se incrementa su precisión ya que aumenta la varianza verdadera a un ritmo más alto que la varianza error, lo cual supone que la precisión del test aumenta porque disminuye la proporción de varianza que se debe al error. Así los resultados obtenidos fueron los siguientes:

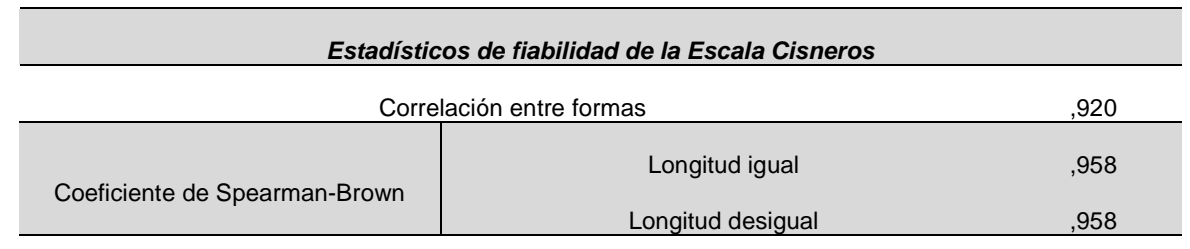

Tabla 8.5. Estadísticos Spearman Brown.

0,958 es la fiabilidad de cada mitad del test.

Para calcular la fiabilidad del test completo se aplica la fórmula de Spearman-Brown:

$$
R x x=\frac{2 \cdot r_{X X}}{1+r_{X X}}=\frac{2 \cdot 0,958}{1+0,958}=0,98
$$

De esta fórmula, se concluye que la fiabilidad resultante es elevada obteniéndose un coeficiente de 0,98 y por tanto la validez del mismo, es correcta en la investigación planteada. 


\section{CAPÍTULO VIII. RESULTADOS OBTENIDOS}

Una vez analizados los estadísticos descriptivos, la fiabilidad y la validez de la Escala Cisneros, procederemos a realizar un análisis de las puntuaciones obtenidas por los sujetos que participaron en la investigación.

\section{3) Las puntuaciones obtenidas por los sujetos.}

Con los resultados obtenidos, y con un Alfa de Cronbach y fórmula de Spearman Brown satisfactorios para la presente investigación, procede realizar la baremación de la escala, facilitándose así a continuación las diferentes puntuaciones directas obtenidas de la puntuación total del cuestionario en los diferentes índices analizados, el primero el número total de estrategias de acoso (NEAP), el segundo el índice global de acoso psicológico (IGAP) y por último el índice medio de la intensidad de las estrategias de acoso (IMAP) (véase tabla 8.6).

\begin{tabular}{l|ccc}
\hline \multicolumn{5}{c}{ Puntuaciones directas obtenidas Escala Cisneros } \\
\hline \multicolumn{4}{|c}{} \\
\hline Sujeto & NEAP & IGAP & IMAP \\
\hline 1 & 8 & 0,19 & 0,01 \\
2 & 0 & 0 & 0 \\
3 & 11 & 0,26 & 0,01 \\
4 & 86 & 2 & 0,05 \\
5 & 5 & 0,12 & 0 \\
6 & 14 & 0,33 & 0,01 \\
7 & 0 & 0 & 0 \\
8 & 18 & 0,42 & 0,01 \\
9 & 101 & 2,35 & 0,06 \\
10 & 0 & 0 & 0 \\
11 & 63 & 1,47 & 0,04 \\
12 & 7 & 0,16 & 0 \\
13 & 2 & 0,05 & 0 \\
14 & 0 & 0 & 0 \\
15 & 0 & 0 & 0 \\
16 & 0 & 0 & 0 \\
17 & 0 & 0 & 0 \\
18 & 0 & 0 & 0 \\
\end{tabular}




\section{CAPÍTULO VIII. RESULTADOS OBTENIDOS}

\begin{tabular}{|c|c|c|c|}
\hline 19 & 14 & 0,33 & 0,01 \\
\hline 20 & 5 & 0,12 & 0 \\
\hline 21 & 0 & 0 & 0 \\
\hline 22 & 3 & 0,07 & 0 \\
\hline 23 & 0 & 0 & 0 \\
\hline 24 & 0 & 0 & 0 \\
\hline 25 & 0 & 0 & 0 \\
\hline 26 & 0 & 0 & 0 \\
\hline 27 & 0 & 0 & 0 \\
\hline 28 & 13 & 0,3 & 0,01 \\
\hline 29 & 11 & 0,26 & 0,01 \\
\hline 30 & 10 & 0,23 & 0,01 \\
\hline 31 & 0 & 0 & 0 \\
\hline 32 & 36 & 0,84 & 0,02 \\
\hline 33 & 0 & 0 & 0 \\
\hline 34 & 91 & 2,12 & 0,06 \\
\hline 35 & 16 & 0,37 & 0,01 \\
\hline 36 & 0 & 0 & 0 \\
\hline 37 & 0 & 0 & 0 \\
\hline 38 & 3 & 0,07 & 0 \\
\hline 39 & 12 & 0,28 & 0,01 \\
\hline 40 & 56 & 1,3 & 0,04 \\
\hline 41 & 43 & 1 & 0,03 \\
\hline 42 & 38 & 0,88 & 0,02 \\
\hline 43 & 11 & 0,26 & 0,01 \\
\hline 44 & 41 & 0,95 & 0,03 \\
\hline 45 & 43 & 1 & 0,03 \\
\hline 46 & 8 & 0,19 & 0,01 \\
\hline 47 & 62 & 1,44 & 0,04 \\
\hline 48 & 29 & 0,67 & 0,02 \\
\hline 49 & 9 & 0,21 & 0,01 \\
\hline 50 & 183 & 4,26 & 0,12 \\
\hline 51 & 56 & 1,3 & 0,04 \\
\hline 52 & 65 & 1,51 & 0,04 \\
\hline 53 & 152 & 3,53 & 0,1 \\
\hline 54 & 112 & 2,6 & 0,07 \\
\hline 55 & 60 & 1,4 & 0,04 \\
\hline 56 & 60 & 1,4 & 0,04 \\
\hline 57 & 19 & 0,44 & 0,01 \\
\hline 58 & 0 & 0 & 0 \\
\hline \multirow[t]{2}{*}{59} & 0 & 0 & 0 \\
\hline & 1576 & 36,68 & 1,03 \\
\hline
\end{tabular}

Tabla 8.6. (continuación) Puntuaciones obtenidas por los sujetos en la Escala Cisneros. 


\section{CAPÍTULO VIII. RESULTADOS OBTENIDOS}

La tabla que precede refleja el resumen de las puntuaciones obtenidas por cada uno de los 59 sujetos, que participaron en la muestra de estudio, obteniéndose que el sujeto con mayores puntuaciones en todos los índices NEAP, IGAP e IMAP es el sujeto número cincuenta, con unas puntuaciones extraídas de 183, 4,26 y 0,12 respectivamente. Este cuestionario se corresponde con un perfil de hombre de 37 años de edad, con una experiencia en el sector de un año, con unos estudios de graduado escolar y con un desempeño laboral anterior al de director como técnico. El sumatorio de las puntuaciones totales arroja una puntuación de 1579 en cuanto al $N E A P$, de 4,26 referente al IGAP y de 0,12 de IMAP, tomando así en consideración para pruebas posteriores el NEAP como índice de referencia del acoso laboral en puestos directivos de centros residenciales. Estas puntuaciones corroboran satisfactoriamente la adecuación de la Escala Cisneros empleada en esta investigación. Para finalizar el análisis estadístico de la primera escala en cuestión abordaremos el llamado análisis factorial de la misma.

\section{4) El análisis factorial.}

El análisis factorial es un modelo estadístico que representa las relaciones entre un conjunto de variables, planteando que estas relaciones pueden explicarse a partir de una serie de variables no observables (latentes) denominadas factores, siendo el número de factores sustancialmente menor que el de variables. El modelo se obtiene directamente como extensión de algunas de las ideas básicas de los modelos de regresión lineal y de correlación parcial. La técnica deriva del siglo XX donde estadísticos tales como Pearson o Spearman se interesaron por los resultados que arrojaba la aplicación de los test destinados a la medición de la inteligencia. Hacia mediados de siglo Thustone, tendió a creer que estos factores no existían realmente sino que eran abstracciones útiles, que permitían reducir un número elevado de variables manifiestas a un conjunto menor de los ya mencionados factores latentes. 


\section{CAPÍTULO VIII. RESULTADOS OBTENIDOS}

Con todo ello lo que pretendemos en esta investigación al hacer uso del análisis factorial como técnica científica es lograr interpretabilidad y claridad en la obtención de los resultados (véase tabla 8.7), además de obtener la llamada parsimonia estadística o la reducción de un conjunto amplio de variables a un número menor, lo que algunos teóricos llaman simplificación residual. Obtenemos así el siguiente análisis:

Análisis Factorial de la Escala Cisneros

\begin{tabular}{|c|c|c|c|c|c|c|}
\hline \multirow[t]{2}{*}{ Componente } & \multicolumn{3}{|c|}{ Autovalores iniciales } & \multicolumn{3}{|c|}{$\begin{array}{l}\text { Sumas de las saturaciones al cuadrado de la } \\
\text { extracción }\end{array}$} \\
\hline & Total & $\%$ de la varianza & $\%$ acumulado & Total & $\%$ de la varianza & $\%$ acumulado \\
\hline 1 & 21,731 & 50,537 & 50,537 & 21,731 & 50,537 & 50,537 \\
\hline 2 & 4,021 & 9,352 & 59,889 & 4,021 & 9,352 & 59,889 \\
\hline 3 & 2,731 & 6,352 & 66,241 & 2,731 & 6,352 & 66,241 \\
\hline 4 & 2,440 & 5,675 & 71,916 & 2,440 & 5,675 & 71,916 \\
\hline 5 & 2,120 & 4,931 & 76,846 & 2,120 & 4,931 & 76,846 \\
\hline 6 & 1,947 & 4,527 & 81,374 & 1,947 & 4,527 & 81,374 \\
\hline 7 & 1,399 & 3,253 & 84,626 & 1,399 & 3,253 & 84,626 \\
\hline 8 & 1,028 & 2,390 & 87,017 & 1,028 & 2,390 & 87,017 \\
\hline
\end{tabular}

Tabla 8.7. Análisis Factorial de la Escala Cisneros.

Como fielmente refleja la tabla el análisis factorial realizado comprueba el número de dimensiones, factores o constructos que miden los ítems del test, así se han encontrado ocho factores significativos, considerándose adecuados los autovalores superiores a 1. El factor extraído explica el 50,537 de la varianza de los resultados. Con los datos que arroja esta prueba estadística, podemos decir que los resultados han sido válidos, interpretables y generalizables para el estudio que se está llevando a cabo, cumpliendo los requisitos necesarios establecidos en las líneas anteriores, alcanzando así valores estables con la muestra seleccionada. Presentaremos de esta manera el gráfico de sedimentación de la muestra tomada para la Escala Cisneros que está siendo objeto de estudio (véase tabla 8.8) : 


\section{CAPÍTULO VIII. RESULTADOS OBTENIDOS}

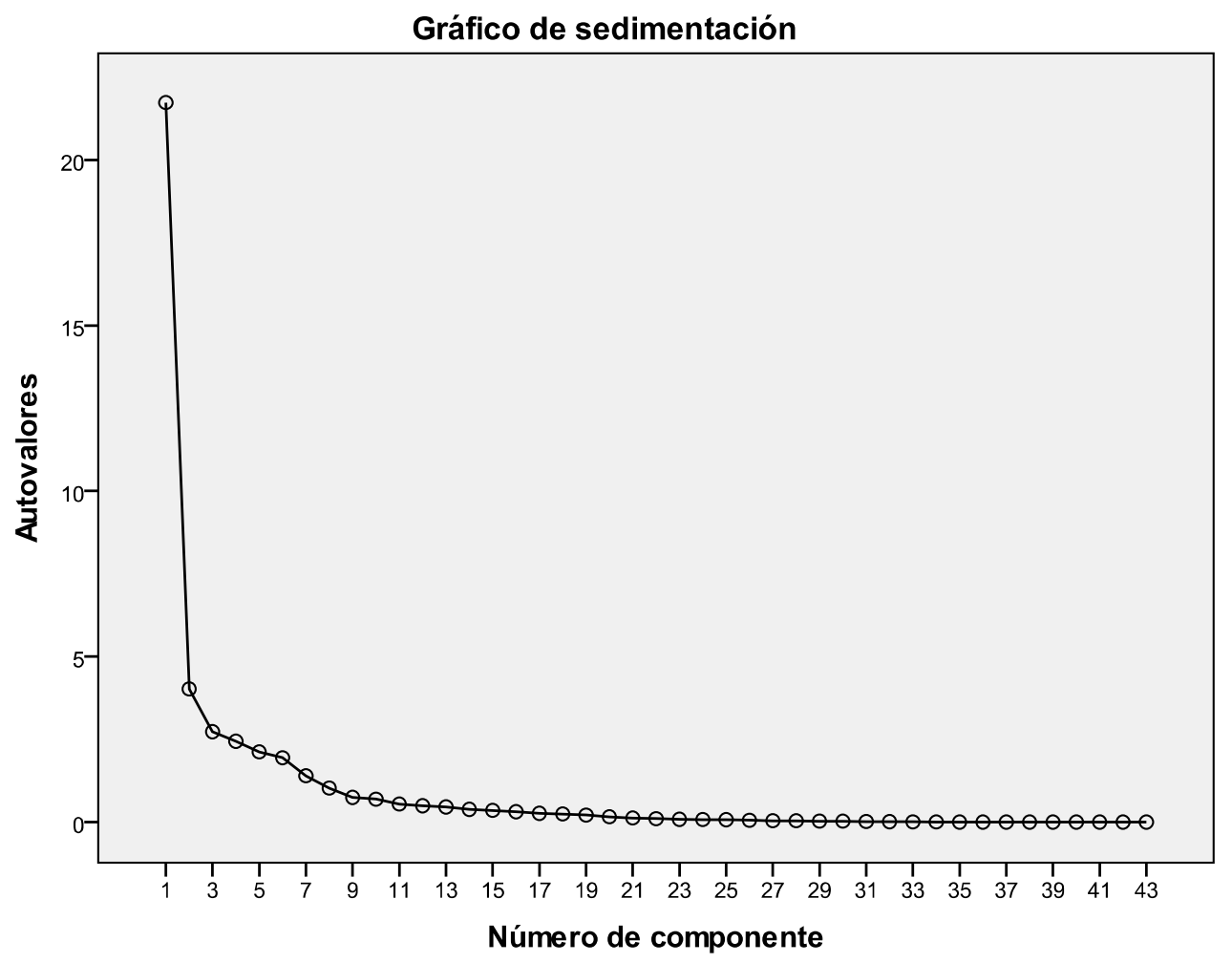

Tabla 8.8. Gráfico de sedimentación de la Escala Cisneros

En esta tabla en la que queda representado el gráfico de sedimentación de la Escala Cisneros observamos las saturaciones factoriales (correlaciones entre cada ítem y el factor extraído), considerándose como relevantes o significativos a partir de aquellos valores de 0,40, resultando así además la siguiente matriz de componentes rotados (véase tabla 8.9) realizada mediante el análisis de los componentes principales como método de extracción y cuyo método de rotación se ha llevado a cabo con la normalización de Varimax con Kaiser. Para evitar los posibles errores en el análisis de la interpretación de los resultados se debe llevar a cabo un tratamiento conjunto de los datos que contiene la tabla como hemos hecho en esta investigación, ya que este tipo de tratamiento de los datos nos permitirá realizar el oportuno análisis de correspondencias. Así se muestra la matriz integra de componentes rotados obtenida. 


\section{CAPÍTULO VIII. RESULTADOS OBTENIDOS}

\begin{tabular}{|c|c|c|c|c|c|c|c|c|}
\hline \multicolumn{9}{|c|}{ Matriz de componentes rotados ${ }^{a}$} \\
\hline & \multicolumn{8}{|c|}{ Componente } \\
\hline & 1 & 2 & 3 & 4 & 5 & 6 & 7 & 8 \\
\hline $\mathrm{EC} 1$ & & ,409 & ,435 & ,371 & & & & ,491 \\
\hline EC2 & &, 550 & &, 539 & & & &, 366 \\
\hline EC3 & & &, 534 & ,377 & & &, 445 & \\
\hline EC4 & & &, 450 &, 608 & & ,404 & & \\
\hline EC5 & & ,325 & & & &, 505 & &, 520 \\
\hline EC6 &, 522 & ,353 & & & & & &, 582 \\
\hline $\mathrm{EC} 7$ & &, 437 & &, 549 & & &, 554 & \\
\hline EC8 & ,339 & & & ,833 & & & & \\
\hline EC9 & ,325 & & &, 855 & & & & \\
\hline EC10 & & & ,663 &, 559 & & & & \\
\hline EC11 &, 879 & & & & & & & \\
\hline EC12 & ,875 & ,333 & & & & & & \\
\hline EC13 & ,449 & & & & & & & ,675 \\
\hline EC14 & &, 776 & ,357 & & & & & \\
\hline EC15 & &, 604 & & ,397 & & &, 376 & \\
\hline EC16 & &, 502 &, 716 & & & & & \\
\hline EC17 & &, 548 &, 518 & & & ,454 & & \\
\hline EC18 & & & ,746 & & & & & ,331 \\
\hline EC19 & ,394 & ,428 & & ,515 & ,304 & & & ,390 \\
\hline EC20 & & ,621 & 346 &, 561 & & & & \\
\hline EC21 & & ,909 & & & & & & \\
\hline EC22 & ,454 & ,525 & & & ,306 & 380 & & \\
\hline EC23 & & & & 655 & & & ,423 & \\
\hline EC24 & &, 544 & &, 577 & & & & \\
\hline EC25 & ,563 &, 713 & & & & & & \\
\hline EC26 & ,487 & & & & & &, 756 & \\
\hline EC27 & ,898 & & & & & & & \\
\hline EC28 & & & & & ,901 & & & \\
\hline EC29 & ,396 & & 818 & & & & & \\
\hline EC30 & ,871 & & & & & & & \\
\hline EC31 & ,604 & ,729 & & & & & & \\
\hline EC32 & ,684 & & 342, & & & ,407 & & \\
\hline EC33 & ,459 & ,611 & 352 & & & & & \\
\hline EC34 & &, 544 & ,581 & & & & & \\
\hline
\end{tabular}

Tabla 8.9. Matriz de Componentes Rotados de la Escala Cisneros. 


\section{CAPÍTULO VIII. RESULTADOS OBTENIDOS}

\begin{tabular}{|c|c|c|c|c|c|c|c|}
\hline EC35 & & & & & 896 & & \\
\hline EC36 & & ,348, & ,832 & & & & \\
\hline EC37 & & ,328 & 830 & & & & \\
\hline EC38 & ,498 & ,373 & & ,474 & & & 490, \\
\hline EC39 & ,314 & 623, & & 363, & & 490, & \\
\hline EC40 & ,373 & 639, & & & & & 394, \\
\hline EC41 & 689, & & & 309, & 423, & & \\
\hline EC42 & ,596 & & & & ,485 & & \\
\hline EC43 & & & & & & ,941 & \\
\hline
\end{tabular}

Tabla 8.9. (continuación) Matriz de Componentes Rotados de la Escala Cisneros.

\subsubsection{Escala de Perfil Profesional.}

Una vez analizados los resultados obtenidos en la Escala Cisneros procederemos a realizar el análisis de los datos, de la Escala de Perfil Profesional obteniendo:

\section{1) Los estadísticos descriptivos.}

Como hemos visto en el análisis de la anterior escala, los estadísticos descriptivos tratan de presentar y caracterizar un conjunto de datos, con el fin de describir apropiadamente la muestra de estudio. Entre los estadísticos más representativos que se pueden obtener debemos destacar la media, utilizada cuando, como en el caso que nos ocupa, deseamos describir determinado grupo de observaciones con un solo valor, para lo cual no debemos usar ni el valor más elevado, ni el valor más pequeño como único representante, ya que solo quedarían representados los extremos. Debemos resaltar además que una de las propiedades más sobresalientes de una distribución de datos es su tendencia a acumularse hacia el centro de la misma. Además de la media, como la tabla siguiente refleja analizaremos la desviación típica, ya que ambos estadísticos determinan la llamada distribución normal o gaussiana. Así ambas medidas serán utilizadas como estimadoras de los parámetros medidos, véase para ello la tabla 8.10, que a continuación se presenta: 


\section{CAPÍTULO VIII. RESULTADOS OBTENIDOS}

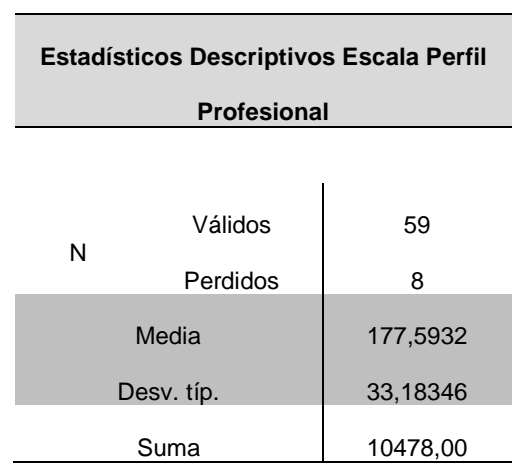

Tabla 8.10.Estadísticos descriptivos de la Escala de Perfil Profesional.

La tabla 8.10. refleja un primer análisis descriptivo de la muestra utilizada en la Escala de Perfil Profesional elaborada ad hoc, obteniendo así una puntuación media de 177,593 y una desviación típica de 33,18 , resultados satisfactorios para la investigación que nos ocupa. Una vez calculados los estadísticos descriptivos de los ítems o elementos de la Escala de Perfil Profesional, obtendremos como ya hicimos en la Escala Cisneros, el llamado índice de homogeneidad corregido de los ítems, (véase la tabla 8.11). Debemos recordar que este índice indica la discriminación de los ítems o elementos evaluada a partir de su relación con el resto de los ítems que componen el test, obteniéndose así los siguientes resultados:

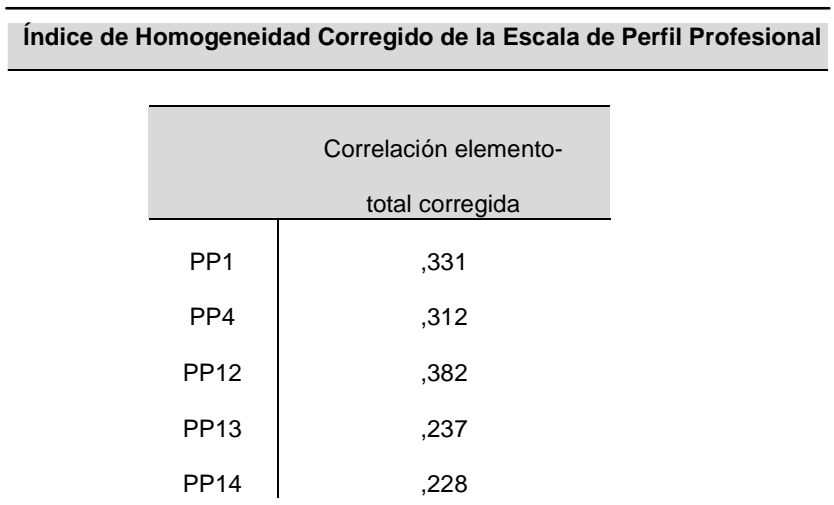

Tabla 8.11. Índice de Homogeneidad Corregido de la Escala de Perfil Profesional. 


\section{CAPÍTULO VIII. RESULTADOS OBTENIDOS}

\begin{tabular}{|c|c|}
\hline PP17 & ,456 \\
\hline PP18 & ,395 \\
\hline PP19 & ,192 \\
\hline PP20 & ,319 \\
\hline PP21 & ,432 \\
\hline PP22 & 289 \\
\hline PP23 & ,447 \\
\hline PP24 & 435 \\
\hline PP25 & ,469 \\
\hline PP26 & 225 \\
\hline PP28 & 636 \\
\hline PP29 & 611 \\
\hline PP30 & 642 \\
\hline PP36 &, 513 \\
\hline PP37 & 448 \\
\hline PP38 & ,335 \\
\hline РP39 & ,422 \\
\hline PP41 & ,724 \\
\hline PP42 & ,700 \\
\hline PP43 &, 506 \\
\hline PP44 & 431 \\
\hline PP45 & ,417 \\
\hline PP47 & ,745 \\
\hline PP50 & ,327 \\
\hline PP51 & ,704 \\
\hline PP52 & 642 \\
\hline PP53 & ,478 \\
\hline PP54 & 411 \\
\hline PP55 & ,331 \\
\hline PP56 & 231 \\
\hline PP57 & 228 \\
\hline PP58 & 483 \\
\hline PP59 & ,595 \\
\hline PP60 & 446 \\
\hline PP62 & ,318 \\
\hline PP63 & 625 \\
\hline PP64 & 647 \\
\hline PP65 & 482 \\
\hline
\end{tabular}

Tabla 8.11. (continuación) Índice de Homogeneidad Corregido de la Escala de Perfil Profesional. 


\section{CAPÍTULO VIII. RESULTADOS OBTENIDOS}

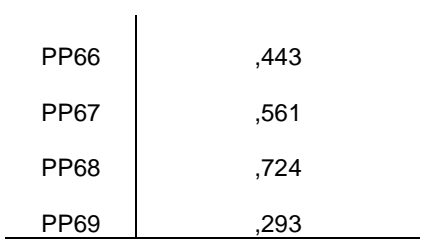

Tabla 8.11. (continuación) Índice de Homogeneidad Corregido de la Escala de Perfil Profesional.

La tabla anteriormente representada establece el llamado índice de homogeneidad corregido de los ítems, considerándose adecuados aquellos ítems con una correlación superior a 0,15 . Así se obtiene siguiéndose el criterio anteriormente planteado, que el ítem PP47 ("me gustaría continuar el resto de carrera profesional en esta organización") presenta el mayor índice de homogeneidad 0,745, siendo el ítem que menor índice presenta el PP19 ("he desempeñado actividades similares a las tareas que realizo en la actualidad"), 0,192. Los resultados así expresados resultan ser ampliamente satisfactorios, aportando evidencia empírica acerca de la adecuación de la prueba al modelo de estudio planteado en esta tesis doctoral, al igual que ocurría en la anterior escala, por lo que podemos afirmar que los instrumentos o escalas utilizadas en el análisis estadísticos son válidas para tal fin. A continuación analizaremos la fiabilidad y validez de la Escala de Perfil Profesional, planteada en esta investigación.

\section{2) La fiabilidad y validez.}

Una vez expuestos los estadísticos descriptivos básicos del instrumento diseñado se pasó a determinar, al igual que se hizo en la Escala Cisneros, su índice de fiabilidad y validez, para lo cual se calculó el coeficiente de fiabilidad Alfa de Cronbach y la fórmula de Spearman-Brown, coeficientes que, considerando el número de ítems que componen la escala, pueden considerarse suficientes a efectos de la estimación o medición experimental realizada (véase tabla 8.12). 


\section{CAPÍTULO VIII. RESULTADOS OBTENIDOS}

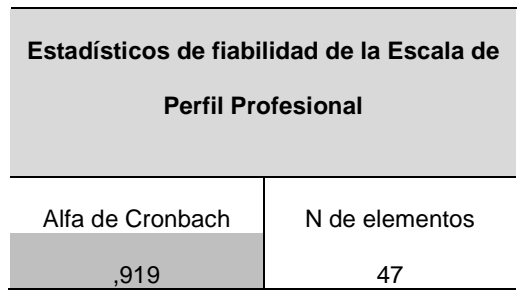

Tabla 8.12. Estadísticos de Fiabilidad Escala de Perfil Profesional

Tal y como se observa en la tabla anterior, el coeficiente de fiabilidad Alfa de Cronbach obtenido resultó satisfactorio (.919). Es además al igual que en la escala anterior un valor significativo, por tanto con una elevada fiabilidad en el estudio que se ha llevado a cabo, lo cual refleja un procedimiento adecuado en el uso de ambas escalas, para el objeto que se quiere determinar. Debemos de recordar que una de las características que debe cumplir un test para ser válido es precisamente la fiabilidad, determinado así que un test o cuestionario de las características del presentado en este estudio, se dice que es fiable si "mide bien aquello que está midiendo", refiriéndose así a la constancia de la medida, para lo cual podemos distinguir dos grandes componentes, la consistencia interna y la estabilidad temporal.

Un test totalmente fiable sería aquel con el que se pudiera medir sin ningún tipo de error, algo verdaderamente utópico en términos estadísticos y probabilísticos. Así, se puede afirmar, que en la práctica científica ningún instrumento de medida es totalmente fiable, ni tan siquiera aquellos que hacen referencia a la medición de características físicas; es decir si midiésemos un mismo objeto repetidas veces con el mismo instrumento obtendríamos medidas ligeramente diferentes, por lo que toda puntuación obtenida se componen de la puntuación verdadera más el error cometido.

En suma puede decirse que la fiabilidad de un test será mayor cuanta mayor variabilidad exista en la muestra de sujetos seleccionados. 


\section{CAPÍTULO VIII. RESULTADOS OBTENIDOS}

Seguidamente calcularemos la fórmula de Spearman Brown (véase tabla 8.13), mediante la cual se puede administrar el cuestionario a una muestra de sujetos de una sola vez, y descomponer el cuestionario en dos partes de modo que tengan el mismo número de ítems y que puedan considerarse paralelas: es común comparar la primera mitad del test con la segunda, o comparar los ítems pares con los impares. Así se obtiene:

\begin{tabular}{ccc}
\hline \multicolumn{3}{c}{ Estadísticos de fiabilidad de la Escala de Perfil Profesional } \\
\hline \multicolumn{2}{c}{ Correlación entre formas } &, 806 \\
\hline \multirow{3}{*}{ Coeficiente de Spearman-Brown } & Longitud igual &, 893 \\
& Longitud desigual &, 893 \\
\hline
\end{tabular}

Tabla 8.13. Estadísticos Spearman Brown

0,893 es la fiabilidad de cada mitad del test.

Para calcular la fiabilidad del test completo se aplica la fórmula de Spearman-Brown:

$$
R x x=\frac{2 \cdot r_{X X}}{1+r_{X X}}=\frac{2 \cdot 0,893}{1+0,893}=0,94
$$

De esta fórmula, se concluye que la fiabilidad resultante es elevada obteniéndose un coeficiente de 0,94 y por tanto la validez del mismo, es nuevamente correcta en la investigación planteada. Por tanto podemos afirmar que la relación entre la fiabilidad y la longitud es la adecuada en el análisis establecido previamente. Seguidamente analizaremos la fiabilidad mediante el Alfa de Cronbach de todas y cada una de las variables establecidas en los capítulos anteriores, mencionadas bien como antecedentes o como consecuentes del modelo de análisis experimental planteado en el estudio de esta tesis, con el fin de determinar las relaciones establecidas entre cada variable y el acoso laboral representado como NEAP. 


\section{CAPÍTULO VIII. RESULTADOS OBTENIDOS}

\section{3) Análisis de la fiabilidad de las diferentes dimensiones establecidas.}

Cómo hemos establecido en líneas anteriores el modelo experimental en el que se ha basado la investigación, exige la necesidad de establecer el índice predictivo entre cada una de las 14 variables enumeradas y el acoso laboral. Cabe recordar que como antecedentes y predictoras del mismo se han establecido: la edad, el sexo, el estilo de liderazgo, las competencias en el sector, la ambigüedad de rol, la justicia organizacional, los resultados económicos y financieros y el grado de autonomía laboral. Como consecuentes del acoso laboral se ha analizado la satisfacción laboral, la intención de abandono, el rendimiento laboral, el compromiso con la organización, el clima organizacional y la finalización de las tareas. Se muestra así a continuación en las siguientes líneas una breve descripción.

Comenzaremos por abordar la edad entendida como la posibilidad de elaborar un rango de edad, en el cual aparezca el acoso laboral con mayor incidencia o asiduidad. Han sido muchos los investigadores que han hecho hincapié en el estudio de estos rangos o categorías, llegando a diversas conclusiones y estableciendo como rango de edad más indicativo del acoso el establecido entre los 25 y los 35 años de edad. En cuanto al sexo, debemos hacer una clara distinción ya que puede llegar a confundirse la violencia sexual en el puesto de trabajo y el acoso laboral. Bien es cierto que en algunos casos de acoso laboral en puestos directivos coexisten además capítulos sexuales no consentidos, máxime aún cuando estamos hablando de que quien ocupe la dirección de un centro pueda ser una mujer. Por tanto se espera no haya resultados discordantes entre hombres y mujeres en puestos directivos. Seguidamente se abordo el estilo liderazgo entendido este como el modelo de gestionar una empresa, en el caso que nos ocupa un centro residencial o sociosanitario. A continuación se estudiaran las competencias en el sector. Definidas como aquellas destrezas adquiridas mediante la antigüedad o la práctica que se pueda haber tenido en puestos similares en el sector residencial. 


\section{CAPÍTULO VIII. RESULTADOS OBTENIDOS}

Inmediatamente después analizaremos la ambigüedad de rol Definida por la claridad en las tareas y papeles que el directivo del centro residencial deberá desempeñar. Seguidamente evaluaremos la justicia organizacional entendida por el propio directivo del centro como las decisiones justas e injustas que los superiores llevan a cabo tanto con él mismo como con los compañeros. Posteriormente se investigara acerca de los resultados económicos puntualizados como aquellos datos económicos negativos y no esperados por los propietarios de los grupos residenciales. Cabe resaltar que la gestión económica de cualquier empresa y/u organización comprende la planificación, ejecución y el análisis de los resultados de las actividades desarrolladas, en el caso que nos ocupa los centros residenciales (siendo conscientes además de que existen grupos gestores que agrupan varios centros simultáneamente), así mediante el estudio de los ingresos y de los costes se obtendrán los resultados necesarios, con el fin de generar conclusiones inexorables al proceso de toma de decisiones. En términos generales en la gestión de los centros suelen contabilizarse los ingresos generados, los costos directos del desempeño residencial, los gastos fijos efectivos, la amortización del mobiliario, y los resultados operativos entre otros más comunes. Más tarde analizaremos el grado de autonomía laboral, precisado como la libertad de decisión a la hora de desempeñar las tareas de manera óptima, respetando las directrices dadas. Después estudiaremos la satisfacción laboral, determinada como el grado en que una persona alcanza sus expectativas respecto a lo esperado de su puesto de trabajo directivo. Ulteriormente reflejaremos la intención de abandono, entendida como la idea de alejarse de su puesto de trabajo y de la empresa a la que pertenece unilateralmente. Posteriormente se pone en relieve el rendimiento laboral conceptualizándolo en el estudio como los resultados obtenidos fruto de las funciones y tareas llevadas a cabo en el puesto de trabajo, en este caso desde la dirección del centro residencial. El antepenúltimo concepto a estudio es el compromiso con la organización, sinónimo del compromiso afectivo y emocional que el trabajador, en este caso el directivo, mantiene con la empresa en la que trabaja. 


\section{CAPÍTULO VIII. RESULTADOS OBTENIDOS}

Seguidamente estudiaremos el clima laboral, definido como el ambiente laboral imperante entre los miembros de una organización en el puesto de trabajo que ocupa, en este caso concreto en el centro residencial y por último abordaremos la finalización de las tareas, entendida como la conclusión de las actividades objeto del cargo que se ostenta, con éxito y en el tiempo estimado previamente.

Así, a continuación se muestra en la tabla 8.14, un breve resumen de las fiabilidades parciales obtenidas, tomándolas como válidas, destacando además que el número máximo de ítems empleados para su cálculo ha sido 5 , y el número mínimo de 2 . Proporcionalmente a lo mencionado en la literatura científica en esta materia estadística, se considerada una fiabilidad elevada, señalando además que la escala empleada es de elaboración propia, como se ha señalado a lo largo de esta tesis de investigación. Dado que el Alfa de la variable intención de abandono no es significativo se ha decidido eliminarlo.

\section{TABLA RESUMEN FIABILIDAD}

\begin{tabular}{l|c}
\hline \multicolumn{1}{c|}{ Variable } & Alfa de Cronbach \\
\hline Estilo de Liderazgo & .339 \\
Competencias en el Sector & .728 \\
Ambigüedad de Rol & .808 \\
Justicia Organizacional & .781 \\
Grado de Autonomía & .475 \\
Satisfacción Laboral & .755 \\
Rendimiento Laboral & .724 \\
Compromiso Organizacional & .330 \\
Clima Organizacional & .720 \\
Finalización de las Tareas & .600 \\
\hline
\end{tabular}

Tabla 8.14. Fiabilidades por variable obtenidas. 


\section{CAPÍTULO VIII. RESULTADOS OBTENIDOS}

\subsection{Resultados de los análisis referidos a las hipótesis.}

Una vez calculados los diferentes parámetros estadísticos de las escalas que conforman el cuestionario utilizado (Escala Cisneros y Escala de Perfil Profesional) en la muestra de estudio realizaremos ahora las pruebas estadísticas necesarias para dar respuesta a las diferentes hipótesis que conforman el grueso de esta investigación, sin las cuales la misma no tendría objeto de ser.

Analizaremos así a continuación:

(1 Las diferencias de medias entre hombre y mujeres.

2 Los resultados del análisis correlacional de los antecedentes.

3 Los resultados del análisis correlacional de los consecuentes.

Antes de realizar ninguna prueba estadística es importante comprobar si se cumplen los supuestos de Normalidad en las variables métricas (Scala) del estudio, que son las variables "NEAP", "Edad", "Estilo_Liderazgo", "Competencias_Sector", “Ambigüedad_Rol”, "Justicia_Organizacional”, "Resultados_Económicos", “Grado_ Autonomía”, "Satisfacción_Laboral”, "Rendimiento_Laboral”, “Compromiso_Organizacio -nal”, "Clima_Organizacional” y "Finalización_Tareas".

Para comprobar el supuesto de normalidad utilizaremos la prueba no paramétrica de "Kolmogorov-Smirnov" (K-S) (véase anexo 2; tablas resultados SPSS 19; prueba de Kolmogorov-Smirnov). Se cumple el supuesto para casi todas las variables, excepto "resultados económicos"; podemos afirmar que todas las variables se distribuyen normalmente ( $p>$. 05) Los resultados obtenidos fueron los siguientes "NEAP" $(p=.061)$, “Edad”( $p=.833)$, “Estilo_Liderazgo"( $p=.141)$, “Competencias_Sector”( $p=.402)$, “Ambigüe dad_Rol”( $p=.537)$, “Justicia_Organizacional” $(p=.618)$, "Resultados_Económicos" $(p=.034)$ ,"Grado_Autonomía” $(p=.369)$, “Satisfacción_Laboral” $(p=.248)$ “Rendimiento_Laboral”( $p$ =.629), “Compromiso_Organi-zacional” ( $p=.276)$, “Clima_Organizacional” ( $p=.639)$ y "Finalización_Tareas" ( $p=.523)$. 


\section{CAPÍTULO VIII. RESULTADOS OBTENIDOS}

Seguidamente y una vez obtenida la normalidad de la muestra comenzaremos por analizar el análisis de medias entre hombres y mujeres.

\subsubsection{Resultados del análisis " $t$ " de diferencias de medias y resultados del análisis descriptivo.}

Comenzaremos el análisis estadístico propiamente dicho realizando el estudio de las diferencias de medias entre hombres y mujeres en el acoso laboral. Para ello Vamos a realizar un contraste " $t$ " de diferencias de medias para muestras independientes para comprobar si se cumple la $\mathrm{H} 2$ : el sexo del directivo promueve la aparición del acoso laboral. Tomando como factor el género de los sujetos y analizando si hay diferencias entre estos grupos en la variable acoso laboral, medida mediante el NEAP.

Los resultados estadísticos obtenidos $\left[t_{57}=1.001 ; p=.321\right]$ nos informan de que no existen diferencias estadísticamente significativas entre el grupo de hombres y mujeres en la probabilidad de sufrir acoso laboral es puestos directivos de centros residenciales.

Tras realizar el análisis de medias pertinente, se ha llevado a cabo el análisis descriptivo de las variables de la muestra (véase tabla 8.15), obteniendo la media, la desviación típica y el rango como parámetros de referencia.

Este análisis nos permitirá entre otras muchas cosas controlar la presencia de posibles errores en la fase de introducción de los datos, es decir podremos detectar con él valores obtenidos fuera del rango establecido. Además se obtendrá una cuantificación inicial de los datos, lo que nos proporcionara una idea inicial de la forma de los datos y su posible distribución de probabilidad. 


\section{CAPÍTULO VIII. RESULTADOS OBTENIDOS}

\section{ANÁLISIS DESCRIPTIVO}

\begin{tabular}{l|ccc}
\hline \multicolumn{1}{c|}{ Variable } & Media & DT & Rango \\
\hline NEAP & 26.71 & 39.35 & $0-183$ \\
Edad & 43.90 & 11.26 & $24-75$ \\
Estilo de Liderazgo & 9.96 & 5.19 & $0-38$ \\
Competencias en el Sector & 17.96 & 3.90 & $10-24$ \\
Ambigüedad de Rol & 22.55 & 4.50 & $12-30$ \\
Justicia Organizacional & 11.74 & 4.61 & $0-23$ \\
Resultados Económicos & 1.97 & 1.73 & $0-6$ \\
Grado de Autonomía & 16.96 & 3.66 & $9-24$ \\
Satisfacción Laboral & 15.74 & 5.33 & $4-30$ \\
Rendimiento Laboral & 19.00 & 4.68 & $5-30$ \\
Compromiso Organizacional & 19.54 & 3.75 & $9-30$ \\
Clima Organizacional & 16.47 & 3.79 & $3-24$ \\
Finalización de las Tareas & 14.54 & 4.06 & $7-24$ \\
\hline
\end{tabular}

Tabla 8.15. Análisis descriptivo parámetros de referencia.

Con los resultados obtenidos, y tras el pormenorizado análisis llevado a cabo, realizaremos el análisis correlacional correspondiente, comenzando por el estudio de la relación existente entre el acoso laboral y los antecedentes planteados.

\subsubsection{Resultados del análisis correlaccional de los antecedentes.}

Una vez realizado el análisis descriptivo de las variables, se ha efectuado el análisis correlaccional de los antecedentes planteados (véase tabla 8.16) donde podremos observar las diferentes relaciones encontradas, y establecidas en los resultados de esta investigación. Cabe recordar que como tales antecedentes encontramos la edad, el estilo de liderazgo, las competencias en el sector, la ambigüedad de rol, la justicia organizacional, los resultados económico-financieros y el grado de autonomía laboral. 


\section{ANÁLISIS CORRELACIONAL ACOSO LABORAL - ANTECEDENTES}

\begin{tabular}{|c|c|c|c|c|c|c|c|c|}
\hline Variable & 1 & 2 & 3 & 4 & 5 & 6 & 7 & 8 \\
\hline 1.Edad & & & & & & & & \\
\hline 2.Estilo de & $r=.025$ & & & & & & & \\
\hline Liderazgo & & & & & & & & \\
\hline $\begin{array}{l}\text { 3.Competencia } \\
\text { s en el Sector }\end{array}$ & $r=.144$ & $r=-.015$ & & & & & & \\
\hline $\begin{array}{l}\text { 4.Ambigüedad } \\
\text { de Rol }\end{array}$ & $r=.080$ & $r=.034$ & $r=.585^{* *}$ & & & & & \\
\hline 5.Justicia & $r=.122$ & $r=.535^{* *}$ & $r=.150$ & $r=.223$ & & & & \\
\hline Organizacional & & & & & & & & \\
\hline $\begin{array}{l}\text { 6.Resultados } \\
\text { Económicos }\end{array}$ & $r=.132$ & $r=-.086$ & $r=.020$ & $r=.042$ & $r=.085$ & & & \\
\hline $\begin{array}{l}\text { 7.Grado de } \\
\text { Autonomía }\end{array}$ & $r=.112$ & $r=.216$ & $r=.333^{* *}$ & $r=.411 * *$ & $r=.503 * *$ & $r=.043$ & & \\
\hline $\begin{array}{l}\text { 8.Acoso laboral } \\
\text { (NEAP) }\end{array}$ & $r=.027$ & $r=-.203$ & $r=.056$ & $r=-.112$ & $r=-.263^{*}$ & $r=-.142$ & $r=-.286^{*}$ & \\
\hline Tabla 8.16. Anc & corr & aroco & $1-$ & nte & & & $\begin{array}{r}* p<.0^{\prime} 5 \\
* * p<.0^{\prime} 1\end{array}$ & \\
\hline
\end{tabular}

De la anterior tabla podemos concluir:

H1: ( $r=.027 ; p=.837)$. Obtenemos que no es significativa la correlación entre la "edad de los sujetos" y su percepción del "acoso laboral" (NEAP).

H3: ( $r=-.203 ; p=.124)$. Obtenemos que no es significativa la correlación entre "el estilo de liderazgo empresarial" y la percepción sobre el "acoso laboral" (NEAP).

H4: $(r=.056 ; p=.676)$. Obtenemos que no es significativa la correlación entre "las competencias de los sujetos en el sector" y su percepción del "acoso laboral" (NEAP).

H5: $(r=-.112 ; p=.397)$. Obtenemos que no es significativa la correlación entre "la ambigüedad de rol observada" y su percepción del "acoso laboral" (NEAP).

H6: ( $r=-263 ; p=.044)$. Obtenemos que si es significativa la correlación entre "la justicia organizacional observada" y su percepción del "acoso laboral" (NEAP). Podemos afirmar que aquellos sujetos que detectan menor justicia organizacional presentan 


\section{CAPÍTULO VIII. RESULTADOS OBTENIDOS}

mayor acoso laboral, corroborándose la hipótesis del estudio.

H7: ( $r=-.142 ; p=.284$.$) . Obtenemos que no es significativa la correlación entre "los$ resultados económicos de la empresa" y su percepción del "acoso laboral" (NEAP).

H8: $(r=-.286 ; p=.028)$. Obtenemos que si es significativa la correlación entre "el grado de autonomía de los sujetos" y su percepción del "acoso laboral" (NEAP). Se corrobora que aquellos sujetos que presentan menor grado de autonomía laboral son los que presentan mayor acoso laboral.

Seguidamente se ha realizado el correspondiente análisis correlaccional entre el acoso laboral y los consecuentes.

\subsubsection{Resultados del análisis correlaccional de los consecuentes.}

Estudiando la relación del acoso laboral con los consecuentes planteados (véase tabla 8.17) (satisfacción laboral, intención de abandono, rendimiento laboral, compromiso organizacional, clima organizacional y finalización de las tareas) encontramos:

\section{ANÁLISIS CORRELACIONAL ACOSO LABORAL - CONSECUENTES}

\begin{tabular}{|c|c|c|c|c|c|c|c|}
\hline Variable & 1 & 2 & 3 & 4 & 5 & 6 & 7 \\
\hline 1.Satisfacción & & & & & & & \\
\hline & & & & & & & \\
\hline $\begin{array}{l}\text { 3. Rendimiento } \\
\text { Laboral }\end{array}$ & $r=.603^{* *}$ & $r=.708^{* *}$ & & & & & \\
\hline 4.Compromiso & $r=.534^{* *}$ & $r=.626^{* *}$ & $r=.714^{* *}$ & & & & \\
\hline Organizacional & & & & & & & \\
\hline $\begin{array}{l}\text { 5.Clima } \\
\text { organizacional }\end{array}$ & $r=.585^{* *}$ & $r=.435^{* *}$ & $r=.521^{* *}$ & $r=.518^{* *}$ & & & \\
\hline $\begin{array}{l}\text { 6.Finalización } \\
\text { Tareas }\end{array}$ & $r=.686^{* *}$ & $r=.566^{* *}$ & $r=.551 * *$ & $r=.455^{* *}$ & $r=.579 * *$ & & \\
\hline $\begin{array}{l}\text { 7.Acoso laboral } \\
\text { (NEAP) }\end{array}$ & $r=-.387^{* *}$ & $r=-.327^{*}$ & $r=-.268^{*}$ & $r=-.194$ & $r=-.485^{* *}$ & $r=-.330^{*}$ & \\
\hline
\end{tabular}




\section{CAPÍTULO VIII. RESULTADOS OBTENIDOS}

De la anterior tabla podemos concluir:

H9: $(r=-.387 ; p=.002)$. Obtenemos que si es significativa la correlación entre su percepción del "acoso laboral" (NEAP) y "el grado de satisfacción laboral de los sujetos". Al ser una correlación de signo negativo, podemos afirmar que la relación entre ambas variables es inversa, corroborándose que a mayor acoso laboral menor satisfacción laboral.

H11: $(r=-.268 ; p=.040)$. Obtenemos que es significativa la correlación entre su percepción del "acoso laboral" (NEAP) y "el rendimiento laboral de los sujetos". La correlación existente es negativa lo que nos indica que la relación entre ambas variables es inversa; por lo tanto se corrobora que a mayor acoso laboral, menor rendimiento.

H12: $(r=-.194 ; p=.140)$. Obtenemos que no es significativa la correlación entre su percepción del "acoso laboral" (NEAP) y "el compromiso organizacional de los sujetos".

H13: $(r=-.485 ; p=.000)$. Obtenemos que es significativa la correlación entre su percepción del "acoso laboral" (NEAP) y "el clima organizacional de los sujetos". Corroborándose que a mayor acoso laboral, peor clima organizacional.

H14: ( $r=-.330 ; p=.011)$. Obtenemos que es significativa la correlación entre su percepción del "acoso laboral" (NEAP) y "la finalización de las tareas de los sujetos". Corroborándose que a mayor acoso laboral menor finalización de las tareas. 


\section{CAPÍTULO VIII. RESULTADOS OBTENIDOS}

\subsubsection{Resultados referidos al modelo de los análisis predictivos.}

En cuanto a los resultados estadísticos referidos al modelo de los análisis predictivos hemos llevado a cabo:

1) Análisis de regresión múltiple "Stepwise o regresión por pasos" para analizar que antecedentes predicen el acoso laboral.

Hemos realizado un método de regresión lineal múltiple por pasos o Stepwise para comprobar si los antecedentes del acoso laboral, como son la justicia organizacional y el grado de autonomía son predictores significativos de las puntuaciones en acoso laboral medida por la Escala NEAP. No ha resultado significativa la variable justicia organizacional como un adecuado predictor del acoso laboral medido por el NEAP, a pesar de que ambas variables presentaban un coeficiente de correlación de Pearson significativo. Al haber utilizado una regresión por pasos, el programa informático solo ha considerado predictor significativo la variable grado de autonomía laboral. La base de este método consiste en mantener las variables independientes que contienen información relevante y a la vez prescindir de aquellas que resulten redundantes respecto a las variables que ya forman parte del modelo. Se trata de un procedimiento de índole exclusivamente estadística que discurren según algoritmos programables en los que se seleccionan las variables relevantes sin la intervención de los juicios teóricos de los investigadores. Este método se basa en construir un modelo predictivo a través del proceso llamado "principio de parsimonia", en el que figuren la menor cantidad posible de predictores, en nuestro caso, para predecir el acoso laboral la regresión por pasos ha considerado como factor verdaderamente influyente, el grado de autonomía laboral, considerando que la justicia organizacional "no añade" nada nuevo sobre el acoso laboral que no sea explicado por el grado de autonomía. Estudiando la colinealidad entre los predictores "justicia organizativa" y "grado de autonomía" podemos decir que no existe 


\section{CAPÍTULO VIII. RESULTADOS OBTENIDOS}

varianza compartida entre ellos; el índice de tolerancia de la variable "justicia organizacional"

$\mathrm{IT}=.747$ por ser un valor superior a la tolerancia mínima de .10 indica que hay alta tolerancia en esta variable, baja relación con la variable "grado de autonomía" incluida en el modelo, lo que no indica que si la variable "justica organizacional" no ha sido incluida en el modelo es porque era un predictor que "no aporta" nada significativo al acoso laboral que no se ha explicado por la variable grado de autonomía.

Ha resultado un predictor significativo del acoso laboral el grado de autonomía laboral, véase tabla 8.18. La prueba del ANOVA de la regresión resultó significativa $F_{(1,57)}=5 \mathrm{p}<.05$. La prueba " $t$ " sobre el coeficiente de regresión también resultó significativa $\mathrm{t}=-2.256 \mathrm{p}<.05$. El Coeficiente de Determinación entre el grado de autonomía y el acoso laboral NEAP $r_{\text {grado de autonomía,acoso }}^{2} 9 \%$, por lo tanto podemos afirmar que es un $9 \%$ el porcentaje de la varianza en las puntuaciones de acoso laboral que se pueden explicar por el grado de autonomía. Podemos construir un modelo de predicción a través de una ecuación de regresión, para pronosticar las puntuaciones en acoso laboral de los sujetos a partir de las puntuaciones obtenidas en grado de autonomía.

$y_{\text {acoso laboral }}=\mathrm{A}+B_{\text {grado de autonomía }}$

$y_{\text {'acoso laboral }}=78.845+(-3.073)_{\text {grado de autonomía }}$

Y la naturaleza de la relación entre ambas variables es inversa, como así queda demostrado analizando el coeficiente de regresión estandarizado Beta = .286 , corroborando la hipótesis de que los sujetos que tienen poco grado de autonomía laboral, presentan puntuaciones más altas en acoso laboral. 


\section{CAPÍTULO VIII. RESULTADOS OBTENIDOS}

Tabla. Análisis de regresión de los Antecedentes predictores del Acoso laboral

\begin{tabular}{llllll}
\hline Criterio & Predictoras & $\beta$ & $\boldsymbol{R}^{2}$ & $\mathbf{F}$ & $\mathbf{t}$
\end{tabular}

NEAP (Acoso Laboral) $\quad$ Grado de autonomía

$*=\mathrm{p} \leq .05 ; * *=\mathrm{p} \leq .01 ; * * *=\mathrm{p} \leq .001$. Se presentan los datos del último modelo obtenido.

Tabla 8.18. Análisis de regresión de los antecedentes predictores del acoso laboral.

2) Análisis de regresión lineal para comprobar si el acoso laboral es un predictor de la satisfacción laboral, intención de abandono, rendimiento laboral, clima organizacional y finalización de las tareas:

2.1.) Considerando como variable independiente predictora el acoso laboral, medido por la escala NEAP, para comprobar si es buen predictor de la variable dependiente criterio satisfacción laboral.

Tras realizar un análisis de regresión lineal, véase tabla 8.19, para comprobar si el acoso laboral medido por el NEAP es buen predictor de las puntuaciones en satisfacción laboral de los directivos de los centros residenciales podemos responder afirmativamente. La prueba del ANOVA de la regresión resultó significativa $F_{(1,57)}=10.062 \mathrm{p}<.01$. La prueba " $t$ " sobre el coeficiente de regresión también resultó significativa $\mathrm{t}=-3.172 \mathrm{p}<.01$. El Coeficiente de Determinación entre el acoso laboral NEAP y la satisfacción laboral $r_{\text {acoso,satisfacción }}^{2}=15 \%$, por lo tanto podemos afirmar que es un $15 \%$ el porcentaje de la varianza en las puntuaciones de satisfacción laboral que se pueden explicar por el acoso laboral. Podemos construir un modelo de predicción a través de una ecuación de regresión, para pronosticar las puntuaciones en satisfacción laboral de los sujetos a partir de las puntuaciones obtenidas en la escala NEAP de acoso laboral.y'satisfacción laboral $=\mathrm{A}+B_{\text {acoso laboral }}$

$y_{\text {'satisfacción laboral }}=17.149+(-.053)$ acoso laboral 


\section{CAPÍTULO VIII. RESULTADOS OBTENIDOS}

Y la naturaleza de la relación entre ambas variables es inversa, como así queda demostrado analizando el coeficiente de regresión estandarizado Beta = .053 , corroborando la hipótesis de que los sujetos que son sometidos a acoso laboral, se sienten menos satisfechos laboralmente.

2.2.) Considerando como variable independiente predictora el acoso laboral, medido por la escala NEAP, para comprobar si es buen predictor de la variable dependiente criterio rendimiento laboral.

Tras realizar un análisis de regresión lineal, véase tabla 8.19, para comprobar si el acoso laboral medido por el NEAP es buen predictor de las puntuaciones en rendimiento laboral de los directivos de los centros residenciales podemos responder afirmativamente. La prueba del ANOVA de la regresión resultó significativa $F_{(1,57)}=4.418 \mathrm{p}<.05$. La prueba " $t$ " sobre el coeficiente de regresión también resultó significativa $\mathrm{t}=-2.108 \mathrm{p}<.05$. El Coeficiente de Determinación entre el acoso laboral NEAP y el rendimiento laboral $r_{\text {acoso, } \text { rendimiento laboral }}^{2}=8 \%$, por lo tanto podemos afirmar que es un $8 \%$ el porcentaje de la varianza en las puntuaciones en el rendimiento laboral que se pueden explicar por el acoso laboral. Podemos construir un modelo de predicción a través de una ecuación de regresión, para pronosticar las puntuaciones en rendimiento laboral de los sujetos a partir de las puntuaciones obtenidas en la escala NEAP de acoso laboral.y'rendimiento laboral $\mathrm{A}+B_{\text {acoso laboral }}$

$y_{\text {'rendimiento laboral }}=19.853+(-.032)$ acoso laboral 


\section{CAPÍTULO VIII. RESULTADOS OBTENIDOS}

Y la naturaleza de la relación entre ambas variables es inversa, como así queda demostrado analizando el coeficiente de regresión estandarizado Beta = .268 , corroborando la hipótesis de que los sujetos que son sometidos a acoso laboral, presentan un menor rendimiento laboral.

2.3.) Considerando como variable independiente predictora el acoso laboral, medido por la escala NEAP, para comprobar si es buen predictor de la variable dependiente criterio clima organizacional.

Tras realizar un análisis de regresión lineal, véase tabla 8.19, para comprobar si el acoso laboral medido por el NEAP es buen predictor de las puntuaciones en clima organizacional de los directivos de los centros residenciales podemos responder afirmativamente. La prueba del ANOVA de la regresión resultó significativa

$F_{(1,57)}=17.524 \mathrm{p}<.001$. La prueba " $t$ " sobre el coeficiente de regresión también resultó significativa $\mathrm{t}=-4.186 \mathrm{p}<.001$. El Coeficiente de Determinación entre el acoso laboral NEAP y el clima organizacional $r_{\text {acoso, } \text {,lima organizacional }}^{2}=8 \%$, por lo tanto podemos afirmar que es un $24 \%$ el porcentaje de la varianza en las puntuaciones en el clima organizacional que se pueden explicar por el acoso laboral. Podemos construir un modelo de predicción a través de una ecuación de regresión, para pronosticar las puntuaciones en clima organizacional de los sujetos a partir de las puntuaciones obtenidas en la escala NEAP de acoso laboral.y' ${ }_{\text {clima organizacional }}=\mathrm{A}+B_{\text {acoso laboral }}$

$y_{\text {clima organizacional }}=17.725+(-.047)$ acoso laboral 


\section{CAPÍTULO VIII. RESULTADOS OBTENIDOS}

Y la naturaleza de la relación entre ambas variables es inversa, como así queda demostrado analizando el coeficiente de regresión estandarizado Beta = .485 , corroborando la hipótesis de que los sujetos que son sometidos a acoso laboral, presentan menores puntuaciones cuando se mide el clima organizacional de la empresa.

2.4.) Considerando como variable independiente predictora el acoso laboral, medido por la escala NEAP, para comprobar si es buen predictor de la variable dependiente criterio finalización tareas.

Tras realizar un análisis de regresión lineal, véase tabla 8.19, para comprobar si el acoso laboral medido por el NEAP es buen predictor de las puntuaciones en la finalización de las tareas de los directivos de los centros residenciales podemos responder afirmativamente. La prueba del ANOVA de la regresión resultó significativa $F_{(1,57)}=6.983 p<.05$. La prueba " $t$ " sobre el coeficiente de regresión también resultó significativa $\mathrm{t}=-2.642 \mathrm{p}<.05$. El Coeficiente de Determinación entre el acoso laboral NEAP y la finalización de las tareas $r_{\text {acoso,finalizaciçon de las tareas }}^{2}=11 \%$, por lo tanto podemos afirmar que es un $11 \%$ el porcentaje de la varianza en las puntuaciones en la finalización de las tareas que se pueden explicar por el acoso laboral. Podemos construir un modelo de predicción a través de una ecuación de regresión, para pronosticar las puntuaciones en finalización de las tareas de los sujetos a partir de las puntuaciones obtenidas en la escala NEAP de acoso laboral. $y_{\text {' }}$ inalización de las tareas $=\mathrm{A}+B_{\text {acoso laboral }}$

$y_{\text {finalización de las tareas }}=15.455+(-.034)_{\text {acoso laboral }}$ 


\section{CAPÍTULO VIII. RESULTADOS OBTENIDOS}

Y la naturaleza de la relación entre ambas variables es inversa, como así queda demostrado analizando el coeficiente de regresión estandarizado Beta = .330, corroborando la hipótesis de que los sujetos que son sometidos a acoso laboral, presentan menores puntuaciones en la finalización de las tareas.

Cabe resaltar antes de concluir este análisis estadístico la importancia que tienen todos y cada uno de los resultados obtenidos debido en gran medida a la sensibilidad de la temática objeto de estudio, y a la dificultad de los mismos en la actualidad. Debemos destacar además la elevada fiabilidad de la que gozan ambas escalas, parámetro esencial para su elección en este estudio, fruto de un estudio pormenorizado de diferentes pruebas que podían ser utilizadas como instrumentos para la obtención y recogida de los datos, tras las cuales se opto por las que a continuación se describen en el siguiente apartado.

Por último reseñar, la importancia derivada de los resultados de esta investigación fruto del estudio del fenómeno del acoso laboral en las circunstancias señaladas a lo largo de esta tesis que no son otras más que las derivadas de la acción empresarial hacia los directivos de centros residenciales.

\begin{tabular}{|llllll|}
\hline \multicolumn{3}{|l|}{ Tabla. Análisis de regresión de los Consecuentes que predice el Acoso Laboral } \\
\hline Criterio & Predictor & $\beta$ & $\boldsymbol{R}^{\mathbf{2}}$ & $\mathbf{F}$ & $\mathbf{t}$ \\
\hline Satisfacción laboral & NEAP (Acoso Laboral) & -.387 & .15 & 10.06 & -3.17 \\
Rendimiento laboral & NEAP (Acoso Laboral) & -.268 & .07 & 4.41 & -2.10 \\
Clima organizacional & NEAP (Acoso Laboral) & -.485 & .23 & 17.52 & -4.18 \\
Finalización de las tareas & NEAP (Acoso Laboral) & -.330 & .10 & 6.98 & -2.64 \\
\hline$*=\mathrm{p} \leq .05 ; * *=\mathrm{p} \leq .01 ; * * *=\mathrm{p} \leq .001$. & & & & & \\
\end{tabular}

Tabla 8.19. Análisis de regresión de los consecuentes que predice el acoso laboral. 


\section{CAPÍTULO VIII. RESULTADOS OBTENIDOS}

Además de todos los análisis ya realizados, mencionados hasta el momento se ha llevado a cabo un minucioso análisis del percentil de NEAP, tomado como referencia del acoso laboral, para lo cual se establecieron tres percentiles bien diferenciados; percentil 25 (acoso laboral bajo), percentil 50 (acoso laboral medio) y percentil 75 (acoso laboral alto). En ellos encontramos una proporcionalidad adecuada de la muestra y diferencias significativas en el análisis de los percentiles, de tal manera que existe una gran variabilidad entre el percentil 25 y el percentil 75 de la muestra. Ello de nuevo es fiel reflejo de la fiabilidad del estudio realizado, y la rigurosidad en el tratamiento de los resultados obtenidos. A continuación se presenta gráficamente el análisis de percentiles;

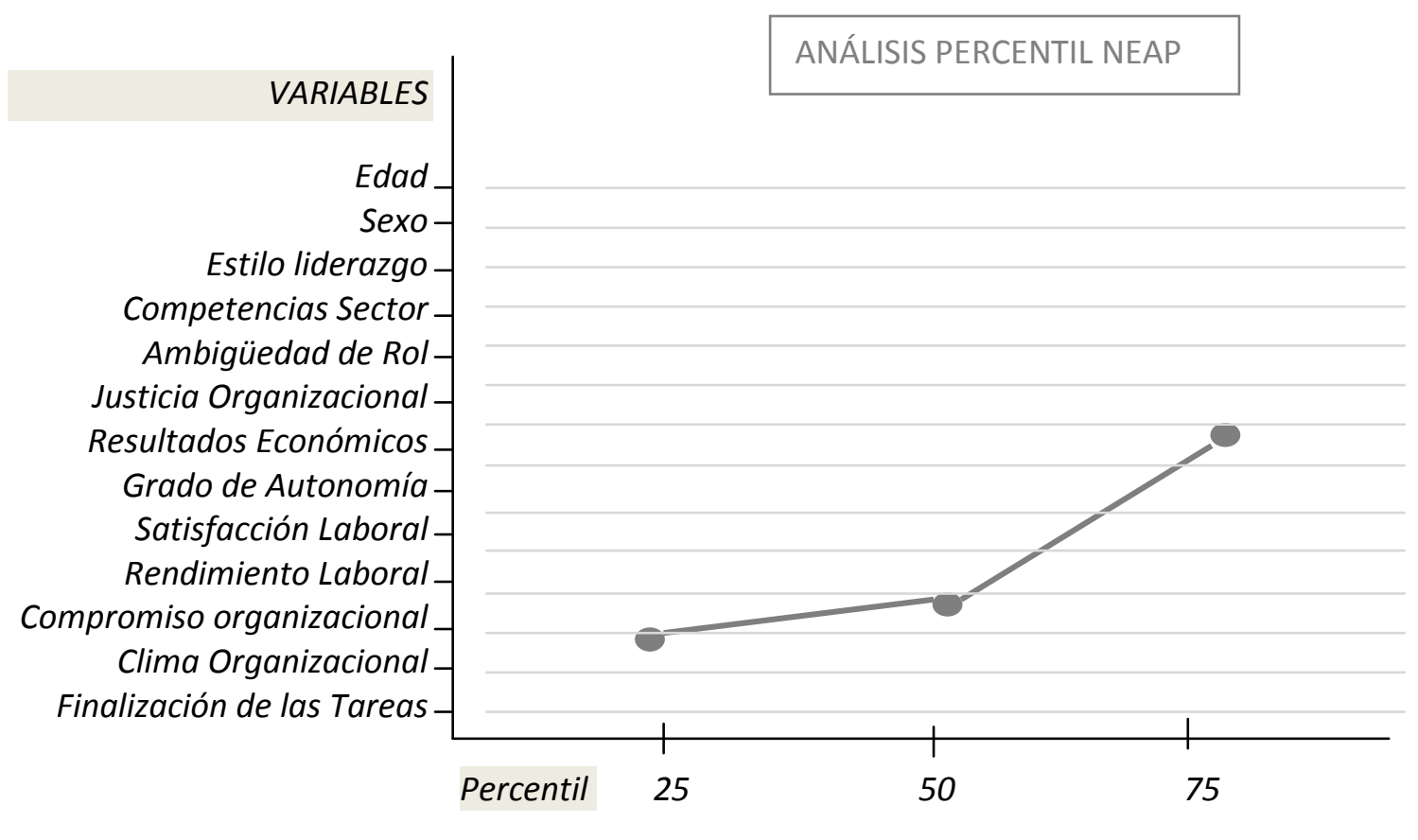

Gráfico 8.1. Análisis Percentil NEAP

Finalizaremos el capítulo con el resumen- abstract del mismo, el cual toma especial relevancia por tratarte del capítulo en el que se abordan entre otros aspectos fundamentales, la obtención de los resultados y la respuesta a las cuestiones planteadas en el comienzo de esta tesis. 
RESUMEN - ABSTRACT

CAPÍTULO VIII.

"Resultados Obtenidos".

En este capítulo se han facilitado los principales resultados obtenidos en el estudio realizado, exponiéndose los datos más significativos y de mayor calado para la tesis planteada. Así, se han analizado los datos estadísticos que han arrojado las escalas que conforman el cuestionario; la Escala Cisneros y la Escala de Perfil Profesional. Para todo ello ha sido necesaria la utilización del programa informático SPSS 19 para Windows 7, creyéndose como el medio y soporte más adecuado para este análisis estadístico.

En consonancia con todo ello, se enuncian los resultados obtenidos por escalas antes del análisis definitivo, obteniéndose así de la Escala Cisneros: 1)los estadísticos descriptivos, tanto de los índices (NEAP, IGAP e IMAP), como de los ítems o elementos que lo conforman, 2)la fiabilidad y validez, mediante el Alfa de Cronbach y la fórmula de Spearman Brown, 3)las puntuaciones obtenidas por los sujetos en los diferentes índices nombrados y 4)el análisis factorial junto con el gráfico de sedimentación y la matriz de componentes rotados. De la Escala de Perfil Profesional, obtendremos: 1)los estadísticos descriptivos (media y desviación típica) y el índice de homogeneidad corregido, 2)la fiabilidad y validez, mediante el Alfa de Cronbach y la fórmula de Spearman Brown y 3)el análisis de la fiabilidad de las diferentes dimensiones establecidas ( edad, sexo, estilo de liderazgo, competencias en el sector, ambigüedad de rol, justicia organizacional, resultados económicos, grado de autonomía laboral, satisfacción laboral, intención de abandono, rendimiento laboral, compromiso organizacional, clima organizacional y finalización de las tareas) mediante el Alfa de Cronbach de las mismas. 


\section{CAPÍTULO VIII. RESULTADOS OBTENIDOS}

Una vez calculados los parámetros estadísticos de las escalas que componen el cuestionario elaborado y antes de realizar el análisis estadístico específico propiamente dicho, se ha realizado el análisis de la normalidad mediante la prueba de Kolmogorov Smirnov (K-S). Posteriormente se obtiene:

1) Los resultados de los análisis referidos a las escalas.

2) El análisis de las diferencias de medias obtenidas entre hombres y mujeres, mediante la distribución " $t$ " de Student.

3) El análisis correlacional de los llamados antecedentes mediante el coeficiente de correlación de Pearson.

4) El análisis correlacional de los denominados consecuentes mediante el coeficiente de correlación de Pearson.

5) Los resultados referidos al modelo predictivo o análisis de regresión.

En el capítulo siguiente, capítulo IX, se discutirán las conclusiones obtenidas, para dar respuesta a las hipótesis planteadas en el estudio. 


\title{
CAPÍTULO IX
}

\author{
"Discusión Final y Conclusiones"
}

VNIVERSITAS STVDII SALAMANTINI

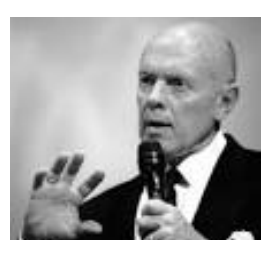

"Trata siempre a tus empleados como quieres que ellos traten a tus mejores clientes".

Stephen Covey (profesor estadounidense). 


\section{CAPÍTULO IX.}

"Discusión Final y Conclusiones".

\section{Discusión Final y Conclusiones.}

La pretensión de esta tesis de investigación es poder haber aportado algunas respuestas a las tantas preguntas que muchos se hacen desde hace mucho tiempo, aunque hay que asumir que probablemente queden muchas otras por indagar $y$ responder. Así pues el mobbing un fenómeno que ha existido, existe y probablemente existirá en el futuro. En ella se han planteado, desde un enfoque psicosocial, una serie de aportaciones escasamente estudiadas hasta el momento, como son el perfil del trabajador o las posibles variables intervinientes en el proceso, intentando realizar una aproximación fiel al contexto socio laboral donde desempeñan su trabajo las personas acosadas, en el caso que nos ocupa los directivos de centros residenciales.

Hasta el momento la mayoría de los autores estudiosos del proceso, concluyen que el fin del acoso se produce, mayoritariamente, con la finalización de la relación laboral en la cual éste se ha desarrollado. La cultura del trabajo se ha ido fraguando y sufriendo cambios a lo largo de los años, así a día de hoy la noción del concepto de trabajo y el valor que se le asigna al mismo, son una construcción social, resultante de las tensiones y los equilibrios entre el trabajador y las organizaciones empresariales, que se van modificando en base a las relaciones laborales y económicas predominantes en el momento histórico. La creencia de que la empresa, debería ser una comunidad de intereses entre los accionistas empresarios, la dirección de la misma y los empleados, supone en sí misma la existencia de un conflicto de intereses contravenidos, en el cual la capacidad en la gestión de las partes y los recursos existentes, junto con la necesidad de entenderse mediante el diálogo conforman el ideal de la cultura del trabajo. 


\section{CAPÍTULO IX. DISCUSIÓN FINAL Y CONCLUSIONES.}

Parece así haber llegado el momento en el que el único protagonista es el capital financiero; hoy en día todo lo demás es considerado como secundario, parece preocupar más el generar más dinero, la busca de la mayor rentabilidad posible, la obtención de maximizar el beneficio cortoplacista, etc....La gravedad de las condiciones laborales es tal para muchos, que se olvida que el trabajo ha de llevarse a cabo en condiciones de libertad, equidad, seguridad laboral y dignidad humana, lo que no excusa de que existan normas y convenios que se han de cumplir rigurosamente. De esta manera está desapareciendo la fidelidad por la empresa y apareciendo el sentimiento de que cualquier práctica es válida si reporta dinero, desapareciendo así día a día la ética social predominante. Se incorpora un nuevo pensamiento social, considerando que estas condiciones tediosas que imperan hoy en día en numerosas empresas "son normales", violentando rotundamente la manera de contemplar el ámbito laboral.

De lo analizado en esta investigación, se puede concluir que en este ámbito, el socio sanitario, predominan la arrogancia y el cinismo, incluso llegándose a convertir en un modelo directivo a seguir por los grandes ejecutivos que imperan en los grupos empresariales que ostentan los diferentes centros, y que presumen incluso, en muchos casos de ser modelos en gestión, ante los diferentes agentes sociales y actores de relevancia social y política de las diferentes comunidades en los que se encuentran ubicados, para regocijo de los propios gerentes que ven "reconocimiento" a su modelo de gestión, nada más lejos de la realidad.

Dicho lo cual, parece una obviedad resaltar como todo ello genera exclusión, desesperanza, sufrimiento, deslealtad, avaricia, competitividad negativa, desilusión, apatía, decaimiento, falta de interés, desmotivación, haciendo que los individuos que lo padecen estén condenados a adaptarse o salir del mercado laboral. 


\section{CAPÍTULO IX. DISCUSIÓN FINAL Y CONCLUSIONES.}

En cuanto a las limitaciones del estudio se refiere debemos mencionar como existe un número importante de aspectos que limitan las contribuciones de las que nos hemos hecho eco en este trabajo de investigación. Una primera fuente de limitaciones procede a que todos los participantes que tomaron parte en la muestra de estudio se encuentran a día de hoy en activo en puestos directivos de centros residenciales, eso sin lugar a duda sesga la muestra, puesto que existe cierto miedo y reticencia a opinar sobre los superiores más inmediatos, los cuales aún hoy lo son. La segunda fuente de la que podemos tomar nota es que todos los datos se han obtenido mediante cuestionario personal rellenado de manera personal por cada uno de los participantes, de tal manera, que quizá en futuras investigaciones deberían diseñarse los métodos que recojan la información de más fuentes de la misma, tales como subdirectores, supervisores, etc... Una tercera limitación es la concerniente a los diferentes constructos incluidos en la matriz meta analítica definitiva lo que puede dar lugar a diferentes interpretaciones a la hora de realizar el estudio. Por último, como cuarta limitación existente, podemos hablar de la imposibilidad de efectuar análisis sobre un abanico más amplio de potenciales variables moderadoras, debido en gran medida a la ausencia de información en los estudios primarios que se llevaron a cabo.

En resumen, esta revisión realizada a lo largo de la tesis, pretende ser lo más integradora posible en el fenómeno de acoso en puestos directivos de centros residenciales, ayudando a reconocer así ciertas inconsistencias relativas halladas en el acoso laboral, tratando de organizar el conocimiento disponible y poner de relieve las importantes consecuencias que como hemos descrito tiene para las personas, las organizaciones y la sociedad en su conjunto.

Así a dia de hoy el acoso psicológico en el trabajo o mobbing, está considerado como uno de los estresores sociales más importantes de la vida laboral actual (Hoel, Rayner \& Cooper, 1999). Parece entonces existir una cultura organizativa permisiva 


\section{CAPÍTULO IX. DISCUSIÓN FINAL Y CONCLUSIONES.}

dentro de este sector socio sanitario, en el cual prevalecen la intimidación y el acoso psicológico al considerarlos como algo natural en el medio laboral. A estos riesgos hay que añadir los de naturaleza psicosocial como son las jornadas laborales por encima incluso de lo permitido legalmente, las dificultades para conciliar la vida laboral y familiar o la carga excesiva de trabajo y la falta de tiempo.

Todos estos factores de riesgo, provocan un empobrecimiento del clima laboral, proporcionando además un terreno fértil para los conflictos y la agresión. Esta idea ha sido defendida por varios autores al comprobar que existe una relación directa entre la presencia de acoso laboral en la organización y los factores psicosociales mencionados. En los estudios meta analíticos de Bowling y Beehr (2006) y de Topa, Depolo y Morales (2007), se realiza un repaso de los principales factores psicosociales relacionados con la presencia de mobbing en las organizaciones; ambos estudios señalan como principales predictores organizacionales de las conductas acosadoras: 1) el conflicto y la ambigüedad de rol, 2)el exceso de demandas laborales, 3)el grado de autonomía en el trabajo y 4)el apoyo social.

Parece pertinente finalizar esta investigación realizando algunas menciones especiales a algunos aspectos que creo pueden considerarse como pequeñas aportaciones, no obstante plantear esta serie de propuestas para la resolución de un fenómeno que tiene que ver con la estructura de la sociedad, es tremendamente complicado, a pesar de lo cual intentaré apuntar algunas sugerencias personales:

$>$ Fomentar el compañerismo.

$>$ Reconocer la aportación de los otros y darle un valor positivo.

$>$ Evitar el descrédito y la ridiculización de los demás.

$>$ Colaborar en todo aquello en lo que consideremos se pueda mejorar.

$>$ Crear un tejido social sólido, que fortalezca y maximice las tareas diarias.

$>$ Premiar el esfuerzo, en confrontación con el éxito fácil. 


\section{CAPÍTULO IX. DISCUSIÓN FINAL Y CONCLUSIONES.}

Recuperar el diálogo y el consenso como medio para el entendimiento, en detrimento de la agresión.

$>$ Transmitir estabilidad y respeto, evitando transgredir las leyes vigentes de empleabilidad.

$>$ Creer en el compromiso, la confianza y la lealtad de los subordinados.

> Premiar la cooperación, la integración y el interés por el otro.

Administrar equitativamente los recursos de los que se dispongan.

$>$ Castigar la arrogancia y la mediocridad inoperativa.

Fomentar la ilusión, la motivación y el trabajo en equipo.

> Hacer partícipe a los trabajadores de los resultados obtenidos.

$>$ Luchar contra la irresponsabilidad y la falta de actitud.

> Mostrarse receptivo a posibles mejoras y/o sugerencias.

$>$ Conocer las fortalezas y debilidades de los trabajadores.

$>$ Considerar las diferentes valoraciones en la toma de decisiones.

$>$ Razonar las decisiones, no utilizar como único argumento el puesto ostentado en la organización.

- Utilizar el conocimiento y la experiencia como medio para facilitar el desarrollo profesional del resto de subordinados, ya que el crecimiento de los mismos será la muestra inequívoca de su valía.

Buscar canales de comunicación que faciliten la comunicación con todos y cada uno de los trabajadores, mostrando interés por los mismos.

$>$ No utilizar las amenazas de sanciones como el medio para lograr el cumplimiento de las tareas.

> Facilitar el desarrollo de programas formativos que le puedan demandar, tendentes a mejorar aspectos concretos de los trabajadores, así como las habilidades sociales y de comunicación.

$>$ Fomentar entre los mandos directivos y medios estilos de dirección que promuevan el crecimiento y la autonomía laboral. 


\section{CAPÍTULO IX. DISCUSIÓN FINAL Y CONCLUSIONES.}

En cuanto al clima organizacional se refiere:

- Desarrollar y difundir por escrito, procedimientos y protocolos para la resolución de conflictos, asegurándose de que sean conocidos por todos.

- Realizar una buena planificación de las tareas, especificando claramente qué personas o áreas son responsables de su realización y de su supervisión.

- Promover procedimientos y conductas para la socialización y acogida de nuevos miembros.

- Tratar de evitar el bloqueo de la información, de tal manera que esta pueda llegar de manera clara y concisa.

- Facilitar el apoyo incondicional entre los diferentes departamentos que componen el centro residencial.

- Valorar públicamente y en las reuniones de equipo la importancia y el esfuerzo realizado dentro de cada área, que tienen para la organización.

- Proporcionar espacios para intentar aprender de los errores cometidos.

- Entrenar a los diferentes mandos y directores de área, o jefes de departamento para que favorezcan las relaciones de apoyo y diseñen acciones comunes.

- Favorecer espacios comunes que permitan la total integración de los nuevos miembros que se puedan ir incorporando a los diferentes departamentos.

- Ofrecer ayuda a aquellas personas con problemas personales, no agravando así la situación que puedan estar viviendo, de tal manera que sientan que les están brindando apoyo.

- Tratar de reducir las murmuraciones y fomentar las quejas de manera formal y constructiva. 


\section{CAPÍTULO IX. DISCUSIÓN FINAL Y CONCLUSIONES.}

- Resaltar la existencia de objetivos y metas comunes.

- Fomentar la existencia de indicadores de desempeño grupal, cohesionando al grupo

- Proporcionar espacios de encuentro adecuados para facilitar el acercamiento afectivo entre los miembros de los diferentes equipos y secciones.

- Desarrollar programas y protocolos con el fin de la detección temprana de conflictos personales que permitan su eliminación en sus primeras etapas de desarrollo.

- Diseñar y difundir por escrito protocolos de actuación entre los diferentes mandos que componen el organigrama ejecutivo del centro, para realizar el óptimo seguimiento de la gestión.

- Utilizar la mediación como estrategia para la resolución de los conflictos, siguiendo procedimientos sencillos para acceder a la misma.

- Llevar a cabo programas de acogida para los nuevos miembros, para asegurarse que se re reduzcan los malentendidos sobre los procesos de trabajo o en la interpretación de las normas internas.

- Analizar las conductas problema con la otra persona para encontrar una solución satisfactoria para ambos.

- Intentar satisfacer las expectativas del otro conociendo en profundidad la normativa vigente.

- No juzgar la información facilitada sin tener toda aquella que se pueda necesitar.

- No tratar de esconder los propios intereses como vía de satisfacerlos de manera satisfactoria.

- No hacer concesiones ni satisfacer los deseos de algún trabajador sin tener en cuenta los intereses comunes. 


\section{CAPÍTULO IX. DISCUSIÓN FINAL Y CONCLUSIONES.}

- No tomar decisiones para fomentar la propia autoestima o la de algún subordinado en particular.

- Evitar actuar como si la opinión de la otra parte tuviera más importancia que la propia, tomado las partes como iguales.

- Intentar negociar acuerdos intermedios, de tal manera que se minimicen los perjuicios para ambas partes.

- Proponer cambios consensuados para desbloquear los posibles desacuerdos.

- Buscar que todas las partes alcancen al menos parcialmente sus objetivos.

- No imponer a la otra parte su propia visión de la situación y de los hechos acontecidos.

- Utilizar de manera adecuada los diversos medios con el fin de favorecer los intereses de todos los trabajadores.

- Prestar atención a todas las opiniones que se emitan aunque estas no coincidan con los intereses que se defiendan.

- Intentar evitar los enfrentamientos

Así, dada la especial sensibilidad y las limitaciones que tiene el estudio del mobbing en puestos directivos de centros residenciales a problemas de distorsión en la respuesta (sinceridad, deseabilidad social o ausencia de respuesta entre otros) se ha diseñado un estudio cuantitativo transversal centrado en el sector socio sanitario, que a priori posee unas características óptimas para su análisis, arrojando los resultados del estudio de la muestra las características que se mencionan a continuación. 


\section{CAPÍTULO IX. DISCUSIÓN FINAL Y CONCLUSIONES.}

\subsection{Conclusiones obtenidas en la Muestra de Estudio.}

En este apartado se pretende aportar los resultados obtenidos en el estudio desarrollado de tal manera que den una respuesta concreta a los diferentes objetivos e hipótesis propuestos y enunciados en esta tesis doctoral. Para ello, se analizaran las características básicas de las situaciones manifiestas en la muestra de estudio analizada, atendiendo así al estudio de las distintas variables de interés estudiadas. Antes de comenzar a describir las conclusiones obtenidas, debemos de señalar que las cifras obtenidas resultan perfectamente compatibles con las obtenidas en otros estudios desarrollados tanto a nivel nacional como internaciones referentes al estudio del acoso laboral en ámbitos similares, donde los datos obtenidos abarcan un amplio rango (Lewis, 2004).

Atendiendo a la operativización del concepto y a los diferentes criterios ya señalados a lo largo de esta investigación prevalecen los siguientes resultados, y por tanto las conclusiones que a continuación se señalan:

1) En cuanto a la primera variable considerada como antecedente, estudiada "Ia edad", el objetivo planteado era "examinar si la edad es un elemento determinante a la hora de sufrir acoso laboral en puestos directivos", planteado en la hipótesis "cuanto menor es la edad del directivo, mayor acoso laboral se produce", la conclusión a la que se llega es que la edad no es un elemento determinante para sufrir acoso laboral ocupando puestos directivos de centros residenciales, ya que la correlación obtenida no ha sido significativa en la percepción del acoso. Debe destacarse que hasta recientemente los estudios llevados a cabo en nuestro país habían señalado a los menores de treinta años como principal grupo de edad señalado ante el fenómeno del mobbing (Piñuel, 2001). 


\section{CAPÍTULO IX. DISCUSIÓN FINAL Y CONCLUSIONES.}

2) La segunda variable considerada como antecedente, estudiada ha sido "el sexo del directivo", derivada del objetivo formulado como "diagnosticar si existe relación alguna entre el sexo del sujeto y la aparición de acoso laboral" propuesto en la hipótesis "el sexo del directivo promueve la aparición del acoso laboral", llegando a la conclusión de que no existen diferencias significativas entre el grupo de hombres y mujeres en la probabilidad de sufrir acoso laboral en puestos directivos de centros residenciales. Por tanto podemos afirmar que el sexo del sujeto no se puede considerar como un predictor del acoso laboral.

3) Como tercera variable considerada igualmente como antecedente, hemos estudiado "el estilo de liderazgo" empresarial, propuesta en el objetivo "identificar si el estilo de liderazgo es un factor que pueda influir positivamente en el acoso laboral", plasmado en la hipótesis "cuanto menor sea el liderazgo, mayor es el acoso laboral que se produce", de lo que podemos concluir que no es significativo el estilo de liderazgo empresarial en la aparición del acoso laboral en puestos directivos de centros residenciales. Afirmaremos así que el estilo de liderazgo en una empresa sociosanitaria no es un elemento indicativo de la aparición del acoso laboral.

4) El cuarto factor estudiado como variable, definida además como antecedente en el estudio propuesto son "Ias competencias de los sujetos en el sector", señalada en el objetivo "constatar como aquellos directivos con menores competencias en el sector sociosanitario sufren un mayor acoso laboral", representado en la hipótesis "cuantas menos competencias se tengan en el sector mayor será la probabilidad de sufrir acoso", la conclusión a la que se llega en este caso al igual que en la variable anterior es que no existe una 


\section{CAPÍTULO IX. DISCUSIÓN FINAL Y CONCLUSIONES.}

relación significativa en la percepción del directivo entre poder sufrir acoso laboral y poseer competencias adquiridas con anterioridad en el sector, por lo que no puede considerar como tal un antecedente inmediato del acoso laboral en puestos directivos de centros.

5) Referente a la quinta variable reflejada como antecedente "la ambigüedad de rol observada", definida en el objetivo "inferir si la ambigüedad de rol puede considerarse como una de las causas del surgir del acoso" bajo la hipótesis enunciada "cuanto menor sea la ambigüedad de rol, menor acoso se producirá", concluiremos que no es significativa la correlación existente con la percepción del acoso laboral, por tanto afirmaremos que la ambigüedad de rol tampoco puede considerarse como un indicador previo a la aparición del acoso laboral.

6) La siguiente variable estudiada como antecedente es la llamada "justicia organizacional", tomada del objetivo "considerar si la justicia organizacional puede ser un factor desencadenante del acoso", bajo la hipótesis "a menor justicia organizacional, mayor acoso laboral", concluyendo que no es significativa la relación entre la justicia organizacional observada y la percepción de la aparición del acoso laboral. Por tanto se considera que aquellos sujetos que detectan menor justicia organizacional no presentan mayor acoso laboral.

7) La séptima variable representada como antecedente son los considerados "resultados económico - financieros de la empresa", tomados en consideración en el objetivo "establecer si puede existir una relación directa entre los resultados económico - financieros de la empresa y el acoso laboral", dada en la hipótesis "a menor resultado económico, mayor acoso laboral se produce", tras lo cual podemos concluir de los resultados que arroja la 


\section{CAPÍTULO IX. DISCUSIÓN FINAL Y CONCLUSIONES.}

investigación que no es significativa la correlación existente entre este parámetro y la percepción del acoso laboral, por lo que los resultados económicos no serían un indicador clave en la aparición del acoso laboral en puestos directivos de centros residenciales.

8) Como octava variable tomada como antecedente en el estudio se ha considerado "el grado de autonomía laboral" del directivo, derivada del objetivo nombrado "confrontar como, cuanto mayor es el grado de autonomía laboral del que dispone el directivo del centro residencial, menor es el grado de acoso laboral", representado en la hipótesis "cuanto menor es el grado de autonomía laboral, mayor es el acoso laboral" , respecto a lo que concluimos que es significativa la correlación entre esta variable y la percepción y surgimiento del acoso laboral. Así se corrobora que aquellos sujetos que presentan menor grado de autonomía laboral son los que presentan mayor acoso laboral.

9) La primera variable considerada como consecuente en este estudio es "el grado de satisfacción laboral de los sujetos", derivada del objetivo "determinar si el acoso laboral tiene menor incidencia en aquellos directivos que experimentan una mayor satisfacción laboral" formulado en la hipótesis "a mayor acoso laboral, menor satisfacción laboral" llegando a la conclusión de que si es significativa la correlación entre esta variable y la percepción del acoso. Así es relevante decir que se corrobora la hipótesis, de tal manera que a mayor acoso laboral, menor satisfacción laboral se experimentará.

Esto es sin duda una conclusión notable, puesto que desde algunas de las teorías de la ergonomía laboral se toma esta hipótesis como punto de partida en el estudio de las variables psicosociales intervinientes en el puesto de trabajo. 


\section{CAPÍTULO IX. DISCUSIÓN FINAL Y CONCLUSIONES.}

10) La segunda variable analizada como consecuente del acoso laboral es la "intención de abandono" del puesto de trabajo y consecuentemente de la empresa, representada en el objetivo "confirmar como el directivo acosado no tiene ninguna intención previa de abandonar su puesto de trabajo", enunciada en la hipótesis "a mayor acoso laboral, mayor intención de abandono", ha sido eliminada de la investigación ya que se ha estimado un Alfa poco significativo para tomarlo como parte de esta investigación empírica. Con esta decisión toma aún más validez la fiabilidad de esta tesis y el rigor con el que se ha elaborado.

11) La siguiente variable a estudio ha sido el tan llamado "rendimiento laboral", proveniente del objetivo "verificar la relación existente entre el rendimiento y el acoso laboral en puestos directivos de centros residenciales", plasmado en la hipótesis "a mayor acoso laboral, menor rendimiento", de lo que podemos concluir tras el análisis realizado, que la relación entre el rendimiento y el acoso laboral es significativa, deduciendo por tanto que efectivamente $\boldsymbol{a}$ mayor acoso laboral, menor rendimiento existe del directivo del centro. Es una conclusión de suma relevancia en la actualidad, ya que la mayor parte de las organizaciones y empresas buscan el mayor beneficio empresarial con los menores costes posibles.

Como resaltamos en capítulos anteriores el acoso laboral, hace que aumenten los costes para la empresa, de tal manera que la hará menos productiva; debemos resaltar además la importancia de la función directiva en un centro residencial, ya que desde este departamento se regula todo el funcionamiento interno del centro. 


\section{CAPÍTULO IX. DISCUSIÓN FINAL Y CONCLUSIONES.}

12) La décimo segunda variable a estudio considerada como consecuente es el "compromiso con la organización" que viene dada del objetivo "mostrar como la existencia de un mayor compromiso del directivo con la organización en la que desempeña su actividad laboral no es sinónimo de no ser objeto de acoso laboral", definido en la hipótesis "a mayor acoso laboral, menor compromiso con la organización", de lo que podemos concluir que la correlación obtenida entre esta variable y el acoso laboral no ha sido significativa, lo cual implica que el compromiso con la organización no está ligado con la posible aparición del acoso laboral en puestos directivos de centros residenciales. Algunos estudiosos, relacionan más el compromiso con la organización con el sueldo percibido, lo cual hace que estadísticamente la muestra pueda aproximarse a estas características percibidas.

13) La penúltima variable analizada como consecuente en esta tesis doctoral es el tan estudiado "clima organizacional", derivado del objetivo enunciado como "corroborar como un clima organizacional positivo hace que se reduzca el número de casos de acoso laboral en puestos directivos de centros residenciales", representado además en la hipótesis "a mayor acoso laboral, peor clima organizacional", de la cual concluimos que si existe una correlación significativa entre el clima organizacional y la percepción del acoso laboral, corroborándose por tanto, que a mayor acoso laboral, peor clima laboral existirá en el centro sociosanitario.

Esta variable es una de las más estudiadas en el ámbito de la psicología del trabajo y de las organizaciones, puesto que tradicionalmente se ha considerado que un clima laboral y organizacional adecuado, hace que aumente el éxito en el desempeño de las tareas, lo cual supondrá además un mayor bienestar laboral para el trabajador. 


\section{CAPÍTULO IX. DISCUSIÓN FINAL Y CONCLUSIONES.}

14) La última variable estudiada como consecuente en esta tesis es "la finalización de las tareas de los sujetos", representada en el objetivo "analizar como el acoso laboral incide directamente en la finalización de las tareas en la dirección de un centro residencial", relatada en la hipótesis "a mayor acoso laboral, menor finalización de las tareas", concluyendo que la correlación existente ha sido significativa entre la variable estudiada y la percepción del acoso, por lo que se corrobora que a mayor acoso laboral, menor finalización de las tareas existe.

Lógicamente la mayor parte de los sujetos evaluados no muestran acoso laboral, puesto que trabajamos con poblaciones no patológicas, por lo que antes de comprobar el supuesto de normalidad se ha llevado a cabo la transformación algorítmica de los datos. Después de este proceso, comprobamos que los datos se ajustan a la normalidad.

A modo de resumen podemos concluir que las variables enumeradas como antecedentes de acoso en la muestra de estudio que han correlacionado positivamente han sido la justicia organizacional y el grado de autonomía laboral, mientras que en lo referente a los consecuentes debemos de indicar como tales el grado de satisfacción laboral, el rendimiento laboral, el clima organizacional y la finalización de las tareas de los directivos. Ello como explicamos en líneas anteriores puede deberse a la actual situación laboral y a la dificultad de desempeñar funciones directivas en el ámbito sociolaboral y más concretamente en los centros de las citadas características estudiados en esta tesis doctoral.

A continuación hablaremos de las características de los perfiles de las víctimas del acoso laboral. 


\section{CAPÍTULO IX. DISCUSIÓN FINAL Y CONCLUSIONES.}

\subsection{Características de los Perfiles Victimológicos.}

Cuando hablamos de perfiles victimológicos estamos haciendo referencia al estudio de las causas por las que determinadas personas son más propensas a ser víctimas de acoso laboral y de cómo el estilo de vida que tienen puede conllevar a una mayor probabilidad de que una persona sea víctima del mismo. La propia victimología incluye o puede incluir un gran número de áreas bien diferenciadas, de las cuales nos intentaremos hacer eco en las siguientes líneas. Por tanto cuando se hace referencia al perfil de la víctima de acoso, se está tratando hacer un estudio científico a la víctima y su papel en el hecho del propio acoso, partiendo de un punto de vista puramente epistemológico y analizando las diferentes causas por las que un sujeto o grupo de sujetos son más o menos susceptibles de resultar afectados.

El estudio del perfil de la persona acosada no se limita únicamente al estudio de la misma, sino que deben analizarse al menos tres niveles: el primero que podíamos nombrar es el individual, cuyo objeto de estudio es la personalidad de la víctima, sus características psicológicas predominantes, el segundo nivel es un nivel conductual, en el cual se estudia el comportamiento de la víctima con relación al resto y finalmente tendremos un tercer nivel denominado general, en el que se estudia el fenómeno como suma de las victimizaciones secundarias.

A partir de la década de los ochenta del siglo XX, y como consecuencia de los simposios mundiales de victimología, la naciente disciplina se emancipa del mero énfasis penal, y comienza a abogar por los derechos de las denominadas víctimas desde una perspectiva constitucional. En España, encontramos en los últimos veinte años a muchos tratadistas de derecho penal que han orientado sus estudios hacia las víctimas. Algunos de ellos son Elena Larrauri, Manuel Cancio Meliá, Jaime Peris Riera, etc.... En Latinoamérica también en estos últimos años, han surgido estudiosos que dedican una parte de sus temas a la víctima, entre los cuales podemos destacar a Juan Bustos Ramírez o Elías Neuman, entre otros. 


\section{CAPÍTULO IX. DISCUSIÓN FINAL Y CONCLUSIONES.}

Con todo ello, la pregunta que todo investigador de esta materia se hace es si verdaderamente existe un perfil victimológico claramente definido. Esta misma pregunta se hicieron en el año 2007 Glasö, Matthiesen, Nielsen y Einarsen. Para ello compararon a un grupo de personas que habían sufrido acoso laboral con otras que nunca habían sido sometidas a ese sufrimiento. Entre los resultados obtenidos encontraron que:

$>$ Existe una diferencia significativa en la inestabilidad emocional del grupo de víctimas, mostrando mayor tendencia a la ansiedad, neurosis y siendo más fácilmente alterables.

> Las víctimas eran más desorganizadas e independientes que el grupo control.

$>$ Los resultados mostraron mayor introversión en las víctimas que en el grupo control.

> Las víctimas mostraban una clara tendencia a resultar menos diplomáticas que el grupo control.

$>$ Curiosamente, y aunque no se trate de una diferencia que permita establecer una correlación, las víctimas mostraron mejores resultados en lo que a inteligencia se refiere.

De todos estos aspectos congrueron por el grado de significatividad, que tan solo el primero de ellos podía considerarse relevante. Así mismo, partiendo de tesis previas, los autores del estudio realizaron una submuestra en la que revisaban si existía una diferencia de perfiles victimológicos, así llegaron a encontrar la existencia de dos perfiles de víctimas diferentes, en el primero de ellos se mostraba menor diferencia de personalidad con el grupo control, mientras que en el segundo existían diferencias significativas en todos los rasgos anteriormente mencionados, resultando un perfil de persona introvertida e inestable emocionalmente. Así los autores concluyeron que no existía un perfil victimológico en las personas que han sufrido acoso laboral; para ello tuvieron en cuenta un aspecto determinante que pudo generar un sesgo dentro del 


\section{CAPÍTULO IX. DISCUSIÓN FINAL Y CONCLUSIONES.}

estudio: el haber sido víctima de acoso laboral puede haber llegado a generar secuelas psicológicas. Hoy en día, podemos afirmar con rotundidad que cualquier persona es susceptible de acabar sufriendo acoso laboral, por lo que no hay un perfil victimológico claro de la víctima. Al contrario de lo que muchos piensas e incluso algunos postulan en algunas lecturas, la persona acosada no suele serlo por presentar deficiencias a nivel personal o profesional que le hagan ser rechazado, es decir cuando alguien acosa a una persona o conjunto de personas, no lo hace porque ésta o éstas sean incompetentes o hagan mal su trabajo o porque no sepa trabajar en equipo y cree un mal clima laboral, sino que esto tan solo son algunas de las excusas que expone el hostigador para justificar sus ataques, ya que la realidad es muy diferente a todo esto.

A pesar de que no exista un perfil victimológico definido si podemos enumerar algunas de las características que se repiten entre quienes sufren y han sufrido este fenómeno en primera persona, que en su gran mayoría suelen ser envidiadas por su acosador bien sea por sus características físicas, psicológicas o sociales, o por ambas en su conjunto. Tal es así que estas personas suelen ser sujetos con unos valores éticos muy elevados, gran rigor profesional, con una elevada capacidad para empatizar con los demás, sensibilidad para el trato, con gran capacidad de sacrificio y esfuerzo en los diferentes ámbitos de su vida, con una actitud laboral muy positiva y creatividad, a menudo muy valorados por el resto de compañeros en su puesto de trabajo, tanto es así que esta valía puede ser interpretada por el acosador como un peligro para sus propios objetivos y su status laboral, lo que desata el acoso más inmediato e intenso. En algunos casos las víctimas pueden ser personas que se han negado a participar o callar ante situaciones laborales poco éticas, que desgraciadamente se producen con demasiada frecuencia en nuestro país. Una característica a tener muy en cuenta a la hora de hablar del perfil victimológico, ha de ser la vulnerabilidad; cuanto más vulnerable perciba el acosador que es su futura víctima, mayores posibilidades tendrá de serlo. 


\section{CAPÍTULO IX. DISCUSIÓN FINAL Y CONCLUSIONES.}

Por ello se ataca con más frecuencia a las personas jóvenes que a las adultas, a los trabajadores denominados temporales antes que a los indefinidos, a los inmigrantes antes que a los del lugar, a las mujeres antes que a los hombres... de tal manera que cuantas menos posibilidades tenga la víctima de enfrentarse a la situación o escapar de ella, más posibilidades y con mayor fuerza se sentirá el posible acosador. Es importante señalar que el hostigador siempre evitará a las personas que puedan suponer algún riesgo o peligro para él, como podrían ser las personas narcisistas, ya que son demasiado similares a él como para enfrentarse a ellas.

En la mayoría de lecturas que podemos realizar hoy en día sobre acoso psicológico en el puesto de trabajo, encontramos un enfoque basado en el perfil del acosador o que parte desde la propia definición del fenómeno, algo erróneo a nuestro juicio y parecer puesto que todo acoso siempre tiene como punto de partida el perfil de la víctima. La mayor parte de los investigadores de la temática siempre se han preguntado si las víctimas podrían ser personas débiles o si a las personas tomadas como fuertes y valientes también podrían sufrirlo, etc....

Más allá de estos rasgos que podríamos llamar "positivos" que hemos definido y de la vulnerabilidad percibida por el agresor, que suelen ser la puerta de entrada al acoso, en este perfil hay otro factor determinante que es la llamada permisividad. Las víctimas cuanto acontecen los hechos de acoso, suelen negarse a "plantar cara" al acosador, tienen la creencia que es un hecho aislado, puntual y que no perdurará en el tiempo, llegando a pensar que la situación pasará a sí sola a ser tan sólo una mala experiencia, nada más lejos de la realidad. Una vez avistado que esto no es así, el acosado como hemos visto en capítulos anteriores, comienza a preguntarse por qué esto tiene que estarle pasando a él, y duda en muchas ocasiones de que el problema no lo esté generando él mismo, de ello deriva su silencio, su miedo a contárselo a sus amigos, familia y más allegados, sienten culpabilidad y se hacen preguntas interiores tales cómo ¿qué he hecho yo para merecer esto?, ¿qué estoy haciendo mal para que 


\section{CAPÍTULO IX. DISCUSIÓN FINAL Y CONCLUSIONES.}

me este ocurriendo algo así a mí?, ¿qué he podido hacer para que me digan todo esto?...piensan así que es algo de lo que no se debe enterar nadie, creerán que es un simple enfado "que ya se pasará", intentarán hacer aún mejor si cabe su trabajo de tal manera cree la víctima, que siendo impecable es el mismo todo terminará, y si no fuera así ya pedirá la baja cuando "ya no pueda más". Desafortunadamente en la mayoría de las ocasiones el afectado comienza a darse cuenta de todo lo que está sucediendo cuando lo ocurrido es ya lo suficientemente grave. Convertirse así en acosado es relativamente fácil, tan solo es necesario colocar a una persona en situación inferior, acusarla de algo, hacerla sentir culpable y utilizar todo tipo de tramas, engaños y recelos para tratar de demostrarlo a toda costa.

El acoso laboral genera de esta manera grandes secuelas psicológicas como vimos en el capítulo correspondiente, que explican el porque es una experiencia traumática, y tan solo realizando una auténtica "autopsia psicológica" de cada víctima en particular podremos determinar algunas de las cuestiones por las que fue objeto de acoso, intentando así reconstruir una completa biografía del hostigador, que incluya los datos necesarios para reconocer algunos de los posibles motivos, que le llevaron a ejercer conductas de tal virulencia.

Seguidamente analizaremos las futuras líneas de actuación, que se deberían llevar a cabo en futuras investigaciones.

\subsection{Líneas Futuras de Investigación.}

Como hemos visto a lo largo de toda la investigación llevada a cabo en esta tesis doctoral, las futuras líneas de investigación han de ir encaminadas a la mejora de la salud y la seguridad de los trabajadores, intentando convencer a los empresarios y a los responsables de la toma de decisiones, de que mejorar las condiciones de trabajo es rentable, e incluso mostrándoles como puede llegar a reportar interesantes 


\section{CAPÍTULO IX. DISCUSIÓN FINAL Y CONCLUSIONES.}

beneficios económicos para sus empresas y la sociedad en su conjunto. Una manera eficaz de lograrlo es llevar a cabo estimaciones financieras o económicas, lo cual permitirá determinar los costos y los beneficios de la gestión de la salud de los trabajadores, siendo por tanto un instrumento útil para fomentar las prácticas correctas complementando además la acción preventiva, fundamental para evitar el acoso laboral.

En los últimos años se han desarrollado varias métodos e instrumentos para evaluar los costos y los beneficios de la salud laboral. Las diversas comparaciones realizadas hasta el momento en numerosas investigaciones, ponen de relieve como las variables organizacionales y sociales que delimitan la acción directiva, presentan grandes diferencias de índole fundamental a nivel de países y empresas, por consiguiente se deduce que los diferentes usuarios deberán elaborar su propio procedimiento de evaluación y concluir si es aplicable a su país y empresa, siendo este uno de los aspectos más discordantes entre los estudiosos.

Estimar el valor de la seguridad y la salud laboral en las empresas no debería ser una cuestión baladí ni únicamente restringida a grandes especialistas en la materia o economistas de prestigio, sino que conviene que todas las personas involucradas de manera directa o indirecta en la propia organización sean capaces de comprender la materia en lo que a estimaciones se refiere, y saber de la importancia que de ella se deriva, tanto para los trabajadores, como para la propia empresa y la sociedad en su conjunto. Por tanto es de obligado cumplimiento aclarar que la seguridad y la salud en el trabajo tienen claras repercusiones económicas; las enfermedades profesionales, (como se conciben las bajas motivadas por acoso laboral a día de hoy) suponen una mayor carga de trabajo para los trabajadores de la empresa, mientras que unas condiciones de trabajo óptimas incrementarán la productividad de los trabajadores y mejorarán la calidad de los bienes y servicios, si bien es verdad que a menudo los 


\section{CAPÍTULO IX. DISCUSIÓN FINAL Y CONCLUSIONES.}

empresarios desconocen los beneficios potenciales de una mayor gestión de la salud laboral, de hecho, estos difieren de unas situaciones a otras:

1) Los trabajadores más sanos son más productivos.

2) Menos bajas laborales suponen menos costes derivados para la empresa.

3) Con unos equipos y un clima organizacional adaptado a las necesidades del centro se logra mejorar la calidad de las relaciones humanas, la calidad del servicio y la reducción de riesgos.

4) Reducir las bajas, supone además menos daño psíquico para el trabajador y menor riesgo de reclamaciones de responsabilidades legales.

5) Supondrá además mejores oportunidades para formar al propio equipo de trabajo, de manera que se tengan más cohesionados a los integrantes del mismo, con el fin de ofrecer el servicio más especializado y personalizado posible.

6) El rendimiento incrementará paulatinamente hasta alcanzar un nivel inesperado en la planificación del año en curso.

7) El equipo del propio centro estará mejor adaptado a los procesos y criterios de trabajo establecidos por el empresario, lo que hará que aumente el nivel de conocimiento de los protocolos previamente establecidos por el grupo.

8) Mejorarán las habilidades de todos los miembros de cada departamento que conforman un centro residencial, de tal manera que se logre alcanzar una interdisciplinariedad muy positiva para el propio empresario.

Podemos así afirmar que existe una clara relación conceptual en términos generales entre la salud laboral y el rendimiento económico, aunque a veces sea difícil discernir la verdadera relación en términos cuantitativos y cualitativos. Por ello un análisis económico optimizado puede contribuir a encontrar información de mayor calidad para mejorar la toma de decisiones y conseguir además un entorno laboral más rentable que garantice el bienestar de los trabajadores. Con la importancia dada al 


\section{CAPÍTULO IX. DISCUSIÓN FINAL Y CONCLUSIONES.}

análisis económico en estas líneas, no se pretende en absoluto racionalizar la toma de decisiones sobre las condiciones de trabajo en forma de cifras frías y métodos rígidos, sino mostrar la incidencia que la misma tiene en la salud laboral de los directivos de los centros residenciales. La formación en materia de prevención no debe ser una cuestión menor, ya que junto con la salud de los trabajadores representan los valores sociales y humanos que a menudo, suelen ser muy difíciles de incorporar a los métodos formalizados en el ámbito empresarial.

Concretamente en el fenómeno que aborda esta tesis, la repercusión incide en numerosas aspectos tanto económicos como socio sanitarios: los accionistas del grupo empresarial obtienen menores beneficios de los que podrían llegar a obtener, su imagen como empresa se deteriora, debido a entre otras cosas, la posibilidad de ver el nombre de su organización en tribunales, los clientes, en el caso que nos ocupa, los ancianos, sufren las consecuencias de la falta de dirección del centro, ya que el personal del mismo carecerá de la motivación necesaria para desempeñar sus funciones de manera satisfactoria, el resto de empresas del sector también se verán afectadas pues ante un fenómeno de tales dimensiones se tiende a generalizar, los trabajadores del centro no tendrán las directrices para realizar su trabajo, o tendrán indicaciones contradictorias acerca del mismo, las familias de los trabajadores como hemos visto a lo largo de la investigación sufrirán las consecuencias de ver a su ser querido en estas circunstancias lo cual agravará aún más si cabe la situación vivenciada por ambos (familiares y trabajadores), los fondos públicos verán cómo debido a una praxis empresarial incorrecta el trabajador en la mayoría de los casos se verá despedido sin motivo justificado, lo cual hará que cobre el subsidio de desempleo, cuando debería de ser un trabajador activo, el sistema sanitario deberá atender así a los trabajadores afectados, tanto a los directivos que sufren el acoso, como a posibles subordinados que se vean afectados debido a las circunstancias en las que se ven inmersos, las compañías de seguros (mutuas) soportarán pagos debidos a las bajas laborales que se producen, y que se podrían evitar, los servicios de seguridad y salud 


\section{CAPÍTULO IX. DISCUSIÓN FINAL Y CONCLUSIONES.}

en el trabajo recibirán denuncias y quejas motivadas por el propio acoso, lo cual también se podría subsanar como el resto de incidencias que se ven afectadas por este fenómeno, que lejos de desaparecer cada día está más presente en las organizaciones.

Una vez matizados todos estos aspectos, las líneas futuras de investigación han de tener en cuenta que a la hora de mejorar las condiciones de trabajo, hay dos agentes clave; el trabajador y sobre todo la empresa. Esto parece una obviedad pero en la actualidad no es así; es responsabilidad del primero tener un comportamiento seguro, saludable y ejemplar acorde con lo que la empresa le demanda, por su parte, la empresa ha de ser la encargada de tomar decisiones sobre las políticas que regirán la misma y sobre los aspectos relacionados con la mejora de la seguridad y la salud de sus propios trabajadores; determinar qué personas o grupos de trabajo se benefician en unas mejores condiciones organizacionales es el primer paso para llevar a cabo una toma de decisiones correcta y encaminada hacia el éxito empresarial. No debemos olvidar que la toma de decisiones no es una actividad estrictamente racional ya que algunas de las decisiones que se toman lo son solo en parte, ya que con demasiada frecuencia las elecciones estratégicas de las empresas, se basan en información muy poco segura o en la visión de unos pocos, lo que a nivel operacional no es una estrategia muy exitosa. En cualquier caso parece que ningún empresario que se precie pueda persistir en tomar decisiones de una manera irracional o parcialmente racional, puesto que las consecuencias que de ello se deriva son claramente muy negativas.

En esencia, tristemente la mayoría de los empresarios del sector socio sanitario consideran únicamente como válido el análisis de costo-beneficio, ya que consideran que esto es predecir el futuro más inmediato, nada más lejos de la realidad, pues en realidad la mayoría de las decisiones que toman son inciertas. Ha de tenerse presente que el momento socio político que vive España hace que se tenga un escenario 


\section{CAPÍTULO IX. DISCUSIÓN FINAL Y CONCLUSIONES.}

verdaderamente incierto surgiendo así entre los empresarios del sector una gran incertidumbre acerca de la evolución del mismo.

Así pues, para la mayoría de las organizaciones, la referencia última en términos de rendimiento de la empresa es el balance financiero, incluso las organizaciones sin ánimo de lucro deben llegar al umbral de rentabilidad. Recientemente avances en la evaluación del rendimiento empresarial dejan claro que la salud laboral contribuye al éxito de una empresa de muchas maneras; en análisis de los costos y los beneficios financieros son necesarios pero ofrecen a este respecto una perspectiva demasiado limitada. No debemos olvidar que las visiones empresariales y los objetivos difieren enormemente de unas empresas a otras, por lo que cada organización debe definir sus propios indicadores y determinar en su caso concreto cómo contribuyen la seguridad y la salud en el trabajo a cada uno de ellos.

En la actualidad numerosos estudios ponen de manifiesto como el dolor, el sufrimiento, y las innumerables secuelas del acoso laboral son consideradas por el gremio empresarial como costos intangibles. Por el contrario son tomados como costos directos la menor productividad y la disminución de la eficacia y eficiencia. Los costos que denominan psicosociales pasan a ocupar un lugar secundario en lo que ellos denominan su plan estratégico de viabilidad empresarial, el cual debería englobar todos los aspectos y acercar tanto al empresario, como al conjunto de los trabajadores al éxito de la empresa.

Con todo ello, podemos afirmar que las decisiones relativas a las condiciones de trabajo afectarán a los intereses de muchas personas o grupos, por lo que la investigación de las posibles partes implicadas será un aspecto fundamental y no una cuestión baladí, en los próximos años. Con todo lo anteriormente planteado podríamos: 


\section{CAPÍTULO IX. DISCUSIÓN FINAL Y CONCLUSIONES.}

1) Referente al empresario: optimizar el rendimiento de la empresa, mejorando la imagen de la misma.

2) Referente a los diferentes departamentos que componen un centro residencial: mejorar la eficacia de cada departamento individualmente y de manera colectiva, facilitando sus actividades diarias.

3) Referente a los propios trabajadores y sus familias: contribuir a la salud laboral plena, sintiéndose más seguros y ofreciéndoles una mayor estabilidad laboral y económica.

4) Referente a los comités de empresa y sindicatos: limitar su actuación debido a la inexistencia de fenómenos relevantes.

5) Referente a los clientes (ancianos) y sus familiares: ofrecerles un servicio de mayor calidad a menor precio y con mayores servicios de los existentes hasta la actualidad.

6) Referente a los organismos denominados en el sector reguladores, la inspección de trabajo: llevar a cabo de manera exitosa el cumplimiento de las normas, y conseguir el objetivo planteado por este organismo, que no es otro más que la protección del trabajador como fin social.

7) Referentes a los fondos públicos: obtener una reducción de daños, limitando así los pagos por compensaciones y garantizar la mejora de la salud y la seguridad en el trabajo.

8) Referente a las compañías de seguros, conocidas como mutuas: disminución de los daños y las responsabilidades legales de la organización, ajustando así las primas al riesgo psicosocial existente en cada puesto de trabajo, recogido en el plan de perfil de puesto de trabajo.

Por tanto las líneas de actuación futuras encaminadas al estudio e investigación de las variables organizacionales y sociales del acoso laboral en puestos directivos de centros residenciales podrían centrarse en: 


\section{CAPÍTULO IX. DISCUSIÓN FINAL Y CONCLUSIONES.}

1-Tomar como muestra de estudio no solo centros del territorio español como es el caso del estudio llevado a cabo, sino ampliar la investigación al ámbito internacional, recogiendo así la opinión de diferentes directivos del exterior de nuestras fronteras. Esto implicaría el condicionamiento necesario de tener en cuenta además a la hora de evaluar los resultados obtenidos, el modelo económico y de servicios sociales imperante en el país en el que se tomara la muestra, y realizar la comparativa correspondiente con el resto de naciones que formaran parte del estudio, con el fin de evitar agravios banales, y de ponderar las condiciones laborales en su justa medida, no emitiendo así conclusiones sesgadas o con disparidad de criterios.

2-Centrar el estudio no solo en los directivos de los centros residenciales sino en todos los empleados que conforman la plantilla de un centro residencial véase, subdirector/a, recepcionista, médico, enfermero/a, terapeuta ocupacional, fisioterapeuta, gerocultores, auxiliar de farmacia, personal de limpieza, cocinera/o, pinche de cocina, supervisor/a, personal de mantenimiento, trabajador/a social, auxiliar administrativo, conductor/a, psicólogo/a ,coordinadores de equipo, o cualquier personal no cualificado que forme parte del centro. Con ello se contribuiría a obtener datos más heterogéneos, ampliar el universo de estudio, tener una mayor perspectiva del fenómeno, confrontar los diferentes resultados obtenidos desde diferentes líneas de cualificación profesional, contrastar el funcionamiento de los diferentes departamentos que componen un centro residencial, estudiar las diferencias intergeneracionales entre los trabajadores que seguramente coexistieran, delimitar aún más si cabe el radio de actuación del acosador, estudiando si el fenómeno es observado desde los diferentes departamentos del centro, o si por el contrario estos permanecen ajenos a las circunstancias que pueda estar vivenciando el directivo acosado. En definitiva el estudio sería aún más preciso si cabe y obtendría un mayor número de matices a la hora de concluir la acción de acoso sobre el directivo. 


\section{CAPÍTULO IX. DISCUSIÓN FINAL Y CONCLUSIONES.}

3-Incluir en la muestra de estudio a directivos que hayan sido víctimas del acoso; debemos recordar que esta tesis recoge el testimonio de directivos únicamente en activo, que en la actualidad ostentan los cargos directivos en sus respectivos centros. Las aportaciones que pudieran recogerse de estas personas podrían ser de un gran valor puesto que serían capaces en su mayoría de reconocer el proceso y de arrojar nuevas aportaciones a las ya mencionadas, puesto que debemos recordar cómo cada caso de acoso laboral se produce en unas condiciones laborales muy determinadas.

4-Otro grupo que podría preciarse como parte de la muestra de estudio sería el gremio de los directivos jubilados o prejubilados, siendo estos últimos los de menor cuantía. Incluyéndolos a todos ellos, minimizaríamos sesgos tales como el miedo o la respuesta socialmente y laboralmente deseable, factor de suma importancia en el momento actual en el que convive la sociedad española. Cabe recordar la sensibilidad de la temática a estudio y la dificultad existente para encontrar hoy en día un puesto de trabajo, más aún tratándose de puestos de reconocida importancia social y laboral como es el de directivo, aún siendo considerado como medio.

5-Mención aparte podríamos hacer de los exdirectivos; sin duda sería una de las líneas futuras de investigación que arrojarían mayores resultados. Los exdirectivos aportarían su visión desde la experiencia en gestión y evaluación, tanto en las variables organizacionales de los centros, como en las sociales tan profundamente estudiadas en esta investigación. Cuando hablamos de exdirectivos, estaríamos haciendo referencia a aquellas personas que han ocupado durante un tiempo prolongado el cargo de directivo de centro, y que en la actualidad se encontraran ocupando otros cargos, bien sea dentro del propio sector sociosanitario u en otro sector de referencia. La inclusión de estas personas puede presentar la peculiaridad (que puede convertirse en sesgo de relevancia) de que aún en la actualidad mantenga relaciones, que puedan llamarse "de interés", con la organización en la que desempeño su función como directivo, lo cual en caso de que se pudiera haber dado el acoso mermaría los resultados que se pudieran obtener de manera científica. 


\section{CAPÍTULO IX. DISCUSIÓN FINAL Y CONCLUSIONES.}

6-Como sexta línea de actuación futura bien podríamos decir que como muestra podríamos incluir a los centros residenciales de carácter público y/o centros de dimensiones reducidas en cuanto a ocupación residencial se refiere, como pueden ser las fundaciones ubicadas en su gran mayoría en localidades próximas a las ciudades y las cuales por norma general, no suelen regentar más que unas veinticinco plazas residenciales.

A modo de conclusión final podemos decir que como solo se ha obtenido como significativa una variable capaz de predecir el acoso laboral, y no han salido significativas el resto de los antecedentes propuestos a nivel teórico, nos lleva a plantearnos que no se puede definir un perfil de personas propensas a sufrir acoso laboral. Cuando se realizó el estudio sobre los consecuentes, es decir si el acoso laboral es una variable significativa para determinar otras variables (consecuentes) planteadas a nivel teórico, si se obtuvieron resultados significativos en prácticamente todas las variables planteadas. Por tanto no se puede determinar un perfil definido sobre la víctima del acoso laboral, todos podemos sufrirlo, pero si se puede estudiar la influencia del acoso laboral en otras variables, lo que nos puede ayudar a saber que muchos problemas dentro de las empresas se deben al acoso laboral y no a otras variables de índole económico.

Una vez enumeradas las futuras líneas de investigación, y mencionados algunos aspectos de especial relevancia, concluiremos este capítulo con el resumen de los principales aspectos tratados en él. 


\section{CAPÍTULO IX. DISCUSIÓN FINAL Y CONCLUSIONES.}

RESUMEN - ABSTRACT

CAPÍTULO IX.

“Discusión final y conclusiones".

En el Capítulo IX, hemos abordado y analizado la discusión final y conclusiones obtenidas a lo largo del desarrollo de esta investigación, haciendo especial hincapié en el enfoque psicosocial y organizacional del proceso de acoso laboral en puestos directivos de centros residenciales. Se enumeran además algunas de las limitaciones existentes en la elaboración de este estudio de campo, neutralizando así las posibles consecuencias que de ello se derive, principalmente resaltando el hecho de que los directivos participes en la investigación, son considerados personal activo de la organización empresarial correspondiente.

Seguidamente se realiza una mención especial a algunos de los aspectos considerados como aportaciones para la reducción del fenómeno, para lo cual se enumera detalladamente cada uno de los mismos, describiendo además los factores considerados como relevantes en la mejora del clima laboral. Detallamos así las características del acoso laboral en la muestra de estudio, manifestando las conclusiones que arrojan los resultados, siendo los aspectos más relevantes la significatividad entre el acoso laboral y las variables; justicia organizacional, grado de autonomía laboral (antecedentes), satisfacción laboral, rendimiento laboral, clima organizacional y finalización de las tareas (consecuentes).

Así se trata de describir en minucia las características de los perfiles victimológicos socialmente estudiados, haciendo referencia al estudio de las causas por las que determinadas personas son más propensas a ser víctimas de acoso laboral y de cómo el estilo de vida que tienen pueden llevar a una mayor probabilidad de 


\section{CAPÍTULO IX. DISCUSIÓN FINAL Y CONCLUSIONES.}

sufrir acoso. Por tanto se concluye en el estudio que a pesar de que no exista un perfil victimológico definido, si existen una serie de características que se repiten entre quienes sufren y han sufrido este fenómeno.

Una vez tratados todos los aspectos anteriores, se definen como culmen de este capítulo, las futuras líneas de investigación, resaltando la mejora para la salud y seguridad laboral, la mayor rentabilidad empresarial, los avances y progresos centrados en el trabajador y en la empresa, el fomento del estudio a nivel internacional, la inclusión en los futuros estudios de todos los empleados de los centros participantes, hacer participes a directivos cuyo acoso haya sido reconocido como tal, incluir además directivos jubilados, intentar que participen en el estudio exdirectivos de centros que se encuentren aún en activo, bien sea en el mismo sector sociosanitario o en otro sector, realizar el estudio en centros públicos e intentar que participen centros pequeños, menores de cincuenta plazas residenciales, todo ello mejoraría sustancialmente la relevancia de la investigación, arrojando datos nuevos a los ya presentados en esta tesis y cuyas conclusiones puedan considerarse como verdaderas aportaciones científicas al mundo empresarial y directivo.

Con todo ello concluye esta tesis doctoral, presentando a continuación en el Capítulo $X$, las referencias bibliográficas y las páginas web de referencia. 


\section{CAPÍTULO X}

\section{“Referencias Bibliográficas y Páginas Web relacionadas"}

\section{VNIVERSITAS STVDII SALAMANTINI}

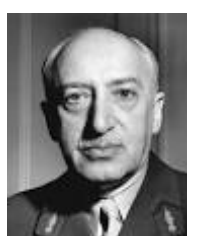

"La lectura de un buen libro es un diálogo incesante en el que el libro habla y el alma contesta".

André Maurois (novelista francés). 


\section{CAPÍTULO X.}

"Referencias Bibliográficas y Páginas Web Relacionadas".

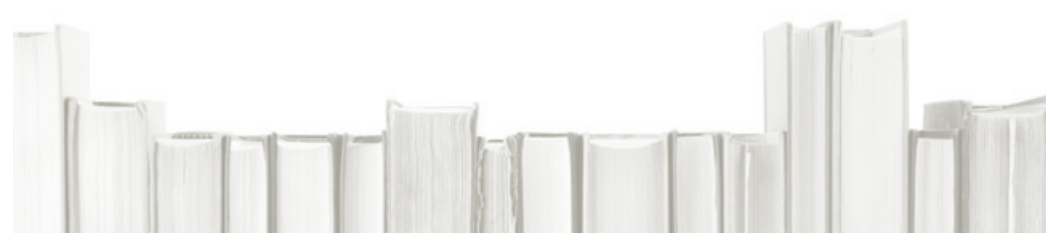

\section{Referencias Bibliográficas.}

- Agra, B. Fernández, R. y Tascón, R. (2004). El acoso moral en el trabajo: análisis sobre la limitada respuesta jurídica a un antiguo problema de reciente estudio y futura solución. Revista de Trabajo y Seguridad Social. Recursos humanos, 233, 3-60.

- Alario, S. (2003). Tratamiento conductual de un caso crónico de acoso moral, mobbing. Cuadernos de Medicina Psicosomática y Psiquiatría de Enlace, no 67.

- Almodóvar, M. A., Berjón, M. A., Cuenca, M. R., Fraile, A., García de Castro, M., Del Hoyo, M. A., Martín-Daza, F., Nogareda, C., Nogareda, S., Oncins, M.,Urrutia, M. y Zubizarreta, I. (2003). Psicosociología del trabajo. Madrid: Instituto Nacional de Seguridad e Higiene en el Trabajo.

$\rightarrow$ Alonso, C. M., Gallego, D. J. y Ongallo, C. (2003). Psicología Social y de las Organizaciones: comportamientos interpersonales. Madrid: Dykinson.

- APA (Asociación de Psiquiatría Americana) (2002). Manual diagnóstico y estadístico de los trastornos mentales, DSM-IV-TR. Barcelona: Masson.

- Ausfelder, T. (2002). Mobbing. El acoso moral en el trabajo. Prevención, síntomas y soluciones. Barcelona: Océano. 


\section{CAPÍTULO X. REFERENCIAS BIBLIOGRÁFICAS Y PÁGINAS WEB RELACIONADAS.}

S Baron, R. A. y Byrne, D. (1998). Psicología social. Madrid: Prentice-Hall.

- Benavides, F. G., Ruiz, C. y García, A. M. (1998). Salud Laboral. Conceptos y Técnicas para la Prevención de Riesgos Laborales. Barcelona: Masson.

- Boada, J., Agulló, E. y Mañas, M. A. (2005). El absentismo laboral como consecuencia de variables organizacionales. Psicothema, Vol. 17, no 2, 212-218.

- Borrás, L. (2002). El mobbing o acoso moral en el trabajo. Psicopatología Clínica Legal y Forense, vol 2., no 2, 113-120.

- Bosqued, M. (2004). Cómo combatir el estrés y la ansiedad en el ámbito laboral. Barcelona: Gestión 2000.

Э Bosqued, M. (2006). Mobbing. Como prevenir y superar el acoso psicológico. Madrid: Paidós.

- Cabaco, A. S. (1995). Indicadores de riesgo en salud mental y estrategias de prevención. Salamanca: UPSA.

- Calero, C. y Navarro, R. (2003). El mobbing o acoso psicológico en el trabajo. Valencia: UGT-PV.

OChappell, D. y Di Martino, V. (1998). Violence at work. Geneva: International Labour Office.

- Cherniss, C. (2005). La inteligencia emocional y la eficacia organizativa. En D. Goleman y C. Cherniss, Inteligencia emocional en el trabajo. Barcelona: Kairós.

$\rightarrow$ Conesa, J. y Sanahuja, M. (2002). Acoso moral en el trabajo: tratamiento jurídico. Actualidad laboral, 30, 639-658.

- CONSTITUCIÓN ESPAÑOLA (1999). 10a Edición. Madrid: Tecnos.

- Cordero, L. (2002). El acoso moral u hostigamiento psicológico en el trabajo. Un problema con incipiente respuesta jurídica. Revista española de derecho del trabajo, 110, 231-249.

S Correa, M. (2006). Acoso moral en el trabajo. Pamplona: Aranzadi. 
$\rightarrow$ De Elena, J. (2005a). Incidencia estadística del mobbing. En J. Romay, J. Salgado, M. Romaní y D. Robla (Eds.), Psicología de las organizaciones, del trabajo y recursos humanos y de la salud. Madrid: Biblioteca Nueva.

Э De Elena, J. (2005b). Los problemas de denominación en el estudio del mobbing.

○ En J. Romay, J. Salgado, M. Romaní y D. Robla (Eds.), Psicología de las organizaciones, del trabajo y recursos humanos y de la salud. Madrid: Biblioteca Nueva.

Einarsen, S. (1998). Dealing with bullying at work: The Norwegian lesson. Paper presented at the 1998 Research Update Conference, Stafforshire University Business School, UK.

- Einarsen, S. y Hauge, L. J. (2006). Antecedentes y consecuencias del acoso psicológico en el trabajo: una revisión de la literatura. Revista del Trabajo y de las Organizaciones, 22 (3), 251-274.

- Escudero, J. F. y Poyatos, G. (2003). Acoso laboral: diversas posibilidades para ejercitar la acción. Actualidad laboral, 47, 803-819.

(2) Escudero, J. F. y Poyatos, G. (2004). Mobbing: Análisis multidisciplinar y estrategia legal. Barcelona: Bosch.

- Fernández, R. (2004). El mobbing. Atención sociosanitaria y bienestar, 1, 44-51.

Fernández, E., Olaizola, I., Sancho, R., Odriozola, I., Gutiérrez, B., Serrano, J. y De Nicolás, L. (2004). El acoso moral en el trabajo. Evaluación, intervención y prevención. Bilbao: Instituto Vasco de Seguridad y Salud Laborales.

O Fernández-Montalvo, J. y Garrido, L. (1999). Psicopatología laboral. Trastornos derivados del trabajo. Pamplona: Universidad Pública de Navarra.

Fernández-Ríos, L. (2006). Aspectos psicológicos del acoso moral. En J. C. Sierra, E. M. Jiménez y G. Buela-Casal (Coords.), Psicología forense: Manual de técnicas y aplicaciones. Madrid: Biblioteca Nueva.

(Fidalgo, A. M. y Piñuel, I. (2004). La escala Cisneros como herramienta de valoración del mobbing. Psicothema, 16 (4), 615-624. 


\section{CAPÍTULO X. REFERENCIAS BIBLIOGRÁFICAS Y PÁGINAS WEB RELACIONADAS.}

- Franco, S. (2003). Factores organizacionales que promueven y/o facilitan la aparición del fenómeno de hostigamiento psicológico en el trabajo. Revista electrónica FCE, 7.

- Fuertes, J. C. (2004). Mobbing! Acoso laboral: Psicoterrorismo en el trabajo. Madrid: Aran Ediciones.

Э Gallego, A. J. (2003). Derecho y obligaciones de los trabajadores. En J. Vida (Dir.), Manual para la formación en prevención de riesgos laborales. Valladolid: LexNova.

O Garrido, V. (2000). El psicópata. Valencia: Algar.

- Gil-Monte, P., Carretero, N., Luciano, J. V. (2006). Prevalencia del mobbing en trabajadores de centros de asistencia a personas con discapacidad. Revista del Trabajo y de las Organizaciones, 22 (3), 275-292.

- Góngora, J. J., Lahera, M. y Rivas, M. L. (2002). Acoso psicológico en el trabajo. Mobbing. Pamplona: Instituto Navarro de Salud Laboral.

- González de Rivera, J. L. (2002). El maltrato psicológico. Cómo defenderse del mobbing y otras formas de acoso. Madrid: Espasa-Calpe.

- González de Rivera, J. L. (2005). Las claves del mobbing. El acoso psicológico en el trabajo visto por los expertos. Madrid: Editorial EOS.

O González de Rivera, J. L. (2006). Claves del mobbing. Madrid: EOS.

- Gutiérrez, J.M. (2001). Ergonomía y psicosociología en la empresa. Valencia: Cis-Praxis.

- Hirigoyen, M. F. (1999). El acoso moral. El maltrato psicológico en la vida cotidiana. Barcelona: Paidós.

S Hirigoyen, M. F. (2001). El acoso moral en el trabajo. Distinguir lo verdadero de lo falso. Barcelona: Paidós.

- Hirigoyen, M. F. (2004). Lugar de trabajo. En J. Sanmartín (Coord.), El laberinto de la violencia: causas, tipos y efectos. Barcelona: Ariel.

Э Lahera, M. y Góngora, J. J. (2002). Factores psicosociales. Identificación de situaciones de riesgo. Pamplona: Instituto Navarro de Salud Laboral. 


\section{CAPÍTULO X. REFERENCIAS BIBLIOGRÁFICAS Y PÁGINAS WEB RELACIONADAS.}

- Lazarus, R. S. y Folkman, S. (1986). Estrés y procesos cognitivos. Barcelona: Martínez Roca.

$\rightarrow$ Leymann, H. (1990). Mobbing and psychological terror at workplaces. Violence and Victims, 5, 119-126.

- López, S. y Camps, S. (1999). Aspectos clínicos y prevención del psicoterror laboral. Mapfre Medicina, 10 (4), 253-260.

- López-Cabarcos, M. A. y Vázquez-Rodríguez, P. (2003a). Mobbing. Como prevenir, identificar y solucionar el acoso psicológico en el trabajo. Madrid: Pirámide.

- López-Cabarcos, M. A. y Vázquez-Rodríguez, P. (2003b). Regulamiento jurídico del acoso moral en el trabajo. Esic Market, 116, 201-216.

- López-García, J. A. y Camps, P. (1999). Aspectos clínicos y prevención del psicoterror laboral. Mapfre Medicina, no 10, 253-260.

- Lorenzo, J. B. (2003). El acoso laboral en el trabajo como nueva patología emergente en el orden jurisdiccional laboral. Capital Humano, 164, 36-40.

- Martín-Daza, F., Pérez-Bilbao, J. y López, A. (1998). NTP 476. El hostigamiento psicológico en el trabajo: mobbing. Madrid: Instituto Nacional de Seguridad e Higiene en el Trabajo.

- Martínez, M. (1994). Métodos y diseños de investigación en psicología. Madrid: Editorial Complutense.

- Martínez, M. (2002). El hostigamiento psíquico laboral. Guía interdisciplinar del hostigamiento psicológico laboral, estrategias y recursos para abordar el mobbing. Zaragoza: Egido.

$\rightarrow$ Medina, F. J., Luque, P. J. y Crucer, S. (2005). Gestión del conflicto. En L. Munduate y F. J. Medina (Coords.), Gestión del conflicto, negociación y mediación. Madrid: Pirámide.

- Molina, C. (2002b). Mobbing o acoso moral en el lugar de trabajo. Comentario a la STSJ de Navarra del 18 de Mayo de 2001. Relaciones laborales: Revista crítica de teoría y práctica, 18 (3), 49-62. 
- Muñoz-Flores, H., Guerra, J. M., Barón, M. y Munduate, L. (2006). El acoso psicológico desde una perspectiva organizacional: el papel del clima organizacional y los procesos de cambio. Revista del Trabajo y de las Organizaciones, 22 (3),347-362.

- OMS (Organización Mundial de la Salud) (2000). Clasificación Internacional de las Enfermedades. Trastornos Mentales y del Comportamiento (CIE-10). Madrid: Editorial Panamericana.

- Ovejero, A. (2006b). Psicología del trabajo en un mundo globalizado: cómo hacer frente al mobbing y al estrés laboral. Madrid: Biblioteca Nueva.

- Piñuel, I. (2001). Mobbing. Cómo sobrevivir al acoso psicológico en el trabajo. Santander: Sal Térrae.

O Piñuel, I. (2003). Mobbing. Manual de autoayuda. Claves para reconocer y superar el acoso psicológico en el trabajo. Madrid: Aguilar.

- Piñuel, I. (2004a). Libro Blanco. Los riesgos psicosociales en la administración: la incidencia del mobbing y el burnout en la Agencia Estatal de la Administración Tributaria (AEAT) y en la intervención General de la Administración del Estado (IGAE). Resultados del Barómetro Cisneros $V$ sobre violencia en el entorno laboral de las administraciones públicas. Alcalá de Henares: Gestha.

O Piñuel, I. (2004b). Neomanagement. Jefes tóxicos y sus víctimas. Madrid: Aguilar.

- Piñuel, I. (2005). La identificación, medida y prevención del mobbing en la organización. Capital humano, 189, 90-105. 357

P Piñuel, I., Fidalgo, A. M., Oñate, A. y Ferreres, D. (2004). Resultados epidemiológicos del barómetro Cisneros III sobre acoso psicológico en el trabajo o mobbing. Comunicación presentada al VIII Congreso de Evaluación Psicológica, Málaga.

- Piñuel, I. y Oñate, A. (2002). La incidencia del mobbing o acoso psicológico en el trabajo en España. Resultados del Barómetro Cisneros II sobre violencia en el entorno laboral. Lan Harramanak. Revista de Relaciones Laborales, 7, 35-62.

- Piñuel, I. y Oñate, A. (2006). La evaluación y diagnóstico del mobbing o acoso psicológico en la organización: el barómetro Cisneros. Revista del Trabajo y de las Organizaciones, 22 (3),309-332. 


\section{CAPÍTULO X. REFERENCIAS BIBLIOGRÁFICAS Y PÁGINAS WEB RELACIONADAS.}

- Polonio, S. (2005). Acoso psicológico en el trabajo: mobbing. Revista de trabajo y Seguridad Social. Recursos Humanos, 268, 227-280. Rivas, L. J. (2003). Mobbing. Madrid: Editorial Entrelíneas.

- Rivas, M. P. (2005). Violencia psicológica en el trabajo: su tratamiento en la jurisprudencia. Estudio, jurisprudencia y formularios. Cizur Menor, Navarra: Aranzadi.

- Rodríguez, N. (2002). Mobbing. Vencer el acoso moral. Barcelona: Planeta.

- Rodríguez-Fernández, A., Díaz, F. y Fuertes, F. (2004). Psicología de las Organizaciones. Barcelona: Editorial UOC.

- Rodríguez-López, P. (2004a). El acoso moral en el trabajo. La responsabilidad en el acoso moral en el trabajo. Madrid: Dijusa.

SRojo, J. V. y Cervera, A. M. (2005). Mobbing o acoso laboral. Madrid: Tebar.

$\rightarrow$ Romero, M. J. (2005). Protección frente al acoso moral en el trabajo. Albacete: Bomarzo.

- Sánchez-Carazo, C. (2002). La ética de las relaciones laborales. En J. L. González de Rivera, El maltrato psicológico. Madrid: Espasa-Calpe.

- Schein, E. H. (1988). La cultura empresarial y el liderazgo. Barcelona: Plaza y Janés.

D Topa, G., Morales, J. F. y Gallastegui, J. A. (2006). Acoso laboral: relaciones con la cultura organizacional y los resultados personales. Psicothema, 18 (4), 766771. 


\section{CAPÍTULO X. REFERENCIAS BIBLIOGRÁFICAS Y PÁGINAS WEB RELACIONADAS.}

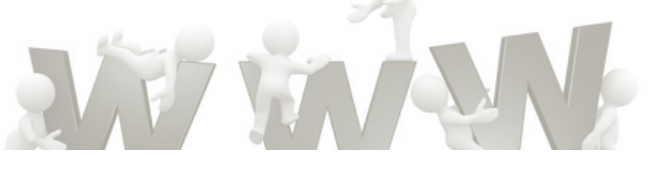

\section{Páginas Web Relacionadas.}

\section{www.acosomoral.org}

Página personal de Dña. Marina Parés, experta en acoso moral, trabajadora social y perito jurídico, terapeuta e investigadora. Preside el Servicio Europeo de Información sobre el Mobbing (SEDISEM) desde el año 2004.

\section{www.anamib.com}

Página de la Asociación de Ayuda por Acoso Moral en el Trabajo, con sede en Palma de Mallorca, cuyo objetivo es ayudar a iniciar el camino de recuperación de las víctimas de acoso moral.

\section{www.psicoterapeutas.com}

Página web especializada en potenciar y difundir las prácticas más eficaces en psicología clínica y en la psicoterapia cognitivo conductual, basándose en los avances mundiales considerados más relevantes.

\section{www.prevention-world.com}

Página web dedicada a Prevention World, plataforma online líder mundial en Prevención de Riesgos laborales, ofreciendo numerosos recursos sobre salud y seguridad laboral en el puesto de trabajo.

\section{www.mobbing.nu}

Página web de divulgación científica, del acoso moral o el acoso laboral en la cual aparecen noticias de relevancia, foros, buscadores y material de actualidad acerca del mobbing. 


\section{CAPÍTULO X. REFERENCIAS BIBLIOGRÁFICAS Y PÁGINAS WEB RELACIONADAS.}

\section{www.lexjuridica.com}

Página web dedicada a resaltar la información y servicios legales de diferentes temáticas, en la que además se puede encontrar un diccionario de terminología jurídica especializada y diferentes contenidos sobre la temática.

\section{$\underline{\text { www.diariomedico.com }}$}

Página web en la que se recoge la prensa médica especializada en la cual podemos encontrar noticias de actualidad acerca del fenómeno. En ella además podemos encontrar material para los profesionales de la materia.

\section{www.rrhh-web.com}

Página web en la que se destacan la importancia de los recursos humanos (rrhh), el empleo y la gestión empresarial, en la que predominan artículos actualizados sobre la gestión de los recursos humanos en las organizaciones modernas.

\section{www.insht.es}

Página web del Instituto Nacional de Seguridad e Higiene en el Trabajo, en la cual podemos encontrar diferentes análisis y estudios sobre las condiciones de seguridad y salud en el trabajo.

\section{www.gestiopolis.com}

Página web dedicada a numerosos post sobre materias tales como administración, emprendimiento, liderazgo, economía, finanzas en la que podemos encontrar una gran diversidad de artículos y temas sobre clima laboral y organizacional, pensamiento administrativo, gerencia y habilidades de gerencia, motivación y remuneración, toma de decisiones, planeación estratégica, comunicación organizacional, competitividad o ética y valores organizacionales entre otros muchos. 


\section{CAPÍTULO X. REFERENCIAS BIBLIOGRÁFICAS Y PÁGINAS WEB RELACIONADAS.}

\section{www.mobbingmadrid.org}

Página web de la asociación de Madrid PRIDICAM, dedicada a la orientación y defensa a los afectados de mobbing, acoso laboral, estrés laboral y discriminación laboral.

\section{www.avalc.es}

Página web perteneciente a la asociación de víctimas de acoso laboral de Cataluña, en la cual colaboran abogados, psicólogos, peritos forenses y personal altamente cualificado en la materia.

www.abecammobbing.wordpress.com

Página web correspondiente a la asociación ABECAM, asociación de Benidorm y Comarca para el apoyo contra el mobbing, formada por víctimas de mobbing, familiares de víctimas y amigos de víctimas.

\section{www.agacamt.es}

Página web de la asociación gallega contra el acoso moral (AGACAM), fundada en Septiembre de 2001 con la intención de apoyar y asesorar a las víctimas de acoso laboral y de difundir ante la opinión pública el fenómeno. 
CITA FINAL.

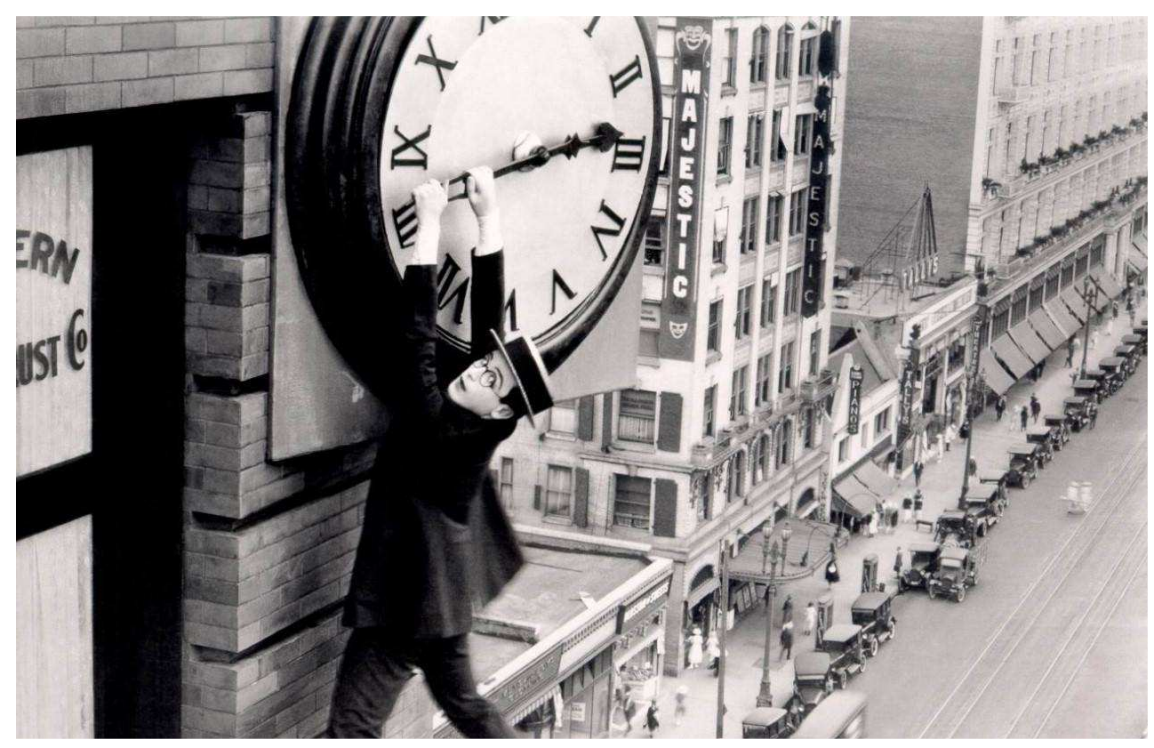

“Capítulo XI, 1 de 365 páginas, empieza una nueva historia.... piensa, cree, sueña y arriésgate... porque el éxito es solo el principio de algo más grande..."

Walt Disney (Productor Estadounidense) \& Josep Guardiola (Manager). 


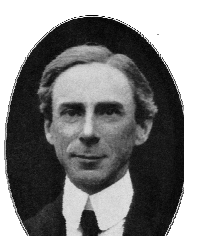

"La conclusión es que sabemos muy poco y sin embargo es asombroso 10 mucho que conocemos (...)".

Bertrand Rusell (filósofo inglés) 
ANEXO 1. CUESTIONARIO 


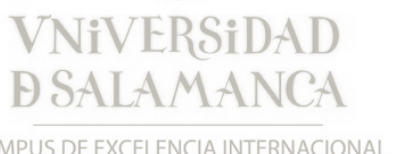

Desde el área de Psicología Social de la Universidad de Salamanca se está realizando un estudio sobre los parámetros organizacionales y sociales que delimitan la actividad directiva en centros residenciales. Quisiéramos conocer su opinión al respecto por lo que le agradeceríamos contestara las preguntas que se detallan a continuación. Su cumplimentación no llevará más de quince minutos.

El cuestionario es anónimo ${ }^{19}$ y le garantizamos la total privacidad de los datos y opiniones que usted nos facilite. Agradecemos de antemano su colaboración y participación. El cuestionario que a continuación se le presenta está compuesto por dos escalas: en primer lugar, la Escala Cisneros y en segundo lugar la Escala de Perfil Profesional.

Seguidamente se le proporcionan las instrucciones para contestar de manera correcta a cada una de las pruebas.

Edad: Sexo: Hombre Mujer .Años de Experiencia en el sector :

Estudios (nivel más alto de estudios): Qué otros puestos ha ocupado:

\section{INSTRUCCIONES}

A continuación se describen una serie de comportamientos que ha podido vivenciar en su trabajo. Para responder tenga en cuenta las siguientes instrucciones.

En la columna "Autor" indique un 1 , si cree que recibe acoso laboral por parte de su jefe 0 supervisor, un 2, si cree que recibe hostigamiento por parte de sus compañeros de trabajo o un 3 , si cree que recibe asedio por parte de sus subordinados. Si no considera que este recibiendo ningún hostigamiento, deje la casilla en blanco. *Sólo se puede marcar una única respuesta, por tanto sólo se puede indicar, 1, 2 ó 3, ó dejando en blanco la casilla.

En la columna "Frecuencia de Comportamiento", indique con una X, con qué frecuencia se producen esos hostigamientos, marcando 0 , si nunca se producirían, marcando 1 , si se producen pocas veces al año, marcando 2 , si se producen una vez al mes o menos, marcando 3 , si se producen algunas veces al mes, marcando 4 , si se producen una vez a la semana, marcando 5 , si se producen varias veces a la semana o marcando 6 , si se producen todos los días.

*Sólo se puede marcar una única respuesta, por tanto sólo se puede indicar, 0, 1,2 3,4, 5 ó 6.

\footnotetext{
${ }^{19}$ Toda la información facilitada será tratada de manera estrictamente confidencial y exclusivamente con fines estadísticos, de acuerdo con la Ley Orgánica 15/1999 de protección de datos de carácter personal. La participación en esta investigación es totalmente anónima y voluntaria.
} 


\section{ESCALA CISNEROS}

¿Cuáles de las siguientes formas de maltrato psicológico (ver lista de preguntas 1 a 43) se han ejercido contra Ud.?

Señale, en su caso, quiénes son el/los autores de los hostigamientos recibidos

1: Jefes o supervisores; 2: Compañeros de trabajo; 3:Subordinados

Señale, en su caso, el grado de frecuencia con que se producen esos hostigamientos

\begin{tabular}{|c|c|c|c|c|c|c|}
\hline Nunca & $\begin{array}{l}\text { Pocas veces al } \\
\text { año o menos }\end{array}$ & $\begin{array}{l}\text { Una vez al } \\
\text { mes o menos }\end{array}$ & $\begin{array}{l}\text { Algunas } \\
\text { veces al mes }\end{array}$ & $\begin{array}{l}\text { Una vez a la } \\
\text { semana }\end{array}$ & $\begin{array}{l}\text { Varias veces a } \\
\text { la semana }\end{array}$ & $\begin{array}{l}\text { Todos los } \\
\text { días }\end{array}$ \\
\hline $\mathbf{0}$ & $\mathbf{1}$ & $\mathbf{2}$ & $\mathbf{3}$ & $\mathbf{4}$ & $\mathbf{5}$ & $\mathbf{6}$ \\
\hline
\end{tabular}

\begin{tabular}{|c|c|c|c|c|c|c|c|c|}
\hline COMPORTAMIENTOS & AUTOR & \multicolumn{7}{|c|}{$\begin{array}{l}\text { FRECUENCIA DEL } \\
\text { COMPORTAMIENTO }\end{array}$} \\
\hline $\begin{array}{l}\text { 1.Mi superior restringe mis posibilidades de comunicarme, hablar } \\
\text { o reunirme con él }\end{array}$ & () & 0 & 1 & 2 & 3 & 4 & 5 & 6 \\
\hline $\begin{array}{l}\text { 2. Me ignoran. Me excluyen o me hacen el vacío, fingen no } \\
\text { verme o me hacen "invisible" }\end{array}$ & ( ) & 0 & 1 & 2 & 3 & 4 & 5 & 6 \\
\hline 3. Me interrumpen continuamente impidiendo expresarme & $($ ) & 0 & 1 & 2 & 3 & 4 & 5 & 6 \\
\hline $\begin{array}{l}\text { 4. Me fuerzan a realizar trabajos que van contra mis principios o } \\
\text { mi ética }\end{array}$ & ( ) & 0 & 1 & 2 & 3 & 4 & 5 & 6 \\
\hline 5. Evalúan mi trabajo de manera equitativa o de forma sesgada & $($ ) & 0 & 1 & 2 & 3 & 4 & 5 & 6 \\
\hline $\begin{array}{l}\text { 6. Me dejan sin ningún trabajo que hacer, ni siquiera a iniciativa } \\
\text { propia }\end{array}$ & ( ) & 0 & 1 & 2 & 3 & 4 & 5 & 6 \\
\hline 7. Me asignan tareas o trabajos absurdos o sin sentido & $($ ) & 0 & 1 & 2 & 3 & 4 & 5 & 6 \\
\hline $\begin{array}{l}\text { 8. Me asignan tareas o trabajos por debajo de mi capacidad } \\
\text { profesional o mis competencias }\end{array}$ & ( ) & 0 & 1 & 2 & 3 & 4 & 5 & 6 \\
\hline 9. Me asignan tareas rutinarias o sin valor o interés alguno & ( ) & 0 & 1 & 2 & 3 & 4 & 5 & 6 \\
\hline $\begin{array}{l}\text { 10. Me abruman con una carga de trabajo insoportable de } \\
\text { manera mal intencionada }\end{array}$ & ( ) & 0 & 1 & 2 & 3 & 4 & 5 & 6 \\
\hline $\begin{array}{l}\text { 11. Me asignan tareas que ponen en peligro mi integridad física } \\
\text { o mi salud a propósito }\end{array}$ & $($ ) & 0 & 1 & 2 & 3 & 4 & 5 & 6 \\
\hline $\begin{array}{l}\text { 12. Me impiden que adopte las medidas de seguridad } \\
\text { necesarias para realizar mi trabaio con la debida seguridad }\end{array}$ & () & 0 & 1 & 2 & 3 & 4 & 5 & 6 \\
\hline $\begin{array}{l}\text { 13. Se me ocasionan gastos con intención de perjudicarme } \\
\text { económicamente }\end{array}$ & $($ ) & 0 & 1 & 2 & 3 & 4 & 5 & 6 \\
\hline 14. Prohíben a mis compañeros o colegas hablar conmigo & $($ ) & 0 & 1 & 2 & 3 & 4 & 5 & 6 \\
\hline $\begin{array}{l}\text { 15. Minusvaloran y echan por tierra mi trabajo, no importa lo que } \\
\text { haga }\end{array}$ & ( ) & 0 & 1 & 2 & 3 & 4 & 5 & 6 \\
\hline $\begin{array}{l}\text { 16. Me acusan injustificadamente de incumplimientos, errores, } \\
\text { fallos inconcretos y difusos }\end{array}$ & () & 0 & 1 & 2 & 3 & 4 & 5 & 6 \\
\hline $\begin{array}{l}\text { 17. Recibo críticas y reproches por cualquier cosa que haga o } \\
\text { decisión que tome en mi trabajo }\end{array}$ & $($ ) & 0 & 1 & 2 & 3 & 4 & 5 & 6 \\
\hline $\begin{array}{l}\text { 18. Se amplifican y dramatizan de manera injustificada errores } \\
\text { pequeños o intrascendentes }\end{array}$ & ( ) & 0 & 1 & 2 & 3 & 4 & 5 & 6 \\
\hline $\begin{array}{l}\text { 19. Me humillan, desprecian o minusvaloran en público ante } \\
\text { otros colegas o ante terceros }\end{array}$ & $($ ( ) & 0 & 1 & 2 & 3 & 4 & 5 & 6 \\
\hline $\begin{array}{l}\text { 20. Me amenazan con usar instrumentos disciplinarios (rescisión } \\
\text { de contrato, expedientes, despido, traslados, etc...) }\end{array}$ & ( ) & 0 & 1 & 2 & 3 & 4 & 5 & 6 \\
\hline 21. Intentan aislarme de mis compañeros dándome trabajos 0 & ( ) & 0 & 1 & 2 & 3 & 4 & 5 & 6 \\
\hline
\end{tabular}




\begin{tabular}{|c|c|c|c|c|c|c|c|c|}
\hline tareas que me alejan físicamente de ellos & & & & & & & & \\
\hline $\begin{array}{l}\text { 22. Distorsionan malintencionadamente lo que digo o hago en mi } \\
\text { trabajo }\end{array}$ & ( ) & 0 & 1 & 2 & 3 & 4 & 5 & 6 \\
\hline 23. Se intenta buscarme las cosquillas para "hacerme explotar" & $($ ) & 0 & 1 & 2 & 3 & 4 & 5 & 6 \\
\hline 24. Me menosprecian personal o profesionalmente & $(1)$ & 0 & 1 & 2 & 3 & 4 & 5 & 6 \\
\hline $\begin{array}{l}\text { 25. Hacen burla de mí o bromas intentando ridiculizar mi forma } \\
\text { de hablar, de andar, etc... }\end{array}$ & $(1)$ & 0 & 1 & 2 & 3 & 4 & 5 & 6 \\
\hline $\begin{array}{l}\text { 26. Recibo feroces e injustas críticas acerca de aspectos de mi } \\
\text { vida personal }\end{array}$ & $($ ) & 0 & 1 & 2 & 3 & 4 & 5 & 6 \\
\hline 27. Recibo amenazas verbales o mediante gestos intimidatorios & ( ) & 0 & 1 & 2 & 3 & 4 & 5 & 6 \\
\hline 28. Recibo amenazas por escrito o por teléfono en mi domicilio & $($ ) & 0 & 1 & 2 & 3 & 4 & 5 & 6 \\
\hline 29. Me chillan o gritan, o elevan la voz de manera intimidante & $(1)$ & 0 & 1 & 2 & 3 & 4 & 5 & 6 \\
\hline $\begin{array}{l}\text { 30. Me zarandean, empujan o avasallan físicamente para } \\
\text { intimidarme }\end{array}$ & $(1)$ & 0 & 1 & 2 & 3 & 4 & 5 & 6 \\
\hline 31. Se hacen bromas inapropiadas y crueles acerca de mí & ( & 0 & 1 & 2 & 3 & 4 & 5 & 6 \\
\hline $\begin{array}{l}\text { 32. Inventan y difunden rumores y calumnias acerca de mí, de } \\
\text { manera malintencionada }\end{array}$ & $(1)$ & 0 & 1 & 2 & 3 & 4 & 5 & 6 \\
\hline $\begin{array}{l}\text { 33. Me privan de información imprescindible y necesaria para } \\
\text { hacer mi trabajo }\end{array}$ & ( ) & 0 & 1 & 2 & 3 & 4 & 5 & 6 \\
\hline $\begin{array}{l}\text { 34. Limitan malintencionadamente mi acceso a cursos, } \\
\text { promociones, ascensos, etc... }\end{array}$ & ( ) & 0 & 1 & 2 & 3 & 4 & 5 & 6 \\
\hline $\begin{array}{l}\text { 35. Me atribuyen malintencionadamente conductas ilícitas o } \\
\text { antiéticas para perjudicar mi imagen y reputación }\end{array}$ & $($ ) & 0 & 1 & 2 & 3 & 4 & 5 & 6 \\
\hline 36. Recibo una presión indebida para sacar adelante el trabajo & $($ ) & 0 & 1 & 2 & 3 & 4 & 5 & 6 \\
\hline $\begin{array}{l}\text { 37. Me asignan plazos de ejecución o cargas de trabajo } \\
\text { irrazonables }\end{array}$ & ( ) & 0 & 1 & 2 & 3 & 4 & 5 & 6 \\
\hline $\begin{array}{l}\text { 38. Modifican mis responsabilidades o las tareas a ejecutar sin } \\
\text { decirme nada }\end{array}$ & ( ) & 0 & 1 & 2 & 3 & 4 & 5 & 6 \\
\hline 39. Desvaloran continuamente mi esfuerzo profesional & $(\mathbf{)}$ & 0 & 1 & 2 & 3 & 4 & 5 & 6 \\
\hline 40. Intentan persistentemente desmoralizarme & $(1)$ & 0 & 1 & 2 & 3 & 4 & 5 & 6 \\
\hline $\begin{array}{l}\text { 41. Utilizan varias formas de hacerme incurrir en errores } \\
\text { profesionales de manera malintencionada }\end{array}$ & ( ) & 0 & 1 & 2 & 3 & 4 & 5 & 6 \\
\hline $\begin{array}{l}\text { 42. Controlan aspectos de mi trabajo de forma malintencionada } \\
\text { para intentar "pillarme en algún renuncio" }\end{array}$ & ( ) & 0 & 1 & 2 & 3 & 4 & 5 & 6 \\
\hline $\begin{array}{l}\text { 43. Me lanzan insinuaciones o proposiciones sexuales directas o } \\
\text { indirectas }\end{array}$ & ( ) & 0 & 1 & 2 & 3 & 4 & 5 & 6 \\
\hline $\begin{array}{l}\text { 44. En el transcurso de los últimos } 6 \text { meses, ¿ha sido usted } \\
\text { víctima de por lo menos alguna de las anteriores formas de } \\
\text { maltrato psicológico de manera continuada (con una frecuencia } \\
\text { de más de una vez por semana)?(ver lista de preguntas hasta la }\end{array}$ & & SI & & & & NO & & \\
\hline
\end{tabular}

\section{ESCALA DE PERFIL PROFESIONAL}

En la Escala de Perfil Profesional se le presentan una serie de enunciados, acerca de su perfil profesional, en el que deberá señalar con una $X$ su grado de conformidad con cada una de las afirmaciones, de acuerdo a la siguiente escala. Recuerde que Sólo se puede marcar una única respuesta, por tanto sólo se puede indicar, $0,1,23,4,5$ ó 6 . 


\begin{tabular}{|c|c|c|c|c|c|c|c|}
\hline aboral & & & & & & & \\
\hline 34. El acoso laboral es fruto de una gestión económica deficiente & 0 & 1 & 2 & 3 & 4 & 5 & 6 \\
\hline $\begin{array}{l}\text { 35. Considero que no existe ninguna relación entre los resultados económicos de } \\
\text { la empresa y el acoso laboral }\end{array}$ & 0 & 1 & 2 & 3 & 4 & 5 & 6 \\
\hline 36. Poseo libertad para elegir el método de trabajo que creo más adecuado & 0 & 1 & 2 & 3 & 4 & 5 & 6 \\
\hline 37. Las actividades que me encomiendan son de una gran responsabilidad & 0 & 1 & 2 & 3 & 4 & 5 & 6 \\
\hline $\begin{array}{l}\text { 38. A menudo debo acudir a mis capacidades personales para realizar mis } \\
\text { tareas }\end{array}$ & 0 & 1 & 2 & 3 & 4 & 5 & 6 \\
\hline 39. Realizo tareas muy variadas en mi puesto de trabajo & 0 & 1 & 2 & 3 & 4 & 5 & 6 \\
\hline horario de trabajo se refiere & 0 & 1 & 2 & 3 & 4 & 5 & 6 \\
\hline 41. Obtengo reconocimiento por el trabajo bien hecho & 0 & 1 & 2 & 3 & 4 & 5 & 6 \\
\hline 42. Se presta atención a las & 0 & 1 & 2 & 3 & 4 & 5 & 6 \\
\hline 43. Mi empresa está gestionada correctamente & 0 & 1 & 2 & 3 & 4 & 5 & 6 \\
\hline 44. Recibo un salario acorde con mi puesto de trabajo & 0 & 1 & 2 & 3 & 4 & 5 & 6 \\
\hline 45. En esta empresa tengo una gran estabilidad laboral & 0 & 1 & 2 & 3 & 4 & 5 & 6 \\
\hline 46. Pienso frecuentemente en dejar este trabajo & 0 & 1 & 2 & 3 & 4 & 5 & 6 \\
\hline 47. Me gi & 0 & 1 & 2 & 3 & 4 & 5 & 6 \\
\hline $\begin{array}{l}\text { 48. No siento ninguna obligación de tener que seguir trabajando } \\
\text { organización }\end{array}$ & 0 & 1 & 2 & 3 & 4 & 5 & 6 \\
\hline 49. Podría & 0 & 1 & 2 & 3 & 4 & 5 & 6 \\
\hline $\begin{array}{l}\text { 50. Creo que } \\
\text { cambio }\end{array}$ & 0 & 1 & 2 & 3 & 4 & 5 & 6 \\
\hline 51. En esta organización las tareas están claramente definidas & 0 & 1 & 2 & 3 & 4 & 5 & 6 \\
\hline 52. La er & 0 & 1 & 2 & 3 & 4 & 5 & 6 \\
\hline $\begin{array}{l}\text { citarme y superarme, es de un nivel máximo } \\
\text { oral }\end{array}$ & 0 & 1 & 2 & 3 & 4 & 5 & 6 \\
\hline 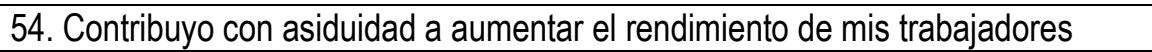 & 0 & 1 & 2 & 3 & 4 & 5 & 6 \\
\hline $\begin{array}{l}\text { 55. Mis superiores evalúan el rendimiento laboral, como un element } \\
\text { tareas directivas }\end{array}$ & 0 & 1 & 2 & 3 & 4 & 5 & 6 \\
\hline ras organizacionales, administrativas o de procedir & 0 & 1 & 2 & 3 & 4 & 5 & 6 \\
\hline $\begin{array}{l}\text { 57. Permanecería en esta organización a p } \\
\text { difíciles }\end{array}$ & 0 & 1 & 2 & 3 & 4 & 5 & 6 \\
\hline de mi decarrollo nrofocional & 0 & 1 & 2 & 3 & 4 & 5 & 6 \\
\hline 59. Pron & 0 & 1 & 2 & 3 & 4 & 5 & 6 \\
\hline 60. Me e & 0 & 1 & 2 & 3 & 4 & 5 & 6 \\
\hline 61. Las $\mathrm{p}$ & 0 & 1 & 2 & 3 & 4 & 5 & 6 \\
\hline 62. Las relaciones con mis compañeros tienden a ser agradables & 0 & 1 & 2 & 3 & 4 & 5 & 6 \\
\hline 63. Los distintos departamentos mantienen un & 0 & 1 & 2 & 3 & 4 & 5 & 6 \\
\hline 64. El grupo de trabajo valora mis decisiones & 0 & 1 & 2 & 3 & 4 & 5 & 6 \\
\hline $\begin{array}{l}\text { 65. Dispongo de los recursos adecuados para desempeñar mi trabajo } \\
\text { positivamente }\end{array}$ & 0 & 1 & 2 & 3 & 4 & 5 & 6 \\
\hline $\begin{array}{l}\text { 66. Nuestros jefes muestran interés porque las normas, métodos y } \\
\text { procedimientos estén claros y se cumplan }\end{array}$ & 0 & 1 & 2 & 3 & 4 & 5 & 6 \\
\hline do tengo una labor difícil & 0 & 1 & 2 & 3 & 4 & 5 & 6 \\
\hline $\begin{array}{l}\text { 68. Considero que en esta organización las tareas se distribuyen de m } \\
\text { equitativa }\end{array}$ & 0 & 1 & 2 & 3 & 4 & 5 & 6 \\
\hline $\begin{array}{l}\text { 69. Mi horario se ajusta al número de tareas que realizo a lo largo de mi jorna } \\
\text { laboral }\end{array}$ & 0 & 1 & 2 & 3 & 4 & 5 & 6 \\
\hline 70. Suelo dejar tareas pendientes, debid & 0 & 1 & 2 & 3 & 4 & & \\
\hline
\end{tabular}

Muchas Gracias por su colaboración. 
ANEXO 2.

TABLAS SPSS 19 


\section{ANEXOS TABLAS RESULTADOS SPSS}

\section{Prueba de Kolmogorov-Smirnov (K-S).}

Prueba de Kolmogorox-Smirnov para una muestra

\begin{tabular}{|c|c|c|c|c|c|c|c|c|c|c|c|c|c|c|c|}
\hline & & Edad & NEAP & Estilo liderazep & $\begin{array}{c}\text { Competencias } \\
\text { sector }\end{array}$ & $\begin{array}{c}\text { Ambigivedad } R \\
8\end{array}$ & $\begin{array}{c}\text { Justicia Organi } \\
\text { zaciona. }\end{array}$ & $\begin{array}{c}\text { Resultados. Ec } \\
\text { onómicos }\end{array}$ & $\begin{array}{c}\text { Grade Autone } \\
\text { mis }\end{array}$ & 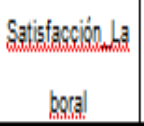 & $\begin{array}{c}\text { Intención Aban } \\
\text { dono }\end{array}$ & $\begin{array}{c}\text { Rendimiente } \\
\text { aboral }\end{array}$ & $\begin{array}{c}\text { Compromiso.e } \\
\text { reanizaciona }\end{array}$ & $\begin{array}{c}\text { Clima Oroaniza } \\
\text { cional }\end{array}$ & $\begin{array}{c}\text { Eing: zación. Ta } \\
\text { rags }\end{array}$ \\
\hline N & & 59 & 59 & 59 & 59 & 59 & 59 & 59 & 59 & 59 & 59 & 59 & 59 & 59 & 59 \\
\hline \multirow[t]{2}{*}{ Parámetros normaleate } & Media & 43,90 & 26,7119 & 9,9661 & 17,9661 & 22,5593 & 11,7458 & 1,97 & 16,9661 & 15,7458 & 5,8305 & 19,0000 & 19,5424 & 16,4746 & 14,5424 \\
\hline & Desviación tipica & 11,261 & 39,35385 & 5,19926 & 3,90829 & 4,50774 & 4,61479 & 1,732 & 3,66703 & 5,33561 & 2,43645 & 4,68674 & 3,75693 & 3,79817 & 4,06975 \\
\hline \multirow[t]{3}{*}{ Diferencias más extremas } & Absoluta & .081 & .256 &, 150 &, 116 &, 105 &, 098 & , 186 & .119 &, 133 & .163 & .097 & .129 &, 097 & 106 \\
\hline & Postiva & .069 & .256 &, 150 &, 116 & .105 &, 092 & .186 &, 078 &, 133 &, 133 &, 095 &, 129 &, 075 &, 106 \\
\hline & Negativa & .081 & -249 & ; 115 & .088 & $\cdot 100$ & - 098 & 128 & ; 119 & ; 101 & .163 & .097 & .088 & .097 & .053 \\
\hline Z de kolmogerov-Sminoov & & .623 & 1,964 & 1,152 & .893 &, 804 &, 756 & 1,430 & .918 & 1,021 & 1,254 &, 749 & 995 &, 743 & .813 \\
\hline Sig. asintóth. (bilsteral) & & 833 & .061 & , 141 & .402 & ,537 &, 618 &, 034 & 2,369 & .248 &, 086 & .629 &, 276 &, 639 &, 523 \\
\hline
\end{tabular}

a. La distribución de contraste es la Normal.

b. Se han calculado a partir de los datos. 


\section{Estadísticos}

Estadíliticos

\begin{tabular}{|c|c|c|c|c|c|c|c|c|c|c|c|c|c|c|}
\hline & NEAP & Elad & $\begin{array}{l}\text { Estillo } \\
\text { lidelazyo }\end{array}$ & $\begin{array}{l}\text { Competencia } \\
\text { s_sector }\end{array}$ & $\underset{\text { Rol }}{\text { Ambigiuldad__ }}$ & $\begin{array}{l}\text { Jussicicia } \\
\text { Orgaganizacion } \\
\text { al }\end{array}$ & $\begin{array}{l}\text { Ressultados } \\
\text { Econónicicos }\end{array}$ & $\begin{array}{l}\text { Grado- } \\
\text { Autonomín'a }\end{array}$ & $\begin{array}{l}\text { Satisíacción- } \\
\text { Laboralal }\end{array}$ & $\begin{array}{l}\text { Imtención } \\
\text { Albandono }\end{array}$ & $\begin{array}{c}\text { Rendimientiono } \\
\text { Laboralal }\end{array}$ & $\begin{array}{c}\text { Compromiso } \\
\text { Organizacio } \\
\text { nal }\end{array}$ & $\begin{array}{c}\text { Clima } \\
\text { Oryananzacion } \\
\text { al }\end{array}$ & $\begin{array}{l}\text { Finalización } \\
\text { Tareass }\end{array}$ \\
\hline N Valilios & 59 & 59 & 59 & 59 & 59 & 59 & 59 & 59 & 59 & 59 & 59 & 59 & 59 & 59 \\
\hline Perdidos & 8 & 8 & 8 & 8 & 8 & 8 & 8 & 8 & 8 & 8 & 8 & 8 & 8 & 8 \\
\hline Medila & 26,7119 & 43,90 & 9,9661 & 17,9661 & 22,5593 & 11,7458 & 1,97 & 16,9661 & 15,7458 & 5,8305 & 19,0000 & 19,5424 & 16,4746 & 14,5424 \\
\hline Dess. fip. & 39,35385 & 11,261 & 5,19936 & 3,90829 & 4,50774 & 4,61479 & 1,732 & 3,66703 & 5,33561 & 2,43645 & 4,68674 & 3,75693 & 3,79817 & 4,06975 \\
\hline Mirimo & .00 & 24 & .00 & 10,00 & 12,00 & .00 & 0 & 9,00 & 4,00 & .00 & 5,00 & 9,00 & 3,00 & 3,00 \\
\hline Máxímo & 183,00 & 75 & 38,00 & 24,00 & 30,00 & 23,00 & 6 & 24,00 & 30,00 & 12,00 & 30,00 & 30,00 & 24,00 & 24,00 \\
\hline
\end{tabular}




\section{Correlaciones Antecedentes}

\begin{tabular}{|c|c|c|c|c|c|c|c|c|c|}
\hline \multicolumn{10}{|c|}{ Correlaciones } \\
\hline & & Edad & $\begin{array}{l}\text { Estilo } \\
\text { liderazgo }\end{array}$ & $\begin{array}{l}\text { Competencia } \\
\text { S_sector }\end{array}$ & $\begin{array}{c}\text { Ambigüedad_ } \\
\text { Rol }\end{array}$ & $\begin{array}{l}\text { Justicia } \\
\text { organizacion } \\
\text { al }\end{array}$ & $\begin{array}{l}\text { Resultados } \\
\text { Económicos }\end{array}$ & $\begin{array}{l}\text { Grado } \\
\text { Autonomia }\end{array}$ & NEAF \\
\hline \multirow[t]{3}{*}{ Edad } & Correlación de Pearson & 1 &, 025 & 144 &, 080 & 122 & 132 &, 112 & .027 \\
\hline & Big. (bilateral) & & .851 & .275 & .546 & .356 & .317 &, 397 & .937 \\
\hline & $\mathrm{N}$ & 59 & 59 & 59 & 59 & 59 & 59 & 59 & 59 \\
\hline \multirow[t]{3}{*}{ Estilo_liderazgo } & Correlación de Pearson & .025 & 1 &,- 015 & .034 & $.535^{x x}$ &,- 086 & .216 &,- 203 \\
\hline & Sig. (bilateral) & .851 & & .908 & .799 & , 000 & .516 &, 100 & .124 \\
\hline & $N$ & 59 & 59 & 59 & 59 & 59 & 59 & 59 & 59 \\
\hline \multirow[t]{3}{*}{ Competencias_sector } & Correlación de Pearson & .144 & -.015 & 1 & $.585^{x x}$ & .150 & .020 & $.333^{x x}$ & .056 \\
\hline & Big. (bilateral) & .275 & .908 & &, 000 & .258 & .879 &, 010 & .676 \\
\hline & $\mathrm{N}$ & 59 & 59 & 59 & 59 & 59 & 59 & 59 & 59 \\
\hline \multirow[t]{3}{*}{ Ambigüedad_Rol } & Correlación de Pearson & .080 & .034 & $.585^{x \pi}$ & 1 & .223 & .042 & $411^{\pi \pi}$ & -.112 \\
\hline & Big. (bilateral) & .546 & .799 &, 000 & &, 089 & .751 &, 001 & .397 \\
\hline & $N$ & 59 & 59 & 59 & 59 & 59 & 59 & 59 & 59 \\
\hline \multirow[t]{3}{*}{ Justicia_organizacional } & Correlación de Pearson & .122 & $.535^{\mathrm{xx}}$ & .150 & .223 & 1 & .085 & $.503^{x \pi}$ & $-.263^{x}$ \\
\hline & Sig. (bilateral) &, 356 & .000 & .258 &, 089 & & .521 &, 000 & .044 \\
\hline & $N$ & 59 & 59 & 59 & 59 & 59 & 59 & 59 & 59 \\
\hline \multirow[t]{3}{*}{ Resultados_Económicos } & Correlación de Pearson & .132 & -.086 & .020 &, 042 &, 085 & 1 &, 043 & -.142 \\
\hline & Sig. (bilateral) & .317 & .516 & .879 & .751 & .521 & & .745 & .284 \\
\hline & $N$ & 59 & 59 & 59 & 59 & 59 & 59 & 59 & 59 \\
\hline \multirow[t]{3}{*}{ Grado_Autonomia } & Correlación de Pearson & .112 & .216 & $.333^{x \pi}$ & $411^{x x}$ & $.503^{x \pi}$ & .043 & 1 &,$- 286^{x}$ \\
\hline & Sig. (bilateral) & .397 & .100 & .010 &, 001 &, 000 & .745 & & .028 \\
\hline & $N$ & 59 & 59 & 59 & 59 & 59 & 59 & 59 & 59 \\
\hline \multirow[t]{3}{*}{ NEAP } & Correlación de Pearson & .027 & -.203 & .056 &,- 112 &,$- 263^{x}$ & -.142 &,$- 286^{x}$ & 1 \\
\hline & Sig. (bilateral) & 837 & .124 & .676 &, 397 &, 044 & .284 &, 028 & \\
\hline & $\mathrm{N}$ & 59 & 59 & 59 & 59 & 59 & 59 & 59 & 59 \\
\hline
\end{tabular}

** La correlación es significativa al nivel 0,01 (bilateral) 


\section{Correlaciones Consecuentes}

\begin{tabular}{|c|c|c|c|c|c|c|c|c|}
\hline \multicolumn{9}{|c|}{ Correlaciones } \\
\hline & & $\begin{array}{c}\text { Satisfaccion_ } \\
\text { Laboral }\end{array}$ & $\begin{array}{l}\text { Intención } \\
\text { Abandona }\end{array}$ & $\begin{array}{c}\text { Rendimiento } \\
\text { Laboral }\end{array}$ & $\begin{array}{l}\text { Compromiso } \\
\text { Organizacio } \\
\text { nal }\end{array}$ & $\begin{array}{c}\text { Clima } \\
\text { organizacion } \\
\text { al }\end{array}$ & $\begin{array}{c}\text { Finalización_ } \\
\text { Tareas }\end{array}$ & NEAP \\
\hline \multirow[t]{3}{*}{ Satisfacción_Laboral } & Correlación de Pearson & 1 & $.640^{\pi x}$ & $.603^{\text {nx }}$ & $.534^{\pi x}$ & $.585^{\mathrm{xx}}$ & $.686^{.7 x}$ &,$- 387^{\pi m}$ \\
\hline & Sig (bilateral) & &, 000 & , 000 & .000 & , 000 & .000 &, 002 \\
\hline & 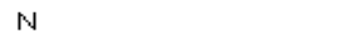 & 59 & 59 & 59 & 59 & 59 & 59 & 59 \\
\hline \multirow[t]{3}{*}{ Intención_Abandono } & Correlación de Pearson & $.640^{x x}$ & 1 & $.708^{x \pi}$ & $.626^{x x}$ & $.435^{x \pi}$ & $.566^{x x}$ &,$- 327^{\pi}$ \\
\hline & Sig. (bilateral) & .000 & &, 000 & .000 &, 001 & .000 &, 012 \\
\hline & $\mathrm{N}$ & 59 & 59 & 59 & 59 & 59 & 59 & 59 \\
\hline \multirow[t]{3}{*}{ Rendimiento_Laboral } & Correlación de Pearson & $.603^{x x}$ & $.708^{x \pi}$ & 1 & $.714^{\pi x}$ & $.521^{\pi \pi}$ & $.551^{x x}$ &,$- 268^{x}$ \\
\hline & Sig. (bilateral) & .000 &, 000 & & .000 &, 000 & .000 &, 040 \\
\hline & $N$ & 59 & 59 & 59 & 59 & 59 & 59 & 59 \\
\hline \multirow{3}{*}{ Gompromiso } & Correlación de Pearson & $.534^{x \times}$ & $.626^{\pi x}$ & $.714^{\mathrm{xx}}$ & 1 & $.518^{x \pi}$ & $.455^{x x}$ & -194 \\
\hline & Sig. (bilateral) & .000 &, 000 &, 000 & &, 000 & .000 & 140 \\
\hline & $\mathbb{N}$ & 59 & 59 & 59 & 59 & 59 & 59 & 59 \\
\hline \multirow[t]{3}{*}{ Clima_organizacional } & Correlación de Pearson & $.585^{x x}$ & $.435^{x \pi}$ & $.521^{\pi x}$ & $.518^{x \pi}$ & 1 & $.579^{x x}$ & $-.485^{\pi x}$ \\
\hline & Sig. (bilateral) & .000 &, 001 &, 000 & .000 & &, 000 &, 000 \\
\hline & 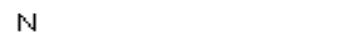 & 59 & 59 & 59 & 59 & 59 & 59 & 59 \\
\hline \multirow[t]{3}{*}{ Finalización_Tareas } & Correlación de Pearson & $.686^{x x}$ & $.566^{x x}$ & $.551^{x x}$ & $.455^{\mathrm{xx}}$ & $.579^{x \times}$ & 1 &,$- 330^{x}$ \\
\hline & Sig. (bilateral) & .000 &, 000 &, 000 & .000 &, 000 & &, 011 \\
\hline & $N$ & 59 & 59 & 59 & 59 & 59 & 59 & 59 \\
\hline \multirow[t]{3}{*}{ NEAP } & Correlación de Pearson &,$- 387^{\pi x}$ &,$- 327^{\pi}$ &,$- 268^{\pi}$ & -.194 & $-.485^{\mathrm{x}}$ &,$- 330^{\pi}$ & 1 \\
\hline & Sig. (bilateral) & .002 &, 012 & .040 & .140 &, 000 & .011 & \\
\hline & $\mathrm{N}$ & 59 & 59 & 59 & 59 & 59 & 59 & 59 \\
\hline
\end{tabular}

*. La correlación es significativa al niwel 0,01 (bilateral).
*. La correlación es significante al nivel 0,05 (bilateral). 
TABLAS SPSS DE LA PRUEBA “ $t$ ” de diferencia de medias.

Prueba de muestras independientes

\begin{tabular}{|c|c|c|c|c|c|c|c|c|c|c|}
\hline & & \multicolumn{2}{|c|}{$\begin{array}{l}\text { Prueba de Levene para la } \\
\text { igualdad de varianzas }\end{array}$} & \multicolumn{7}{|c|}{ Prueba T para la igualdad de medias } \\
\hline & & \multirow[b]{2}{*}{$\mathrm{F}$} & \multirow[b]{2}{*}{ Sig. } & \multirow[b]{2}{*}{$\mathrm{t}$} & \multirow[b]{2}{*}{ gl } & \multirow[b]{2}{*}{ Sig. (bilateral) } & \multirow[b]{2}{*}{$\begin{array}{l}\text { Diferencia de } \\
\text { medias }\end{array}$} & \multirow[b]{2}{*}{$\begin{array}{c}\text { Error tip. de la } \\
\text { diferencia }\end{array}$} & \multicolumn{2}{|c|}{$\begin{array}{c}95 \% \text { Intervalo de confianza para } \\
\text { la diferencia }\end{array}$} \\
\hline & & & & & & & & & Inferior & Superior \\
\hline \multirow[t]{2}{*}{ NEAP } & $\begin{array}{l}\text { Se han asumido } \\
\text { varianzas iguales }\end{array}$ &, 029 &, 865 & 1,001 & 57 & 321 & 10,60688 & 10,59479 & $-10,60883$ & 31,82259 \\
\hline & $\begin{array}{l}\text { No se han asumido } \\
\text { varianzas iguales }\end{array}$ & & & 971 & 40,186 &, 337 & 10,60680 & 10,92182 & $-11,46375$ & 32,67751 \\
\hline
\end{tabular}

